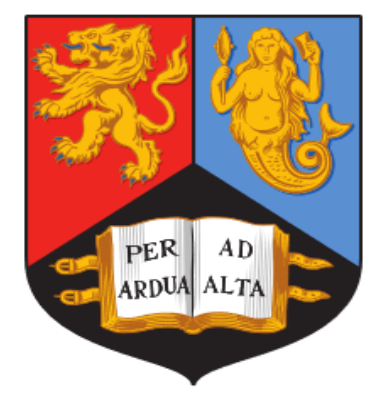

\title{
ASSESSING IRON AGE MARSH-FORTS
}

by

Shelagh Margaret Norton BA (University of Birmingham), MPhil (University of Birmingham)

being a thesis submitted for the degree of Doctor of Philosophy

at the University of Birmingham

(Volume 1 of 2)

Classics, Ancient History and Archaeology

School of History College of Arts and Law University of Birmingham

January 2019

Word count: 81082 


\section{UNIVERSITYOF BIRMINGHAM}

\section{University of Birmingham Research Archive \\ e-theses repository}

This unpublished thesis/dissertation is copyright of the author and/or third parties. The intellectual property rights of the author or third parties in respect of this work are as defined by The Copyright Designs and Patents Act 1988 or as modified by any successor legislation.

Any use made of information contained in this thesis/dissertation must be in accordance with that legislation and must be properly acknowledged. Further distribution or reproduction in any format is prohibited without the permission of the copyright holder. 


\section{DECLARATION}

I, Shelagh Norton, confirm that the work presented in this thesis is my own. Where

information has been derived from other sources, I confirm that this has been indicated in the text. 


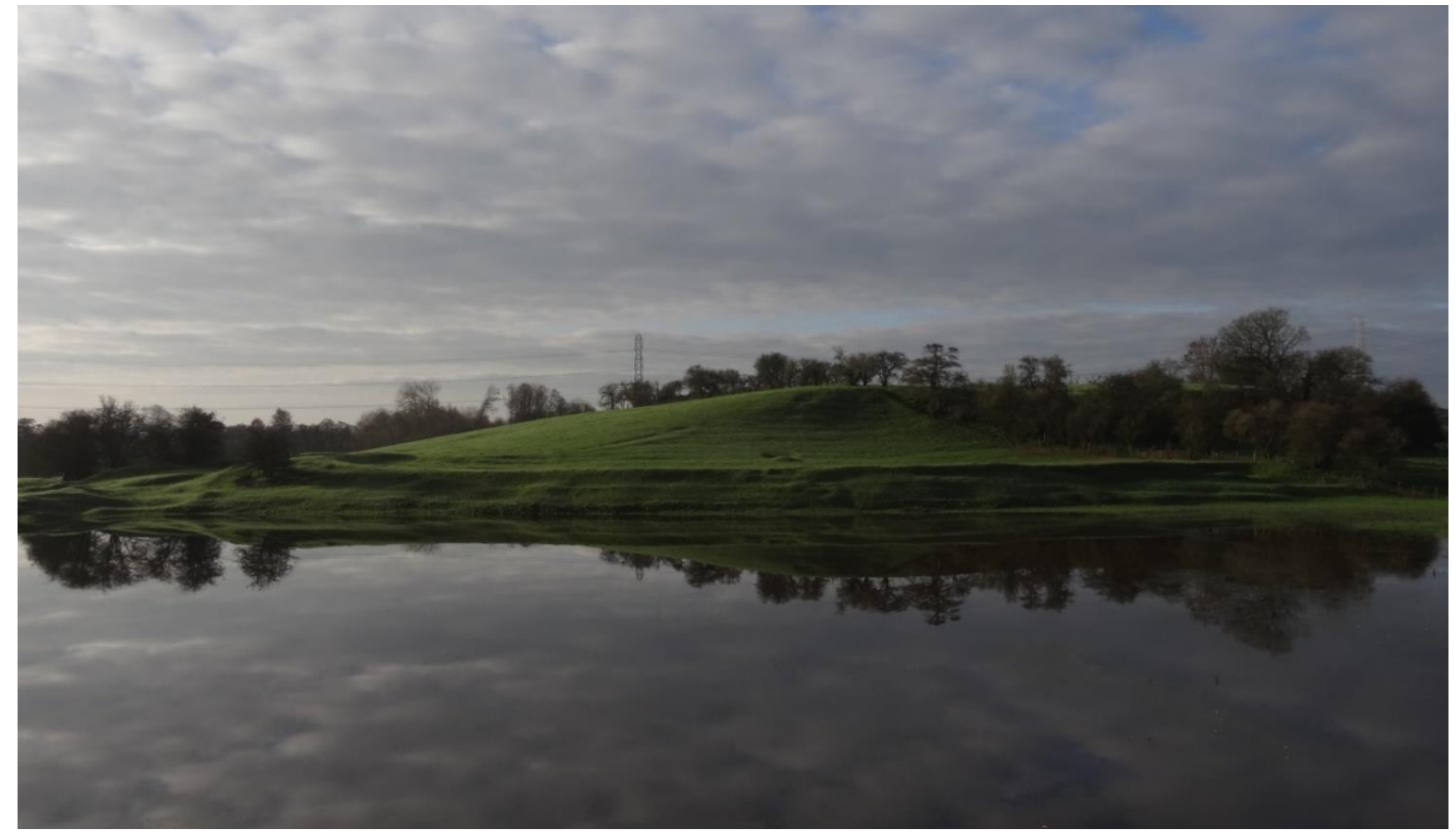

The Berth, Baschurch, North Shropshire. January 2016 


\title{
ASSESSING IRON AGE MARSH-FORTS
}

\author{
ABSTRACT \\ Iron Age marsh-forts are large, monumental structures located in low-lying waterscapes. Although \\ they share chronological and architectural similarities with their hillfort counterparts, their locations \\ suggest that they may have played a specific and alternative role in Iron Age society. Despite the \\ availability of a rich palaeoenvironmental archive at many sites, little is known about these \\ enigmatic structures and until recently, the only acknowledged candidate was the unusual, dual- \\ enclosure monument at Sutton Common, near Doncaster. \\ This thesis assesses marsh-forts as a separate phenomenon within Iron Age society through an \\ understanding of their landscape context and palaeoenvironmental development. At national level, \\ a range of Iron Age wetland monuments are compared to Sutton Common to generate a gazetteer \\ of potential marsh-forts. At local level, a case-study is presented of the Berth marsh-fort in North \\ Shropshire, applying a multi-disciplinary approach which incorporates GIS-based landscape \\ modelling, multi-proxy palaeoenvironmental analysis (plant macrofossils, beetles and pollen) and \\ excavation.
}

The results of both the gazetteer and the Berth case-study challenge the view that marsh-forts are simply a topographical phenomenon. These substantial Iron Age monuments appear to have been deliberately constructed to control areas of marginal wetland, and may have played an important role in the ritual landscape. 
For Trevor 


\section{ACKNOWLEDGEMENTS}

This project owes thanks to many people:-

- Dr David Smith and Prof Henry Chapman, UoB - supervisors, excavation leaders, expert guides and labour! - for their help in the understanding of landscape processes, ArcGIS, and beetle identification

- Gill Campbell, Historic England and Dr Wendy Smith, UoB, for their help with the identification of plant macrofossils and wood identification

- Dr Warren Eastwood and Richard Johnson, UoB, for fieldwork expertise, use of the Russian corer and guidance in the use of TILIA software; and to Rebecca Eastwood, undergraduate, for undertaking the pollen analysis

- Dr Andy Howard for help with field work and moral support

- Dr Elaine Morris, for providing background to her ceramics assessment and for remembering what she saw many years ago

- Members of the Hillfort Studies Group, for academic input and moral support

- The landowners at both the Berth and Wall Camp (the Edwards family, Rod Timmis, Mrs Lea and the Dobson family)

- The staff of Shropshire Council Historic Environment Team, Shropshire Archive and Shropshire Museum Services (Andy Wigley, Charlotte Orchard, Penny Ward, Hugh Hannaford, Giles Carey, and Emma-Kate Lanyon) and the Portable Antiquities Scheme (Peter Reavill, Herefordshire and Shropshire Finds Liaison Officer)

- Shelagh Hampton, for sharing her local knowledge and her photographs of the Berth

- Midlands 3 Cities Doctoral Training Partnership/Arts and Humanities Research Council, for their sponsorship

- Family and friends, for their unfailing confidence

Ultimately though, were it not for Trevor - for his patience and tolerance, for following me up more hillforts than you can shake a stick at and for making me laugh at all the right moments, but mostly for his love and support - this research would not have been possible. 


\section{TABLE OF CONTENTS}

\section{ABSTRACT}

ACKNOWLEDGEMENTS

LIST OF FIGURES

\section{LIST OF TABLES}

\section{LIST OF ABBREVIATIONS}

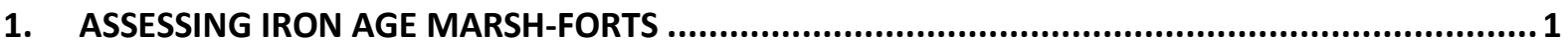

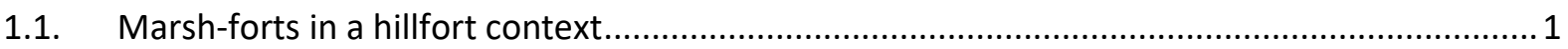

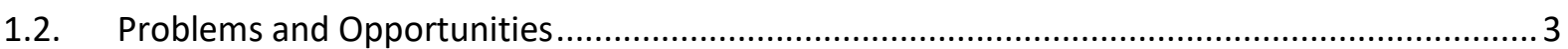

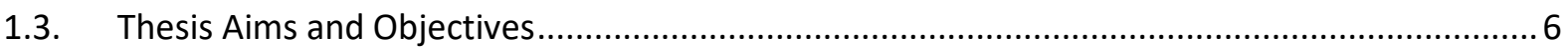

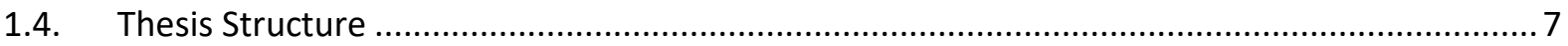

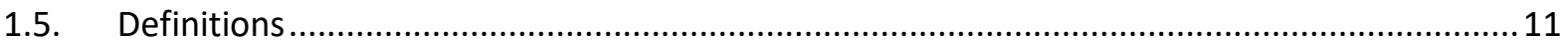

2. THE BRITISH IRON AGE, HILLFORTS AND MARSH-FORTS - LITERATURE REVIEW................... 13

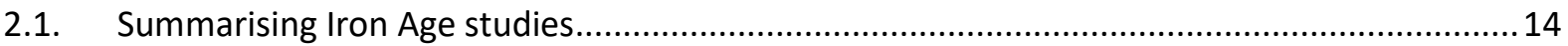

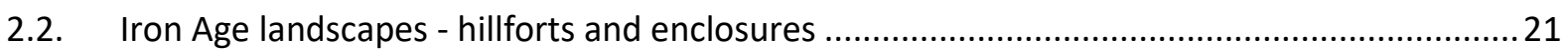

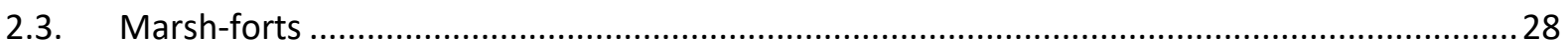

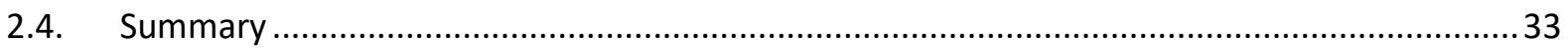

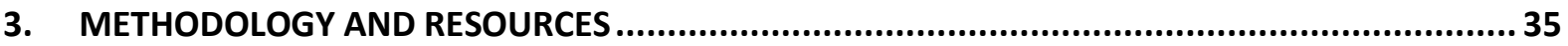

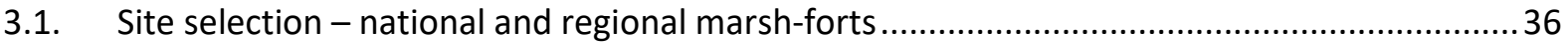

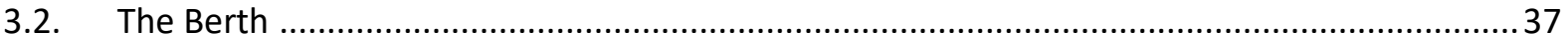

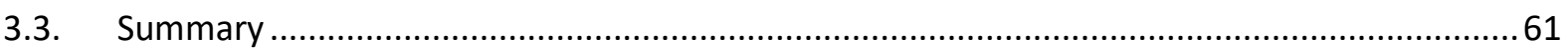

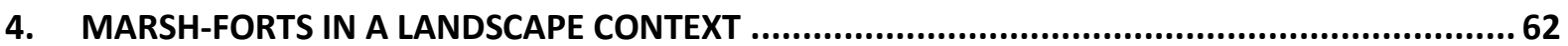

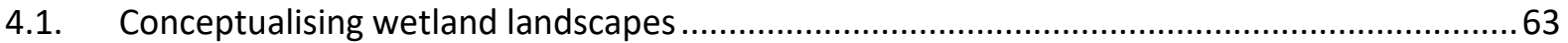

4.2. Marsh-fort Gazetteer - a survey of potential marsh-forts ................................................. 72

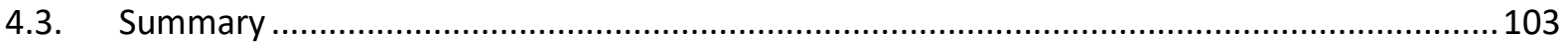




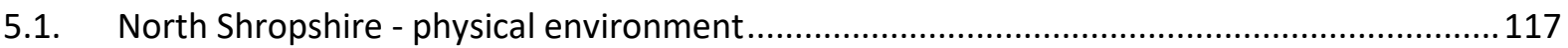

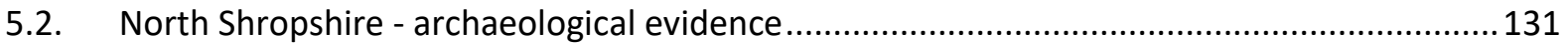

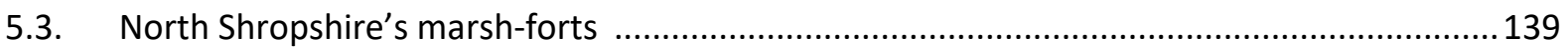

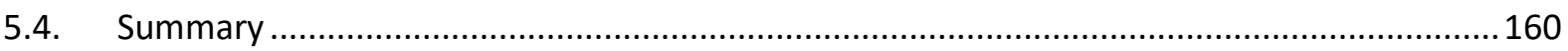

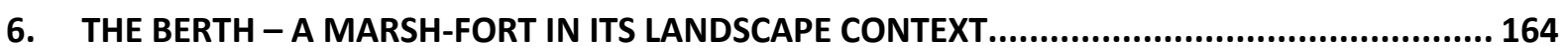

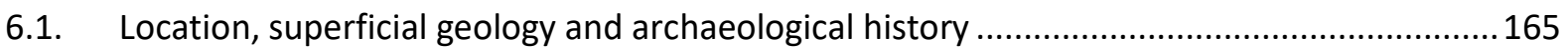

6.2. The Berth and the Upper Perry - macro-scale landscape analysis.....................................170

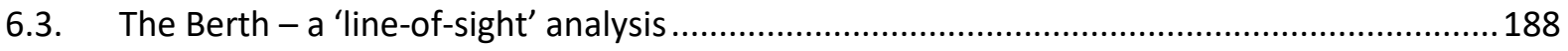

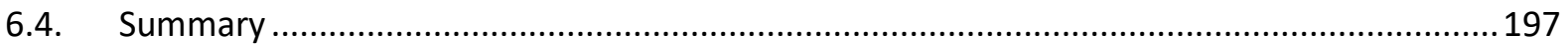

7. THE BERTH - STRATIGRAPHIC SEQUENCING AND RADIOCARBON DATING........................ 199

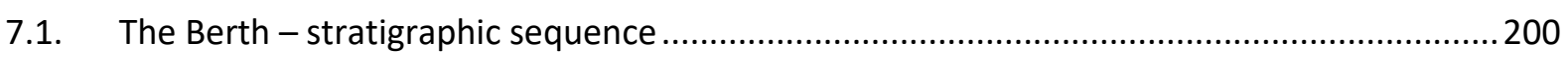

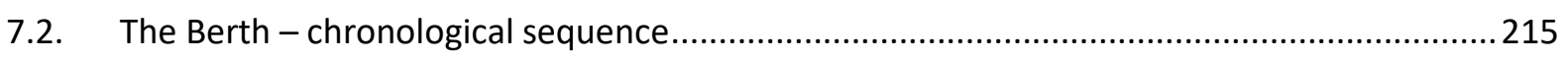

7.3. Stratigraphic summary and cross-correlation of peat deposits...........................................220

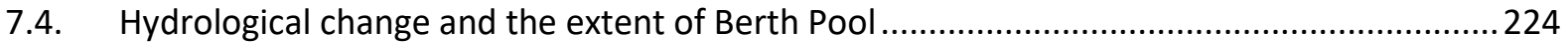

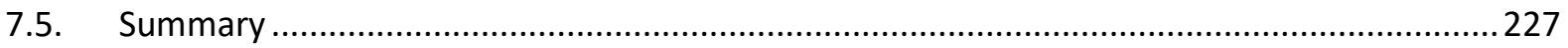

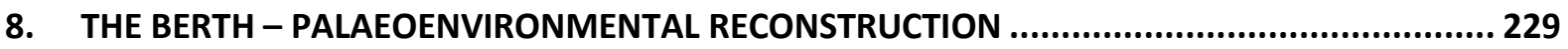

8.1. BNP15 - Berth North Pasture- stratigraphy and taphonomy ............................................231

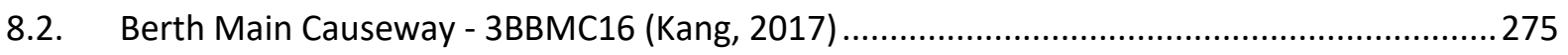

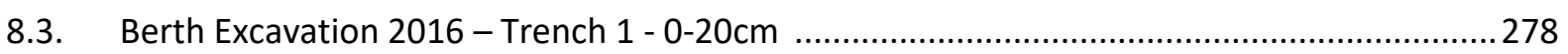

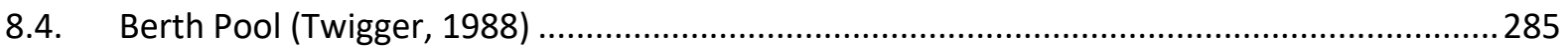

8.5. The Berth - Palaeoenvironmental Reconstruction - spatial coverage and landscape evolution

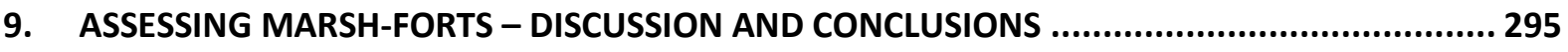

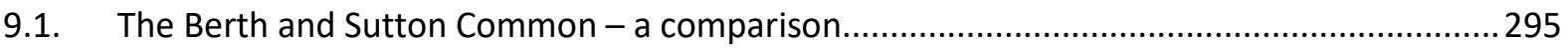

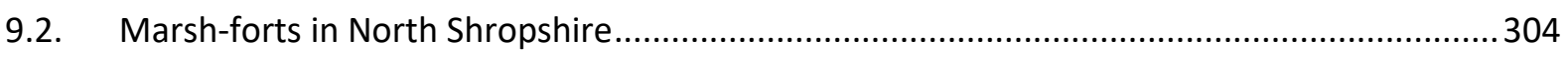

9.3. Marsh-forts in England and Wales - supra-regional perspectives and themes ......................306 


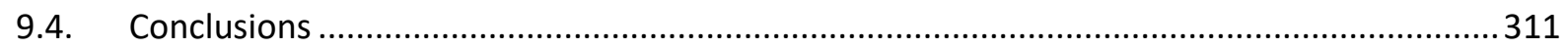

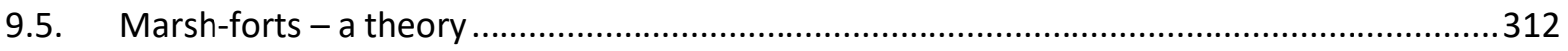

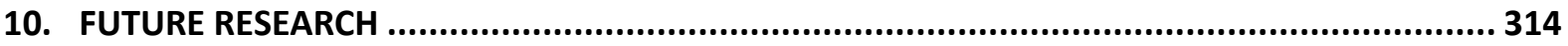

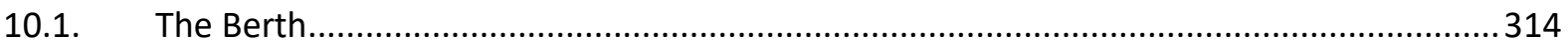

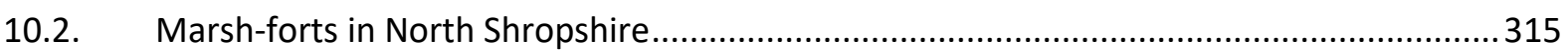

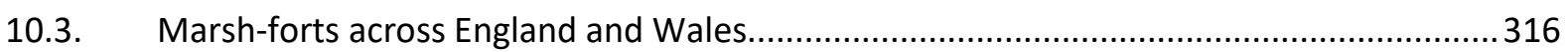

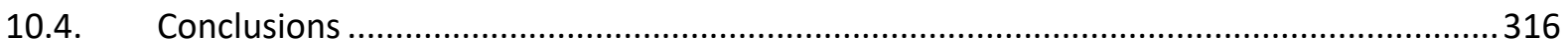

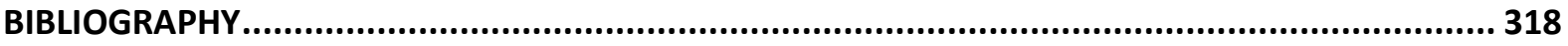




\section{LIST OF FIGURES}

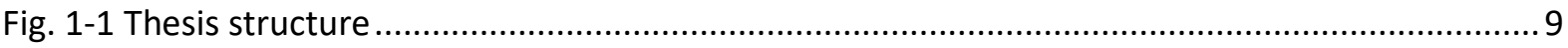

Fig. 2-1 Generalised structure of a Celtic community .................................................................... 17

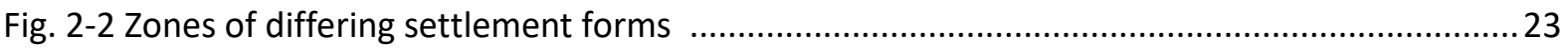

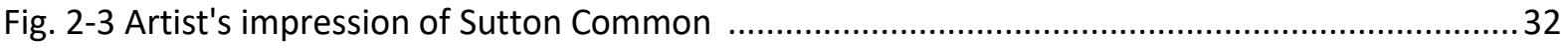

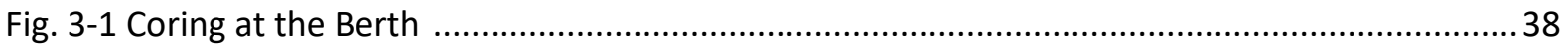

Fig. 3-2 The Russian Sampler in photograph and diagram .............................................................. 39

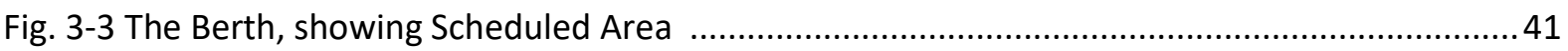

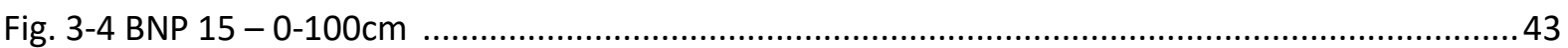

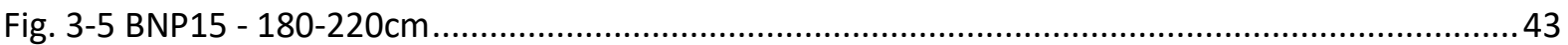

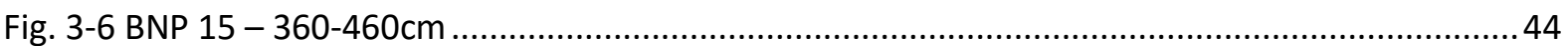

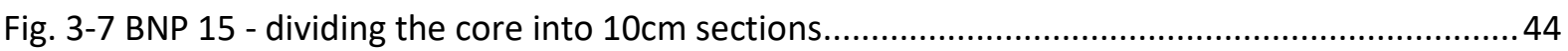

Fig. 3-8 Berth Causeway - Trench 1 showing stone construction .................................................... 45

Fig. 3-9 An indication of the spatial representation available from nested data-sets ........................56

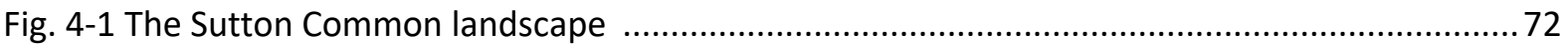

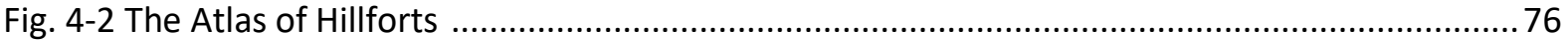

Fig. 4-3 Distribution of potential marsh-forts - England and Wales .................................................77

Fig. 4-4 North/South Yorkshire - distribution of potential marsh-forts around Sutton Common ....... 78

Fig. 4-5 Moorhouse Farm, Tickhill, showing ditch circuits ............................................................. 80

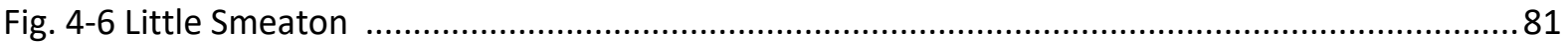

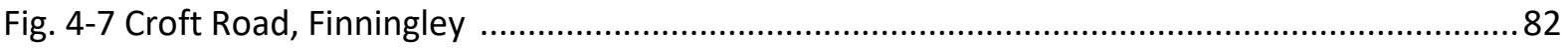

Fig. 4-8 Lincolnshire, Fenland and East Anglia - distribution of potential marsh-forts ........................ 83

Fig. 4-9 Tattershall Thorpe in relation to Fiskerton and the Iron Age coastline ................................ 85

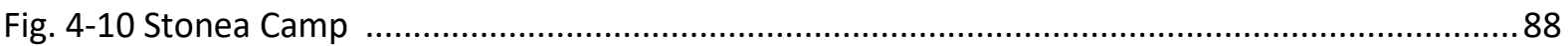

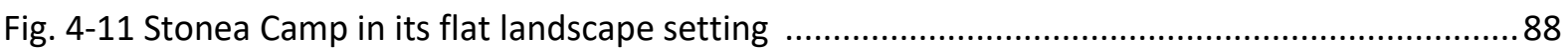

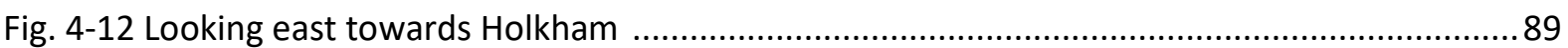

Fig. 4-13 Warham Camp - external defences, looking west ............................................................ 90

Fig. 4-14 Central and Southern England - distribution of potential marsh-forts ................................91

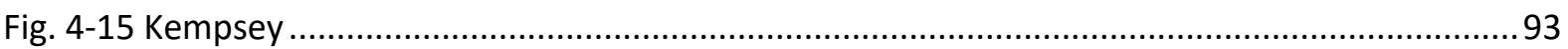

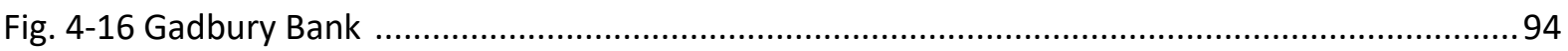

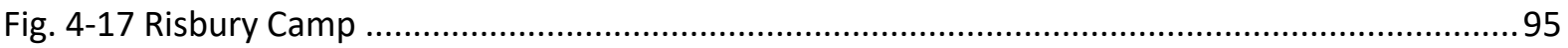

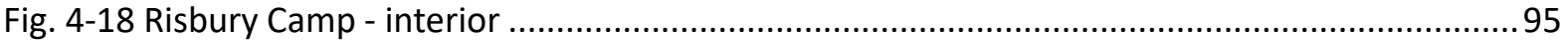

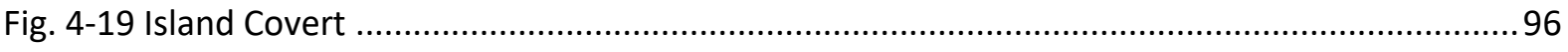

Fig. 4-20 Cheshire- distribution of potential marsh-forts .................................................................. 97 
Fig. 4-21 Peckforton Mere from Peckforton enclosure

Fig. 4-22 Oakmere from across the lake

Fig. 4-23 Somerset Levels and Severn Estuary - distribution of potential marsh-fort and lake villages

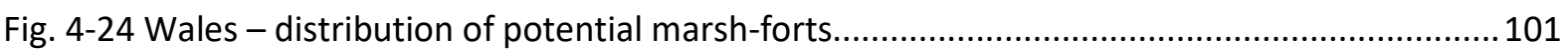

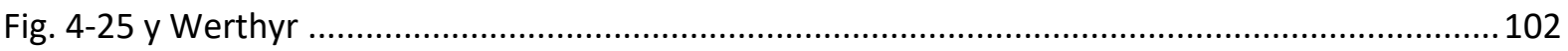

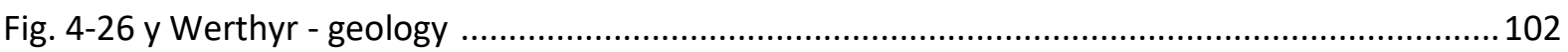

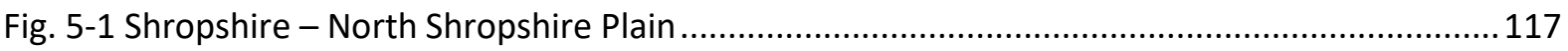

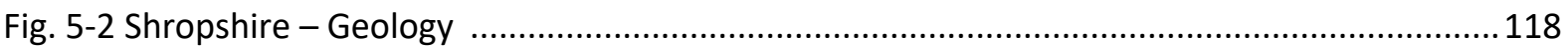

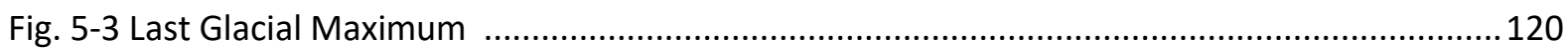

Fig. 5-4 Lakes Lapworth, Buildwas and Newport, and the line of the Ellesmere/Whitchurch moraine

Fig. 5-5 Core section showing 'true boulder clay' (right) at 620-720cm ........................................121

Fig. 5-6 North Shropshire - relief, hydrology ............................................................................... 123

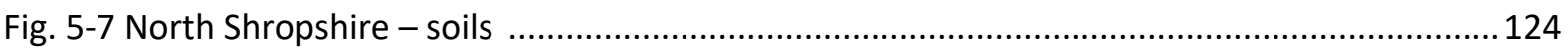

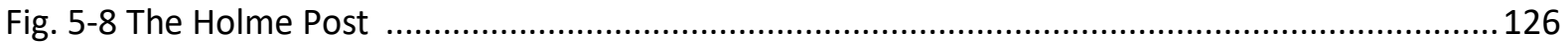

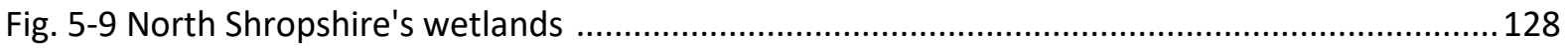

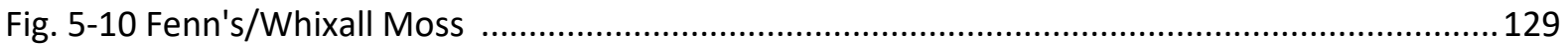

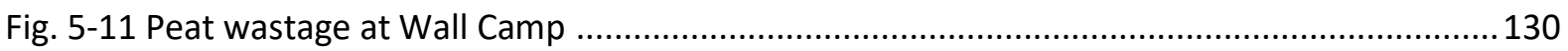

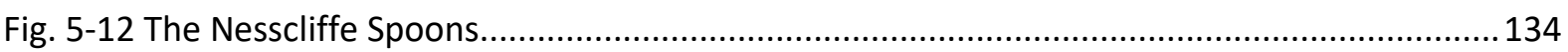

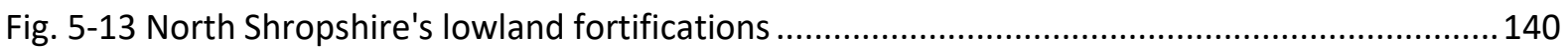

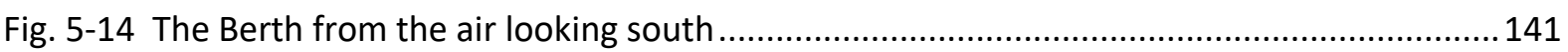

Fig. 5-15 The Weald Moors - superficial geology .....................................................................143

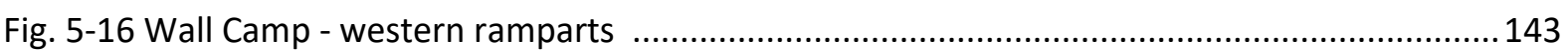

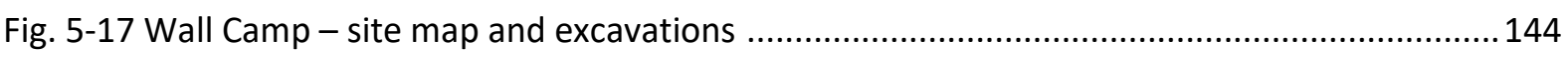

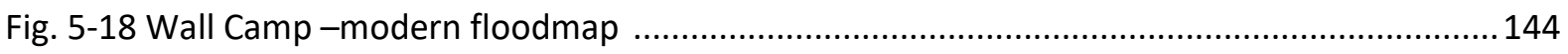

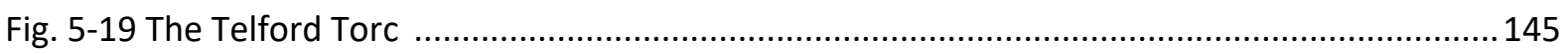

Fig. 5-20 Wall Camp - WC5 stratigraphy and auger locations..........................................................

Fig. 5-21 The Weald Moors - archaeological locations and find spots ...........................................148

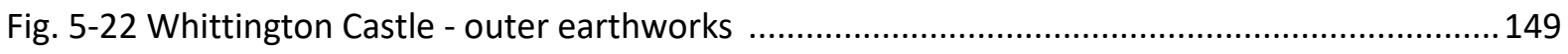

Fig. 5-23 Whittington Castle area showing sites and embanked areas, overlain with modern flood

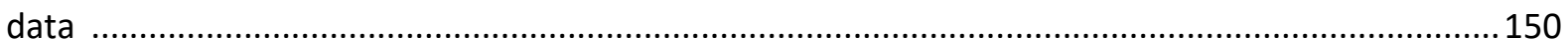

Fig. 5-24 Whittington Castle and Old Oswestry - superficial geology...........................................151

Fig. 5-25 Whittington Castle and Old Oswestry - LiDAR ..............................................................152 
Fig. 5-26 Stocketts Enclosure - site location 153

Fig. 5-27 Stocketts Enclosure and Crose Mere - superficial geology 154

Fig. 5-28 Stocketts Enclosure and Crose Mere - LiDAR 155

Fig. 5-29 Pan Castle 156

Fig. 5-30 Schematic map of Pan Castle 157

Fig. 5-31 Pave Lane from the road 158

Fig. 5-32 Bomere Wood 159

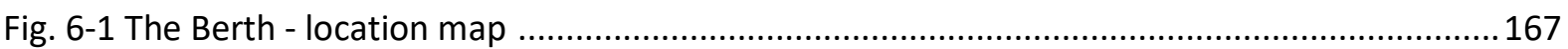

Fig. 6-2The Berth: superficial geology and contour ......................................................... 168

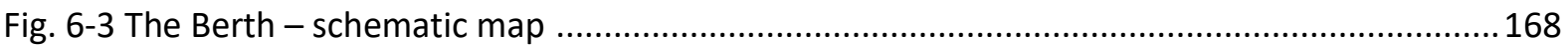

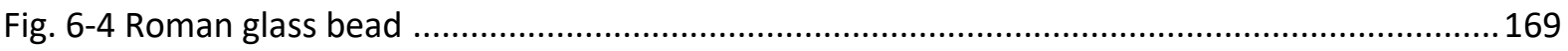

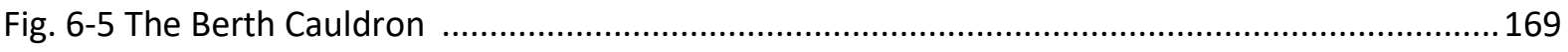

Fig. 6-6 One of a series of railway embankments at Caldon Low, Staffordshire ...........................170

Fig. 6-7 The Berth/Upper Perry - all sites; superficial geology ................................................. 172

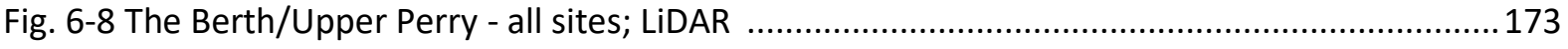

Fig. 6-9 The Berth/Upper Perry - Prehistoric/Mesolithic/Neolithic .............................................175

Fig. 6-10 Unexcavated burnt mound adjacent to the Berth's small enclosure ..............................177

Fig. 6-11 The Berth/Upper Perry - Bronze Age ................................................................ 179

Fig. 6-12 The Berth/Upper Perry - Iron Age/Undated ............................................................ 182

Fig. 6-13 The Berth - cemetery, pit alignment, enclosures and field systems ............................. 183

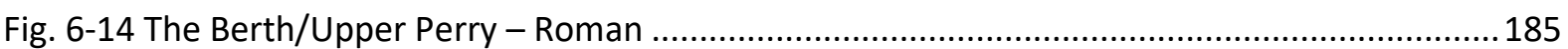

Fig. 6-15 Tetchill Brook - depositionary evidence ........................................................... 187

Fig. 6-16 Berth Hill, seen from Berth Pool ........................................................................... 190

Fig. 6-17 The Berth - Line-of-sight analysis; 97mOD ........................................................ 193

Fig. 6-18 The Berth - Line-of-sight analysis; 80mOD ......................................................... 194

Fig. 6-19 The view from the summit of Berth Hill looking west. ................................................. 195

Fig. 6-20 The North Shropshire Plain viewed from Llanymynech, looking east towards the Berth ...195

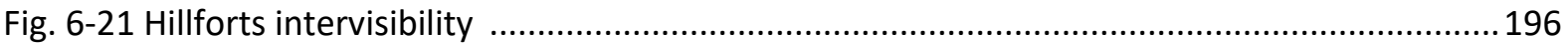

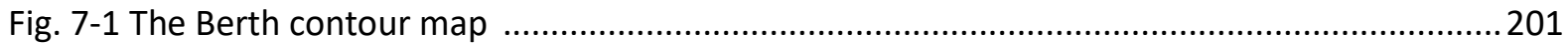

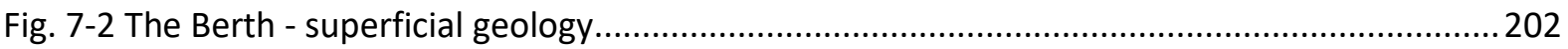

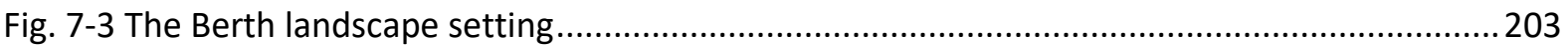

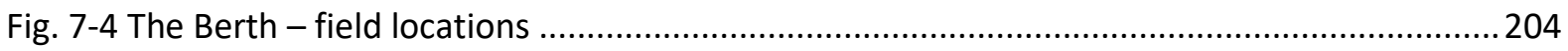

Fig. 7-5 The Berth - 2016 and 2017 coring transects and position of radiocarbon dated cores ........205

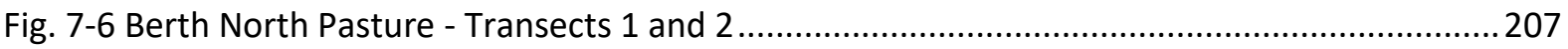




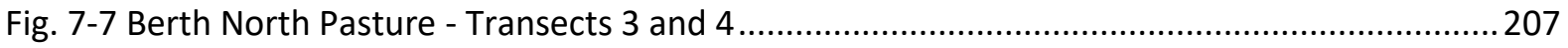

Fig. 7-8 Berth North Pasture - Transect 5a-5g and Lea Field transect .............................................208

Fig. 7-9 Berth North Pasture - cores illustrating depth bordering the main enclosure ....................208

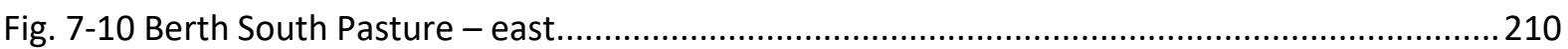

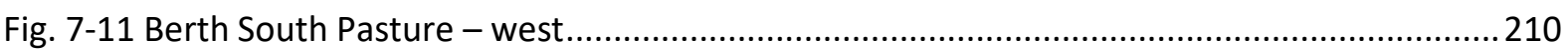

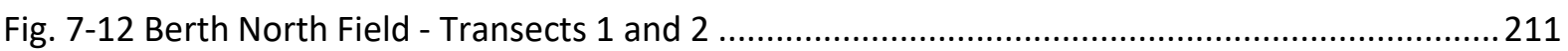

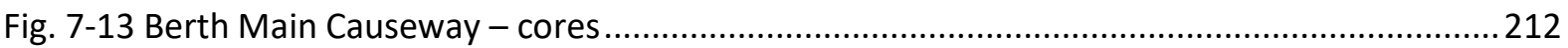

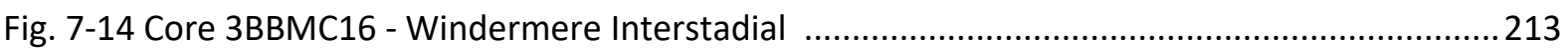

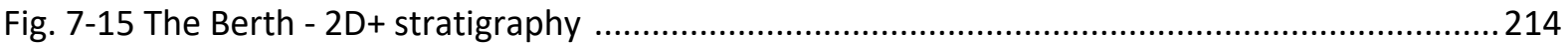

Fig. 7-16 Natural water flow from north to south showing the water course (dotted line) across

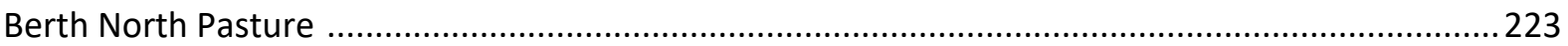

Fig. 7-17 Looking towards the small enclosure across Berth North Pasture .....................................223

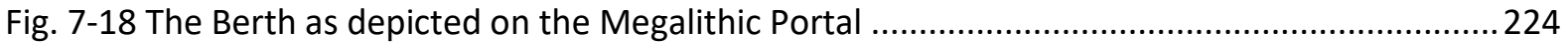

Fig. 7-19 Berth Pool; contour and variations in the snail/Chara horizon .......................................226

Fig. 8-1 Berth North Pasture - BNP15 - stratigraphy annotated with pollen zones ..........................232

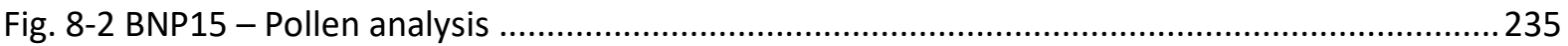

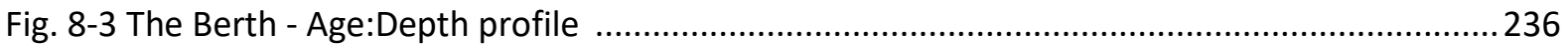

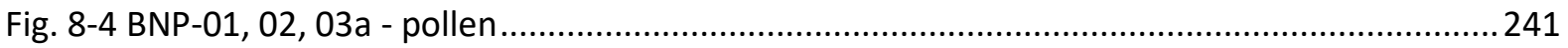

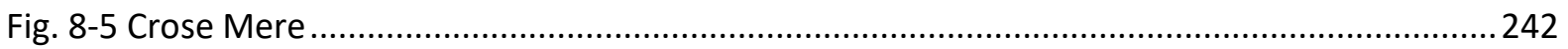

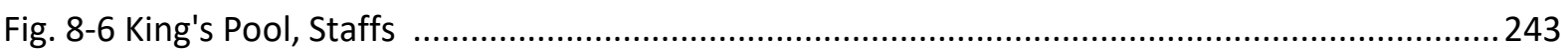

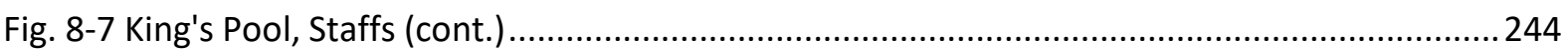

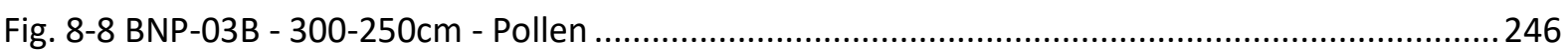

Fig. 8-9 BNP-03B -300-250cm - Plant Macrofossil and Coleoptera …..........................................247

Fig. 8-10 BNP-03B -300-250cm - Woodland Coleoptera expressed as percentages of terrestrial taxa

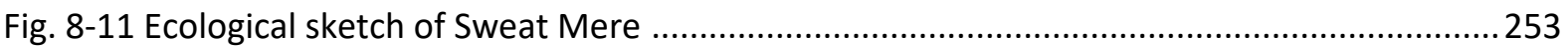

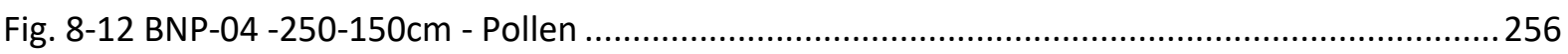

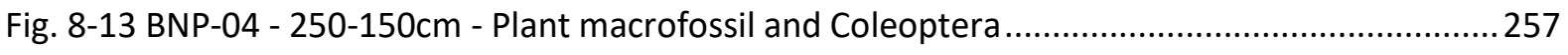

Fig. 8-14 The Berth 150-250cm Woodland Coleoptera expressed as percentages of terrestrial taxa

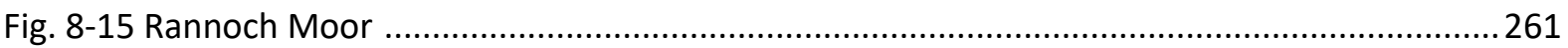

Fig. 8-16 Examples of alder-carr in Worcestershire and Fenn's/Whixall Moss ................................263

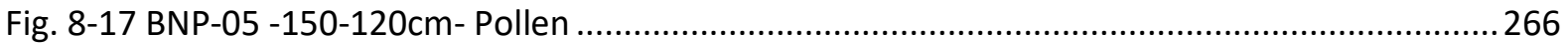

Fig. 8-18 BNP-05 150-120cm - Plant macrofossil and Coleoptera ....................................................267 
Fig. 8-19 The Berth 120-150cm Woodland Coleoptera expressed as percentages of terrestrial taxa

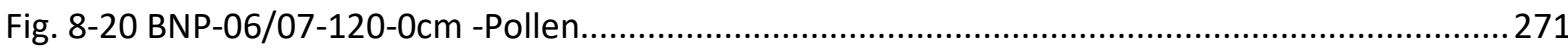

Fig. 8-21 BNP-06 120-100cm Plant macrofossil and Coleoptera .......................................................272

Fig. 8-22 3BBMC16 - Stratigraphy and dating; Fig. 8-23 3BBMC16 - Coleoptera - habitat groupings

Fig. 8-24 The Berth - plant macrofossil and Coleoptera remains - Trench 1 ..................................282

Fig. 8-25 Berth Trench 1 - comparison between plant macrofossil and Coleoptera samples ............284

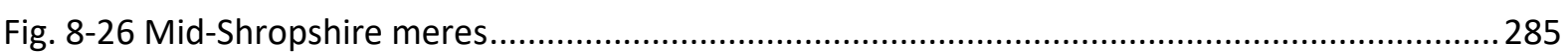

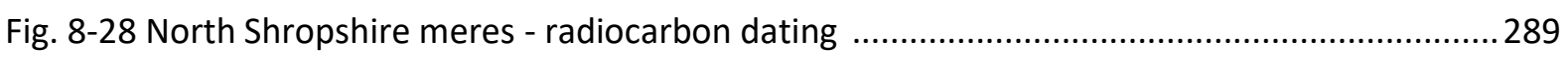

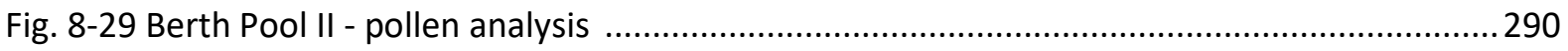

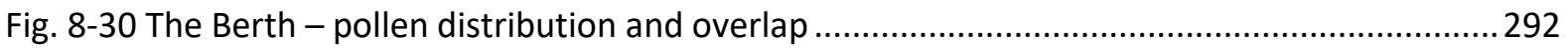

Fig. 8-31 The Berth - plant macrofossil distribution - BNP15; 3BBMC16 and Trench 1....................293

Fig. 9-1 Regional traditions of metalwork deposition in the Iron Age and marsh-fort locations ........310

\section{LIST OF TABLES}

Table 3-1 The Berth - plant macrofossil and beetle samples by location ........................................... 46

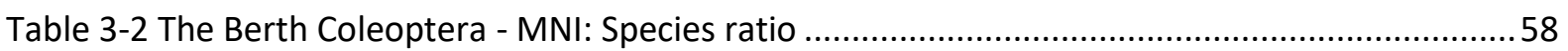

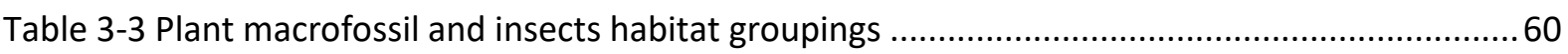

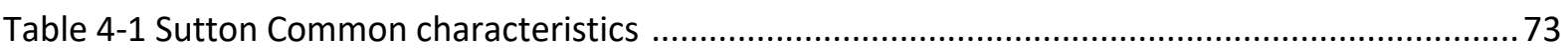

Table 4-2 Marsh-forts and potential marsh-forts, England and Wales ..........................................115

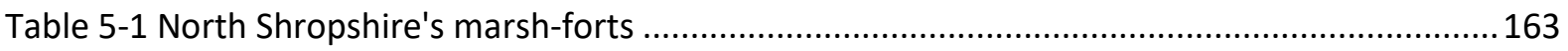

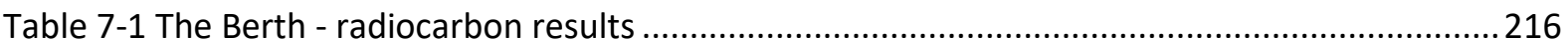

Table 7-2 The Berth - chronological multi-plot of radiocarbon dates ...............................................217

Table 7-3 The Berth - radiocarbon dates grouped by depth and age ..............................................219

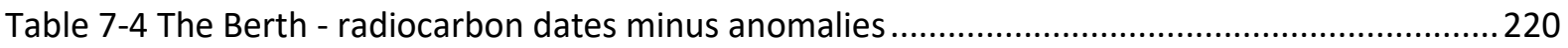

Table 8-1 -The Berth - Holocene palaeoenvironmental data; chronological coverage and overlap .230

Table 8-2 BNP15 - Proxy analysis and chronological phases .............................................................233

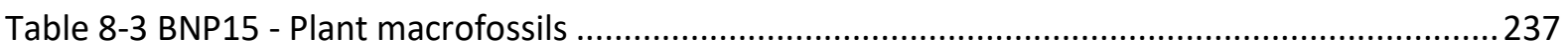




\section{LIST OF ABBREVIATIONS}

\begin{tabular}{|c|c|}
\hline AP & Arboreal Pollen \\
\hline AHRC & Arts and Humanities Research Council \\
\hline BGS & British Geological Survey \\
\hline BIIS & British Irish Ice Sheet \\
\hline BSW & Bog Surface Wetness \\
\hline CAHA & Classics, Ancient History and Archaeology Dept., University of Birmingham \\
\hline DEM & Digital Elevation Model \\
\hline DSM & Digital Surface Model \\
\hline DTM & Digital Terrain Model \\
\hline EIA & Early Iron Age \\
\hline FLO & Finds Liaison Officer \\
\hline GEES & Geography, Earth and Environmental Sciences \\
\hline GIS & Geographic Information System \\
\hline ..ha & Hectares \\
\hline HER & Historic Environment Record \\
\hline ...ka & ..thousand years ago \\
\hline LPAZ/PAZ & Local/Pollen Assemblage Zone \\
\hline LGM & Last Glacial Maximum \\
\hline LIA & Late Iron Age \\
\hline LiDAR & Light Detection and Ranging \\
\hline MIA & Middle Iron Age \\
\hline $\mathrm{MNI}$ & Minimum Number of Individuals \\
\hline ...mya & million years ago \\
\hline NAP & Non-arboreal Pollen \\
\hline NWWS & North West Wetland Survey \\
\hline OD & Ordnance Datum \\
\hline OS & Ordnance Survey \\
\hline PAS & Portable Antiquities Scheme \\
\hline UKRDB & UK Red Book \\
\hline SMR & Sites and Monuments Record \\
\hline TLP & Total Land Pollen \\
\hline UoB & University of Birmingham \\
\hline VCP & Very Coarse Pottery (briquetage) \\
\hline WHP & Wroxeter Hinterland Project \\
\hline ...ya & years ago \\
\hline
\end{tabular}




\title{
1. Assessing Iron Age marsh-forts
}

\author{
'Time present and time past
}

Are both perhaps present in time future...' (Burnt Norton, Eliot, 1979) Later prehistoric marsh-forts are amongst the most enigmatic and scarce of British Iron Age structures. These monumentalised enclosures are found in wetlands, and although their settings offer unparalleled opportunities for landscape and palaeoenvironmental research, they have only recently been acknowledged as a site-type, research is extremely limited, and there are no synthesised studies of their form and function.

This thesis begins to address these omissions by presenting the results of an investigation of Iron Age marsh-forts from across England and Wales, comparing their similarities and differences with the only acknowledged marsh-fort at Sutton Common, and drawing conclusions from their landscape setting, their morphology, and their chronology. A comprehensive gazetteer is offered which supports the increased use of the term 'marsh-fort' as a classification for these monuments. The results indicate that marsh-forts and their wetland landscapes are sufficiently different from their hillfort counterparts to contribute new facets to our understanding of Iron Age society.

In particular, this thesis collates data from a group of low-lying Iron Age fortifications in North Shropshire, focussing on the dual-enclosure, causewayed example of the Berth, near Baschurch, as a subject for extended study. Situated within a low-lying wetland, the Berth combines monumental fortifications with evidence of ritualised metalwork deposition. The case-study presented here charts the evolution of this unique monument through landscape study and multi-proxy palaeoenvironmental analysis.

\subsection{Marsh-forts in a hillfort context}

The British Iron Age (circa 800BC-AD43) was a period of profound social transformation (e.g. Cunliffe, 2005; Haselgrove and Pope, 2007; Haselgrove and Moore, 2007). The ritual hoarding of bronze ceased and metalworking focussed increasingly on the use of iron. Farming and subsistence continued the changes begun in the Late Bronze Age, and land became increasingly enclosed and bounded (e.g. Haselgrove in Hunter and Ralston, 2009:149-174). In some regions, local populations proclaimed their strategic intelligence and territorial claims through the construction of highly visible, rampart-and-ditch fortifications - hillforts. There are in excess of 4000 hillforts in the British Isles (Lock and Ralston, 2017) and whilst they come in a myriad of shapes, sizes and locations, they are conjoined by the monumentality of their architecture and their size. 
The functionality of these enclosures has been subject to a range of interpretations which have reflected the socially important mores of the day. Between the 1920s and the 1970s, hillforts were thought of as defensive structures, mirroring the Western world's preoccupation with security and warfare (e.g. Hawkes, 1931; 1959; Wheeler, 1972; Forde-Johnston, 1976; Hogg, 1979; Stanford, 1980). However, from the 1970s/80s onwards, social evolutionary models emphasised hillforts as visible metaphors for power and territorial control (e.g. Bowden and McOmish, 1987; Hingley, 1999; Bowden, 2005; Driver, 2007), and/or as communal centres for gatherings or storage (e.g. Gent, 1983; Gent and Dean, 1986). Settlement was a function of many but not all sites (e.g. Bowden, 2005). Their prominence in the landscape suggests that being seen was a matter of considerable significance, either to display dominance or to deter marauding neighbours.

However, some Iron Age structures do not appear to be designed for visual dominance. A number of fortifications echo the monumentality of visually-prominent hillforts but are located in low-lying wetlands. Examples include the Berth, near Baschurch and Wall Camp, near Telford on the Weald Moors, both in North Shropshire, and Stonea Camp, near March, Cambridgeshire. As seeing and being seen appear to be fundamental to the construction of hillforts, this practice seems counterintuitive. The reasoning behind this behaviour, the functionality of such structures, and their role in a progressively enclosed landscape, form the underlying research questions for this thesis.

Increasingly, such monuments are referred to as marsh-forts (Riley, 1980; Brown, 2008; English Heritage, 2011; Lock and Ralston, 2017). Little is known about these structures, and detailed investigation is confined to one site - the enclosures of Sutton Common near Doncaster (Parker Pearson and Sydes, 1997; Van de Noort et al., 2007), a marsh-fort in a region not renowned for its hillforts. Sutton Common provided a suite of evidence which is hard to explain in everyday terms. Situated in a floodplain environment, its dual enclosures were connected by a causeway over an infilled palaeochannel. Its chronology (Middle/Late Iron Age) is short and discontinuous. The site was not a settlement, but 150+ four- and six-post structures (possible granaries) occupied the interior; human remains and 'mortuary rings' also form part of the recovered evidence. Taken together, these data suggests a site dedicated not to domestic activities but to remembrance, ritual and ceremony (Van de Noort et al., 2007:176-7). One of the questions addressed by this thesis is whether this interpretation can be applied more widely.

Sutton Common provides a template against which other similar monuments can be assessed. No systematic evaluation has been made of potential marsh-fort sites across England and Wales, nor has a methodical multi-proxy analysis been undertaken of marsh-fort landscapes. This study takes a comprehensive, two-part approach to address these issues: 
- Firstly, by reassessing the existing dataset to see whether sites previously classified as hillforts or enclosures could be classified as marsh-forts, and whether the assembled body of information points towards a site-type which was culture-specific, convergent or universal, and

- Secondly, by analysing the micro-ecology surrounding the Berth marsh-fort to reconstruct the longue durée of its landscape development.

\subsection{Problems and Opportunities}

\subsubsection{The problem with 'hillforts'}

The hillfort phenomenon is highly varied - chronologically, morphologically, topographically and functionally. Their construction spans the first-millennium BC and they are seen as the enduring symbol of the British Iron Age. Many conform to one of several morphological patterns; others do not. They are associated mainly with uplands and down-land, in southern England, Wales and the Welsh Marches and Scotland. Any one hillfort may evince a single purpose or a range of functions during its lifetime, from domestic to industrial to ceremonial, reflecting profound differences at a practical, social and symbolic level (Harding, 2012:27). Only a few indicate a violent past. These features, together with the broader concept of enclosure, are discussed more fully in Chapters 2 and 4.

However, and despite their obvious variety, hillforts have come to dominate our understanding of Iron Age communities in Britain (e.g. Hawkes, 1931; 1951; Stanford, 1967; Wheeler, 1972; Guilbert, 1975a; Cunliffe, 1983; Gent and Dean, 1986; Haselgrove, 1986; Sharples, 1991a; Hamilton and Manley, 2001). They have been presented as the main societal model for the Iron Age despite their regional and topographical bias.

A study of marsh-forts offers a unique opportunity to expand Iron Age studies away from this uniform interpretive model. Living in a wetland would require different skills and generate a separate set of social norms (e.g. Van de Noort, 2004), and although wetland living has been addressed by some highly influential studies, investigation is limited to sites which were predominantly domestic or specialist in function, for example the Late Iron Age lake villages of Glastonbury and Meare (e.g. Coles and Minnitt, 1995), and crannogs (e.g. Cavers, 2006). Marsh-forts are neither upland hillforts nor lowland settlements and do not conform to either model. These monumental structures share size and architectural similarities with hillforts, but appear to be sited to exploit both the potential richness of resources and the inherent spirituality associated with 
wetlands during the Iron Age (e.g. Bradley, 2000). They have the potential to identify an alternative for Iron Age praxis.

There is also an issue of nomenclature. The term 'hillfort' has been in use throughout the twentiethcentury to refer to a range of later prehistoric structures which are defined by their impressive architecture and spectacular locations. This 'portmanteau' classification (Cunliffe, 2005:347) has become conflated over the years; its use has grown to cover a genre so wide that making hillforts fit a pattern has been likened to a Procrustean treatment of the archaeological facts (Hogg, 1975), enforcing uniformity where none exists. Forde-Johnston found the term 'misleading' (FordeJohnston, 1976:3) whilst Hogg contended that '...all the alternatives which have been suggested are open to even more objections...' (Hogg, 1975:xv). Various attempts have been made to re-define it; a recent example - 'an enclosed place constructed in a highly visible location to serve as a focus (if sporadic) for communal activity' - stresses the key elements of enclosure, visibility and community (Cunliffe, 2006:152). Most of the marsh-forts considered in this thesis are classified as hillforts in the Historic Environment Record (HER) but would fail Cunliffe's test on visibility grounds.

Systematically codifying hillforts according to topographic similarities has been undertaken several times (e.g. Forde-Johnston, 1976; Hogg, 1979; Dyer, 1981; Lock and Ralston, 2017). Such typological groupings have not necessarily deepened understanding. Whilst it could be argued that marsh-forts are simply one more variation on this theme, this thesis contends that they are defined by more than their topographic setting and that they warrant a comprehensive investigation. Monuments which are not reviewed collectively run the risk of being overlooked, with the associated loss of chronological, morphological, functional and phenomenological detail. The classification and language used to describe landscape features is more important than it seems. Not only does it 'allow us to speak clearly about such places' (Macfarlane, 2015:26), but, additionally, '...once a landscape goes undescribed and therefore unregarded, it becomes vulnerable to unwise use or improper action.'(Macfarlane, 2015:27). Whilst Macfarlane was describing natural landscapes in the Outer Hebrides, the same is true for archaeological sites and the landscapes they occupy. It may seem pedantic, but the nomenclature used to describe different types of later prehistoric structures - in this case, marsh-forts - does matter. 


\subsubsection{The archaeological and ecological opportunities presented by wetlands} ‘..Quagmire, swampland, morass,

the slime kingdom...

\section{Ruminant ground.}

\section{Digestion of mollusc}

$$
\text { and seed pod, }
$$

deep pollen bin.

... a bag of waters... ' (Kinship, Heaney, 1975)

Evidentially, marsh-forts are found in wetlands. These resource-rich environments were highly utilised throughout prehistory, and as a consequence, frequently incorporate a palimpsest of archaeological features reflecting different stages of human exploitation.

'Wetland' is a generic term, covering numerous topographical types (explored in Chapter 5). These often well-preserved and deeply stratified locations can preserve a wealth of archaeological and ecological information. The internationally significant palaeolake at Star Carr, North Yorkshire provided evidence of Mesolithic and Neolithic hunting camps and occupation sites; seasonality of use and the ritual nature of some artefacts were established through analysis of the well-preserved animal remains (Legge and Rowley-Conwy, 1988; Mellars and Dark, 1998; Milner et al., 2011). Bronze Age settlement evidence has been found preserved at such sites as Must Farm in Fenland (Knight, 2009), whilst other Bronze Age wetland sites have a greater association with ritual deposition, such as Flag Fen near Peterborough (e.g. Pryor, 2005). Wetland exploitation continued into the Iron Age, where, for example, the wetlands of the Somerset Levels preserved extraordinary evidence for everyday living and craft specialisation at Glastonbury and Meare (see above) (e.g. Coles and Minnitt, 1995). The ritual deposition of metalwork during the Iron Age is evidenced, sometimes on a grand scale, along some major watercourses (such as the Witham Valley in Lincolnshire; Bradley, 1990) and in lakes (Llyn Cerrig Bach, Anglesey; Lynch, 1970). Ecologically, the anaerobic conditions prevailing in wetlands are unparalleled in preserving a wealth of artefactual and ecofactual evidence from which to recreate ancient landscapes, for example in Littleton Bog, Co. Tipperary (Mitchell, 1965) and the Somerset Levels (e.g. Girling, 1980; Coles, 1988; Aalbersberg and Brown, 2011). 
Marsh-forts therefore promise a wealth of evidence which is often unavailable at hillfort sites. As much as any hillfort, their remains need to be examined temporally, regionally and culturally for their social and symbolic importance.

\subsubsection{The broader opportunity}

Marsh-forts pose many questions. What differentiated those who built in wetlands from those who chose to build at higher altitudes? Was it a choice, or did those who monumentalised wetland landscapes simply have no other options (cf. Forde-Johnston, 1976)? Did the impetus to build in wetlands stem from the lure of a resource-rich environment, or did it provide access to, and control of, an environment that had important ritual connotations?

This research looks at the syntax of Iron Age wetland landscapes and in particular the role played by marsh-forts in the lives of the people who constructed and used them. Whilst this thesis does not answer all the questions, it establishes a set of criteria (based on Sutton Common) against which marsh-forts can be assessed. Additionally, by using the Berth as a case-study, it investigates the spatial and palaeoenvironmental context of a marsh-fort in the North Shropshire wetlands. This research is new, timely and important, presenting a model of landscape evolution which ultimately resulted in the building of unusual, large scale fortifications. The continual threat to wetland environments from farming practices and development (e.g. Van de Noort et al., 2002) places the unique phenomenon of marsh-forts at critical risk. Unless looked at specifically and collectively, this lens into Iron Age society may be lost.

\subsection{Thesis Aims and Objectives}

\subsubsection{Aim}

The aim of this thesis is to assess marsh-forts as a separate phenomenon within Iron Age society through an understanding of their landscape context and palaeoenvironmental development. To that end, this research presents a complex and original methodology for evaluating Iron Age marshforts at national, regional and local level.

\subsubsection{Objectives}

The objectives are:

To establish a basic methodology for evaluating marsh-forts by

\section{Identifying and assessing sites, nationally}

- Create a set of criteria against which potential marsh-forts can be assessed, based on the Sutton Common hypothesis 
- Construct a template for the marsh-fort genre and systematically apply it to wetland Iron Age fortifications in England and Wales

\section{Focusing on a group of sites, regionally}

- Identify a suitable group of sites for in-depth examination (North Shropshire)

- Define the character, morphology, development, spatial patterning and palaeoenvironmental context of the marsh-forts in the area

\section{Reconstructing the local palaeoecological landscape which supported the}

\section{construction and functioning of one marsh-fort}

- Identify a suitable site as a case-study (the Berth), and undertake a multi-disciplinary and multi-proxy analysis of its archaeological landscape and environmental evolution

* To develop a theoretical concept of marsh-fort chronology and functionality by maximising and contextualising the evidence from the Berth and applying it locally, regionally and nationally to sites in North Shropshire and across England and Wales

* To determine the extent to which marsh-forts played a social and physical role in Iron Age society and whether they are more than just a topographical phenomenon

\subsubsection{Scope}

Marsh-forts occur across the mainland of Britain (Lock and Ralston, 2017). As the Scottish Iron Age comprises its own set of cultural norms (Harding, 2004; 2006), the investigation presented here concentrates on sites in England and Wales. Scottish marsh-forts are potential targets for a future comparative study, as is the absence of this phenomenon from Ireland.

\subsection{Thesis Structure}

The scale of this research encompasses macro- and micro-level landscape investigation. The principal argument of this thesis is that marsh-forts are not simply a topographical variation of a hillfort phenomenon, and this premise flows through the thesis structure, outlined in Fig. 1-1.

Beginning with a review of the current literature, Chapter 2 places hillfort studies in context, highlighting the problems arising from conflating the hillfort genre and omitting site-types such as marsh-forts. The project-based methodology adopted by this thesis is explained in Chapter 3. A nested set of processes is described which drills down from national level, to regional-, site- and finally micro-environmental level. The methodology is multi-disciplinary, combining multi-proxy environmental analysis (pollen, plant macrofossil and Coleoptera) with extensive auger-based coring, GIS modelling and a robust radiocarbon dating programme. To date, excavation at the Berth has been limited, but is now playing an important role in unravelling the site's history (Chapman, Smith and Norton, 2017); this work is ongoing and available information is incorporated where appropriate. 
Chapter 4 reviews marsh-forts nationally across England and Wales. Landscape theory (e.g. Aston, 1985; Tilley, 1994; Strang, 2008; Bowden and McOmish, 2012) is used to emphasise the socially constructed nature of landscape and to support the identification of marsh-forts within wetland landscapes/waterscapes. The chronological, artefactual, palaeoenvironmental and morphological features which characterise Sutton Common are used to provide criteria from which to create a base-line hypothesis - the 'archetypal' marsh-fort. A range of sites, identified through a combination of literary review, HER (Historic Environment Record) search and site visits, are then compared to this hypothesis and the resulting gazetteer lists and ranks each site's potential as a marsh-fort. Marsh-forts appeared to be local to eastern England (Riley, 1980; Parker Pearson and Sydes, 1997), but the results of the gazetteer indicate a wider distribution, with implications for the Iron Age agenda regionally and nationally (Haselgrove, 2001a; 2001b).

A group of potential marsh-forts in North Shropshire, including the Berth near Baschurch, form the basis of a more detailed study. North Shropshire's geology, hydrology, landscape features and archaeological heritage are introduced in Chapter 5, together with descriptions of the landscape and archaeological characteristics surrounding each of North Shropshire's marsh-fort candidates. In particular, the results of a palaeoenvironmental case-study (palaeoentomological investigation and a small-scale auger-based coring programme) undertaken at Wall Camp on the Weald Moors, near Telford, are summarised and compared with both Sutton Common and the Berth (Norton, 2013; 2016).

All these sites have the potential for further research. However, the Berth, with its highly unusual morphology and striking similarities to Sutton Common, has been selected as a subject for an indepth case-study, and its extensive organic archive offers the potential to establish the longue durée of its landscape development. Chapters 6, 7, and 8 present the results of the field work, site visits, palaeoenvironmental study and excavation described in Chapter 3. Chapter 6 summarises the known evidence from the Berth, placing the monument within its wider topographical landscape and archaeological context, using data from HER and PAS (Portable Antiquities Scheme) records. The results are modelled using ArcGIS 10.2 software ${ }^{1}$. A chronologically-based stratigraphic analysis of the area immediately surrounding the Berth is reconstructed from the data obtained through a transect coring programme and presented in Chapter 7. Chapter 8 narrows the focus further. A multi-proxy palaeoenvironmental analysis of samples taken from locations adjacent to the Berth's earthworks and causeways reconstructs a detailed environmental sequence which encompasses almost the entire Holocene, including the period when the Berth was in use; the

\footnotetext{
${ }^{1}$ A geographic information system (GIS) for the management, analysis, and display of geographic information; https://www.arcgis.com
} 
palaeoenvironmental data is compared with existing pollen studies from Berth Pool (Twigger, 1988) and Crose Mere (Beales, 1980).

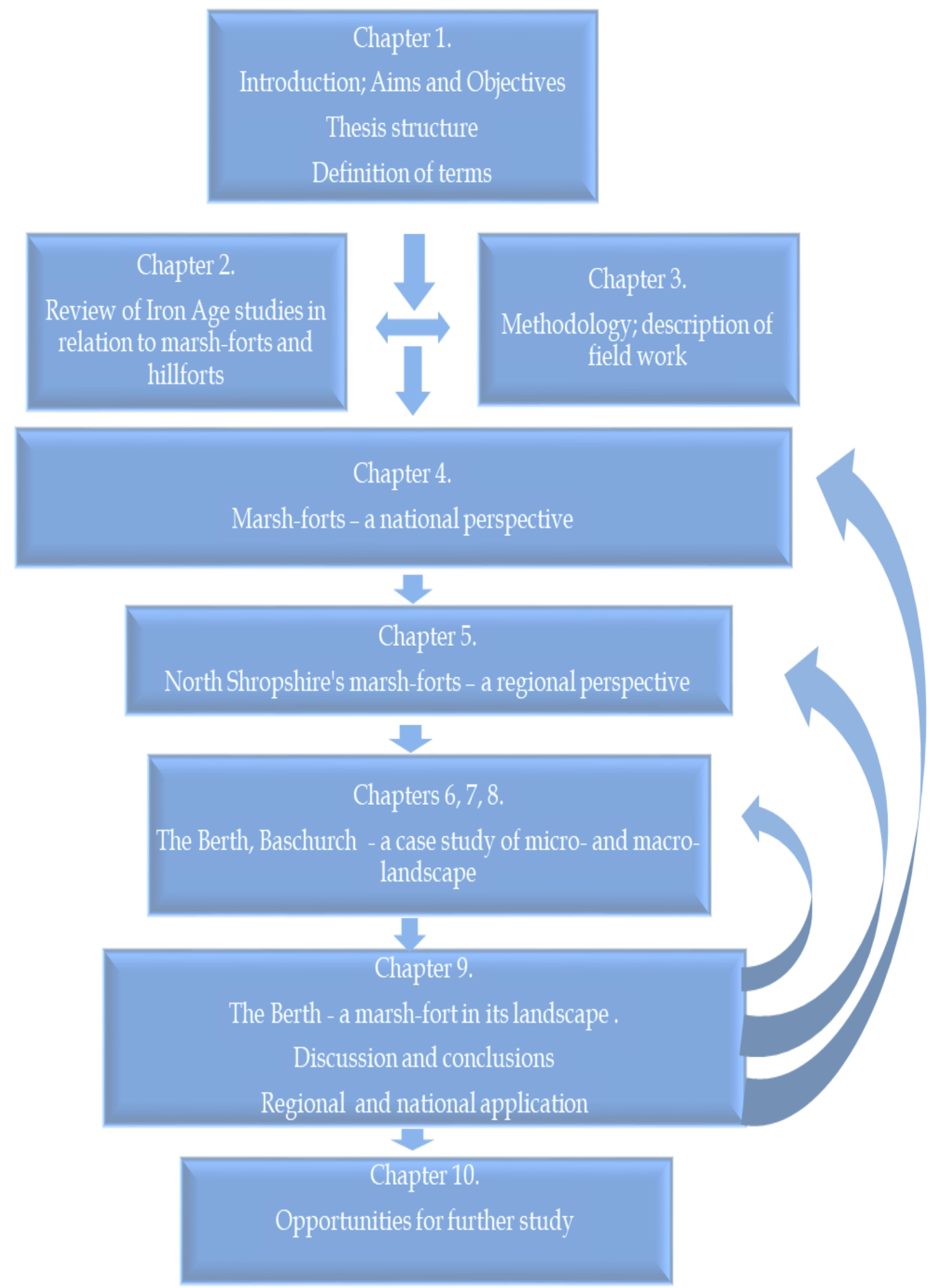


'It is often said that the object of science is to consider metaphysical propositions and bring them into focus within a system of theoretical knowledge which has clear empirical consequences' (Murray and Walker, 1988:284). This approach is adopted in Chapter 9, which discusses the results presented in Chapters 4-8 with reference to the literary review and landscape theory expounded in the text, opening up new fields of knowledge and constructing the case for the Berth as a marsh-fort. This discussion is expanded to encompass the marsh-forts highlighted in the gazetteer.

There are competing interpretations in the presented evidence which are intended to foster debate. This thesis does not purport to be the final word on marsh-forts, but will hopefully act as a prompt for further study. Suggestions for future work can be found in Chapter 10.

Full species lists of plant macrofossil and coleopteran data, plus details of all radiocarbon determinations can be found in the Appendices, together with summaries of several seasons of excavation at the Berth undertaken in the 1960s by the late Peter Gelling (Gelling, 1962/5; 1964; Gelling and Stanford, 1965 (1967); Guilbert et al., 1977; Morris and Gelling, 1991). A summary of the relevant map and archival records held by the Shropshire Archive and the British Library are also included. Neither the Gelling finds nor the evidence from the Shropshire Archive are presented as expert summaries, and each dataset warrants a more thorough and discursive approach to its analysis. They are offered here as background to the Berth case-study. Diagrams and pictorial evidence are embedded within the text; these are also available in Appendix 1 (see CD-ROM), together with full results from the marsh-fort gazetteer.

The places discussed in this thesis are particularly wet and boggy, a landscape which would have materially affected the lives of those who lived there. To conjure this sense of place (e.g. Tuan, 1974; 2011), poetry quotations from Seamus Heaney's Bogland series (Heaney, 1972; 1975; 1996; 2002) and other poets are included in the text. Heaney viewed wetlands as deeply spiritual places and, in many of his works, the bog is seen as a membrane through which we can access the past. At a more prosaic level, the approach adopted by this thesis accesses the past through the membrane of palaeoenvironmental analysis. These inclusions aim to be allusive and evocative rather than intrusive.

This study is exploratory in nature, and unique in approach. It draws conclusions from a number of research fields which have application across Iron Age studies. These include the utilisation of marginal environments, the articulation of the wetland/dryland interface, economic strategies, the blurring of purpose of high-status Iron Age monuments, and the possibility of direct communication between geographically spread regions. It delivers a framework for understanding marsh-forts as a site-type, placing them in a chronological and spatial perspective, and creating opportunities for 
further study.The uniqueness of the methodology has applications elsewhere in the study of wetland phenomena, including other marsh-forts.

By rethinking the existing archaeological evidence and adding in-depth analysis, the whole fills a conspicuous gap in the current research. This thesis looks at a group of Iron Age monuments that have been hidden in plain sight, and presents a framework through which to investigate their role in later prehistoric society:

'The hardest thing of all to see is what is really there...' (Baker, 1967)

\subsection{Definitions}

\subsubsection{Defining terms}

Key words are defined throughout the thesis; a List of Abbreviations is included in the Contents.

\subsubsection{Chronology}

This text uses common short-hand when referring to archaeological time-periods, as follows:

\begin{tabular}{|c|c|c|}
\hline & Period & $\begin{array}{l}\text { Approximate time frame } \\
\text { (after Hunter and Ralston, 2009) }\end{array}$ \\
\hline \multirow[t]{3}{*}{ Geological } & Devensian glaciation & $110,000-11,700 \mathrm{BP}$ \\
\hline & Younger Dryas & 14,500 - 11,5000 BP \\
\hline & $\begin{array}{l}\text { Holocene (individual chronozones are } \\
\text { discussed within the text) }\end{array}$ & $10,000 \mathrm{BP}$ to date \\
\hline \multirow[t]{10}{*}{ Archaeological } & Mesolithic & $\begin{array}{l}11,600-4,000 B P(9,600-4,000 \\
B C)\end{array}$ \\
\hline & Neolithic & $6,000-4,400 \mathrm{BP}(4,000-2,400 \mathrm{BC})$ \\
\hline & Earlier Bronze Age & $4,500-3,500 B P(2,500-1,500 \mathrm{BC})$ \\
\hline & Later Bronze Age & $3,500-2,750 \mathrm{BP}(1,500-750 \mathrm{BC})$ \\
\hline & Iron Age & $\begin{array}{l}2,800 \mathrm{BP}(800 \mathrm{BC}) \text { - AD first- } \\
\text { century }\end{array}$ \\
\hline & Earliest Iron Age & $2,800-2,600 \mathrm{BP}(800-600 \mathrm{BC})$ \\
\hline & Early Iron Age & $\begin{array}{l}2,600-2,400 / 2,300 \mathrm{BP}(600- \\
400 / 300 \mathrm{BC})\end{array}$ \\
\hline & Middle Iron Age & $\begin{array}{l}2.400-2,300-2,100 \mathrm{BP}(400 / 300- \\
100 \mathrm{BC})\end{array}$ \\
\hline & Late Iron Age & $2,100 B P(100 B C)-A D 43 / 84$ \\
\hline & Roman & AD $43-410$ \\
\hline
\end{tabular}




\subsubsection{Radiocarbon dates}

The details of radiocarbon dates obtained by this research are presented in Table 7.2 and Appendix 5 (results before present (BP); laboratory numbers; calendrical date range at the $2 \sigma / 95.4 \%$ level of confidence). The dates for environmental evaluation cited in the text are presented as uncalibrated dates BP. Where radiocarbon dates are quoted for specific site dating, they have been re-calibrated using the OxCal (v4.3) radiocarbon calibration programme (https://c14.arch.ox.ac.uk/oxcal.html). Where this was not possible, dates are incorporated using $B C, A D$ or $B P$, depending on the source text. 


\section{The British Iron Age, hillforts and marsh-forts - Literature Review}

'...the past exists only in the things we say about it' (Johnson, 2010:12)

This thesis contends that marsh-forts should not be viewed simply as another variation on the theme of hillforts, but can contribute an additional narrative to Iron Age studies. The literature review presented here creates a knowledge foundation on which to build an investigation of marshforts, and establishes a vocabulary to be used throughout this thesis.

As late as 1995, Hill considered that there had 'been little concern with either documenting or analysing the history of Iron Age studies' (Hill, 1995a:51). This intervention was written when British Iron Age studies were starting to develop increasingly sophisticated societal models to explain the pre-Roman era. Since then, many volumes have amalgamated and synthesised the archaeological evidence (e.g. Cunliffe, 1974; 1991; 2005; Gwilt and Haselgrove, 1997; Bevan, 1999; Haselgrove and Pope, 2007; Haselgrove and Moore, 2007) and the body of work devoted to the Iron Age is now considerable. The accumulated data reflect changes in archaeological theory and practice and present a shifting picture of what we now think of as Iron Age society.

Hillforts are the most archetypal and investigated monuments of the British Iron Age and have been studied individually and grouped typologically; they have been interpreted as defensive forts, power bases or centres for communal and ceremonial activities. Despite their regional nature, the study of hillforts dominates the later prehistoric record and has an overarching impact on the paradigms created for Iron Age society (e.g. Hawkes, 1931; 1959; Hodson, 1964; Collis, 1981; Cunliffe, 1983; Haselgrove, 1986; Gent and Dean, 1986; Bowden and McOmish, 1987). However, individual sitetypes within the hillfort genre are often neglected, and this is especially true of marsh-forts. Whilst marsh-forts share chronological and general morphological similarities with their hillfort counterparts, their location in low-lying wetlands sets them apart. The marsh-fort literature relates almost exclusively to Sutton Common (Parker Pearson and Sydes, 1997; Van de Noort et al., 2007), a synopsis of which is presented below.

The process adopted by this literature review is a traditional one, and is presented in two parts. Firstly, a concise historiographic review introduces key published material and grey literature pertaining to the development of Iron Age studies. Secondly, and drawing heavily on excavational data, hillforts and settlement patterns are presented to establish a baseline for Iron Age landscape studies. This chapter concludes with an introduction to marsh-forts and in particular the site of 
Sutton Common. The literature for landscape and wetland archaeology is reviewed as required throughout the remainder of the thesis.

\subsection{Summarising Iron Age studies}

\subsubsection{Antiquarian and early twentieth-century paradigms}

From the fifteenth-century onwards, antiquarians often described those who inhabited the British Isles before the Roman conquest under the broad heading of 'the Celts' (e.g. Hunter, 1971; Hides, 1996; Collis, 2003; Thurston, 2009). The Celtic myth was enhanced throughout the nineteenthcentury by discoveries at sites both in Continental Europe (at Hallstatt and Lake Neuchâtel) and at major British sites such as Glastonbury lake village, Hengistbury Head, and hillforts across southern England, creating 'an Iron Age romanticized through a millennium of folkloric literature' (Thurston, 2009:347). Early British archaeologists concluded that the arrival of Celtic tribes from Central Europe overtook the indigenous population of pre-Roman Britain (e.g. James, 1993; Hill, 1995a; Collis, 2003), providing '... a series of ready-made societal models against which the archaeology (including hillforts) of Iron Age Britain could be assessed' (Armit, 2007:25). To an extent, these models still pervade studies of the British Iron Age (Hingley, 1984; James, 1993) and they represent one stage in the evolution of archaeological thought from Restoration, through the Enlightenment, Romanticism and Colonialism, and into today's post-modernist world (Trigger, 2006).

Early twentieth-century archaeologists drew heavily on the Celtic model. Applying a culture-history approach to the architecture and morphology of hillforts, Hawkes was the first to propose a coherent hypothesis for the British Iron Age (Hawkes, 1931), associating the temporal and spatial development of hillforts with waves of Celtic incursion. The resulting chronological segmentation, into Iron Age A, B, and C, portrayed Britain as the passive recipient of this sequence of cultural invasions. At around the same time, Fox (1933) proposed a model on which to build theories of British prehistory which separated Britain into two topographical zones - an agricultural Lowland (south/east) which was influenced by ideas from Continental Europe, and a more conservative, pastoralist, Highland (north/west). The models proposed by Hawkes and Fox were hugely influential and gained an immediate audience. For example, Lily Chitty, Shropshire historian and Fellow of the Society of Antiquaries, used both to conclude that the hillforts in the Welsh Marches were the result of Iron Age B/Belgic invaders who arrived around the fourth-century BC via the Severn Estuary (Chitty, 1937; Cunliffe, 2005:10).

Fox's Highland/Lowland segmentation prevailed until the 1960s, but thanks to an improved understanding of regionality, palaeoenvironment and climatic change, it is now substantially overturned (Haselgrove, 2009:151). Hawkes' A, B, C hypothesis lasted a similar length of time. 
However, despite a major revision (1959), his model continued to see social change as the result of continental invasion and conflict between ethnic groups, whilst its chronology developed algebraic complications. The revision was attacked, first by Hodson, who considered that Britain in the Iron Age was "...peripheral to, but still in touch with the main centres of development..." (Hodson, 1964:105), and then by Clark, in whose opinion “...the correlation of hillfort construction with external menace is at best no more than a hypothesis..." (Clark, 1966:186). Clark cited pā sites in New Zealand as evidence of non-invasion driven social and technological change. 'Here the construction of hillforts had...nothing whatever to do with external enemies: on the contrary the hillforts were an expression of a particular form of society in which prowess in fighting conferred status on leaders and lent spice to the lives of their followers.' (Clark, 1966:186) ${ }^{2}$. Surprisingly, Hawkes' invasionist model was not quick to die and was still being promulgated well into the 1970s (e.g. Stanford, 1972a; Powell, 1974:291; Hogg, 1975).

Where low-lying Iron Age fortifications were described at all during the early years of archaeological investigation, they were interpreted as Celtic, Roman or Dark Age monuments (see Chapter 5 and Appendix 3). During the 1870s, Sutton Common was considered to be 'A Roman Camp' (Whiting, 1936:57). Whiting, who undertook excavations at the site in the 1920s/30s, subsequently described it as a contour camp and marvelled that anyone should make use of such a benighted place when there was higher and drier ground about a mile away. He concluded that 'perhaps weak and timid people found refuge here amongst the waters' (Whiting, 1936:79-80). In Norfolk, Holkham and Bloodgate Hill (see Chapter 4) were considered to have been erected as protection against the Danes (Spelman, 1698). Stonea Camp in the Cambridge Fens was known for its 'earthen rings' in Victorian times, and its past was considered Anglo-Saxon or Viking (Malim, 2005:45,52). Interpretations of the antiquity of the Berth and Wall Camp in North Shropshire were fuelled by references in early Welsh poetry to Cynddylan, a seventh-century Prince of Powys who was slain by 'the English'. The Welsh lays record that he was buried at the Churches of Bassa (Eg/wyseu Bassa) which has been interpreted as Baschurch, near the Berth (e.g. Owen and Blakeway 1825; Hartshorne, 1841) (see Appendix 3). The Berth has also been connected with the Arthurian legend (e.g. Phillips and Keatman 1992).

\subsubsection{A 'New Archaeology' for the Iron Age}

By the 1960s, archaeological methodology and interpretation were beginning to benefit from the innovations and methods which are now commonplace. Cognisant of the criticism that a culture-

\footnotetext{
${ }^{2}$ Whilst there are elements of truth in this, it is now accepted that the main drivers for pā development in New Zealand were inter-tribal rivalry and early population pressure on horticultural lands, prompted in part by the extinction of the moa (e.g. Davidson, 1987; Anderson, 1991).
} 
history approach lacked both objectivity and an anthropological core (Binford, 1962; Binford and Binford, 1968; Schiffer, 1972; Johnson, 2010), archaeological investigation became increasingly scientific and systematic and established itself as 'New (Processual) Archaeology' (Clarke, 1968). Processual thinking revolutionised archaeological excavations, applying a project-based methodology to answer pre-defined research questions, explaining rather than simply describing social and economic aspects of past societies. It brought together a range of applications, some of which, for example aerial photography and palaeoenvironmental studies, had been in existence since the 1920s but had not been combined within the archaeological discipline (e.g. Crawford, 1928; Godwin, 1934). Chronologies which had previously relied on typology became more objective through the routine application of radiocarbon dating. A more scientific approach to climatic modelling identified temperature fluctuations throughout the Holocene which had a direct impact on human development; for example, cooler and wetter climatic conditions from circa 800BC were interpreted as forcing a contraction of landuse as people retrenched from upland areas (Limbrey and Evans, 1978; Lamb, 1981; Balaam et al., 1982) (however, see 2.2.3 below). Many of the models presented as part of the 'New Archaeology' seem simplistic now, and individual case studies confirm that the overall pattern was more regional and more nuanced (Tipping, 2008; Armit et al., 2014), but at the time, they were revolutionary.

Hillforts and hillfort settlements continued to be the prime focus for Iron Age studies and benefitted from a systematic and increasingly scientific approach. Excavation techniques moved away from the narrow trenches-through-earthworks favoured before the 1940s and turned increasingly to hillfort interiors (e.g. Guilbert, 1975b; Cunliffe, 1983), using techniques first applied by Bersu at Little Woodbury (1940). However, ramparts and ditches, with their military and defensive overtones, continue to be a focus and still prompt debate (Collis, 2010). The knowledge gained was blended with a range of techniques drawn from the geographical and social sciences to create new models for Iron Age communities. Core-Periphery Analysis (Haselgrove, 1982) proposed hierarchical societies organised around clan groupings, commanded by chiefs (e.g. Millett, 1992), whilst Central Place Theory and Site Catchment Analysis proposed a hierarchy and structure for wider settlement patterns (Haselgrove, 1986; Gent and Dean, 1986); each model placed hillforts at its core.

This was also an era of long-term, large scale hillfort excavations. Whilst the Welsh Marches and North Wales attracted attention (e.g. Stanford, 1967; 1980; Guilbert, 1975a; 1978; Musson et al., 1991), Wessex, with its profusion of sites and rich material culture, provided the backbone from which Iron Age societal models were constructed. Of all the Wessex hillforts, the results from Cunliffe's excavations of Danebury in Hampshire continue to influence modern thinking (e.g. 
Cunliffe, 1983; 2000; 2005; Lock and Harris, 1996). Dating from the sixth-century BC and occupied for over 500 years, the archaeological evidence charts the increasing complexity of Danebury's external architecture and internal patterning, as ramparts were remodelled, entrances altered, fourand six-post structures (interpreted as granaries) replaced round houses, and, later, shrines were created. Danebury's evidence provided an example of the consolidating settlement patterns of the Middle Iron Age where fewer 'developed' hillforts overtook smaller fortifications and appeared to exercise control and military dominance over the local community and accompanying trade routes (see below). Danebury was presented as an example of Sahlins' 'redistributing chiefdoms'(1963), where a hierarchical Iron Age/Celtic 'tribe' led by a 'chief' controlled a defined territory from a hillfort base (see Fig. 2-1).

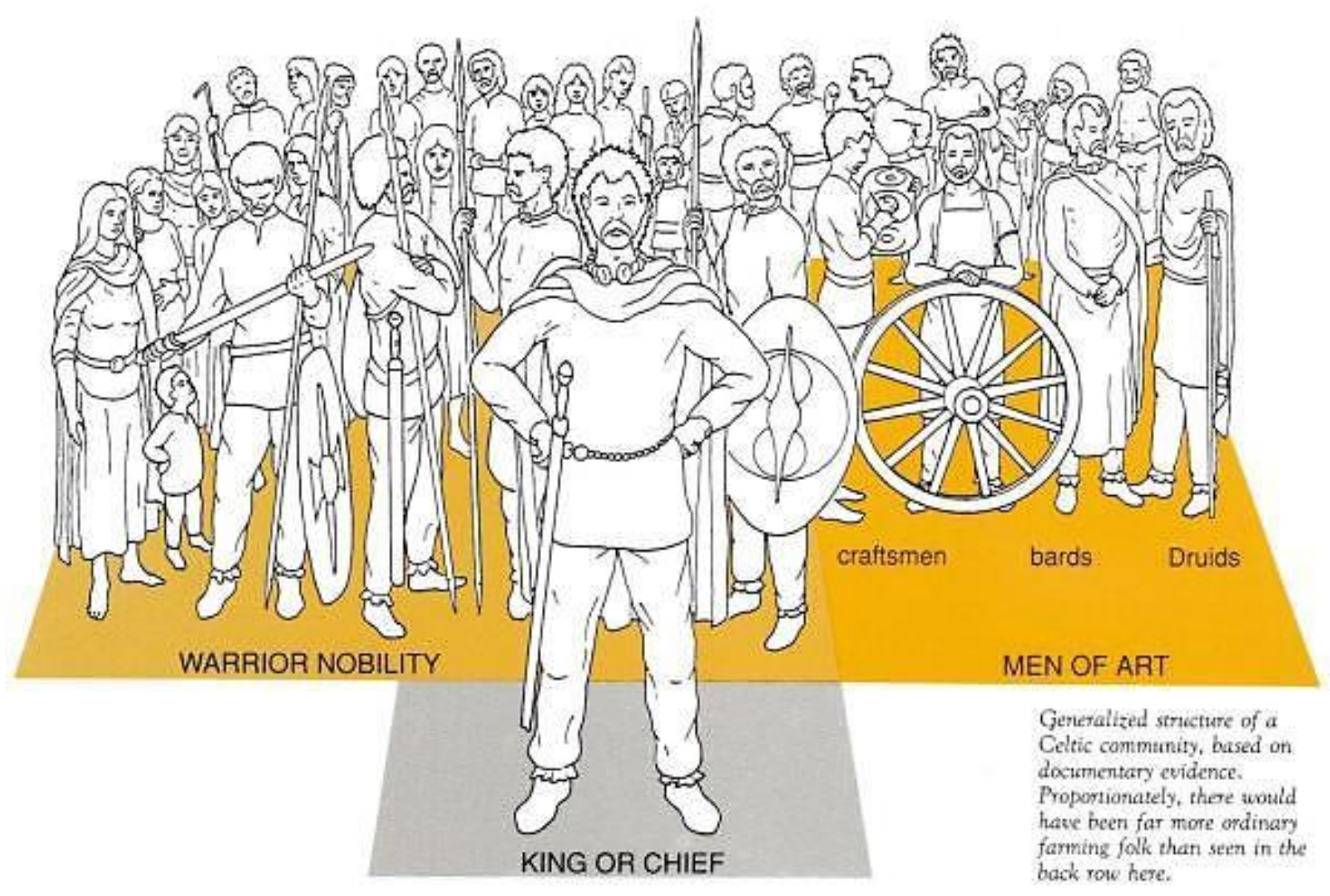

Fig. 2-1 Generalised structure of a Celtic community (James, 1993:53)

Cunliffe's presentation of Danebury as a universal model for Iron Age society and settlement was attacked on numerous fronts almost as soon as it was proposed (Collis, 1981; Haselgrove, 1986; Hill and Cumberpatch, 1995). Not only did it ignore topographical and environmental differences between Wessex and other hillfort zones, it was also criticised for disregarding the fact that some regions of Britain did not have hillforts at all. Hill launched a devastating attack on the perceived notion that 'biggest (Danebury) was best' and always lay at the top of the settlement structure (Hill, 
1995). In societal terms, it has been criticised for presenting 'a quasi-feudalistic model of 'Celtic' Iron Age society' (Wigley, 2002:65), synthesising concepts of Celtic societies and Medieval Irish heroic literature and retro-fitting the result onto the Iron Age. In spite of a certain 'rowing back' on Cunliffe's part (Cunliffe, 2006), the criticisms continued (e.g. Sharples, 2010). However, Cunliffe's hierarchical model has been used extensively (e.g. James, 1993), and hillforts are still, deliberately and knowingly, referred to as 'Celtic Fortifications' (Ralston, 2006).

Despite these differing opinions, the 'new terminology' coined as part of the processual approach 'central places, site hierarchies, ports of trade, pre-industrial cities' (Collis, 2010:31) - remains part of the Iron Age vocabulary to this day.

\subsubsection{A post-processual perspective}

Processual archaeology was ultimately criticised, principally for a dehumanising, overly scientific approach (e.g. Shanks and Tilley 1987; Bender, 1993; Tilley, 1994). Post-processualism proposed that the phenomenological landscape was not a passive backdrop to human agency, the human body was a metaphor through which landscapes were construed, and the whole was imbued with symbolic and philosophical meaning (e.g. Tilley, 1994; 2010; Gosden, 1997). This is explored in more detail in Chapter 4.

When applied to the Iron Age, the result was an outpouring of alternative interpretations for the bread-and-butter of Iron Age studies (Hingley and Miles, 1984; Collis, 1987; Bowden and McOmish, 1987; Stopforth, 1987; Marchant, 1989; Sharples, 1991b; Hill, 1995; Hill and Cumberpatch, 1995; Parker Pearson, 1999). Hillforts had been seen as martial in nature ever since Hawkes' categorisation of the Iron Age, albeit that some (e.g. Alcock, 1965) argued for a wider role. This function was now actively questioned and their status as purely practical structures was challenged (Bowden and McOmish, 1987; 1989; Hill, 1995). New and alternative hypotheses ranged from hillforts as examples of the conspicuous consumption of labour, as the visible manifestation of power (Trigger, 1990:127), as nodal points in the exercise of trade and the control of routeways (Sherratt, 1996; Bowden, 2005), and/or as the means of facilitating exchange and production (Gosden, 1997). Driver interpreted hillfort sites in Mid-Wales as symbolic 3D artefacts-in-a-landscape revealing 'a society bent on achieving monumental display, ...sharing façade schemes and design concepts, and 'harnessing' the landscape through architectural complexity and symbolic projection' (Driver, 2007:87). Driver's suggestions exemplified an emerging emphasis on the relationship between 'place' and the human experience (Gosden and Lock, 2007).

It had long been thought that hillfort construction was the result of gang-working and a fulfilment of community obligations (Piggott, 1931; Wigley, 2002). Lock took this further, viewing these 
monuments as community-level demonstrations of prestige and status, structuring 'the sociality of people whose interests are in creating a harmonious existence' (Lock, 2011:355), but stopping short of seeing them as 'prehistoric anger management therapy' (Lock, 2011:359)! Brown reiterated these views, suggesting that hillfort construction was an end in itself, reflecting the Iron Age preoccupation with controlling the land and the agricultural process (Brown, 2008:195).

Despite such philosophical discourse, the case for hillforts as strongholds against endemic violence continues to be promoted (James, 2007; Armit, 2007; 2011; Harding, 2012). Keeley has suggested that archaeologists and anthropologists have connived to pacify the past, airbrushing the unpleasantness of war from prehistory and creating 'the past as wished for' (Keeley, 1996). The evidence is mixed. Whilst violence was apparent at hillforts such as Maiden Castle, Dorset (Sharples, 1991a), Sutton Walls (Kenyon, 1953) and Fin Cop (Waddington, 2011), the overall volume of evidence is not huge. History tells us that a millennium without skirmishes or intertribal conflict is unlikely; perhaps, when hostilities occurred, they happened away from hillforts. Whilst this debate is sure to continue, these views confirm that hillforts were multi-faceted phenomena, variable across space and time at both intra- and inter-site level (Sharples, 1991a; Lock, 2011), a summary which may prove equally applicable to marsh-forts.

Interest in ritual and religious behaviour in Iron Age societies also increased from the 1990s onwards, and began to be recognised in each aspect of Iron Age living, from the construction of houses and hillforts to depositionary practice. High-status offerings, for example of prestige metalwork, were shown to be geographically localised and chronologically phased throughout the first-millennium BC, and favoured specific sites in wetlands (Wait, 1985). Finds deposited at the Iron Age causeway site of Fiskerton indicated a practice similar to that identified at the nearby Late Bronze Age site of Flag Fen (Field and Parker Pearson, 2003; Pryor, 2005). At a different end of the spectrum, Hill concentrated on the ritual elements embedded in the structured deposition of what appeared to be everyday rubbish on domestic sites (Hill, 1995b), and demonstrated that the intertwining of domestic and ritual behaviour was apparent in '...offerings of food and objects associated with daily life...' which were '... part of a general ritual focus on home and harvest' (Hill, 1995a:66). Hill's findings have recently been criticised as overly interpretive (Garrow, 2012; Thomas, 2012) but they were integral to conclusions that all actions associated with fertility and productivity were imbued with meaning during the formative years of the agricultural economy (Bradley and Yates, 2007), and that modern divisions between ritual and domestic behaviour should not be retrofitted onto prehistoric societies (e.g. Brück, 1999). 
Symbolic metaphors suggesting belief in a wider cosmology were identified within the concept of enclosure, depositionary practice and the layout and orientation of structures. For example, 'foundation' deposits have been recognised in numerous hillforts and marsh-forts (for example, at Borough Fen; French, 1988). The dominant orientation for entrances (to hillforts and Iron Age houses) was mainly east, to face the rising sun (Oswald, 1997; Giles and Parker Pearson, 1999). Wider cosmological beliefs were also identified from the Arras burials in East Yorkshire (Stead, 1991), leading Parker Pearson to propose that this particular community was strongly hierarchical and supported a concept of sacred leadership (Parker Pearson, 1999).

Although some of these models are highly localised, they continue to inform debate regarding ritual and ceremonial behaviour during the Iron Age and emphasise the regionality of Iron Age communities. By the later Iron Age, religious practice was becoming increasingly formalised, as evidenced by the creation of shrines, for example, at Fison's Way, Thetford (Gregory, 1991), Hayling Island (Wait, 1985) and Uley Bury in the Cotswolds (Woodward and Leach, 1993).

\subsubsection{Thematic Studies and Agendas}

The broad narrative of Britain's Iron Age came together for the first time in Cunliffe's Iron Age Communities in Britain (1974), and subsequent editions remain the main synthesis of Iron Age studies $(1991 ; 2005)$. However, as Wessex continued to be the only landscape for which there was a cohesive understanding, a wider scope was required. Reflecting the growth in developer-funded archaeology (Haselgrove, 2001b), settlement studies replaced hillforts as the main target of research during the 1990s, and several addressed settlement patterns outside southern England for the first time (e.g. Reid, 1989; Ferrell, 1995). Thematically structured publications and overarching summaries also became the norm, addressing issues of inter-regional difference, societal change, ritual and symbolism, and producing high quality data and argument which transformed obsolete interpretations (Hill and Cumberpatch, 1995; Hill, 1995a; Gwilt and Haselgrove, 1997; Bevan, 1999). In line with the call for local and regional research strategies (e.g. Olivier, 1996; Glazebrook, 1997), the academic community published 'Understanding the British Iron Age: An Agenda for Action' (Haselgrove, 2001b), which established a programme for future research under six thematic headings - chronology, settlement, landscape, material culture, regionality and the process of change - and continues to inform current debate.

The thematic approach to publication has continued in recent years. The first-millennium BC, which had been seen as homogenous and a slide into Romanisation, has now been split chronologically into two volumes (Haselgrove and Pope, 2007; Haselgrove and Moore, 2007). These volumes highlight the crucial differences between the Early and Later Iron Age in areas of settlement, land 
division, material culture and social structure, and attempt to redress the imbalance which had consistently favoured Wessex. Armada and Moore extended this thematic approach to cover the European Iron Age, addressing landscape, social identity and the interaction between Britain, the Iberian Peninsula and the rest of Continental Europe (Armada and Moore, 2011).

\subsection{Iron Age landscapes - hillforts and enclosures}

By combining processual and post-processual methods and ideas, the British Iron Age is now presented as more nuanced and complex than at any time since Hawkes' invasionist hypotheses. Although neither chronologically nor geographically homogenous, the first-millennium BC is linked by themes of enclosure, the development of an agricultural economy and an increasingly bounded landscape. Hillforts run as a leitmotif through this period and represent the most complex, symbolic and variable of all the enclosure types. This next section draws on the existing literature to present a broad overview of Iron Age hillfort and enclosure landscapes, and proposes that marsh-forts are sufficiently distinctive to be reviewed separately.

Enclosure is a complex process with multiple functions and meanings. With identifiable roots in the Neolithic (causewayed enclosures) and Bronze Age (henges and palisaded enclosures), Iron Age hillforts are essentially defendable enclosures on a large scale. However, their significance and symbolism extends beyond this simplistic definition. In each case, ramparts and ditches define an interior space, and entrances allow access and egress for people and/or animals. For all its practical benefits, enclosure was a symbolic act, separating inside from outside, including and excluding, defining within and without, us and them. The process was not necessarily illustrative of a power structure or an elite - Brück interpreted enclosure as 'a means of making life more predictable in a changing world' (2000:294).

Whilst smaller enclosure sites are found across the later prehistoric British landscape, hillforts are concentrated in Wessex, southern England, the Welsh Marches, Wales and Scotland (Fig. 2-2). Although this geographic distribution largely reflects Fox's Highland Zone, Forde-Johnston (1976) noted that the majority of sites in England and Wales fall south-west of a line between the Mersey and the Thames. Large contour forts characterise Wessex and the Welsh Marches; the rounds of south-west England and the raths of south-west Wales are more accurately defined as small defended farmsteads, although many, such as Helsbury Castle, Cornwall, are classified as hillforts. Eastern England is characterised by villages and open settlements and the near absence of hillforts is much debated; the likely cause is thought to lie more in differences in social or economic structure than in simple topography (e.g. Dyer, 1981:45; Cunliffe, 2005). 
Topography plays an obvious role in the siting of hillforts, although there are wide variations, from the exposed summits of the Wrekin to the coastal peninsula site at Embury Beacon, Devon. Some sites occupy settings so extreme that they were unlikely ever to have functioned as settlements; for example, the exposed Pennine hillfort on the summit of Ingleborough (720m OD) is now considered ceremonial in nature (Luke, 2003) and the wetland nature of marsh-forts may suggest that they too were topographically extreme. Hill was amongst the first to acknowledge that differences were to be found amongst contemporary hillforts, and highlighted Stonea Camp as an example of a hillfort in a low-lying location (Hill, 1995a:68). Topography underpins most typological groupings and these are discussed below (see 2.2.1).

Hillfort chronology follows a broad pattern, although away from Wessex, detail is lacking and there are many exceptions (Cunliffe, 2005). Some hillforts, such as The Breiddin, Powys (Musson et al., 1991), originated in the Late Bronze Age circa 900BC as palisaded hilltop enclosures (a ditch combined with a substantial timber fence). Others began as univallate constructions (a single timber-framed rampart and ditch) dating from circa $700 \mathrm{BC}$. By the fourth/third-centuries $\mathrm{BC}$, some had been abandoned, whilst others became 'developed' (multivallate) especially in Wessex. Entrances through the ramparts were single or dual, seldom more, with multiple variations in the architecture including hornworks or offset ramparts; some hillforts, especially in the Welsh Marches and North Wales, exhibit recesses in the entrance passages known as 'guard chambers', although their correct function is unknown (Bowden, 2006). Most hillforts had been abandoned well before the Roman invasion in AD43; there is some evidence for re-use in later Roman times (for example, at Maiden Castle, Sharples, 1991a), and their prominent locations were often reutilised as medieval fortifications, for example at British Camp on the Malvern Hills (see also Chapter 5).

Hillforts exhibit wide disparities in size and functionality. Llanymynech on the Wales/Shropshire border is one of the largest and encloses 57ha, and its size may relate to the control of local mineral resources (copper and limestone) (Jones, Hankinson and Silvester, 2012). At the other end of the scale, the defended farmsteads (raths) of south-west Wales average less than 1.2ha. Such wide disparities are difficult to reconcile within one monument type, or between types such as smaller hillforts, defended farmsteads and enclosures (Brown, 2008:14). According to Harding, such differences are largely semantic (Harding, 2012) but, in Ralston's view, 'size matters' (Ralston, 2006:13). Jackson (1999) classified hillfort size into four categories - small (0.1-1.2ha), medium (1.33ha), large (3.1-6ha) and very large (6.1ha+); these classifications have been updated by English 
Heritage, although the size criteria are now simply 'Large' and 'Small'. ${ }^{3}$ Collfryn in Powys exemplifies the difficulties in classification. This multivallate enclosure covers $0.56 \mathrm{ha}$ and in terms of morphology and size, it would fulfil Jackson's 'small hillfort' category. However it has been referred to as both a hill-slope enclosure and a defended farmstead and in spite of its size, it has never been classified as a hillfort, presumably because it is set in an undulating, pastoral landscape. The archaeological evidence suggests an extended family homestead (Britnell et al., 1989).

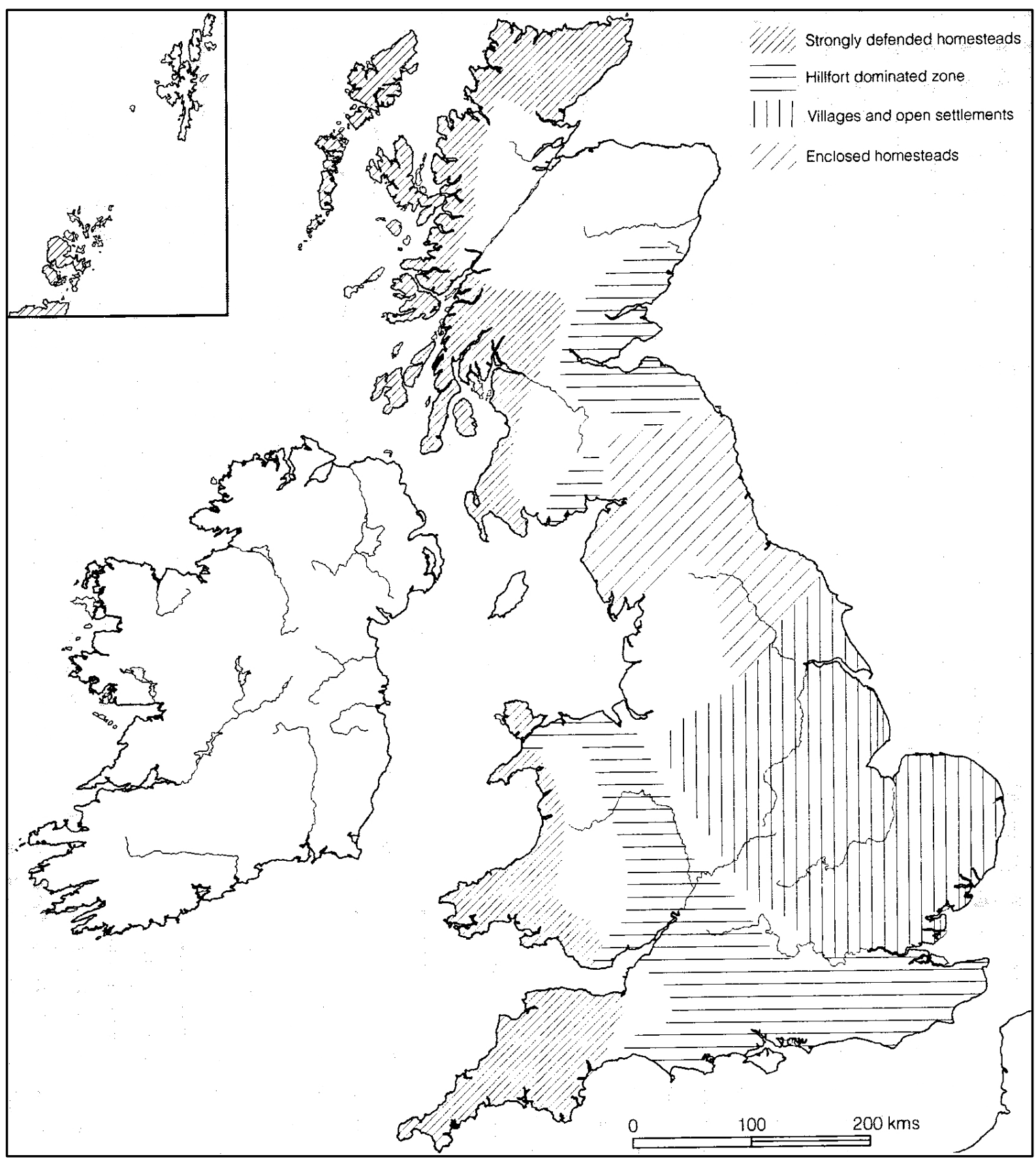

Fig. 2-2 Zones of differing settlement forms (Cunliffe, 2005 Figure 4.3)

\footnotetext{
${ }^{3}$ http://thesaurus.historicengland.org.uk/thesaurus.asp?thes no=1.
} 
Hillforts are often positioned at the pinnacle of landscape settlement hierarchies (English Heritage, 2011), and many examples - Danebury in Hampshire, Moel-y-Gaer, Rhosesmor in North Wales, Hod Hill in Dorset, Midsummer Camp on the Malvern Hills - evince internal settlement evidence ; however, there appear to be few rules in terms of which sites were settled and which were not. For example, the large exposed hilltop enclosure at Bathampton Camp, Somerset shows no evidence of settlement and may have acted as a central point for stock control within a settled landscape; it was unlikely to have been a hillfort in the conventional sense. Conversely, Penycloddiau in the Clwydian Range is also large and exposed but was extensively settled.

Given their prominent earthworks, hillforts appear defensive in character, but scenes of violent conflict were few (see 2.1.3 above). Their function as places of refuge has been frequently questioned as many hillforts have no permanent water supply. However, they clearly fulfilled a community function and Cunliffe has recently described a hillfort as '...a defined place proclaiming social unity and set aside for community activities' (Cunliffe, 2013:306). They have been interpreted as centres for territorial control (Haselgrove, 1986), central places for an annual livestock round-up (Hawkes, 1931:64; Harding, 2012:281), places for grain storage as inferred from the many four- and six-post structures at sites such as Croft Ambrey (Gent, 1983), centres for metalwork production (Hunsbury Hill, Northamptonshire), and/or as nodal points to co-ordinate trade (Sherratt, 1996). Other hillforts, such as Scratchbury Camp, Wiltshire were almost certainly centres for ritual or ceremonial activity (Forde-Johnston, 1976; Hogg, 1979). However, functionality is unlikely to have been exclusive and such interpretive divisions, especially between domestic and sacred sites, reflect a modern desire to separate and categorise (Wait, 1985; Giles and Parker Pearson, 1999). For example, both British Camp and Midsummer Hill have extensive settlement evidence, but their location also suggests that they controlled the routeways over the Malvern Hills, and their marginality has suggested a spiritual function as 'remote retreats' (Bowden, 2005:24-5), although this sounds rather like a yoga weekend. Wider cosmological issues are evident in the construction of many hillfort sites for which all other evidence appears domestic, as shown, for instance in the eastward orientation of many entrances; the distinctive stone used in some rampart fascia has also been cited in support of this argument but it may simply have been a means of displaying prominence to a wider world (also seen at Midsummer Hill, Bowden, 2005:24). This multiplicity of evidence argues strongly for what the modern world would consider a blurring of functionality.

It is also unlikely that one monument/monument type would have retained its original function and status across, for some monuments, 1000 years of social development. Hillforts in south-east England have been re-contextualised to reach a finely-tuned spatial and chronological narrative, where distinct functional changes reflect 'broad reconfigurations within social systems through the 
first-millennium BC' (Hamilton and Manley, 2001:34). Danebury was also adapted as social and practical imperatives changed (Cunliffe, 1983).

In summary, many hillforts are neither on hills, nor are they guaranteed to be forts. The variety and contradictory nature inherent in much of the hillfort evidence should act as a warning to treat the labelling of hillforts, and marsh-forts for that matter, cautiously (cf. Collis, 1996).

\subsubsection{Inventories, classifications and groups}

Perhaps because hillforts exhibit such differences, they have been subject to numerous attempts at indexing and classifying, and many frameworks for hillfort and settlement studies have used topographical groupings as aids to clarification and classification. Hogg produced the first recognisable inventory of hillforts across Britain (Hogg, 1979). Forde-Johnston (1976) classified hillforts under seven topographical categories, whilst Dyer used five (1981). Those more or less level with their immediate surroundings and relying on water for their defences (and therefore closest to marsh-forts) were included in 'Grp VII - Plateau \& Low Lying Situations' by Forde Johnston and as valley-forts - 'a rare subspecies' - by Dyer (1981:13). Many of these classifications are still in use.

The recently published Atlas of Hillforts of Britain and Ireland, Version 1.0.1 (hereafter referred to as the Atlas) (Lock and Ralston, 2017) builds on previous indices. Sponsored by the Arts and Humanities Research Council (AHRC) and run as a joint project between the Universities of Oxford and Edinburgh, this online resource aims to remedy the patchy quality of documentation and analysis seen in previous hillfort publications. The Atlas summarises hillforts under seven headings, albeit different from Forde-Johnston's, and is the first to use 'Marsh-fort' as a category. Information from the Atlas has been used extensively in this thesis (see Chapter 4).

Several volumes explore and summarise hillforts without providing an inventory or typological assessment. Beacons in the Landscape (Brown, 2008) contains well-illustrated surveys, and makes reference to 'marsh-forts' as a site-type, whilst Iron Age Hillforts in Britain and Beyond (Harding, $1976 ; 2012$ ) presents a survey which ranges across landscape, chronology, function, and ethnographic studies but without referencing marsh-forts.

\subsubsection{Hillfort, enclosure and the implications for settlement}

Many studies of Iron Age landscapes position hillforts as central points in a wider settlement. However, Iron Age enclosure types and settlement patterns show marked regional variations irrespective of whether they are associated with hillforts (Fig. 2-2). 'Open' and enclosed homesteads - single farmsteads with or without enclosing earthworks - are found primarily in eastern England; curvilinear and rectilinear enclosures are associated with the hillfort zone of the Welsh Marches 
(Whimster, 1989) and banjo enclosures are largely found in southern England (Hingley, 1984; Lang, 2016).

Settlement studies have tended to reflect the same southern bias as hillforts, often concentrating on Wessex and the Upper Thames Valley. In one study of the Oxford Clay Vale gravels, Hingley (1984) demonstrated that a dense but fairly open pattern of enclosure was associated with larger scale communities which controlled access to specific agricultural lands in river valleys. These were separated from the more widely dispersed communities of the uplands, where banjo enclosures indicated an economy with common access to upland pasture (Hingley, 1984:85). Conversely in Wiltshire, site distribution indicated a preference for farmsteads which combine rather than separate access to pasture and arable agricultural land (Ellison and Harriss, 1972). More recent studies have looked north (e.g. Ferrell, 1995; Chadwick, 1999;2010); in north-east England, Willis found a similar patterning to that found in the Upper Thames, where the nature and morphology of the settlement enclosure were closely associated with its landscape setting (Willis, 1999).

Settlement studies of the Iron Age in the Welsh Marches and Wales are not extensive. However, the case-study element of this thesis is located in North Shropshire and therefore, the area is of direct relevance to this literature review. Excavations that centred on hillforts in the 1970s tended to concentrate on the hillfort itself and not the surrounding settlement pattern (e.g. Stanford, 1972b; Guilbert, 1975a; 1975b). Hogg's analysed the region's small hillforts/enclosures (<.7ha) and concluded that smaller 'forts' occur in clusters and show a distribution markedly different from larger forts (Hogg, 1972). Jones assessed Iron Age settlement and material culture across Wales and the Marches, and concluded that hillforts reflected landscapes where threat was inherent (Jones, 1984:28). The Welsh Marches is a far from homogenous landscape, and this shows in the literature; Carver concluded that enclosures in lowland Shropshire in particular do not divide easily between hillfort and lowland farm (Carver, 1991:4). Jackson (1999) divided the Marches into zones each of which indicates a difference in social organisation. Small settlements associated with large hillforts acted as a cohesive focus for the needs of the surrounding community in Hereford and Shropshire, whilst a more segmented and separate society was organised at individual household level in western Shropshire and Powys; a separate pattern in Clwyd and Gwent was characterised by the amalgamation of settlements into larger communities (Jackson, 1999:212). Wigley sought to bring some structure to these various arguments (Wigley, 2002) and identified that hillforts were often associated with linear ditches and clusters of smaller enclosures, suggesting a social structure in which land was increasingly organised and territory controlled (Wigley, 2002; 2017a). 


\subsubsection{Iron Age climatic change and changes in landuse}

Each of the settlement patterns referred to above is a reflection of the profound societal changes which characterise the Iron Age, as people created tenured landscapes by clearing land, growing crops and adopting agricultural/pastoral lifestyles. Numerous palynological and alluvial studies provide evidence for anthropogenic woodland clearance and increased alluviation from the Late Bronze Age onwards (Shotton, 1978b; Brown, 1988; 1990; Macklin and Lewin, 2003; Macklin et al., 2005), a process which intensified as the Iron Age progressed (e.g. Fyfe et al., 2004).

However, this period of intense social change coincided with 'a catastrophic decline to a cooler and/or wetter climate around 2850 - 2550 BP' (Barber, 1982:110; Barber et al., 1994; 2003; Brown, 2008), a climatic shift which continued, with fluctuations, for the remainder of the first-millennium BC. Earlier studies (Limbrey et al., 1975; Limbrey and Evans, 1978; Lamb, 1981) drew the conclusion that, as the climate worsened, upland areas became agriculturally unproductive whilst river valleys, lowland marsh and shorelines became increasingly prone to flooding, with land abandonment and population decline the ultimate outcome. Recently however, this interpretation has been questioned. Dark reviewed the results from seventy-five pollen cores from across northern England and Wales and concluded that '...climatic deterioration in the Late Bronze Age and Iron Age did not trigger large scale long-term land abandonment across Britain as a whole' (Dark, 2006:1391); marginal uplands showed no obvious evidence of wholesale abandonment (except perhaps in Wales) and there was no appreciable shift from arable to pastoral farming (Dark, 2006:1392). A regional study of landuse in later prehistoric Devon indicated continuity in pastoral landuse throughout the Iron Age and into the Roman period with no retreat from more marginal areas (Fyfe et al., 2004:1712), whilst a compilation of later prehistoric pan-European palaeoenvironmental data indicated that agricultural land expanded into higher latitudes after circa 3000BP (Fyfe et al., 2015). The current conclusion is that, although climatic worsening may have led to a re-ordering of landuse and settlement, the effects were localised and influenced by topography and altitude.

However, there appears to be an 'indisputable' (Harding, 1982) connection between climatic change and settlement evidence in some lowland locations. The latter half of the first-millennium BC saw the emergence of lake villages and crannogs, settlement types which made express use of wetland. Glastonbury and Meare lake villages on the Somerset Levels have produced some of the most important evidence for how people lived during the later Iron Age, and the excavation of these sites has been extensively summarised (Bulleid, 1968; Coles and Coles, 1986; Coles and Minnitt, 1995). The two settlements were built on raised mounds within an extensive wetland environment and were contemporary. The material remains suggest that Glastonbury was primarily a domestic settlement and a centre for exchange, and provided a wealth of evidence for textile production and 
metal working (Coles and Minnitt, 1995). Meare produced finds which suggest that it specialised in glass production and it has also been interpreted as the location for a seasonal fair (Haselgrove and Moore, 2007:4; Haselgrove, 2009:165). The wetland conditions in both villages preserved extensive artefactual and ecofactual evidence which enabled not only the reconstruction of the domestic environment but also the wider landscape. For example, recent palaeoenvironmental analysis suggests that Glastonbury village was surrounded by water during the winter months only; in summer, the site would have been more accessible, suggesting that 'swamp' village was a more accurate label than 'lake' village (Aalbersberg and Brown, 2011).

Glastonbury and Meare are considered unique and have no true parallels elsewhere in Britain (Minnitt, 2000); however, they do share some similarities with crannogs. These multi-functional, multi-temporal (Neolithic to post-medieval) islet sites were built on piles and located in lakes across Ireland and Scotland. Most were circular in form with earth or clay floors which were repeated renewed because of the wet conditions; the artificial island was usually connected to the mainland by a causeway of some sort. Examples include Buiston in Scotland (Barber and Crone, 1993) and Knocknalappa and Clonfinlough in Ireland (cited in Crone, 1993). As a site-type, they are generally thought of as domestic, single or extended family sites (Harding, 2000).

The increased exploitation of wetlands evinced by the emergence of lake villages and crannogs in later prehistory may have relevance for the creation of marsh-forts. Each provides comparative evidence for Iron Age praxis and extensive reference is made to both site-types in the remainder of this thesis.

\subsection{Marsh-forts}

The earliest references to marsh-forts occur in a review of cropmarks in South Yorkshire and North Nottinghamshire (Riley, 1980; Parker Pearson and Sydes, 1997; Chadwick, 1999; 2010). Riley coined the term, without explanation, for the low-lying, double-ditched enclosure of Moorhouse Farm, Tickhill (1980:35), using it descriptively but without considering the potential of such sites. Parker Pearson then applied the term 'marsh-fort' to Sutton Common (see below).

In a secondary review of the cropmarks of South Yorkshire and Nottinghamshire, Chadwick reflected Riley's use of 'marsh-forts' cautiously - 'located in some of these low-lying areas are so-called 'marsh-forts', such as Little Smeaton... Moorhouse Farm and Sutton Common' - and concluded that these low-lying sites were simply 'earlier enclosed sites predating the later Iron Age' (Chadwick, 1999:152). Continuing his exploration of the area's prehistoric cropmarks and field systems in his thesis, Chadwick (2010) summarised low-lying sites as '...defended refuges and centralised storage 
areas...'. With reference to Sutton Common, he concluded that '... the lack of contemporary settlement and arable production in its immediate vicinity might suggest that it was not a 'marshfort', but rather a communal focus and even a ritual centre for more dispersed communities.' (Chadwick, 2010:35). Chadwick rejected the term 'marsh-fort' because of its defensive overtones (2010:238), preferring the somewhat bland terminology of 'enclosed sites'. Although his conclusions regarding community focus and a possible ritual function are in line with current thinking (see 2.3.1 below), issues of size, monumentality and control in a wetland landscape remain unexplored in his thesis.

In fairness to Chadwick, there are difficulties in classifying low-lying marshland fortifications. Cunliffe does not reference the term, preferring wording such as 'defended enclosures of hillfort proportions' (Cunliffe, 2005:397) for low-lying sites in East Anglia such as Arbury Camp, Cambridgeshire, or South Creake, Norfolk. Both Harding (2012) and Ralston (2006) see low-lying fortifications as simply supplementing their defences by their proximity to the surrounding marsh.

Brown (2008) however, included a list of sites which could be classified as 'marsh-forts' - Ebury Hill, the Berth and Wall Camp (all in Shropshire), Sutton Common in South Yorkshire, and Warham Camp in East Anglia. Historic England adopted the term with clear reference to Sutton Common as follows:

'there are some instances of sites that from their form would be classified as hillforts but which are in very low-lying situations, one of the more extreme examples of which has been called a 'marsh-fort' (English Heritage, 2011).

Whether 'marsh-fort' is a legitimate classification has been substantially resolved with the publication the Atlas (see 2.2.1 above) in which they are classified as

'Defined by much of, if not the entire circuit, of the enclosing works being set within a marshy area, usually by definition a fairly level area'

With such a range of terminology - 'marsh-fort', 'enclosure', 'enclosed site', 'defended enclosures of hillfort proportions' - the Atlas provides welcome clarity.

\subsubsection{Sutton Common (Fig. 2-3)}

The archaeological site of Sutton Common is the one acknowledged 'marsh-fort' in England and Wales (Parker Pearson and Sydes, 1997; Van de Noort et al., 2007; Lock and Ralston, 2017), albeit that the South Yorkshire HER 133/01 continues to classify it as an enclosure. It defines the site-type and is used in this thesis to establish the criteria used for marsh-fort comparison (see Chapter 4). 
Sutton Common lies approximately $500 \mathrm{~m}$ to the south of Askern and $8 \mathrm{~km}$ north of Doncaster (SE563120). The site covers 6ha ('large' in hillfort terms (Jackson, 1999)), and comprises one partially multivallate larger enclosure (Enclosure A) and a univallate smaller enclosure (Enclosure B). These were set within very low-lying, flat marshland (5m OD) and are connected by a causeway over the relic palaeochannel known as the Hampole Beck. The prominent earthworks would have been a defining feature in a landscape that was topographically undistinguished. Along with other similar (though smaller) enclosure sites, Sutton Common sits '... astride an ecotone between the limestone hills to the west and the clay lowlands to the east...' and '...may have formed a social or political barrier or interface between them' (Parker Pearson and Sydes, 1997:288).

The site has been excavated several times. Whiting found evidence for a revetted palisade, several hut circles and pits, part of a human skull, animal bones and organic remains, a portion of a wheel, and a possible well or plank-lined pit (Whiting, 1936). He concluded that the findings represented two phases of occupation which occurred before the end of the second-century AD. Parker Pearson and Sydes addressed the site over several seasons (Parker Pearson and Sydes, 1997). Finds included a possible ladder, metalwork fragments, several beads, and part of a quern; pottery remains were limited. Early Mesolithic flints were recovered north-west of the small enclosure.

Palaeoenvironmental evidence indicated that the enclosures were positioned in a relatively wooded landscape which had been cleared to create pasture. The date suggested for the occupation of

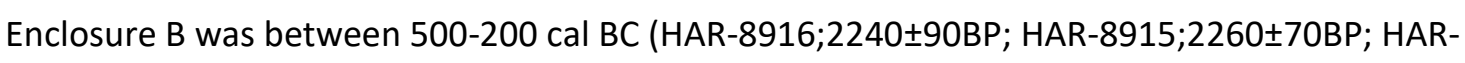

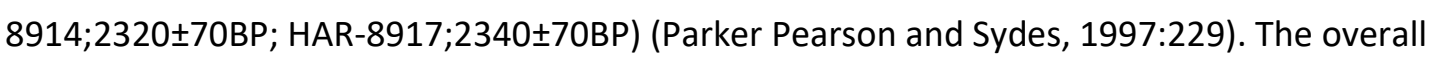
conclusion was that the site provided no evidence for a permanent elite, but was a community monument, possibly constructed under the guidance of a peripatetic architect or transitory leader (Parker Pearson and Sydes, 1997:254).

Concern for Sutton Common's safety grew following plough damage and a lowering of the water table (Van de Noort et al., 2001; Chapman and Van de Noort, 2001; Chapman and Cheetham, 2002; Cheetham, 2004), leading to wide-scale excavations of Enclosure $A$ between 1998 and 2003. The resulting monograph (Van de Noort et al., 2007) described the site as a "large enclosed Iron Age site in a wetland context' - a 'marsh-fort' - and consolidated Sutton Common's reputation as an unconventional monument (Fig. 2-3). Finds which predated the Iron Age included more Mesolithic flints and a Bronze Age mortuary enclosure (Van de Noort et al., 2007:57). The Iron Age enclosures presented no evidence for round houses or settlement; instead, over 150 four- and six-post structures were identified in the interior, and some of the post-holes contained carbonised grain. Post structures like these are frequently interpreted as domestic granaries (Gent, 1983; Cunliffe, 
2005:411), but this interpretation was considered unlikely at Sutton Common as uncharred grain was sparse (Van de Noort et al., 2007:132-5). This led to a conclusion that, and in line with findings at sites such as Danebury, their purpose was ritualistic (Ellison and Drewett, 1971; Cunliffe, 2005:593). By using dendrochronological analysis, it was possible to date the construction of the defences very precisely. The monument was built quickly between 372-350 cal BC (Van de Noort et al., 2007:113); its usage was discontinuous and short. The causeway over the Hampole Beck was shown to be a substantial, wide structure; a further causeway was identified which led away from a monumental gateway at the eastern entrance of Enclosure A towards Shirley Pool and has been suggested as a 'water-gate'(Van de Noort et al., 2007:112).

Palynological and coleopteran evidence confirmed that the woodland clearance preceded the construction of the Iron Age monument (Gearey et al., 2009). The area around the marsh-fort defences 'did not see intense or prolonged anthropogenic activity after its construction' (Van de Noort et al., 2007:113), and was used for pasture. Dense alder-carr woodland grew in the Hampole Beck channel at the time of Sutton Common's usage and may have masked the site itself. Damage to the eastern gateway suggests the site may have been ritually 'closed' during the Late Iron Age (Van de Noort et al., 2007:175-9).

Although finds were few, they included a gold bracelet/ingot, a weaving comb, amber and glass beads, and several ceramic sherds, all dating from the Middle to Late Iron Age. Human and animal remains were found on site together with 'mortuary rings', small circular areas used for the deposition of cremated human remains (Van de Noort et al., 2007:151-165). Viewshed analysis of the possible way in which Sutton Common was accessed indicated that a formalised route was used to navigate the monument, approaching it through the 'annex' of Enclosure B and processing around its ramparts, before crossing the causeway over the Hampole Beck into Enclosure A. This would create a structure which was 'revealed in stages' and reinforces the conclusion that access was likely to have been a ritualised and formal event (Chapman, 2000; 2006).

In summary, the marsh-fort at Sutton Common was constructed over a short period of time and incorporated the remains of an earlier Bronze Age mortuary site. It was then used in a three discontinuous phases, none of which were domestic in function. Combining the available evidence (excavation, palaeoenvironmental analysis, radiocarbon dating, viewshed analysis and finds), this has led to the interpretation of Sutton Common as a site of ritual or ceremonial significance for at least part of its chronology. 


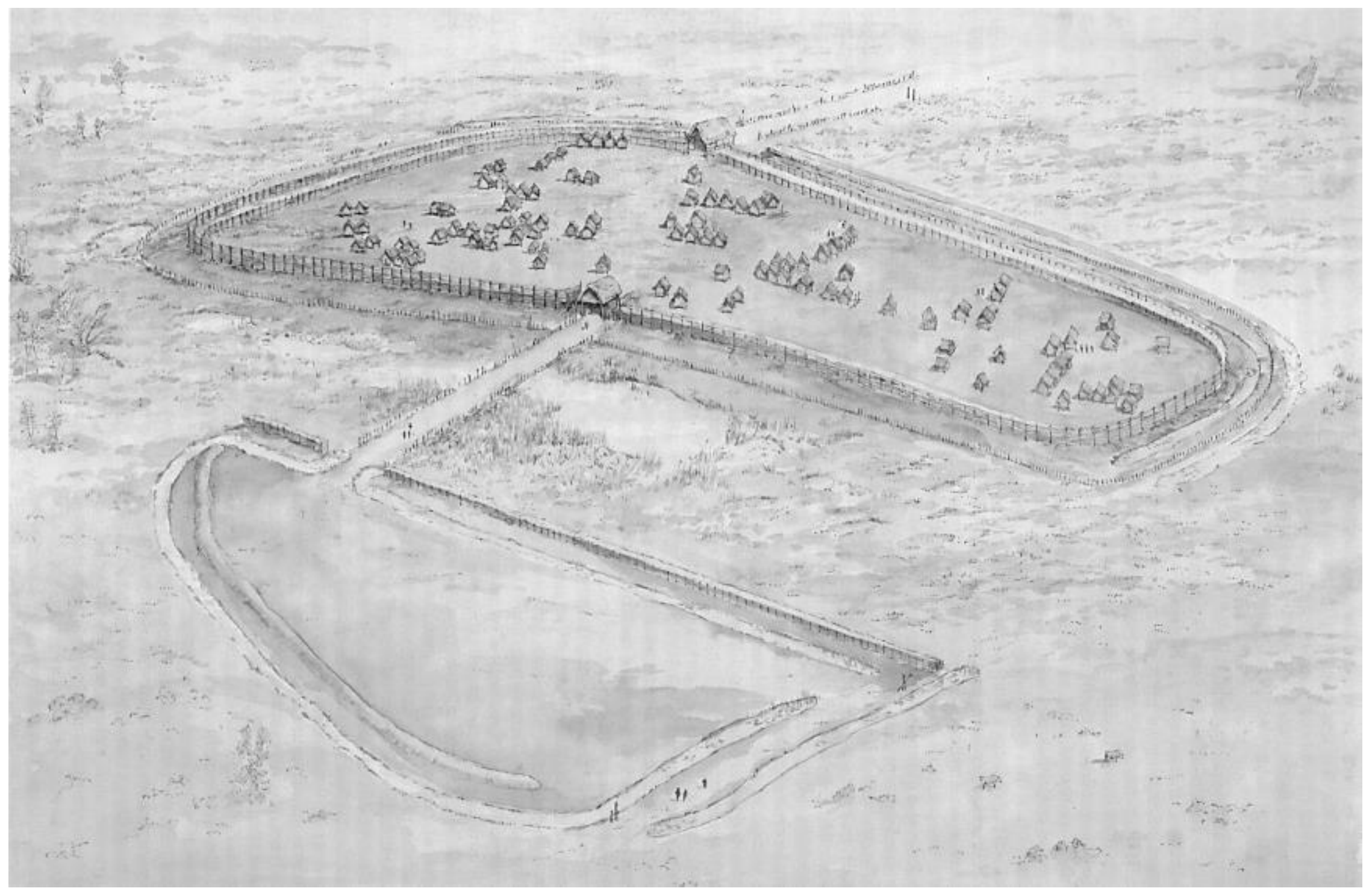

Fig. 2-3 Artist's impression of Sutton Common, showing twin enclosures, multivallation, causeways and 4- and 6-post structures (Van de Noort et al., 2007: Fig.10.1) 
In order to contextualise Sutton Common within its wider landscape, Chapman and Fletcher searched for similar sites locally, regionally and nationally (Van de Noort et al., 2007:167-174). Several of the sites in Riley's original synthesis were highlighted as being of interest in the immediate locality. At national level, the research looked for '...evidence of large, often multivallated, enclosed sites from lowland contexts in England' (Van de Noort et al., 2007:170) and a number of sites were suggested as possible 'marsh-forts'. Whilst no firm conclusions were drawn, these sites have been incorporated for comparison in the Marsh-fort gazetteer (Chapter 4).

\subsection{Summary}

This literature review charts the studies and interpretive frameworks which have characterised the British Iron Age and in particular, those associated with the development of hillforts, enclosures and marsh-forts.

In the earlier twentieth-century, Hawkes hypothesised that the British Iron Age was subject to waves of Celtic invasion from Continental Europe, bringing new material cultures and concepts of social organisation in its wake. This thinking is now substantially overturned. The social, economic and political developments which characterise Late Bronze Age and pre-Roman Iron Age Britain are now seen as largely internally driven and the British Iron Age is interpreted as a period of dramatic change coupled with regional and chronological diversity. Where hillforts dominate the landscape, they are construed less as practical and military constructions and more as prestige monuments, a 'step-up' in social organisation. However, the role of hillforts within the wider settlement system is still subject to debate, and the criteria which separate hillforts from enclosures continue to lack clarity; in the past, these criteria have concentrated on form and size but now the processes of construction and maintenance as a means of elucidating social structure are increasingly highlighted (Wigley, 2002).

However, despite of the adoption of Understanding the Iron Age: An Agenda for Action (Haselgrove, 2001b), some mighty publications (Cunliffe, 2005; Haselgrove and Pope, 2007; Haselgrove and Moore, 2007), and Collis' view that Iron Age studies are 'in good shape' (Collis, 2008), many gaps still exist. There remains an historic bias towards the south of England and Wessex. This is epitomised by the use of hillforts as the lens through which to model Iron Age society, notwithstanding that they were absent from many parts of the country, including most wetlands. Studies which concentrate on these archetypal monuments - on a hill, with ramparts and ditches - often ignore wider settlement issues, and the use of this polythetic label, often conferred historically, may hide details which may turn out to be crucial in providing the light and shade of Iron Age studies. This is the case to be made for marsh-forts within Iron Age literature. 
The importance of separating out marsh-forts for intensive study lies in the potential of their defining attribute - the surrounding wetland. Wetlands were highly utilised in prehistory for both economic and ritual purposes (e.g. Van de Noort and O'Sullivan, 2006), and the traces of how these practices occurred can often be found within the organic archive. Consequently, marsh-fort locations provide opportunities for Iron Age study which are often unavailable on hillforts. The wetland resource is often threatened by drainage and farming (for example, drainage and ploughing at Sutton Common), adding urgency to the need to look at marsh-forts individually and collectively. 


\section{Methodology and Resources}

This research was prompted by two questions - are there more marsh-forts than just Sutton Common and what evidence can they provide about Iron Age society? These questions are summarised in the aim of the thesis:-

'...to assess marsh-forts as a separate phenomenon within Iron Age society through an understanding of their landscape context and palaeoenvironmental development. To that end, this research presents a complex and original methodology for evaluating the landscape evolution of Iron Age marsh-forts at national, regional and local level.' (see 1.3.1).

This chapter describes the methodology used to fulfil this aim at each spatial scale. At macro-level and by combining literature review with site visits, a gazetteer was created of potential marsh-forts across England and Wales. Through this process, several geographical concentrations were identified. Sites in the North Shropshire group were selected for more detailed investigation of their archaeological and landscape features. From this group, two marsh-forts were selected for microlevel palaeoenvironmental and landscape study - the Berth and Wall Camp.

The Berth was chosen as a case-study site because it offered the better organic archive and shared the greatest architectural similarities with Sutton Common. The approach blends a range of disciplines, including above- and below-ground topographical modelling using ArcGIS, reconstruction of the surrounding ecosystem using multi-proxy palaeoenvironmental analysis (pollen, plant macrofossils and Coleoptera), and two seasons of excavation. The results are supported by a robust radiocarbon dating programme. Together with a comprehensive archival search (see Appendices 2 and 3) these elements contribute towards a conceptual reconstruction of the Berth's landscape across the longue durée.

This is primary research. The combination of literature search, ArcGIS modelling, palaeoenvironmental analysis, archival search and excavation expand the methodology from a multiproxy palaeoenvironmental analysis to a more comprehensive multi-disciplinary investigation, an approach thought to be unique in Iron Age studies. Whilst elements of the case-study were collaborative (two contributions are included from others who worked on the palaeoenvironmental data, and the excavations and coring formed part of CAHA field schools), subject identification, overall strategy, methodology, stratigraphic coring, plant macrofossil/beetle analysis, archival search and thesis construction were all undertaken personally. 


\subsection{Site selection - national and regional marsh-forts}

The process for site identification has been broadly outlined in Chapter 1.

\subsubsection{National Level - the Marsh-Fort Gazetteer (Objective 1 - 1.3.2)}

In order to establish the spatial extent of marsh-forts across England and Wales, possible sites were identified through a combination of literature review (including the online Atlas of Hillforts of Britain and Ireland - https://hillforts.arch.ox.ac.uk/) and desk-top analysis. 50\% of the sites were visited and a photographic record maintained; this aspect of the research is ongoing. Records for each site were interrogated via the HER (Historic Environment Record) (http://www.heritagegateway.org.uk/gateway; http://www.cofiadurcahcymru.org.uk/arch/; https://new.shropshire.gov.uk/environment/historic-environment) and the PAS (Portable Antiquities Scheme) (https://finds.org.uk/). The results were mapped using Google Earth (https://www.google.co.uk/int//en uk/earth//), with additional locational data obtained from the UK Grid Reference Finder (http://gridreferencefinder.com).

Each potential marsh-fort was then compared to criteria established by reference to the published literature for Sutton Common (see 2.3.1). An assessment was made of their similarities and differences, and conclusions were reached regarding the universality or uniqueness of the marshfort site-type (see Chapters 4, 5 and 9); sites were grouped into one of four categories depending on their level of similarity. The resulting gazetteer is presented in summary form in the text with additional detail provided on CD-ROM (Appendix 1).

\subsubsection{Regional Level - North Shropshire's marsh-forts (Objective 2 - 1.3.2)}

Several geographical concentrations of potential marsh-forts were identified in wetland locations across England and Wales. The North Shropshire concentration contains two outstanding marsh-fort examples (the Berth and Wall Camp) as well as several lesser known sites, and this combination led to its selection for further study. The archaeological and landscape attributes for each site in the North Shropshire group were mapped to establish the relationship between the underlying topography and the archaeological record, and to quantify the spatial patterning between sites.

The topographical data used in this research comprises Ordnance Survey and British Geological Survey maps (obtained via Edina Digimap - http://digimap.edina.ac.uk ) and LiDAR. LiDAR (standing for Light Detection and Ranging) is an optical remote-sensing technique that uses laser light to map and visualise the earth's surface and has become an essential part of the archaeological geoprospection toolkit (Challis, 2006; Howard et al., 2016). It provides high-resolution altitudinal data that can be used to construct Digital Terrain Models (DTMs), which represent the bare ground 
surface with all objects and vegetation removed, and Digital Surface Models (DSMs), which represent the earth's surface and all objects on it. Both models were used in this study to identify subtle variations in the topography of the study areas, such as palaeochannels which may occur in wet terrain. LiDAR files were obtained from the UK Environment Agency (http://environment.data.gov.uk/ds/survey) at $1 \mathrm{~m}$ and $2 \mathrm{~m}$ spatial resolution. Data were provided as ASCII grid files which were converted to ArcGIS Raster grid format before modelling; the scale of resolution is referenced in the text.

Archaeological data for each site were obtained from Shropshire Council's HER and PAS records (https://www.shropshire.gov.uk/environment/historic-environment/historic-environment-record; https://finds.org.uk).Geographical Information System software (ArcMap 10.2 http://arcviewgis.software.informer.com/10.2/release: July 2013) was used to consolidate the data files and model the topographical and archaeological landscapes.

\subsubsection{Locall level - The Berth and Wall Camp}

The results obtained from the regional mapping of the North Shropshire marsh-forts indicated that the Berth and Wall Camp share considerable similarities with Sutton Common and present opportunities to compare landscape and environmental data. For both sites, preliminary reconnaissance visits were followed by an exploratory programme of stratigraphic coring by auger transect to assess the quality and extent of the organic remains (see Appendix 4, Site Visit Record). The spatial datasets were processed using ArcGIS 10.2 and stratigraphically modelled using Strater ${ }^{\circledR}$ software (geophysical mapping and modelling software used in the visualisation of borehole data, supplied by http://www.goldensoftware.com/products/strater)).

The results, detailed in Chapters 5-8, illustrate spatial and depth variability across both sites and support the rationale for selecting the Berth as the case-study site.

\subsection{The Berth (Objective 3 - 1.3.2)}

The objective of the landscape and palaeoenvironmental analyses undertaken at the Berth is to reconstruct the archaeological landscape evolution of this Iron Age marsh-fort preceding, during and following its occupation, and to draw conclusions about the site's function and chronology in comparison to the data from Sutton Common.

The methodology adopts a multi-disciplinary and multi-proxy approach to fulfil this objective. The auger survey provided data which was used to model the Berth's sub-surface topography. Its surrounding ecosystem was reconstructed using multi-proxy palaeoenvironmental analysis (pollen, plant macrofossils and Coleoptera). A radiocarbon dating programme was completed to position the 
results within a chronological framework. A line-of-sight analysis was modelled in ArcGIS to suggest possible visual interactions across the North Shropshire landscape. Background data was obtained from archival searches at the Shropshire Archive and the British Library. The site was also the subject of two field school excavations led by the University of Birmingham. Each process is described below.

\subsubsection{Ground conditions and equipment}

The ground conditions were wet, muddy and occasionally flooded irrespective of season (see Appendix 4).

A standard $5 \mathrm{~cm}$ gouge auger with extension rods was used to assess the peat deposits, undertake coring transects, and to obtain samples for radiocarbon dating (Fig. 3-1). Organic samples used for palaeoenvironmental analysis were obtained from Berth North Pasture and Berth Main Causeway using a $1 \mathrm{~m}$ Russian sampler, diameter $5 \mathrm{~cm}$ (Fig. 3-2) (Jowsey, 1966). Experiments to obtain larger samples by using a Van Walt Cobra Vibracore were unsuccessful due to poor ground conditions, and the waterlogged remains drained from the sample chamber. Coordinates for cores and samples were recorded using a Leica TS06 Total Station.

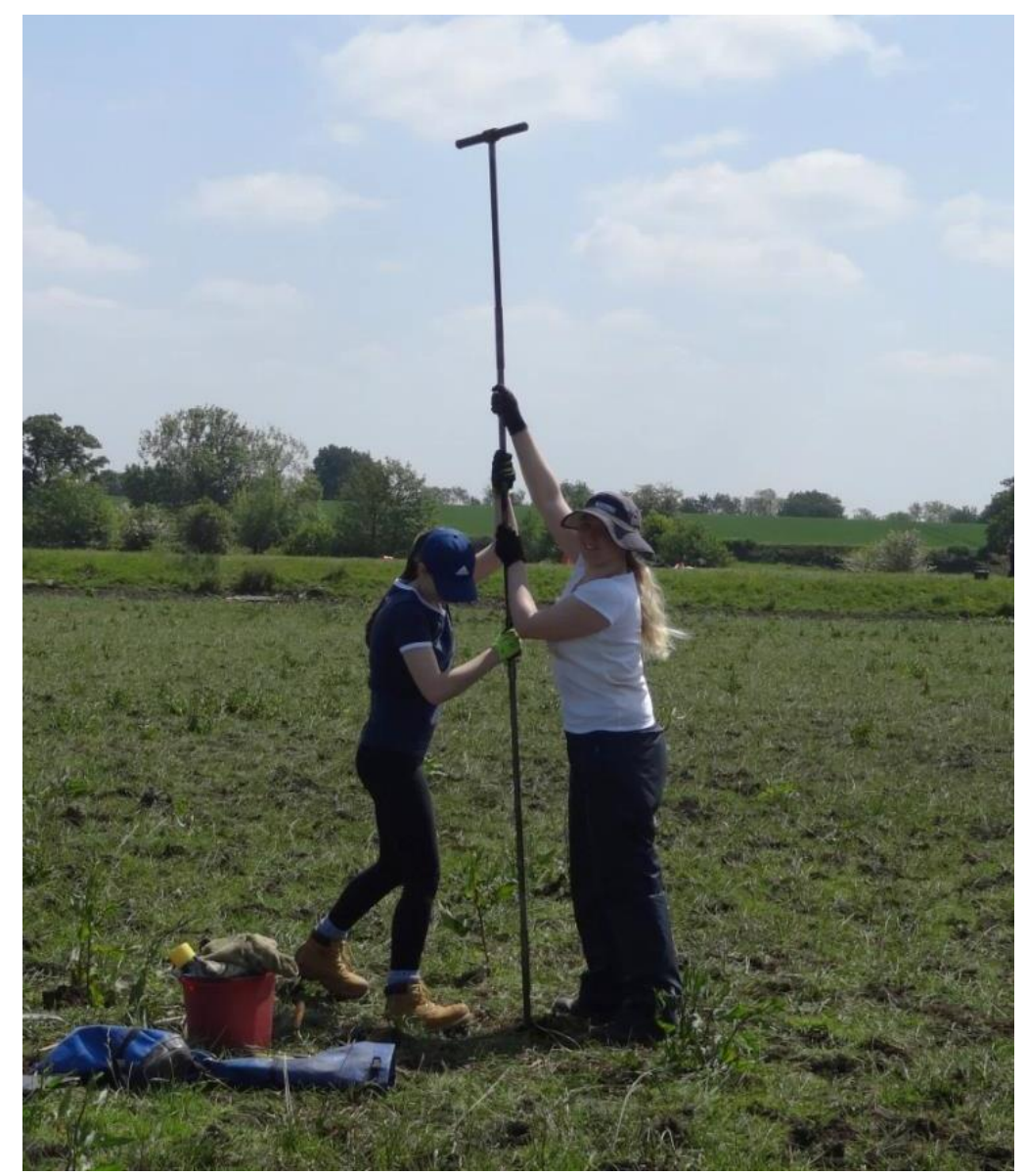

Fig. 3-1 Coring at the Berth - June 2016 (Norton 2016) 

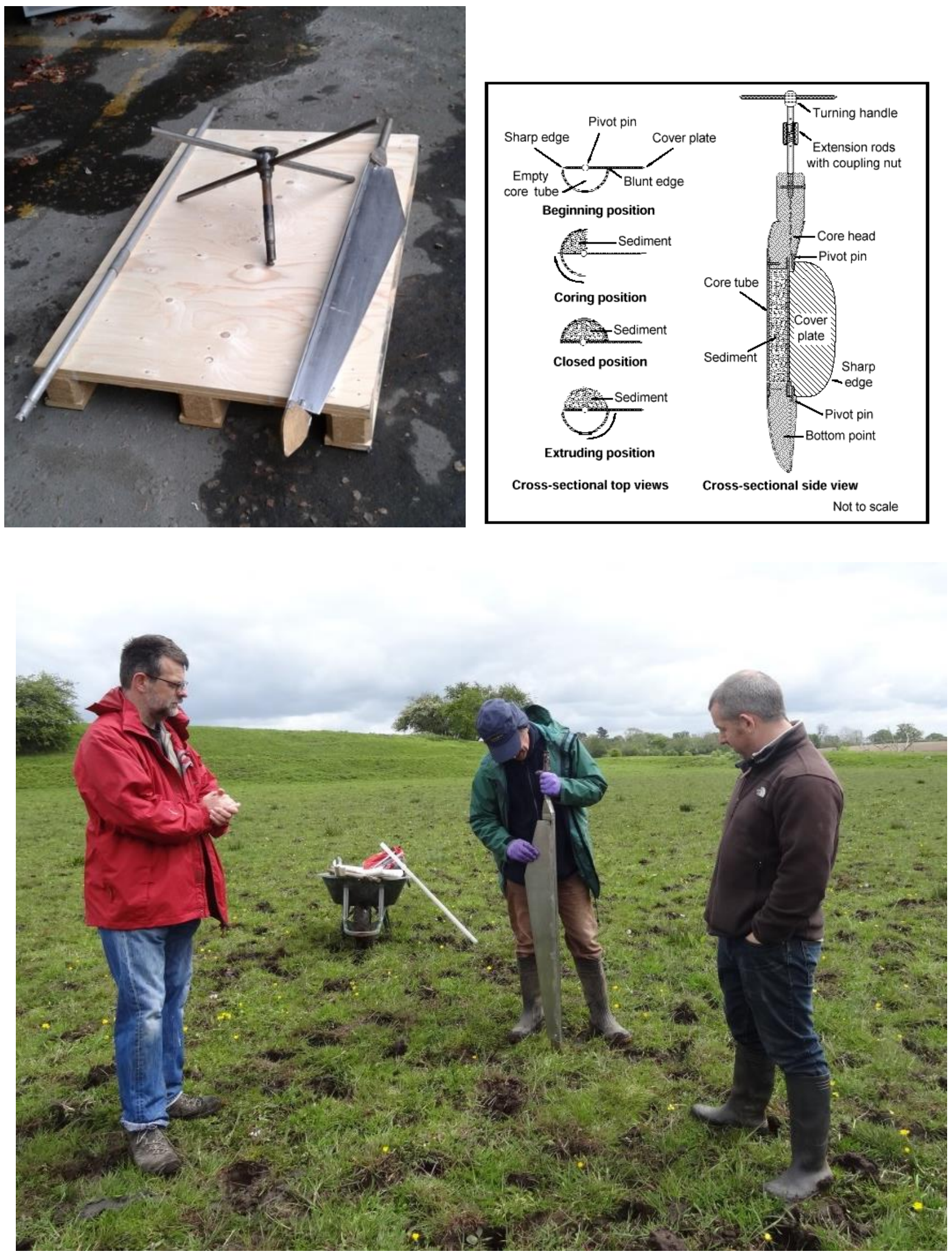

Fig. 3-2 The Russian Sampler in photograph and diagram (http://www.aquaticresearch.com/images/news.h2.gif), and in use (from left, Drs Smith, Eastwood, and Chapman) (Norton 2015) 


\subsubsection{Stratigraphic coring and palaeoenvironmental sampling} 'Every palaeoenvironmental, palaeoecological and palaeogeochemical study on a peatland begins with coring or section sampling and sub-sampling.' (De Vleeschouwer et al., 2010).

The coring programme of the peat basin surrounding the Berth had two objectives - to locate boreholes which would provide data for sub-surface landscape modelling and to obtain samples for palaeoenvironmental analysis and radiocarbon dating. All locations are shown in Fig. 3-3.

\subsubsection{Borehole transects}

Auger surveys were undertaken during six episodes of field work over four years between 2014 and 2017. Using the gouge auger with extension rods, seventy-three boreholes were excavated across approximately 5ha of marshy ground and pasture covering Berth North Field, the Lea Field, Berth North Pasture, Berth South Pasture and the area south of Berth Stream at between $10 \mathrm{~m}$ and $50 \mathrm{~m}$ intervals (depending on the terrain), using a rough grid pattern. The top soil was removed using a $60 \mathrm{~mm}$ diameter bucket auger bit and the underlying stratigraphy investigated using $1 \mathrm{~m} \times 30 \mathrm{~mm}$ extension rods. The sub-surface remains comprised peat with wood, silt or shell inclusions to a depth in excess of $7 \mathrm{~m}$. The bottom was deemed to have been reached when the glaciated (Devensian) landscape, evidenced by an impenetrable layer of coarse gravel, was encountered (pers.comm. Dr A. Howard http://landscape-research-management.co.uk/andy-howard/); a number of boreholes, especially those near the main enclosure and Berth Pool, failed to reach this level as the overlying organic deposits proved too deep for the coring rods available.

A sedimentological record of each core was made in situ and the stratigraphy was modelled using Strater $^{\circledast}$. The spatial datasets were integrated within ArcGIS 10.2, interpolated using a Regularised Spline with Tension method (see Chapman, 2006:67-87) and modelled using ArcScene, the visualisation application within ArcGIS which allows the overlay of layers of data in a 3D environment.

The results of the coring programme show variations in the sequential layers that make up the peat basin and are presented in Chapter 7. 


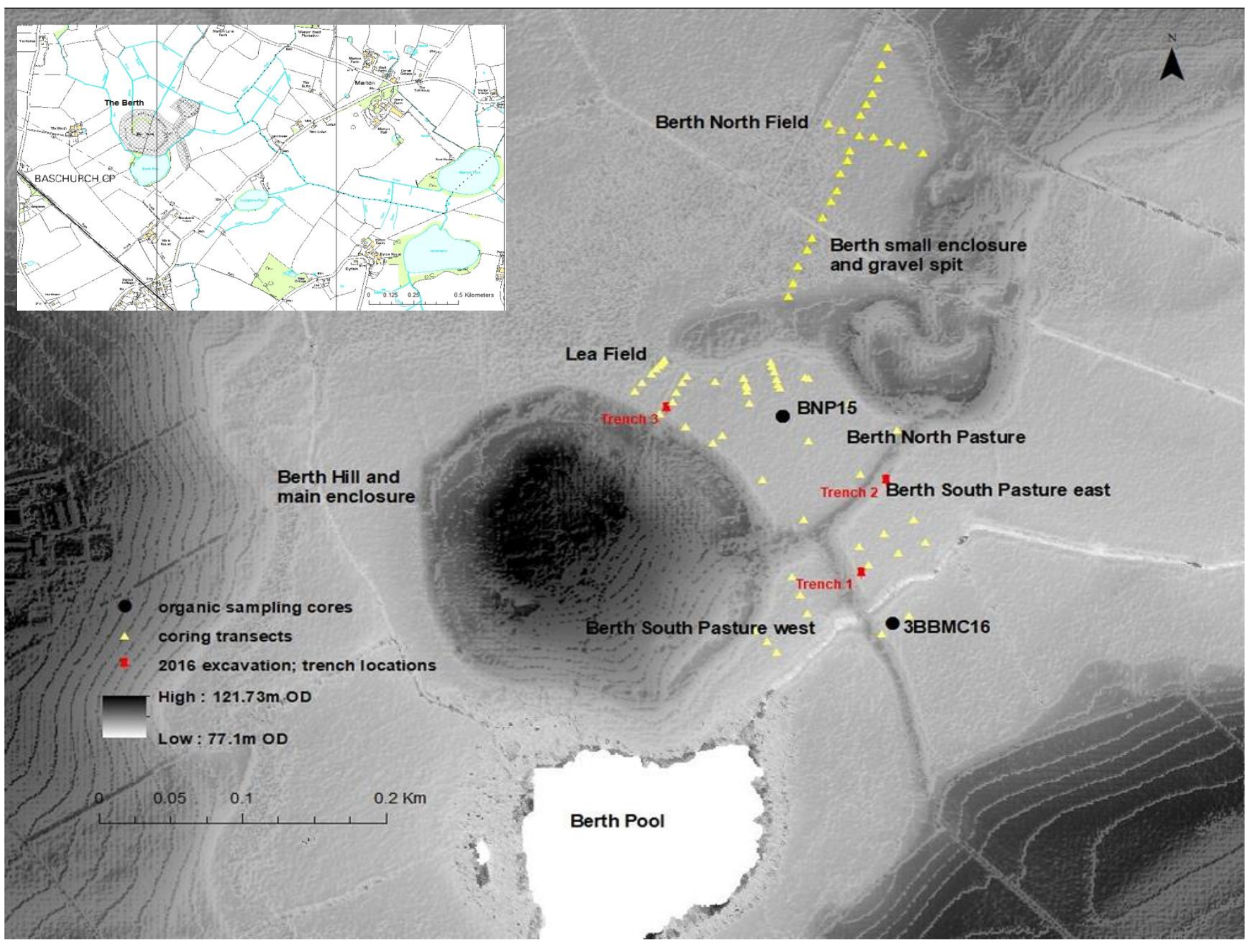

Fig. 3-3 The Berth, showing Scheduled Area, large and small enclosures, Berth Pool and field names together with coring and organic sampling locations and 2016 trench positions (Source: LiDAR 1m DSM; accessed May 2017) 


\subsubsection{Organic samples}

Three sets of organic samples were obtained for palaeoenvironmental analysis, as follows:

Berth North Pasture -BNP15 - May 2015 (Fig. 3-4 -Fig. 3-7)

To maximise the chances of identifying anthropogenic impact on the surrounding peat basin, a location equidistant from the Berth's two enclosures in Berth North Pasture was selected for initial palaeoenvironmental sampling (BNP15).

- Core 1 - Two parallel cores were taken $0.5 \mathrm{~m}$ apart creating a continuous sequence (for methodology, see De Vleeschouwer et al., 2010) to a depth of $5.3 \mathrm{~m}$ (solid geology) using the Russian sampler. The stratigraphy consisted of bands of waterlogged wood, sedge, and reed peat, shelly marl, silt and glacial clay. This core was analysed for pollen remains.

- Core 2 - An additional, shorter sequence was taken $0.5 \mathrm{~m}$ away from the full core to a depth of $3 \mathrm{~m}$, a stratigraphic level which had previously been dated to the Iron Age (see below). In order to obtain sufficient organic material, three column samples (sensu General Biological Analysis samples, see Dobney et al., 1992) were taken from adjacent pits. Each sample was divided into $10 \mathrm{~cm}$ units, amalgamated, bagged and labelled in situ. Twenty separate samples were analysed for plant macrofossil and beetle analysis.

\section{Berth - Main Causeway -3BBMC16 - November 2016}

Four locations adjacent to the Berth Main Causeway and south of Berth Stream were core-sampled using the gouge auger as part of the initial exploration of the Berth's stratigraphy, one of which (2BBMC14) provided an Iron Age radiocarbon date. This location was re-cored in November 2016, this time using the Russian corer, to obtain further samples for dating and multi-proxy palaeoenvironmental analysis. The process used to obtain the organic remains mirrored that used in BNP15. Three samples were obtained for plant macrofossil and beetle analysis; analysis of the pollen core is pending.

BNP15 and 3BBMC16 were retrieved with guidance from Dr Warren Eastwood, School of Geography, Earth and Environmental Studies (GEES), University of Birmingham. 


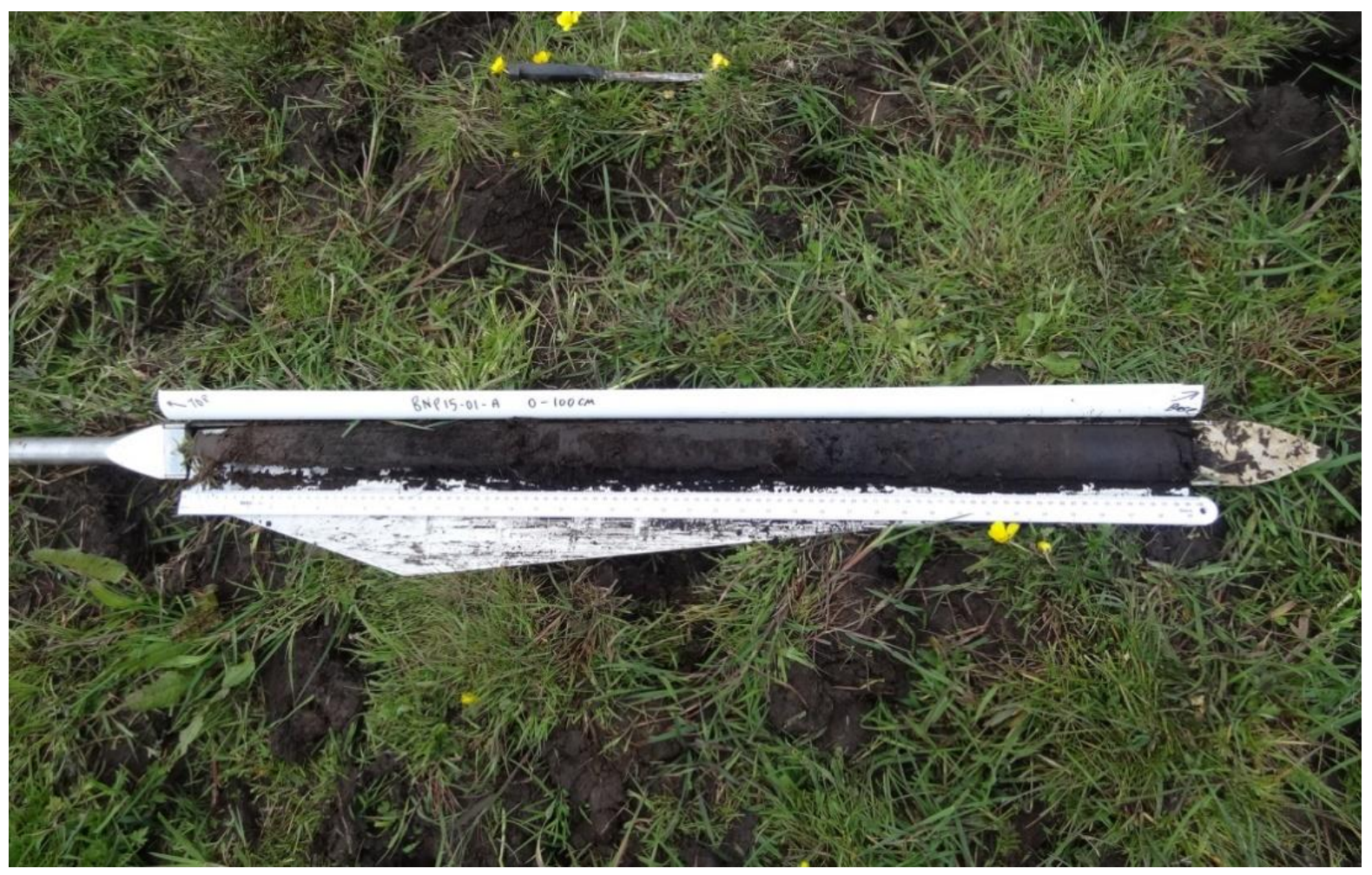

Fig. 3-4 BNP $15-0-100 \mathrm{~cm}$, showing the transition from top soil (left) to peat (right)

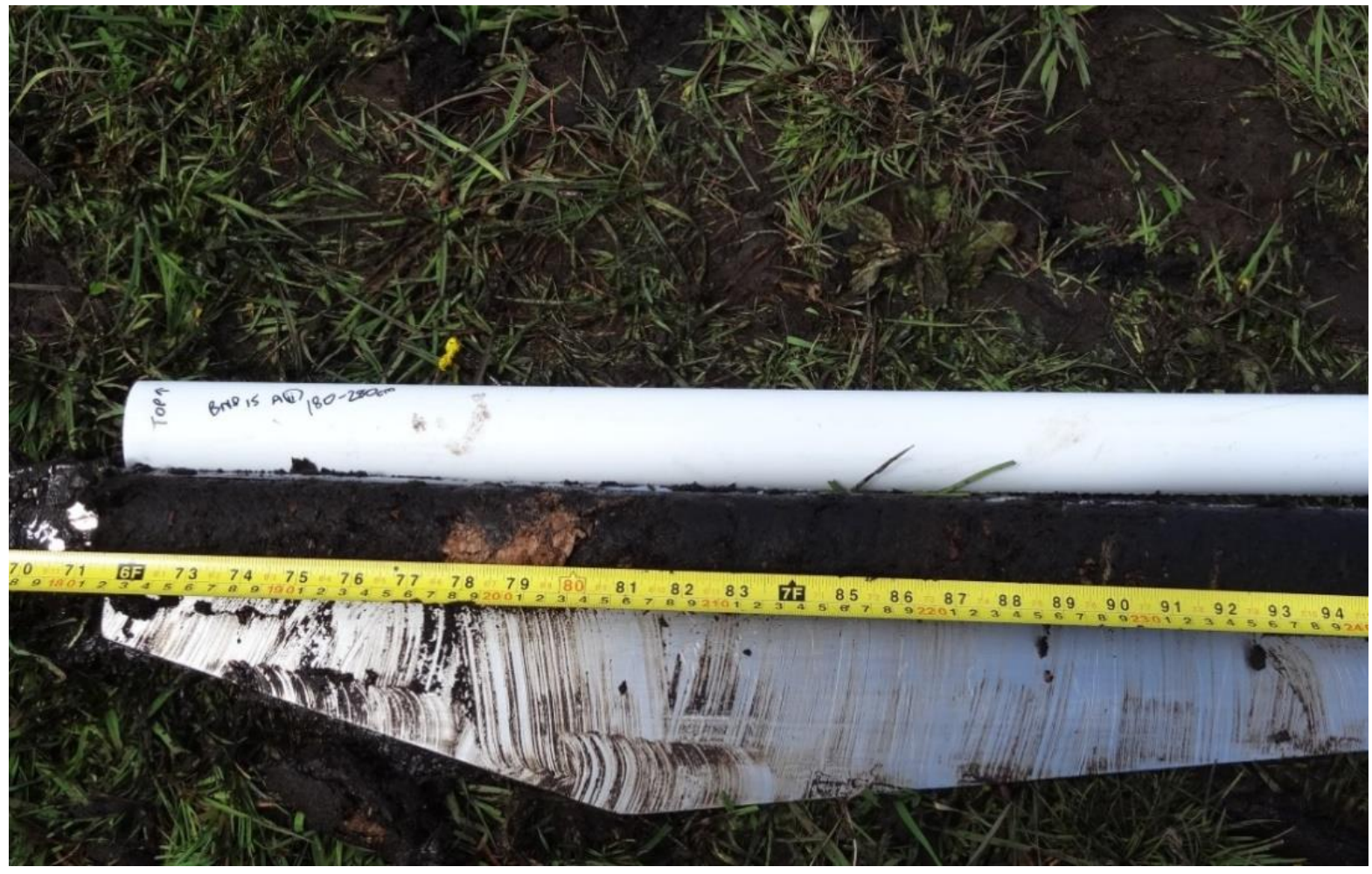

Fig. 3-5 BNP15 - showing large wood inclusion between $180-220 \mathrm{~cm}$ 


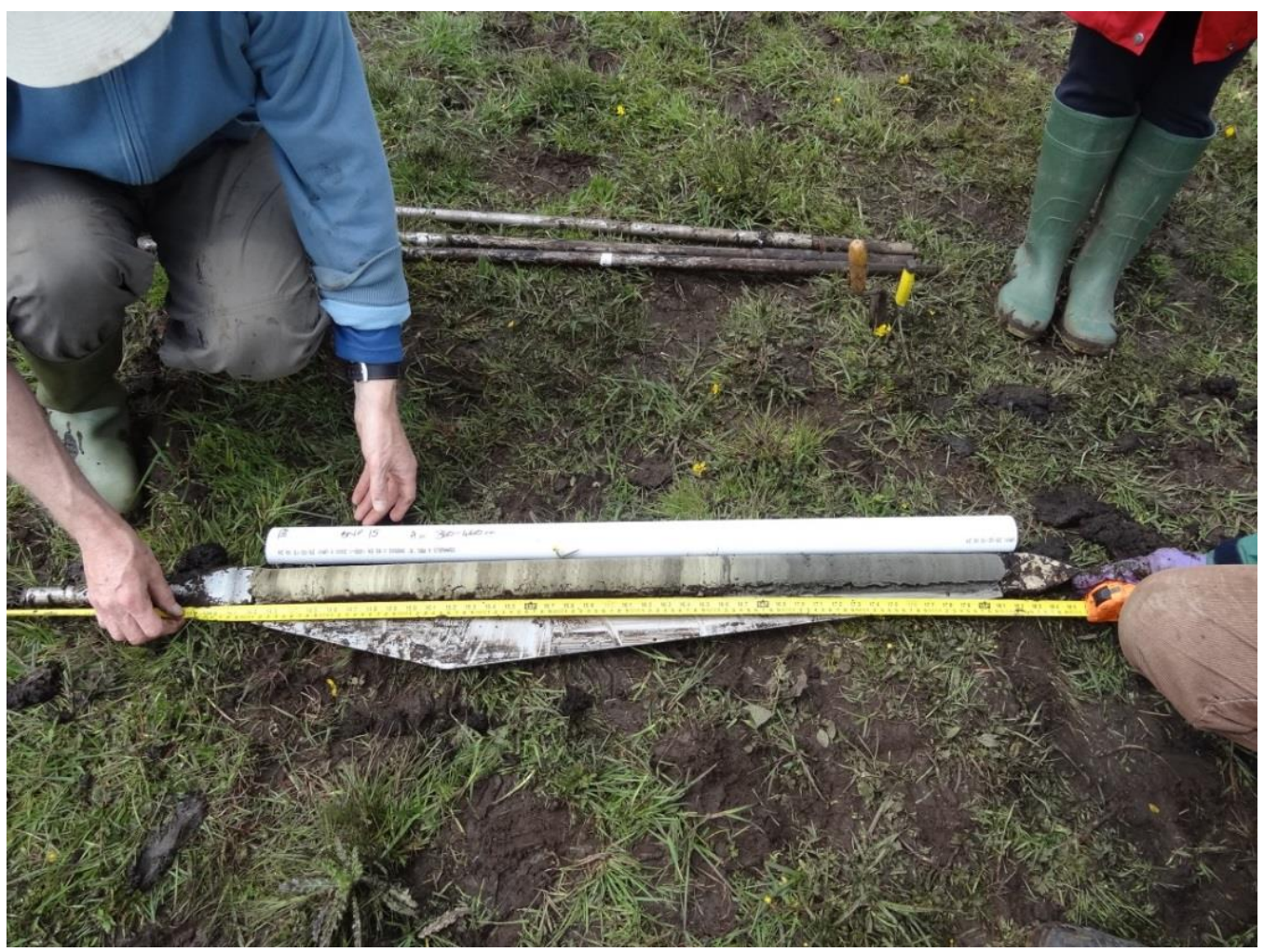

Fig. 3-6 BNP 15 - varved shelly marl between $360-460 \mathrm{~cm}$

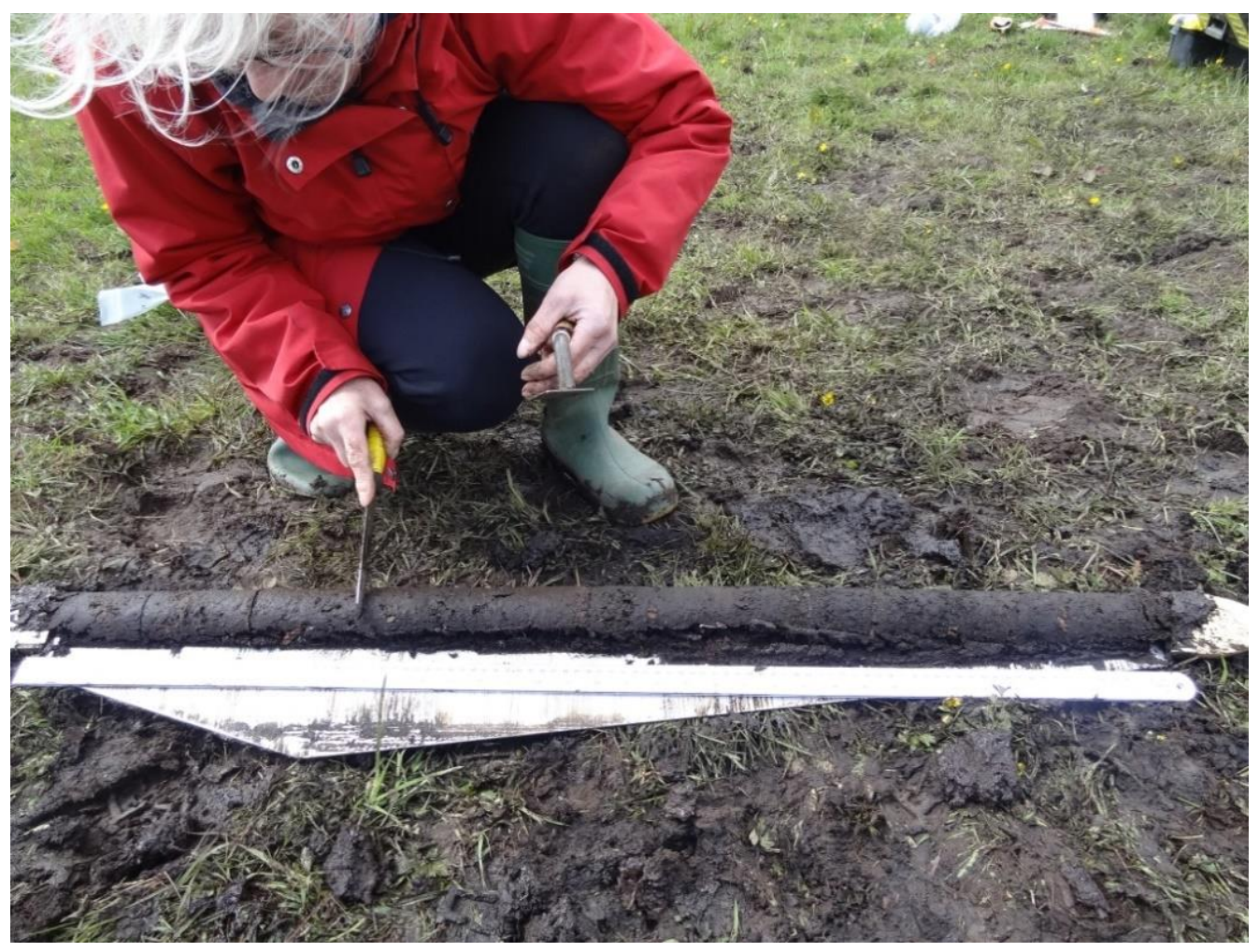

Fig. 3-7 BNP 15 - dividing the core into $10 \mathrm{~cm}$ sections on site 


\section{Excavation - June 2016}

Excavation at the Berth is ongoing. Two seasons have been completed; both were field schools for students of the Department of Classics, Ancient History and Archaeology (CAHA), University of Birmingham, led by Prof Henry Chapman. Research questions so far have concentrated on site access (Chapman, Smith and Norton, 2017). A geophysical survey of Berth Hill is forthcoming.

Two trenches were excavated to assess whether the Berth's upstanding causeways were contemporary with the Iron Age marsh-fort (for trench locations, see Fig. 3-3). Trenches 1 and 2 were de-turfed. The underlying stone construction was then dismantled in layers until the foundations were uncovered, or until it became apparent that the construction had reached the natural ground surface (Fig. 3-8). Palaeoenvironmental samples were recovered from each trench, at $0-10 \mathrm{~cm}$ and $10-20 \mathrm{~cm}$ intervals immediately beneath the stone construction. Samples were also obtained from a potential third causeway (Trench 3) located to the north-east of the main enclosure, although the stone structure for this causeway is somewhat ephemeral.

Six samples were analysed in total for plant macrofossil and beetle remains.

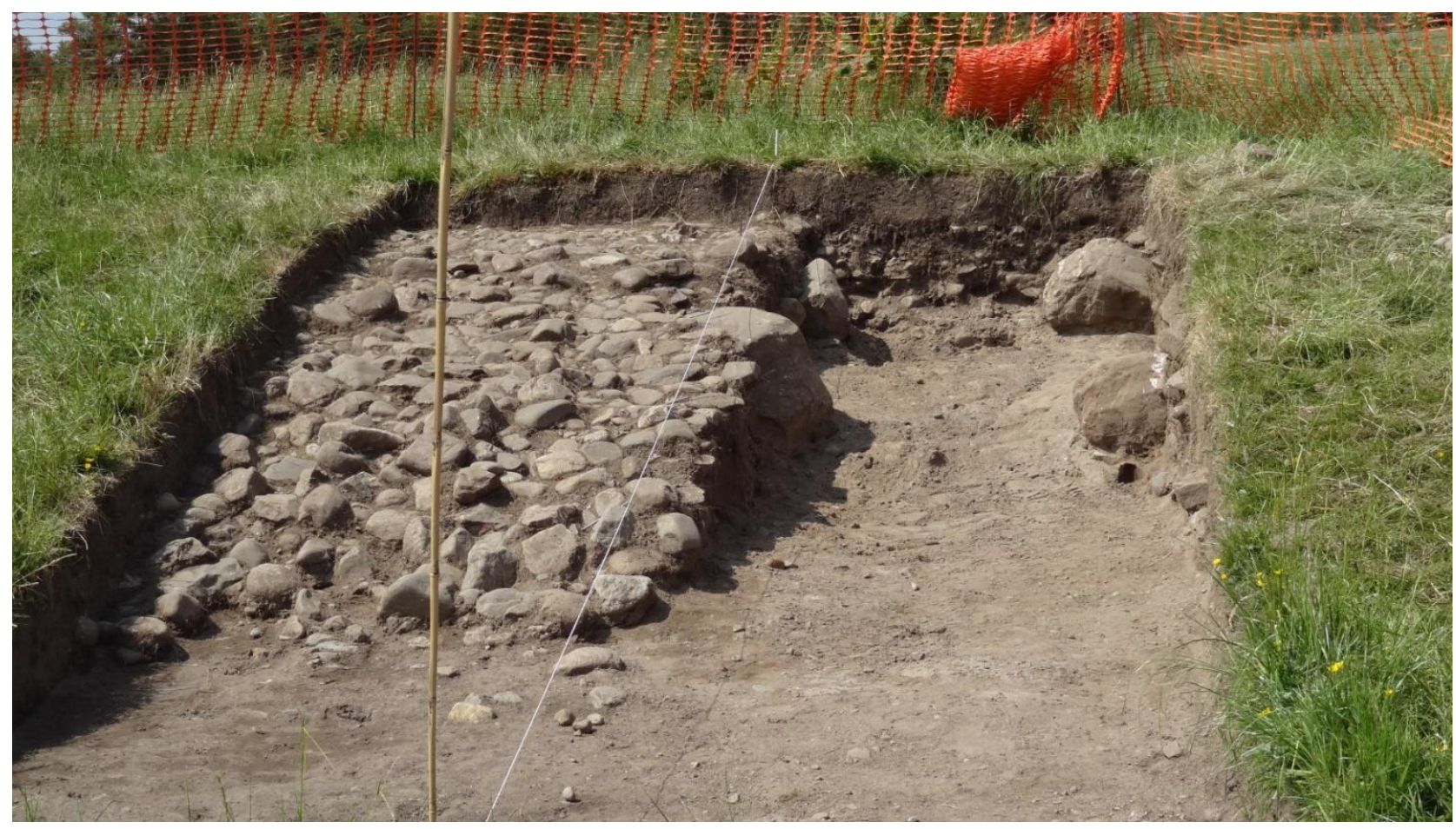

Fig. 3-8 Berth Causeway - Trench 1 showing stone construction (Norton 2016) 


\subsubsection{Radiocarbon determinations}

Altogether, sixteen radiocarbon determinations were obtained from across the Berth's peat basin enabling the cross-correlation of litho- and bio-stratigraphic horizons. Fourteen dates came from eight boreholes, including a sequence of five dates from BNP15. A further two dates originate from the peat horizon beneath the north-south causeway (2016 Excavation, Trench 1). 'Single entity' samples, such as wood, seeds and fruiting cones, were used in preference to mixed organic or sedimentary remains to ensure more accurate results; wood samples were identified to species with guidance from Dr Wendy Smith. All samples were processed using Accelerator Mass Spectrometry. Site chronology is presented in Chapter 7; laboratory reports are presented in Appendix 5.

\subsubsection{Post-fieldwork - processing and analysis of palaeoenvironmental data} This thesis adopts a multi-proxy approach (pollen, plant macrofossils and Coleoptera) to palaeoenvironmental analysis, and the benefits of each proxy are explained below (see 3.2.5). This section concentrates on the methodology for post-fieldwork processing and laboratory analysis of plant macrofossils and beetle remains.

Pollen analysis of BNP15 Core 1 was undertaken by Rebecca Eastwood (GEES undergraduate), under the supervision of Dr Warren Eastwood. The resulting analysis provides contextual information for the plant and beetle analysis (see Chapter 8).

Of the twenty-seven samples retrieved for plant macrofossil and beetle examination (see Table 3-1), processing and analysis of BNP15 and Trenches 1-3 were undertaken personally; 3BBMC16 was analysed by Yuxiao Kang (CAHA, Masters student), under the supervision of Drs David and Wendy Smith.

\begin{tabular}{|c|c|c|c|}
\hline CORE & & EXTENT & NUMBER OF SAMPLES \\
\hline BNP15 & Core 2 & $1 \mathrm{~m}-3 \mathrm{~m}$, analysed in $10 \mathrm{~cm}$ spits * & 20 \\
\hline 3BBMC16 & Core 2 & $\begin{array}{l}150-160 \mathrm{~cm} \\
160-170 \mathrm{~cm} \\
170-180 \mathrm{~cm}\end{array}$ & 3 \\
\hline \multirow[t]{3}{*}{$\begin{array}{l}\text { Berth } 2016 \text { - } \\
\text { Excavation }\end{array}$} & Trench 1 & $\begin{array}{l}0-10 \mathrm{~cm} \\
10-20 \mathrm{~cm}\end{array}$ & 2 \\
\hline & Trench 2 & $\begin{array}{l}0-10 \mathrm{~cm} \\
10-20 \mathrm{~cm}\end{array}$ & Not viable \\
\hline & Trench 3 & $\begin{array}{l}0-10 \mathrm{~cm} \\
10-20 \mathrm{~cm}\end{array}$ & 2 \\
\hline
\end{tabular}

Table 3-1 The Berth - plant macrofossil and beetle samples by location 
[* The sample from $0 \mathrm{~m}-1 \mathrm{~m}$ is retained, but is unlikely to be of value due to the disturbed nature of the upper surface. This was amply illustrated during one winter visit when the farmer's Hereford bull was seen sinking into the mud up to his hocks, a depth of about $1 \mathrm{~m}]$.

\section{Laboratory processing}

All samples were processed in laboratory conditions at University of Birmingham. Each sample was weighed and the volume calculated (for details, see Appendix 6).

\subsubsection{Plant Macrofossils}

Samples were initially processed for the extraction of plant macrofossils. $500 \mathrm{ml}$ was taken from each sample, and gently washed over a $300 \mu$ sieve to remove fine debris and inorganic fraction. As the samples were of medium compaction and well hydrated, it was not necessary to use chemical additives to soak the residue (for example, sodium hexametaphosphate can be used as an emulsifier to break up solid samples). As a result, calcareous remains (Molluscae; Characeae) were retained unaltered; seeds were uncontaminated and could be used for radiocarbon dating.

Small sections of the residue were placed in a petri dish and systematically inspected under a Meiji binocular microscope (magnification 10-40x) until each sample had been scanned. For BNP15, alternate samples (100-110cm; $120-130 \mathrm{~cm}$ etc.) were analysed first to obtain a broad understanding of the stratigraphic sequence before returning to 'fill in the gaps'. Seeds and other recognisable macrofossils (such as leaves and fruiting cones) were extracted for identification and partially dried if necessary to reveal any patterning on their outer casing. Guidance was provided by Dr Wendy Smith (University of Birmingham) and Gill Campbell (Historic England). Identification was further supported by comparisons to reference volumes (e.g. Berggren, 1969; Ross-Craig, 1979; Schoch et al., 1988; Clapham et al., 1987; Cappers et al., 2006), the plant collection held by Historic England (Centre for Archaeology, Fort Cumberland), and comparison with modern analogues recovered from fields and gardens nearby. Field notes were made as each section was processed. Robust seeds were separated for radiocarbon dating. All extracted remains were counted, recorded, and stored in a water/ethanol mix.

\subsubsection{Coleoptera}

Following processing for plant macrofossil remains, the samples were re-amalgamated with the remaining organic residues for the extraction of beetle remains. Using a standard methodology (Kenward et al., 1980), each sample was washed over a $300 \mu$ sieve, before being floated in paraffin. The flot was then washed in household detergent, jarred and stored in a water/ethanol mix and inspected for beetle remains using a Meiji microscope (as above). Field notes on the taphonomy of each sample 
were maintained throughout. The sorted remains were identified with help from Dr David Smith (University of Birmingham) and Dr Geoff Hill, with direct comparison to the Gorham and Girling Collections of British Coleoptera (University of Birmingham). Identification was supplemented by the use of reference volumes (e.g. Tottenham, 1954; Pearce, 1957; Harde, 1984; Hansen, 1987; Luff, 2007; Morris, 2002; 2008). Extensive use was made of the insect database www.bugscep.com, and the website https://www.kaefer-der-welt.de/index.htm. All extracted remains were counted, recorded, and stored in a water/ethanol mix.

\subsubsection{Adopting a multi-proxy palaeoenvironmental approach to landscape} reconstruction

Reconstruction of former environments is possible from a range of source material, for example, ancient plant and animal remains, sediments and ice-cores (Lowe and Walker 1997; Roberts, 1998) and is reliant on the principle, drawn from the theory of Uniformitarianism, that the physical laws and interrelationships that operate in the modern world have been constant throughout geological time 'the present provides the key to the past' (see Roberts, 1998:27 et seq). This section explains the benefits of each of the individual bioproxies used in this research and argues that a more robust and detailed approach to landscape reconstruction is achieved when they are combined in a multi-proxy analysis.

Environments are created through a combination of dynamic processes, each of which can be traced in the palaeoecological record. Organic remains arrive in the biosphere through on-site burial and incorporation or transportation to the place of deposition by air, water or scavengers (for example, flooding or dumping) (e.g. Efremov, 1940; Martin, 1999; Campbell, 1999). Each is subject to taphonomic processes which can include chemical changes, carbonisation, bioturbation and compaction (e.g. Efremov, 1940; Spicer, 1989; Martin, 1999; Donovan, 2002); if unaccounted for, these processes can lead to bias in interpretation of the fossil record (Cherns, 2014).

Preservation depends on local circumstances. Waterlogging produces anaerobic conditions which halt decay and preserve organic remains (e.g. Coles and Coles, 1986; Dincauze, 2000). Variations in the regularity and volume of waterlogging can affect preservation; for example, an absence of organic remains in some strata can indicate drier episodes or a depositional hiatus. The degree of fragmentation can indicate the speed and energy with which the deposit was initially laid down, as well as any subsequent bioturbation. The composition of the plant community and the inherent rate of decomposition play a more important role in the formation of peat and blanket bogs than the water table or pH levels (Coulson and Butterfield, 1978). Whilst well preserved samples are more informative, 
each sample tells a story, and even without accompanying artefacts, a well-dated, high quality environmental sequence (e.g. Beales, 1980) provides contextual background through which other studies can be calibrated. The whole combines to create the palaeoenvironmental record that we see today.

\subsubsection{Plant macrofossils}

The identification of plants by their macroscopic remains - palaeobotany - enables the reconstruction of palaeoenvironments and was one of the first branches of Quaternary science (Dickson, 1970). Preserved plant macrofossils - '...the accumulation of plant parts, derived from one or several individuals, that is entombed within a volume of sediment that is laid down in essentially the same conditions...' (Spicer, 1989) - comprise seeds/fruits, root systems, bud scars and stems, and although each is valuable 'almost every plant that can be distinguished by other characteristics can be distinguished also by the seed alone' (Dickson, 1970:233). Seeds are readily recoverable, and, with a median size of $0.5 \mathrm{~mm}-2 \mathrm{~mm}$, many are visible to the naked eye (Birks, 2001). They are often identifiable to species level and, as preserved organic matter, they are datable through radiocarbon dating. Other useful plant bioproxies include algae in the form of diatoms and Characeae, which are important as indicators of past salinity, pH values and water depth.

Each plant species has a range of environmental conditions in which it can grow. An assemblage therefore reflects the originating environment, indicating which plants were dominant and likely to be growing in optimal conditions, and which were marginal and at the edge of their range (Stace, 2010). For example, whilst some plants may demand or thrive in specialist conditions (halophytes such as sea purslane, Halimione portulacoides L.), others simply tolerate them (for example, barley (Hordeum vulgare L.) is halotolerant), and their presence in an assemblage is likely to be reflected accordingly.

An assemblage can be preserved by charring, waterlogging, smoking (for example, in thatch) and desiccation (Greenwood, 1991:154); wood is commonly preserved as charcoal. In wet (anaerobic) conditions such as peat deposits, plant macrofossils make up the bulk of the organic fraction. However, whilst waterlogged plant remains indicate a water table that has remained high enough to inhibit destruction, they also contribute to an inherent bias in the record towards plants which favour such conditions (Greenwood, 1991: 143). Preservation varies between plant parts - for example, woody stems preserve better than stamens. Seeds and fruits made of thick walled plant material can be highly resistant to biodegradation and also preserve better than less durable deposits; many also float (Greenwood, 1991: 152). Some sections of the seed are designed not to survive if their function is to aid 
dispersal, such as the spines on Bidens spp. seeds and the 'wings' on the seeds of Betula spp. (Greenwood, 1991:157-8). Most leaves are fragile and do not preserve well, however conifer leaves, for example pine (Pinus sp.), will preserve better than those of deciduous trees such as alder (Alnus glutinosa L.) due to their coriaceous (leathery) nature and high tannin/lignin content (Greenwood, 1991:148).

Plant macrofossils have both advantages and disadvantages as an environmental bioproxy. Although some plant parts, especially seeds, can be widely dispersed through aeolian or fluvial transportation (Birks and Birks, 2006:12), most do not travel far from the parent plant, and therefore the information they contribute is highly localised (Dincauze, 2000:332; Mauquoy et al., 2010); this even applies to leaf rain, which, according to one study, falls circa $24 \mathrm{~m}$ from the parent plant (Greenwood, 1991:Fig.7.3). Plant macrofossils are useful in that they are frequently identifiable to species level and can also help to overcome the scant representation in pollen diagrams of plants which are poor pollen producers or distributors (e.g. Dincauze, 2000; Birks and Birks, 2005); conversely, whilst most sites have a reliable pollen record, the same may not be true for plant macrofossils if preservation is poor (Birks and Birks, 2011:738). Partially because of their localised representation and the variable nature of macrofossils production, plant macrofossils are not statistically representative of the source population (Dincauze, 2000:340; Zhao et al., 2006) and therefore are better interpreted through their presence or absence in the assemblage rather than through their quantity.

Plant macrofossils have been used frequently in environmental contexts as a proxy for changing landscape and climate change (e.g. Barber et al., 1994). In archaeological contexts and as part of a multiproxy approach, they are used extensively to identify functionality (for example, the built structures at Coppergate, York; Kenward and Hall, 1995). They can also provide subtle indications of past land use, for example, detecting the presence of such features as hedgerows as indications of anthropogenic landscape management (Greig, 1994).

\subsubsection{Insect remains}

Palaeoentomology is the study of past environments through the proxy of preserved insect remains. Insects occupy almost every terrestrial, aquatic and intertidal habitat. They are characterised as invertebrates with an exoskeleton made of chitin and jointed limbs, and are readily preserved in anaerobic conditions. All orders are studied, with some having a specialised niche value in tracing past environments; for example, fleas (Siphonaptra) and lice (Anoplura/Mellophaga) are indicative of the 
presence of host organisms (e.g. Buckland, 2000). Extensive palaeontological research has confirmed that many insects have been morphologically constant, and stable in their environmental and climatic requirements, for up to 3,000,000 years (Elias, 2010b). By virtue of sheer number and diversity of species (over 300,000 worldwide, Elias, 2010c), the study of Coleoptera (beetles) dominates the discipline. They form the most important insect order in the Quaternary fossil record (Elias, 2010c:39).

The use of insect remains, and Coleoptera in particular, as bioproxies for past environments is at its most developed in the British Isles. In large part, this can be attributed to research in the 1950/1960s by Prof Russell Coope at the University of Birmingham. His analysis of Quaternary deposits at Upton Warren, Worcestershire confirmed that modern beetle analogues could be used to draw conclusions about past climatic conditions (Coope et al., 1961). The theory of species constancy underpins this conclusion - that, under conditions of repeated change, insect communities migrate rather than adapt through evolution, responding to large-scale climatic oscillations by shifts in distribution and rapid reoccupation of ecological niches (Coope, 1970; 1978). The discipline was quickly adapted to identify palaeoenvironmental conditions associated with archaeological deposits, both in semi-natural wetland (for example, on the Somerset Levels: Girling, 1985) and in areas associated with human occupation, such as Anglo-Scandinavian York (e.g. Kenward and Hall, 1995; Kenward and Carrott, 2006).

Coleoptera are characterised by forewings modified into hard outer casings (elytra) and biting mouthparts. They are abundant, mobile, diverse, robust, and, in many instances, can be identified to species level. Their disarticulated remains (head, thorax and elytra) survive well in both waterlogged environments and in some dry conditions such as thatch (Lowe and Walker 1997; Smith et al., 2005) and can preserve diagnostic features which aid identification (for example setae and scales). Although easier from whole remains, many beetles are identifiable from fragments (sclerites).

Beetles are sensitive environmental indicators and paint a picture of the ecology at both wide area and local level (Osborne, 1988:715). However knowledge of species behaviour is necessary for accurate interpretation. Some beetles are stenotopic, tolerating or adapting to a small range of environmental conditions. At the extreme end of this spectrum, some species have obligate relationships with specific plants; for example, the (now rare) bark beetle Ernoporicus caucasicus is obligate on lime (Tilia spp.) (Duffy, 1953). Other species are eurytopic and live in a wide range of environments; for example, the presence of the ground beetle Pterostichus nigrita suggests little more than a range of damp places (Duff, 2012). Some fauna, especially from Families Carabidae or Dytiscidae, are predacious and indicate the presence of other species by proxy. Palaeoenvironmental reconstruction can be further refined by 
whether a species is autochthonous (internal to the site area), or allochthonous (external to the site area/randomly accumulated) (Kenward, 1978). Allochthonous species are usually determined by their propensity to fly, to travel, or to be transported to the site by some means, such as via bird droppings or human agency, and have been summarised by Kenward (1978) as 'background' fauna. Information obtained from autochthonous and/or stenotopic species provides greater definition but is inevitably limited, whilst more generalist species provide information which may reflect wider environmental conditions but can be too general to be useful.

The potential pitfalls in using beetles arise from the origin of the assemblage, the taphonomic conditions and the nature of the fauna. An assemblage may include imported remains and may not represent local conditions if, for example, they were part of a flood event (Smith et al, 2005) or introduced in farmyard litter (Smith, 1998). The fact that many beetles are good fliers is both an advantage, in that those species may represent the wider locale, but a disadvantage in that their final resting place can be somewhat random (Kenward, 1975; 1978); this issue is compounded by limited research into beetle dispersal (e.g. Roslin, 2000). Beetle assemblages can also be skewed by the preservational qualities of individual fauna. For example, the robust sclerites of weevils (Family Curculionidae) and ground beetles (Family Carabidae) are likely to preserve well; sclerites from large beetles are more likely to fragment, whilst those from small beetles may be whole but are more difficult to retrieve (Kenward and Large, 1997). Some deposits yield few/no insects despite their apparent anaerobic nature, perhaps due to subtle variations in preservation or repeated drying/wetting of the deposit, which can eventually reduce sclerites to fragments so small as to be useless. Further biases which can also occur in an insect death assemblage include time-integration from successive habitats (bioturbation) or differences in species richness and abundance (e.g. Kenward, 1975; 1976; Kenward and Allison, 1994). Recording the condition of the assemblage can be informative of taphonomic processes and several systems have been trialled (e.g. Kenward and Large, 1997). The objective of any analysis is accurate interpretation and these disadvantages are potentially damaging. This can be alleviated to an extent by grouping species into habitat indicator groups and drawing conclusions from the collective rather than from individual species data (e.g. Robinson, 1981; 1983; 1991). Habitat groups form an integral aspect of palaeoentomological interpretation and are discussed below (see 3.2.6).

\subsubsection{Pollen}

Pollen is perhaps the most commonly used of all bioproxies in palaeoecological reconstruction, and has been employed extensively since the $1920 / 30$ s as an aid to stratigraphic and chronological control 
(Godwin, 1934; Dickson, 1970). Likened to a 'remote sensing tool' (Prentice, 1988), pollen as a bioproxy has two main advantages - it is ubiquitous, and the uniqueness of many individual palynomorphs enables identification to genus/species level. The cumulative presence of each taxon, tabled as series of graphs for different plant species, creates a pollen diagram illustrating the prevailing environment within a catchment through time (e.g. Grimm, 2015).

Pollen production and distribution vary with species, and, as with plant macrofossil and coleopteran analysis, knowledge of species behaviour is essential in order to interpret the record without bias (e.g. Prentice, 1985; Brostrum et al., 2008). For example, both pine (Pinus sp.) and oak (Quercus spp.) produce abundant pollen which is both light and easily dispersed anemophilically (by wind) (Jones, 1959; Carlisle and Brown, 1968; Sugita et al., 2010); conversely, lime produces low quantities of heavy pollen which is distributed entomophilically (by insects), hence its underrepresentation in many pollen diagrams (Greig, 1982; Pigott, 1991). Generally speaking, arboreal pollen is more likely to be distributed in air streams and therefore travels further; pollen from lower level and understorey plants including grasses and cereals is more likely to be slowed by standing vegetation and travels less far (Vuorela, 1973). Running water or a fluctuating water table can re-distribute pollen into artificial contexts, a factor which compromised some strata, for example, in the pollen analysis from King's Pool, Staffordshire (Bartley and Morgan, 1990). Many aquatic species distribute their pollen underwater and as a consequence aquatic plants are often poorly represented in pollen diagrams (Dincauze, 2000:344; Zhao et al., 2006).

Pollen accumulates in palaeochannels, peat bogs, lakes and ponds, and the preservation of palynomorphs in these anaerobic environments can be affected by compaction/crushing, the effects of transportation or re-deposition, chemical oxidation, repeated wet and dry cycles and the actions of bacteria and fungi (Moore et al., 1991; Birks and Birks, 2011). Pollen spores also differ in their susceptibility to corrosion which, if severe, can distort assemblages (Hall, 1981); the more susceptible types such as poplar and aspen (Populus spp.) can be lost or rendered unidentifiable, whilst those that are more resistant such as taxa from the daisy family (Asteraceae) become artificially concentrated (Campbell, 1999). In extreme cases, such as the artificiality of many archaeological deposits, the effects of differential pollen loss can be dramatic (Tweddle and Edwards, 2010). The taphonomic record is also a repository of dispersal information although heavier grains find their own level, which can compromise the stratigraphy (Campbell, 1999). 
Pollen is dispersed by a variety of methods (wind, insects, birds, animals or water) across varied terrain, and can represent a wider spatial scale than either plant macrofossils or beetles. The size and nature of the pollen trap and the prevailing wind direction affect spatial distribution (e.g. Edwards, 1999; Davies and Tipping, 2004). Generally, lakes gather pollen from wider catchments than bogs (Dincauze, 2000:345), and a lake circa 500-750m in diameter suggests a catchment of approximately $1 \mathrm{~km}$ (Birks and Birks, 2011). However, such calculations should be used as rules-of-thumb and the composition of the assemblage will be heavily influenced by the patterning of different topographical and vegetational elements within the landscape (e.g. Fossitt, 1994; Bunting et al., 2004). For example, a pollen study from a series of small lakes in an open, treeless landscape in northwest Britain was found to reflect a wide ranging catchment of $0.2 \mathrm{~km}-10 \mathrm{~km}$, and included long distance pollen (Fossitt, 1994). Similarly, a study of birch pollen (Betula spp.) from western Norway and Scotland revealed that the pollen signature was not borne out by the plant macrofossils but represented long-distance pollen from further south in Europe (Birks, 2003). These examples emphasise that although pollen is numerically related to the vegetation of the site area, the relationship is neither linear nor straightforward (Edwards, 1999), and an understanding of pollen behaviour requires complex modelling if it is to indicate species abundance or be attributed to the right location (Moore et al., 1991:12-14; Sugita, 1994).

Pollen diagrams display the results of analysis as Arboreal (AP) and Non-Arboreal Pollen (NAP) (mainly herbs) which are combined to produce Total Land Pollen (TLP). They are used extensively to reconstruct vegetational histories and to identify increases or fluctuations in anthropogenic impact throughout the Holocene. Such changes, visible in the ratio of woodland: cereal/weed pollen (e.g. Sugita et al., 1999), can indicate woodland clearance for agriculture and the concomitant impact on floodplain morphology and alluviation (Shotton, 1978b; Brown and Barber, 1985). However, changes in the pollen record throughout the Holocene are not all anthropogenic in cause and conclusions should not be drawn from single evidence streams. For example, the Mid-Holocene elm decline (Ulmus spp.) was originally thought to be due to anthropogenic woodland clearance, but disease and changing climate are now thought to have been additional factors (Parker et al., 2002).

Whilst pollen is a powerful tool in reconstructing past landscapes, over-reliance can lead to problems (Caseldine et al., 2008). For example, Kenward has shown that pollen is insufficiently sensitive to represent local plant diversity and that localised clearances or patch vegetation (such as hedgerows) are more accurately determined through beetle analysis (Greig, 1994; Kenward, 2006:1373). One particularly fierce debate has stemmed from the nature of woodland cover during the early Holocene 
and in particular, how forest clearances were created and maintained. Vera (2000) used pollen analysis alone to hypothesise that early Holocene primary forest should be interpreted as a mosaic rather than continuous woodland, with clearances maintained by large herbivores. This model was criticised by Mitchell based on the rationale that, although forest in early Holocene Ireland displays the same mosaic pattern as the rest of Britain, there were no large herbivores to maintain the clearings (Mitchell, 2005). Further criticism has come via an assessment of contemporary beetle fauna, which showed that autogenic causes (wind-throw or fire) were equally valid as the cause of forest clearances and would contribute to the same mosaic patterning (Whitehouse and Smith, 2010). Whitehouse and Smith considered that Vera underestimated 'the complexity of the physical landscape and environmental backdrop of the wildwood, creating a model which is at times simplistic, especially when considering the diversity across Europe' (2004:205). Whilst refinements in the interpretation of pollen diagrams are ongoing, these examples alone support a strong argument for a multi-proxy approach.

\subsubsection{Combining bioproxies as a multi-proxy/multi-disciplinary method of landscape reconstruction}

From these high level summaries, it can be seen that each ecological indicator has its strengths and weaknesses, and, if '...one of the tasks of palaeoecology is to test between competing causal hypotheses...' (Roberts, 1998:36), adopting a multi-proxy approach to environmental reconstruction must facilitate a better result. It widens the spatial scope, reflects the interdependence of all the environmental sciences, and has developed over recent years to overcome problems such as variable deposition, bias in the record caused by species which are super-abundant, and differential taphonomy (e.g. Dincauze, 2000; Chambers and Charman, 2004; Birks and Birks, 2005;2006). A multi-proxy methodology provides corroborative, supportive and/or contradictory lines of evidence and aids the complex process of site understanding. It is the approach taken by this thesis.

Multi-proxy studies have been cited as 'deceptively simple, highly seductive, and seemingly full of promise...' whereas... 'In practice, they are a huge amount of work, they are never simple, they are full of surprises, even shocks, and they are rarely neat, tidy or simple to interpret.' (Birks and Birks, 2006:15). Whilst acknowledging this healthy caution, there are many examples which demonstrate that a multiproxy approach is worth the effort. Combining pollen, invertebrates and diatoms provided evidence of variable rates of environmental change at Clettnadel on West Burra (Whittington et al., 2003). A multiproxy approach combining Trichoptera, Chironomid and Coleoptera data enabled the reconstruction of 
the river flows on the River Trent (Howard, 2007). In an analysis of the mid-Holocene environment at the Humberhead Levels, Whitehouse combined beetle analysis with palynological and dendrochronological data to enable a precise reconstruction of a Pinus-dominated forest and demonstrated the value of using Coleoptera to reflect local edaphic factors (Whitehouse, 1997; Boswijk and Whitehouse, 2002). The bioproxies used to reconstruct local and regional environmental change at Ballywillin Crannog, central Ireland, included sedimentary analysis, plant macrofossils, Coleoptera, pollen and spores, diatoms, and Chironomids (O'Brien et al., 2005) allowing an in-depth reconstruction of the site's chronology, functionality and impact on the local environment.

One of the main benefits of a multi-proxy approach is spatial representation. The methodology employed in this thesis combines plant macrofossils, beetles and pollen to create a series of nested datasets which overcome the limitations inherent in the spatial representation of each bioproxy (see Fig. 3-9). As has been shown, plant macrofossils generate data for the immediate eco-locality, beetles indicate the composition of the local ecological structure up to a range of circa $50 \mathrm{~m}$ (dependent on species), and pollen, given its regional nature, provides evidence for complex environmental modelling for a spatial context of circa 0.2km+ (e.g. Fossitt, 1994; Birks and Birks, 2011). Whilst none of these measurements is definitive, by employing a multi-proxy approach, a comprehensive picture of the local palaeolandscape can be reconstructed.

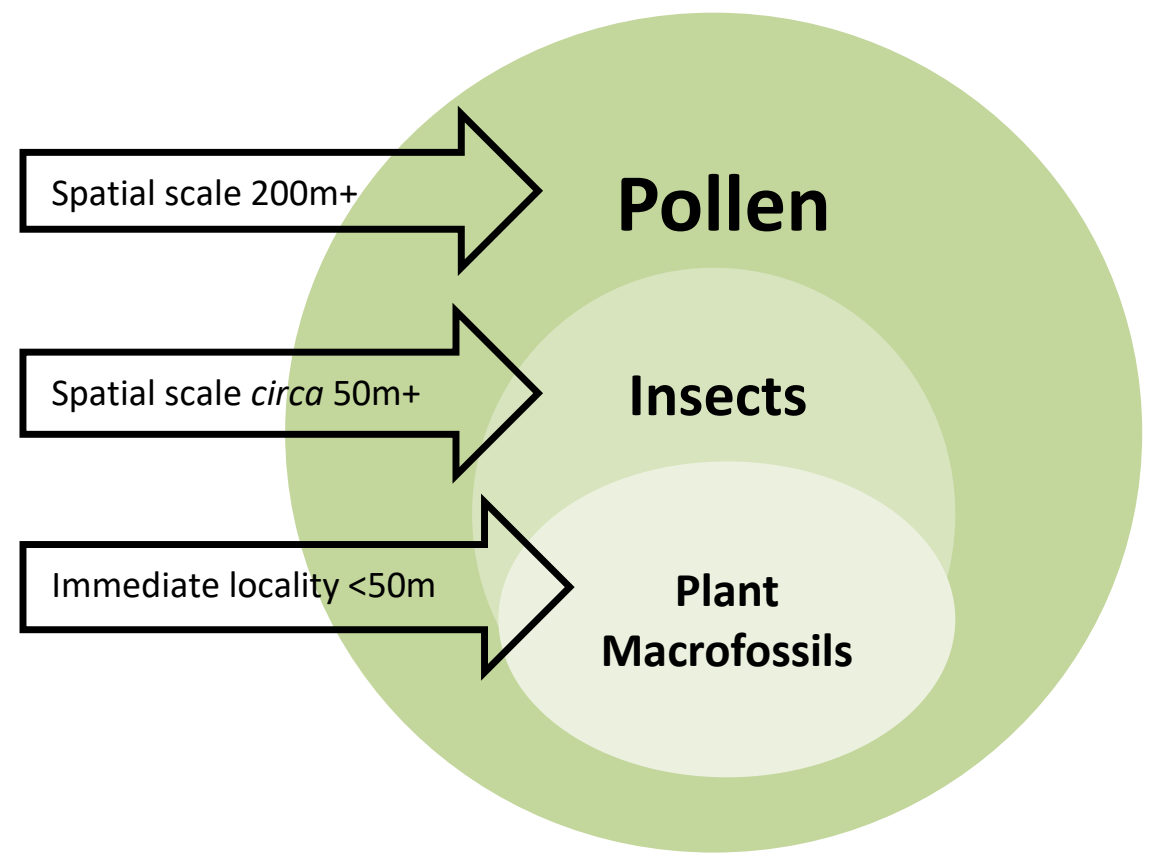

Fig. 3-9 An indication of the spatial representation available from nested data-sets 


\subsubsection{Presentation of palaeoenvironmental data}

The manner in which data, be it organic assemblages or coring profiles, are presented has a direct bearing on interpretation.

\subsubsection{Pollen}

The pollen data presented in this thesis provides a background context for sample BNP15. The results are presented using TILIA-GRAPH software (Grimm, 2015) as standard graphed pollen diagrams; the accompanying Age:Depth profile was determined using CONISS within TILIA.

\subsubsection{Plant Macrofossils}

A review of recent issues of the journal Environmental Archaeology shows that the protocols used for presenting plant macrofossil analyses are varied. Many studies simply present a species list in column form with an indication of presence, abundance or super-abundance; this has the advantage of simplicity but lacks detail and makes little visual impact. Data have also been expressed in spreadsheet form and organised against axes as Age:Depth profiles by species, arranged vertically or horizontally; when supported by histograms, graphs and charts, this presentation format can address the visual impact lacking in tabular presentation (examples are numerous, e.g. Moreno-Larrazabal et al., 2014). TILIA-GRAPH can also be adapted to show zonal chronology for both plant macrofossils (and insects) although there are disadvantages. Statistical treatment of the plant macrofossil data is only viable when sample sizes are large (Dincauze, 2000:342), and percentage diagrams are not generally used as there is no consistent 'macrofossil rain' as compared to 'pollen rain' (Birks, 2001:2268). As there is a limited relationship between the number of items in an assemblage and the dominance of a particular plant, TILIA-GRAPH diagrams for plant macrofossils can be misleading.

In this research, various methods of presentation are combined to maximize their respective value. Plant macrofossils are presented in tabular form indicating presence, abundance and super-abundance. Although numeric values are not an exact representation of the abundance of parent plants, they are indicators of presence and therefore represent a likely habitat. Counts of macrofossils for superabundant species (Betula spp.; Alnus spp.; algal oospores (Family Characeae) and water snail opercula (Bithynia spp.) have been removed from the analysis as indicated. Charts are presented as percentages based on numeric count; other variants were tried, for example as 'presence only' diagrams, but the overall distribution of habitat groups (see below) remained the same. A simplified chronological sequence showing the most abundant species is also used which indicates vegetational succession throughout the Holocene (Table 8-3). 
In all instances, nomenclature and taxonomy follow Stace (2010). For a full list of plant and insect taxa see Appendix 7.

\subsubsection{Coleoptera}

Coleoptera are presented as full species lists (see Appendix 7), including total MNI (Minimum Number of Individuals), calculated as follows:

- $\quad$ one single pronotum $=$ one insect

- $\quad$ one right + one left elytron = one insect

Ideally, samples for insect processing are in the region of 5 I-10l per sample (Kenward, 1978; Kenward et al., 1980). This was possible for the samples taken for Berth - Trenches 1 and 3, but not for the samples taken by Russian sampler (BNP15 and 3BBMC16). Hence the MNI for these samples is not large; however, they appear to be homogenous and are likely to be characteristic. A number of statistical techniques are available to estimate species richness (Whitehouse, 2004:82), such as Correspondence Analysis (CA) and Detrended Canonical Correspondence Analysis (DCCA) which examine species association (Carrott and Kenward, 2001). These were explored but not applied in this methodology as the samples were not large enough; instead, a straightforward ratio of MNI: species was calculated to express diversity of the assemblage. MNI and species ratio for each sample is shown in Table 3-2:

\begin{tabular}{llll}
\hline Sample & MNI & Species & MNI:Species ratio \\
\hline BNP15 & 635 & 142 & $1: 4.5$ \\
3BBMC16 & 70 & 19 & $1: 3.6$ \\
2016 Excavation Trench 1 & 141 & 88 & $1: 1.6$ \\
2016 Excavation Trench 3 & 24 & 19 & $1: 1.3$ \\
\hline
\end{tabular}

Table 3-2 The Berth Coleoptera - MNI: Species ratio

Additional diagrams (graphs, histograms etc.) are presented in the text which summarise the findings as raw data and as percentages.

Nomenclature follows Duff (2012) and taxonomy follows Lucht (1987). For the data presented here, only one species was super-abundant throughout the assemblage (Cyphon sp.) and has been removed from the calculations as indicated. 


\subsubsection{Habitat groups}

In order to establish broader interpretations from individual proxy counts, plant macrofossils and Coleoptera were grouped by habitat.

Habitat preferences are widely used by palaeoentomologists but less so by palaeobotanists. Placing plants into ecological groupings is a matter of judgment, and even the conclusions drawn by Stace in the latest edition of the New Flora of the British Isles have been criticised (Fay, 2011). However, organising plant macrofossils by ecological niche is becoming more acceptable. Groupings can be complex or simplistic but need to reflect the research question. For example, multiple plant groupings were used to reflect palaeoenvironmental change at the multi-period site at Goldcliff on the Severn Estuary (Bell and Neumann, 1997; Bell et al., 2000), whereas a more simplistic approach (Cultivated/Weeds) was applied to assess hemp (Cannabis sativa L.) production in southern Sweden during the first-second century AD (Larsson and Lagerås, 2015). On anthropogenic sites, it may be useful to depict cereal crops and plants favoured by human activity (weeds) against wild plants, meadow or light-demanding species (e.g. Soltvedt and Henningsmoen, 2016).

By contrast, grouping Coleoptera by environmental preference has been in development for over 40 years (e.g. Kenward, 1975; 1978; Kenward and Hall, 1997; Robinson, 1981; 1983; 1991; 2001; Coope et al., 1997; Elias, 2010c). Summarising taxa by habitat overcomes the problem of undue weight being attached to a single species and provides a robust summary of the environmental factors prevailing at the time the assemblage was created. Groupings can be simplistic, for example, a division into Aquatic or Terrestrial species, or more complex, for example, estimating the proximity of nearby woodland by identifying woodland taxa as a proportion of Terrestrial fauna (e.g. Robinson, 1991; 2000; Kenward, 2006). Other approaches adopt greater complexity and hence provide more detail, especially important when synanthropic species are involved (e.g. Kenward, 1985; Kenward and Hall, 1997; Smith, 2013).

For this thesis, habitat groupings for insect species follow Kenward (1997), Robinson (1981; 1983; 1992; 2001) and Smith (2009), whilst those for plant macrofossils combine information from Stace (2010) and Rodwell (1991a; 1991b; 1995); where a plant can thrive in a range of environments, a maximum of three classifications were applied. The habitat groupings used are shown in Table 3-3.

The multi-proxy palaeoenvironmental results are discussed in Chapter 8. 


\begin{tabular}{|l|l|l|l|}
\hline & Plant macrofossil groupings & Coleoptera groupings & \\
\hline $\begin{array}{l}\text { Open water/ } \\
\text { waterside }\end{array}$ & Aquatic/Riverine & $\begin{array}{l}\text { Aquatic/Riverine fast/slow/stagnant } \\
\text { water }\end{array}$ & AQUATIC \\
\hline Woodland & $\begin{array}{l}\text { Woodland scrub/ } \\
\text { edge/hedgerow }\end{array}$ & $\begin{array}{l}\text { Woodland (includes } \\
\text { scrub/hedgerow/woodland } \\
\text { edge/saproxylic/decaying wood) }\end{array}$ & TERRESTRIAL \\
\hline $\begin{array}{l}\text { Damp and dry } \\
\text { grassland }\end{array}$ & $\begin{array}{l}\text { Damp fen } \\
\text { Moorland/Bog } \\
\text { Meadow/open grassland } \\
\text { including waste ground }\end{array}$ & $\begin{array}{l}\text { Damp fen } \\
\text { Pasture/Dung } \\
\text { Rotting matter }\end{array}$ & \\
\hline Other & Charred & Synanthropic & \\
\hline
\end{tabular}

Table 3-3 Plant macrofossil and insects habitat groupings

\subsubsection{Wider landscape modelling - Line-of-sight analysis}

In addition to modelling the Berth's sub-surface stratigraphy and reconstructing its palaeoenvironment through multi-proxy analysis, a line-of-sight model was created to illustrate the visual interactions that the Berth may have had with other landmarks around the North Shropshire area.

Using a $2 \mathrm{~m}$ LiDAR DTM as a base-map and Historic England Scheduled Monument data (Historic England 20150925_ScheduldMonument.shp) to identify the main archaeological sites in the wider vicinity, a lineof-sight model was constructed within ArcGIS 10.2 which looked across the North Shropshire Plain and the northern Welsh Marches from both the 80mOD contour and the 97mOD spot height of Berth Hill. The model assumes an observer viewing height of 1.7m (average male height; see Chapman, 2006:85). The results were compared with an existing study (Matthews, 2014) and empirical evidence was gathered through site visits. The results are discussed in Chapter 6.

\subsubsection{Archival Search}

The methodological approach applied to investigation of the Berth marsh-fort incorporated archival research. The Berth is a Shropshire icon and has featured in local historical records since the nineteenth-century (e.g. Hartshorne, 1841). In order to determine whether any major changes to the modern landscape were recorded in the historic maps and records, web-searches were made at https://www.old-maps.co.uk; http://www.visionofbritain.org.uk/, and investigations were made at the Shropshire Archive (http://www.shropshire.gov.uk/archives/) and the British Library (https://www.bl.uk). Records of historic mineral extraction at the Berth were reviewed via the Shropshire Planning Service (https://new.shropshire.gov.uk/planning). 
The Berth was excavated in the 1960s, although the results were never fully published (Gelling, 1964; Gelling and Stanford, 1965 (1967); Morris and Gelling, 1991). The material remains from these investigations are held by Shropshire Museum Services, and were investigated as part of this research https://shropshire.gov.uk/museums/).

A photographic record was maintained of all items and the results are summarised in Appendices 2 and 3 and referred to in the text.

\subsection{Summary}

This chapter has described the multiple disciplines used in the exploration of marsh-forts across England and Wales. The structure drills down from national to regional level to local level. An in-depth multidisciplinary analysis was undertaken of one site which has similarities to Sutton Common - the Berth in North Shropshire - incorporating topographical modelling, palaeoenvironmental analysis, excavation, and archival search. The results of each of these approaches are described in the remainder of this thesis and illustrate that a multi-disciplinary approach provides synthesised results which are greater than the sum of its parts. 


\section{Marsh-forts in a landscape context}

Iron Age marsh-forts are found in low-lying wetlands, and their functionality and symbolism were most probably defined by their marshy surroundings. In choosing a wetland location, the builders differentiated themselves from those who built hillforts. These observations raise significant questions - was marshland the only available choice for those denied more elevated settings? did these monuments provide a unique community function? does the watery location suggest ritual functionality? These questions are material to the interpretation of marsh-forts but remain unaddressed in most expositions of Iron Age society and landscape theory.

The term 'marsh-fort' has been in use for nearly four decades, but has never been explored. Riley's original concept implied something bigger and more monumental than a low-lying enclosure, whilst Sutton Common was identified as a large, Middle Iron Age fortification used for non-domestic purposes. The Atlas of Hillforts (Lock and Ralston, 2017) has adopted the 'marsh-fort' classification for those sites which incorporate wetland within their defences. However, between Riley's original interpretation, Sutton Common and the Atlas of Hillforts, the question of what constitutes a marshfort remains open. Marsh-fort research lacks consistent criteria and a theoretical basis, and risks repeating the lack of clarity which has beset the use of the term 'hillfort' for almost a century (see Chapter 2).

In line with Objective 1 (see 1.3.2), this chapter will establish marsh-forts within their cultural and physical landscape. Firstly, this will be achieved by charting the development of landscape studies and the way in which GIS has emerged as an indispensable aid to landscape reconstruction, particularly in wetlands. Secondly, criteria derived from the Sutton Common model are used as a high-level template against which to compare other marsh-fort candidates. The resulting sites are then used to position marsh-forts within a temporal and spatial context.

Developing a framework for marsh-forts is an important step towards their recognition, and helps to create a comprehensible narrative for the way in which these monuments functioned; this is expanded in Chapter 9. The marsh-forts identified here are unlikely to be exclusive, and many have a poor underlying dataset. Chapter 10 suggests way in which this framework can be developed. 


\subsection{Conceptualising wetland landscapes}

'Landscape ...is a broad, inclusive, holistic concept created intentionally to include humans, their anthropogenic ecosystem and the manner in which these landscapes are conceptualized, experienced and symbolized.' (Fisher and Thurston, 1999:630).

\subsubsection{Defining landscape}

'Landscape' is not the same as 'land'. It is a human construct, with etymological origins in Middle German (landschaft) and Middle Dutch (landschap). It suggests a visualised and delimited section of the world through which we comprehend both our surroundings and ourselves (Hirsch, 1995; Cosgrove, 1998). It is a 'unit of human occupation' (Schama, 1995:10), 'a cultural image' and 'a pictorial way of representing, structuring or symbolising surroundings' (Cosgrove and Daniels 1988:1). Cartesian-based landscapes present a diagrammatic, objectivised and detached view of the world where vision is paramount (Jay, 1984 cited in Thomas, 1993), but global ethnographic studies illustrate alternative and equally legitimate ways in which landscape is perceived and interpreted. Amongst the Sami of Northern Scandinavia, a shift to pastoralism brought about a change in perception from landscape as a source of mystical power to landscape as a mode of production (Mulk and Bayliss-Smith, 1999); in Peru, the Piro 'see' a landscape in terms of kinship rather than anthropogenic or topographical features (Hirsch, 1995); for New Zealand Māori, land and genealogy are indivisible and each tribe is tāngata whenua, the people of the land (King, 2003:167).

Each cultural group fashions a natural landscape into a cultural landscape from within its own cultural paradigm or habitus (Bourdieu, 1977) - the deeply ingrained and socialised norms, ideas, customs, skills and values that inform our consciousness through our life experiences, and which are constantly reinforced through social structures and human agency. These cultural processes are bound by the twin poles of space and place (Hirsch, 1995). Anonymous space is given meaning and significance through socially constructed places, which act as repositories for individual and collective history and memory (Tuan, 1974; 2011). Over time and through daily and seasonal repetition, people unite with the places in their environment (Thomas, 1993:28) creating a 'taskscape', a place where each and every human activity is imbued with meaning (Ingold, 1993).

Studying ancient landscapes and taskscapes provides frameworks through which different aspects of human existence can be integrated and interpreted (Thomas, 2012:316). Western artists create comprehensible and relevant landscapes by placing features within a frame to form a narrative; by including that which is deemed relevant to the research of past societies, landscape archaeologists do the same. 


\subsubsection{Landscape archaeology, methodology and interpretation}

'Material objects, empirical data, and appropriate analytical techniques are indispensable to elucidating cultural history and the dynamics of ancient societies.'(Butzer, 1978:192). As the ultimate artefact, landscape is no exception, and like many artefacts, landscape is also a process, and its cultural meaning is created and recreated as society changes (Morphy, 1995). The purpose of landscape archaeology is to elucidate such change, positioning past societies and individuals within a dynamic contextual paradigm against which multiple theories about a site or a society can be tested (Butzer, 1978). Through this, we create a narrative based on the archaeological evidence available (Andrews et al., 2000).

Landscape archaeology has evolved to become the dominant integrative strategy for regional and local history and prehistory' (Fleming, 1999:65). As early as the 1960s, Binford (1964) argued for archaeological research to be undertaken at regional (landscape) rather than local (site) level. Since then, the scope has widened from analysing sites and settlements, into wider environmental and cultural reconstruction (Miles, 1981; Fisher and Thurston, 1999), and thence into post-processual interpretive frameworks drawn from landscape phenomenology (e.g. Bender, 1993; Tilley, 1994). It is multi-disciplinary; by compiling data from a range of sources - stratigraphic and topographical survey, palaeoenvironmental analysis, aerial reconnaissance, geophysical prospection, material culture and historical ecology (e.g. Meyer and Crumley, 2011) - it seeks to present a comprehensive picture of past human activity.

An inhabited landscape is as much a palimpsest as any medieval document (Bailey, 2007) and each layer of past evidence must be teased apart spatially and temporally. Spatially, landscapes are experienced through the impact of landmarks and boundaries - natural or anthropogenic, prominent or obscure, some with special physical properties. For example, the ritual landscape at Avebury is experienced through a sequence of visually prominent Neolithic monuments which command attention through their scale and conspicuousness (e.g. Devereux, 1991; Whittle, 1993). Conversely, the spring at Blick Mead, $2 \mathrm{~km}$ from Stonehenge, is visually obscure but it maintains a constant temperature of $11^{\circ} \mathrm{C}$ and contains rare algae which turn objects pink; the quantities of feasting debris suggest that the site was special beyond its function as a Mesolithic campsite (Jacques, 2016). Field boundaries, ditches, and living areas provide evidence for the way in which social norms were reinforced through the architecture of everyday lives (Chadwick, 1999:158). These ceremonial and domestic landmarks are rarely distributed evenly throughout the landscape, and it has also been suggested that the 'empty' spaces in-between may have held equal importance (Darvill, 1999), although Layton and Ucko (1999) point out in the same volume that they are filled at their peril by over-enthusiastic archaeologists (see 4.1.3 below). 
Temporal analysis of landscape requires the same degree of precision as spatial analysis (Butzer, 1978). 'Time perspectivism' is needed to understand differences between the short, medium or long term timescales of past landscapes and avoid the modern tendency to telescope the past (Bailey, 1981; 2007; Fletcher, 1992; Seawright 2015). Monuments, landmarks and living areas may not have been contemporary or in continuous use, and anthropogenic landscape phenomena may or may not have held their importance down the generations (Barrett, 1999a). There are many examples of those that did, such as the Coneybury Anomaly and its ongoing relevance to the Stonehenge landscape (Richards, 1990). Other monuments or phenomena were subsumed or marginalised, either because their meaning changed (Giddens, 1984), or because they fell outside of collective remembrance (Rowlands, 1993; Schama, 1995); examples include settings which were sacred in Neolithic and Bronze Age times but were no longer seen as important within the structure of a settled Iron Age agricultural landscape (Bradley, 1991; Barrett, 1999b:254). These spatial and temporal examples illustrate that landscapes were, and are, 'work-in-progress'.

Landscape interpretation has tended to reflect whichever philosophical approach was prevalent at the time - be it culture-historical, empirical/processual or humanistic/post-processual - and each has provided a target for subsequent criticism. For example, and using a processual approach, Aston (1985) described medieval landscapes in terms of boundaries, mounds, field systems and abandoned villages. This was deemed to be overly deterministic by the post-processual movement, and Aston and his contemporaries were criticised for 'simply describing' what they found, and reducing people to 'ghosts in the machine' (Thomas, 1993:26). Instead, post-processual landscapes were increasingly expressed in terms of the dynamic relationships between people, things and places (Thomas, 2012), where, in order to interpret accurately, we must 'put ourselves inside a set of material circumstances which were integral to a meaningful world in the past' (Thomas, 2012). Landscape became a medium for action (Tilley, 1994:10-11).

As post-processual archaeologists turned their attention to bigger prizes, they often developed single-issue landscape interpretations. The ritual landscape of Cranbourne Chase in Dorset became an upland metaphor for Chesil Beach, symbolised as 'The Beach in the Sky' (Tilley, 1999; 2010). Stonehenge, the canvas upon which each generation paints its own heuristic model, became a casestudy for Bender's theory of contested space and appropriation by powerful elites, showing the 'different ways in which those with economic and political power and necessary cultural capital have attempted... to appropriate the landscape' (Bender, 1993; 1998:98). This interpretation was criticised on many counts, mainly for its superficiality and for giving voice to the 'unofficial, opposed, 
(and) dispossessed'; at a deeper level, it was also seen as little more than an echo chamber for the 'cloned voices' of like-minded academics (Chippindale, 1999:387-388).

A further example concerned Bender's interpretation of the upland Bronze Age settlement at Leskernick on Bodmin Moor (Bender et al., 1997). Bender conceptualised the easterly orientation of round house entrances as offering viewsheds which would greet the approaching dawn and were wholly symbolic in nature. However, a detailed pollen analysis proved that these viewsheds were masked by the surrounding vegetation and probably non-existent during the Bronze Age (Chapman and Gearey, 2000), illustrating the risks involved in ignoring scientific/processual approaches to archaeological interpretation - '...if 'scientific' sources of data pertaining to landscapes are given a low priority by landscape theoreticians, meanings gained from them will be incomplete' (Chapman and Gearey, 2000:318). These few examples give a flavour of why phenomenological interpretations of landscape were disparaged as platforms to promote personal agendas, and criticised as fanciful notions which lacked intellectual rigour (Chippindale, 1999; Ingold, 2005; Fleming, 2006). However, if approached with objectivity, they provide an important balance to overtly empirical ideas.

One further point concerning landscape interpretation is illustrated by the way in which modern landscapes differentiate between and compartmentalise domestic and spiritual functions, whereas past landscapes did not (cf. Barrett, 1994). What a modern world would term a blurring of functions is shown in many examples. Hill's seminal study of settlement in Iron Age Wessex (see Chapter 2) indicated that structured, and what would today be interpreted as ritualised, deposition was routine in domestic contexts (Hill, 1995b). The large defended farmstead of Collfryn appeared wholly domestic in function, but cattle bones were deposited at specific points around the settlement indicating the special significance of both beast and place (Britnell et al., 1989). Wellington Quarry, Hereford, combined a multi-period landscape of both funerary and domestic activities (Jackson and Miller, 2011).

Taking the above into account, landscape archaeology and interpretation can be encapsulated under three unifying principles which influence interpretation (Fisher and Thurston, 1999:631):-

- Landscapes are dynamic and humanly maintained,

- Events conspire to create a landscape; they are, as a consequence, historically contingent

- Landscapes are the product of a recursive interaction; the people shape the landscape which shapes the people and so on.

Each of these principles should be borne in mind when interpreting the landscape settings of marshforts. 


\subsubsection{Landscape reconstruction and Geographical Information Systems (GIS)} Landscape interpretation is greatly influenced by the detail and accuracy of any reconstruction, be it conceptual or empirical, the practicalities of which are greatly aided by the use of GIS. GIS encompasses a range of software (ArcGIS v.10.2 is used in this study) used to capture, organise and manipulate quantitative, qualitative, spatial and chronological data. There has been debate over whether the acronym stands for System or Science; this is now substantially resolved, and both are applicable, with 'science' capturing the philosophical and epistemological constructs, whilst 'system' indicates the infrastructure, tools and methods which allow data to be captured and manipulated (Wright et al., 1997).

Provided it has a spatial dimension, any data - artefactual, topographical, environmental, geophysical, LiDAR or aerial photography - can be applied to a base map to create a landscape model (Chapman, 2006). Earlier approaches to organising and presenting data relied on hand-drawn models, laborious but sophisticated for their time. Now, using a GIS, the click of a mouse-button can propel the user between temporal and spatial scales, providing a unique view of socially constructed space across thousands of years of human history. The data can be interrogated using query attributes to create datable layers, build virtual landscapes through cost-path analysis and viewshed reconstruction (Chapman, 2006:107-111), and create archaeological simulations such as Clonehenge (Fletcher and Spicer, 1988) or Stonehenge (e.g. Gaffney et al., 2012). By analysing gaps in the distribution of finds and sites, it is also used for archaeological prospection (Gaffney and van Leusen, 1995a/b; Wheatley and Gillings, 2002; Ebert, 2004). With its capacity to model a range of surveyed data such as LiDAR, GIS is invaluable in mapping the dynamic landscapes of changing river channels and peat encroachment which characterise wetland environments (Chapman and Gearey 2013; Howard et al., 2016).

There are many examples. A GIS-based analysis of the viewsheds from Rudston 'Cursus A', East Yorkshire, demonstrated a previously unknown visual relationship between the Neolithic cursus and two long barrows (Chapman, 2003). The palaeolandscape of the Hatfield Moors was reconstructed to demonstrate peat growth and re-interpret the Mesolithic environment (Chapman and Gearey, 2013). The use of GIS was crucial in recreating the landscape around Danebury, establishing the Neolithic long barrows as highly visible territorial markers and linking the hillfort to the surrounding settlements (Lock and Harris, 1996). Llobera used GIS generated visual models to emphasise the need for rigour in the interpretation of movement across and around archaeological landscapes, and his study of round barrows and linear ditches in the Yorkshire Wolds demonstrated that the size of a monument is directly relevant to its influence on the landscape (Llobera, 2001; 2007). Using Higuchi viewshed analysis, it has been demonstrated that short, medium and long viewsheds differ in their 
accuracy and effectiveness (Wheatley and Gillings, 2000). Recently, GIS modelling has turned away from the obviously visual towards the spaces between monuments (however, see Layton and Ucko, 4.1.2 above) and the affordances they offer (Gibson, 1979; Gillings, 2012). In an analysis of a Bronze Age landscape in the southern Netherlands, Fontijn used GIS to contrast the positioning of highly visual Bronze Age barrows and hidden deposition sites, suggesting that the invisibility of deposition sites may have been 'an authoritative resource, defining insiders from outsiders' (Fontijn, 2007:81). These examples are but a fraction of the literature generated from the GIS store; they facilitate both interpretation of newly identified landscape and the recreation of landscapes that were previously thought to be understood.

Although criticisms abound, these may represent the teething troubles inherent in a developing medium. Two of the weaknesses levelled at GIS have been perennially levelled at archaeology in general, namely, the pitfalls inherent in drawing conclusions from incomplete data, and verifying those conclusions in the absence of testable models (Chapman, 2006:23). GIS usage is also criticised for offering a single non-contradictory view of the world which gives rise to accusations of technological and environmental determinism (Lock, 2001), a theme which Thomas pursued when criticising the use of virtual reality modelling (2004:171). GIS is accused of bias towards quantitative rather than qualitative data and of not expressing the nature of the human experience (e.g. Witcher, 1999). The software itself is criticised for being unnecessarily difficult and complicated (Hu, 2012); however, it was written for a wider range of disciplines (for example, the military, and utility and forestry companies) than simply archaeology. The examples offered in this chapter also illustrate that the visual bias within established landscape theory is reinforced by the use of GIS (see also, Chapter 6 - The Berth - Line-of-sight analysis). As a recent contrast, Gillings analysed movement and mobility patterns around a group of stone rows sited on high ground on Exmoor, concluding that they were 'hidden in plain sight' and that 'visibility (in all its manifestations) is the least relevant aspect ...of assembling this tiny group of stones and setting them upright' (Gillings, 2015:13). One consequence of a visual bias is that wetland landscapes, which often lack prominent viewsheds and elevated monuments, are analysed less often using GIS than the more open, upland landscapes such as Bodmin Moor or Danebury. Ultimately however GIS is criticised for lacking a theoretical framework (Lock, 2001; Gillings, 2012; Hu, 2012) and, from an elevated Cartesian viewpoint, of performing the 'God trick', creating a landscape that past inhabitants would hardly recognise (Harraway, 1991:189).

As with any computerised system, such criticisms should be directed at the user not the software, and are equally valid whether the preferred interpretation follows processualist or post- 
processualist principles. The danger lies in simply describing rather than interpreting the results that GIS produces, bringing criticism full circle and back to Thomas' views of Aston's medieval landscapes (see 4.1.2 above). In order to create theoretical models of the relationship between humans and their environment, users of GIS must begin with a research question and work within landscape theory to summarise the existing records (normative), construct practical and empirical models (scientific) and draw theoretical conclusions which interpret thought and motives for action (theoretical) (Chapman, 2006). GIS does not generate theory or interpretation; people do (Hu, 2012).

GIS is much more than an improved way of processing archaeological data $(\mathrm{Hu}, 2012)$ or 'the presentation of aesthetically pleasing maps' (Ebert, 2004:320). It is the most powerful tool to be applied to the past since the advent of radiocarbon dating (Conolly and Lake, 2006) and has been termed 'a place to think' rather than a simple mapping tool (Gillings and Goodrick, 1996). It offers a detachment which allows new knowledge to be evaluated. The end result should form a recursive loop back to the landscape principles detailed above (see Fisher and Thurston, 1999) and a framework for studying and understanding sites within their surroundings (Chapman, 2000). With the exception of the analysis of the emerging viewsheds at Sutton Common (Chapman, 2000), the landscapes surrounding marsh-forts (and many hillforts) have not benefited from GIS analysis and this thesis opens up that the process.

\subsubsection{Landscapes as waterscapes}

Wetland landscapes as ecosystems and the practicalities of wetland formation are addressed in Chapter 5. However, the social and symbolic aspects of wetlands are integral to the siting of marshforts. These environments are increasingly referred to, not as landscapes, but as 'waterscapes' (Strang, 2008), a term which summarises the interplay between bogs, lakes, alluvial wetlands, peatlands, streams and rivers and offers a precise grammar to describe wet and peaty environments.

Normally, people wish to avoid the rotting stores and failing health associated with wet environments, not to mention the problems of flooding, keeping dry and the occasional drowning. Glastonbury Lake Village has been described thus: 'The site chosen was almost deliberately difficult: difficult to establish a foundation, difficult to keep dry, difficult to maintain, and impossible to guarantee against natural disaster' (Coles and Minnitt, 1995:207). Life in a wetland environment would have been affected by climatic change (increasing flood events or peat encroachment) and occupation may have been routinely disrupted. However, the archaeological record testifies to many Bronze Age and Iron Age sites in wetland contexts, the locations of which had been carefully selected; therefore, there must have been advantages. 
Economically wetlands were and are amongst the most productive systems on earth (Dinnin and Van de Noort, 1999; Keddy, 2000), providing a natural abundance of resources such as fish, fowl, bog ore, and reeds for thatch. Practically, wetlands provided a degree of safety in the form of lessening the risk of fire, although it was not eliminated entirely as excavations at Must Farm in Fenland show (Knight, 2009). Knowledge of the intricacies of a waterscape would combine ease of transport and communication with secrecy, protection or security, and the littoral space may have provided opportunities for those living on society's edge (Van de Noort, 2004) - outcasts or criminals. Wetland sites may have been sufficiently remote to perform actions that might otherwise pollute or endanger society (e.g. Douglas, 1966). Metalworking is one example, a hazardous activity with a high fire risk, but which also embodies an act of creative transformation possibly perceived as magical (Hingley, 1997; 2006). More prosaically, flax retting requires running water and was undertaken in wetlands, but is malodorous enough to preclude living nearby (Andresen and Karg, 2011).

Symbolically, it is impossible to separate wetlands from acts of votive deposition, rites of passage and religious practice (e.g. Wait, 1985; Van de Noort, 2004; Van de Noort and O'Sullivan 2006). Water and bog have long been seen as transitory membranes through which people (and objects) may pass to access a spiritual dimension (e.g. Ross, 1967; Merrifield, 1987). In many ethnographic studies, water is presented 'as a matter of life and death; as a potent generative and regenerative force; as the substance of social and spiritual identity; and as a symbol of power and agency' (Strang, 2008:115). Such liminal places are associated with ceremonies of personal transition where separation from the community into a marginal place or landscape is followed by reintegration into society as a 'new' person, for example, at puberty (van Gennep, 1960).

Throughout prehistory and particularly during the Bronze and Iron Ages, metalwork and weaponry (Fitzpatrick, 1984; Bradley, 1990; Mullin, 2012), ecofacts such as bog butter (Evans, 1947; Earwood, 1997), and animal and human remains/bog bodies (Bourke et al., 1986; Turner and Scaife 1995), were deposited into watery contexts and are frequently interpreted as votive offerings to chthonic deities. The practice of depositing metalwork burgeoned in Europe during the Middle Bronze Age and by the Late Bronze Age, it had developed a high degree of symbolism; the sheer quantity of bronze that was placed beyond reach is interpreted as evidence for the conspicuous consumption of (votive) artefacts (Bradley, 1990). Although depositing bronze in quantity went into rapid decline circa 800BC (Needham, 2007), iron and copper-alloy metalwork, especially weaponry and cauldrons, continued to be deposited in watery places throughout the first-millennium BC (Fitzpatrick, 1984; Wait, 1985; Hingley, 2006). The nature of the watery context - be it flowing, still or mineral rich also mattered (e.g. Strang, 2005; Yates and Bradley, 2010). For example, swords are closely aligned 
with flowing water (e.g. Fitzpatrick, 1984), especially easterly flowing rivers such as the Witham and the Thames; more general Iron Age weaponry and hoards have a greater affinity with lakes, such as at Llyn Cerrig Bach on Anglesey (Lynch, 1970). Platforms were built in some wetland locations to facilitate the act of deposition, for example the Late Bronze Age causeway at Flag Fen (Pryor, 2005) and the Iron Age depositionary platform at Fiskerton (Field and Parker Pearson, 2003).

Controlling access to ritual sites, sites of deposition and the sacred places associated with water is also likely to have mattered. Access routes may have involved the symbolic crossing of water or the following of rivers. Whilst this has been cited by Thomas in reference to Neolithic Orkney (Thomas, 2012), the same is potentially true elsewhere and the idea could be extended to following a difficult path through treacherous bogland. There have been metalwork finds along a putative routeway across the boggy wetlands of the Weald Moors adjacent to the marsh-fort of Wall Camp (Chitty, 1953; Norton, 2013:37), and these monuments may yet prove to be connected with the control of ritual sites in waterscapes. Sutton Common was accessed by crossing water and the same may be true of other marsh-fort candidates.

The relationship of deposition to other sites in the wider landscape/ waterscape is also revealing. Metalwork deposition frequently shows a negative correlation with settlement and field systems (Van de Noort, 2004), but is often positively correlated with the phenomenon of burnt mounds. Also known as 'boiling mounds', these enigmatic piles of heat-cracked stone are found near watercourses or palaeochannels (Ehrenberg, 1991; Hodder, 2002; Ó'Néill, 2009). They have been associated with cooking, or industrial processes such as fulling. They are generally attributed to the Bronze Age, although their use is known to span a much wider timescale. Concentrations are found in the peatlands of the Fens (Yates and Bradley, 2010) and North Shropshire (Halsted, 2007), often in association with metalwork deposition. They have also been interpreted as having ritual significance (Barfield and Hodder, 1987; Bayliss, 1991; Hodder and Barfield, 1991) and are discussed with reference to North Shropshire in Chapter 5.

The artefacts recovered from all these contexts paint pictures of what people valued either as individuals or as a community. Coles has suggested that votive deposition was a highly symbolic, ceremonial act, undertaken at community level, where items were often intentionally and publically damaged to illustrate that such pieces were to be placed beyond the realm of the everyday (Coles, 2001). The siting of large monumental enclosures in some waterscapes is likely to have a profound relevance to the waterscape itself and the functionality of the fortification. 


\subsection{Marsh-fort Gazetteer - a survey of potential marsh-forts}

Building on the review of landscapes and waterscapes discussed above, this section of the thesis develops a set of characteristics based on the Sutton Common model and uses those as criteria against which to assess other potential marsh-forts. By asking the questions 'What are marsh-forts, where do you find them and why are they there?', the aim is to review and analyse marsh-forts in England and Wales (this chapter), and to develop that analysis further through case studies of marsh-forts in North Shropshire (Chapter 5), focussing specifically on the Berth, near Baschurch (Chapters 6-8).

The purpose of this analysis is not to identify every potential low-lying Iron Age enclosure site across England and Wales, nor to pigeon-hole those considered, but to identify sites which may contribute to a marsh-fort model and use the evidence to illustrate similarities and differences.

\subsubsection{Marsh-fort Criteria}

It has long been accepted that some Iron Age fortifications were built in low-lying topographical locations, described variously as valley-forts or low-lying promontory forts (Forde-Johnston, 1976; Dyer, 1981; Cunliffe, 2005). Whether anything other than topography linked such monuments was not explored, and when Riley labelled Moorhouse Farm, Tickhill, as a 'marsh-fort' (1980), he did not define the classification.

It was only with the detailed excavations at Sutton Common that 'marsh-fort' as a site-type attained a degree of acceptance (Van de Noort et al., 2007; English Heritage, 2011). Its unique combination of chronology, morphology, and artefactual remains define a highly unusual monument that is more than its topographical setting (Fig. 4-1).

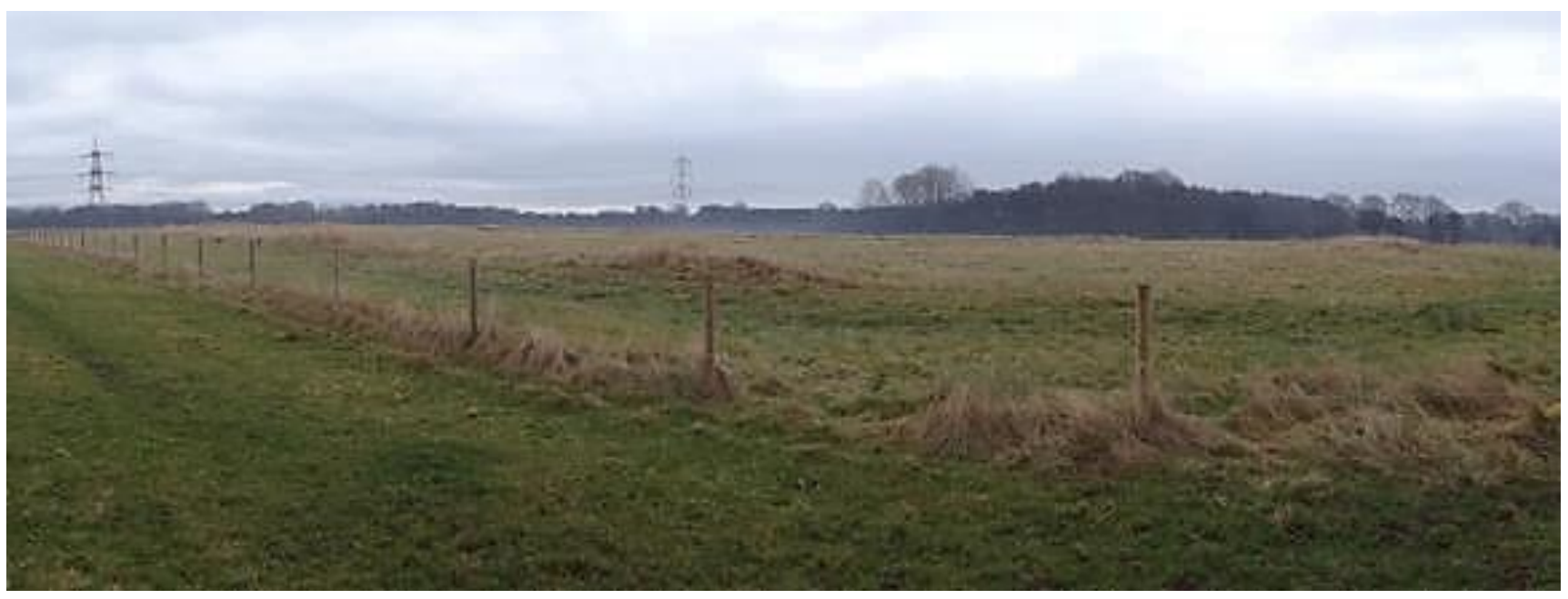

Fig. 4-1 The Sutton Common landscape, looking east across the large enclosure, towards Shirley Pool (Norton, 2017) 
The characteristics that define Sutton Common are:-

\begin{tabular}{|c|c|}
\hline $\begin{array}{l}\text { Size } \\
\text { - } \quad \text { large (cf Jackson, 1999) - circa } 6 \text { ha }\end{array}$ & $\begin{array}{l}\text { Chronology } \\
\text { - lengthy landscape chronology }\end{array}$ \\
\hline $\begin{array}{l}\text { Location } \\
\text { - occupying an 'island' location within low- } \\
\text { lying marshland (5mOD), controlling } \\
\text { access to a flooded area/wetland } \\
\text { - field systems in the surrounding } \\
\text { landscape }\end{array}$ & $\begin{array}{l}\text { Mesolithic and Neolithic flint scatters } \\
\text { Bronze Age mortuary enclosure } \\
\text { short, intensive, discontinuous monument } \\
\text { chronology } \\
\text { phased use during the Middle Iron } \\
\text { Age (fourth-second centuries BC) } \\
\text { site 'closure' and abandonment } \\
\text { during the Late Iron Age }\end{array}$ \\
\hline $\begin{array}{l}\text { Morphology } \\
\text { - } \text { two enclosed areas - a large main } \\
\text { enclosure and a smaller annex/outworks } \\
\text { monumental architecture (uni- } \\
\text { /multivallate) with an unusual } \\
\text { arrangement of ditches and ramparts } \\
\text { (the ditch of the small enclosure is inside } \\
\text { the rampart) } \\
\text { the enclosures were connected by a } \\
\text { substantial causeway across the wet } \\
\text { ground of the Hampole Beck } \\
\text { an access route to Shirley Pool was } \\
\text { sufficiently important to warrant an } \\
\text { avenue of stakes which emanated from a } \\
\text { monumental, east-facing 'water-gate' } \\
\text { people were 'directed' through the small } \\
\text { and towards the large enclosure via a } \\
\text { proscribed routeway (Chapman, 2000) } \\
\text { the site's defensive values were } \\
\text { questionable (Parker Pearson and Sydes, } \\
\text { 1997) }\end{array}$ & $\begin{array}{l}\text { Palaeoenvironmental record } \\
\text { - building and usage was synchronous with } \\
\text { forest clearance (circa fourth-third century } \\
\text { BC); the surrounding area was used as pasture } \\
\text { the palisades (6000 trees) were oak which } \\
\text { was not sourced locally (mass felling is not } \\
\text { obvious from the palaeoenvironmental } \\
\text { remains); the species chosen and the non- } \\
\text { local nature of the trees may confer special } \\
\text { status } \\
\text { Non-Domestic use } \\
\text { whilst domestic architecture/ roundhouses } \\
\text { were absent, Enclosure A contained multiple } \\
\text { four- and six-post structures with charred } \\
\text { grain foundation deposits } \\
\text { a few significant artefacts (beads, a gold } \\
\text { fragment), fleshed heads, animal bones and } \\
\text { querns were interpreted as structured } \\
\text { deposits } \\
\text { cremated human remains were placed in } \\
\text { site usage }\end{array}$ \\
\hline
\end{tabular}

Table 4-1 Sutton Common characteristics (after Van der Noort et al., 20007) 
Van de Noort proposed three possible interpretations for the site (Van de Noort et al., 2007:175185):

\author{
Interpretation 1 \\ Looking at Sutton Common from a purely functional perspective, this was a defensible \\ refuge, which proved too damp to store grain, and was then reused as a cemetery
}

\title{
Interpretation 2
}

Taking a more processual approach and citing evidence of centralised grain stores protected by marshland and monumental defences, Sutton Common was a specialised form of habitation

\section{Interpretation 3}

Post-processually, (Van de Noort used 'humanistically'), Sutton Common was a sacred, wetland-encircled dune within a marsh landscape, with an east-facing ceremonial gateway accessing a (sacred?) pool, where social identity and shared memory (cf. Rowlands, 1993) were reinforced from at least the Bronze Age onwards. The monument embodied communal effort and reflected the surrounding cosmos, the granaries acting as testament to the transition from a warrior to farming culture - an example of the transition from space to (symbolic) place over time.

These interpretations are not mutually exclusive. However, the combination of a wetland location, a lack of evidence for domestic occupation, and a ritual function in a place which held a special resonance argues strongly for a humanistic interpretation.

Sutton Common's characteristics have been summarised as follows to create a working hypothesis (sensu Murray and Walker, 1988) against which potential marsh-forts can be assessed:-

1. Large size (cf. Jackson,1999; 3.1ha-6ha)

2. Marshland/wetland location - a lowland setting where the defences or access incorporate river or marsh. Elevated promontory forts are excluded.

3. Monumental with an unusual morphology - the site has substantial ramparts and ditches, and a morphology which enabled and possibly formalised access across surrounding wetland. Features can include multivallation, causeways, monumental gateways or dual enclosures.

4. Predominantly MIA with a LIA phase. 
5. Discontinuity of monument use, and/or a lengthy landscape chronology - evidence of Mesolithic, Neolithic and/or Bronze Age use of the landscape; discontinuity of use within the Iron Age

6. Palaeoenvironment - localised woodland clearance with evidence for a pastoral economy; field systems may exist in the wider landscape.

7. Non-domestic use/ ritual or ceremonial functionality - evidence is predominantly nondomestic and may include ritual or structured deposition - animal bones, grain, metalwork, human remains, votive offerings.

\subsubsection{Marsh-fort Gazetteer - regional analysis}

The extent to which Sutton Common was unlike other Iron Age monuments posed a question - was it unique? Following Riley's original use of the term, Field and Parker Pearson suggested that there might be 'two or three marsh-forts' east of Lincoln (2003:160-2) (see Tattershall Thorpe, below), whilst Fletcher identified seventeen sites similar to Sutton Common across England and Wales (Fletcher in Van de Noort et al., 2007:170-174). Brown also proposed several sites as possible marshforts (Brown, 2008). The Atlas of Hillforts (Lock and Ralston, 2017) classifies twenty-three sites as marsh-forts (twenty in England and Wales; three in Scotland; none in Ireland (Fig. 4-2)), and follows a traditional route by confining its selection criterion to topographical location (see 2.3 above). None of these compilations agree - a recurring theme in hillfort studies.

For this research, sites which have been suggested as marsh-forts, valley-forts or low-lying hillforts have been amalgamated to produce a gazetteer of fifty-four sites; these have been compared to Sutton Common's characteristics by means of a 'tick-box' system (for details of landscape setting, morphology, HER records, finds, excavation, and selected references - see Appendix 1; CD-ROM). Whilst it is possible to disagree with either the base-line criteria or their application, this unique approach enables the sites to be 'thought through' in detail rather than relying on topography alone. Despite the poor quality datasets which exists for many sites, the results show that, across England and Wales, potential marsh-forts are concentrated in South Yorkshire, Lincolnshire and the Fens, East Anglia and the North Shropshire/Cheshire Plain; outliers are present in Northumbria, Wales, and the river valleys of the Upper Thames and the Severn (Fig. 4-3). A high-level summary of each site is presented below (for sites in North Shropshire, see Chapter 5). The results have been grouped and summarised in Table 4-2. 


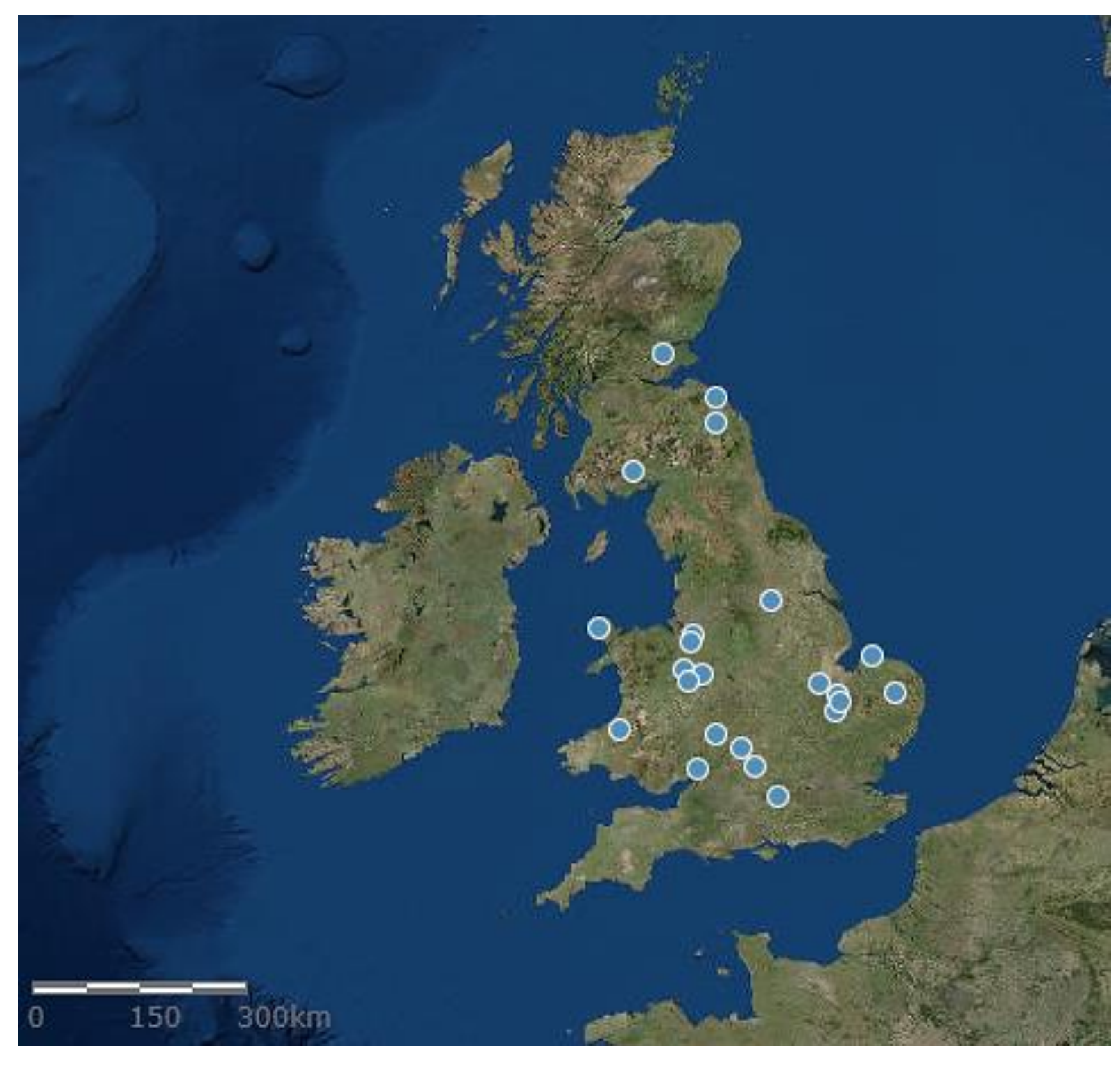

Fig. 4-2 The Atlas of Hillforts - marsh-forts (https://hillforts.arch.ox.ac.uk: January 2018)) 


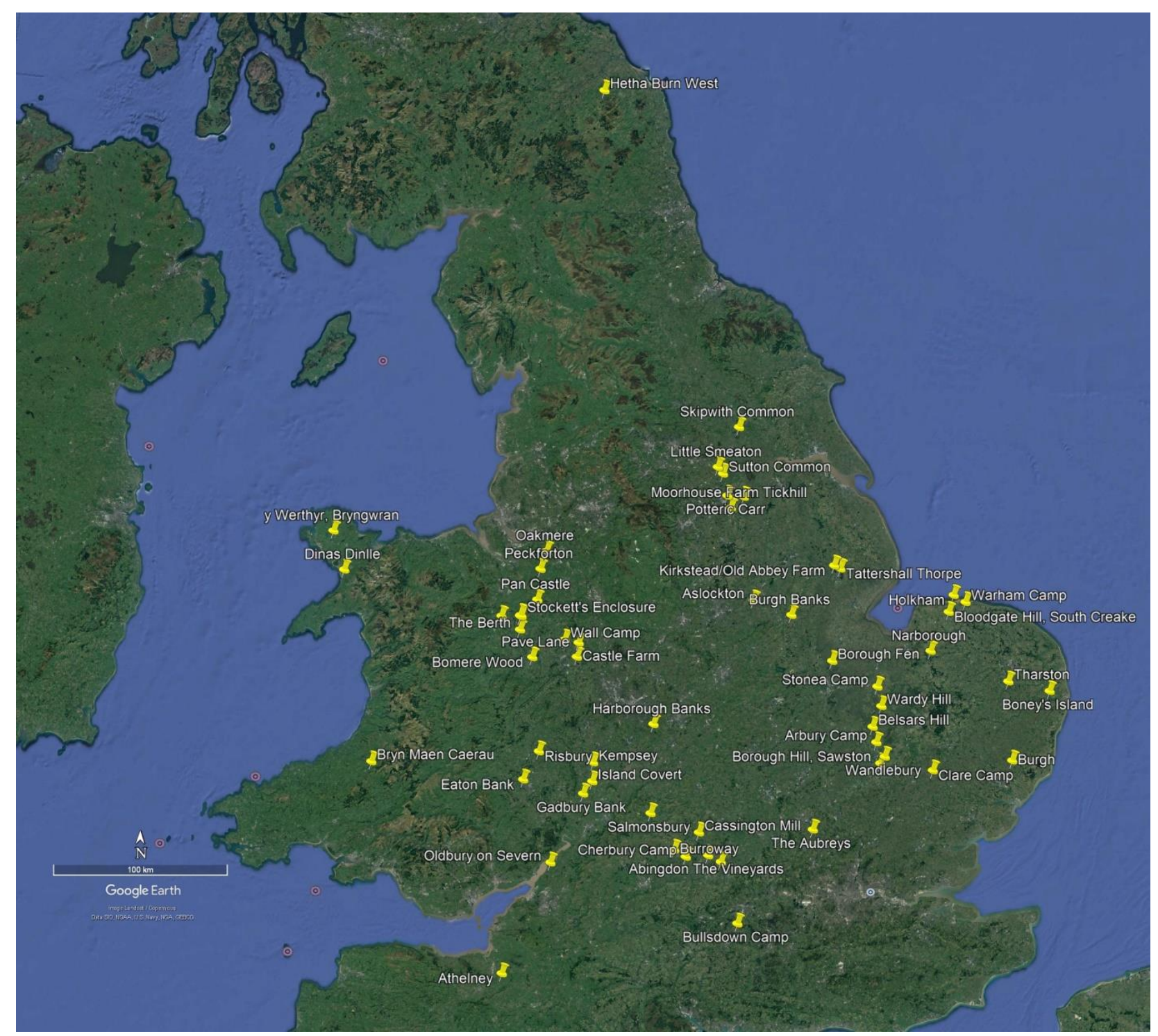

Fig. 4-3 Distribution of potential marsh-forts - England and Wales (Google Earth: January 2018) 
YORKSHIRE - Fig. 4-4

There are numerous enclosure sites and associated field systems within a $20 \mathrm{~km}$ radius of Sutton Common. Those highlighted here - Moorhouse Farm, Tickhill, Little Smeaton, Potteric Carr and Croft Road Finningley - lie south of the River Humber and east of Thorne and Hatfield Moors. An outlier, Skipwith Common, lies further north. Riley suggested several of these sites as unusual and coined the term 'marsh-fort' before they were collectively summarised by Chadwick in his review of the field systems of South Yorkshire (1999; 2010). However, Fletcher did not include any in his comparison and none are included within the Atlas. With the exception of Sutton Common, which falls into this group, all are represented by cropmarks; none has been investigated and the archaeological record is limited.

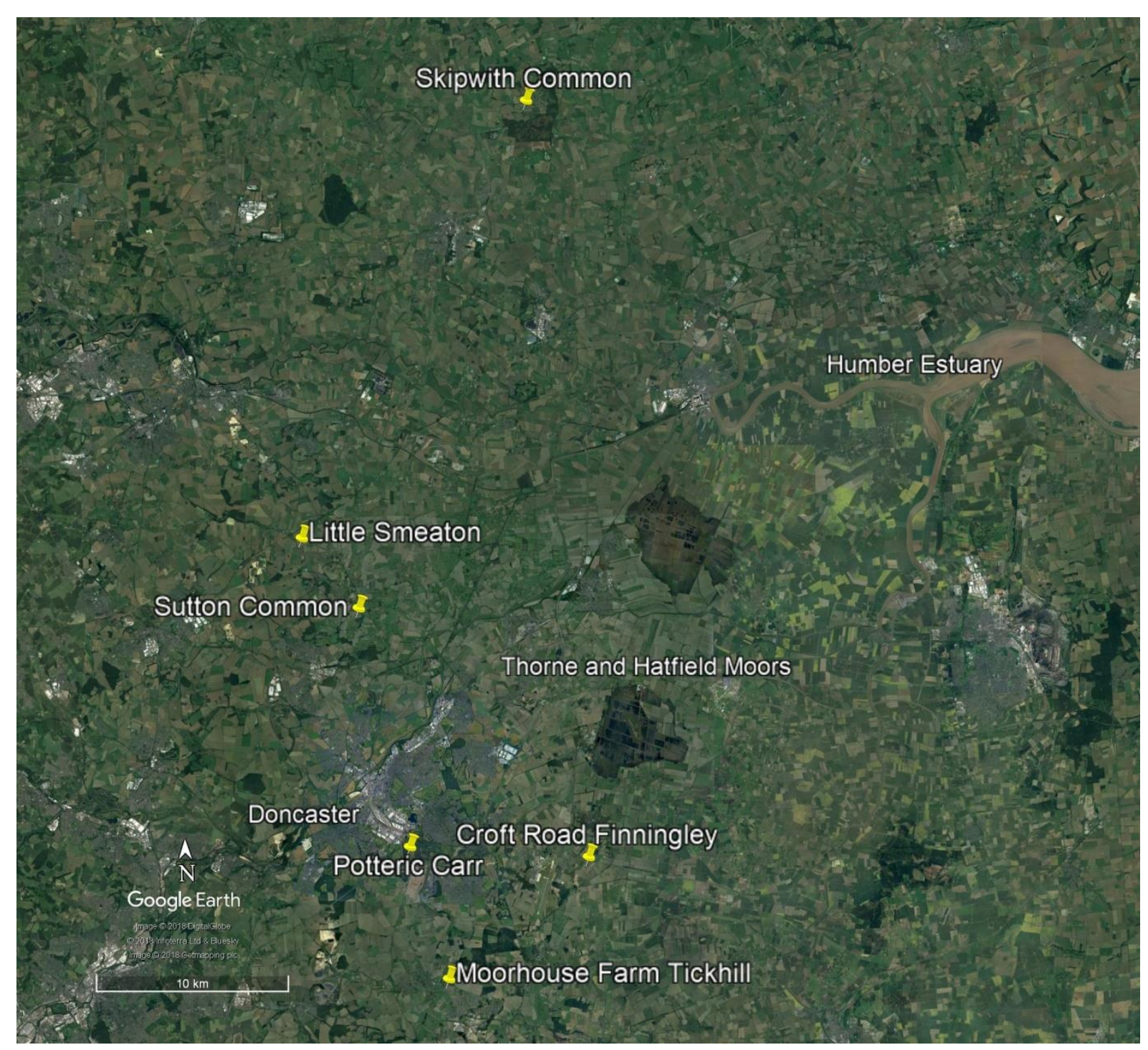

Fig. 4-4 North/South Yorkshire - distribution of potential marsh-forts around Sutton Common (Google Earth: January 2018) 
Moorhouse Farm, Tickhill was identified by Riley as a marsh-fort; it is older than the nearby brickwork field system and considered Early Iron Age in date (1980:100). Modern farm buildings partly overlie a kidney shaped enclosure with an internal ditch of 1.1 ha (possibly larger), occupying a low sandy tongue of land which protrudes into a peat bog. No more is known. A confusing suggestion in the HER that this feature is natural (South Yorkshire SMR 01994/01) is refuted by an aerial photograph and by Google Earth (Fig. 4-5).

Little Smeaton lies between the Rivers Wiske and Went (Fig. 4-6). It shares some topographical and morphological characteristics with Sutton Common, although it is much smaller (possibly 0.9ha). The site comprises a complex of enclosures within four ditched circuits which accessed the River Went; it is overlooked, suggesting that defence was not a major issue (e.g. Bowden and McOmish, 1987; 1989; Driver, 2007). The cropmarks suggest domestic occupation (possible round houses), but other unusual characteristics - for example, a square feature lying outside the east entrance (Deegan 2007, cited in Chadwick, 2010:831) and a complex eastern entrance - suggest some additional purpose. Mesolithic flints have been found at the site, indicating longevity of site use. As Little Smeaton lies just $4 \mathrm{~km}$ to the north of Sutton Common, the two sites may have had spatial and/or temporal connection, although Little Smeaton lacks dating evidence. The site has also been suggested as a Roman fort.

Riley did not use the term marsh-fort for the enclosure complex of Potteric Carr, although its unusual nature was acknowledged (Riley, 1980:91; Chapman in Van de Noort et al., 2007:170). The 1.7ha double ditched enclosure comprised an internal circle plus two attached enclosures sited in very low, marshy ground (Chadwick, 2010:1197-1199), close to a peat-filled palaeochannel of the River Torne; it is largely ploughed out and in part covered by forestry land. Its chronology is unknown, but it may have provided a focal point to the south of Sutton Common, whilst Little Smeaton provided a similar function to the north. 
Chapter 4-Marsh-forts in a landscape context
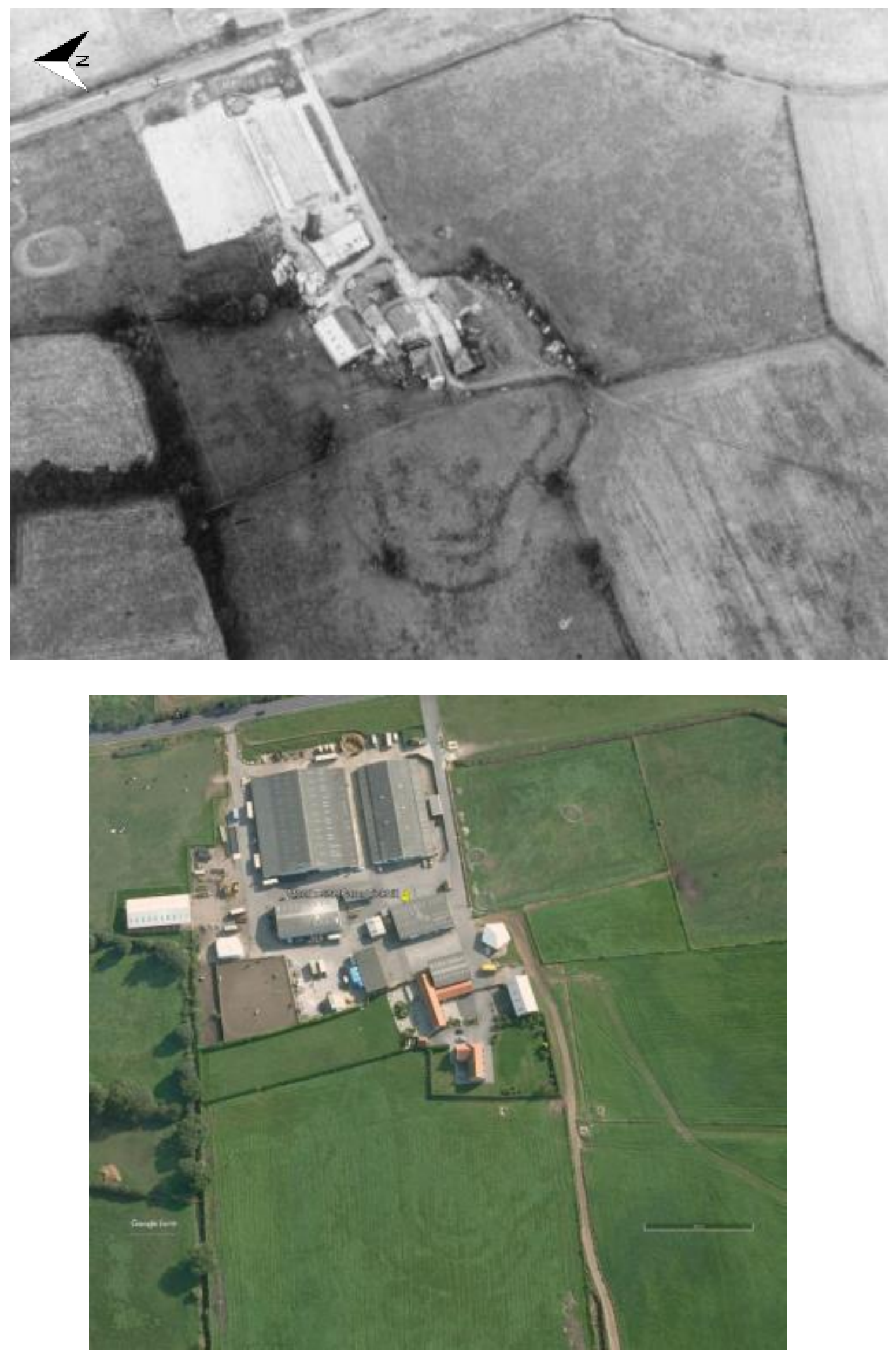

Fig. 4-5 Moorhouse Farm, Tickhill, showing ditch circuits (Riley, 1980:66 - top) (Google Earth: January 2018 - bottom) 

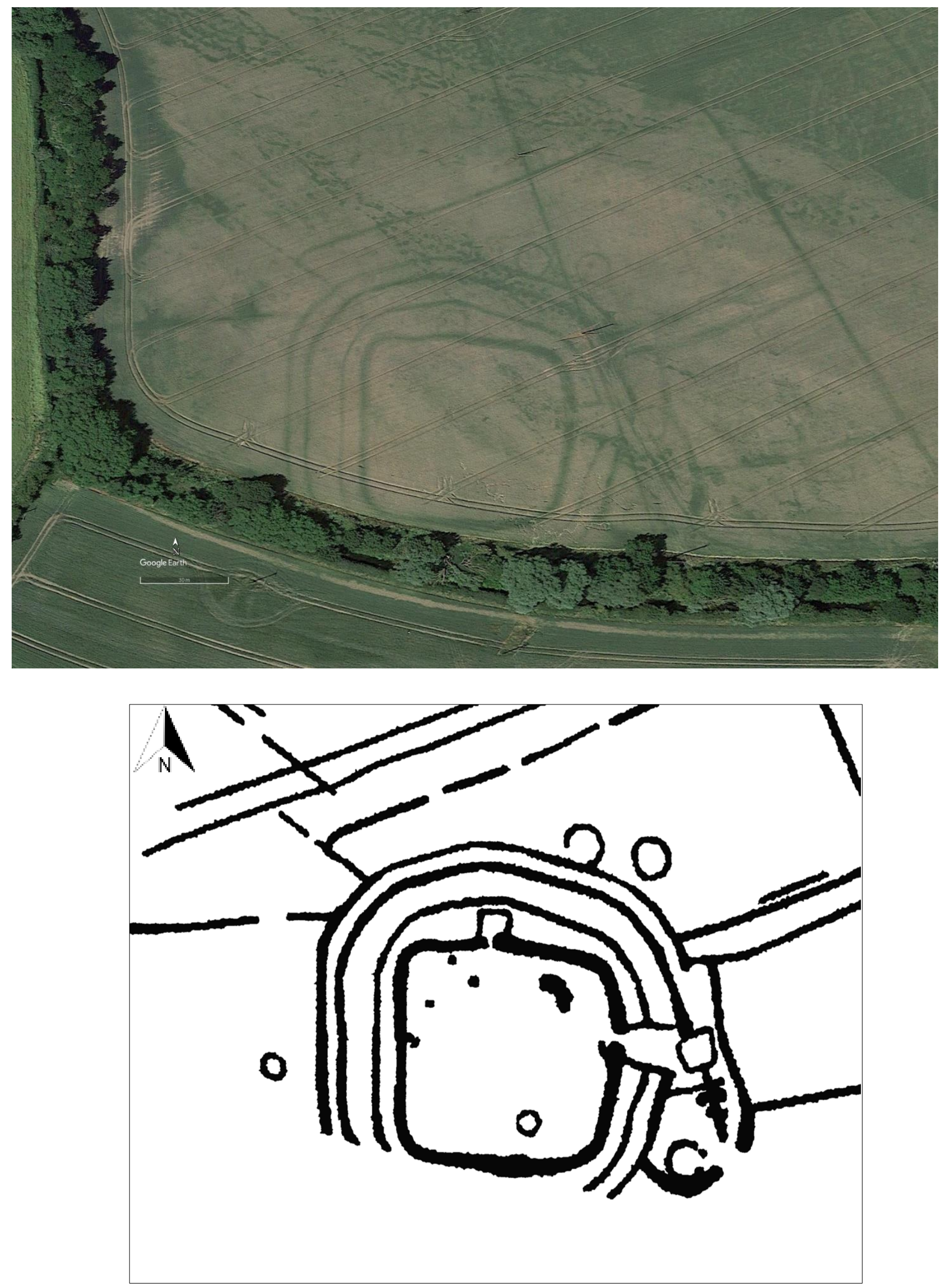

Fig. 4-6 Little Smeaton (Google Earth, December 2018 - top) and Deegan 2007 (bottom, cited in Chadwick, 2010:830) 
Identified as unusual by Chadwick but not mentioned by Riley, little is known about the enclosure at Croft Road, Finningley. It was multivallate with a trackway, and occupied a gravel island in a lowlying location (Chadwick, 2010:1112).

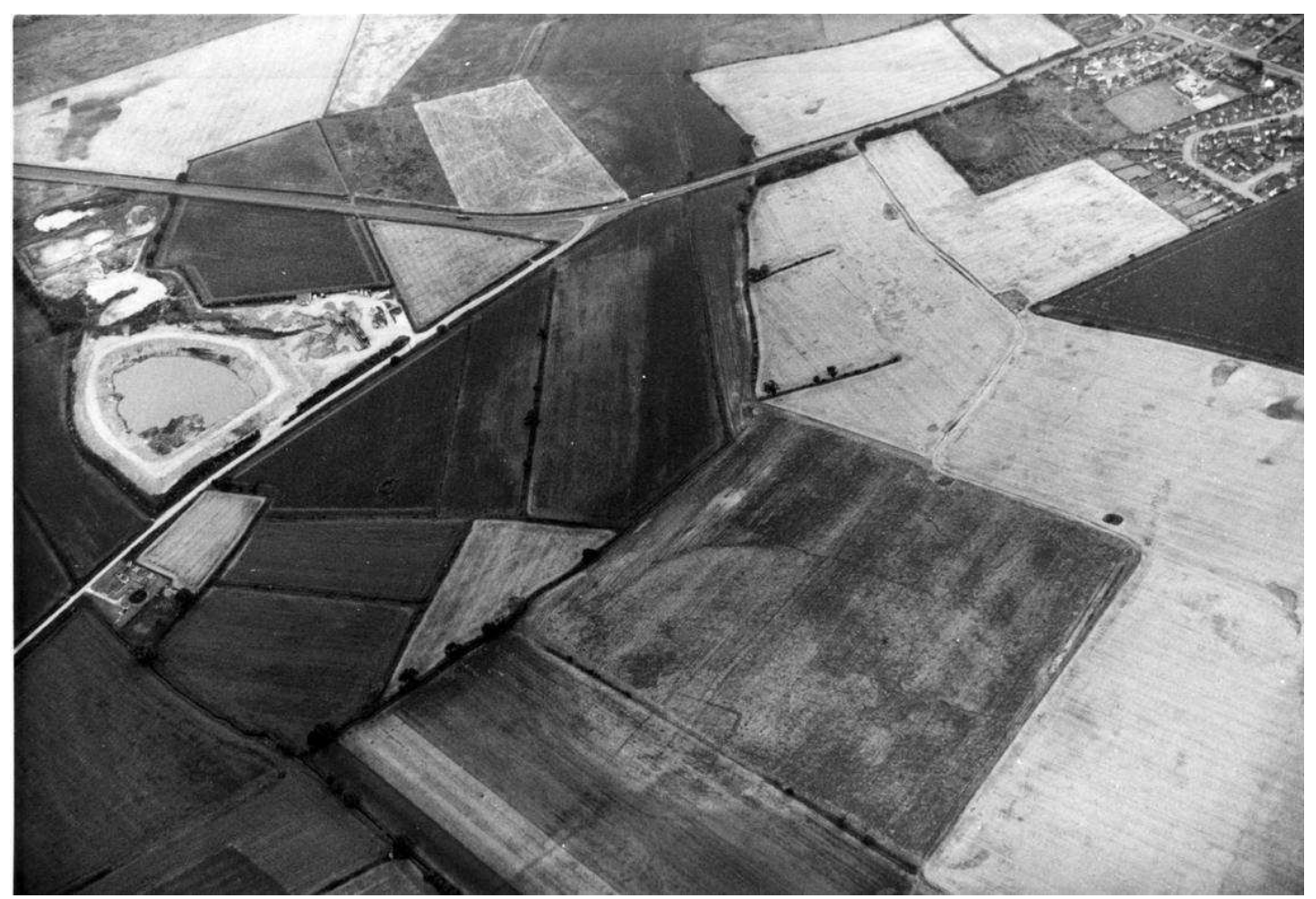

Fig. 4-7 Croft Road, Finningley (Riley, cited in Chadwick, 2010:1110)

The degree of connectivity between these sites and between the sites and their surrounding landscape is largely unexplored. Topographically, the marsh-forts/enclosures detailed here were located in flood-prone areas, often occupying outcrops of solid ground which intruded into the peat. Each has an unusual morphology although detail is limited due to years of plough damage and modern land use. Moorhouse Farm, Potteric Carr and Croft Road, Finningley form the points of an $8 \mathrm{~km}$ triangle, $13 \mathrm{~km}$ south of Sutton Common. The adjacent field systems indicate that, by the Iron Age, this landscape was well organised, with a large farming community, cultivating areas of lowland which later became marginalised through climatic change (Chadwick, 2010), a pattern similar to many Iron Age landscapes (Taylor, 1975:33). In their summary of the palaeoenvironment and field systems surrounding Sutton Common, Van de Noort and Chapman concluded that the site provided a focal point in a local/regional taskscape (Van de Noort et al., 2007:166-70, 180); the possibility that this may have formed a group of interlocking sites which controlled the surrounding landscape was not explored.

Chadwick's preferred interpretation was that these sites were firstly, enclosures within an agrarian economy, or, in the case of Little Smeaton, perhaps had a ritual function. His second conclusion was 
that they acted as territorial markers, occupying a tribal borderland between the Corieltauvi and the Brigantes, and were linked to other, more conventional, enclosed sites/hillforts such as the hillfort of Wincobank, near Sheffield (Chadwick, 1999:152). This echoes a conclusion previously drawn by Parker Pearson in reference to Sutton Common (Parker Pearson and Sydes, 1997). The theme of fortified sites positioned in lowland which acted as territorial makers is continued in the discussion of the East Anglian Fens (see below).

Further north, the sites at Skipwith Common contain a wealth of archaeological data including an Iron Age square barrow cemetery, and were highlighted by Van de Noort (2004:104-106). The area is poorly drained but functioned as both a multi-purpose settlement and a cemetery unit during prehistory (MAP Archaeological Consultancy Ltd, 1994). One of the larger enclosures to the west of the barrow cemetery was highlighted as a possible marsh-fort (Van de Noort, 2004:104-106;

Fletcher in Van de Noort et al., 2007:171), but there is no further detail.

\section{LINCOLNSHIRE, FENLAND AND EAST ANGLIA - Fig. 4-8}

A number of potential marsh-fort sites occupy the wetlands of Eastern England, encompassing the Lincolnshire and Cambridgeshire Fens, and coastal and pasture-based sites in Norfolk and Suffolk.

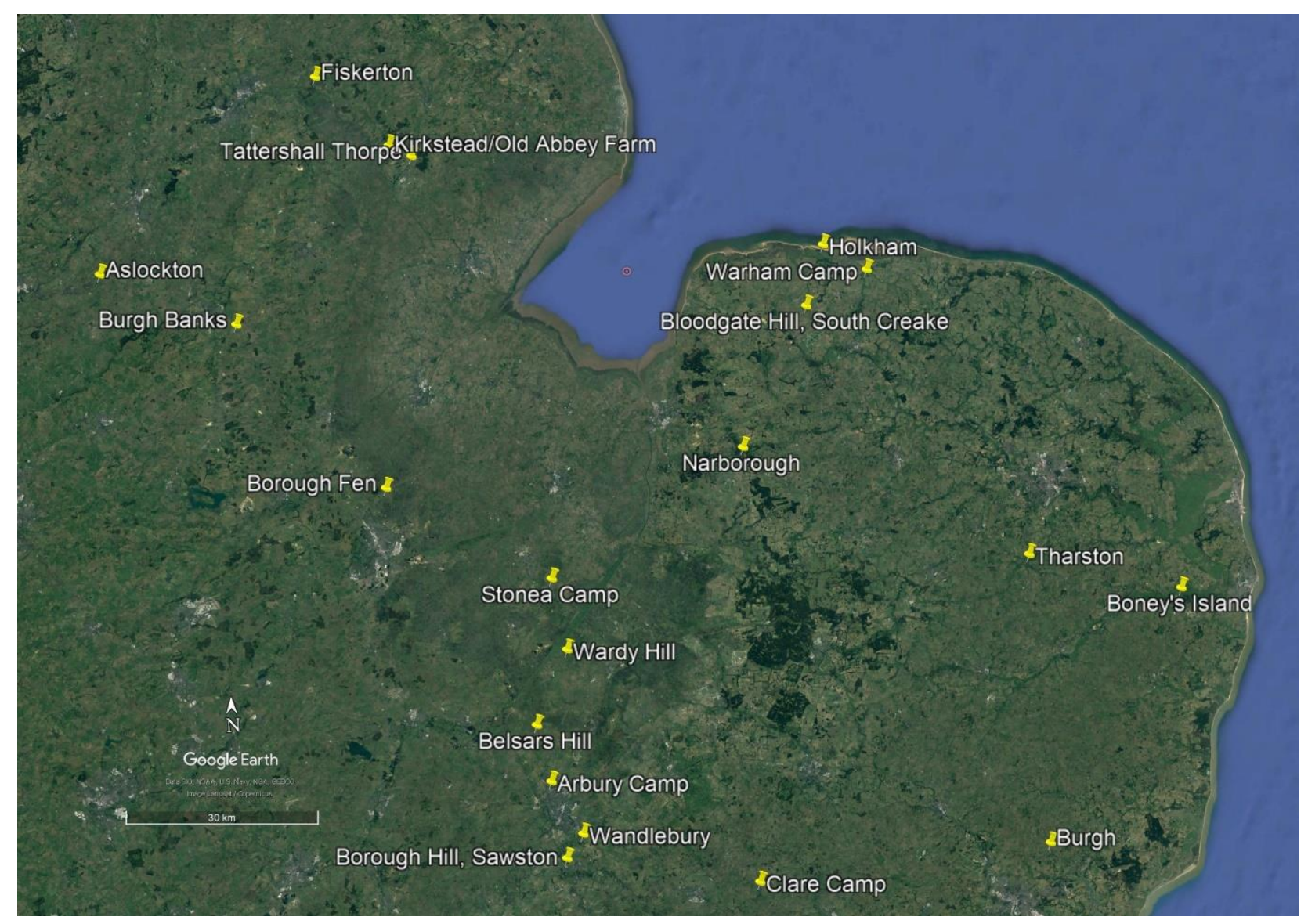

Fig. 4-8 Lincolnshire, Fenland and East Anglia - distribution of potential marsh-forts (Google Earth: January 2018) 


\section{Lincolnshire and Cambridgeshire Fens}

In the Lincolnshire Fens, the bivallate enclosure of Tattershall Thorpe was highlighted by Fletcher as comparable to Sutton Common in terms of its palaeoenvironmental and morphological similarities. The site is the most monumental of several defended Middle-Late Iron Age settlements in the Witham valley. Little evidence exists for the sites of Kirkstead, Old Sleaford (Field and Parker Pearson, 2003:160-161) and Burgh Banks; however, Tattershall Thorpe was excavated in the 1980s. It was defined by prominent earthworks and a ditch crossed by a possible causeway into the surrounding wetland (Chowne et al., 1986:184). The presence of high quantities of dung beetles in the palaeoentomological evidence (Girling in Chowne et al., 1986) led to the conclusion that Tattershall Thorpe performed a key role in communal stock management.

Tattershall Thorpe was labelled as a marsh-fort by Field and Parker Pearson (2003:160), who highlighted the site's location within the depositionary landscape of the River Witham and its proximity to the Iron Age depositionary causeway at Fiskerton. The Witham valley has yielded many items of high-quality metalwork, including the Witham Shield, and Fiskerton produced Iron Age artefact and bone deposits in some quantity; in this wider context, the Iron Age chariot fittings found near Tattershall Thorpe are not unusual.

Although Fiskerton is obviously not a marsh-fort, its function and location may have a bearing on Tattershall Thorpe. Both sites occupy strategic points along the Witham (Fig. 4-9). Tattershall Thorpe lies close to the north bank near its confluence with the River Bain, and occupied a strategic point on the Iron Age coastline (Simmon, 1980, cited in Chowne et al., 1986:184; Field and Parker Pearson, 2003:Fig.12.1). Fiskerton, $20 \mathrm{~km}$ to the north, occupies solid ground surrounded by peat deposits at the neck of the 'island' of Lindsey; this is also the point at which the Witham turns abruptly to flow south. It could be argued that Tattershall Thorpe controlled access to Fiskerton from the seaward side. Chowne also drew parallels between Tattershall Thorpe and other similar monuments further afield, notably Cherbury Camp and Holkham (1986:184); both are discussed below. The site is classified in the HER as a defended enclosure, and as a level terrain fort by the Atlas.

At a slight remove, in Nottinghamshire, the low-lying settlement at Aslockton is a site of interest with extensive evidence for animal husbandry and domestic structures (Knight and Howard, 2004:94-95; Chadwick, 2010:1205). However, its morphology indicates a complex settlement enclosure associated with feasting activity, and does not compare conclusively with Sutton Common. 


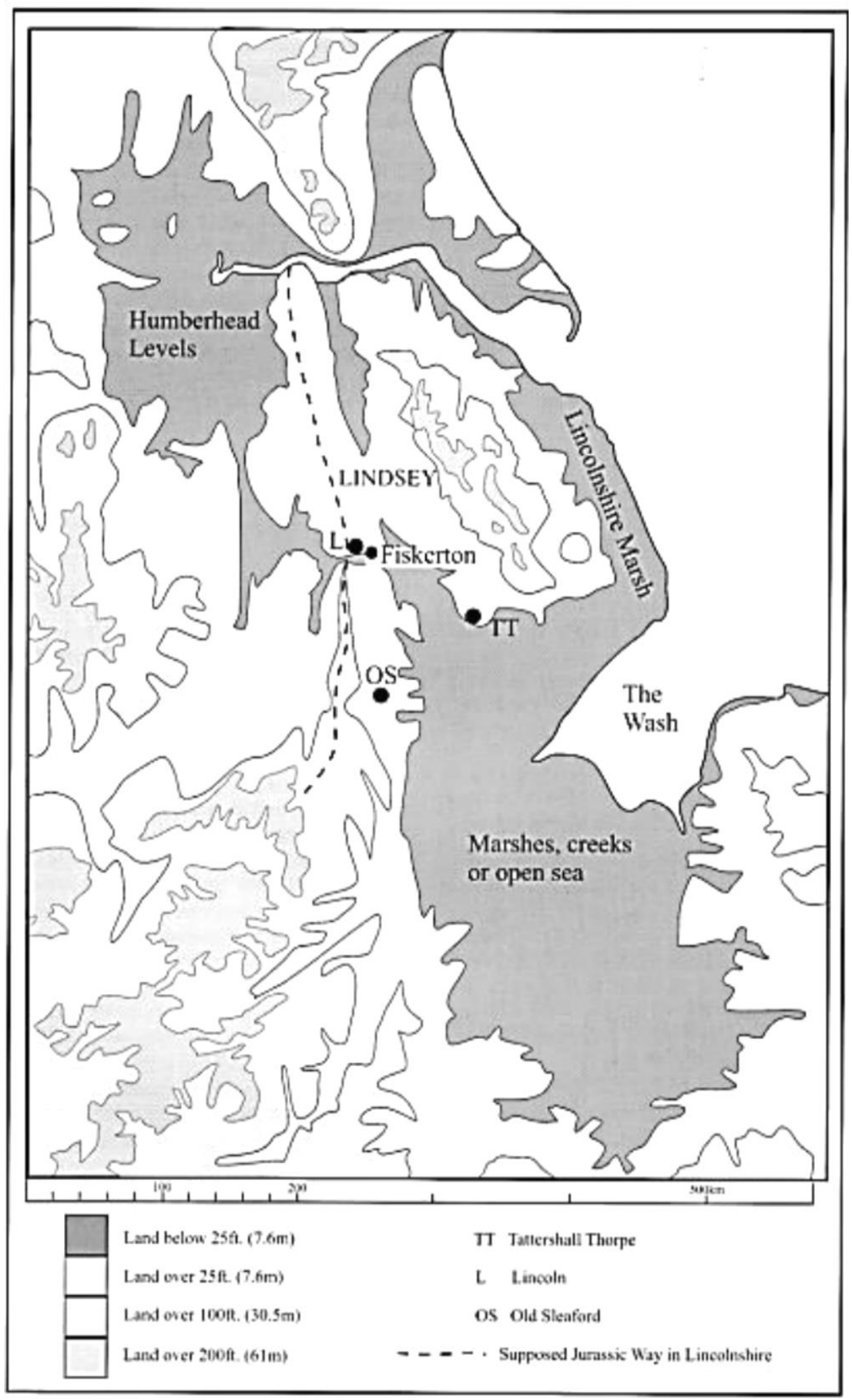

Fig. 4-9 Tattershall Thorpe in relation to Fiskerton and the Iron Age coastline (Field and Parker Pearson, 2003: Fig.12.1)

Turning to the Cambridgeshire Fens, the enclosures at Arbury, Borough Fen, Wardy Hill and Stonea Camp were considered as possible marsh-forts by Fletcher and these sites can be extended to include Belsar's Hill and Borough Hill. The 'Great Circle' at Arbury (Evans and Knight, 2002) was 
univallate and compares with Sutton Common for its size, location, chronology, and a lack of domestic evidence. Although attributed to the Middle Iron Age, the site had a lengthy chronology, with possible earlier origins and later reuse. Arbury was located on the clay plain on heavily marled gravels, and had a monumental gateway (cf. Sutton Common) which would have stood out prominently in the surrounding flat grassland. Excavations concluded that it may have been used seasonally as a gathering point or was simply a visual statement of territorial control; its excavators considered it was unlikely to be a ceremonial centre due to the lack of artefactual evidence (Evans and Knight, 2002:44-50), although this also applies to Sutton Common. Its morphology was almost identical to Wandlebury, $10 \mathrm{~km}$ to the south, which is at higher elevation overlooking the Cambridgeshire Fens. Wandlebury produced settlement and stock rearing evidence but does not occupy wetland and is not a good fit for the marsh-fort criteria considered here; it is included mainly because of a suggested 'twinning' with Arbury (Evans and Knight, 2002:48). The concept of twinning or pairing has been recognised between some hillforts, although the form and extent of any interaction has not been investigated further (e.g. Payne and Corney, 2006:135; Dorling et al., 2017:80). Whilst Wandlebury is well preserved, Arbury is now destroyed, a possible consequence of its lowland location.

Belsar's Hill lies 3km from the Great River Ouse in the area of the Upper Delphs (Evans and Hodder, 2006). The site consists of a medieval ring-work (possibly a motte-and-bailey) built on top of an Iron Age fortification (for which evidence is extremely limited), bisected by a track accessing the medieval Aldreth Causeway. Borough Hill's defensive location makes use of a bend in the River Cam, although the geophysical and artefactual evidence is firmly domestic, therefore does not meet one of Sutton Common's key criteria. As their names suggest, Belsar's Hill and Borough Hill are on slightly higher ground, but at $5 \mathrm{mOD}$ and $20 \mathrm{mOD}$, higher is a relative term.

For all there are differences in morphology (univallate/bivallate), similarities have been highlighted between Belsar's Hill and Borough Fen near Peterborough. Borough Fen has clear evidence of domestic occupation, although its location is unusual. Flooding in the Roman period preserved intact floors and other occupational remains and the enclosure/fort is considered to be one of the most important Iron Age sites in eastern England (Pastscape 350093). The defleshed horse's head found in one of the ditches is most likely a foundation deposit (French, 1988). Borough Fen differs from Sutton Common in terms of its occupational use and a lack of monumentality, but is similar in size, chronology and location.

The sites reviewed so far only partially meet the criteria identified for Sutton Common; however, Stonea Camp and Wardy Hill are closer comparators, identified by both Fletcher and the Atlas. Both 
occupied the fen edge and were surrounded by tidal flats; the sites are $10 \mathrm{~km}$ apart. Stonea Camp (Fig. 4-10; Fig. 4-11) is classified as a hillfort, notwithstanding its elevation (Om OD). It is large (9.6ha) and the defences are multivallate and monumental. The site occupies a very low-lying gravel outcrop surrounded by marsh. Archaeological evidence includes Neolithic flints, and Bronze Age burials. The earthworks are Iron Age and were constructed when the landscape was largely open terrain with some sparse woodland; a lack of evidence for cereal cultivation is unsurprising given the nature of the surrounding wetland (Murphy, 1992). Whilst human and animal remains were identified during excavation, artefacts (pottery, metalwork) were scarce. There are settlement sites in close proximity to Stonea, and there is no evidence for domestic use within the camp, suggesting it was set aside by the community for special purposes. This combination of evidence points to a monument which at the very least, delimited space, but more likely acted as a ceremonial location (Malim, 2005:84). The Roman settlement at Stonea Grange, which possibly functioned as a control point for trade, lies 500m north (Malim, 2005).

At Wardy Hill, the substantial defences, including a 'water-gate' similar to Sutton Common, appear to be out of proportion to its limited occupational evidence (Evans, 2003). The dry island on which Wardy Hill is located controlled access to the wetland 'bay' of Coveney, an area noted for finds of Bronze Age metalwork (Yates and Bradley, 2010), and was connected to the adjacent dryland by a causeway. Given the high quality of artefacts recovered from the site, a chieftain centre has been suggested (Malim, 2005:37). Ritual deposits of charred grain were recovered from the ditches (Murphy in Evans, 2003:109-10).The dating evidence for the Wardy Hill enclosure indicates usage (including functioning as a shrine site) in the Later Iron Age, but the chronology is more extensive. The site is located close to a group of burnt mounds, although their chronology is unknown.

The north Cambridge clay plain represented a cultural border in the Middle/Late Iron Age between Icenian, Catuvellaunian and Trinovantian territory (Evans and Knight, 2002:47; Malim, 2005:37), and the Fenland sites have been suggested as territorial markers, forming a rough border running northsouth (although this may simply reflect the modern mind's desire for straight lines). They may have played a part in either separating tribes or bringing them together in neutral spaces, but the finds record varies considerably, and attributing one purpose to all may be unwise. Clare Camp in Suffolk may also form part of this territorial set. In similar vein, it has been suggested that Sutton Common stood on a border between the Corieltauvi, the Parisi and the Brigantes by both Parker Pearson and by Chadwick (Parker Pearson and Sydes, 1997; Chadwick, 2010) - see above. 


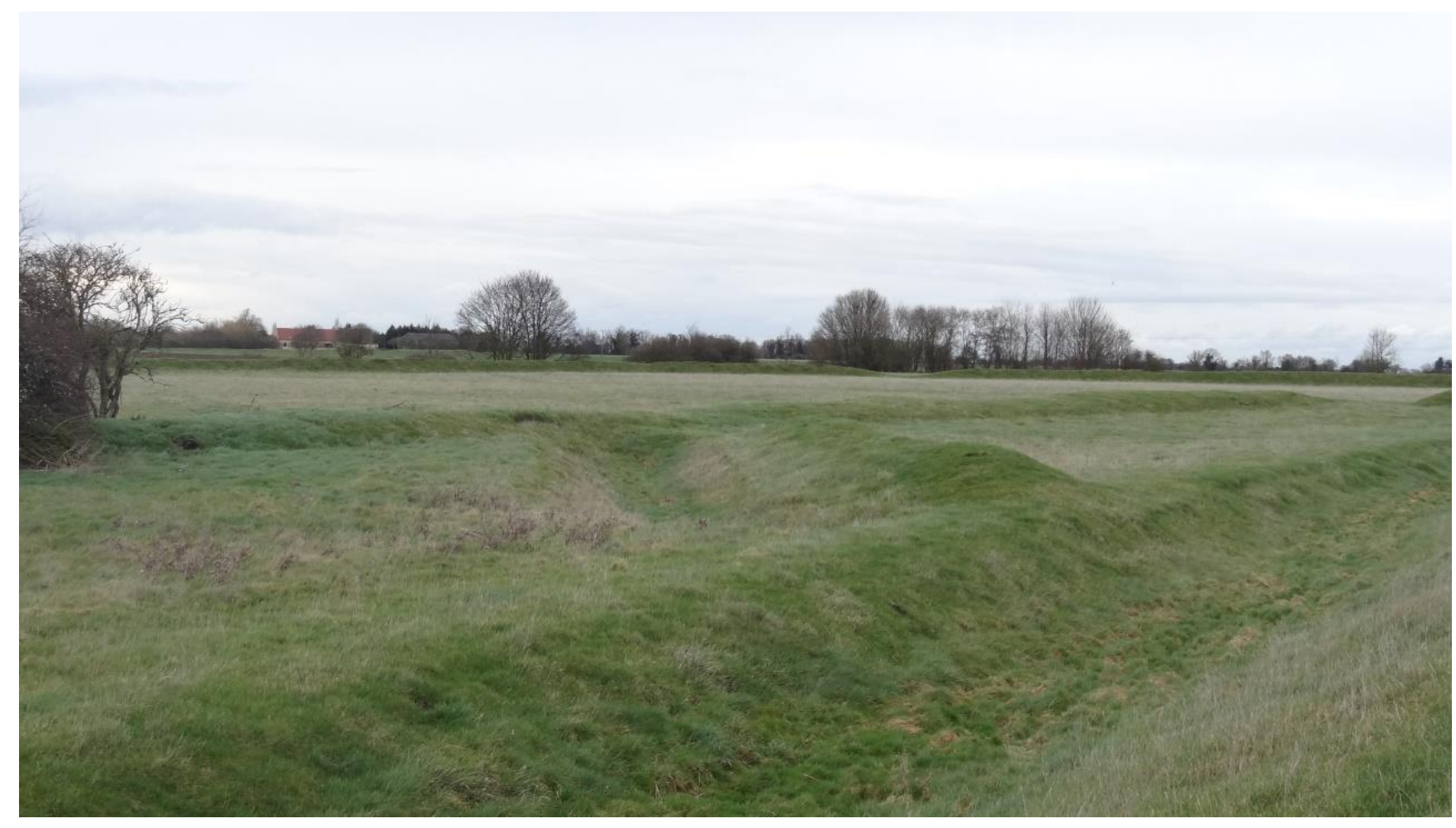

Fig. 4-10 Stonea Camp - upstanding earthworks (Norton, 2017)

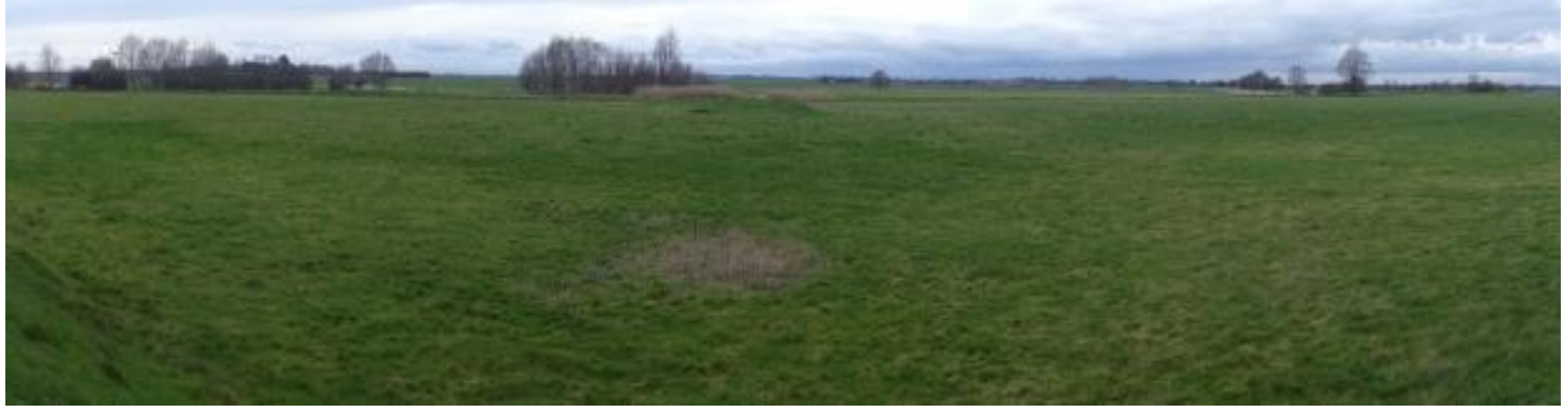

Fig. 4-11 Stonea Camp in its flat landscape setting (Norton, 2017) 


\section{Norfolk/Suffolk}

The Iron Age fortifications in Norfolk include Holkham, Warham Camp, Bloodgate Hill at South Creake, and Narborough (Davies et al., 1992) and these sites were suggested by Fletcher as similar to Sutton Common on topographical grounds. Those in Suffolk comprise Boney's Island, Clare Camp and Burgh.

Holkham is the most unusual of the Norfolk group (Fig. 4-12). This irregular oval enclosure is located on the southern end of a sand/gravel spit which extends southwards into the salt marsh away from the north Norfolk coast. A gap in the southern part of the earthworks accesses the marsh and is assumed to be an entrance. Finds are few but range from Mesolithic and Neolithic flints, through Iron Age metalwork and a little pottery, and include human remains. Unfortunately, fossicking and unstructured excavations in the early twentieth century were not followed up by modern investigations, and further details are lacking. Its chronology is considered to be Iron Age, and its location alone suggests non-domestic use.

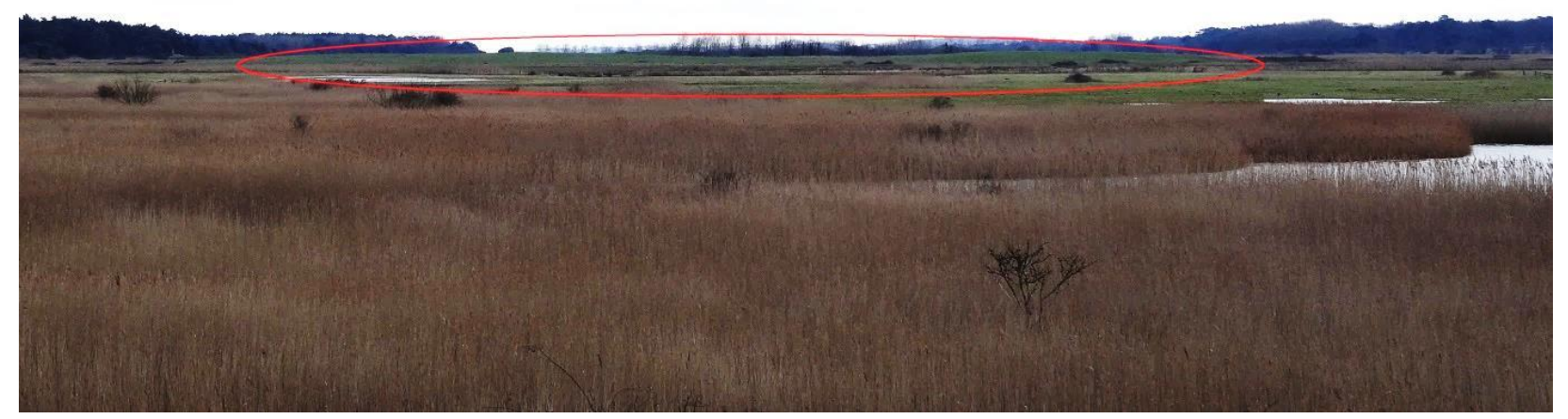

Fig. 4-12 Looking east towards Holkham (Norton, 2017)

Warham Camp (Fig. 4-13) is a circular, bivallate fortification with impressive ramparts and ditches, pierced by two post-medieval entrances. It occupies a valley location, and its western edge was defended by the River Stiffkey and adjacent marshland. The fort was originally accessed from the river via steps; these are no longer extant, damaged by channel straightening in the eighteenth century (Gregory and Gurney, 1986). The adjacent area includes at least one Bronze Age barrow and several burnt mounds, and the finds evince a lengthy chronology from the Neolithic onwards. The 
Iron Age is characterised by a limited amount of domestic evidence, and the area was also the site of a Romano-British settlement.

Fig. 4-13 Warham Camp - external defences, looking west (Norton, 2017)

Given its riverside location, Warham may have served as a control point on the River Stiffkey, fulfilling a similar function to the small site of Narborough, a univallate fort built on a knoll overlooking the River Nar, which produced Iron Age and Romano-British pottery. Bloodgate Hill, South Creake (destroyed) occupied the head of a valley; its internal area encompassed a ring-ditch at its highest point and its eastern earthworks and gateway were monumental. Finds included pre-Iron Age lithics, Iron Age pottery and metalwork, plus Roman artefacts including a brooch and a cosmetic pestle. Tharston (Norfolk HER 9989) is low-lying and a possible twin with the nearby hillfort site of Tasburgh. It is identifiable from aerial photography only; apart from a nearby Roman coin hoard found by metal-detecting, there is no further information.

In Suffolk, Clare Camp and Burgh are also set in marshland. Whilst Burgh suggests domestic use especially during the Romano-British era, the morphology of Clare Camp is unusual and includes a possible causeway. However, information is scarce for both these sites. Boney's Island near Beccles is recorded as a marsh-fort (Suffolk HER BCC 023) but there is no further information.

Control of territorial boundaries or specifically, control of the local river, appears to be a common factor for Warham, Narborough, Bloodgate Hill, Clare Camp and Burgh. Holkham may be different. 
CENTRAL AND SOUTHERN ENGLAND - Fig. 4-14

Whereas the sites thus far have been associated mainly with peatlands, those in central and southern England (Oxfordshire/ Hampshire/ Herefordshire/ Worcestershire/ Gloucestershire) are more closely associated with watercourses. Several of the sites which occupy the Thames valley use the river and its tributaries as part of their defences.

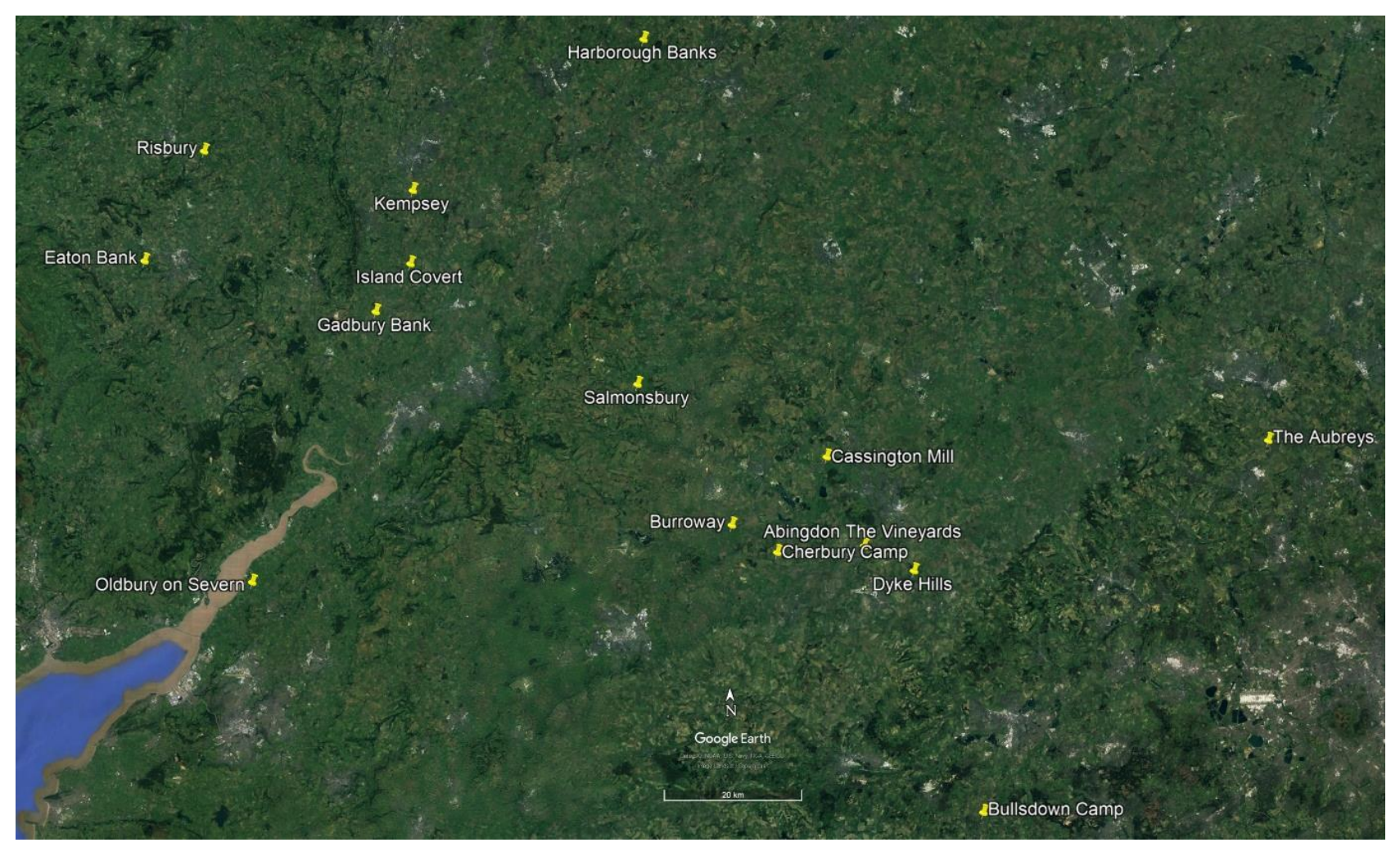

Fig. 4-14 Central and Southern England - distribution of potential marsh-forts (Google Earth: January 2018)

Cherbury Camp and Cassington Mill are in Oxfordshire, surrounded by the wealth of prehistoric sites along the Ridgeway and in the Upper Thames area (e.g. Hingley, 1984) and fulfil many of the marshfort criteria. At 9.6ha, Cherbury Camp is a substantial fortification located on a flat gravel terrace, occupying a strategically important position between the Thames and the River Ock. The morphology is multivallate and the site's defences made use of a narrow-necked peninsula created by a stream and the surrounding marshland - 'the truly strategic choice of an inherently defensible site' (Bradford, 1940:3). Evidence from excavations in the late 1930s (Arkell, 1939; Bradford, 1940) were supplemented by a recent geophysical survey (Bartington Instruments, 2007) which suggested mainly domestic evidence. Finds demonstrate a lengthy chronology from the Neolithic through to Roman times, whilst the fortifications suggest an Early Iron Age date (Hingley, 1983). As with several other sites already discussed, Cherbury appears to have been a major control point in the surrounding landscape. 
Cassington Mill comprises a multi-period, multi-functional group of sites occupying a gravel island at the junction of the River Evenlode and the Thames; its location was important over a lengthy chronology (Bradford, 1951; Sutton, 1966). Dyer (1981:13) referred to the Iron Age element within this complex as 'The Great Enclosure' and classified it as a valley fort. Now largely destroyed, the earthworks covered 13ha, had six entrances, and encompassed multiple earlier sites. In addition to numerous burials, finds have included Mesolithic, Neolithic and Late Bronze Age flints. Intensive trenching produced postholes, gullies and pits, which together with relatively large quantities of Late Bronze Age /Early Iron Age pottery and quern fragments, suggest a date circa $800 \mathrm{BC}$, whilst Roman finds included a La Tène III brooch. Given its lengthy chronology and topographic location, a review of the extensive evidence could bring this site into the marsh-fort category. Similarly, Salmonsbury in neighbouring Gloucestershire is also a site of considerable longevity (Dunning, 1931). It lies at a strategic point on a gravel terrace at the junction of the Rivers Dikler and Windrush, and was bounded on two sides by swamp and lake. This location has been the site of a (possible) Neolithic causewayed enclosure, a Bronze Age ring-ditch, a later Iron Age fortification, settlement site and trading post, and an enclosed oppidum. (Several suggested marsh-forts overlap with enclosed or territorial oppida (Salmonsbury; Abingdon; Dyke Hills), a category of monument with known associations with low-lying marsh (English Heritage, 2011b)).

The remaining sites along the Thames Valley comprise Abingdon the Vineyards, Dyke Hills, and Burroway. These are not classified as marsh-forts by the Atlas, but occupy low-lying valley-bottom locations alongside the Thames or its tributaries. Abingdon is a complex, multi-phase site spanning the Early Neolithic to the Middle Ages, with Iron Age evidence coming from a dense series of intercutting ditches, gullies and pits (e.g. Allen, 1993). It dates from the Early Iron Age with some features indicating later Iron Age/ Early Roman occupation; in similar vein to Salmonsbury, it has been suggested as an enclosed oppidum. The multiple earthworks of Dyke Hills delineate a very large (46ha) interior between the Thames and Thame rivers (Sutton, 1966). Aerial photography has indicated extensive occupation and the site has been suggested as another enclosed oppidum. The (much smaller) univallate site of Burroway (2ha) occupies the Thames floodplain and the aerial photographic evidence indicates roundhouses and pits (Sturdy and Case, 1961-62; Lambrick, 1984; Lambrick et al., 2009). These sites show signs of extensive domestic use and overlap with Sutton Common mainly in terms of low-lying topography and use of wetland.

There is little information about Bullsdown Camp, a 4ha multivallate fortification at the confluence of the River Lodden with the Bow Brook in Hampshire, surrounded by field systems. It is included by the Atlas as a marsh-fort on the strength of its location alone and further evidence is scarce. The 
Aubreys hillfort in Hertfordshire is similarly short on evidence, and is included because of its lowlying location, the suggestion that it acted as a control point for the surrounding land and its lack of domestic evidence (Stansbie, Bashford and Bridgman, 2012).

The three candidates in Worcestershire occupy the floodplain of the River Severn. Each one has a visual relationship with the prominent Iron Age hillforts of British Camp and Midsummer Hill on the Malvern Hills to the west, and Conderton/Kemerton Camps on Bredon Hill to the east. The possible Iron Age valley-fort/marsh-fort at Kempsey (Fig. 4-15) lies on the east bank of the River Severn, on a gravel terrace at river level, at the confluence of the Severn with the Hatfield Brook. Today, the site is overbuilt by a church (with Saxon origins) and modern housing, and it is not possible to understand the morphology from the existing remains; the artefactual evidence is limited to one Iron Age sherd. However its position appears to have been strategically important enough to warrant coping with the risk of flood, probably as much a threat in prehistory as it is today (Maddy et al., 1995).

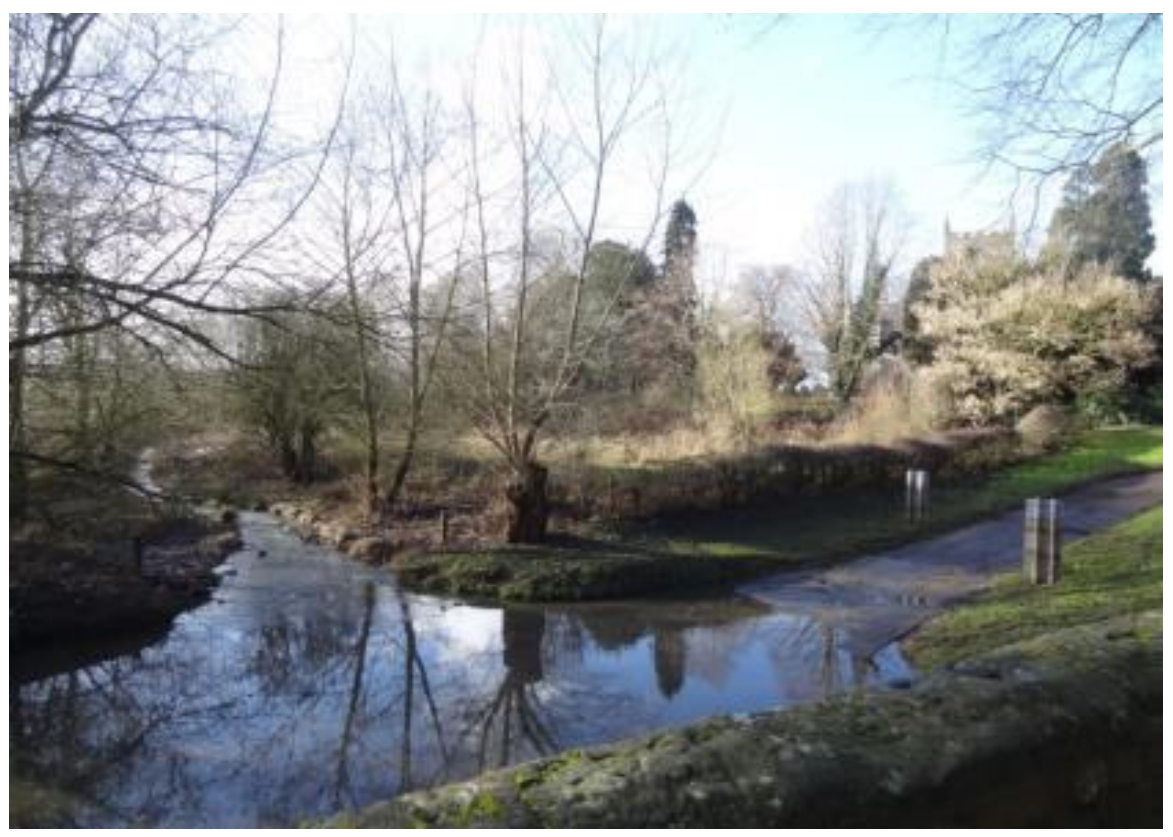

Fig. 4-15 Kempsey; channels flow left towards the River Severn (Norton, 2017)

The univallate site of Gadbury Bank (Fig. 4-16) occupies a prominent rise overlooking the flat lowland of the river valley to the west of the Severn; artefactual evidence is limited to a few Iron Age potsherds. Gadbury appears to control the surrounding low-lying marshy ground but is elevated and does not use water or marsh in its defences. It may have similarities with other sites on prominent 
knolls which overlook marshland (such as Ebury in North Shropshire), but is too elevated to be considered a marsh-fort.

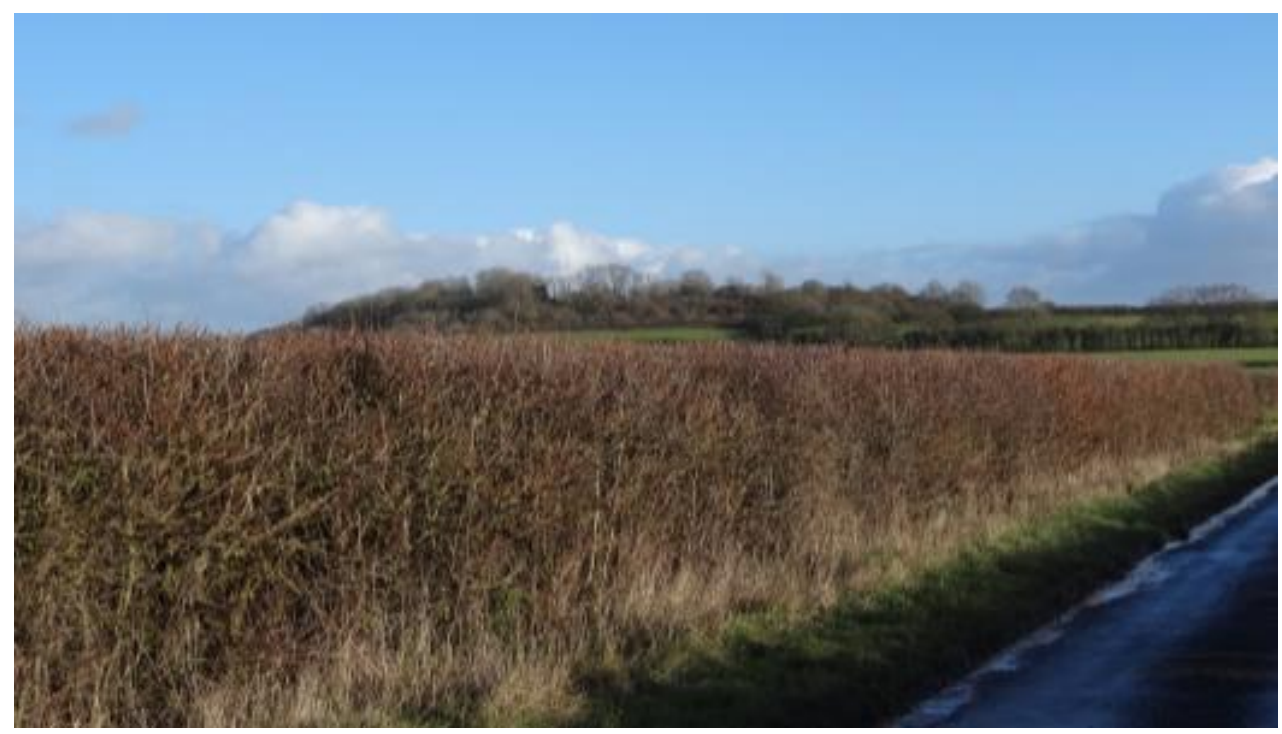

Fig. 4-16 Gadbury Bank (no public access) (Norton, 2017)

Amongst the myriad of hillfort sites along the Welsh Marches, Risbury Camp in Herefordshire is perhaps the only one which could be considered a possible marsh-fort (Fig. 4-17; Fig. 4-18). The site is multivallate, and is situated on a low-rise platform which controls the junction of the Holly and Humber Brooks. With a footprint of 11.3ha, its substantial size and fortifications compare, locally, only with Wapley Camp (Stanford, 1980:68). It overlooks marshy ground from a slight knoll, and is overlooked, suggesting that defence was not a prime concern.

Island Covert (Fig. 4-19) near Upton-upon-Severn is located in the middle of a swampy thicket at 15$20 \mathrm{~m}$ OD, $1 \mathrm{~km}$ from the River Severn, and is classified by the Atlas as a marsh-fort. However, the site is small (0.28ha) and it is probably more correctly described as an enclosure. There is no excavational evidence or further detail of its landscape features, but its proximity to the Severn suggests that it was built to utilise the surrounding terrain, perhaps as a refuge during times of flood. 
Chapter 4-Marsh-forts in a landscape context

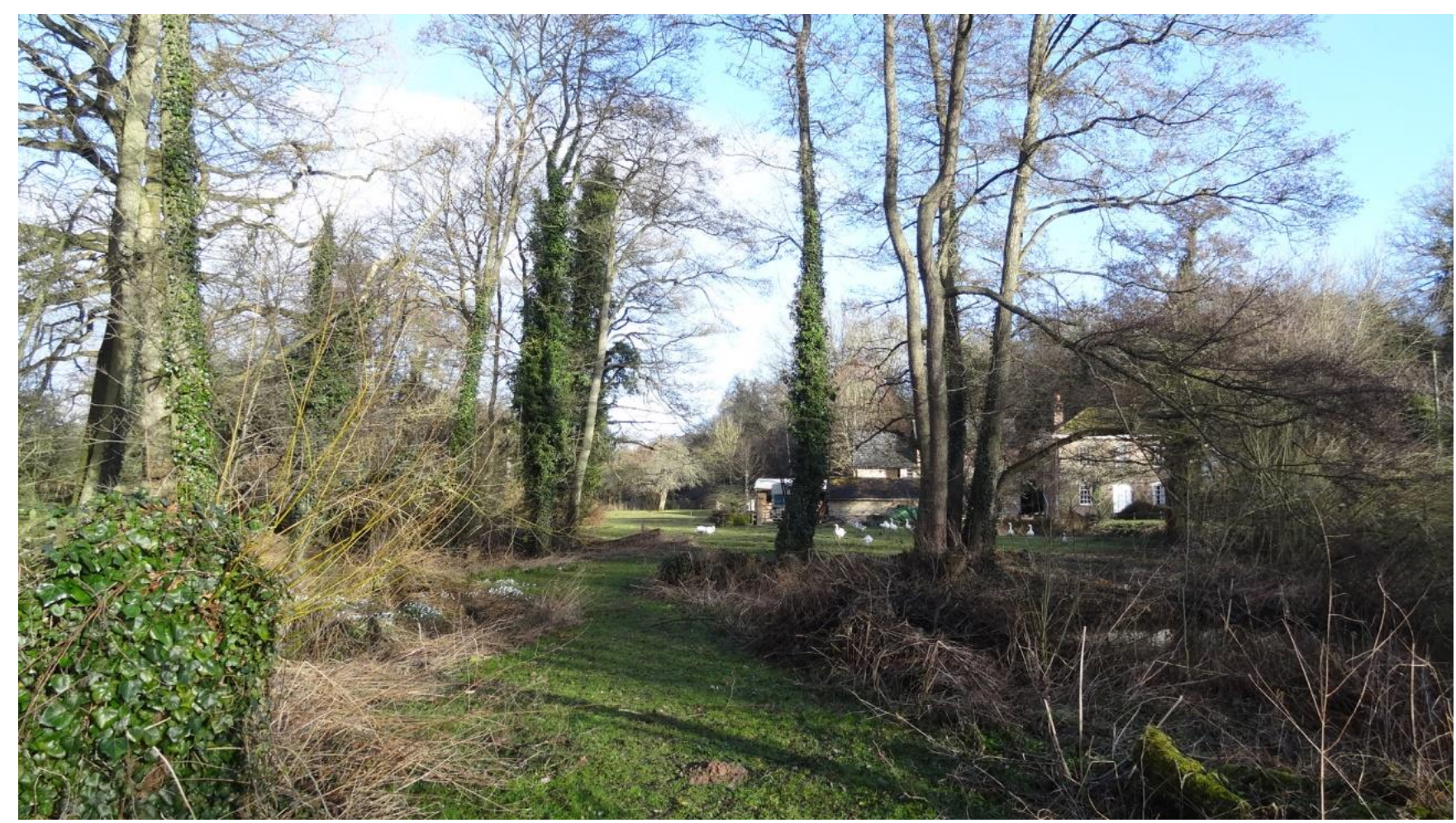

Fig. 4-17 Risbury Camp lies behind the houses on the right, with the Humber Brook (left) (Norton, 2018)

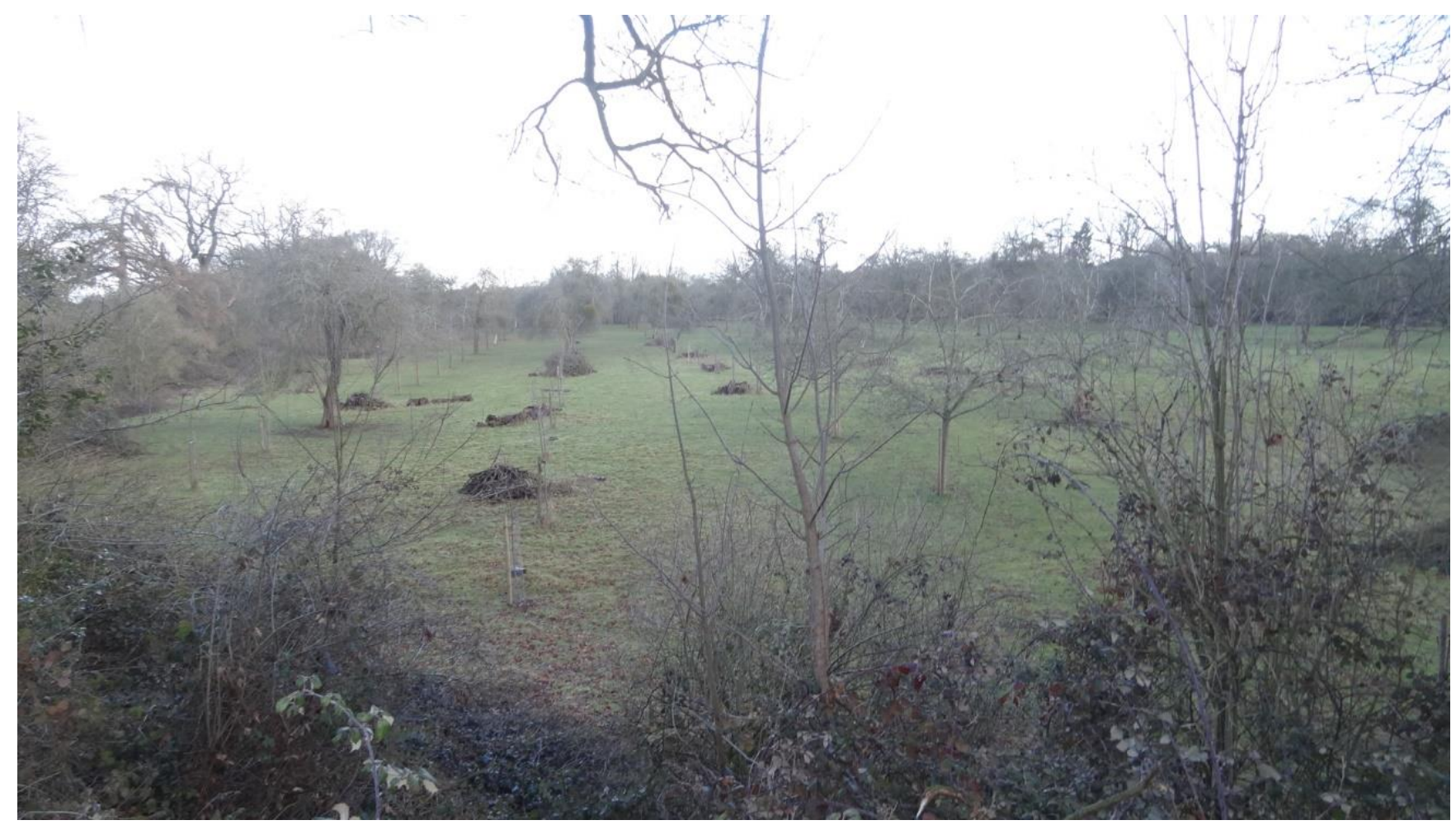

Fig. 4-18 Risbury Camp showing the large interior area; the tree line represents the extent of the fortifications (Norton, 2018) 


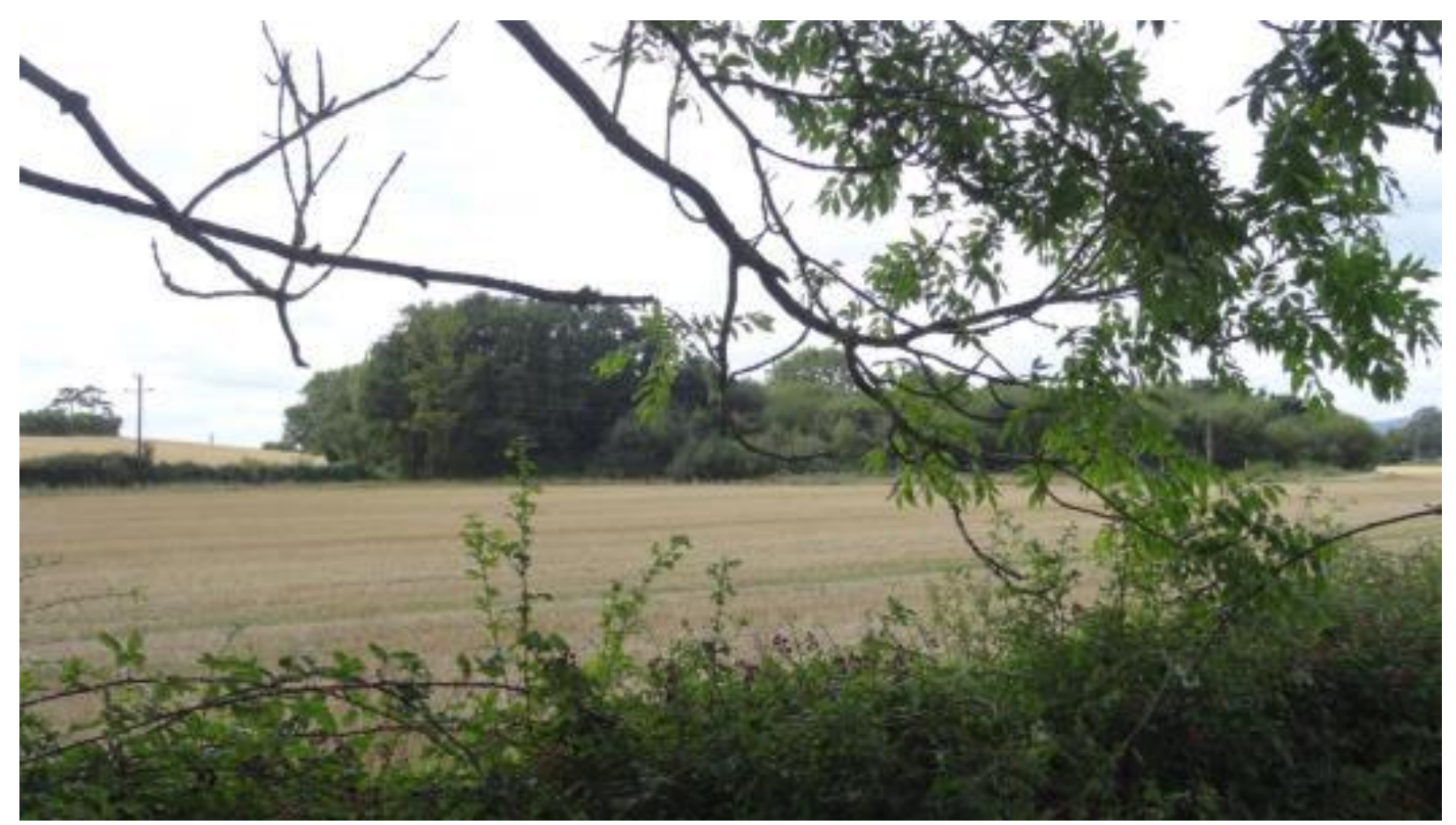

Fig. 4-19 Island Covert (no public access) (Norton, 2017)

Dyer considered Risbury to be a valley-fort (Dyer, 1981:13); the Atlas considers it a contour hillfort, and Stanford was clearly puzzled that such sizeable defences were created to protect small local communities (Stanford, 1980:70). The site has never been investigated. Eaton Camp is also considered as a valley-fort but actually occupies a high promontory overlooking the River Wye, and fulfils few of the marsh-fort criteria.

The unusual site of Oldbury Camp (aka The Toot) is on the east bank of the Severn Estuary in Gloucestershire. Even in its damaged state (mostly overlain by a modern village), its morphology and size are substantial and impressive. The site is difficult to decipher. The outer earthwork is larger than the inner by some margin and its entrance is a matter of conjecture. It is located on what may possibly have been a low-lying island in tidal saltings and marshland; it fronted the navigable River Pill, which in turn may lend weight to its function as a trading post. The Atlas considers it a marshfort.

The multivallate fortification of Harborough Banks near Lapworth, Warwickshire, is mostly destroyed, but originally enclosed an area of around $10 \mathrm{ha}$, and is classified as a valley-fort by the Atlas. It occupies a valley location but has no obvious overlap with the Sutton Common criteria. 


\section{CHESHIRE - Fig. 4-20}

The sites in North Shropshire are explored in detail in Chapter 5. However, two sites further north in Cheshire are considered as marsh-forts by the Atlas. The majority of hilltop enclosures in Cheshire lie on the Mid-Cheshire Ridge, but Oakmere and Peckforton occupy lake-side locations.

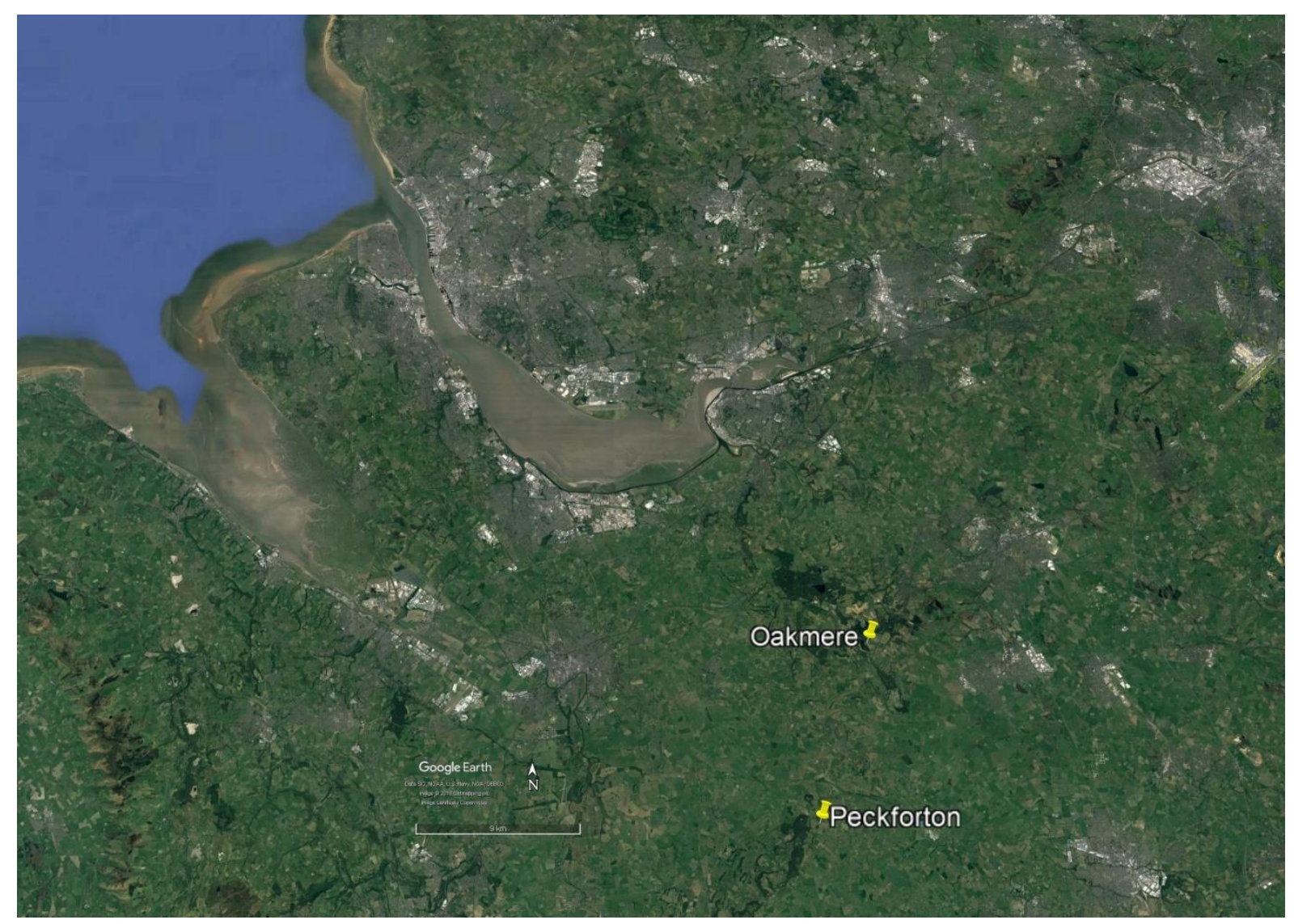

Fig. 4-20 Cheshire- distribution of potential marsh-forts (Google Earth: December 2018)

The small enclosure site of Peckforton is adjacent to Peckforton Mere (Fig. 4-21), and utilised the mere and a former watercourse in its defences. Palaeoenvironmental records from mere sediments indicate woodland clearance and agricultural intensification occurred in phases from the Bronze Age onwards (Schoemwetter, 1982:10-11), a pattern also seen in North Shropshire (Twigger and Haslam, 1991). Peckforton enclosure is indistinct on the ground; upstanding remains require the 'eye of faith' and no artefactual evidence is forthcoming. The site lies within the copper-ore producing Peckforton Hills (Ellis, 1993:43), close to Beeston Castle. 


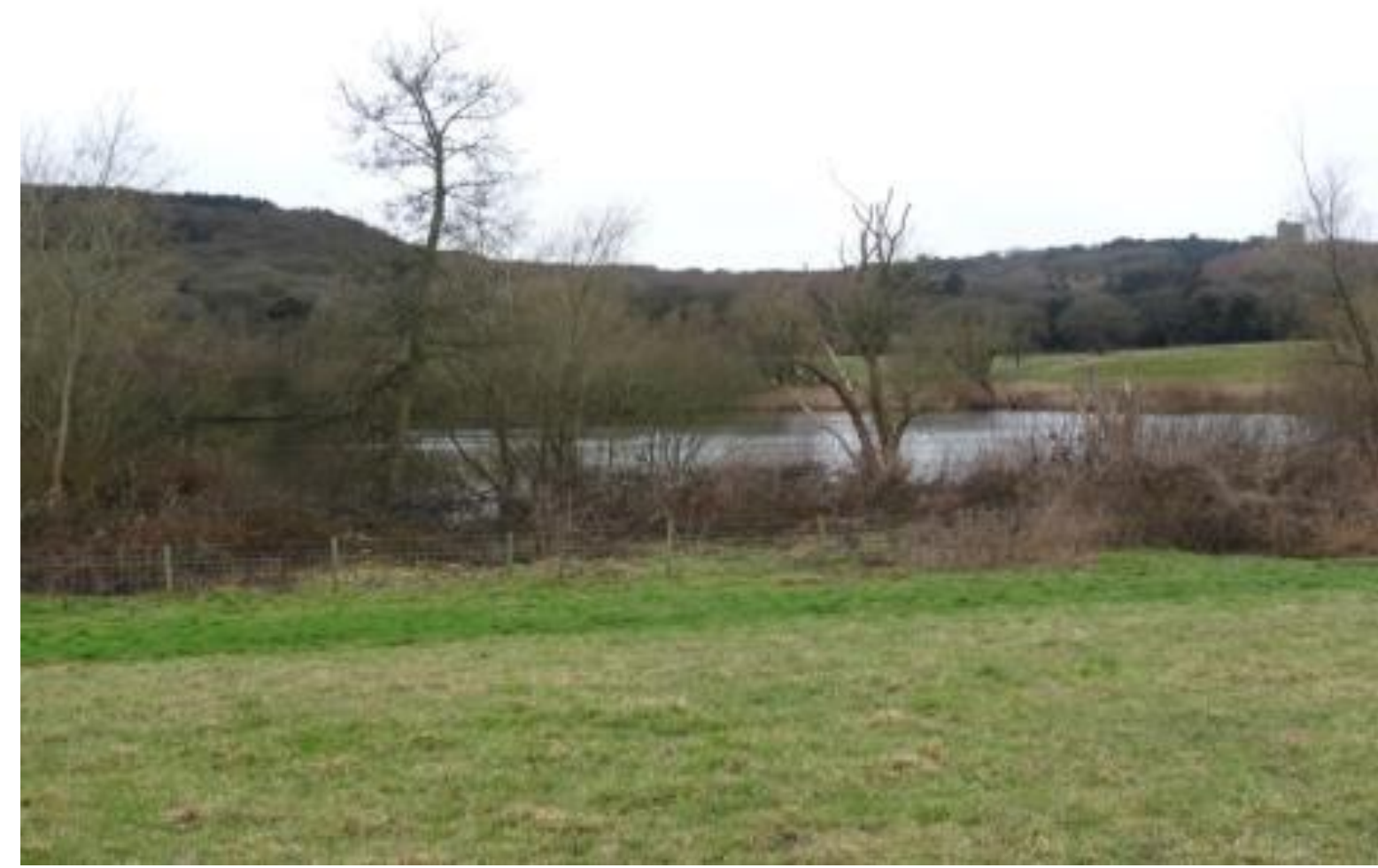

Fig. 4-21 Peckforton Mere from Peckforton enclosure with Beeston Castle in the background (right) (Norton, 2015)

Oakmere (Fig. 4-22) is a univallate 'hillfort' of circa 0.9ha occupying a low sandy ridge which juts into Oakmere lake. The mere contains a number of islands and a large area of marshland lies immediately to the north. Forde-Johnston thought that the water level may have been higher in prehistory (1962:21), and although it is suggested that the mere maintains its water level 'by mysterious means' (Leah et al., 1997:116), it probably drains underground. Oakmere has a lengthy chronology, dating back to the Neolithic (Leah et al., 1997:150), and, like the Berth (see Chapters 6-8 and Appendix 3), Oakmere has attracted its share of local myths (Leah et al., 1997:116). The upstanding defences include a ditch crossed by a narrow causeway, although there is a suggestion that the fortifications remained unfinished (Forde-Johnston, 1962:22). The Scheduling (List Entry Number: 1013291) interprets the site as a defended settlement in prime agricultural land. Roman evidence was recovered from the shore of the mere, and the site is close to a Roman road (Leah et al., 1997:109).

Both Oakmere and Peckforton appear to reference larger Iron Age fortifications on the nearby MidCheshire Ridge - Peckforton: Beeston Castle; Oakmere: Castle Ditch (Ellis, 1993). When compared to the Sutton Common criteria, both these sites lack size and monumentality, and are hampered by lack of evidence; however, Oakmere shares morphological and topographical attributes with Sutton Common. 


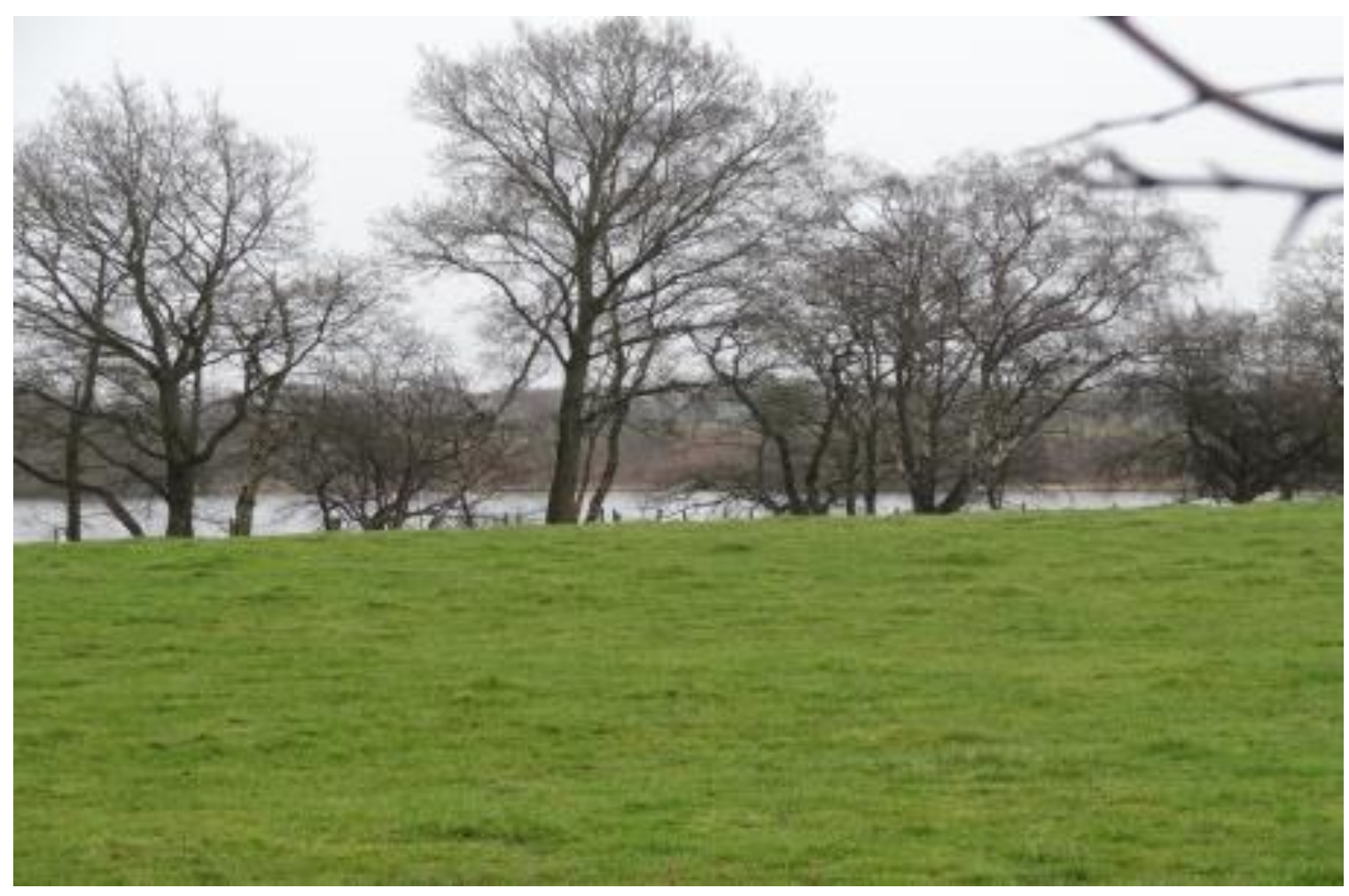

Fig. 4-22 Oakmere from across the lake (no public access) (Norton, 2015)

\section{NORTHUMBERLAND}

Hetha Burn West in Northumberland is an Iron Age 'scooped' defended settlement on low ground next to the Hetha Burn; trackways enabled the surrounding marsh to be negotiated. The site is a small, bivallate enclosure overlooked by the strongly defended Iron Age hillfort of Great Hetha, immediately to the east. It has been suggested as a cattle enclosure but evidence is scanty. It is included in the Atlas as a marsh-fort.

\section{THE SOMERSET LEVELS - Fig. 4-23}

The late Iron Age lake villages of Glastonbury and Meare have already been referenced and are not directly compared with Sutton Common in this thesis (see Chapter 2). However, $17 \mathrm{~km}$ from the lake villages lies the site of King Alfred's church and the later Saxon Abbey at Athelney, the remains of which overlie a large Iron Age ditched enclosure. The site occupies a low knoll which overlooks the flat wetland of the Somerset Levels. The Anglo-Saxon site covers 8ha but the dimensions of the Iron Age site are unknown. It may represent an unremarkable Iron Age enclosure although its location suggests that the site was significant from at least the Iron Age onwards. An excavation by Time Team (Time Team S10-E08 Athelney; 2003) concentrated on the remains associated with King Alfred and no further evidence is available. Although it was included as a possible marsh-fort by Fletcher, it is not included in the Atlas. 


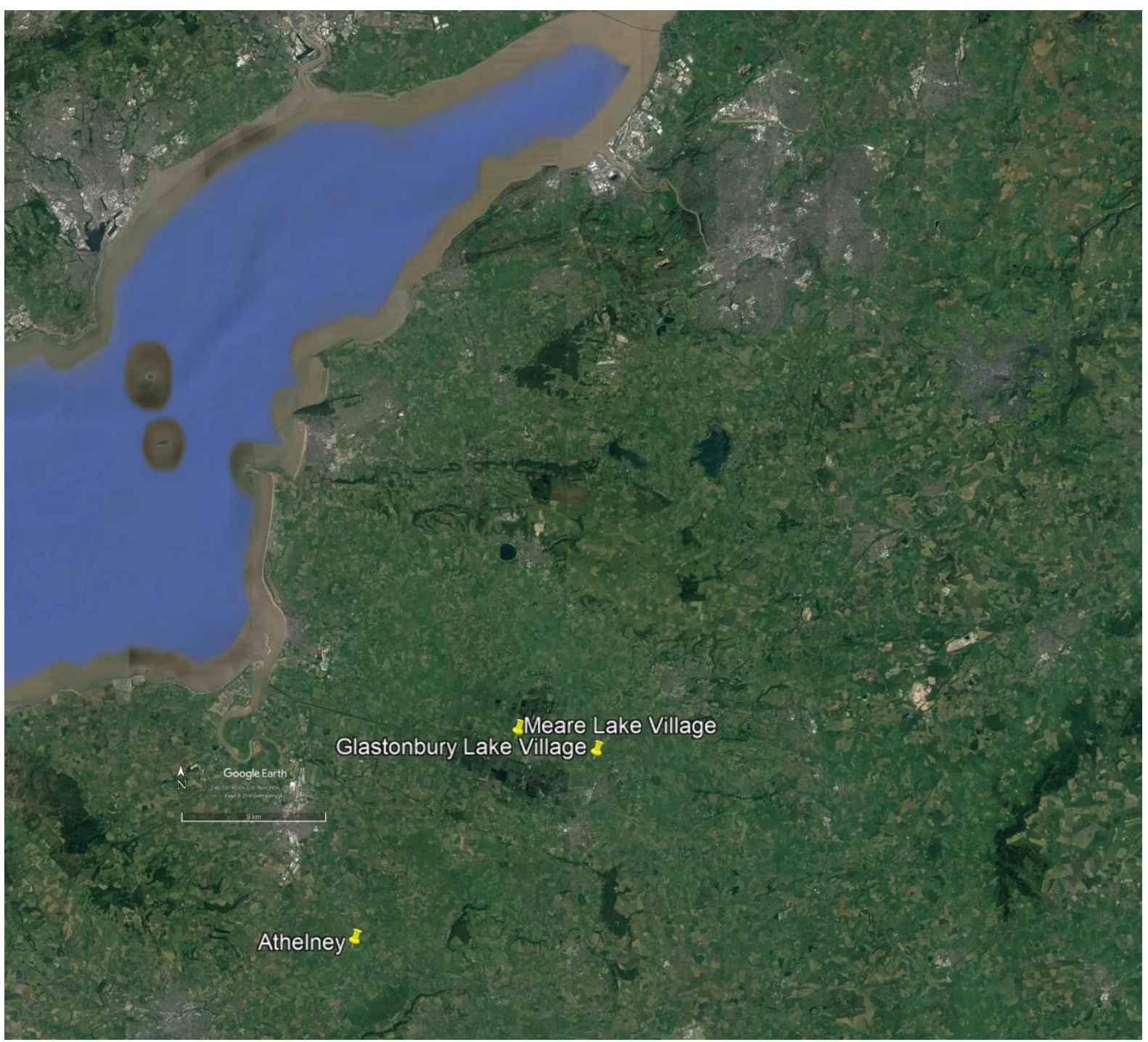

Fig. 4-23 Somerset Levels and Severn Estuary - distribution of potential marsh-fort and lake villages (Google Earth: December 2018)

WALES - Fig. 4-24

In Wales, the Atlas highlighted two sites occupying marshland - Bryn Maen Caerau, Dyfed and y Werthyr, Bryngwran, Isle of Anglesey. Of the two, y Werthyr comes closest to Sutton Common's criteria, being monumental and without domestic evidence, albeit only 0.65ha in size (Fig. 4-25).The site is much denuded; finds are few and there have been no investigations. According to the Atlas, it was surrounded by marsh; however, there are no peat deposits in the vicinity (Fig. 4-26). Instead, the site overlooks Afon Caradog and is adjacent to the only outcrop of mafic gneiss, a rock with a banded, glittery appearance, on Anglesey. y Werthyr lies 7km from Llyn Cerrig Bach.

Bryn Maen Caerau is a possible marsh-fort or defended enclosure a few metres above the floodplain of Afon Teifi. Its remains are compromised by the modern village of Cellan. A small site, it has a long history of occupation and an Early Iron Age signature. 
Dinas Dinlle was highlighted by Fletcher and occupies a high glacial mound on the coast of Caernafon Bay to the south of the Menai Straits. It may have protected the surrounding salt marsh in prehistory.

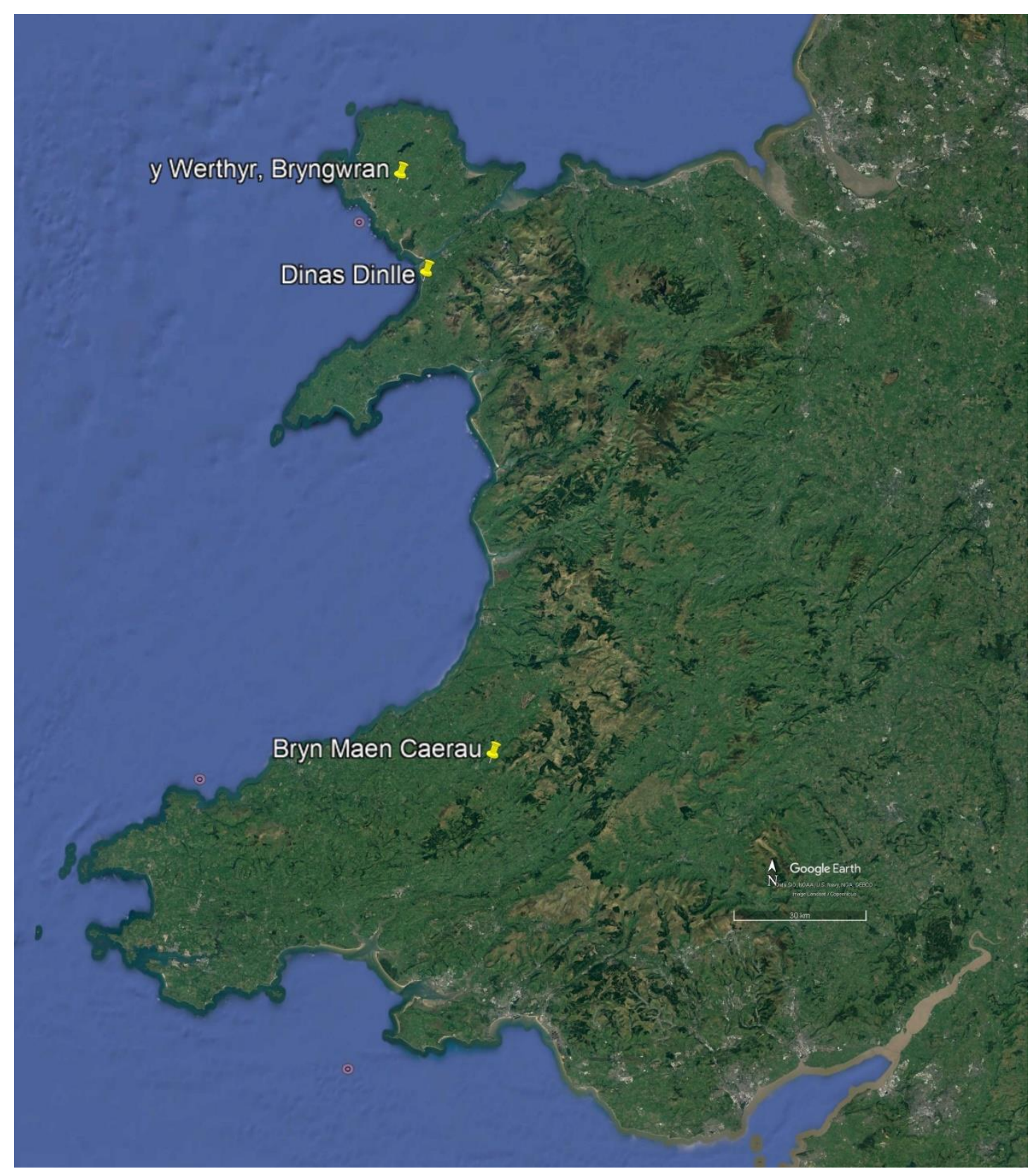

Fig. 4-24 Wales - distribution of potential marsh-forts (Google Earth: December 2018) 


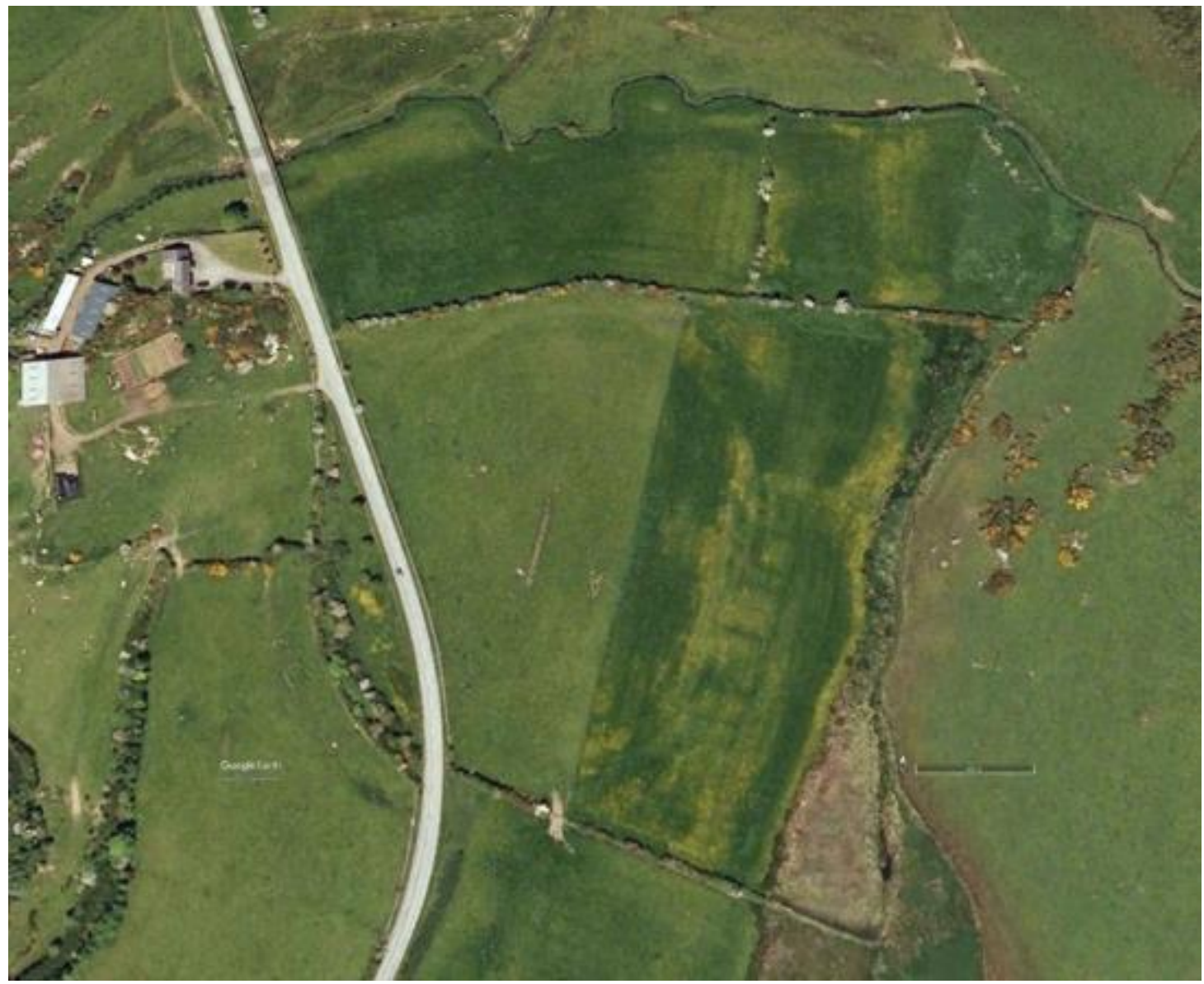

Fig. 4-25 y Werthyr, Anglesey (Google Earth; January 2018)

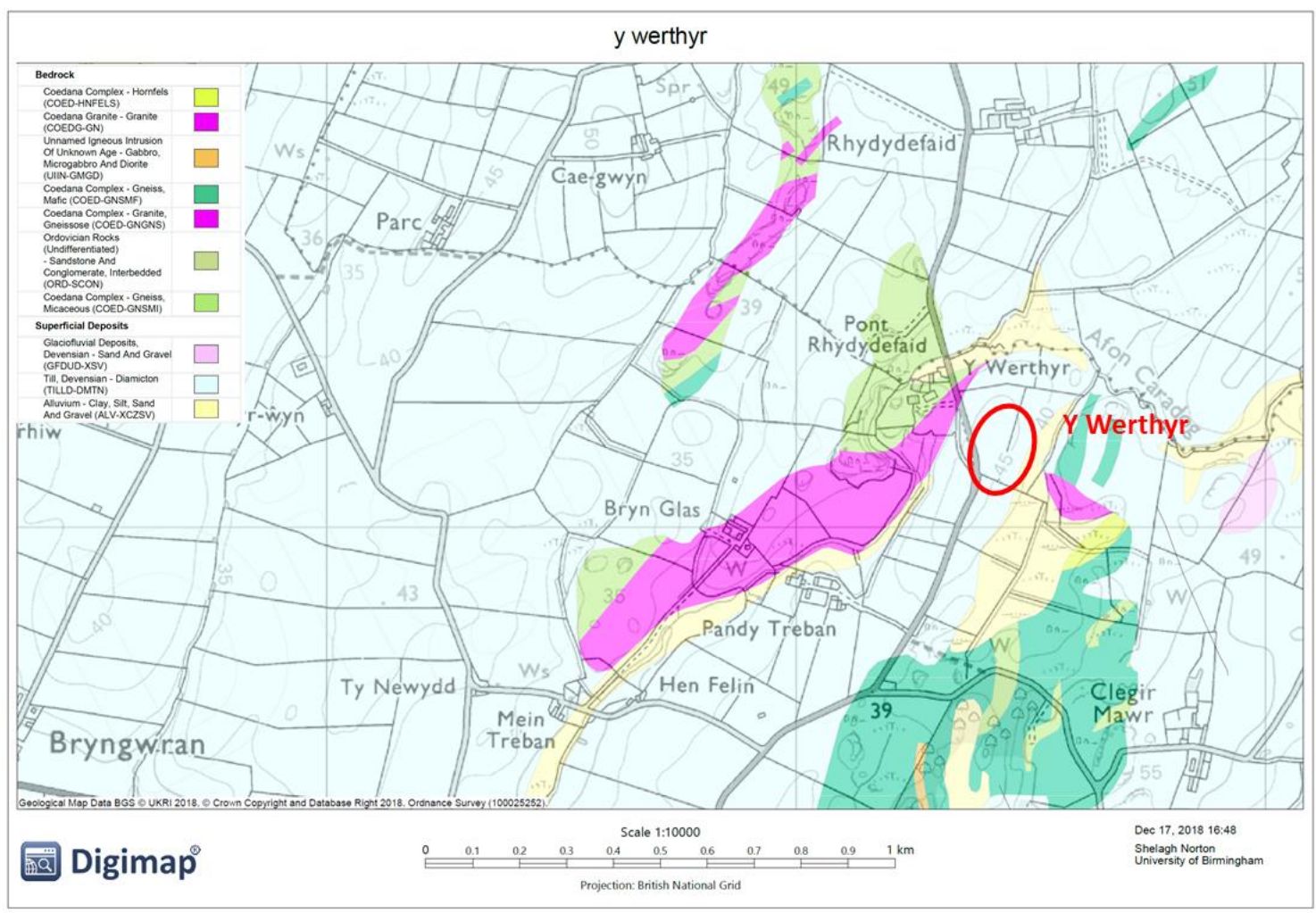

Fig. 4-26 y Werthyr - geology (Edina Digimap; December 2018) 


\subsection{Summary}

This gazetteer presents the results of a systematic data search of marsh-fort candidates from across England and Wales. It is the first time that a body of evidence examining substantial Iron Age wetland fortifications has been brought together and assessed. The sites highlighted in this chapter are summarised in Table 4.2; supporting detail can be found in Appendix 1 (CD-ROM).

Each site has been compared to Sutton Common, and is considered to be a marsh-fort (Groups 1-3) if it meets four of Sutton Common's seven characteristics, as follows:

Group 1. Marsh-forts in the Sutton Common model, used for non-domestic/ritual purposes

Group 2. Potential marsh-forts similar to Sutton Common, which may have been used for non-domestic/ritual purposes

Group 3. Low-lying, monumental, marshland sites which probably exercised a controlling function (economic, territorial, ritual) across the surrounding wetland landscape, but where evidence is principally domestic

A residual group (Group 4) comprises sites which have insufficient similarities or the dataset is too poor to allow classification.

\section{Group 1}

Two sites in the Cambridgeshire Fens - Stonea Camp and Wardy Hill - reflect the Sutton Common hypothesis most fully. (Whilst Wardy Hill does not fulfil the criterion of 'large size', its true extent is unclear). These sites delimit space in a flat, wetland environment and appear to control access to the wet:dry interface. Evidence for domestic activity is limited or non-existent, whilst other characteristics - for example, a water-gate at Wardy Camp, and human remains at both sites reinforce a ritual purpose. Chronologically, Stonea Camp may have marginally preceded Wardy Hill; spatially, they are sufficiently close together to suggest they may have acted sequentially, or in unison, or, possibly, as rival sites.

\section{Group 2}

A further nine sites share many of Sutton Common's characteristics and could be considered as marsh-forts, if allowances are made for size, chronology, or morphology, or if more evidence were available. In Cambridgeshire, Arbury lacks domestic evidence; the interior appears 'empty' and the site had a monumental, east-facing gateway. In Norfolk, Holkham is the most intriguing - a monumental enclosure which controlled access to an area of salt marsh/coast. Although a lack of evidence precludes any firm conclusions, human remains were recovered from the site. In the Thames Valley, Cassington was clearly a place of ritualised memory and was considered sufficiently important for the creation of a monumental earthwork - the 'Great Enclosure' - the construction of 
which would represent a significant investment of time and labour and signify the site as important. Salmonsbury in Gloucestershire developed in later prehistory as a territorial oppidum, but a lengthy landscape chronology together with a multiplicity of specialised metalwork deposition and the presence of human remains indicate that it held a wider significance than as a domestic site. In Lincolnshire, Tattershall Thorpe is the most positive candidate and its location on the Iron Age coastline could have had a bearing on access to Fiskerton. Evidence from y Werthyr is extremely limited but its location on a river bend, close to the only outcrop of mafic gneiss on Anglesey and near to Llyn Cerrig Bach may be significant. The sites of Little Smeaton and Moorhouse Farm in South Yorkshire are both unusual and locationally positioned to take advantage, in the same way as Stonea Camp, Wardy Hill and Sutton Common, of the interface between the peat edge and minerogenic soils.

\section{Group 3}

An additional nine large, monumental sites make use of a wetland location and may have been positioned to control territory or access, however, evidence tends more towards domestic use. These include sites in the Cambridgeshire Fens (Burough Hill and Burough Fen), in Norfolk/Suffolk (Bloodgate Hill, Burgh and Clare), and in the Thames Valley (Cherbury, Abingdon), as well as the unusual site of Oldbury on the Severn estuary. Warham Camp is contentious. It shares many of Sutton Common's characteristics. The evidence was considered to be primarily domestic, however, a recent, unpublished geophysical survey suggests that the interior was empty (pers.comm.Prof. Martin Bell). Whilst these sites lack the ritual connotations of Sutton Common, they may have played an important role in the control of the wetland landscape.

\section{Group 4}

The remaining sites have been excluded for a variety of reasons; for example, Dinas Dinlle is a coastal promontory fort, and Croft Road, Finningley and Peckforton appear as simple enclosures, albeit in wetland locations. However, the most obvious reason for exclusion or equivocation about these sites is a lack of evidence - most have not been excavated, or when excavated, the question of how this site fitted into an Iron Age wetland landscape was never considered. These exclusions can be overturned as more data becomes available, and as with Van der Noort's summary of Sutton Common, the 'labelling' does not exclude other functions.

All the surveys/reviews referred to in this chapter highlight that marsh-forts are a rarity. Of the 1,915 hillforts in England and Wales, the Atlas classified twenty (1.2\%) as marsh-forts. These monuments are a highly unusual, scarce resource, and their wetland settings and palaeoenvironmental archives proffer a unique insight into Iron Age society. Given the ritualised importance of waterscapes during the first-millennium BC, deliberately siting a monumental structure in a wetland must have been a 
significant act and the contribution of each of these sites to a theory of marsh-forts is discussed in Chapter 9. In the meantime, the answer to the question posed earlier in this section - is Sutton Common unique? - is clearly 'no'. 


\section{IRON AGE MARSH-FORTS - ENGLAND AND WALES}

\begin{tabular}{|c|c|c|c|c|c|c|c|c|c|}
\hline & & & & & & LEGEND & $\begin{array}{l}\text { Group } 1 \\
\text { Marsh-fort } \\
\text { used for } \\
\text { ritual/non- } \\
\text { domestic } \\
\text { purposes }\end{array}$ & $\begin{array}{l}\text { Group } 2 \\
\text { Possible marsh- } \\
\text { fort: } \\
\text { ritual/non- } \\
\text { domestic } \\
\text { functionality }\end{array}$ & $\begin{array}{l}\text { Group } 3 \text { Possible marsh-fort. } \\
\text { Evidence is predominantly } \\
\text { domestic; potential economic } \\
\text { centre or territorial marker }\end{array}$ \\
\hline Region & Site & $\begin{array}{l}\text { large } \\
\text { size }\end{array}$ & $\begin{array}{l}\text { location/ } \\
\text { marshland } \\
\text { setting }\end{array}$ & $\begin{array}{l}\text { monumentality/ } \\
\text { morphology }\end{array}$ & $\begin{array}{l}\text { MIA/LIA } \\
\text { chronology }\end{array}$ & $\begin{array}{l}\text { Lengthy } \\
\text { landscape } \\
\text { chronology/ } \\
\text { discontinuity } \\
\text { of use }\end{array}$ & $\begin{array}{l}\text { Localised } \\
\text { woodland } \\
\text { clearance/ } \\
\text { pasture }\end{array}$ & $\begin{array}{l}\text { Non-domestic; } \\
\text { possible } \\
\text { ceremonial or } \\
\text { ritual use }\end{array}$ & Summary \\
\hline \multirow[t]{4}{*}{ Cambridgeshire } & $\begin{array}{l}\text { Arbury Camp, } \\
\text { Hinton (dest) }\end{array}$ & $\checkmark$ & $\checkmark$ & $\checkmark$ & $\checkmark$ & $\checkmark$ & unk & $\checkmark$ & $\begin{array}{l}\text { A seasonal camp/ territorial } \\
\text { marker. Possibly a ceremonial } \\
\text { centre, territorial marker or } \\
\text { marsh-fort? }\end{array}$ \\
\hline & $\begin{array}{l}\text { Belsars Hill, } \\
\text { Willingham }\end{array}$ & $x$ & $\checkmark$ & $x$ & unk & & unk & unk & $\begin{array}{l}\text { Limited information; univallate } \\
\text { hillfort/enclosure in fenland; } \\
\text { possible territorial marker }\end{array}$ \\
\hline & Borough Fen & $\checkmark$ & $\begin{array}{l}\checkmark \text { drained } \\
\text { marsh }\end{array}$ & $\checkmark$ & $\checkmark$ & unk & unk & $x$ & $\begin{array}{l}\text { Based on the evidence, the site } \\
\text { may be a possible territorial } \\
\text { marker or domestic enclosure of } \\
\text { some standing }\end{array}$ \\
\hline & $\begin{array}{l}\text { Borough Hill, } \\
\text { Sawston }\end{array}$ & $\checkmark$ & $\checkmark$ & $\checkmark$ & $\checkmark$ & $\checkmark$ & $\checkmark$ & $x$ & $\begin{array}{l}\text { Domestic evidence; possible } \\
\text { territorial marker; defences } \\
\text { augmented by river bend }\end{array}$ \\
\hline
\end{tabular}




\section{IRON AGE MARSH-FORTS - ENGLAND AND WALES}

\begin{tabular}{|c|c|c|c|c|c|c|c|c|c|}
\hline & & & & & & LEGEND & $\begin{array}{l}\text { Group } 1 \\
\text { Marsh-fort } \\
\text { used for } \\
\text { ritual/non- } \\
\text { domestic } \\
\text { purposes }\end{array}$ & $\begin{array}{l}\text { Group } 2 \\
\text { Possible marsh- } \\
\text { fort: } \\
\text { ritual/non- } \\
\text { domestic } \\
\text { functionality }\end{array}$ & $\begin{array}{l}\text { Group } 3 \text { Possible marsh-fort. } \\
\text { Evidence is predominantly } \\
\text { domestic; potential economic } \\
\text { centre or territorial marker }\end{array}$ \\
\hline \multirow[t]{3}{*}{ Region } & Site & $\begin{array}{l}\text { large } \\
\text { size }\end{array}$ & $\begin{array}{l}\text { location/ } \\
\text { marshland } \\
\text { setting }\end{array}$ & $\begin{array}{l}\text { monumentality/ } \\
\text { morphology }\end{array}$ & $\begin{array}{l}\text { MIA/LIA } \\
\text { chronology }\end{array}$ & $\begin{array}{l}\text { Lengthy } \\
\text { landscape } \\
\text { chronology/ } \\
\text { discontinuity } \\
\text { of use }\end{array}$ & $\begin{array}{l}\text { Localised } \\
\text { woodland } \\
\text { clearance/ } \\
\text { pasture }\end{array}$ & $\begin{array}{l}\text { Non-domestic; } \\
\text { possible } \\
\text { ceremonial or } \\
\text { ritual use }\end{array}$ & Summary \\
\hline & $\begin{array}{l}\text { Stonea Camp, } \\
\text { Wimblington }\end{array}$ & $\checkmark$ & $\checkmark$ & $\checkmark$ & $\checkmark$ & $\checkmark$ & $\checkmark$ & $\checkmark$ & $\begin{array}{l}\text { Morphology, size, chronology and } \\
\text { usage indicate a marsh-fort }\end{array}$ \\
\hline & Wardy Hill & $x$ & $\checkmark$ & $\checkmark$ & $\checkmark$ & $\checkmark$ & $\checkmark$ & $\checkmark$ & $\begin{array}{l}\text { Morphology and chronology } \\
\text { consistent as a small marsh-fort; a } \\
\text { possible control point governing } \\
\text { fen access; possibly a chieftain's } \\
\text { centre }\end{array}$ \\
\hline \multirow[t]{2}{*}{ Cheshire } & Oakmere & $x$ & $\checkmark$ & $\checkmark$ & $\checkmark$ & unk & unk & unk & $\begin{array}{l}\text { Small but monumental } \\
\text { fortification commanding the lake } \\
\text { edge; possible marsh fort }\end{array}$ \\
\hline & Peckforton & $x$ & $\checkmark$ & $x$ & $\checkmark$ & $x$ & $\checkmark$ & unk & $\begin{array}{l}\text { A small enclosure on the edge of a } \\
\text { mere. }\end{array}$ \\
\hline Gloucestershire & Oldbury Camp & $\checkmark$ & $\checkmark$ & $\checkmark$ & $\checkmark$ & unk & unk & unk & $\begin{array}{l}\text { Ongoing excavation should } \\
\text { provide more evidence; possible } \\
\text { control point on the Severn } \\
\text { estuary or trading port }\end{array}$ \\
\hline
\end{tabular}




\section{IRON AGE MARSH-FORTS - ENGLAND AND WALES}

\begin{tabular}{|c|c|c|c|c|c|c|c|c|c|}
\hline & & & & & & LEGEND & $\begin{array}{l}\text { Group } 1 \\
\text { Marsh-fort } \\
\text { used for } \\
\text { ritual/non- } \\
\text { domestic } \\
\text { purposes }\end{array}$ & $\begin{array}{l}\text { Group } 2 \\
\text { Possible marsh- } \\
\text { fort: } \\
\text { ritual/non- } \\
\text { domestic } \\
\text { functionality }\end{array}$ & $\begin{array}{l}\text { Group } 3 \text { Possible marsh-fort. } \\
\text { Evidence is predominantly } \\
\text { domestic; potential economic } \\
\text { centre or territorial marker }\end{array}$ \\
\hline \multirow[t]{2}{*}{ Region } & Site & $\begin{array}{l}\text { large } \\
\text { size }\end{array}$ & $\begin{array}{l}\text { location/ } \\
\text { marshland } \\
\text { setting }\end{array}$ & $\begin{array}{l}\text { monumentality/ } \\
\text { morphology }\end{array}$ & $\begin{array}{l}\text { MIA/LIA } \\
\text { chronology }\end{array}$ & $\begin{array}{l}\text { Lengthy } \\
\text { landscape } \\
\text { chronology/ } \\
\text { discontinuity } \\
\text { of use }\end{array}$ & $\begin{array}{l}\text { Localised } \\
\text { woodland } \\
\text { clearance/ } \\
\text { pasture }\end{array}$ & $\begin{array}{l}\text { Non-domestic; } \\
\text { possible } \\
\text { ceremonial or } \\
\text { ritual use }\end{array}$ & Summary \\
\hline & $\begin{array}{l}\text { Salmonsbury } \\
\text { Camp }\end{array}$ & $\checkmark$ & $\checkmark$ & $\checkmark$ & $\checkmark$ & $\checkmark$ & unk & $x ?$ & $\begin{array}{l}\text { Multi-functional, multi-period } \\
\text { enclosure/oppidum; evidence of } \\
\text { continuous use and importance. } \\
\text { Possible marsh-fort in origin }\end{array}$ \\
\hline Hampshire & $\begin{array}{l}\text { Bullsdown } \\
\text { Camp }\end{array}$ & $\checkmark$ & $\checkmark$ & $\checkmark$ & unk & unk & unk & unk & $\begin{array}{l}\text { Field systems and marshland } \\
\text { surround this fortification, but } \\
\text { evidence is too limited to draw a } \\
\text { conclusion }\end{array}$ \\
\hline Hertfordshire & $\begin{array}{l}\text { The Aubreys, } \\
\text { Redbourne }\end{array}$ & $\checkmark$ & $\checkmark$ & $\checkmark$ & unk & unk & unk & unk & $\begin{array}{l}\text { A possible control point in a low- } \\
\text { lying landscape; insufficient } \\
\text { evidence }\end{array}$ \\
\hline \multirow[t]{2}{*}{ Herefordshire } & Eaton Camp & $\checkmark$ & $\mathrm{x}$ & $\checkmark$ & $\checkmark$ & unk & unk & $\mathrm{x}$ & $\begin{array}{l}\text { Promontory fort overlooking River } \\
\text { Wye }\end{array}$ \\
\hline & Risbury Camp & $\checkmark$ & $\checkmark$ & $\checkmark$ & unk & unk & unk & unk & $\begin{array}{l}\text { Possible control point at river } \\
\text { junction; evidence too limited to } \\
\text { draw conclusion }\end{array}$ \\
\hline Lincolnshire & Burgh Banks & $\checkmark$ & possible & unk & unk & unk & unk & unk & Insufficient evidence \\
\hline
\end{tabular}




\section{IRON AGE MARSH-FORTS - ENGLAND AND WALES}

\begin{tabular}{|c|c|c|c|c|c|c|c|c|c|}
\hline & & & & & & LEGEND & $\begin{array}{l}\text { Group } 1 \\
\text { Marsh-fort } \\
\text { used for } \\
\text { ritual/non- } \\
\text { domestic } \\
\text { purposes }\end{array}$ & $\begin{array}{l}\text { Group } 2 \\
\text { Possible marsh- } \\
\text { fort: } \\
\text { ritual/non- } \\
\text { domestic } \\
\text { functionality }\end{array}$ & $\begin{array}{l}\text { Group } 3 \text { Possible marsh-fort. } \\
\text { Evidence is predominantly } \\
\text { domestic; potential economic } \\
\text { centre or territorial marker }\end{array}$ \\
\hline \multirow[t]{3}{*}{ Region } & Site & $\begin{array}{l}\text { large } \\
\text { size }\end{array}$ & $\begin{array}{l}\text { location/ } \\
\text { marshland } \\
\text { setting }\end{array}$ & $\begin{array}{l}\text { monumentality/ } \\
\text { morphology }\end{array}$ & $\begin{array}{l}\text { MIA/LIA } \\
\text { chronology }\end{array}$ & $\begin{array}{l}\text { Lengthy } \\
\text { landscape } \\
\text { chronology/ } \\
\text { discontinuity } \\
\text { of use }\end{array}$ & $\begin{array}{l}\text { Localised } \\
\text { woodland } \\
\text { clearance/ } \\
\text { pasture }\end{array}$ & $\begin{array}{l}\text { Non-domestic; } \\
\text { possible } \\
\text { ceremonial or } \\
\text { ritual use }\end{array}$ & Summary \\
\hline & $\begin{array}{l}\text { Tattershall } \\
\text { Thorpe }\end{array}$ & $x$ & $\checkmark$ & $\checkmark$ & $\checkmark$ & $\checkmark$ & $\checkmark$ & unk & $\begin{array}{l}\text { One of several defended } \\
\text { enclosures in the Lincolnshire } \\
\text { Fens, occupying a strategic point } \\
\text { between the River Witham and } \\
\text { the Iron Age coast. Possible } \\
\text { marsh-fort }\end{array}$ \\
\hline & $\begin{array}{l}\text { Kirkstead/ Old } \\
\text { Abbey Farm }\end{array}$ & $x$ & $\checkmark$ & $\checkmark$ & $\checkmark$ & unk & unk & unk & $\begin{array}{l}\text { One of several defended } \\
\text { enclosures in the Lincolnshire Fen; } \\
\text { occupied similar location to } \\
\text { Tattershall Thorpe. Insufficient } \\
\text { information }\end{array}$ \\
\hline Northumberland & $\begin{array}{l}\text { Hetha Burn } \\
\text { West }\end{array}$ & $x$ & $\checkmark$ & $\checkmark$ & unk & unk & unk & unk & $\begin{array}{l}\text { A likely annex to Great Hetha. } \\
\text { Small enclosure on river, possibly } \\
\text { for stock control }\end{array}$ \\
\hline Norfolk/Suffolk & $\begin{array}{l}\text { Bloodgate Hill, } \\
\text { South Creake } \\
\text { (dest) }\end{array}$ & $\checkmark$ & $x$ & $\checkmark$ & $\checkmark$ & $\checkmark$ & unk & possible & $\begin{array}{l}\text { Sizeable fortification and possible } \\
\text { control point in shallow valley; } \\
\text { possible central Bronze Age round } \\
\text { barrow; limited settlement } \\
\text { evidence. However, some distance } \\
\text { from wetland }\end{array}$ \\
\hline
\end{tabular}




\section{IRON AGE MARSH-FORTS - ENGLAND AND WALES}

\begin{tabular}{|c|c|c|c|c|c|c|c|c|c|}
\hline & & & & & & LEGEND & $\begin{array}{l}\text { Group } 1 \\
\text { Marsh-fort } \\
\text { used for } \\
\text { ritual/non- } \\
\text { domestic } \\
\text { purposes }\end{array}$ & $\begin{array}{l}\text { Group } 2 \\
\text { Possible marsh- } \\
\text { fort: } \\
\text { ritual/non- } \\
\text { domestic } \\
\text { functionality }\end{array}$ & $\begin{array}{l}\text { Group } 3 \text { Possible marsh-fort. } \\
\text { Evidence is predominantly } \\
\text { domestic; potential economic } \\
\text { centre or territorial marker }\end{array}$ \\
\hline \multirow[t]{5}{*}{ Region } & Site & $\begin{array}{l}\text { large } \\
\text { size }\end{array}$ & $\begin{array}{l}\text { location/ } \\
\text { marshland } \\
\text { setting }\end{array}$ & $\begin{array}{l}\text { monumentality/ } \\
\text { morphology }\end{array}$ & $\begin{array}{l}\text { MIA/LIA } \\
\text { chronology }\end{array}$ & $\begin{array}{l}\text { Lengthy } \\
\text { landscape } \\
\text { chronology/ } \\
\text { discontinuity } \\
\text { of use }\end{array}$ & $\begin{array}{l}\text { Localised } \\
\text { woodland } \\
\text { clearance/ } \\
\text { pasture }\end{array}$ & $\begin{array}{l}\text { Non-domestic; } \\
\text { possible } \\
\text { ceremonial or } \\
\text { ritual use }\end{array}$ & Summary \\
\hline & $\begin{array}{l}\text { Boney's } \\
\text { Island, Beccles }\end{array}$ & unk & $\checkmark$ & $x$ & unk & unk & unk & $x$ & $\begin{array}{l}\text { Too little evidence to draw a } \\
\text { conclusion; lack of monumentality } \\
\text { suggests enclosure }\end{array}$ \\
\hline & Burgh & $\checkmark$ & $x$ & $\checkmark$ & $\checkmark$ & $\checkmark$ & unk & $x$ & $\begin{array}{l}\text { A large enclosure/fortification } \\
\text { with mainly LIA and extensive } \\
\text { Romano-British evidence. Usage } \\
\text { was probably domestic, albeit } \\
\text { with a lengthy chronology. Close } \\
\text { to River Lark }\end{array}$ \\
\hline & Clare Camp & $\checkmark$ & $\checkmark$ & $\checkmark$ & $x ?$ & $\checkmark$ & unk & $x$ & $\begin{array}{l}\text { A fortification with defences } \\
\text { augmented by marshland and a } \\
\text { possible causeway. Scant evidence } \\
\text { suggests a possible territorial } \\
\text { marker }\end{array}$ \\
\hline & Holkham & $x$ & $\checkmark$ & $\checkmark$ & $\checkmark$ & $\checkmark$ & salt marsh & $\begin{array}{l}\text { human } \\
\text { remains/unk }\end{array}$ & $\begin{array}{l}\text { Although evidence is severely } \\
\text { limited, the lengthy chronology, } \\
\text { highly unusual morphology and } \\
\text { location indicate something more } \\
\text { than a straightforward enclosure - } \\
\text { possibly a (small) marsh-fort }\end{array}$ \\
\hline
\end{tabular}




\section{IRON AGE MARSH-FORTS - ENGLAND AND WALES}

\begin{tabular}{|c|c|c|c|c|c|c|c|c|c|}
\hline & & & & & & LEGEND & $\begin{array}{l}\text { Group } 1 \\
\text { Marsh-fort } \\
\text { used for } \\
\text { ritual/non- } \\
\text { domestic } \\
\text { purposes }\end{array}$ & $\begin{array}{l}\text { Group } 2 \\
\text { Possible marsh- } \\
\text { fort: } \\
\text { ritual/non- } \\
\text { domestic } \\
\text { functionality }\end{array}$ & $\begin{array}{l}\text { Group } 3 \text { Possible marsh-fort. } \\
\text { Evidence is predominantly } \\
\text { domestic; potential economic } \\
\text { centre or territorial marker }\end{array}$ \\
\hline \multirow[t]{4}{*}{ Region } & Site & $\begin{array}{l}\text { large } \\
\text { size }\end{array}$ & $\begin{array}{l}\text { location/ } \\
\text { marshland } \\
\text { setting }\end{array}$ & $\begin{array}{l}\text { monumentality/ } \\
\text { morphology }\end{array}$ & $\begin{array}{l}\text { MIA/LIA } \\
\text { chronology }\end{array}$ & $\begin{array}{l}\text { Lengthy } \\
\text { landscape } \\
\text { chronology/ } \\
\text { discontinuity } \\
\text { of use }\end{array}$ & $\begin{array}{l}\text { Localised } \\
\text { woodland } \\
\text { clearance/ } \\
\text { pasture }\end{array}$ & $\begin{array}{l}\text { Non-domestic; } \\
\text { possible } \\
\text { ceremonial or } \\
\text { ritual use }\end{array}$ & Summary \\
\hline & Narborough & $x$ & $\checkmark$ & $x$ & $\checkmark$ & unk & unk & unk & $\begin{array}{l}\text { Fortification which possibly } \\
\text { controlled a river crossing }\end{array}$ \\
\hline & Tharston & $\checkmark$ & $\checkmark$ & $\checkmark$ & unk & unk & unk & unk & $\begin{array}{l}\text { Too little evidence to determine } \\
\text { marsh-fort status; a possible twin } \\
\text { with Tasburgh }\end{array}$ \\
\hline & $\begin{array}{l}\text { Warham } \\
\text { Camp }\end{array}$ & $\checkmark$ & $\checkmark$ & $\checkmark$ & $\checkmark$ & $\checkmark$ & unk & $x$ & $\begin{array}{l}\text { A lengthy chronology, however, } \\
\text { (limited) Iron Age evidence } \\
\text { suggests that this was a domestic } \\
\text { site and a possible control point } \\
\text { on River Stiffkey }\end{array}$ \\
\hline Nottinghamshire & Aslockton & $\checkmark$ & $x$ & $\checkmark$ & $\checkmark$ & unk & unk & $x$ & $\begin{array}{l}\text { Complex settlement and enclosure } \\
\text { with evidence of feasting }\end{array}$ \\
\hline Oxfordshire & $\begin{array}{l}\text { Abingdon, The } \\
\text { Vineyard } \\
\text { (dest) }\end{array}$ & $x$ & $\checkmark$ & $\checkmark$ & $\checkmark$ & $\checkmark$ & unk & $\mathrm{x}$ & $\begin{array}{l}\text { Important enclosed } \\
\text { settlement/oppidum utilising river } \\
\text { as defence; LIA; lengthy } \\
\text { chronology }\end{array}$ \\
\hline
\end{tabular}




\section{IRON AGE MARSH-FORTS - ENGLAND AND WALES}

\begin{tabular}{|c|c|c|c|c|c|c|c|c|c|}
\hline & & & & & & LEGEND & $\begin{array}{l}\text { Group } 1 \\
\text { Marsh-fort } \\
\text { used for } \\
\text { ritual/non- } \\
\text { domestic } \\
\text { purposes }\end{array}$ & $\begin{array}{l}\text { Group } 2 \\
\text { Possible marsh- } \\
\text { fort: } \\
\text { ritual/non- } \\
\text { domestic } \\
\text { functionality }\end{array}$ & $\begin{array}{l}\text { Group } 3 \text { Possible marsh-fort. } \\
\text { Evidence is predominantly } \\
\text { domestic; potential economic } \\
\text { centre or territorial marker }\end{array}$ \\
\hline \multirow[t]{5}{*}{ Region } & Site & $\begin{array}{l}\text { large } \\
\text { size }\end{array}$ & $\begin{array}{l}\text { location/ } \\
\text { marshland } \\
\text { setting }\end{array}$ & $\begin{array}{l}\text { monumentality/ } \\
\text { morphology }\end{array}$ & $\begin{array}{l}\text { MIA/LIA } \\
\text { chronology }\end{array}$ & $\begin{array}{l}\text { Lengthy } \\
\text { landscape } \\
\text { chronology/ } \\
\text { discontinuity } \\
\text { of use }\end{array}$ & $\begin{array}{l}\text { Localised } \\
\text { woodland } \\
\text { clearance/ } \\
\text { pasture }\end{array}$ & $\begin{array}{l}\text { Non-domestic; } \\
\text { possible } \\
\text { ceremonial or } \\
\text { ritual use }\end{array}$ & Summary \\
\hline & Burroway & $x$ & $\checkmark$ & $x$ & $\checkmark$ possibly & $x$ & unk & $x$ & $\begin{array}{l}\text { Extended settlement on } \\
\text { floodplain; enclosure is LIA }\end{array}$ \\
\hline & $\begin{array}{l}\text { Cherbury } \\
\text { Camp }\end{array}$ & $\checkmark$ & $\checkmark$ & $\checkmark$ & $\checkmark$ & $x$ & unk & $x$ & $\begin{array}{l}\text { Multi-period, multi-use } \\
\text { settlement; a fortification } \\
\text { controlling the surrounding } \\
\text { marshland }\end{array}$ \\
\hline & $\begin{array}{l}\text { Cassington } \\
\text { Mill (largely } \\
\text { dest) }\end{array}$ & $\checkmark$ & $\checkmark$ & $\checkmark$ & $\checkmark$ & $\checkmark$ & $\checkmark$ & possible & $\begin{array}{l}\text { Multiperiod, multi-use settlement } \\
\text { and ceremonial site; possibly a } \\
\text { marsh-fort, now largely destroyed }\end{array}$ \\
\hline & Dyke Hills & $\checkmark$ & $\begin{array}{l}\text { river } \\
\text { promontory }\end{array}$ & $\checkmark$ & $\checkmark ?$ & $x$ & $\checkmark$ & $x$ & $\begin{array}{l}\text { Limited evidence of pre-Iron Age } \\
\text { occupation; Romano-British } \\
\text { oppidum/enclosed settlement }\end{array}$ \\
\hline Somerset & Athelney & $\checkmark$ & $x$ & unk & possible & unk & unk & unk & $\begin{array}{l}\text { Occupying an isle on the } \\
\text { Somerset Levels; evidence is too } \\
\text { limited to draw conclusions }\end{array}$ \\
\hline
\end{tabular}




\section{IRON AGE MARSH-FORTS - ENGLAND AND WALES}

\begin{tabular}{|c|c|c|c|c|c|c|c|c|c|}
\hline & & & & & & LEGEND & $\begin{array}{l}\text { Group } 1 \\
\text { Marsh-fort } \\
\text { used for } \\
\text { ritual/non- } \\
\text { domestic } \\
\text { purposes }\end{array}$ & $\begin{array}{l}\text { Group } 2 \\
\text { Possible marsh- } \\
\text { fort: } \\
\text { ritual/non- } \\
\text { domestic } \\
\text { functionality }\end{array}$ & $\begin{array}{l}\text { Group } 3 \text { Possible marsh-fort. } \\
\text { Evidence is predominantly } \\
\text { domestic; potential economic } \\
\text { centre or territorial marker }\end{array}$ \\
\hline Region & Site & $\begin{array}{l}\text { large } \\
\text { size }\end{array}$ & $\begin{array}{l}\text { location/ } \\
\text { marshland } \\
\text { setting }\end{array}$ & $\begin{array}{l}\text { monumentality/ } \\
\text { morphology }\end{array}$ & $\begin{array}{l}\text { MIA/LIA } \\
\text { chronology }\end{array}$ & $\begin{array}{l}\text { Lengthy } \\
\text { landscape } \\
\text { chronology/ } \\
\text { discontinuity } \\
\text { of use }\end{array}$ & $\begin{array}{l}\text { Localised } \\
\text { woodland } \\
\text { clearance/ } \\
\text { pasture }\end{array}$ & $\begin{array}{l}\text { Non-domestic; } \\
\text { possible } \\
\text { ceremonial or } \\
\text { ritual use }\end{array}$ & Summary \\
\hline \multirow[t]{3}{*}{ Wales } & Dinas Dinlle & $x$ & $x$ & $\checkmark$ & $\checkmark$ & $\mathrm{x}$ & $x$ & $x$ & $\begin{array}{l}\text { Promontory hillfort on coast; } \\
\text { eroding rapidly }\end{array}$ \\
\hline & $\begin{array}{l}\text { Bryn Maen } \\
\text { Caerau, } \\
\text { Cellan, Dyfed }\end{array}$ & $x$ & river terrace & $\checkmark$ & $\checkmark$ & $\checkmark$ & unk & unk & $\begin{array}{l}\text { Long history of occupation, } \\
\text { possibly a defended farmstead on } \\
\text { a river terrace }\end{array}$ \\
\hline & $\begin{array}{l}\text { y Werthyr, } \\
\text { Bryngwran, } \\
\text { Isle of } \\
\text { Anglesey }\end{array}$ & $\checkmark$ & $\checkmark$ & $\checkmark$ & $\checkmark$ & unk & unk & unk & $\begin{array}{l}\text { Lacks evidence but fulfilling a } \\
\text { central function in marshland; its } \\
\text { proximity to Llyn Cerrig Bach may } \\
\text { be significant }\end{array}$ \\
\hline Warwickshire & $\begin{array}{l}\text { Harborough } \\
\text { Banks }\end{array}$ & $\checkmark$ & $x$ & $\checkmark$ & $?$ & unk & unk & unk & $\begin{array}{l}\text { Large univallate enclosure; limited } \\
\text { information }\end{array}$ \\
\hline \multirow[t]{2}{*}{ Worcestershire } & Gadbury Bank & $\checkmark$ & $x$ & $\checkmark$ & $\checkmark$ & unk & unk & $x$ & Promontory hillfort in river valley \\
\hline & Kempsey & $x$ & $\checkmark$ & $x$ & unk & unk & unk & $x$ & $\begin{array}{l}\text { Evidence is too limited to draw } \\
\text { conclusions; possibly a control } \\
\text { point along the River Severn }\end{array}$ \\
\hline
\end{tabular}




\section{IRON AGE MARSH-FORTS - ENGLAND AND WALES}

\begin{tabular}{|c|c|c|c|c|c|c|c|c|c|}
\hline & & & & & & LEGEND & $\begin{array}{l}\text { Group } 1 \\
\text { Marsh-fort } \\
\text { used for } \\
\text { ritual/non- } \\
\text { domestic } \\
\text { purposes }\end{array}$ & $\begin{array}{l}\text { Group } 2 \\
\text { Possible marsh- } \\
\text { fort: } \\
\text { ritual/non- } \\
\text { domestic } \\
\text { functionality }\end{array}$ & $\begin{array}{l}\text { Group } 3 \text { Possible marsh-fort. } \\
\text { Evidence is predominantly } \\
\text { domestic; potential economic } \\
\text { centre or territorial marker }\end{array}$ \\
\hline \multirow[t]{2}{*}{ Region } & Site & $\begin{array}{l}\text { large } \\
\text { size }\end{array}$ & $\begin{array}{l}\text { location/ } \\
\text { marshland } \\
\text { setting }\end{array}$ & $\begin{array}{l}\text { monumentality/ } \\
\text { morphology }\end{array}$ & $\begin{array}{l}\text { MIA/LIA } \\
\text { chronology }\end{array}$ & $\begin{array}{l}\text { Lengthy } \\
\text { landscape } \\
\text { chronology/ } \\
\text { discontinuity } \\
\text { of use }\end{array}$ & $\begin{array}{l}\text { Localised } \\
\text { woodland } \\
\text { clearance/ } \\
\text { pasture }\end{array}$ & $\begin{array}{l}\text { Non-domestic; } \\
\text { possible } \\
\text { ceremonial or } \\
\text { ritual use }\end{array}$ & Summary \\
\hline & Island Covert & $x$ & $\checkmark$ & $x$ & unk & unk & unk & $\begin{array}{l}\text { unk (local name } \\
\text { suggests } \\
\text { 'stronghold' in } \\
\text { Old English) }\end{array}$ & $\begin{array}{l}\text { Too little evidence to draw any } \\
\text { conclusions }\end{array}$ \\
\hline \multirow[t]{4}{*}{ Yorkshire } & $\begin{array}{l}\text { Sutton } \\
\text { Common, } \\
\text { South Yorks }\end{array}$ & $\checkmark$ & $\checkmark$ & $\checkmark$ & $\checkmark$ & $\checkmark$ & $\checkmark$ & $\checkmark$ & Marsh-fort \\
\hline & Potteric Carr & $x$ & $\checkmark$ & $\checkmark$ & $\checkmark$ & $x$ & $x$ & $x$ & $\begin{array}{l}\text { Its very small size and lack of } \\
\text { other features suggests this is an } \\
\text { enclosure however its location is } \\
\text { unusual }\end{array}$ \\
\hline & $\begin{array}{l}\text { Little } \\
\text { Smeaton, } \\
\text { North Yorks }\end{array}$ & $x$ & $\checkmark$ & $\checkmark$ & $\checkmark$ & $\checkmark$ & $x$ & unk & $\begin{array}{l}\text { Unusual morphology and access } \\
\text { via the adjacent river suggest this } \\
\text { as a possible (small) marsh-fort; } \\
\text { evidence is lacking }\end{array}$ \\
\hline & $\begin{array}{l}\text { Moorhouse } \\
\text { Farm, Tickhill, } \\
\text { South Yorks }\end{array}$ & $\checkmark$ & $\checkmark$ & $\checkmark$ & $\checkmark$ & unk & unk & unk & $\begin{array}{l}\text { Sizeable, important enclosure on } \\
\text { the peat edge controlling wetland } \\
\text { resources; possibly a marsh-fort. } \\
\text { Lacks information }\end{array}$ \\
\hline
\end{tabular}




\section{IRON AGE MARSH-FORTS - ENGLAND AND WALES}

\begin{tabular}{|c|c|c|c|c|c|c|c|c|c|}
\hline & & & & & & LEGEND & $\begin{array}{l}\text { Group } 1 \\
\text { Marsh-fort } \\
\text { used for } \\
\text { ritual/non- } \\
\text { domestic } \\
\text { purposes }\end{array}$ & $\begin{array}{l}\text { Group } 2 \\
\text { Possible marsh- } \\
\text { fort: } \\
\text { ritual/non- } \\
\text { domestic } \\
\text { functionality }\end{array}$ & $\begin{array}{l}\text { Group } 3 \text { Possible marsh-fort. } \\
\text { Evidence is predominantly } \\
\text { domestic; potential economic } \\
\text { centre or territorial marker }\end{array}$ \\
\hline \multirow[t]{3}{*}{ Region } & Site & $\begin{array}{l}\text { large } \\
\text { size }\end{array}$ & $\begin{array}{l}\text { location/ } \\
\text { marshland } \\
\text { setting }\end{array}$ & $\begin{array}{l}\text { monumentality/ } \\
\text { morphology }\end{array}$ & $\begin{array}{l}\text { MIA/LIA } \\
\text { chronology }\end{array}$ & $\begin{array}{l}\text { Lengthy } \\
\text { landscape } \\
\text { chronology/ } \\
\text { discontinuity } \\
\text { of use }\end{array}$ & $\begin{array}{l}\text { Localised } \\
\text { woodland } \\
\text { clearance/ } \\
\text { pasture }\end{array}$ & $\begin{array}{l}\text { Non-domestic; } \\
\text { possible } \\
\text { ceremonial or } \\
\text { ritual use }\end{array}$ & Summary \\
\hline & $\begin{array}{l}\text { Croft Rd } \\
\text { Finningley, } \\
\text { South Yorks }\end{array}$ & unk & $\checkmark$ & $\checkmark$ & $\checkmark$ & $x$ & $x$ & $x$ & most likely an enclosure \\
\hline & $\begin{array}{l}\text { Skipwith } \\
\text { Common }\end{array}$ & unk & $\checkmark$ & $\checkmark$ & unk & unk & unk & unk & $\begin{array}{l}\text { An enclosure within a settlement } \\
\text { and funerary complex; insufficient } \\
\text { detail to determine marsh-fort } \\
\text { status }\end{array}$ \\
\hline
\end{tabular}

Table 4-2 Marsh-forts and potential marsh-forts, England and Wales. See Appendix 1, CD-ROM for full details. For Shropshire - see Chapter 5 


\section{North Shropshire's marsh-forts}

‘...The low ground, the swart water, the thick grass,

$$
\text { Hallucinatory and familiar...' (Tollund, Heaney, 1996) }
$$

'From the point of view of the archaeologist, (Shropshire) can claim to be one of the least interesting localities in the whole of the British Isles' (Pevsner, 1958:13). In spite of one of the most remarkable Iron Age hillfort landscapes in Britain, and reflective of a lack of research, Pevsner condemned Shropshire as an archaeological backwater. However, from the 1960s onwards, as increasing professionalism and the application of new scientific techniques were applied to regional research, Shropshire was revealed to have a broad narrative available for study, from the Mesolithic to the post-medieval.

This chapter presents the second group of results from the marsh-fort gazetteer (Chapter 4; Appendix 1). The focus is narrowed from a national to a regional perspective, concentrating on the physical and archaeological landscapes surrounding eight potential marsh-forts in North Shropshire's wetlands - the Berth, Wall Camp, Stocketts Enclosure, Whittington Castle, Bomere Wood, Pan Castle, Pave Lane and Castle Farm. The artefactual and ecofactual landscapes surrounding the principal sites (the Berth, Wall Camp, Stocketts Enclosure and Whittington) have been mapped using time-sliced GIS diagrams to build a series of site narratives. Each site has been placed within its topographical setting and ranked against the Sutton Common characteristics (see Table 5-1). This comparison also provides the opportunity to review marsh-forts collectively rather than as single sites, and assess whether they may have acted as a group.

The Berth fulfils many of the Sutton Common criteria and is the most outstanding example of a marsh-fort in North Shropshire. Its features are introduced at high-level in this chapter whilst the results of a macro- and micro-scale landscape and palaeoenvironmental case-study of the site are presented in Chapters 6, 7 and 8 .

This chapter concludes with a summary of all the marsh-forts discussed in Chapters 4 and 5. 


\subsection{North Shropshire - physical environment}

Risking an accusation of environmental determinism (cf. Gaffney and van Leusen, 1995b), we are the product of our surroundings and we structure our behaviour to maximise the physical environments in which we find ourselves. Humans live in uplands and lowlands, on dry plains or in wetlands, in landscapes suited to pastoral or arable economies. This affects how we communicate and forage, what we grow and what we eat, and the wealth (mineral, agricultural) at our disposal.

'...there are not two worlds of persons (society) and things (nature), but just one world...saturated with personal powers and embracing both human beings, the animals and plants on which they depend, and the landscape in which they live and move...'(Ingold, 1992:42). The effect of the North Shropshire landscape, with its boglands, meres and mires, on the lives of those who dwelt there is fundamental to our understanding of the marsh-fort narrative.

\subsubsection{Geography, geology and glaciation}

Shropshire lies between the England's West Midlands Plain and Wales (Fig. 5-1). The North Shropshire Plain (the study area) covers roughly $250^{2} \mathrm{~km}$, and is bounded by the River Severn to the south, the northern Welsh Hills to the west, the Staffordshire Moorlands to the east and the Cheshire Plain, which runs into the West Lancashire Coastal Plain, to the north.

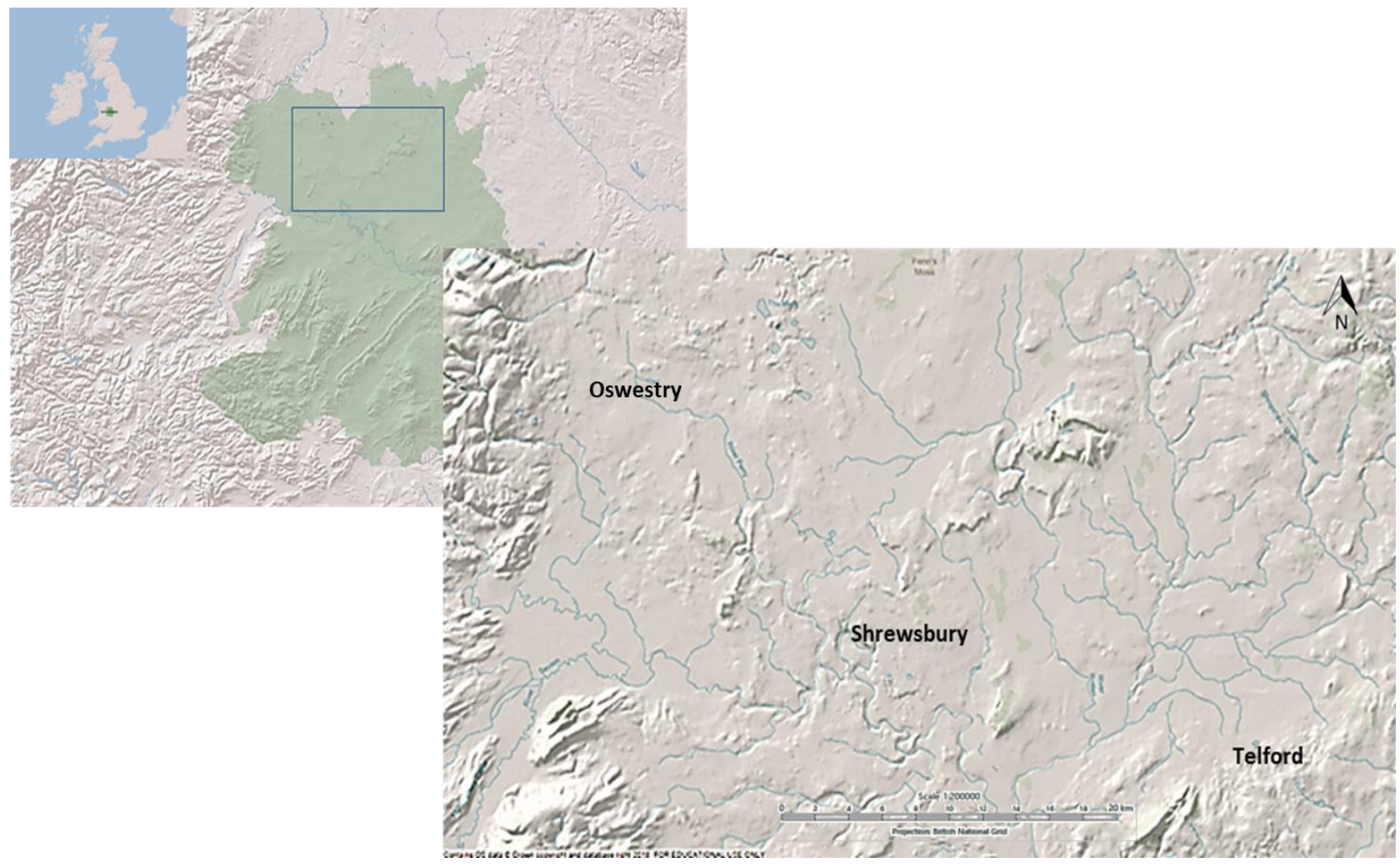

Fig. 5-1 Shropshire - North Shropshire Plain, shown in relief (Source: http://digimap.edina.ac.uk/ June 2017) 
Shropshire's geology is divided into three geographic regions (Fig. 5-2). To the north and east, glacial deposits overlie an irregular buried landscape of Carboniferous, Permo-Triassic (Sherwood

Sandstone Group) and Jurassic (mainly Liassic clays) rock. The northern plain began to subside during the Triassic (252-201mya) (Dineley, 1960:104), as hot desert conditions created playa lakes which evaporated to form salt deposits. The resulting line of salt springs are at their most well-known at Middlewich, Cheshire (Roman Salinae Cornoviorum) and Droitwich, Worcestershire (Roman Salinae Dobunnorum) (Toghill, 1990; Cooper, 2002) but are also present in several North Shropshire locations; for example Whitchurch (Roman Mediolanum) was a small scale salt producer towards the end of the Roman incursion (Matthews, 2001:20). Salt springs are also present on the Weald Moors near Wall Camp.

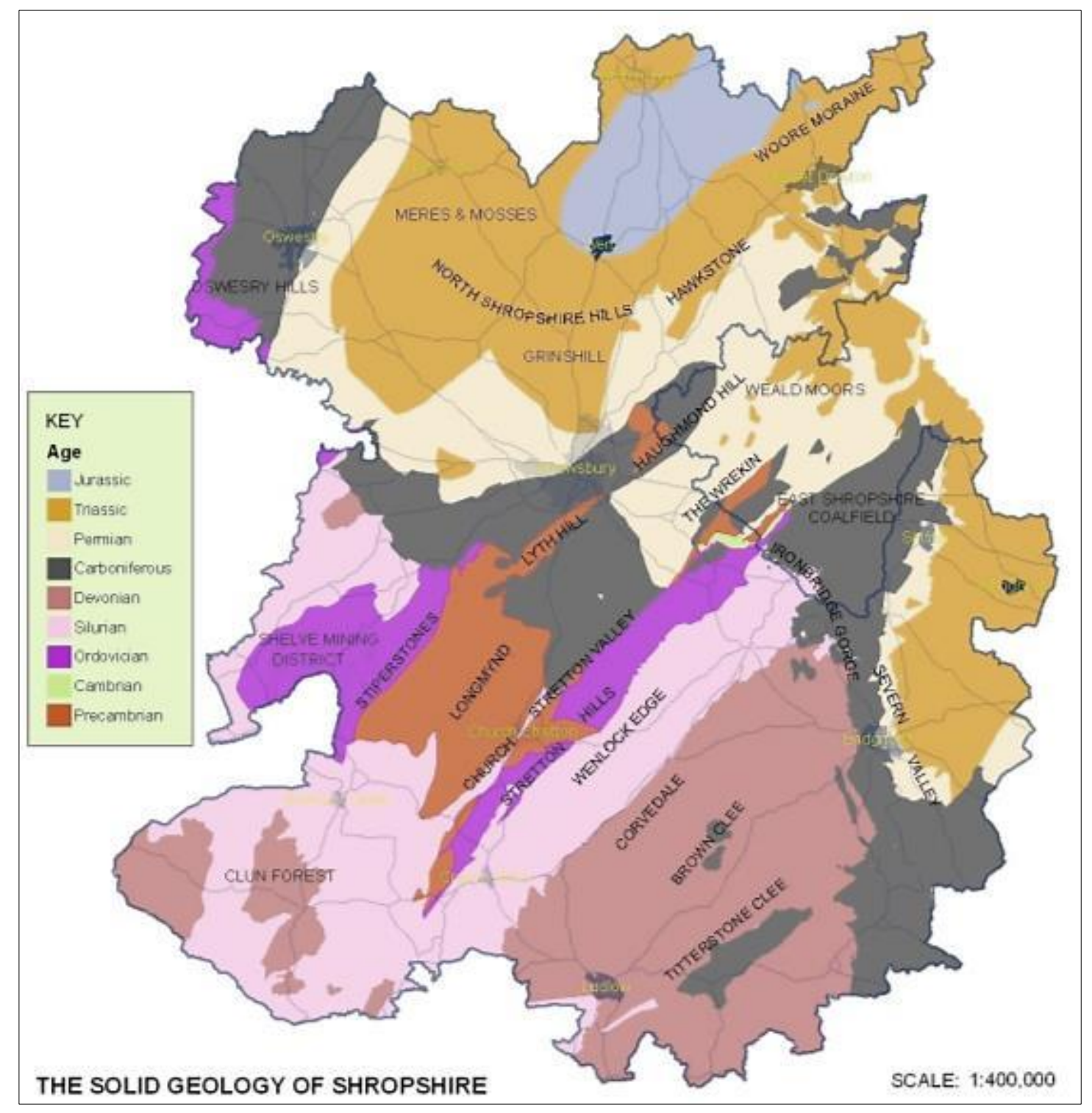

Fig. 5-2 Shropshire - Geology (Source: http://betweenarock.co.uk/fieldwork/blue-remembered-hills-shropshire-for1/attachment/shropshire-geology-map) 
The southern and western uplands are made up of Pre-Cambrian and Palaeozoic strata (541 252 mya). Many of the landmark hillforts of the region such as Caer Caradoc near Long Mynd are founded on Pre-Cambrian and Ordovician rocks, which extend westwards into the Cambrian Mountains and intrude north-eastwards into the North Shropshire Plain (Toghill, 1990). Carboniferous deposits (coal, ironstone and limestone) extend discontinuously north-west/southeast across Shropshire's central area and are the prime source of the county's mineral wealth; limestone and copper were mined at the Late Bronze Age/Iron Age hillfort of Llanymynech (Shropshire HER 1117/6644) and lead was mined at Snailbeach by the Romans (Shropshire HER 984). The Church Stretton Fault runs north-east/south-west across the county from south of Newport on the Weald Moors along the main strike of the geology (Dineley, 1960:91).

The last glaciation which affected the British Isles was the Devensian Cold Stage $(115,000-$ 10,000ya). At the height of the Last Glacial Maximum (LGM), around 18,000ya, the British-Irish Ice Sheet (BIIS) extended in a roughly north-east/south-west diagonal across Britain, reaching as far south as the Scilly Isles (Fig. 5-3). Across the West Midlands, its extent can be traced from modernday Stoke, to Stafford, Wolverhampton, and Bridgnorth, and thence to Shrewsbury (Chiverrell and Thomas, 2010:541). Glaciation dramatically changes landscapes, eroding uplands, scouring lowlands, reworking drainage and redepositing large quantities of material. As the glaciers covering Britain retreated, vast lakes were formed covering an area from Manchester to Wenlock, which merged to create a super-lake - Lake Lapworth (Fig. 5-4). The current course of the River Severn was formed when Lake Lapworth burst through the Ironbridge Gorge to flow south (Murton and Murton, 2012), creating a dividing line between Shropshire's northern/eastern plain and the southern/western uplands.

The Devensian glaciation is visible in the North Shropshire landscape as a thick deposit of glacial drift comprising glacial till (boulder clay), fluvio-glacial sands and gravels, and erratics (from Scotland and the Lake District), deposited across the region as glacial fans, eskers, and moraines; the drift varies in thickness but is at its deepest around Oswestry (around 46m thick; Cantrill, 1908:11). Within the drift, stranded blocks of ice melted in situ to create steep-sided kettle holes, accounting for many of the meres and mosses which occur in an arc across the region (Rowley, 1972; Reynolds, 1979) and resulting in 'an ice-moulded landscape of sand and gravel hillocks with clay lined hollows' (Toghill, 1990:171). Sticky blue-grey clay - 'true boulder clay' (Toghill, 1990:168) - is found at the base of core deposits, including those at the Berth (Fig. 5-5; see also Chapter 7). The effects of the last glaciation on the geology of North Shropshire has left a gently undulating lowland punctuated by small lakes, peaty wetlands and raised bogs with outcrops of solid geology (Toghill, 1990). These topographical 
zones were utilised during the Iron Age as fortifications and settlements - for example, as hillforts at Nesscliffe and Old Oswestry, and as multiple enclosure sites (e.g. Whimster, 1989).

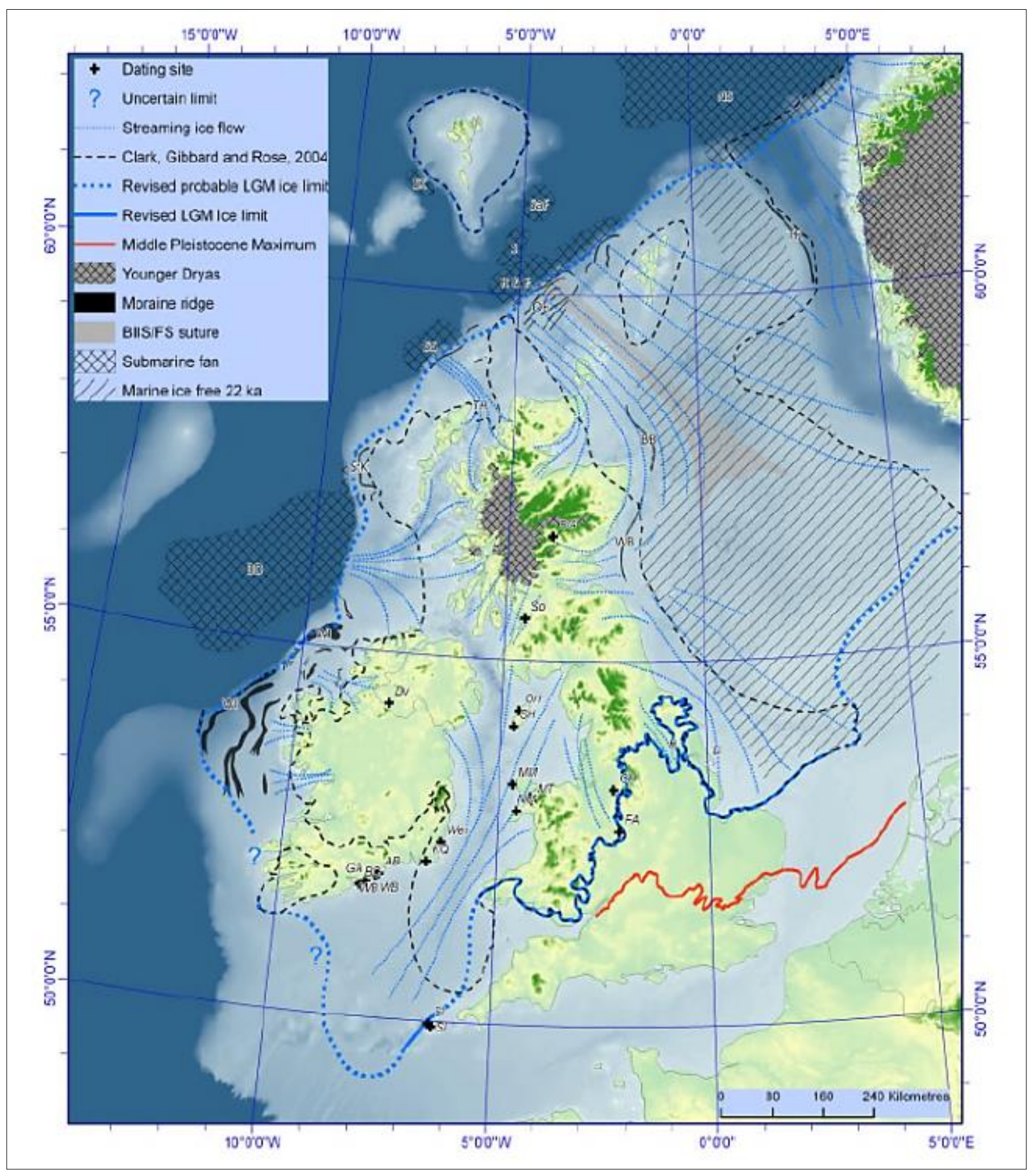

Fig. 5-3 Last Glacial Maximum (heavy blue line) (Chiverrell and Thomas, 2010:537) 


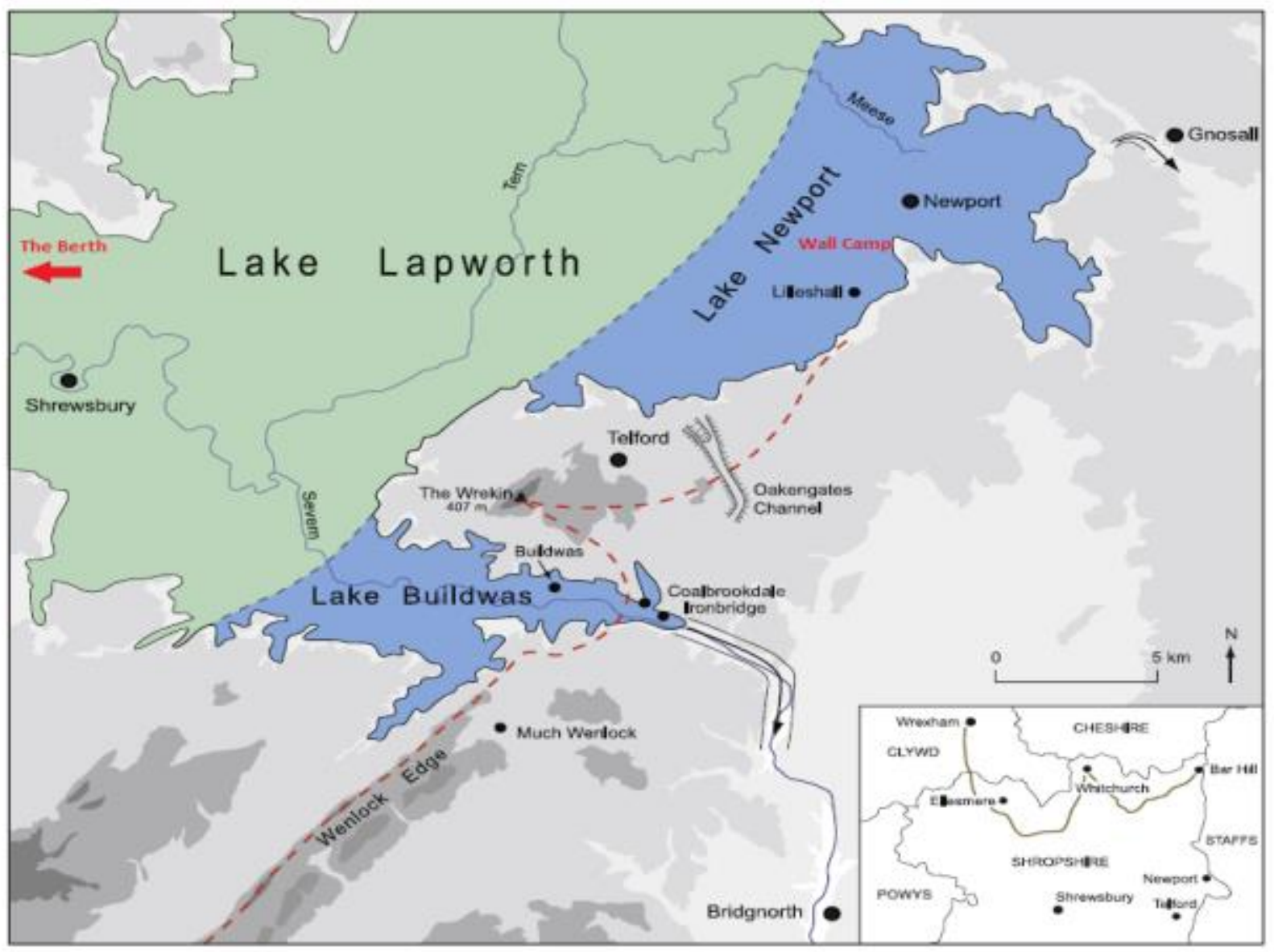

Fig. 5-4 Lakes Lapworth, Buildwas and Newport, and the line of the Ellesmere/Whitchurch moraine (Murton and Murton, 2012:127 Fig. 10.)

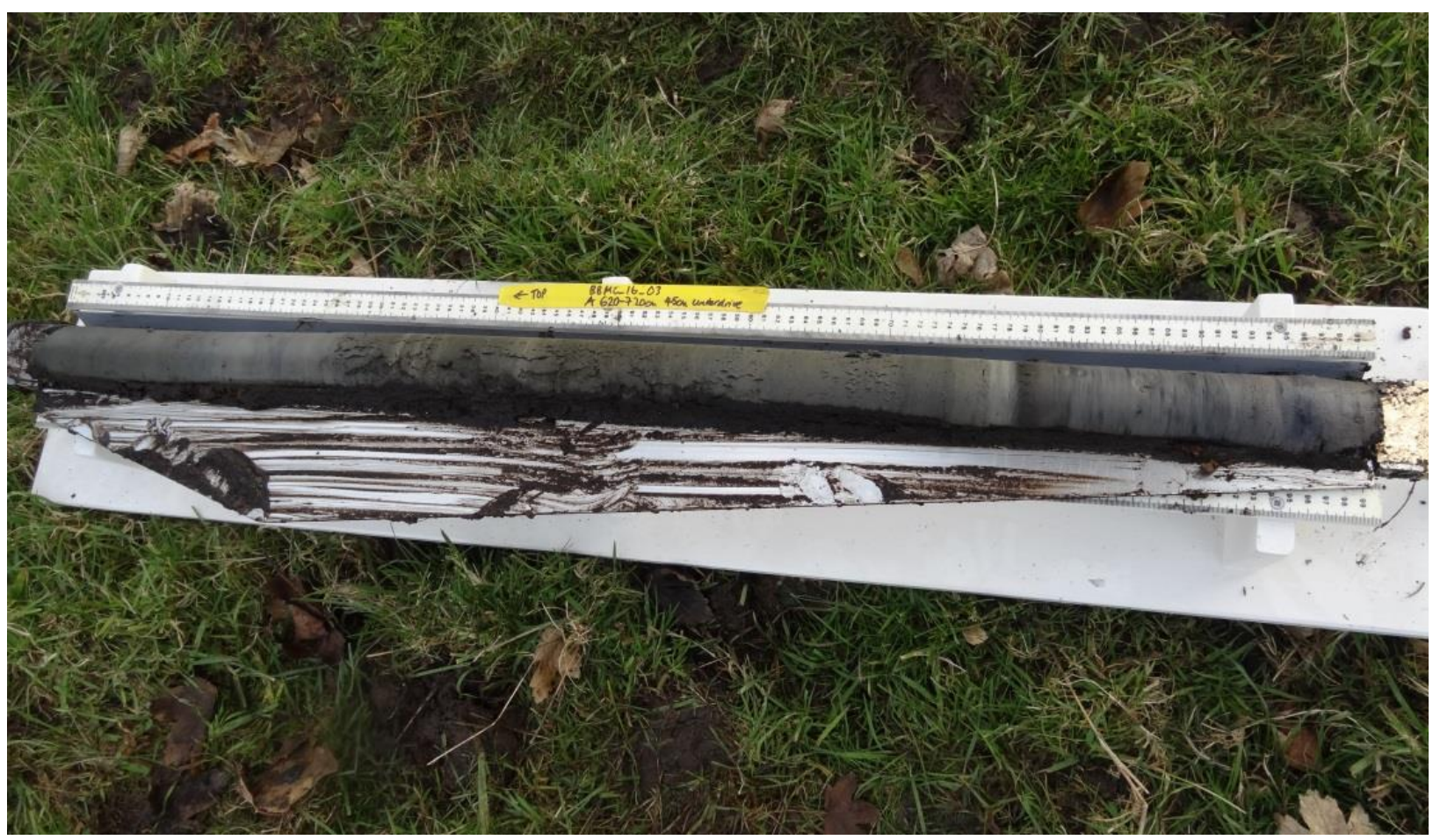

Fig. 5-5 Core section showing 'true boulder clay' (right) at 620-720cm (The Berth, Norton; November 2016) 


\subsubsection{Hydrology and soils}

The hydrology of the North Shropshire Plain, together with relevant place names and the marsh-fort and hillfort sites discussed in this chapter is shown in Fig. 5-6. This landscape of low-lying wetlands and farmland drains southwards into the River Severn via the Rivers Perry and Roden/Tern, and northwards towards the Irish Sea by the Rivers Weaver and Dee; the watershed roughly follows the Ellesmere/Whitchurch moraine. This is one of the primary lowlands which 'interrupt' Fox's Highland zone (1933).

Soils reflect the underlying drift geology (Fig. 5-7). In general terms, glacial sands and gravels occur around most of the Shropshire meres and are associated with Brown Earths, providing good arable land; poorly drained stagnogleys predominate on areas of boulder clay/till and are more associated with pasture (Ragg et al., 1984). The areas around the Berth, Whittington and Crose Mere lie at the interface of the leached brown and acid soils, making them more suitable for pasture. Along the valley mires of Baggy Moor (on the Upper Perry) and on the Weald Moors, the soil types are more varied, containing peat, alluvial and till-derived mineral soils and peaty loams (Crompton and Osmond, 1954; Burnham and Mackney, 1964:108; Ragg et al., 1984). Where the peat/peaty soils associated with kettle holes developed in conjunction with groundwater, the acidity is not high $(\mathrm{pH}$ 5.5 or higher), the organic remains reflect swampy woodland, and preservation of organic remains is good (Sinker, 1962) (see Chapter 8). 


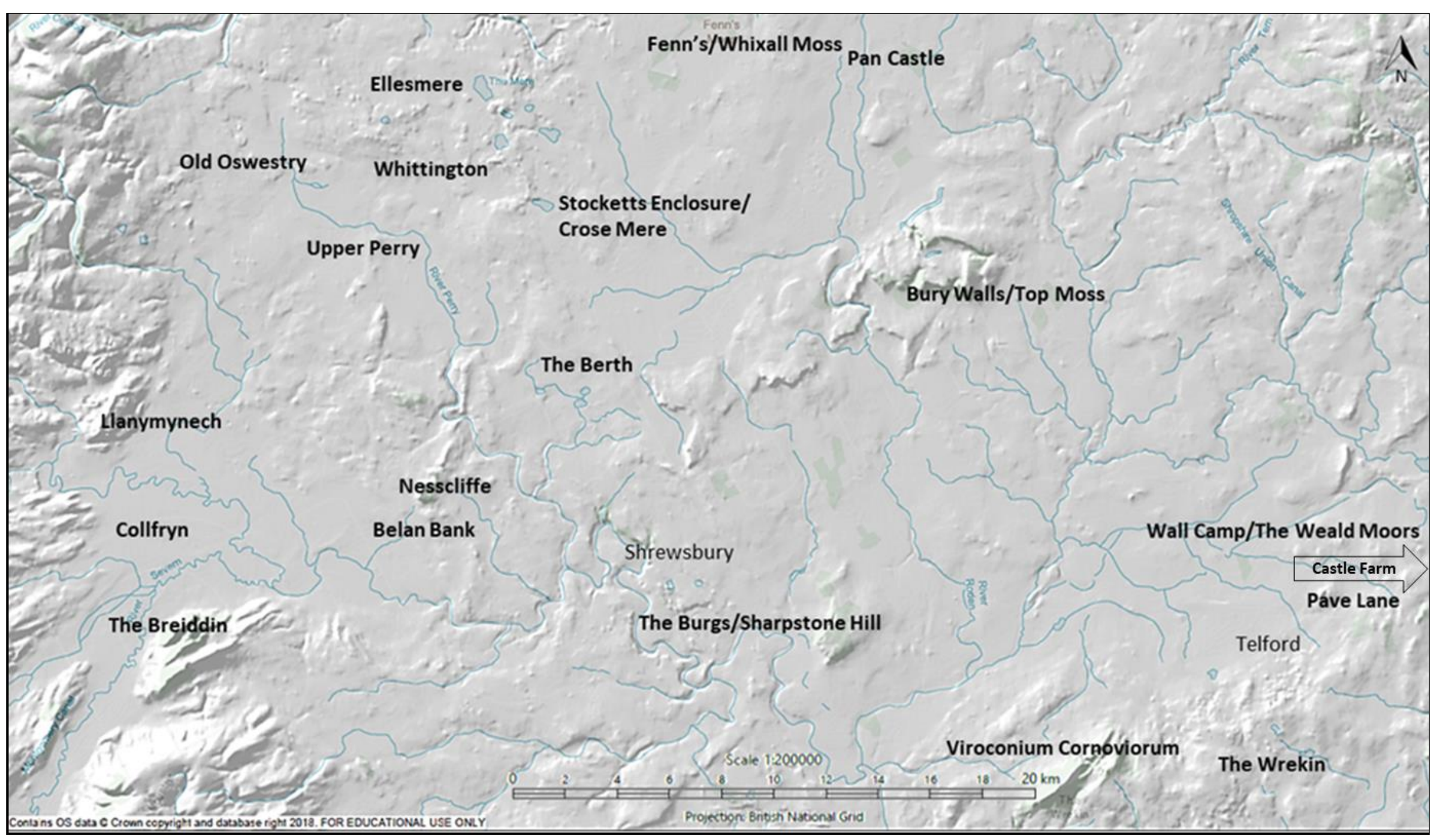

Fig. 5-6 North Shropshire: relief, hydrology together with sites mentioned in the text (Source: http://digimap.edina.ac.uk/roam/os: January 2018) 


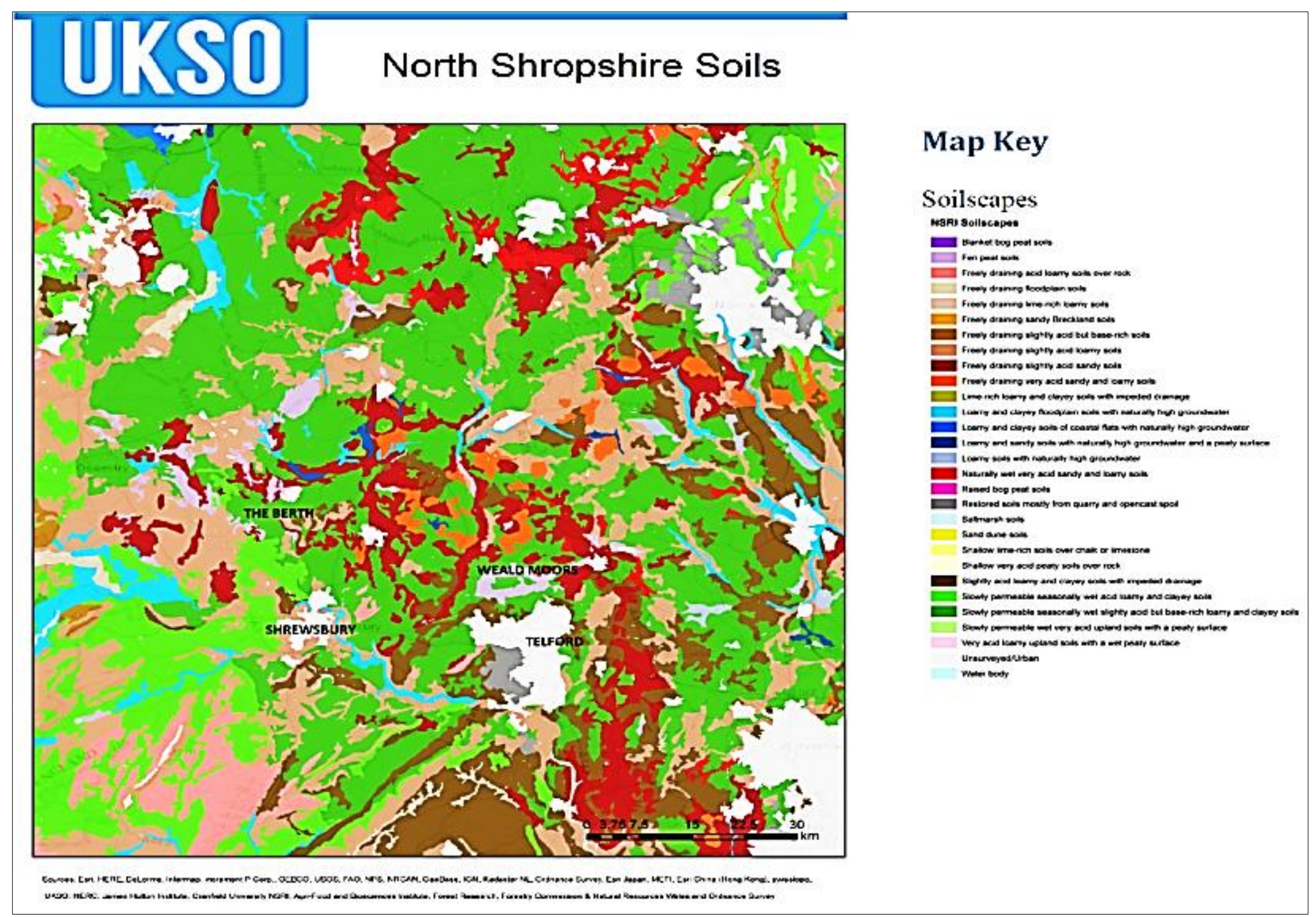

Fig. 5-7 North Shropshire - soils (Source: http://www.ukso.org/mapViewer.html Accessed July 2017) 


\subsubsection{Wetland development and peat formation}

Whereas wetlands as archaeological and symbolic waterscapes were discussed in Chapter 4, this section concentrates on wetlands as ecosystems and the practicalities of wetland formation, with specific reference to those in North Shropshire.

Wetlands arise 'when inundation by water produces soils dominated by anaerobic processes and forces the biota, particularly rooted plants, to exhibit adaptations to tolerate flooding' (Keddy, 2000:3). Differences in geology, topography, water sources, climate and timespan create a variety of wetland bioscapes - bogs, swamps, fens, and meres. Each is specifically constituted in terms of its biogenic (decayed vegetation and detritus) to minerogenic (sands and clays) sediments, acidity, topography and hydrology (Keddy, 2000). Prior to widespread drainage in the late- and post-medieval periods, it is estimated that as much as $\mathbf{2 0 - 2 5 \%}$ of the English landscape was lowland wetland (Cook and Williamson, 1999). They would be hard to avoid in prehistory, and each wetland type would require strategies for successful living.

Biogenic sediments form peat, which develops in conditions where moisture increases, evapotranspiration lessens, bioturbation is minimal, and the ground becomes waterlogged throughout the year rather than seasonally. The onset of peat formation during the Holocene is generally linked with the warmer and wetter Atlantic climatic period (Blytt Sernander Climatic Sequence) circa 7500-5500BP (e.g. Frolking et al., 2001). Peat depth relates to rates of accumulation. As a very broad generalisation, Keddy (2000) suggests a rate of around $1000 \mathrm{~mm}$ per 1,000 years, however this varies considerably with botanical composition (more luxuriant growth equals greater peat deposits (Durno, 1961; Frolking et al., 2001)), and topography (for example, accumulation is greater in lowlands than on hill slopes (Charman, 2002:112)). Peat growth can be reversed or halted by changes in hydrology and vegetation.

Peat deposits create stratified time-capsules through which climatic, topographical or anthropogenic change can be identified over lengthy chronologies (e.g. Brown, 1997; Keddy, 2000; Charman, 2002). The organic archive contained in an $8 \mathrm{~m}$ peat core from Littleton Bog, Ireland, enabled the palaeoenvironmental reconstruction of a complete Holocene vegetational sequence (Mitchell, 1965). Climatic variations (warmer/cooler periods) have been identified in studies of the Bog Surface Wetness (BSW) of raised bogs across Ireland and Scotland from circa 4400BP onwards (Barber et al., 1994; Barber et al., 2003). By tracing palaeochannels in peat deposits, it is possible to identify changes in water courses (Brown, 1997), bog extent (Caseldine and Gearey, 2005) and water table (e.g. Van de Noort et al., 2001; Cheetham, 2004), each of which may indicate past human activity. Alterations to hydrology are also caused by windthrows and landslips, and the damming activities of beavers also played a part in 
landscape and wetland development until their extinction in Britain in the fourteenth-century AD (Coles, 2006).

Archaeologically, the analysis of organic remains from the wetlands of the Somerset Levels enabled the reconstruction of the natural and anthropogenic landscape during the Neolithic, Bronze Age and Iron Age (e.g. Girling, 1985), including the living conditions at the lake villages of Glastonbury and Meare (e.g. Girling, 1982; Coles and Minnitt, 1995). Such analyses can indicate whether a site was open or hidden, whether it was easily accessible, and whether it formed part of an arable, pastoral or woodland landscape. The causes of peat initiation became more complex from the Neolithic onwards as the actions of people affected the natural hydrology, and numerous studies have linked soil erosion and paludification to anthropogenic woodland clearance (e.g. Moore, 1975; Charman, 2002; Fyfe et al., 2003). Anthropogenic impact can also be seen in drainage programmes and peat cutting (turbary) which was a recognised practice since Roman times (Van de Noort, 2004:166); both can result in peat loss or deflation - the peat simply dries out and blows away. The Holme Post on the Cambridgeshire Fens provides a dramatic example of peat loss (3.7m in 100 years) in a deliberately drained environment (Waltham, 2000) (Fig. 5-8). These processes are evident in the North Shropshire wetlands.

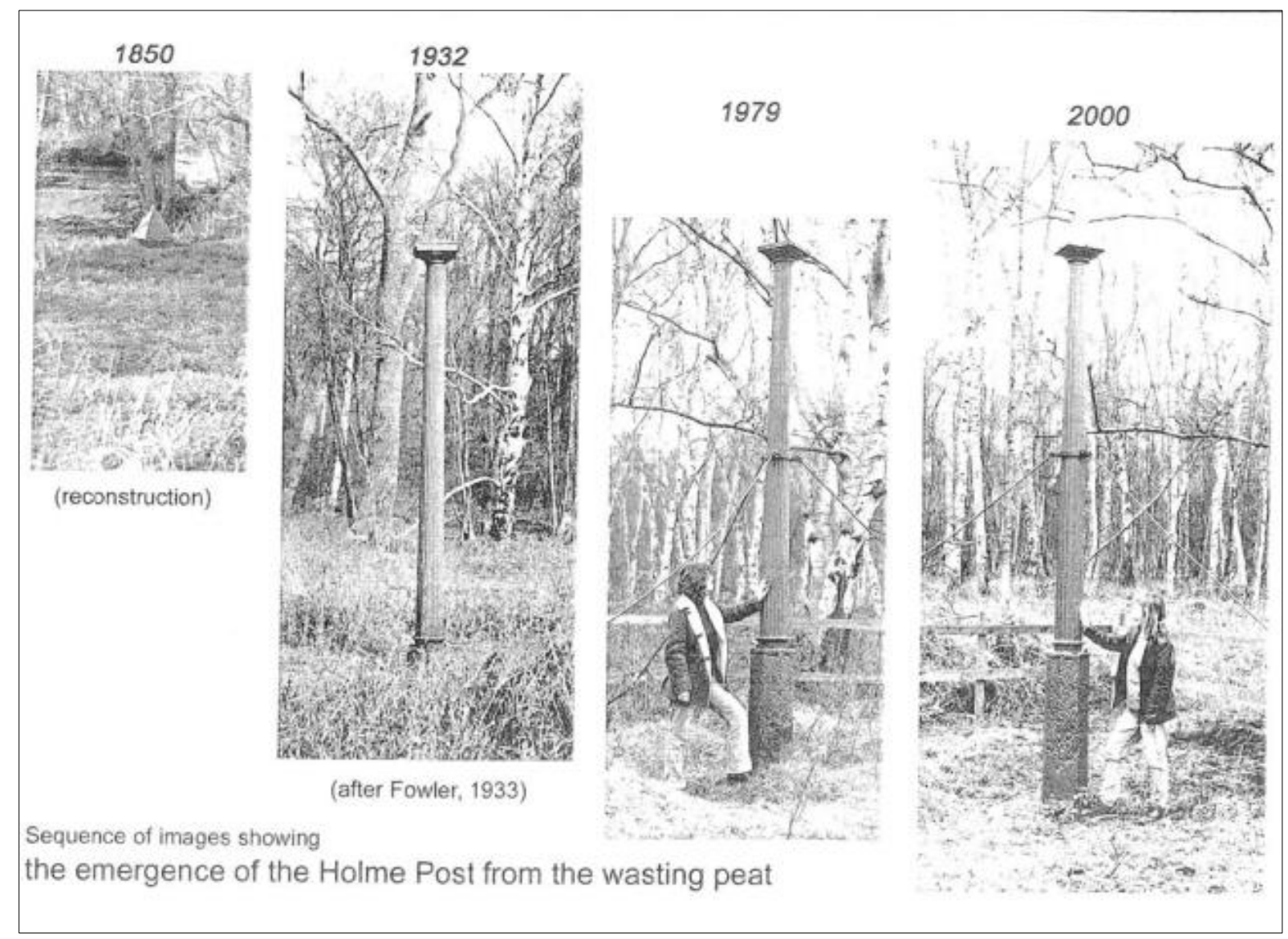

Fig. 5-8 The Holme Post - today and in the past (Waltham, 2000: Fig.2) 


\subsubsection{North Shropshire's wetlands and palaeoenvironmental record}

North Shropshire is recognised as one of the most important freshwater wetlands in Britain (Reynolds, 1979) with a range of ecosystems including raised bogs, meres and valley mires (Fig. 5-9). To the north of the region, Fenn's/Whixall Moss straddles the Shropshire/Clwyd border and forms the most southerly acid raised bog in Britain; it is a site of international ecological importance. The area around Ellesmere and the Mid-Shropshire wetlands comprises numerous small peat fringed lakes and ponds, of which Ellesmere, Fenemere and Berth Pool are amongst the largest. Extensive valley mires are found in the Weald Moors just north of Telford, and along the Upper Perry on Baggy and Tetchill Moors (Sinker, 1962). Most of the mosses and meres are emptied by evaporation and slow percolation through the drift rather than by streams, resulting in comparatively high salt and ion concentrations (Reynolds, 1979:109; Sinker, 1962:104). Many mires have become terrestrialised through hydroseral succession (the gradual drying out of open water and colonisation by dryland species), although a combination of topography and substrate means that not all of these wetlands achieved raised bog (ombrotrophic) conditions (Sinker, 1962).

Peat initiation began at Whattal and Fenn's/Whixall mosses during the Atlantic period (circa 75003750BP), with a secondary sequence associated with the onset of the wetter conditions during the SubAtlantic (Late Bronze Age, circa 3000BP) (Hardy, 1939). However, earlier dates were recovered from nearby Wem Moss (circa 9500BP) indicating that peat development was ongoing throughout the Holocene (Slater, 1972). Fenn's/Whixall Moss contains a stratified archive covering the last 7000 years, shown in levels of basal 'coal' deposits (lacustrine peat), black peat (fen and swamp peat), 'grey peat' (well-rotted bogmoss peat formed in a dry warm climate), and 'white peat' (well-rotted bogmoss peat formed in a cool wet climate), each phase denoting periods of vegetational change and climatic fluctuation (Reynolds, 1979:150). During her investigation of these raised bogs, Hardy identified a layer of pine stumps at a depth of $57 \mathrm{~cm}$ (Hardy, 1939). The trees were associated with a drier period in the bog's development (earlier Bronze Age), and were subsequently overcome when the bog became wetter during the Middle Bronze Age. The dating was originally suggested by the deposition of a bronze looped palstave on one of the pine stumps (Chitty, 1933) and although there has been debate over its accuracy (Turner, 1964), recent palaeoenvironmental studies confirm that the original dating was correct (Chambers et al., 1996, cited in Leah et al., 1998:16). Three bog bodies were also recovered from Fenn's/Whixall Moss during the nineteenth-century AD. Records refer to an Iron Age/Romano-British young man, partly covered by a leather apron and near a three-legged stool, a similarly dated woman, and an Early Bronze Age man. The bodies were recovered from near the modern England/Wales border, which runs through the moss (Fig. 5-10), and reburied in local churchyards (Turner and Penney, 1996; Natural England, 2014). 


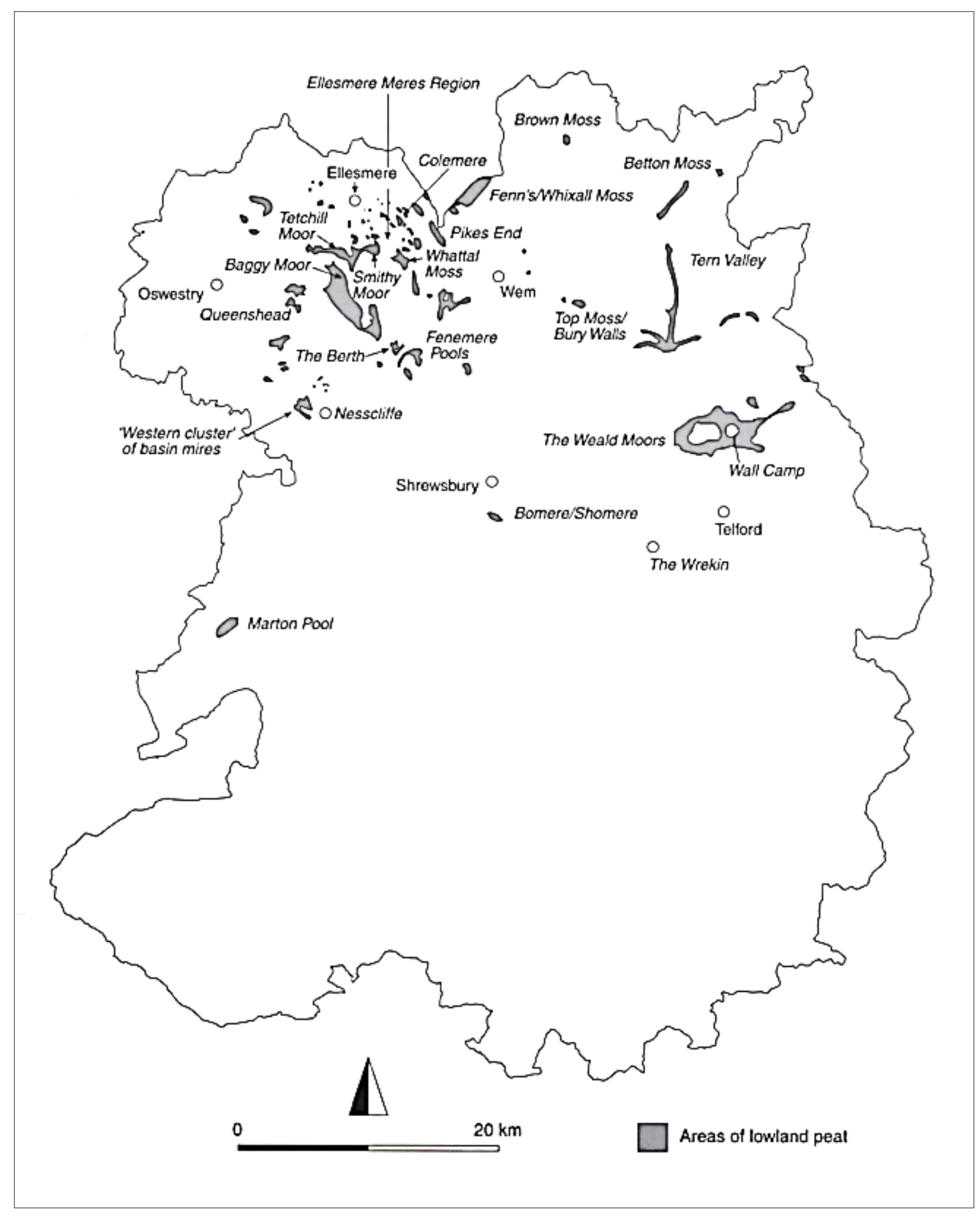

Fig. 5-9 North Shropshire's wetlands (Leah et al., 1998: Fig. 3) 


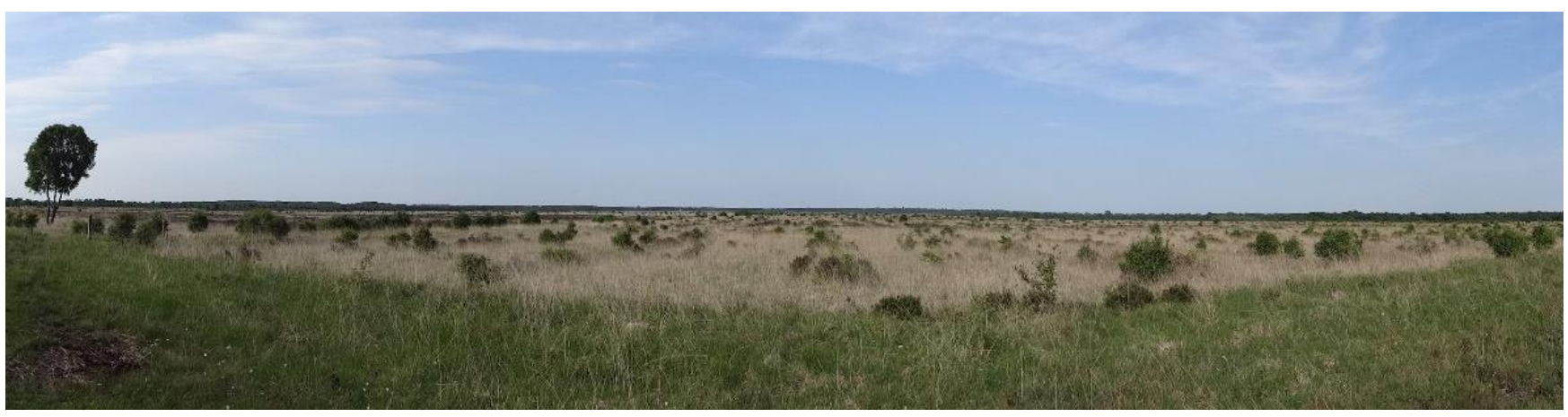

Fig. 5-10 Fenn's/Whixall Moss - the bog bodies were reputedly recovered from centre foreground (Norton, 2016)

In addition to the studies of Fenn's/Whixall Moss, a further three palynological analyses provide important palaeoenvironmental detail to aid landscape reconstruction. Top Moss is a relict raised mire situated beneath Bury Walls hillfort, and encompasses an environmental archive spanning the mid-late Neolithic/Late Iron Age (Leah et al., 1998:173-180). It provided evidence for a Middle Bronze Age decline in Tilia (lime), periods of woodland clearance and burning, and a period of increased wetness during the latter half of the Iron Age. Sporadic evidence for Secale (rye) from the Neolithic onwards was interpreted as a possible sign of early farming, although rye also occurs naturally as a weed (Behre, 1992). A similar profile was obtained from a study of the Mid-Shropshire meres (Twigger, 1988). Thirdly, a study at Crose Mere, immediately south of Fenn's/Whixall Moss and north of the Mid-Shropshire meres, produced one of the most extensive palaeoenvironmental records in north-west England (Beales, 1980). These palaeoenvironmental studies are discussed in detail in Chapter 8 , with specific reference to the ecology surrounding the Berth.

Twigger and Haslam (1991) and the North West Wetlands Survey (NWWS) for Shropshire and Staffordshire (Leah et al., 1998) provided a synthesis of these studies. The overall pattern reflects a marked increase in settlement and farming from the Late Bronze Age onwards. Widespread (anthropogenic) woodland clearance at the beginning of the first-millennium BC was followed by repeated episodes of clearance and regeneration as arable farming increased. This pattern is broadly synchronous with alluviation events and hydrological change seen throughout the Severn/Avon catchment at this time (Brown and Barber, 1985; Brown, 1988; 1990; 1991; 2008). This was identified initially by Shotton at Pilgrim Lock, Warwickshire, as a highly visible layer of organically poor, stoneless, 'buff-red silty clay', dated circa 650BC (1978b:28); similar deposits were identified in a study of the Leighton silts near Welshpool which produced a slightly earlier date (Taylor and Lewin, 1996). Numerous cropmarks interpreted as field systems and enclosures provide the corresponding archaeological evidence (Whimster, 1989). 
Many of North Shropshire's organic deposits show signs of peat deflation, with anthropogenic drainage (modern or historic) being the most likely cause (e.g. Wolfshead Moss, Leah et al., 1998:169). On the Weald Moors, peat cutting and drainage were recorded from the seventeenth-century AD onwards (Leah et al., 1998:79) and the peat reserves are heavily deflated (Fig. 5-11; husband (1.8m) provides scale!); this has affected the availability of the organic archive - see 5.3.2. Today, although the Moors are used primarily as agricultural land and the 'strines' (streams) are routinely managed, ${ }^{4}$ the low-lying peatland still floods extensively in winter. There are no records of peat cutting or drainage at the Berth.

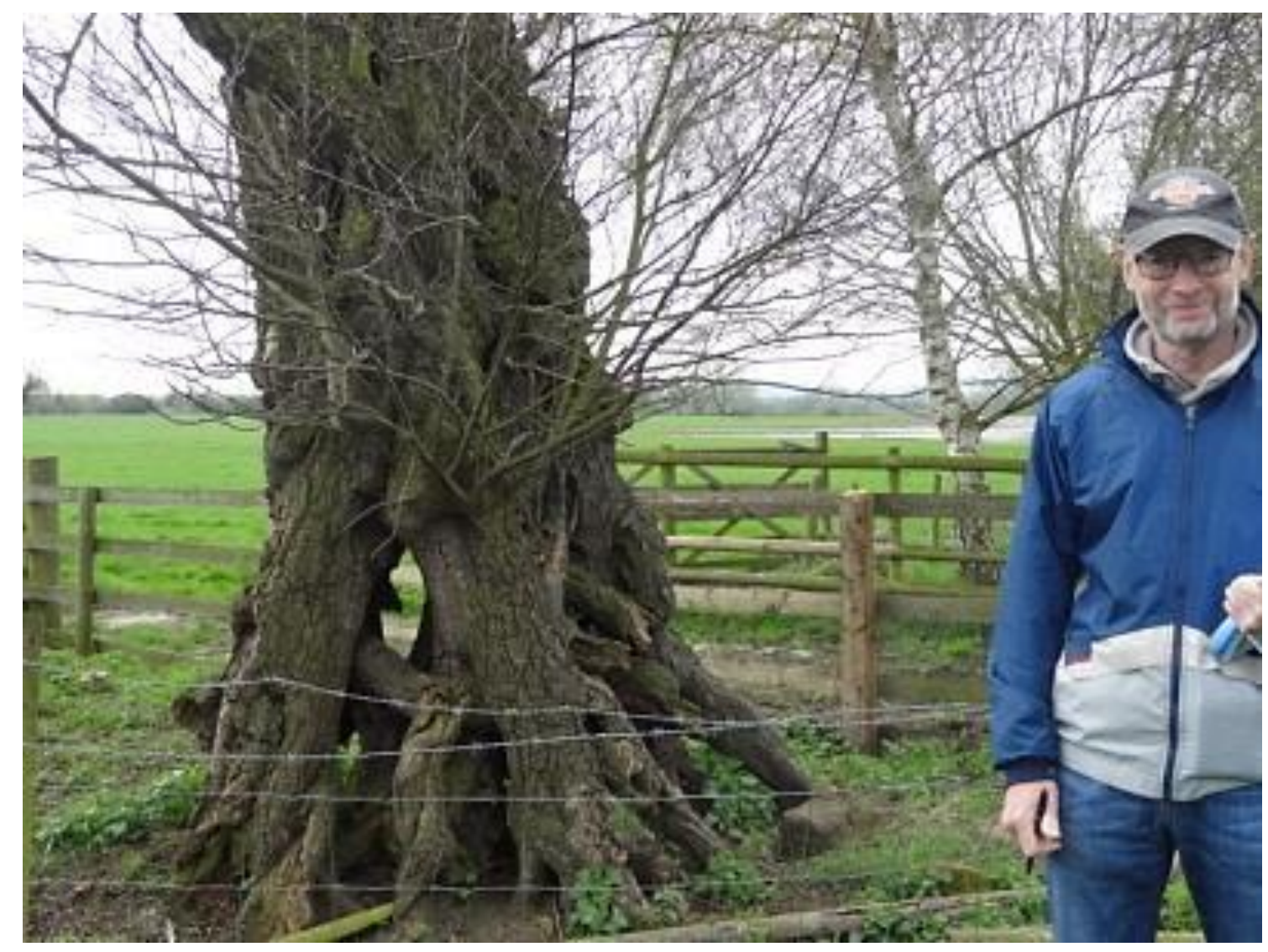

Fig. 5-11 Peat wastage at Wall Camp (Norton, 2014)

Whilst the Weald Moors have suffered peat loss, the Upper Perry valley mire maintains considerable peat deposits in spite of recent drainage and water management (Leah et al., 1998:48). Fluvial analysis of the Upper Perry yielded vegetational and alluviational sequences which indicated peat accumulation

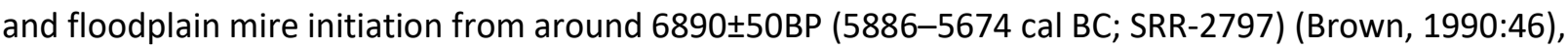
and the valley mire maintained its wet woodland cover until well into the Anglo-Saxon period (circa AD700). There is considerable prehistoric archaeological activity on the Upper Perry floodplain (for example, burnt mounds and metalwork deposition), suggesting that these activities took place in a wooded landscape (see Chapter 6).

\footnotetext{
${ }^{4}$ by the Strine Internal Drainage Board http://www.telford.gov.uk/info/1008/environment and conservation/672/strine internal drainage board sidb
} 


\subsection{North Shropshire - archaeological evidence}

'The power of environmental archaeology lies predominantly in its ability to identify and define patterns of changes over broad spatial and temporal scales, but incorporating and assessing these data alongside the cultural record remains problematic on both methodological and theoretical levels' (Chapman and Gearey, 2013).

Although Chapman and Gearey were referring to Neolithic studies on the Hatfield Moors, the same criticism can be applied elsewhere. This thesis aims to overcome the problem by linking North Shropshire's environmental and archaeological narrative and in doing so, provide a cultural and landscape setting for the development of North Shropshire's marsh-forts. This requires an understanding of the regional archaeological picture.

Before the 1960s, interpreting Shropshire's archaeology had been the domain of Victorian antiquarians and the local historian Lily Chitty who actively promoted and documented the prehistory of Shropshire and the Welsh Marches until her death in 1979. Her archive (Chitty, 1992) is extensive and valuable in itself but has the added benefit of capturing contemporary evidence, for example, documenting artefacts which have subsequently been lost (Chitty, 1953). She was, inevitably, a product of her time, and her earlier work drew heavily on Hawkes' and Fox's hypotheses (see Chapter 2) in portraying prehistoric Shropshire as an impenetrable, densely forested landscape subject to Celtic invasion (Chitty, 1937). Nevertheless, 'An Introduction to the Archaeology of Shropshire' (Chitty, 1956) provides a solid foundation for regional study.

Excavation during the 1940/1950s concentrated on some of the region's more spectacular hillforts (e.g. Kenyon, 1942; 1953; Varley, 1948), and this focus continued throughout the 1960/1970s (Gelling, 1965; Stanford, 1967). Stanford was among the first to understand that Shropshire (and the Welsh Marches) evinced a broad chronology; the multi-period settlement and funerary complexes at Bromfield near Ludlow and Sharpstone Hill near Shrewsbury provide examples (Stanford et al., 1982; Barker et al., 1991; White and Wigley, 2010). Although Stanford's work is considered to be the 'proper point of departure for any consideration of prehistoric Shropshire' (Carver, 1991:1), two publications have recently synthesised the region's prehistory (Garwood, 2007b; Hurst, 2017), illustrating contrasting patterns of settlement and landuse and demonstrating the inaccuracy of Pevsner's conclusion of Shropshire as a thinly populated land covered only by trackways. The impact of the Roman conquest can be seen in the extent of roads, forts and marching camps, whilst the civitas of Viroconium Cornoviorum (Wroxeter) provided a case-study for the rise and fall of one of Britain's most important Roman conurbations (e.g. White and Barker, 2002). 
In terms of lowland fortifications, some were recognised by antiquarians as being more than simple enclosures and different from their hillfort counterparts (e.g. Downman, 1906), although addressing the archaeology of lowland Shropshire had to wait until the development of regional agendas and the growing emphasis on landscape archaeology in the 1990s (Carver, 1991; Haselgrove, 2001b). It is impossible to contextualise the lowland fortifications without an understanding of the wider archaeological text. Therefore, this section will summarise the trajectory of Shropshire's later prehistory, beginning with a hillforts and settlement and following its path towards Romanisation.

\subsubsection{Settlement and occupation - hillforts}

The later prehistory of Welsh Marches and Shropshire is dominated by its hillforts, which occupy outcrops and higher ground in a band from the Cotswold Ridge to the Clwydian Range in North Wales. The reasons behind such a rash of construction are far from clear. They can be roughly divided into those which occupy exposed sites and were possibly used seasonally (for example, Titterstone Clee and the Wrekin), large forts which occupy outcrops in either upland or lowland settings and more likely to be permanently settled (Old Oswestry and Croft Ambrey), and lowland fortifications, herein referred to as marsh-forts (Wall Camp and The Berth). White and Barker considered that lowland fortifications were created for the exploitation of the wetland resources (2002:36); although this thesis does not disagree, such a broad generalisation requires refinement. Each topographical location could encompass other functions, such as a refuge in times of trouble or a centre for ceremonial or religious functions. Some, for example Earl's Hill, positioned on a hilltop south-west of Shrewsbury, suggest hillfort 'twinning' (Alcock, 1965; White, 2001:36; Dorling et al., 2017:80), a concept also suggested for some marsh-forts in East Anglia and discussed in Chapter 4.

Hillforts in the Welsh Marches reflect the overall chronological and developmental pattern established elsewhere in England and Wales (see Chapter 2) (Cunliffe, 2005). Several palisaded hilltops, such as the Breiddin, date from the Late Bronze Age, followed in the sixth-century BC by univallate fortifications, such as Caynham Camp. During the fifth- to fourth-centuries BC, many were subsequently abandoned, whilst others, such as Burrow Hill and Old Oswestry, became elaborated (multivallated). Cunliffe considers that the pattern of hillfort elaboration in the Welsh Marches contains a north-south divide, with the region's southern hillforts closely paralleling the construction techniques and material culture seen in Wessex (Cunliffe, 2005:400). However, the architecture of some hillforts on the North Shropshire Plain is highly developed, suggesting that Cunliffe's conclusion is too simplistic; Old Oswestry is the prime example. Each stage in this chronology reflects a change in the contemporary social structure, and the social circumstances which prompted hillfort construction in the Welsh Marches have been widely interpreted. Suggestions range from community tension with separate chiefdoms vying for power at one end of the scale, to community cohesion seen through gang working at the other (e.g. 
White and Barker, 2002:35; Wigley, 2017a; 2017b). The building of hillforts (and marsh-forts) required an extensive labour force, large scale organisation, and significant quantities of timber; each project would have been a serious undertaking (although not necessarily a lengthy one, Van de Noort et al., 2007) with evidence pointing more towards conspicuous consumption/swagger than the mark of a warlike society (White and Barker, 2002:38). However, the phenomenon had a life and by the Late Iron Age, most hillforts had been either abandoned or were only occupied episodically; for example, palaeoentomological evidence from Buckbean Pond on the summit of the Breiddin suggests seasonal occupation was seasonal (Musson et al., 1977; Buckland et al., 2001), and raises the possibility of a close relationship with the Collfryn enclosure/farmstead nearby.

Moving specifically to North Shropshire, the range of hillforts, marsh-forts and enclosures suggests that this wetland plain was well populated in later prehistory. Three large and complex hillforts are located on lowland outcrops overlooking the mosses and wetlands - Old Oswestry, Bury Walls and Nesscliffe. These sites lie within a $15 \mathrm{~km}$ radius of the Berth and are likely to have been contemporary.

Old Oswestry is a spectacular and impressive hillfort which crowns a low glacial mound, with panoramic views across the North Shropshire Plain and into Wales. The only recorded excavation was by Varley before World War 2, with the detail later summarised by Hughes (Varley, 1948; Hughes, 1994). The fort began as a univallate, palisaded enclosure in the Late Bronze Age, developing, by the Middle Iron Age, into a complex multivallate enclosure enclosing 8.4ha with two opposing entrances - a simple eastern entrance, and a highly complex, not to say flashy, western entrance facing the Welsh Hills (Smith, 2010). The large pits immediately outside the west entrance have been never been adequately explained, with suggestions including water tanks, storage bays, quarry pits and livestock enclosures (White and Barker, 2002:80). The amount of labour needed for such a construction speaks of its importance to those who occupied the area, which in turn was possibly connected to its location on a strategic routeway between the Rivers Dee and Severn. Occupational evidence in later prehistory is limited, but includes ceramics and Cheshire briquetage (pottery containers for salt, also known as Very Coarse Pottery or VCP), crucibles and a few Roman artefacts, and Old Oswestry has been put forward as one of a few sites where occupation resumed after the end of the Roman era (Rowley, 1972:40). At only $3 \mathrm{~km}$ from the Iron Age settlement/defences at Whittington Castle (see below), it offers another example of possible hillfort 'twinning'.

$20 \mathrm{~km}$ from Old Oswestry, Bury Walls is a large (10ha), partially multivallate hillfort occupying the top of a sandstone outcrop with cliffs on three sides, overlooking the North Shropshire Plain and the relict mire of Top Moss (see 5.1.3 above). The evidence suggests that this was the site of an extensive settlement, and benefited from an internal spring. The fort was re-used during the later Roman period, as indicated 
by two large rectangular buildings, late Roman pottery and Valentinian coinage (AD364-78). A possible late Romano-Celtic temple (originally thought to be medieval) was found during an excavation in 1930 (Morris, 1932), and a recent geophysical investigation revealed several previously unknown features (for example, a cross-dyke, internal dwellings and roads) (Murdie et al., 2003).

Nesscliffe is a medium sized (2.8ha) multivallate hillfort occupying a sandstone outcrop with commanding views across North Shropshire. The enclosed area is surrounded by rubble ramparts and is separated into two distinct sections. The inner area appears to be the principal focus for settlement, with finds indicating Romano-British occupation from the late second- to fourth-century AD. The Nesscliffe Spoons (PAS: HESH-9A4B83; Fig. 5-12) were found in lowland bog near to the hillfort. These copper-alloy, palm-shaped, nested spoons occur in pairs and are a rare type of Iron Age ritual object.

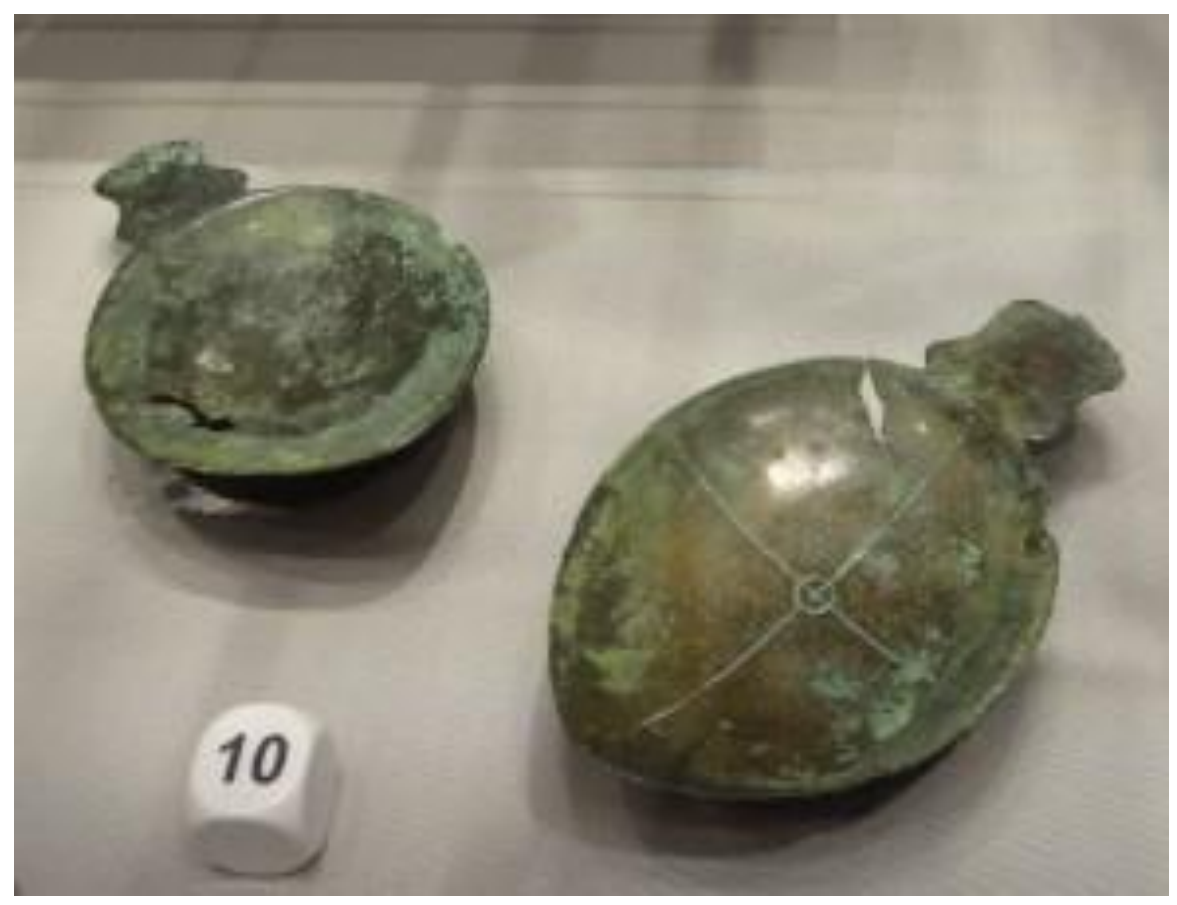

Fig. 5-12 The Nesscliffe Spoons - Shrewsbury Museum (Norton, 2014)

The excavational evidence for all three sites is poor given their interest and importance, but they share more helpful commonalities. Each occupies a low outcrop overlooking the wetland plain. They appear to have been contemporary during the Middle/Late Iron Age, and they are intervisible (Matthews, 2006). Each has produced evidence which contributes to the growing picture of hillfort re-use in later Roman times (Reid and Marriott, 2010, cited in Smith, 2010:65) with Bury Walls leaning towards religious and Nesscliffe more towards domestic use, not that these purposes are mutually exclusive (e.g. Buteux and Hughes, 1995). Both Bury Walls and Old Oswestry have been suggested as an 'enclosed oppida', a scarce category of proto-urban settlement this far north (Murdie et al., 2003). 
Additionally in the North Shropshire area, the two paired, smaller hillfort/camps of Haughmond Hill and Ebury Hillfort share one of the outcrops which overlook the plain east of Shrewsbury. A small investigation at Ebury produced evidence of two small pits and some Iron Age pottery (Stanford, 1977). The oval hillfort at Bomere Heath/ Pimhill (HER 02418) occupies a lower outcrop closer to the Berth; no further evidence is available.

This high level summary of hillforts in northern Shropshire is intended to provide a contemporary baseline for marsh-fort studies, and indicates that, whatever position marsh-forts occupied in the Iron Age settlement hierarchy, they were far from alone.

\subsubsection{Cropmarks and enclosure}

With the notable exceptions of the Breiddin hillfort (Musson et al., 1991) and the large defended farmstead at Collfryn (Britnell et al., 1989) (both sites just over the border in Powys), large scale excavation of hillforts declined after the 1970s. However, there was a corresponding increase in smaller scale rescue and developer-funded excavations and less invasive forms of archaeological prospection. These included aerial photography (Whimster, 1989; Watson and Musson, 1993; Watson, 2001) and geophysical prospection (in particular for the Wroxeter Hinterland Project - see 5.2.4 below).

Aerial photography identified literally hundreds of previously unknown cropmarks - ring-ditches, pit alignments, linear boundaries and enclosures - which provided evidence for the complexity and extent of prehistoric settlement especially in the Shropshire lowlands; few have been subject to excavation or rigorous dating. Ring-ditch cropmarks are usually interpreted as the remnants of Bronze Age round barrows, although some, for instance at Bromfield and Meole Brace/Sharpstone Hill, evince a deeper chronology. Particular concentrations are found in the Upper Severn and Upper Teme valleys (Watson, 1991). It has been suggested that they may have served as communal foci and demonstrate evidence for territorial land division at a time when settlement was dispersed and ephemeral (Buteux and Hughes, 1995). In some instances they appear to have retained their importance over time and support an argument for social continuity; at Sharpstone Hill, one barrow appeared to be used as a pivot to orientate later field boundaries (Carver, 1991:2). The Bronze Age cemetery near to the Berth is discussed in Chapter 6.

The barrow tradition had ceased by the late second-millennium BC (Garwood, 2007a; Wigley, 2017a). Instead, and from the Late Bronze Age onwards, linear cropmarks - in the form of cross-ridged dykes at higher elevation (for example, on Long Mynd) and pit alignments at lower elevation (for example, along the Upper Severn valley) - provide evidence for land division and control on a wider scale. These increasingly bounded landscapes also demonstrate associations and mutual exclusions. For example, pit alignments correlate positively with barrow/ring-ditch concentrations (in the Upper Severn valley) and 
both suggest territorial control of good land or common pasture (Wigley, 2002). However, they are peripheral to wetlands and are negatively correlated with burnt mounds (for example, on the Weald Moors and Baggy Moor) (Wigley, 2017a, Figs 7.1 and 7.2).

The enclosures, settlements, boundary markers and field systems developing evidenced by the aerial photography reflect the development of an arable economy from the Bronze Age onwards. Enclosures make up the largest recorded category of cropmarks and can be divided on morphological grounds into curvilinear/rectilinear/hybrid, univallate or bivallate (Whimster, 1989). Investigations are few (less than $5 \%$ as at year 2000, Buteux et al., 2000:73) and dating is imprecise. Those that have been investigated are confirmed as Iron Age and/or Romano-British (Whimster, 1989), with occasional evidence of earlier Neolithic and Bronze Age occupation (for example at the extensive roadside settlement of Meole Brace; Hughes and Woodward, 1995); however, there is no straightforward morphological correlation between construction style and chronology (White and van Leusen, 1995). Whilst cropmarks frequently represent farmsteads, perhaps for single families or kinship groups, they may also represent functional structures such as stockyards and corrals. Significant clusters are located around Roman military camps, for example, at Leintwardine (Whimster, 1989); however, these areas were actively targeted for aerial reconnaissance between 1940 and 1970, possibly skewing the distribution (Wigley, 2002:221).

Enclosures frequently correlate with boundary and field systems (Wigley, 2017b). The excavated examples at Sharpstone Hill show an intensively exploited landscape of open settlements combined with field systems of Iron Age date (Barker et al., 1991; Buteux and Hughes, 1995:160). Similarly, excavation at Duncote Farm as part of the A5/Shrewsbury By-pass project revealed extensive Iron Age field systems which were then regularised/Romanised during the second-century AD (White and Barker, 2002:66). Several enclosure sites are found near the Berth.

The nomenclature for hillforts and enclosures in Shropshire is as problematic as elsewhere, with some cropmarks referred to as 'small hillforts' (Wigley, 2007) and others labelled 'farmsteads'. In 'A Strategy for Lowland Shropshire', Carver (1991) summarised Shropshire's enclosures as occupying

'a spectrum, from the simple enclosure of Site A, and the defended Site E (at Sharpstone Hill), through the hillfort-like enclosure and outworks at Wall Camp with its round house and four posters, to the Berth, Old Oswestry, Bury Walls and the rocky Wrekin, which suggest a chronological, functional or social hierarchy of a most complex kind.' (Carver, 1991:4)

\subsubsection{The Cornovii - social structure and identity}

The first mention of the tribal cantons of first-century BC Britain was by Ptolemy (e.g. Jones and Mattingly 1990), who reported the Cornovii as occupying an area covered by the modern counties of 
Shropshire, Staffordshire, and Cheshire (Millett, 1992; White and Barker, 2002); however, the name is ambiguous and is also applied to tribes in northern Scotland and in Cornwall. Their societal organisation has been interpreted variously as a pyramidical Wessex-type structure (Stanford, 1972b; Webster, 1991), or 'decentralized and egalitarian', in which the effect of Roman rule was 'stimulating to a nascent elite' (Millett, 1992: Table 4.3). Such varied views reflect just how little is known about the people indigenous to the north-west Midlands, whether they (or other tribes) had any degree of longevity, or indeed, whether the tribal concept existed primarily as a Roman administrative imposition (Moore, 2006:80; 2011; Wigley, 2001). Less is known about the Cornovii than many other tribes because the material record is poor. Their society was largely aceramic, did not use coinage and finds of luxury goods and precious metals are scarce. Consequently, they have been characterised as an underdeveloped and disparate people (Richmond, 1963; Millett, 1992); however, this may understate the case.

Firstly, as seen from cropmark evidence, settlement was plentiful and the hillfort evidence indicates a society organised enough to create large landscape structures, at least during the period of hillfort development in the Early/Middle Iron Age. Although the nature of that organisation is not clear, constructing a dense concentration of highly complex fortifications across a geographically wide area required either the co-operation of a sophisticated community, or coercion associated with considerable centralisation.

Secondly, the Cornovii could command a wealth of natural resources. Large areas of pastoral and arable land lying between the Welsh Hills and the Midlands Plain, salt, mineral ores (copper, lead, silver), and a thriving population all came within their territorial boundaries and could be trafficked via extensive trade routes along the Dee and Severn catchments and from the entrepôt at Meols on the Wirral (Matthews, 1999). The extent of the pastoral economy is apparent in the processing of cattle carcasses at Wroxeter (White and Barker, 2002:141). By the Iron Age, salt was used extensively in food preservation and textile production and was transported from centres around Middlewich in briquetage containers. The Cheshire salt trade was extensive and its local importance shows in the quantity of VCP sherds found throughout the northern part of the Severn valley, Wales and as far away as the North Cotswolds and the Trent Valley (Morris, 1985; Matthews, 1999). Large quantities have been recovered from the hillforts and marsh-forts of the Welsh Marches and the North Shropshire Plain, including the Berth (Morris and Gelling, 1991), Wall Camp (Morris, 1991), Collfryn (Morris, 1985) and Old Oswestry (Morris, 1994). Copper, lime, iron ore and silver were mined at Llanymynech and Snailbeach and presumably transported along the road which tracked south of Shrewsbury - Margary 64 (Malim and Hayes, 2010). 
Much is made of the Cornovi's lack of ceramics (e.g. Richmond, 1963) however this is to ignore other complex societies which were aceramic both in the British Isles, such as Iron Age Ireland (e.g. Henderson, 2007) and globally, for example, New Zealand Māori (e.g. Davidson, 1987). Ceramic pots are replaceable at an everyday level by wooden vessels such as those recovered from the Breiddin (Britnell and Earwood, 1991), and for more ceremonial purposes they could be replaced with the equivalent of the copper-alloy and leather cup found at Beeston Castle, Cheshire (Ellis, 1993).

Iron Age wealth may have been valued in terms of, for example, livestock, slaves or furs (Bradley, 1987) which leave little trace in the archaeological record (e.g. Jones, 1984). Roman luxury goods were not plentiful in the Wroxeter archive, but this may simply mean that such goods were not as valued as more perishable items (Gaffney et al., 2007). The Cornovii may have maintained their cultural norms by choosing selectively from the Roman catalogue; even the defences of Wroxeter's post-legionary earthwork ramparts are more reminiscent of hillforts than normal Roman defences (White and Barker, 2002). Potentially, Cornovian society was more sophisticated than the material record suggests and Shropshire's prehistory indicates a well-populated, organized, controlled, agricultural landscape from at least the Late Bronze Age onwards. The body of evidence may suggest that, from within a stratified society, an elite, perhaps made up of dominant local families, chose which new opportunities and material goods to adopt and which existing cultural practices to keep. Assuming that the Cornovii were the tribal unit which occupied and controlled North Shropshire, they potentially built marsh-forts.

\subsubsection{Romanisation}

Drawing on this body of archaeological evidence, the societal landscape which greeted the Romans when they arrived in North Shropshire circa AD40 was well-organised and well-populated. However, although military suppression must have been traumatic and defences were reinforced at several hillforts (for example, the Wrekin (Kenyon, 1942) and Titterstone Clee (White et al., 2013)), indications of conflict are few and uncertain, and the Roman invasion of this area did not appear to result in wholesale slaughter (Millett, 1992; White and Barker, 2002:32). The most regularly cited evidence for conflict was the burning of the Wrekin circa AD90 (Stanford et al., 1984; Webster, 1991; Millett, 1992); however, the radiocarbon dating for this action is questionable, and the two Roman javelin heads found on site are not guaranteed to be directly associated with battle (Wigley, 2017a).

The Roman legionary fort at Wroxeter was founded circa AD60. Located at the northern terminus of Watling Street, it was strategically placed at a crossing point over the River Severn to control the northwestern Roman frontier. Thereafter, the site developed as the civitas Viroconium Cornoviorum, the fourth largest urban centre in Roman Britain, with a thriving economy and many public buildings, markets and residences (Webster, 1988). 
Woxeter has been subject to antiquarian interest and more recent excavational research (e.g. Atkinson, 1942; Barker, 1973; Webster, 1988). There was a conundrum however. In spite of its size and importance, there appeared to be a stark contrast between the highly urbanised Roman civitas and its rural surroundings. This was addressed by the Wroxeter Hinterland Project (WHP) which collated the results of geophysical prospection, aerial photography, field walking and excavation 'to produce $a$ georeferenced graphical database of Wroxeter and its direct environs' (Gaffney and van Leusen, 1995a:299), with the aim of unpicking this apparently discontinuous relationship (Gaffney and White 2007; White et al., 2013). The results were revelatory, providing a multi-layered understanding of the functioning relationship between civitas and surroundings, and scotching the notion that Viroconium Cornoviorum stood in splendid isolation. Although the landscape lacked the villa complexes seen elsewhere in Roman Britain, enclosures were plentiful and an additional 187 sites were identified in the Upper Severn valley (White and Barker, 2002; Gaffney and White, 2007), reflecting the agricultural intensification which surrounded the urban centre, although how many of these preceded the Roman invasion is not known. Perhaps due to their earlier abandonment, the region's many hillforts were not specific targets for Romanisation, although Nesscliffe, Bury Walls and Old Oswestry on the North Shropshire Plain all carry evidence of Roman re-use (see above).

Viroconium remains one of the few sites in Britain with direct continuity from the late Romano-British to early medieval periods, providing rare evidence for post-Roman occupation. Analysis of late occupation animal bone assemblages indicated that the local pastoral economy and gastronomy were largely unchanged by the demise of the Western Roman Empire, and that initially at least, long distance trade networks were maintained; the presence of the bone of a Barbary ape provides an example (Hammon, 2011). The city's resurgence after the Roman withdrawal around AD400 has been connected with its possible use as a power base for the kings of Powys or by the emerging Christian church (White and Wigley, 2010). It has also been postulated as the possible site of Pengwern, the residence of Cynddylan, Prince of Powys (see Chapter 2 and Appendix 3); however, this claim has been made for several sites in Shropshire and North Wales, including the Berth (Rowley, 1972:43; Newman and Pevsner, 2006:136). Archaeological evidence to support the claim that the Berth was a late-Roman/Anglo-Saxon fortress is scant, the only evidence being several large post-holes which Gelling interpreted as post-Roman (Gelling, 1962/5); two sherds of Severn Valley Ware also recovered by Gelling date from AD50 onwards. The Roman evidence found at the Berth is discussed in Chapter 6 and Appendix 2.

\subsection{North Shropshire's marsh-forts (Fig. 5-13)}

The above summary of North Shropshire's archaeological and palaeoenvironmental evidence showcases the rich heritage available for study. The remainder of this chapter presents the spatial and temporal evidence from each of the North Shropshire marsh-forts identified through the survey process described 
in Chapter 4. Wall Camp, Stocketts Enclosure and Whittington Castle are described using geological and LiDAR mapping, overlain with evidence collated from HER/PAS records; Pave Lane, Castle Farm, Bomere Wood and Pan Castle (less obvious candidates) are discussed in less detail.

The Berth is the prime candidate for inclusion within the marsh-fort category. Whilst the results of a macro- and micro-scale landscape investigation are presented in Chapters 6-8 and Appendices 2-7, a brief summary is included here to enable comparison with the Sutton Common criteria. The results for all North Shropshire's marsh-forts are summarised in Table 5.1.

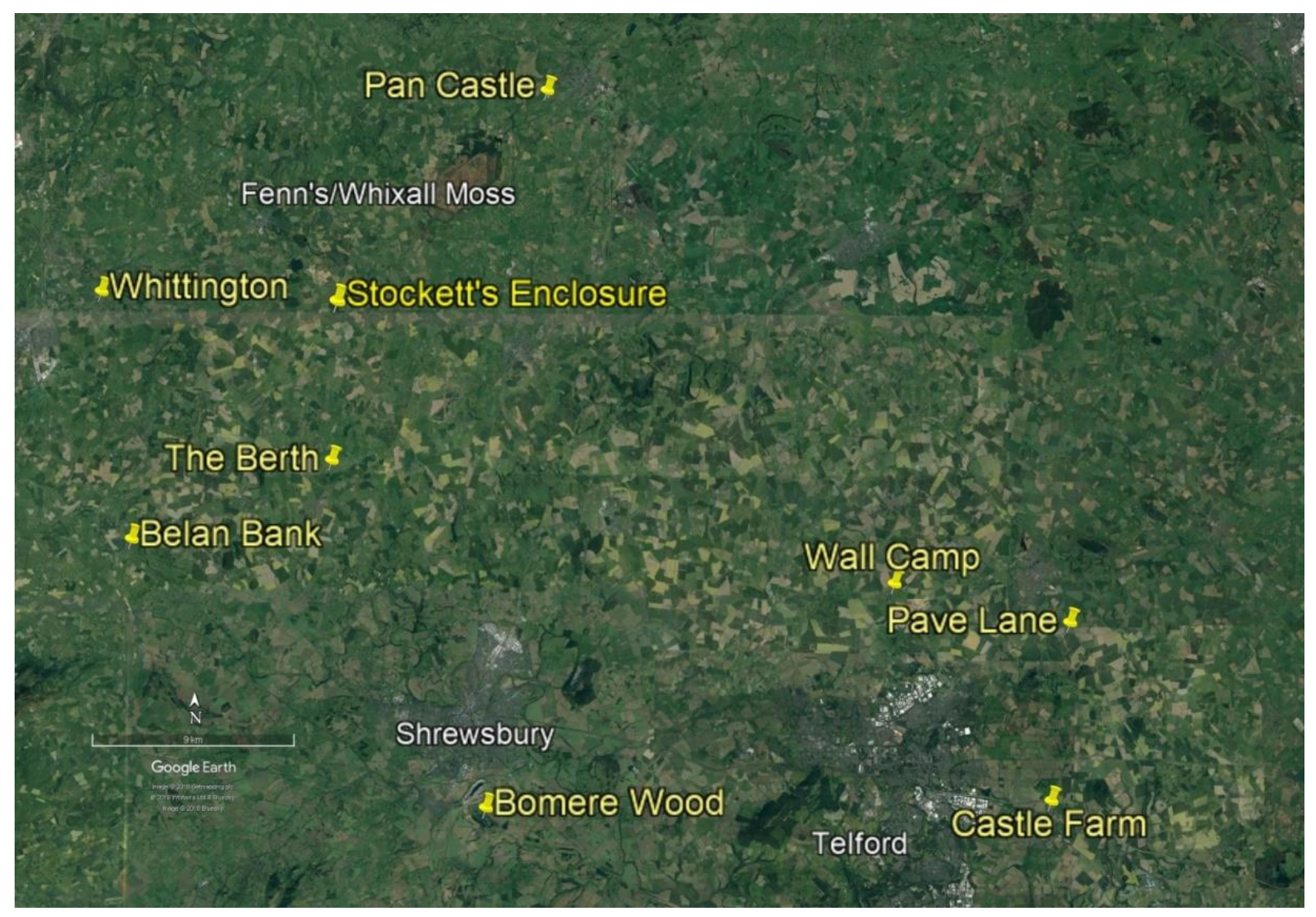

Fig. 5-13 North Shropshire's lowland fortifications, showing sites referenced in the text (Google Earth; January 2018)

\subsubsection{The Berth (Fig. 5-14)}

The Berth is a large (Scheduled Area 8ha) Iron Age fortification with an unusual morphology comprising dual enclosures connected by two upstanding causeways. The smaller enclosure is kidney-shaped and occupies a gravel spit at the $80 \mathrm{mOD}$ contour, whilst the (possibly) bivallate main enclosure encircles Berth Hill, a flat-topped gravel mound which rises to a spot height of 97mOD; Berth Pool lies 40m to the south, at the foot of Berth Hill. 


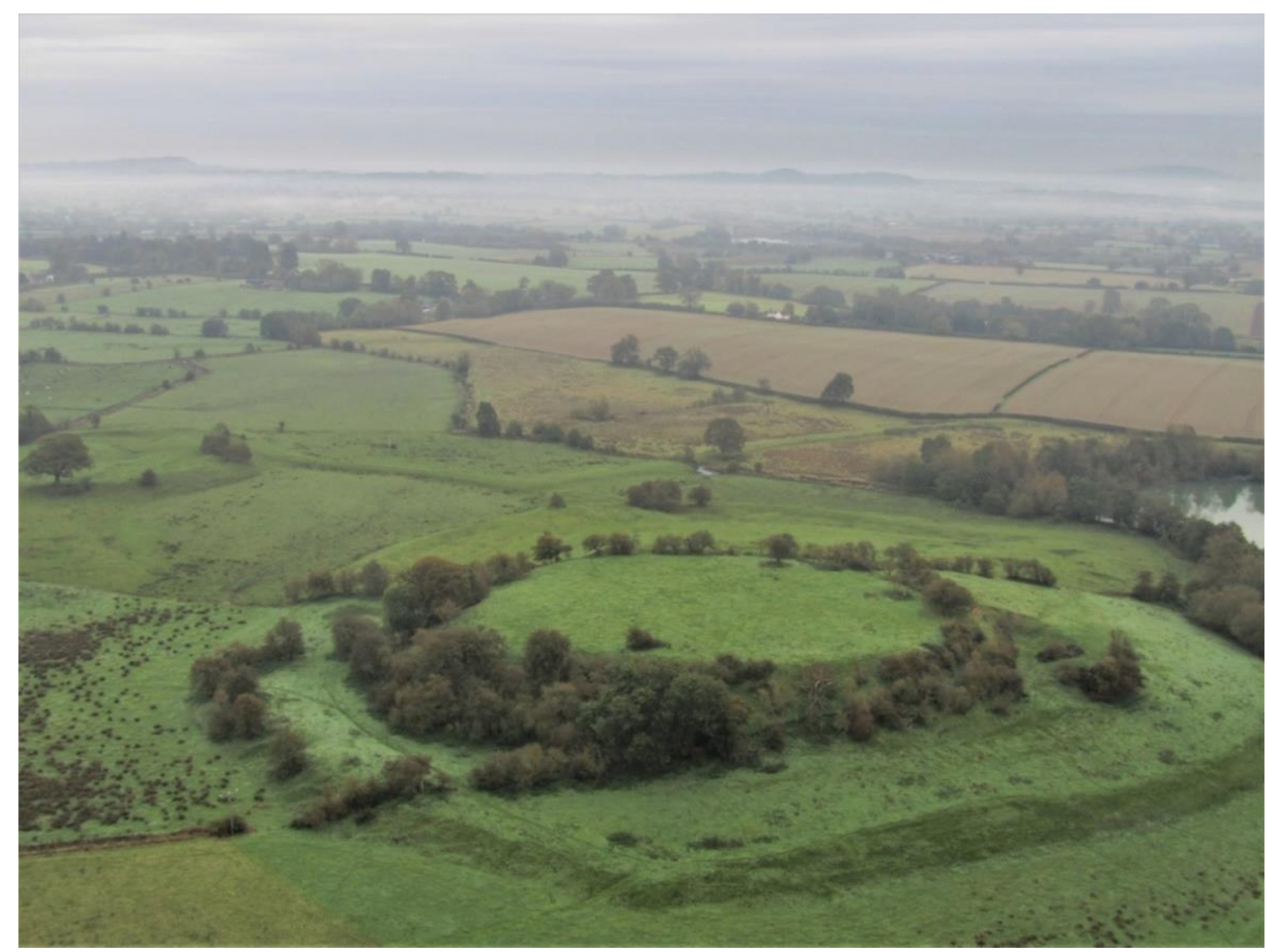

Fig. 5-14 The Berth from the air looking south, showing the main enclosure (centre), the small enclosure (left) and the causeways. The edge of Berth Pool is visible (right) and the Wrekin is visible in the far distance (Hampton, 2017)

The surrounding area is marshy throughout the year; access can be difficult even in modern times, and the causeways are used routinely. Recent excavations have shown that whilst both the upstanding causeways are most likely to be post-medieval, a third, hitherto unknown, causeway connected the two enclosures at their northern corners (Chapman, Smith and Norton, 2017). It led to a previously unknown entrance in the main enclosure and is currently thought to be the main means of access during the Iron Age. Therefore, the main enclosure had entrances both to the north-east and the south-east, whilst the small enclosure had entrances to the east across drier land, and to the west and north towards the main enclosure.

Excavation of the main enclosure in the 1960s identified three phases of use, separated by sterile layers (Gelling, 1962/5; 1964; 1977); although post-holes and a cobbled surface were discovered, it is not certain what type of structures these findings relate to. Analysis of the ceramics recovered during investigation indicated site usage between the Middle Iron Age and the Middle Roman periods (Morris and Gelling, 1991). The Berth Cauldron (first/second-century AD) was recovered from Berth Stream in 1906 and was likely to be a votive offering (Joy, 2014). 
The Berth is sizeable and monumental, located in wetland, with an unusual morphology. It dates from the Middle Iron Age, and was used discontinuously until the first/second-century AD, possibly later. Its purpose may or may not have been domestic, and there is evidence of votive deposition. It fulfils many of the criteria established by the Sutton Common hypothesis. This similarity, together with the extensive palaeoenvironmental archive available for investigation (see Chapters 7 and 8), were the prime reasons why the Berth was selected as the case-study site for this thesis. The Berth is classified as a marsh-fort by the Atlas of Hillforts.

\subsubsection{Wall Camp, Kynnersley (Fig. 5-15 - Fig. 5-20)}

Wall Camp is a very large (Scheduled Area 12ha), heart-shaped, Iron Age fort situated near Kynnersley village on the Weald Moors; at an elevation of 70mOD, it occupies one of several sandstone 'islands' in this low-lying valley mire (Fig. 5-15). Its ramparts are upstanding and multivallate to the north and west (Fig. 5-16; Fig. 5-17); the entrance is assumed to be at its southern tip, although this section of the fort has been lost through ploughing. A causeway-type outwork bridges the ramparts to the east; its purpose is unknown but it may have provided access to the eastern floodplain - in modern times, the fort is prone to flooding on three sides (Fig. 5-18). Wall Camp is well camouflaged within the flat landscape, and shares hillfort intervisibility only with the Wrekin.

There have been two periods of excavation (Fig. 5-17). In the 1960s, Pagett concentrated on a section of the banks/ditches on the western ramparts. Although the findings were never published, the field notes have been summarised and indicate a revetted main bank and at least four periods of construction (Malim and Malim, 2010), separated by periods of disuse; the site appears to have been abandoned by Roman times (Malim and Malim, 2010:94). An excavation of the interior in the 1980s found one, possibly two, round houses (one with a clay floor), two possible four-post structures, and a possible midden (Bond, 1991). The pottery recovered from the site included Cheshire briquetage and a few sherds of Group D ware, all ascribed to the third-century BC (Morris, 1991). A radiocarbon date of 2110 $\pm 90 B P$ (371 cal BC-cal AD53; Har-6392) was obtained from willow/oak charcoal from a round house gully. Animal bone was recovered from the site but not analysed. 


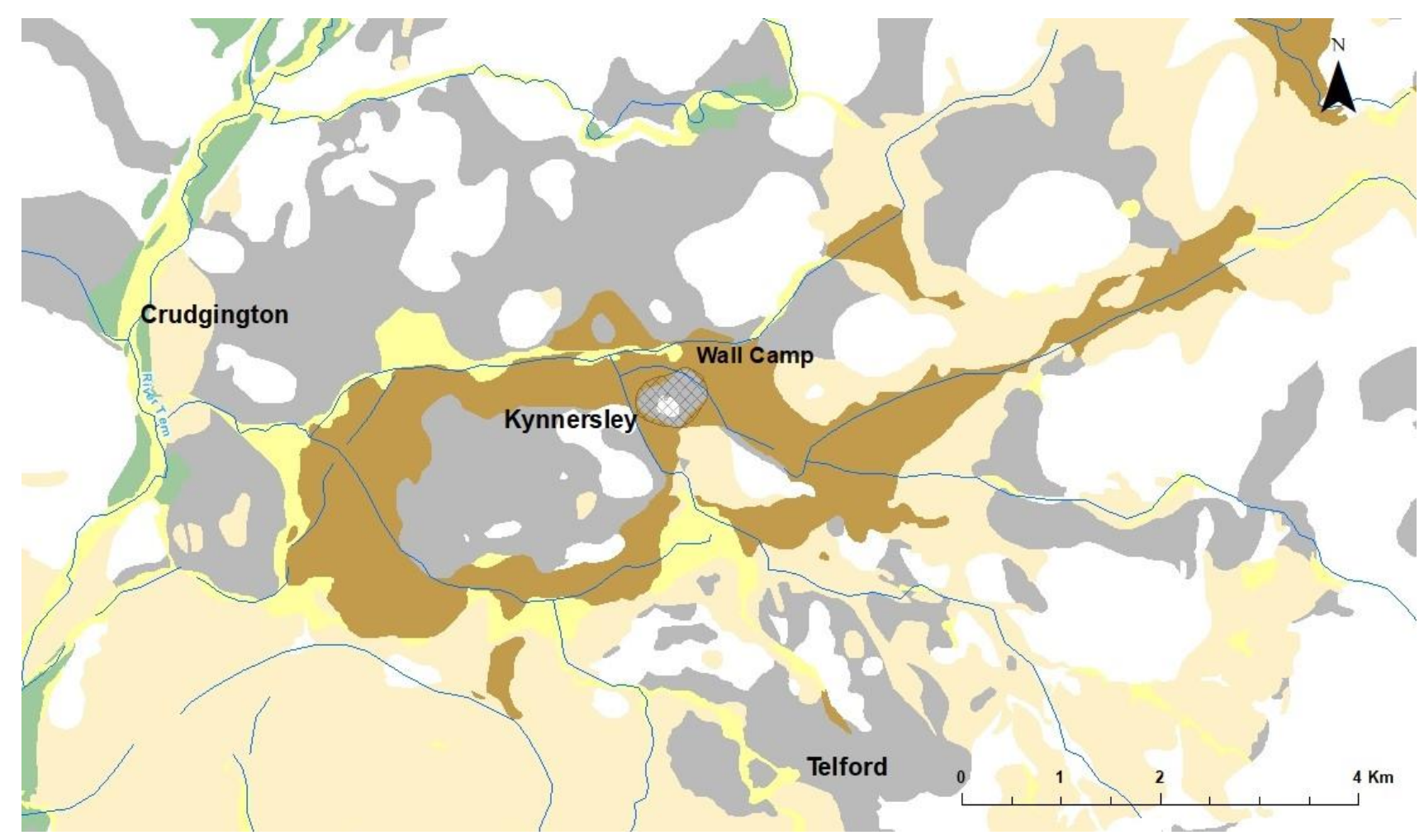

Fig. 5-15 The Weald Moors - superficial geology (BGS 1:50000; July 2017)

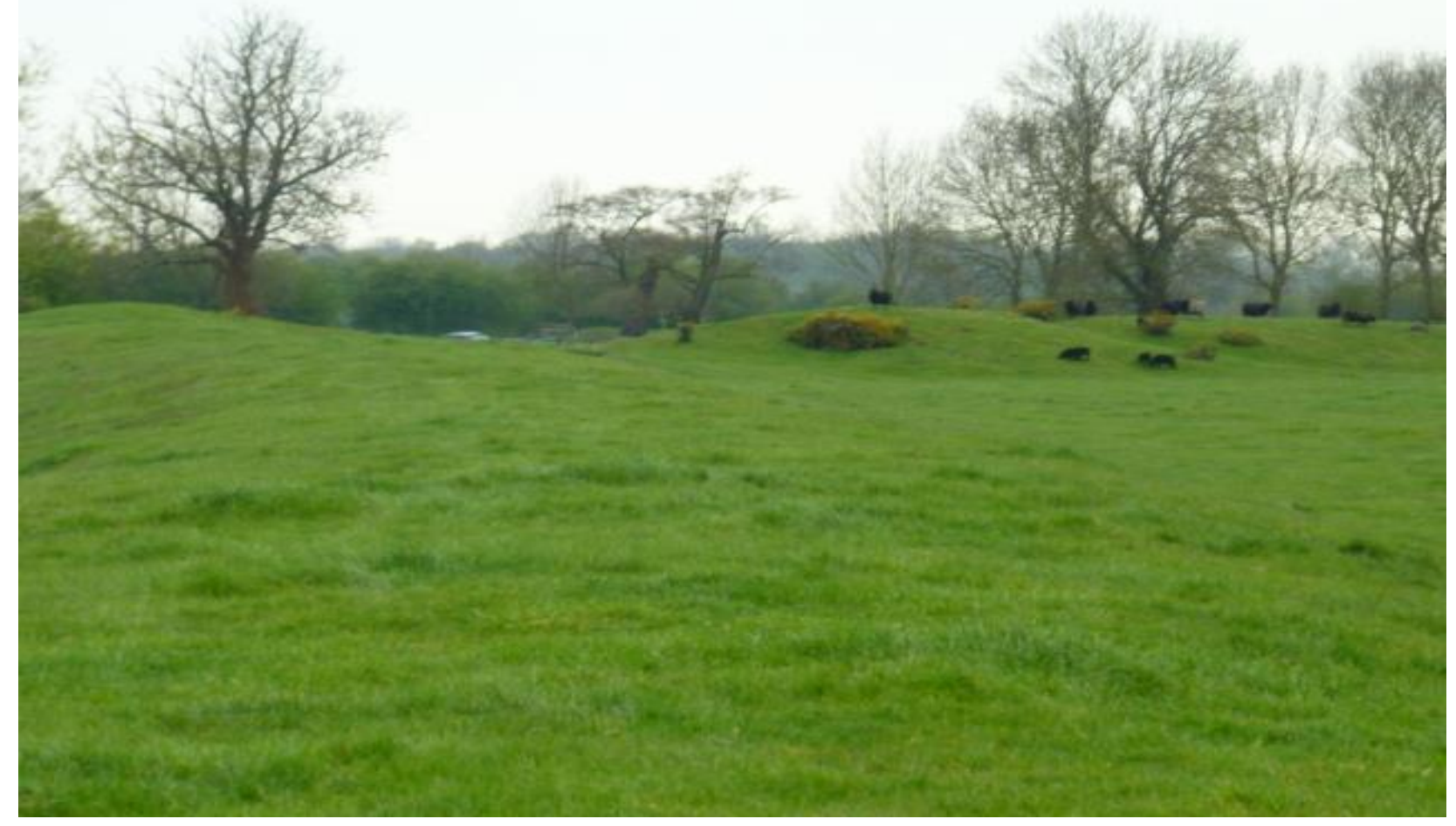

Fig. 5-16 Wall Camp - western ramparts - sheep provide scale (Norton, 2014) 


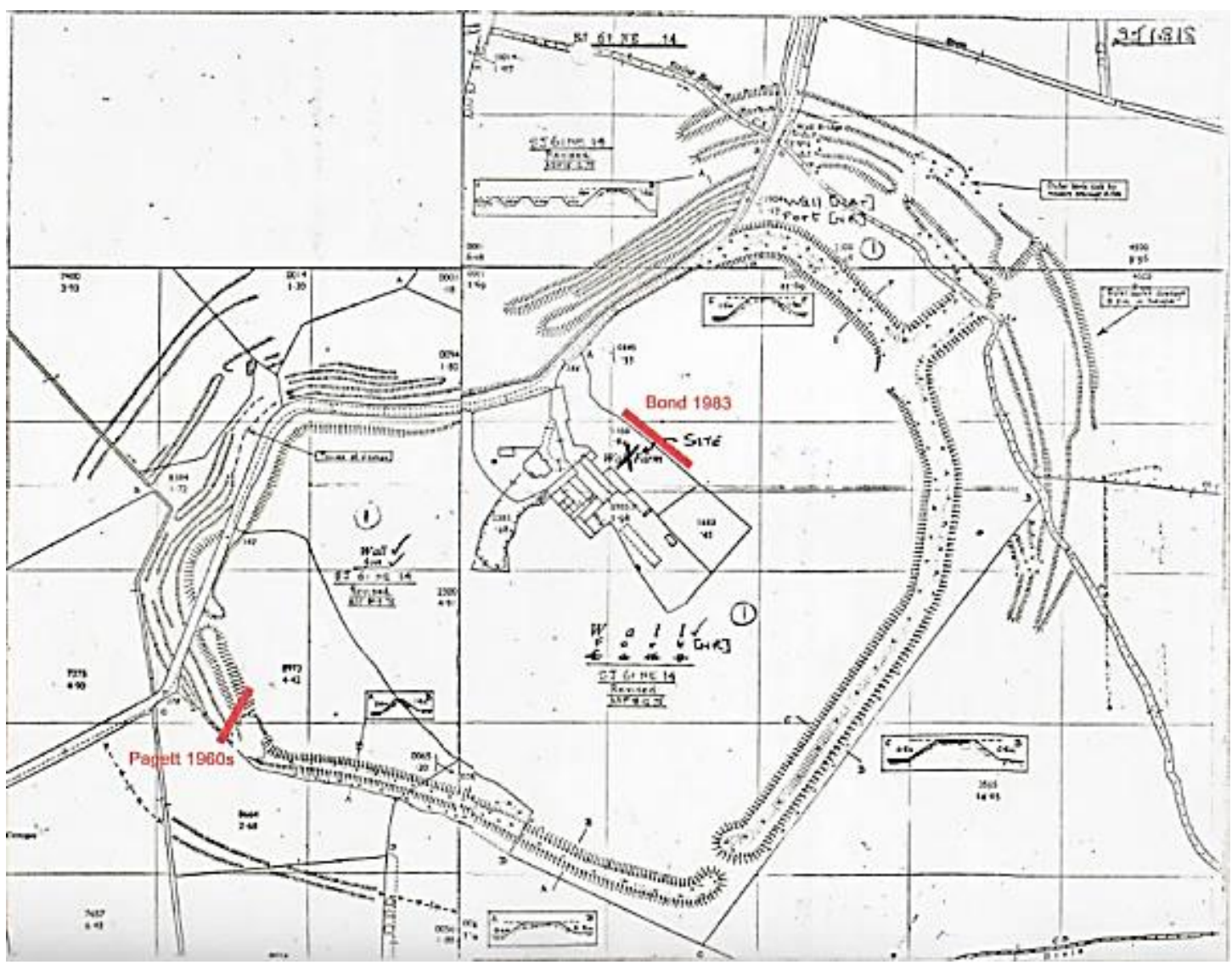

Fig. 5-17 Wall Camp - site map and excavations (Malim and Malim, 2010:Fig.2b)

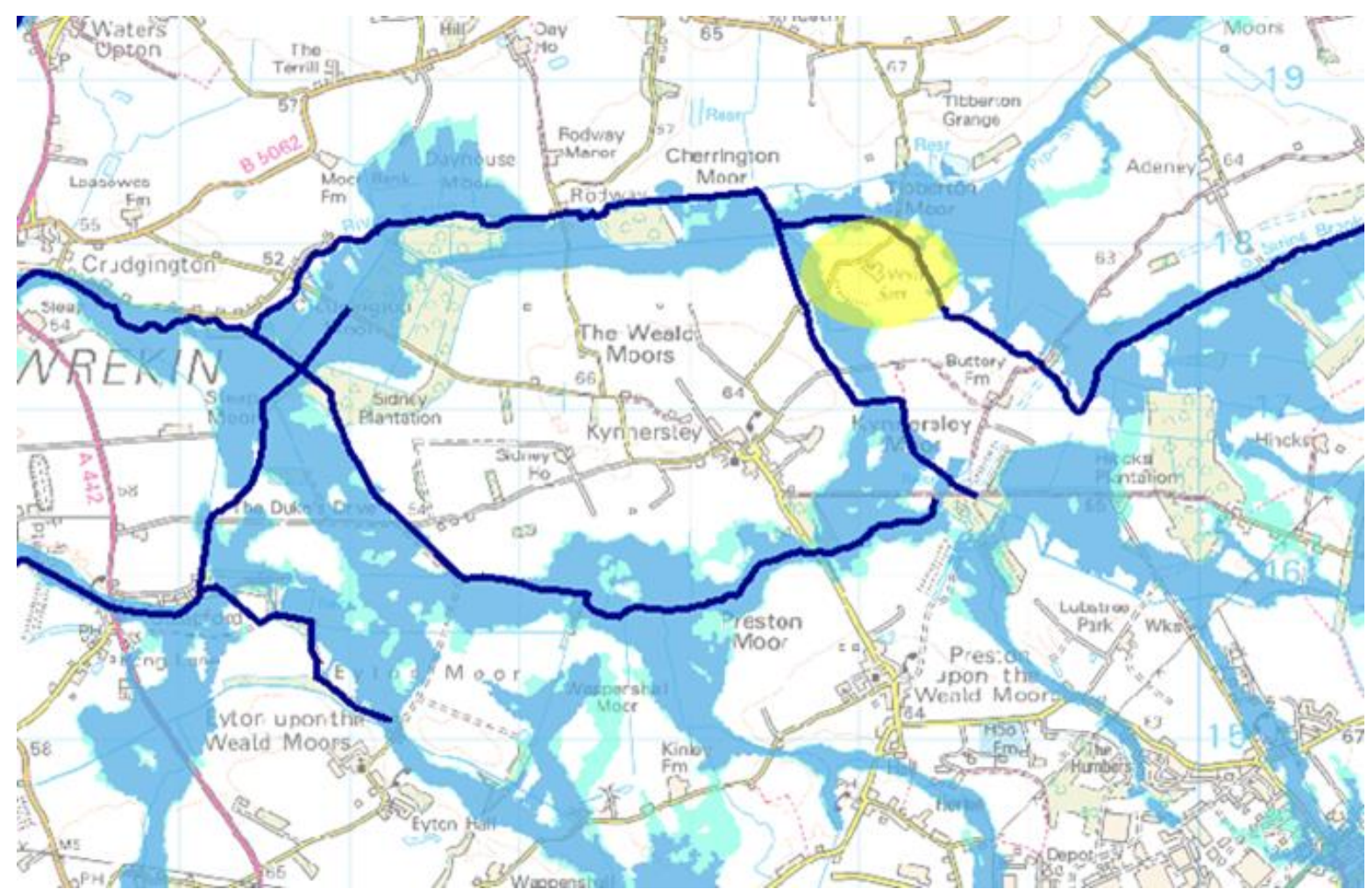

Fig. 5-18 Wall Camp -modern floodmap (Source: Edina Digimap: Geological Indicators of Flooding Accessed May 2017) 
Finds from around the site are few, comprising several Neolithic flints and a single Iron Age Guido Class 6 triskele bead (probably first-century BC; pers.comm.P.Reavill, FLO Shropshire and Herefordshire). A gold/silver alloy torc - the Telford torc - was recovered nearby (Fig. 5-19) and has been dated between 200-50BC; there is evidence that it was broken before entering the ground, possibly as part of a public act of ceremonial deposition (Coles, 2001). The torc shares stylistic similarities with the Snettisham Hoard and is the most westerly example of its type.

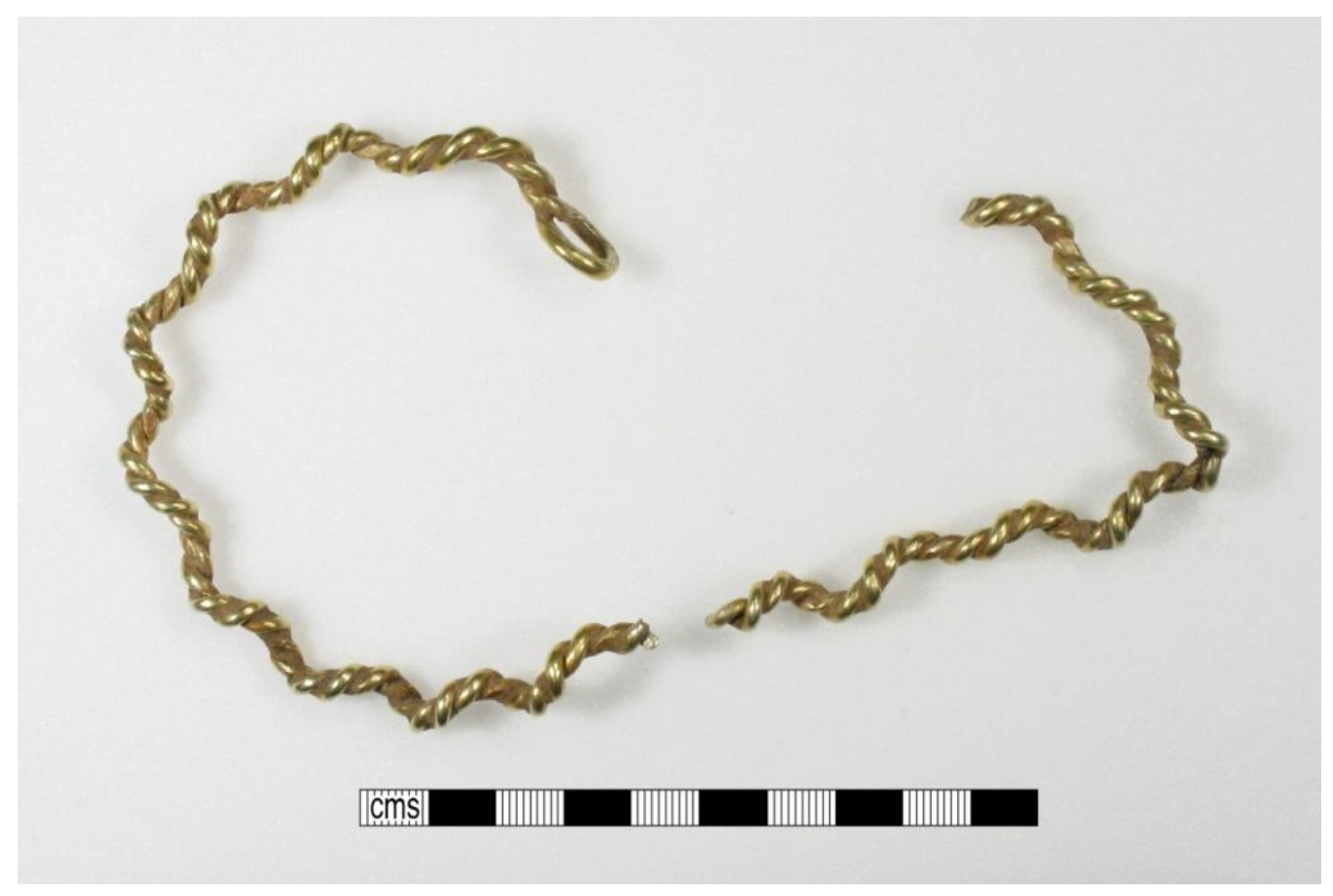

Fig. 5-19 The Telford Torc (PAS: WMID-C53CB8)

The peat deflation described above (see 5.1.4) has seriously affected the organic archive on the Weald Moors and around Wall Camp in particular, and the NWWS concluded that further work was unlikely to yield substantial evidence (Leah et al., 1998). Whilst this is largely correct, two recent investigations suggest that the potential is better than originally thought.

Firstly, a 70cm core taken from a palaeochannel close to Wall Camp's ramparts (Norton, 2013) provided

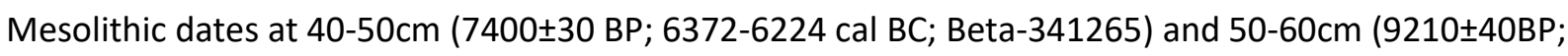
8547-8303 cal BC; Beta-341619). Palaeoentomological analysis indicated an environment of reed-bed and slow moving water with some alder and willow; no evidence was found of grazing animals and no significant woodland was located in the immediate vicinity. The results were homogenous throughout the core and could be extrapolated to suggest that these conditions had prevailed during the Iron Age, but this is far from certain. The presence of the halophilous species Dyschirius salinus Schaum indicated that the local strines were saline, and this may be connected with the presence of the three burnt mounds which cross the site. A variety of uses have been proposed for these sites and whilst cooking is 
the most common interpretation, salt evaporation has also been suggested (Hodder and Barfield, 1991). The burnt mounds located on the Wall Camp strines may have been used for evaporation before it became more efficient to import salt from Cheshire (Norton, 2013). Salt was extracted commercially from one of the salt springs on the Weald Moors during the eighteenth-century AD, at Kingley Wich, $3 \mathrm{~km}$ south of Wall Camp (Shropshire HER 1369), and this location is also associated with the recovery of the Preston Hoard (five Bronze Age palstaves (Chitty, 1953)) during the nineteenth-century AD. The function and chronology of burnt mounds are described in Chapter 6.

Secondly and as part of the research for this thesis, a discontinuous set of auger cores was undertaken around Wall Camp and in the field immediately to its east (see Fig. 5-20). The cores were generally shallow (between $0.3 \mathrm{~m}$ and $1 \mathrm{~m}$ ) and do not form a transect for analysis. However, one core taken from the field to the east of Wall Camp reached a depth of $1.9 \mathrm{~m}$. The stratigraphy comprised well-humified reedy peat interspersed with silt to a depth of $1.45 \mathrm{~m}$, followed by a layer of silt with shell fragments, granular lake clay and solid geology. Therefore this core suggests that the area to the east of Wall Camp had been open water or reed bed at some point.

Analysis of the archaeological sites and findspots in the wider area reveals that the Weald Moors were an important location throughout prehistory (Fig. 5-21). Lithic scatters, although sparse, show that the area was in use during the Mesolithic and Neolithic. The Weald Moors were central to a range of nondomestic practices during the Bronze Age, as the 35+ burnt mounds, metalwork deposition and ringditches show, and may indicate that the wetlands of the Weald Moors were borderland or liminal space (see 4.1.4). The burnt mounds tend to follow the water courses. The Iron Age is represented by enclosure sites along the River Tern, begging the question of their relationship with the much larger fortification of Wall Camp. Roman evidence is largely absent from the Weald Moors with only a few findspots which are confined to the eastern and southern outskirts, perhaps reflecting the proximity of the fort at Redhill/Uxacona $9 \mathrm{~km}$ to the south and the Roman road (Margary 19) to the east; a coin hoard dated between AD330-340 was recovered from the area in the nineteenth-century AD but the location is lost. If Wall Camp's prime function was as a hub for summer grazing and stock rearing (Bond, 1991), usage might be expected to continue into Roman times, but the evidence so far suggests otherwise.

Wall Camp parallels the Sutton Common model in many respects. The fortification is large, with monumental banks and ditches. The earthworks to the east of the fort suggest a causeway which may have given access to a floodplain. The site was used discontinuously; however, the excavational evidence suggests domestic use in the Middle/Late Iron Age. It is classified as a marsh-fort in the Atlas. 


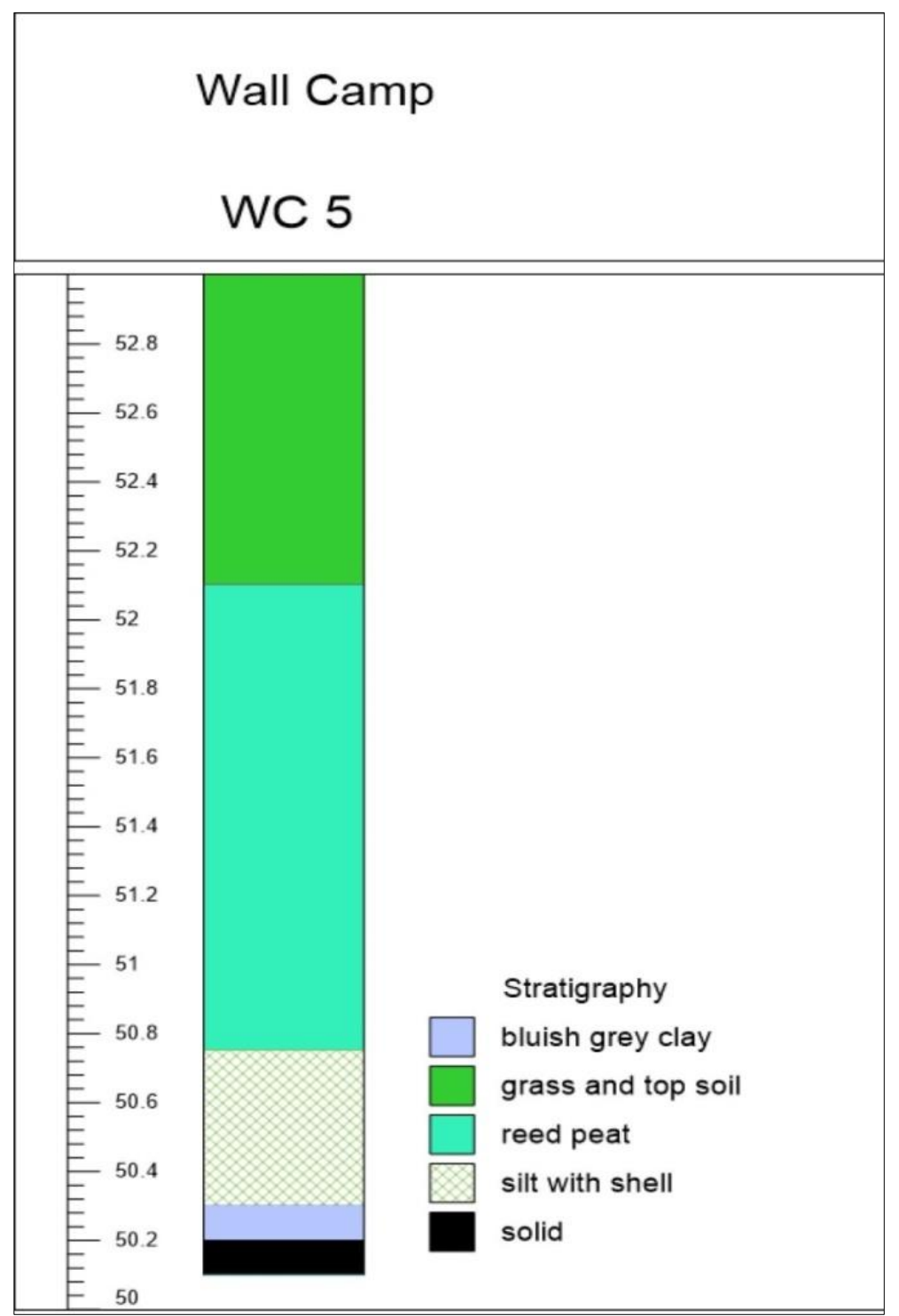

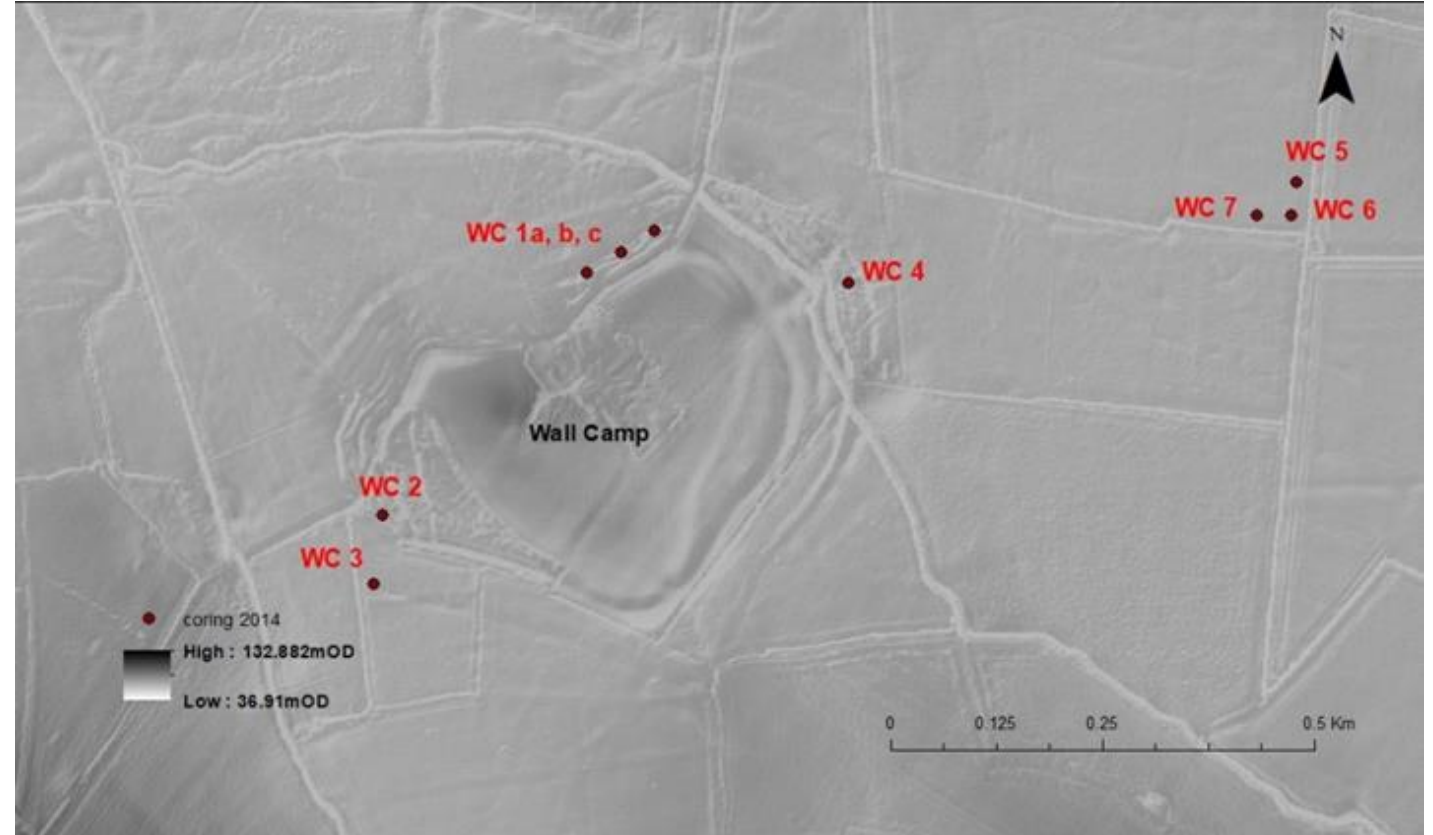

Fig. 5-20 Wall Camp - WC5 stratigraphy and auger locations (LiDAR DTM 1m) 


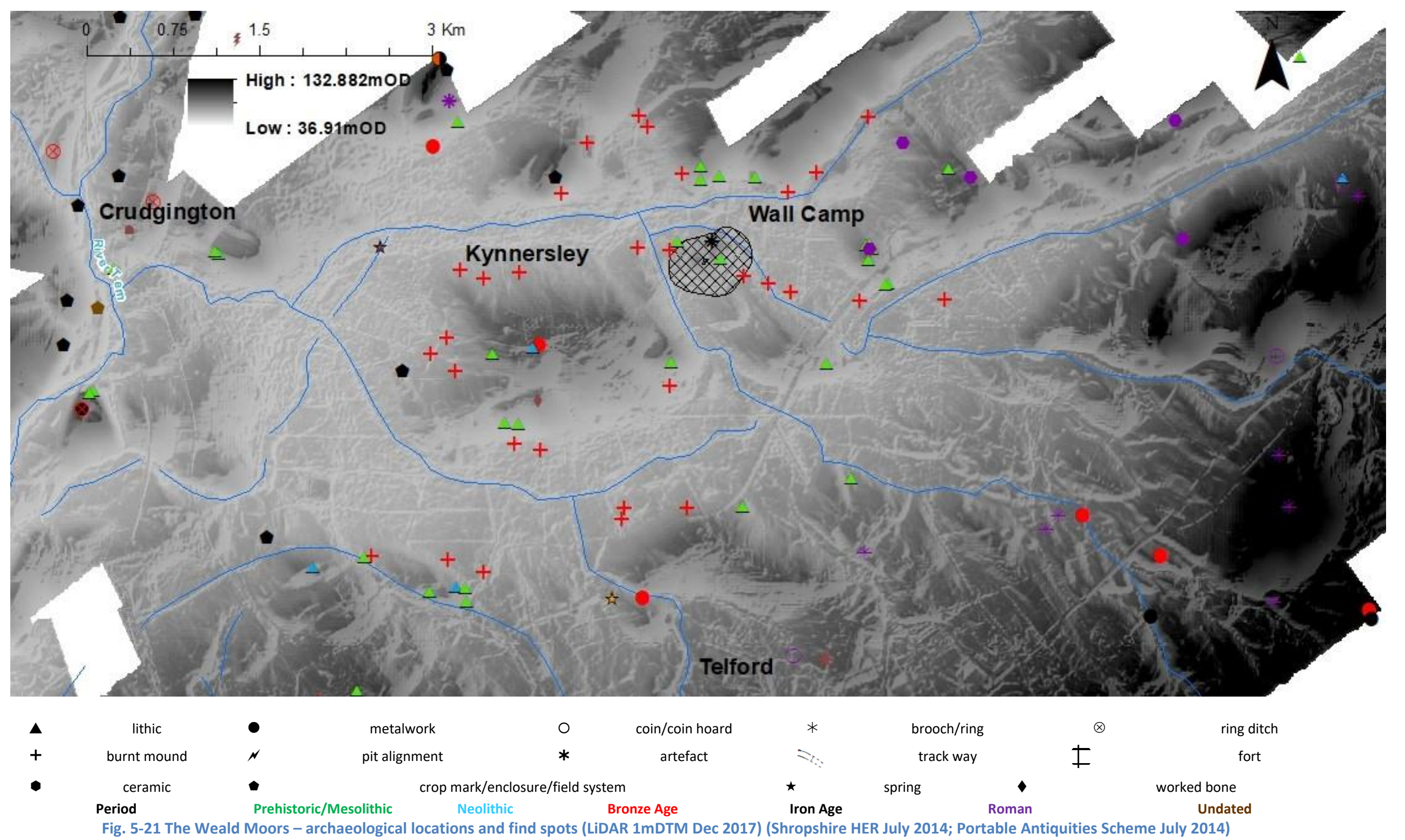




\subsubsection{Whittington (Fig. 5-23 -Fig. 5-24)}

The upstanding remains of the twelfth-century AD Whittington Castle are built on the site of a tenth/eleventh-century AD motte-and-bailey. However, a 4ha, D-shaped multiple-banked enclosure comprising two/three concentric ditches lies behind the castle and is considered later prehistoric (Brown, 2003) (Fig. 5-22). Geophysical research in 2001 demonstrated that the ditches extend to form a broken circuit (HER 01003; 32853). If the circuit took in streams to north and south, the enclosure may encompass 8ha, suggesting a 'hamlet-type' settlement or marsh-fort structure; the modern floodmap suggests their course (Fig. 5-23) and the site contains at least one spring (Brown, 2003). A mound the centre of the castle environs, part of the medieval 'Pleasure Garden', may have deeper chronological roots and a Bronze Age burial mound has been suggested (Malim and Malim, 2010:112).

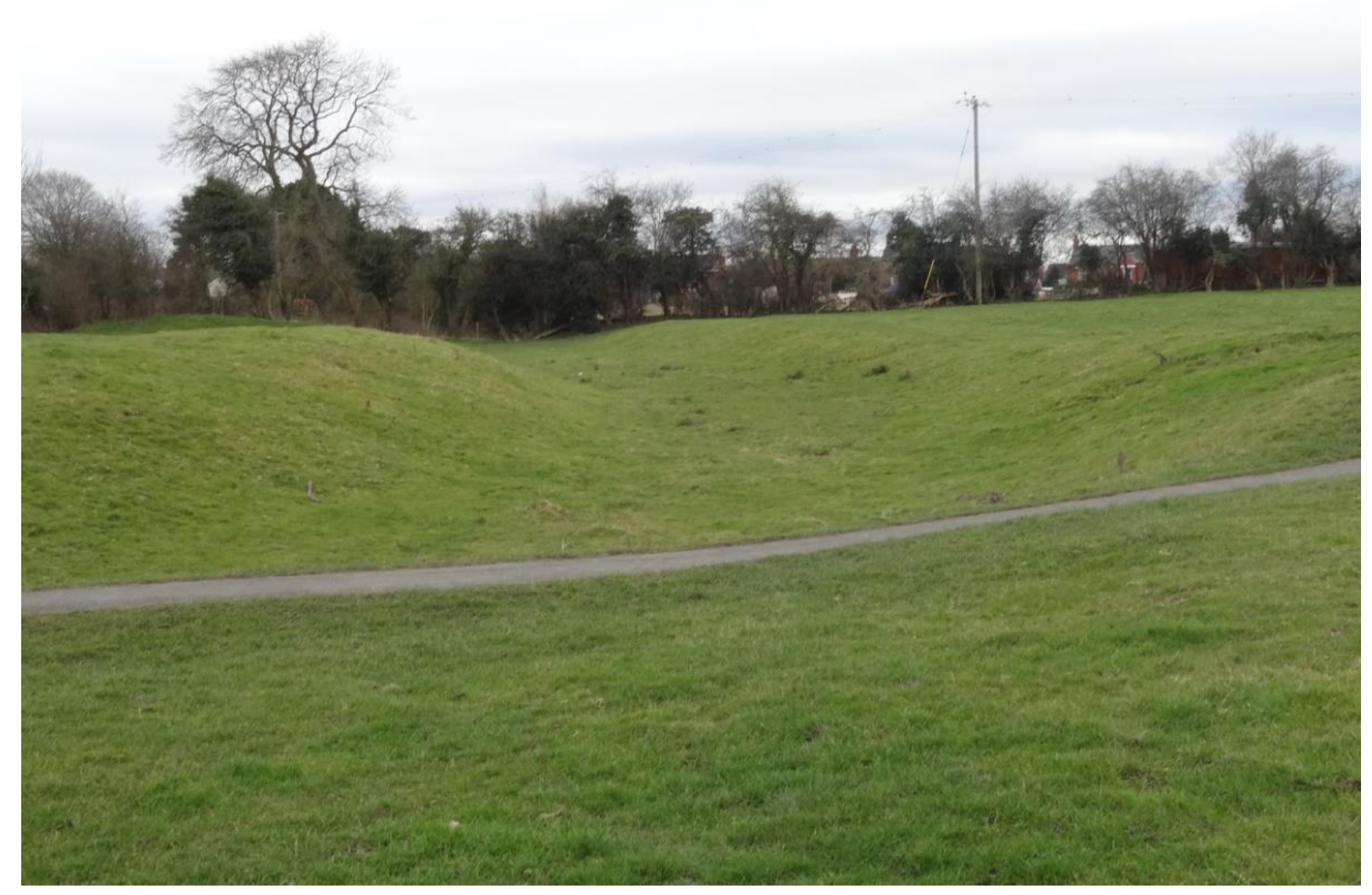

Fig. 5-22 Whittington Castle - outer earthworks (Norton, 2015) 


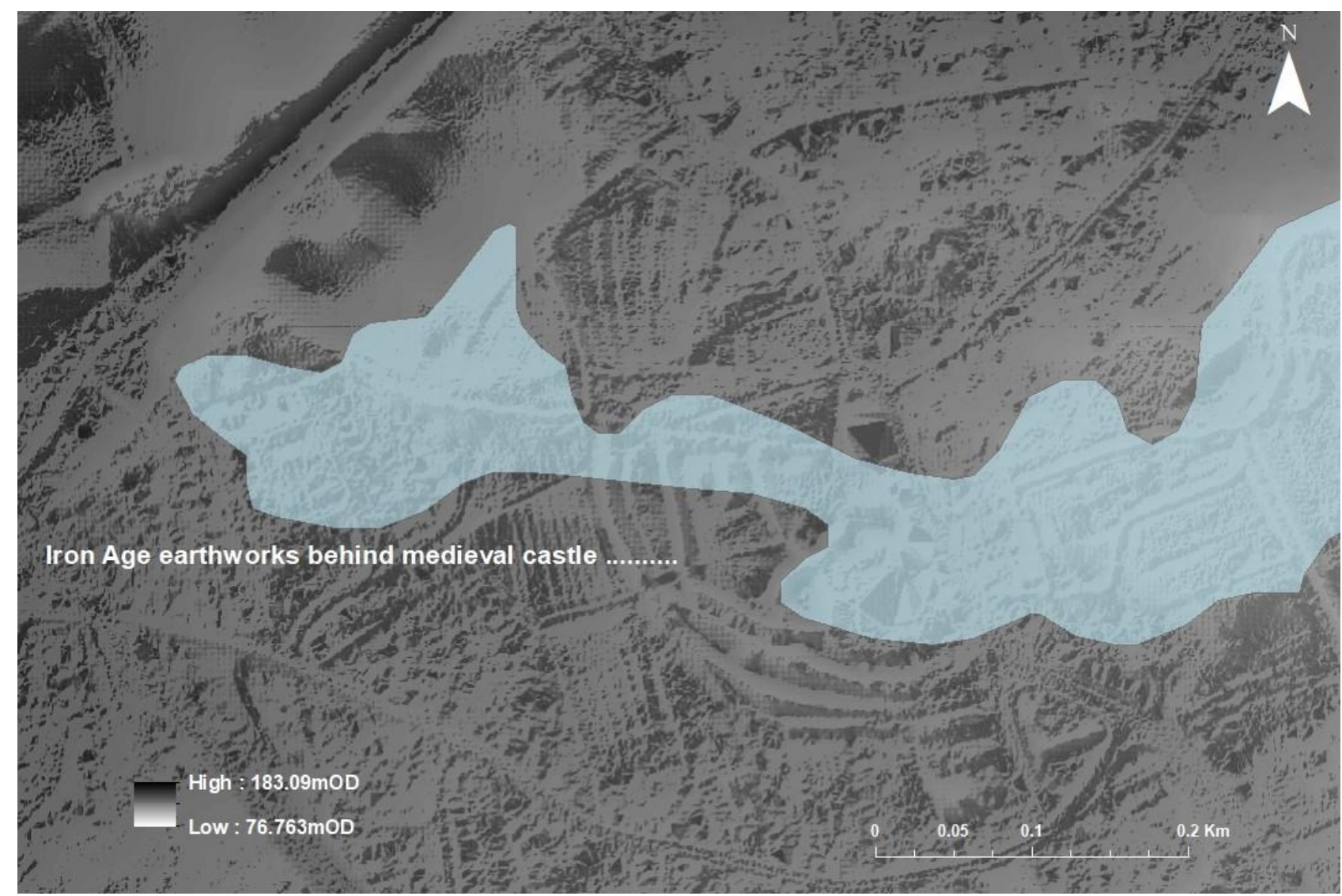

Fig. 5-23 Whittington Castle area showing sites and embanked areas, overlain with modern flood data (Source: LiDAR 1mDSM; BGS: Geological Indicators of Flooding July 2017)

The underlying geology and surrounding archaeological features are seen in Fig. 5-24. The geology is primarily till and alluvium, and therefore this site lacks the extensive peat deposits found around some other marsh-forts. Archaeologically, the medieval castle dominates the site but two more enclosure sites are recorded nearby.

Assuming that the ditch/ramparts are indeed Iron Age, a relationship with Old Oswestry hillfort, $3 \mathrm{~km}$ due west is probable. The wider area has a complex Bronze Age past, including a possible line of standing stones, human remains and metalwork deposition. The ring-ditches to the south are clustered around a water course and occupy well-drained glacial deposits, a topography similar to the Bronze Age cemetery near the Berth. Whilst the Iron Age is determined by the hillfort and enclosure, the Roman presence is signified by a concentration of artefacts and coins found east of Oswestry, around the village of Middleton. Analysis of the coin dates is not conclusive, but suggests a Roman presence in this area before AD250. Rhyn Park, a large first-century AD Roman military site, lies 8km north of Oswestry.

A combination of size, monumentality and the wetland setting could position Whittington as a potential marsh-fort, with a possible relationship to the nearby hillfort of Old Oswestry. However, the information is limited and further research is required. 


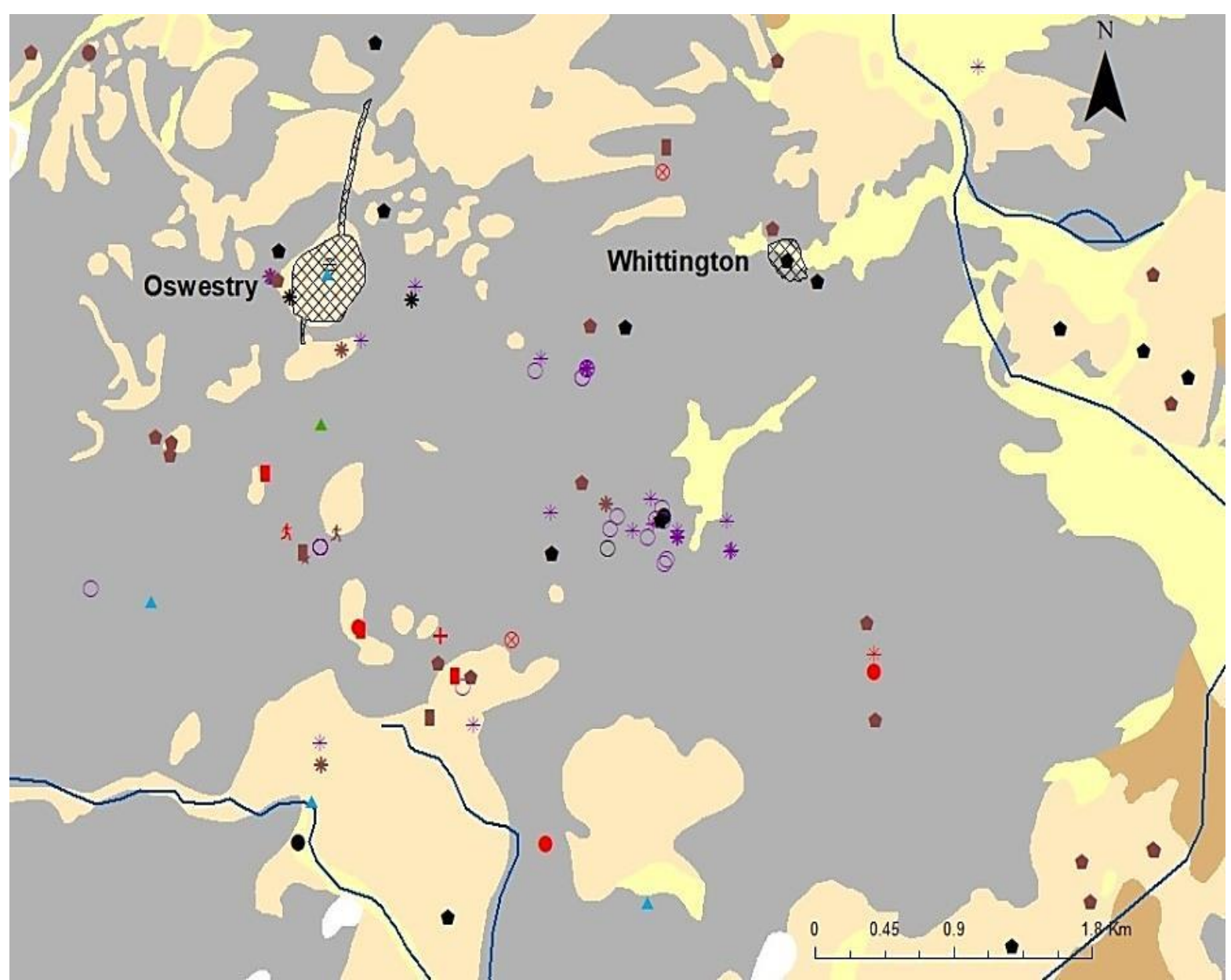

Fig. 5-24 Whittington Castle and Old Oswestry - superficial geology (BGS 1:50000 July 2017); sites (Shropshire HER July 2014; Portable Antiquities Scheme July 2014)

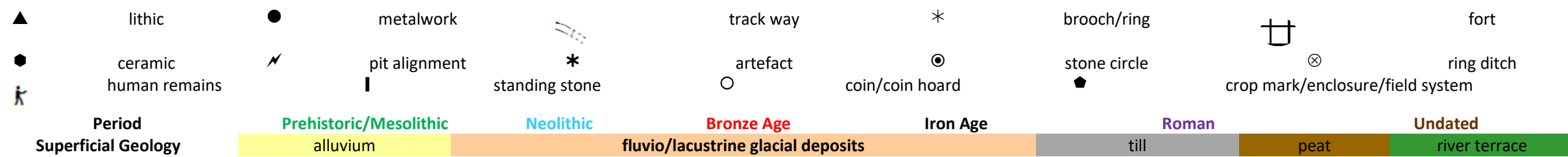




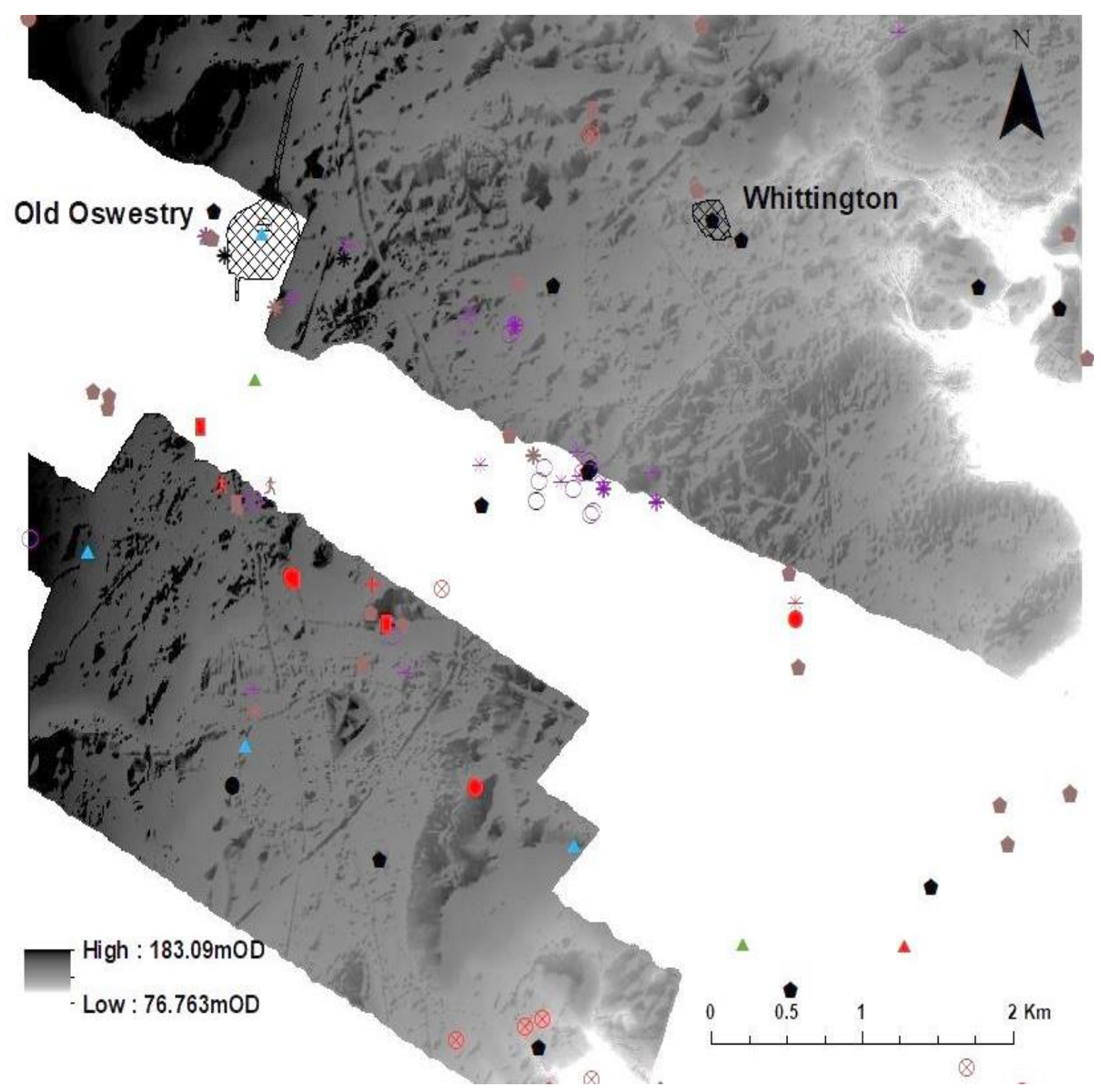

Fig. 5-25 Whittington Castle and Old Oswestry - LiDAR 1m DTM (Dec 2017) (legend - see Fig. 5-24) 
5.3.4. Stocketts Enclosure (Fig. 5-26 - Fig. 5-28); Pan Castle (Fig. 5-29; Fig. 5-30) Stocketts Enclosure occupies a natural defensive position on top of a low ridge separating Crose Mere from Whattal Moss and Sweat Moss. The remains include the mounded earthwork of a motte-and-bailey castle with a ditch to the south-west, but the results of an excavation in the 1890s (Peake, 1909), together with artefactual evidence, indicate that the medieval castle rests on an enclosure of deeper chronology, although the relationship is difficult to untangle. The excavation showed that the ditch to the south-west of the site had once been steeper and filled with water, and historic evidence indicates that the water levels in the area were substantially lowered during the latter part of the nineteenth-century AD. Therefore Crose Mere, Whattal and Sweat Moss would have formed a single wetland of open water/bog which would have surrounded the ridge (Hardy, 1939; Reynolds, 1979) with Stocketts Enclosure strategically sited to control the area (see Fig. 5-27). An Early/Middle Iron Age canoe, recovered from Whattal Moss in the 1860s supports this conclusion (Chitty, 1927). Excavation also indicated that the mound to the west of the ditch had once been higher and perhaps stockaded. The lower deposits in the ditch, which were waterlogged during the excavation, produced animal bones, a cylindrical piece of iron and a fragment of bronze which was interpreted as part of a sword sheath. Additional evidence includes a stone causeway close to Sweat Mere (position unknown), which included half a limestone quern amongst the stones, and a fragment from a late Iron Age gold torc was recovered closer to Sweat Moss in 2012 (PAS:HESH-D6AEA2). Further afield, there is a small concentration of Roman artefacts and coinage to the south of Stocketts Enclosure. These are mainly brooches and potentially the product of numerous deposition events (Haselgrove, 1997). The coinage can be dated mainly to the earlier phase of Roman incursion AD43-180. The burnt mounds to the southwest appear to relate to small areas of water rather than watercourses.

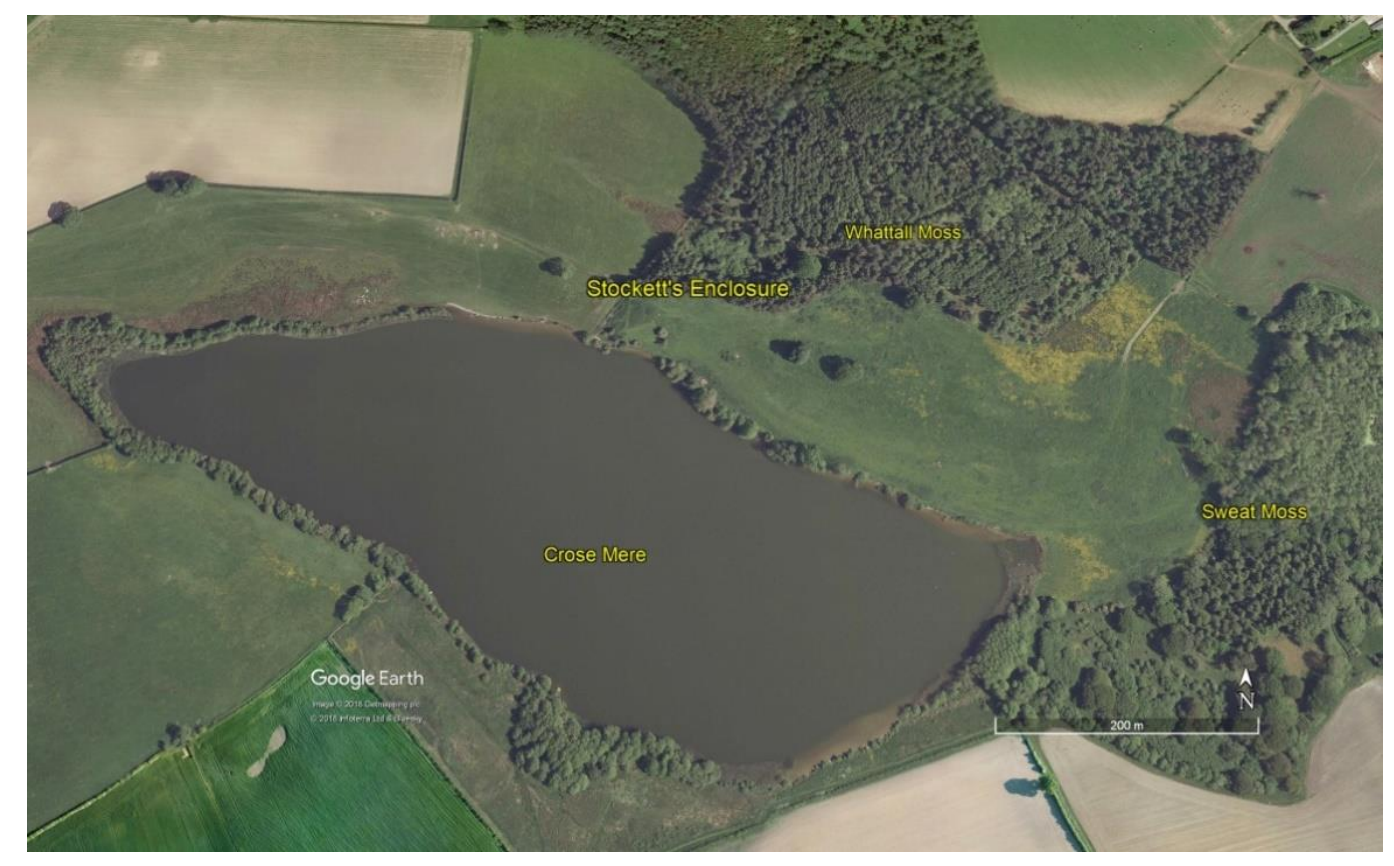

Fig. 5-26 Stocketts Enclosure - site location (Google Earth; January 2018) 


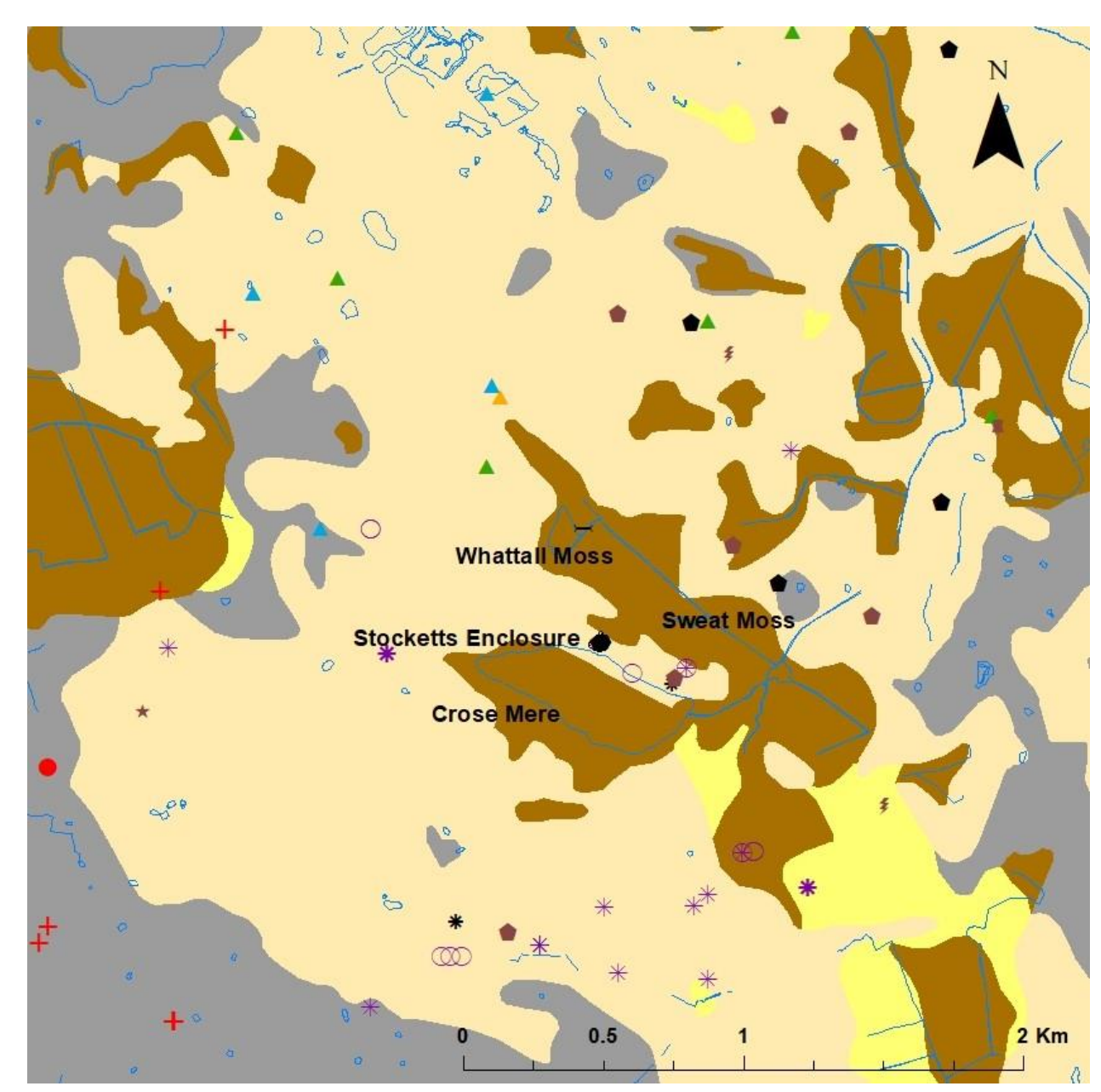

Fig. 5-27 Stocketts Enclosure and Crose Mere - superficial geology (BGS 1:50000 July 2017); sites (Shropshire HER May 2014; Portable Antiquities Scheme; July 2017)

\begin{tabular}{ccc} 
lithic & - & metalwork \\
burnt mound & $*$ & artefact \\
\multicolumn{2}{c}{ crop mark/enclosure/field system }
\end{tabular}

$$
\begin{array}{ccc}
\smile & & \text { canoe } \\
* & & \text { brooch/ring }
\end{array}
$$
Prehistoric/Mesolithic Neolithic

Bronze Age alluvium fluvio/lacustrine glacial deposits

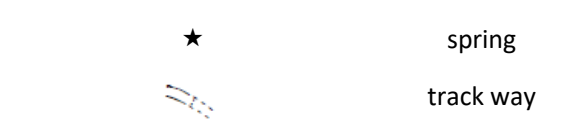

track way Iron Age

coin/coin hoard 


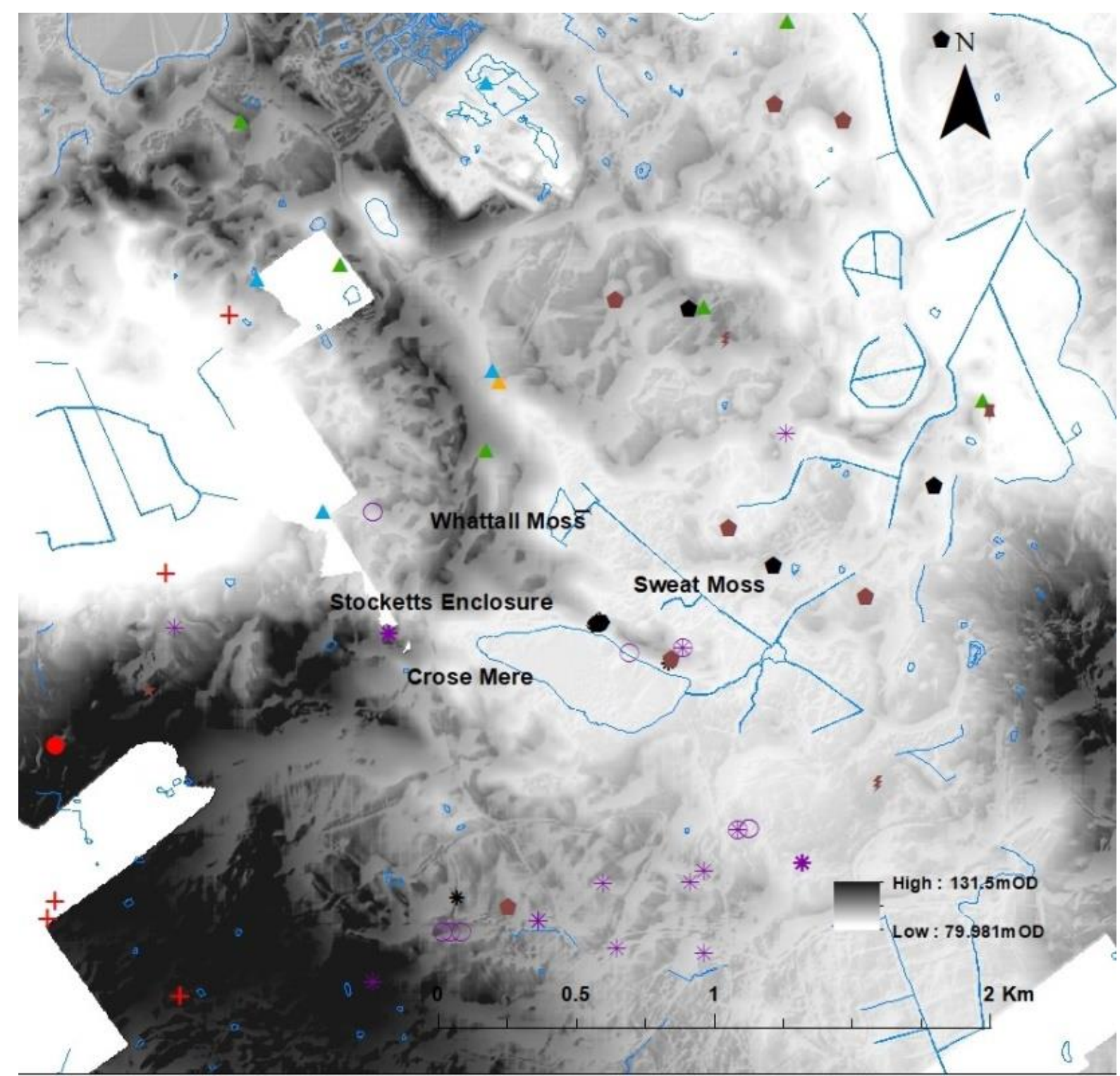

Fig. 5-28 Stocketts Enclosure and Crose Mere - LiDAR 1m DTM (Dec 2017); (legend - see Fig. 5-27) 
Although small, Stocketts Enclosure may contain the necessary evidence to be counted as a marsh-fort. Data regarding the site itself are less than precise, but the locational evidence is persuasive and the possibility of a causeway into Sweat Moss has some potential. The artefactual evidence, limited though it is, may suggest this as a place of depositional rather than a domestic environment. Beales' palynological study of Crose Mere indicated that the first-millennium BC was a time of woodland regeneration and limited grassland. However, although evidence for cereal crops is low during the Middle Iron Age, ruderals were evident and cereal-type pollen increased significantly circa 2000BP (Beales, 1980) (see Chapter 8).

Iron Age sites were regularly reused as medieval fortifications, and in particular, as motte-and-bailey castles; examples include Barwick-in-Elmet and Castle Hill in Yorkshire, Thetford in Norfolk and Old Sarum in Wiltshire. Several of the well-preserved motte-and-bailey castles located in North Shropshire's wetlands utilised water and marshland as part of their defensive structures. This thesis is not suggesting that all the motte-and-bailey castles in the North Shropshire wetlands were marsh-forts, but evidence from other sites encourages the keeping of an open mind. Pan Castle is a motte-and-bailey occupying low-lying wetland south-west of Whitchurch (Fig. 5-29). It lies at the 90mOD contour and was defended by a swamp to the south; it was referenced by Downman (1906) in his summary of Shropshire antiquities (Fig. 5-30). It is of interest because its life as a motte-and-bailey follows an earlier incarnation as one of the 'White Towns of Powys' (Thomas, 1907), the strongholds of the princes of Powys during their ongoing skirmishes with the Anglo-Saxons during the sixth and seventh centuries AD. Whittington and Wall Camp were also 'White Towns'.

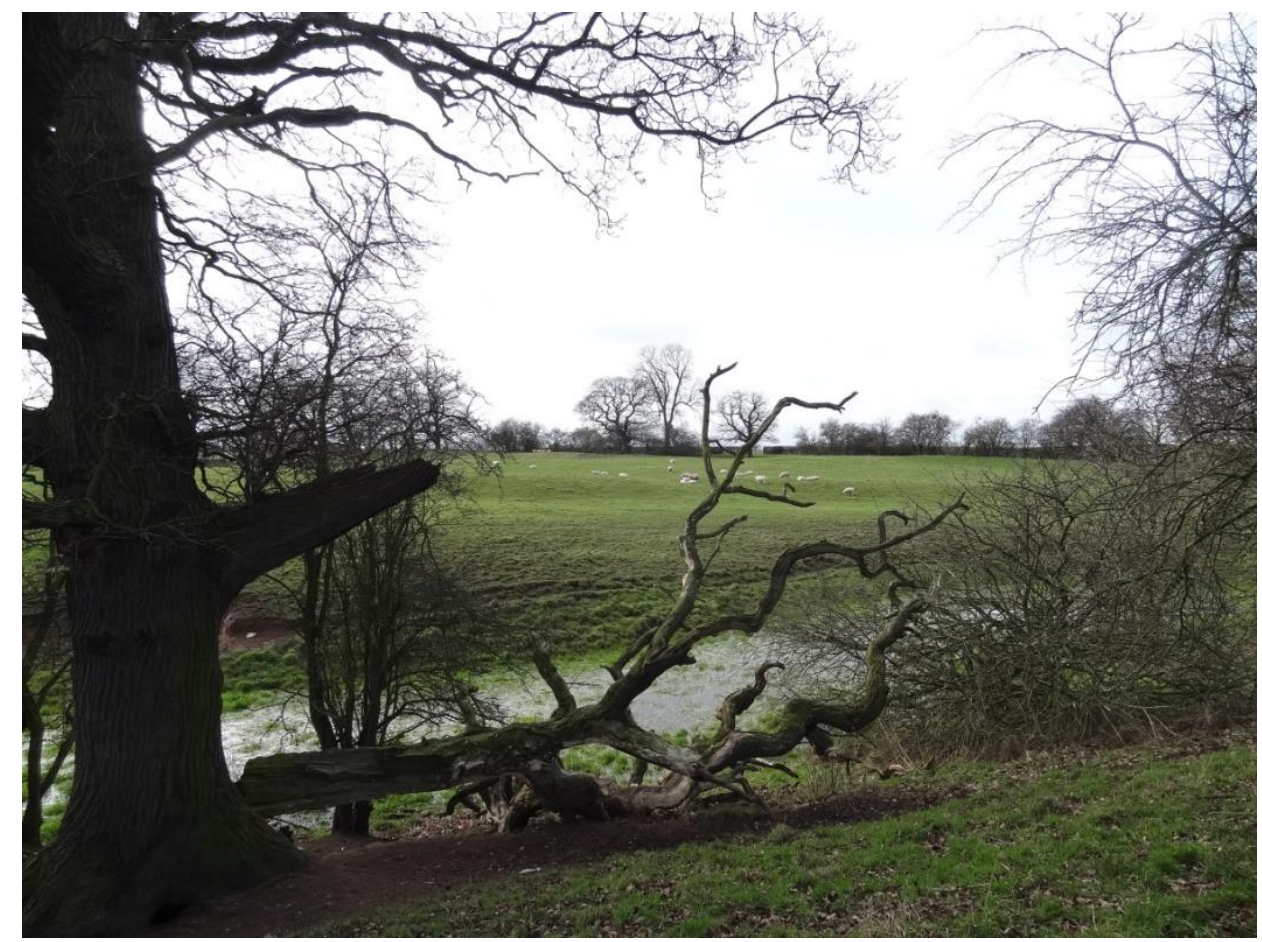

Fig. 5-29 Pan Castle, looking south from the motte to the bailey; earthworks are visible in the middle distance (Norton, 2015) 


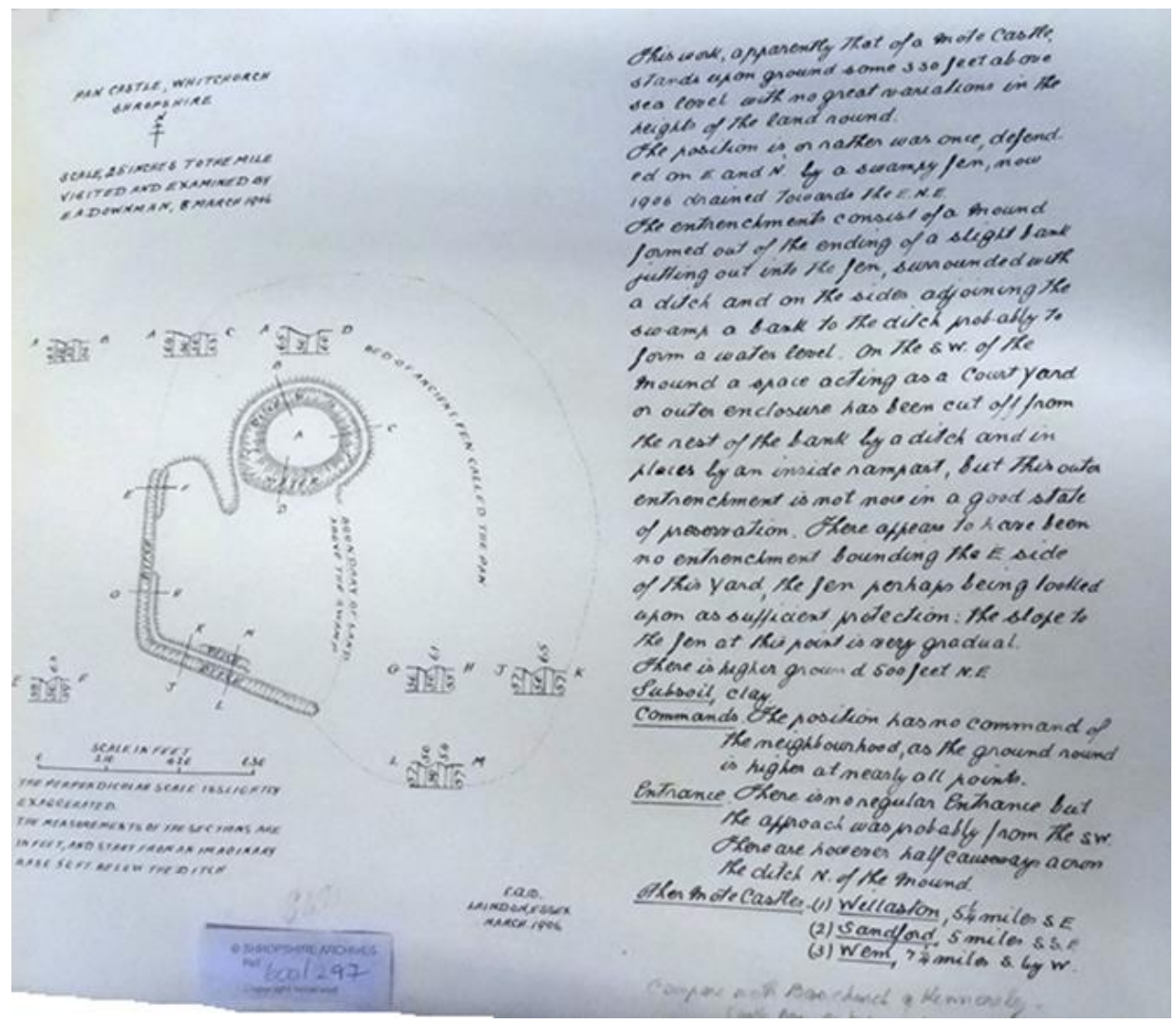

Fig. 5-30 Schematic map of Pan Castle (Downman, 1906)

Three other sites - Pave Lane, Castle Farm and Bomere Wood - complete this overview of North Shropshire's low-lying wetland fortifications.

\subsubsection{Pave Lane, Newport (Fig. 5-31)}

Pave Lane is a substantial trivallate enclosure of circa 3ha, located about $8 \mathrm{~km}$ east of Wall Camp and the Weald Moors, in similar low-lying terrain. The settlement occupied a gravel headland overlooking a peat basin. Discovered originally by aerial photography, a detailed excavation and geophysical exploration in 1990 identified enclosure ditches, a cobbled surface and a likely south-west entrance which accessed drier ground (Smith, 1991). Eaves gullies for two roundhouses were identified in the interior. The site has proven palaeoenvironmental potential and pollen analysis has already indicated that the surroundings were largely open grassland. The site is now a private garden and there is no public access. One section of the earthworks lies in the area shown in photograph Fig. 5-31 and the site utilised the water course as part of its defences. The excavation concluded that this was a defended enclosure in a pastoral landscape. Archaeological evidence in the immediate vicinity is limited to one burnt mound and a possible Roman enclosure. 


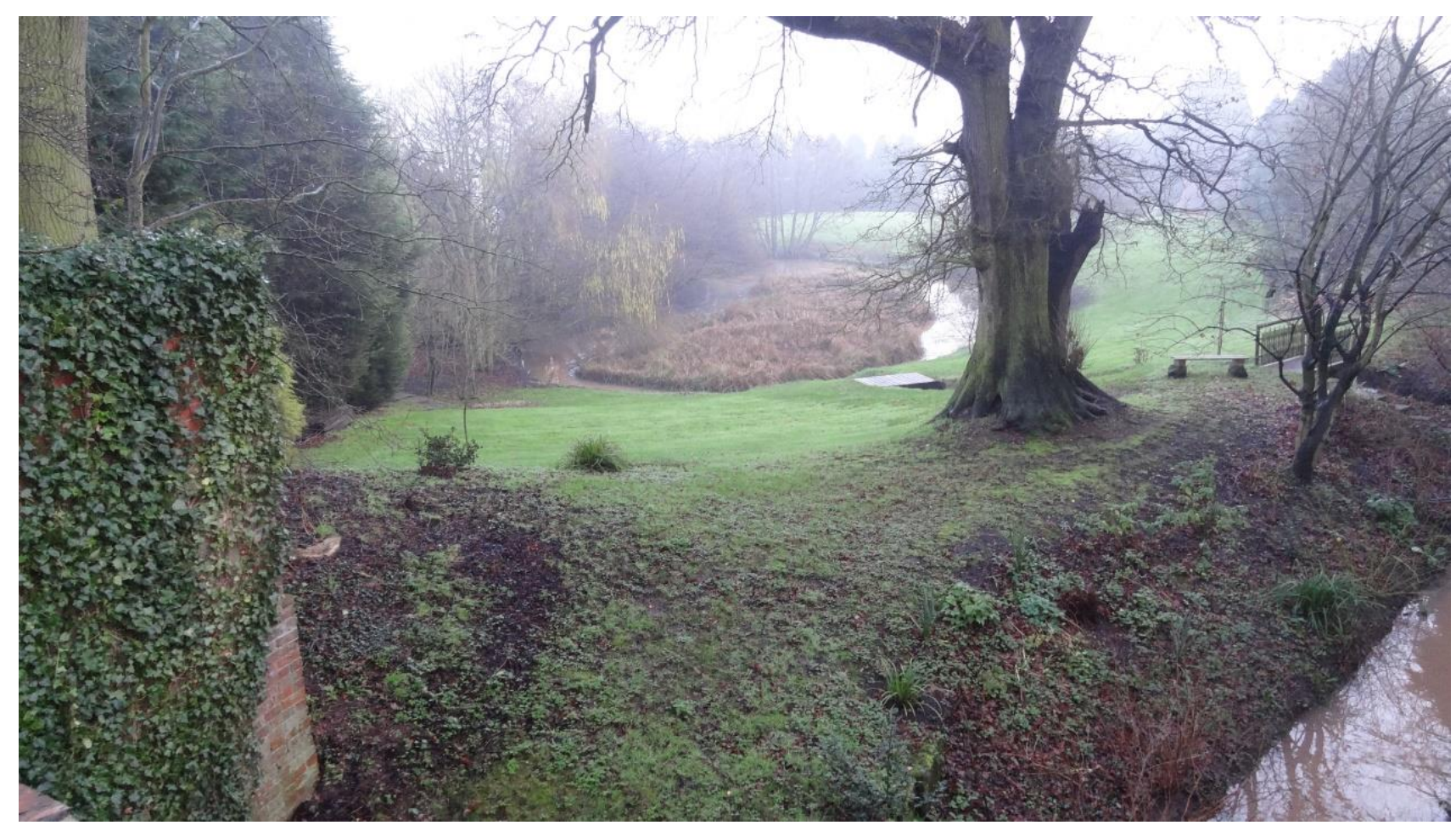

Fig. 5-31 Pave Lane from the road (Norton, 2015); given the amount of modern landscaping, establishing which earthworks relate to the Iron Age farmstead is difficult but the water course (right) formed part of the enclosure defences

\subsubsection{Castle Farm, Shifnal}

Castle Farm (destroyed) comprised three main elements - a cropmark enclosure, a medieval moated site and a post-medieval farm complex. It was discovered by aerial photography in 1959 and excavated as a salvage operation in advance of the construction of a reservoir in 1980 (Roe, 1991). Excavation revealed that the original cropmark was probably of Iron Age date and comprised a single-ditched curvilinear enclosure which may have been constructed by gang-working. The enclosure was unfinished and largely unoccupied, but was then re-fortified in the Roman period. Evidence was recovered for pits, a large post-hole, and a hearth of burnt clay which was associated with spreads of charcoal and fragments of briquetage; other finds were few and preservation was poor. Further work on Castle Farm is not possible and evidence is too limited to draw any conclusions.

Other than their low-lying, wetland topography, there is no convincing argument to suggest that Pave Lane or Castle Farm were anything other than enclosed farmsteads within a pastoral economy.

\subsubsection{Bomere Wood (Fig. 5-32)}

Bomere Wood occupies a glacial moraine about $50 \mathrm{~m}$ above water level between Bomere and Shomere Pools, near Bayston Hill, to the south of Shrewsbury. Although the earthworks could be interpreted as anthropogenic in origin, it has also been suggested that the site is natural (pers.comm. Historic England March 2014; Shropshire HER 59); there would have been little level ground for any settlement and there is 
no artefactual evidence. It is heavily wooded and there have been no investigations. The site is classified as a marsh-fort by the Atlas.

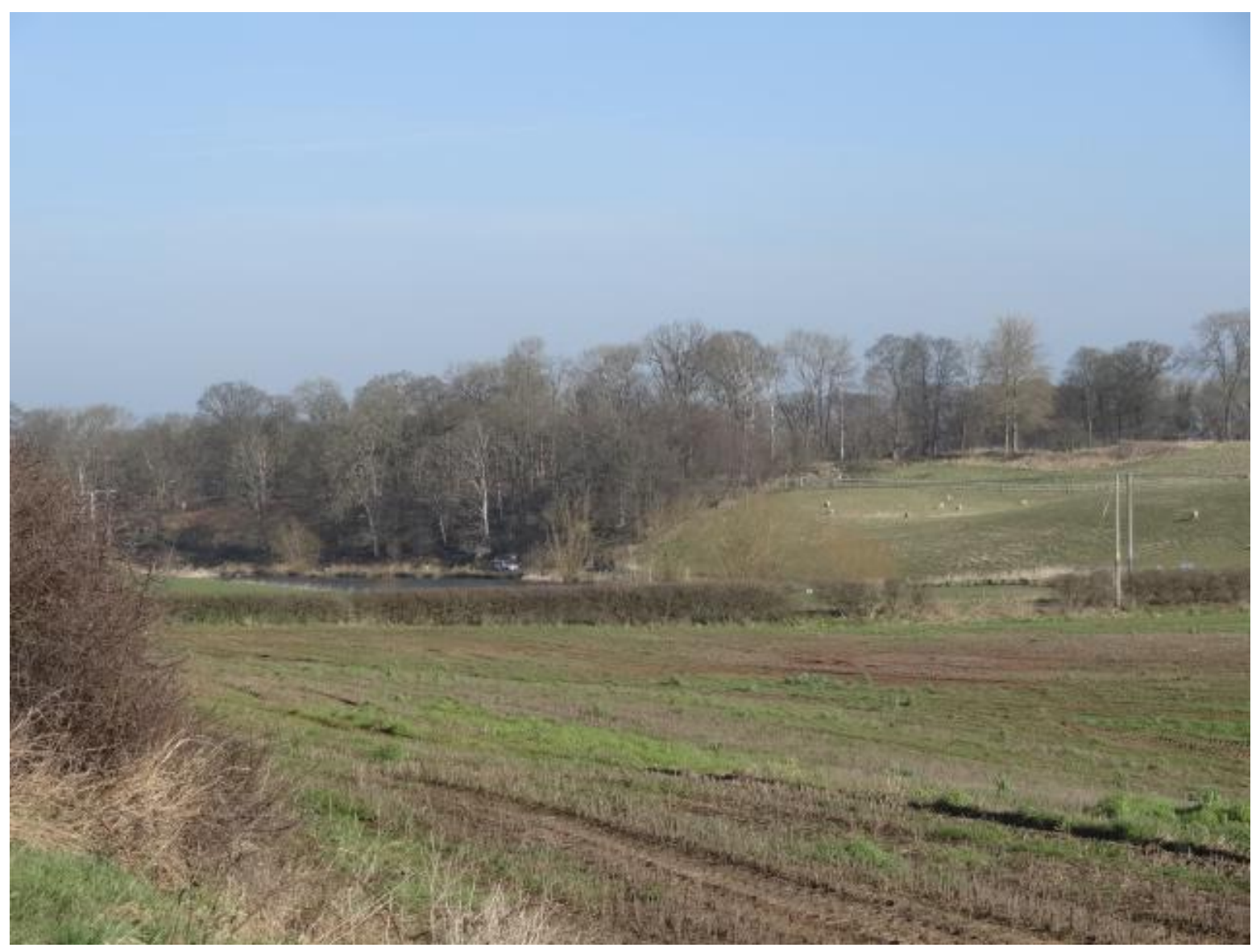

Fig. 5-32 Looking from the south, Bomere Wood occupies the wooded ridge above the pool (Norton, 2014) 


\subsection{Summary}

The archaeological evidence summarised in this chapter indicates that the Welsh Marches and North Shropshire were vibrant and well-populated throughout the Iron Age/Roman period. The organisation required to build substantial monuments in uplands areas - hillforts - was matched at lower elevation by building significant fortifications in wetland. In this chapter, North Shropshire's geological and topographical data has been used as a foundation to describe the archaeological and environmental history for each of the region's potential marsh-forts.

The same methodology as applied in Chapter 4 has been used to group North Shropshire's potential marshforts and the results are summarised in Table 5-1. Wall Camp and the Berth come closest to fulfilling the Sutton Common criteria and have been classified as Group 1 sites (see 4.3). At 12ha, Wall Camp is a 'very large' fortification (Jackson, 1999), twice as large as Sutton Common, with substantial earthworks, set in marshland, with complex access and morphology, and two possible entrances. Archaeological sites and findspots from the surrounding wetland indicate that the area was associated with metalwork deposition and possible ceremonial activity during the Bronze Age. During the Iron Age, settlement activity focussed on the Tern Valley, whilst Wall Camp was almost isolated. The excavational evidence from Wall Camp suggests limited domestic usage during the Middle/Late Iron Age. However votive deposition continued in the wider area (as evidenced by the Telford torc) and the wetland to the immediate east of Wall Camp may also hold votive deposits.

The Berth's macro- and micro-landscape features are explored as an in-depth case-study in Chapters 6, 7 and 8.

Conclusions from the remaining marsh-fort candidates are necessarily tentative. Castle Farm and Pave Lane (Group 4 sites) are of Iron Age/Roman chronology, with defensive architecture, occupying low-lying wetland, but there is nothing in the morphology or the finds record to suggest that these sites were anything other than defended farmsteads. Of the marsh-fort candidates subsequently overwritten by medieval occupation, archival data for Pan Castle (Group 4) may suggest a deeper past, but no evidence directly links this site with prehistory. Whilst Whittington's medieval past dominates the site record, substantial earthworks surrounding the castle indicate an earlier structure which was more than a simple settlement; the site is defended by watercourses. Given its location and tentative finds record, Stocketts Enclosure is worth further consideration, although evidence is scarce. Both Whittington and Stocketts Enclosure have been classified as potential marsh-forts (Group 2 sites). The superficial geology for Wall Camp, Whittington and Stocketts Enclosure suggest that they were strategically positioned to control wetland during the Iron Age.

Commonality of function and interaction between these sites and site hierarchy are discussed in Chapter 9 , where the evidence is combined with that discussed in Chapters 4, 6, 7, and 8 to develop a theory for marsh- 
forts across England and Wales. In 1991, it was Carver's view that 'Shropshire is one of the regions in England where...we are still learning how to do archaeology' (Carver, 1991:1). Examination of Shropshire's Iron Age marsh-forts can help to take that learning a little further forward. 


\section{IRON AGE MARSH-FORTS - ENGLAND AND WALES}

\begin{tabular}{|c|c|c|c|c|c|c|c|c|c|}
\hline & & & & & & LEGEND & $\begin{array}{l}\text { Group } 1 \text { Marsh- } \\
\text { fort used for } \\
\text { ritual/non- } \\
\text { domestic } \\
\text { purposes }\end{array}$ & $\begin{array}{l}\text { Group } 2 \\
\text { Possible marsh- } \\
\text { fort: ritual/non- } \\
\text { domestic } \\
\text { functionality }\end{array}$ & $\begin{array}{l}\text { Group } 3 \text { Possible marsh-fort. } \\
\text { Evidence is predominantly } \\
\text { domestic; potential economic } \\
\text { centre or territorial marker }\end{array}$ \\
\hline Region & Site & $\begin{array}{l}\text { large } \\
\text { size }\end{array}$ & $\begin{array}{l}\text { location/ } \\
\text { marshland } \\
\text { setting }\end{array}$ & $\begin{array}{l}\text { Monumentality } \\
\text { / morphology }\end{array}$ & $\begin{array}{l}\text { MIA/LIA } \\
\text { chronology }\end{array}$ & $\begin{array}{l}\text { Lengthy } \\
\text { landscape } \\
\text { chronology/ } \\
\text { discontinuity } \\
\text { of use }\end{array}$ & $\begin{array}{l}\text { Localised } \\
\text { woodland } \\
\text { clearance/ } \\
\text { pasture }\end{array}$ & $\begin{array}{l}\text { Non- } \\
\text { domestic; } \\
\text { possible } \\
\text { ceremonial or } \\
\text { ritual use }\end{array}$ & Summary \\
\hline \multirow[t]{5}{*}{ Shropshire } & The Berth & $\checkmark$ & $\checkmark$ & $\checkmark$ & $\checkmark$ & $\checkmark$ & $\checkmark$ & $\begin{array}{l}\checkmark / \text { unk } \\
\text { (deposition of } \\
\text { Berth Cauldron) }\end{array}$ & $\begin{array}{l}\text { Marsh-fort; highly unusual } \\
\text { morphology; internal } \\
\text { evidence for settlement is } \\
\text { unproven; Berth Cauldron } \\
\text { discovered on site }\end{array}$ \\
\hline & $\begin{array}{l}\text { Bomere } \\
\text { Wood }\end{array}$ & unk & $\begin{array}{l}\text { on a higher } \\
\text { ridge } \\
\text { above } \\
\text { Bomere } \\
\text { pool }\end{array}$ & unk & unk & unk & unk & unk & $\begin{array}{l}\text { Natural - possibly } \\
\text { anthropogenically enhanced }\end{array}$ \\
\hline & $\begin{array}{l}\text { Castle Farm } \\
\text { (dest) }\end{array}$ & $x$ & $x$ & $x$ & $x$ & $\checkmark$ & unk & $x$ & $\begin{array}{l}\text { Enclosure; evidence limited; } \\
\text { site now destroyed }\end{array}$ \\
\hline & Pan Castle & unk & $\checkmark$ & unk & unk & unk & unk & unk & $\begin{array}{l}\text { Too little evidence to } \\
\text { suggest anything other than } \\
\text { a Motte and Bailey }\end{array}$ \\
\hline & Pave Lane & $\checkmark$ & $\checkmark$ & $\checkmark$ & $\checkmark$ & unk & $\checkmark$ & $x$ & $\begin{array}{l}\text { A large defended } \\
\text { farmstead/enclosure; } \\
\text { evidence is domestic }\end{array}$ \\
\hline
\end{tabular}


IRON AGE MARSH-FORTS - ENGLAND AND WALES

\begin{tabular}{|c|c|c|c|c|c|c|c|c|c|}
\hline & & & & & & LEGEND & $\begin{array}{l}\text { Group } 1 \text { Marsh- } \\
\text { fort used for } \\
\text { ritual/non- } \\
\text { domestic } \\
\text { purposes }\end{array}$ & $\begin{array}{l}\text { Group } 2 \\
\text { Possible marsh- } \\
\text { fort: ritual/non- } \\
\text { domestic } \\
\text { functionality }\end{array}$ & $\begin{array}{l}\text { Group } 3 \text { Possible marsh-fort. } \\
\text { Evidence is predominantly } \\
\text { domestic; potential economic } \\
\text { centre or territorial marker }\end{array}$ \\
\hline \multirow[t]{4}{*}{ Region } & Site & $\begin{array}{l}\text { large } \\
\text { size }\end{array}$ & $\begin{array}{l}\text { location/ } \\
\text { marshland } \\
\text { setting }\end{array}$ & $\begin{array}{l}\text { Monumentality } \\
\text { / morphology }\end{array}$ & $\begin{array}{l}\text { MIA/LIA } \\
\text { chronology }\end{array}$ & $\begin{array}{l}\text { Lengthy } \\
\text { landscape } \\
\text { chronology/ } \\
\text { discontinuity } \\
\text { of use }\end{array}$ & $\begin{array}{l}\text { Localised } \\
\text { woodland } \\
\text { clearance/ } \\
\text { pasture }\end{array}$ & $\begin{array}{l}\text { Non- } \\
\text { domestic; } \\
\text { possible } \\
\text { ceremonial or } \\
\text { ritual use }\end{array}$ & Summary \\
\hline & $\begin{array}{l}\text { Stocketts } \\
\text { Enclosure }\end{array}$ & $?$ & $\checkmark$ & $\checkmark$ & $x$ & unk & $\checkmark$ & unk & $\begin{array}{l}\text { Landscape context and a } \\
\text { few finds could suggests this } \\
\text { was possibly a (small) } \\
\text { marsh-fort before use as a } \\
\text { Motte and Bailey }\end{array}$ \\
\hline & Wall Camp & $\checkmark$ & $\checkmark$ & $\checkmark$ & $\checkmark$ & $\checkmark$ & unk & $\begin{array}{l}x, \text { however, } \\
\text { Telford Torc } \\
\text { was found } \\
\text { nearby }\end{array}$ & $\begin{array}{l}\text { In spite of some domestic } \\
\text { evidence, monumentality } \\
\text { and landscape context } \\
\text { suggest this as a marsh-fort; } \\
\text { the Telford torc was found } \\
\text { nearby }\end{array}$ \\
\hline & $\begin{array}{l}\text { Whittington } \\
\text { Castle }\end{array}$ & $\checkmark$ & $\checkmark$ & $\checkmark$ & $\checkmark ?$ & unk & unk & unk & $\begin{array}{l}\text { Evidence is limited and } \\
\text { dominated by the medieval } \\
\text { castle; nevertheless, this } \\
\text { was a sizeable, riverside } \\
\text { Iron Age settlement and } \\
\text { possible marsh-fort. } \\
\text { Possibly twinned with Old } \\
\text { Oswestry }\end{array}$ \\
\hline
\end{tabular}




\section{The Berth - a marsh-fort in its landscape context}

The criteria developed for Sutton Common are reflected in greater detail by the Berth than by other marshforts, and the site presents an important opportunity to assess whether the marsh-fort phenomenon was culture-specific, convergent or universal. To date, the Berth's wider landscape, morphology and environment have only been explored superficially, and its extensive palaeoenvironmental archive presents an opportunity to establish the site within its environmental setting.

The following three chapters present the results of a macro- and micro-scale case-study of a marsh-fort in its landscape. At macro-scale, topographical mapping is combined with the archaeological records to position the Berth within its socio-economic context and illustrate the extent of possible interaction with sites across Upper Perry river valley and the North Shropshire Plain (Chapter 6). The Berth's archival record and previous excavations on site are summarised in Appendices 2 and 3.

At micro-level and concentrating on the peat basin surrounding the marsh-fort, the results are presented firstly, of a coring programme which describes the Berth's underlying Late Glacial topography and stratigraphy (Chapter 7), and secondly, of a multi-proxy palaeoenvironmental analysis which describes an almost complete Holocene sequence of vegetational development (Chapter 8). The micro-scale analysis is supported by a radiocarbon dating programme. Data from excavations are limited, and are incorporated where appropriate, elevating the study from multi-proxy to multi-disciplinary.

The results of the micro-analysis illustrate the nature of the marshland surrounding the Berth and the challenges faced by those who constructed the marsh-fort, and asks the question - what were the forces at play in later prehistory which led to the creation of an Iron Age fort in an extreme environment? This is discussed in Chapter 9.

This work illustrates the value and diversity of wetland archaeology. This was not a dynamic landscape - in fact, it was quite quiet - getting wetter, drying out, wetter again, being cleared of woodland, regenerating. Nevertheless, it affords a unique opportunity to investigate the creation of a significant monument in its landscape context. 


\subsection{Location, superficial geology and archaeological history}

The Berth has been referenced many times in this thesis and is introduced here as an archaeological entity.

The Berth lies in the area of the Mid-Shropshire meres, $1.5 \mathrm{~km}$ north-east of Baschurch and $12 \mathrm{~km}$ north-west of Shrewsbury (Fig. 6-1). The site has no public access and ownership is split between three landowners. It is located in an 80ha bowl-shaped peat basin at the south-eastern end of the Upper Perry valley mire, from which it is separated by shallow ridges (Fig. 6-2) (see also Chapter 7).

The monument lies in wetland at the $80 \mathrm{mOD}$ contour and its total Scheduled Area covers 8 ha including causeways. It comprises two enclosures connected by a T-shaped causeway (Fig. 6-3). The earthworks of the main enclosure surround the base of a flat-topped mound (Berth Hill) of glacial sands and gravel which rises to $97 \mathrm{mOD}$. The rampart is univallate for most of its circuit, but bivallate in places, and was originally faced with large stones (Guilbert et al., 1977). Its most obvious entrance lies close to Berth Pool, faces south-east, and is sharply in-turned. The smaller enclosure lies approximately $100 \mathrm{~m}$ to the east of the main enclosure; it is kidney-shaped with entrances to the east and west, and an additional gap/entrance to the north (highlighted Fig. 6-3). Schematic maps made in the 1980/1990s indicate that the site had been subject to extensive gravel extraction, presumed to be in the nineteenth and twentieth-centuries (Shropshire HER: Tyler/Smithson maps); this has affected both enclosures, especially around the entrances.

The monument was subject to several seasons of excavation during the 1960s (Gelling, 1962/5; Gelling, 1964; Gelling and Stanford, 1965 (1967)) (see Appendix 2). Two trenches placed close to the south-east entrance revealed three phases of use separated by sterile layers. A cobbled surface was found, together with several post-holes which were assumed to relate to house structures. A range of finds including a La Tène III brooch, two spindle whorls and metal objects (including a possible knife and dagger) were also recovered. The pottery finds remain the only accurate means of dating the site. A large quantity of Cheshire briquetage/VCP and thirty-one sherds of Iron Age pottery (mainly Malvernian Ware and Clee Hills dolerite fabric) indicate that the site was used from the Middle-Iron Age onwards, and that its people communicated with others throughout the Severn Valley; the site was in use during the Roman period, as indicated by three sherds of Severn Valley ware (Peacock, 1965-7; Morris and Gelling, 1991). Given the aceramic nature of Cornovian society, the assemblage could be seen as quite plentiful; Sutton Common produced very little ceramic evidence (Van de Noort et al., 2007:143). Two (possible) crucibles indicate that metal (bronze) was worked on site. Several agricultural implements, two currency bars and a 'slave chain' survive as photographic records only, and originated from an unrecorded trench which was opened by local archaeologist, Ernie Jenks, at the same time as the Gelling excavation. These items are now lost, but a desktop comparison with the Llyn Cerrig Bach Hoard indicates that the chain was unlikely to be large enough to restrain slaves (https://museum.wales/iron age teachers/artefacts/gang chain/) and is better categorised 
as a vessel suspension chain (Manning, 1983). The Gelling archive is confused and was never adequately documented. It contains two diaries plus photographs of the excavations, few of which are captioned; one photograph shows a handful of grain (probably spelt wheat; pers.comm. Dr Wendy Smith, University of Birmingham) but it is not clear which part of the site it relates to, or whether indeed it relates to the Berth at all, as Gelling was excavating at Caynham Camp around the same time (pers.comm. Shelagh Hampton, local historian). Around 1974, a blue-green glass bead was found in disturbed ground on the top of the Berth Hill and is considered to be Roman (pers.comm. Dr Denise Allen) (Fig. 6-4).

The Berth was of considerable interest to antiquarians who focussed mainly on the site's (assumed) Dark Age past and associated folklore (e.g. Buckler, 1787 - 1897; Hartshorne, 1841; Jackson, 1883) (see Appendix 3). Twentieth-century historians (e.g. Chitty, 1923-32) also visited the site, enticed not only by its folklore, unusual location and morphology, but by the discovery, in 1906, of the Berth Cauldron (Fig. 6-5). This copper-alloy vessel, measuring $0.45 \mathrm{~m} \times 0.3 \mathrm{~m}$, was found during ditch clearance at the point where the Berth Stream crosses the north-south causeway. A manufactured hole in its base led to its initial interpretation as a water-clock (Smith, 1907) and it was allocated a sub-Roman date (circa seventh-century AD). The waterclock theory was subsequently refuted by Hawkes and the hole was re-interpreted as the attachment point for the lathe used in its manufacture (Hawkes, 1951). Its dating is now established as Roman, between the mid-first to second-centuries AD (pers.comm. Dr J. Farley, British Museum, 2015; Joy, 2014:6). Its importance as a depositionary object within the Berth landscape is explored below (see 6.2.4). The Berth was assumed to have become the central stronghold of the Cornovii after the Romans left Viroconium, (Trinder, 1983:22; Gelling, 1992:25); however, the archaeological remains are too few to justify this conclusion.

Recent excavations (2016/2017) of the Berth's two upstanding causeways were undertaken to provide information regarding site access (Chapman, Smith and Norton, 2017). Their construction style and two artefact finds (a copper belt buckle and a piece of medieval tile found in Trench 2) suggest that these causeways are post-medieval and possibly built to facilitate quarrying and gravel extraction, in similar fashion to other sites locally in Staffordshire (e.g. Blockley and Shaw, unpublished; see Fig. 6-6). However, whilst no underlying prehistoric structure was identified, the underlying deposits have been radiocarbon dated to the Iron Age (see 7.2) and a nineteenth-century eye-witness account describes the causeways as parch-marks level with the surrounding peat (Hartshorne, 1841); this conundrum is explored below (see 7.3 and 7.5 and Appendix 3). A newly found entrance to the north-east of the main enclosure was accessed by a hitherto unknown causeway which connected the small and large enclosures across the shortest part of the peat basin (Fig. 6-3). Excavations are ongoing. 


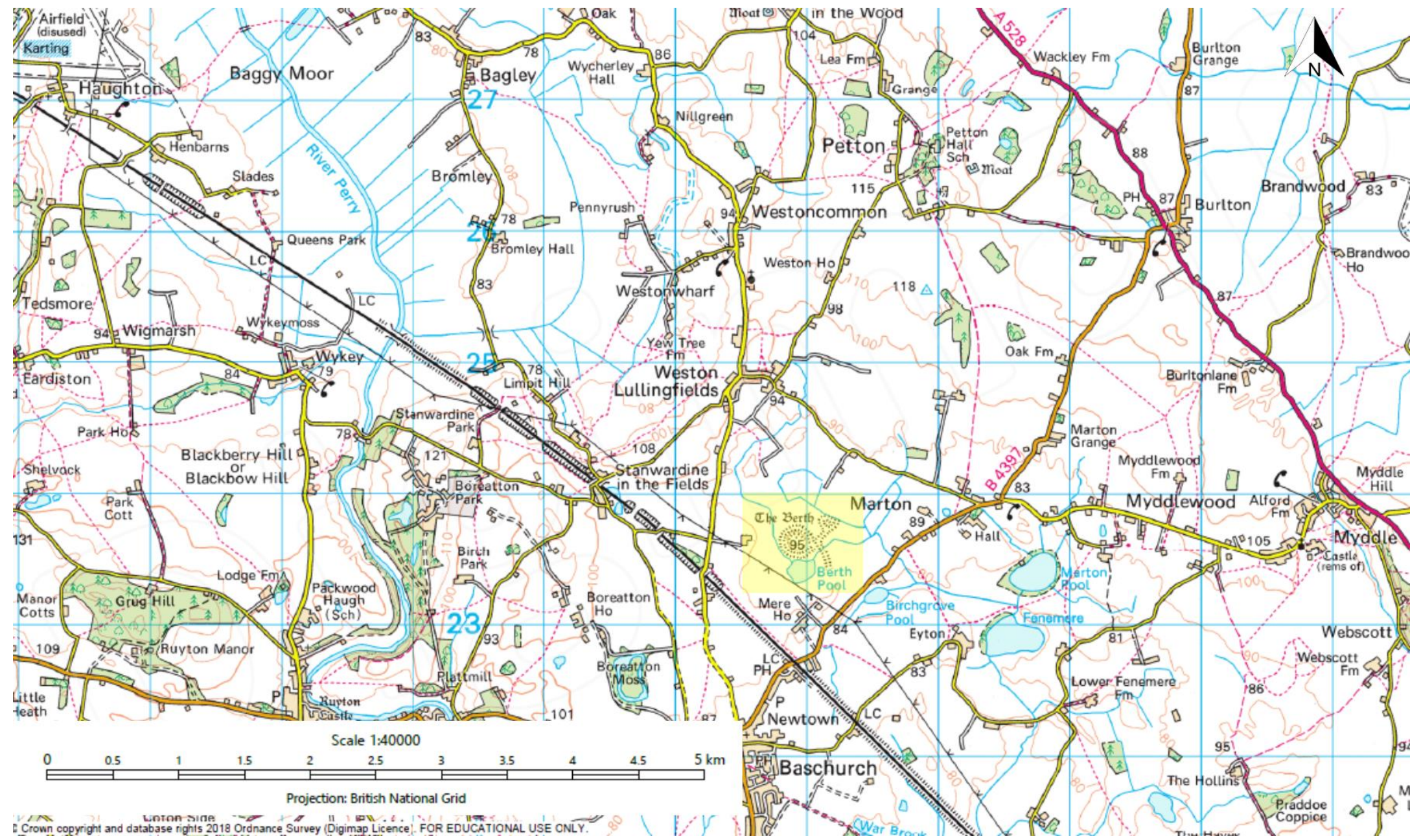

Fig. 6-1 The Berth - location map (OS 1:50,000 series; Edina Digimap; January 2018) 


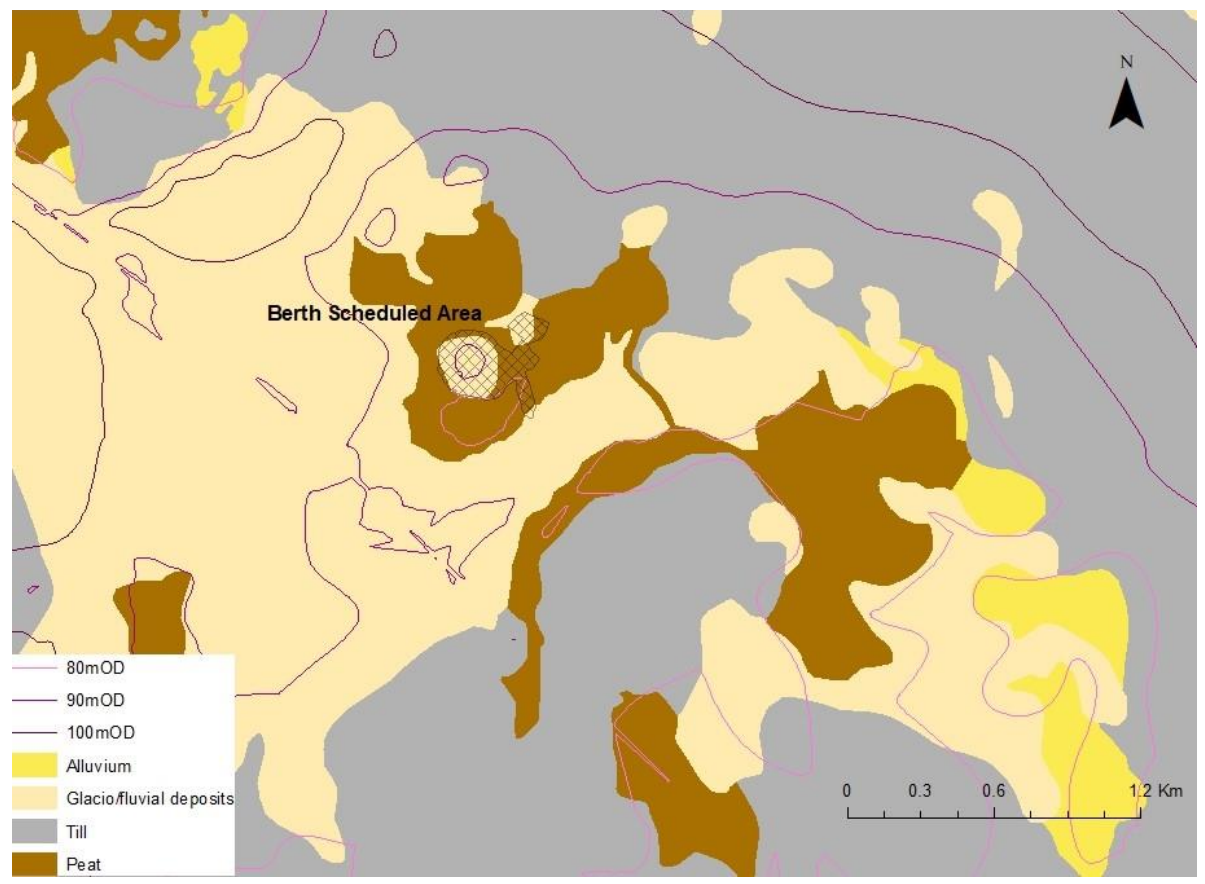

Fig. 6-2The Berth: superficial geology and contour (BGS 1:50,000; June 2017)

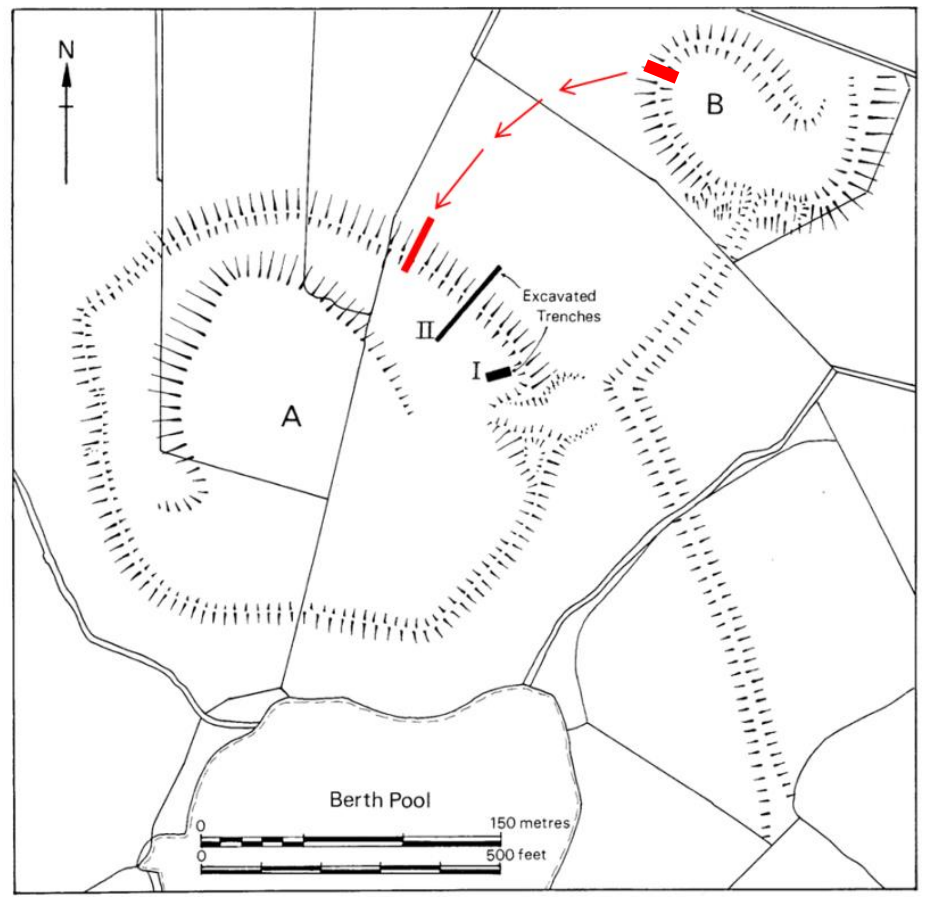

Fig. 6-3 The Berth - schematic map showing trenches excavated by Gelling (Morris and Gelling, 1991: Fig. 17). The trench excavated in $\mathbf{2 0 1 7}$ plus the line of the third causeway are shown in red 
Chapter 6 - The Berth and Upper Perry - macro-scale landscape analysis

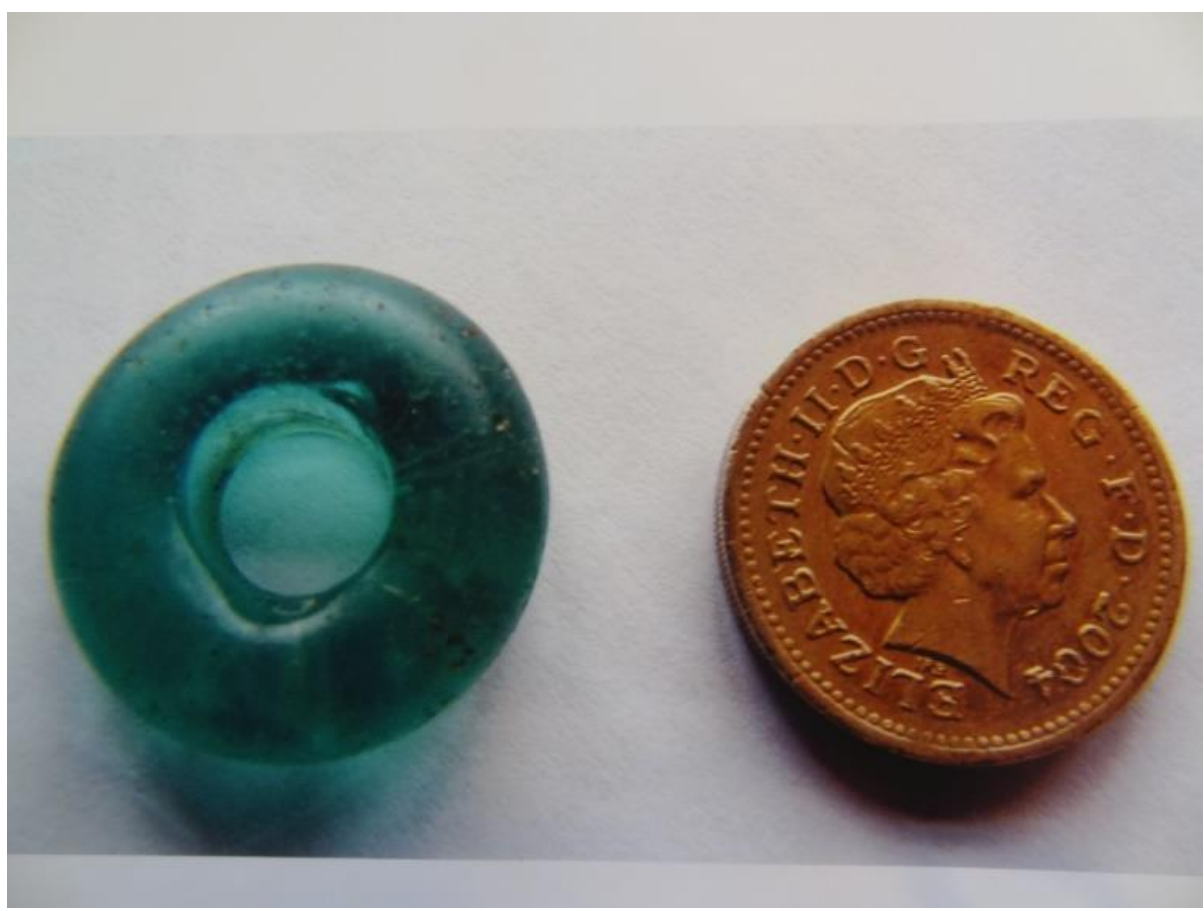

Fig. 6-4 Roman glass bead (D. Allen)

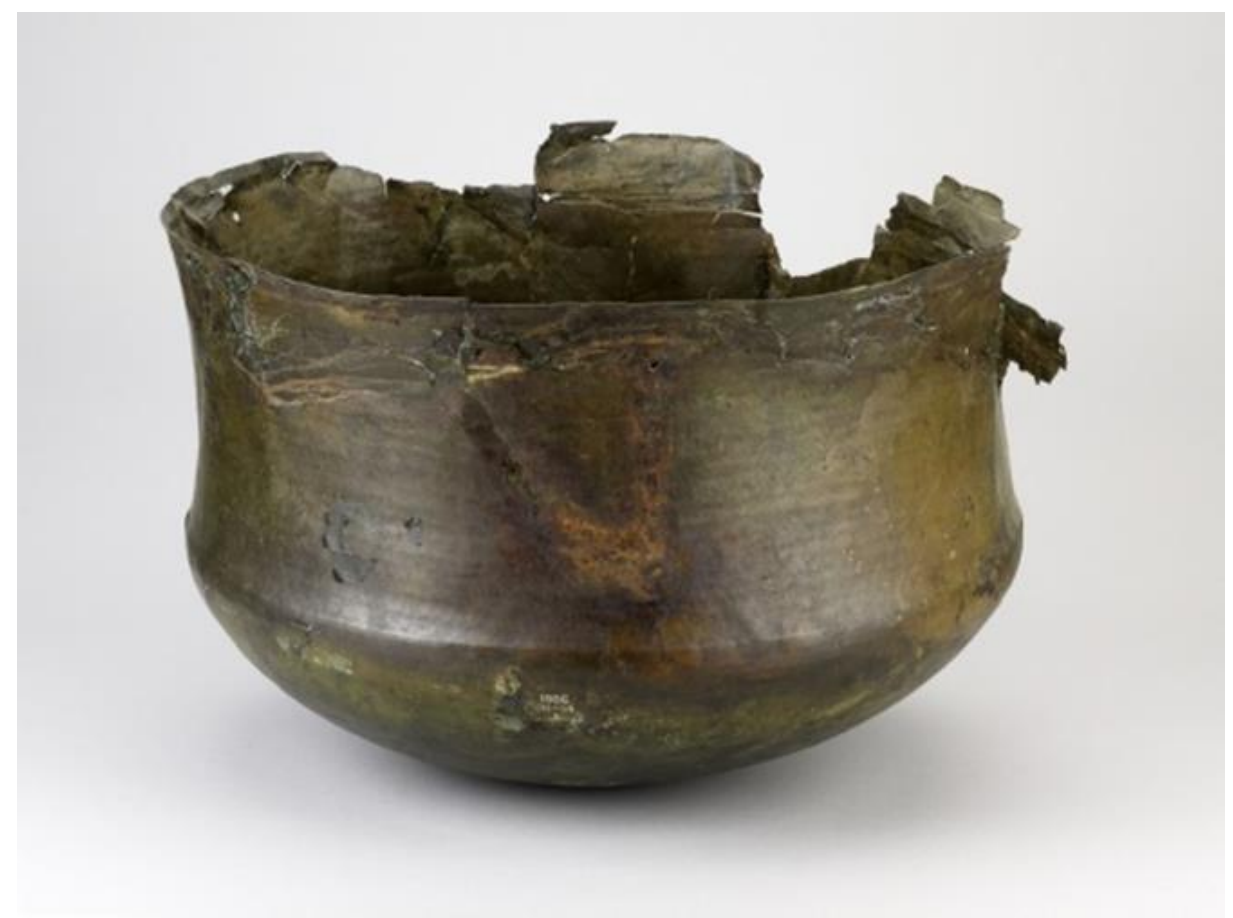

Fig. 6-5 The Berth Cauldron (British Museum/Shrewsbury Museum) 


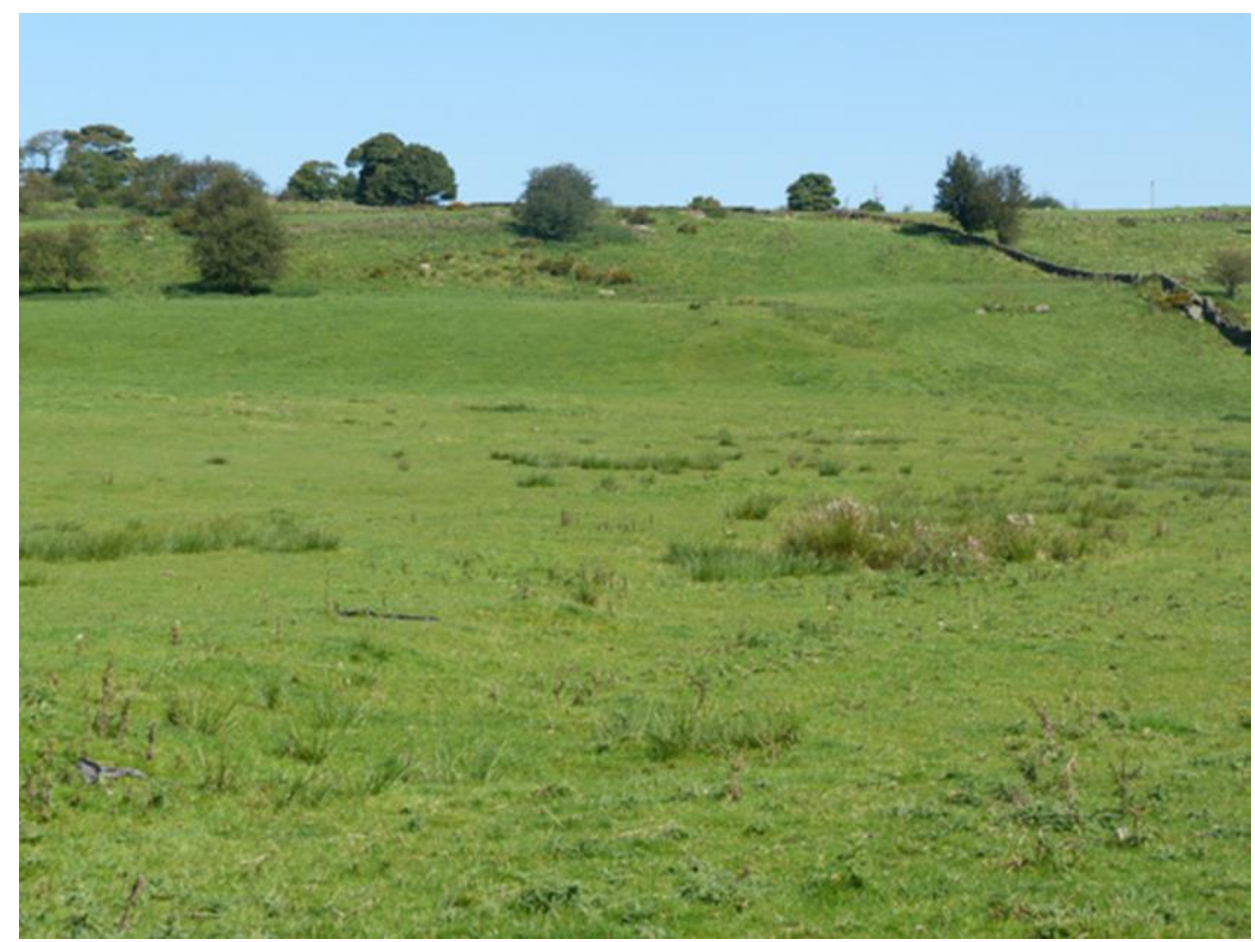

Fig. 6-6 One of a series of railway embankments at Caldon Low, Staffordshire, which are similar to the Berth's causeways (Blockley and Shaw, unpublished: Plate 8)

\subsection{The Berth and the Upper Perry - macro-scale landscape analysis} 'Landscape provides both a broad scale over which to think about human action in the past and allows for an holistic consideration of the archaeological evidence in its relations to topography, plants and animals, (and) climate.' (Gosden, 2013:3).

The Berth's hinterland presents a wealth of archaeological evidence including lithics from the Mesolithic onwards, evidence for an encultured, tenured landscape during the Bronze Age, and from the Iron Age onwards, increasing evidence for settlement and farming. As land tenure solidified, large scale Iron Age fortifications were constructed in highly visible places in the wider environment as well as in low-lying marsh-land.

The aim of the following macro-scale analysis is to recreate this landscape temporally and spatially and provide a broad context for the micro-landscapes discussed in the next two chapters. Topographical data (1mDTM LiDAR; superficial geology data) is combined with 
archaeological evidence (HER/PAS records), and deployed within a GIS (ArcGIS 10.2), to create multi-chronological models illustrating change in land use through time, and reconstructing some of the relational dynamics that were active when the Berth was built. Setting a boundary in which to contextualise the Berth is somewhat arbitrary. The selected area encompasses the Berth and the Upper Perry river valley as far north as the Tetchill Brook, which was a focus for depositionary activities from the Bronze Age onwards. This area covers approximately $50 \mathrm{~km}^{2}$ and the results illustrate how the focus of human activity shifted across the landscape over time. This projection orientates the Berth to the north and north-west; with the exception of some enclosure sites, the areas due north of the Berth and beyond the enclosures to the south and south-east are virtually blank in terms of archaeological evidence.

This normative data is supplemented by a phenomenological line-of-sight model which suggests possible relationships between the Berth and other prominent features in the landscape (sensu Tilley, 1994). This approach should be seen as a precursor to additional work on viewshed analysis at the Berth, in much the same way as has been achieved at, amongst other sites, Avebury (Thomas, 1993), the Rudston Cursus complex and Sutton Common (Chapman, 2000; Chapman, 2003).

The area can be divided into three broad sections according to its superficial geology; these divisions reflect changes in land use and occupation during prehistory (see Fig. 6-7):-

- North-west of the Berth, the Upper Perry valley mire is formed of peat and glacial deposits and shows mainly Mesolithic/Neolithic and Bronze Age use - lithics, metalwork deposition and burnt mounds

- To the south-west, slightly higher ground comprising more solid geology was occupied by Bronze Age funerary monuments and numerous Iron Age/Roman enclosures

- South-east of the Upper Perry, the landscape is occupied by the Bronze Age Baschurch cemetery, the Berth and a number of later prehistoric enclosures

- The Berth is shown on all maps irrespective of chronology 


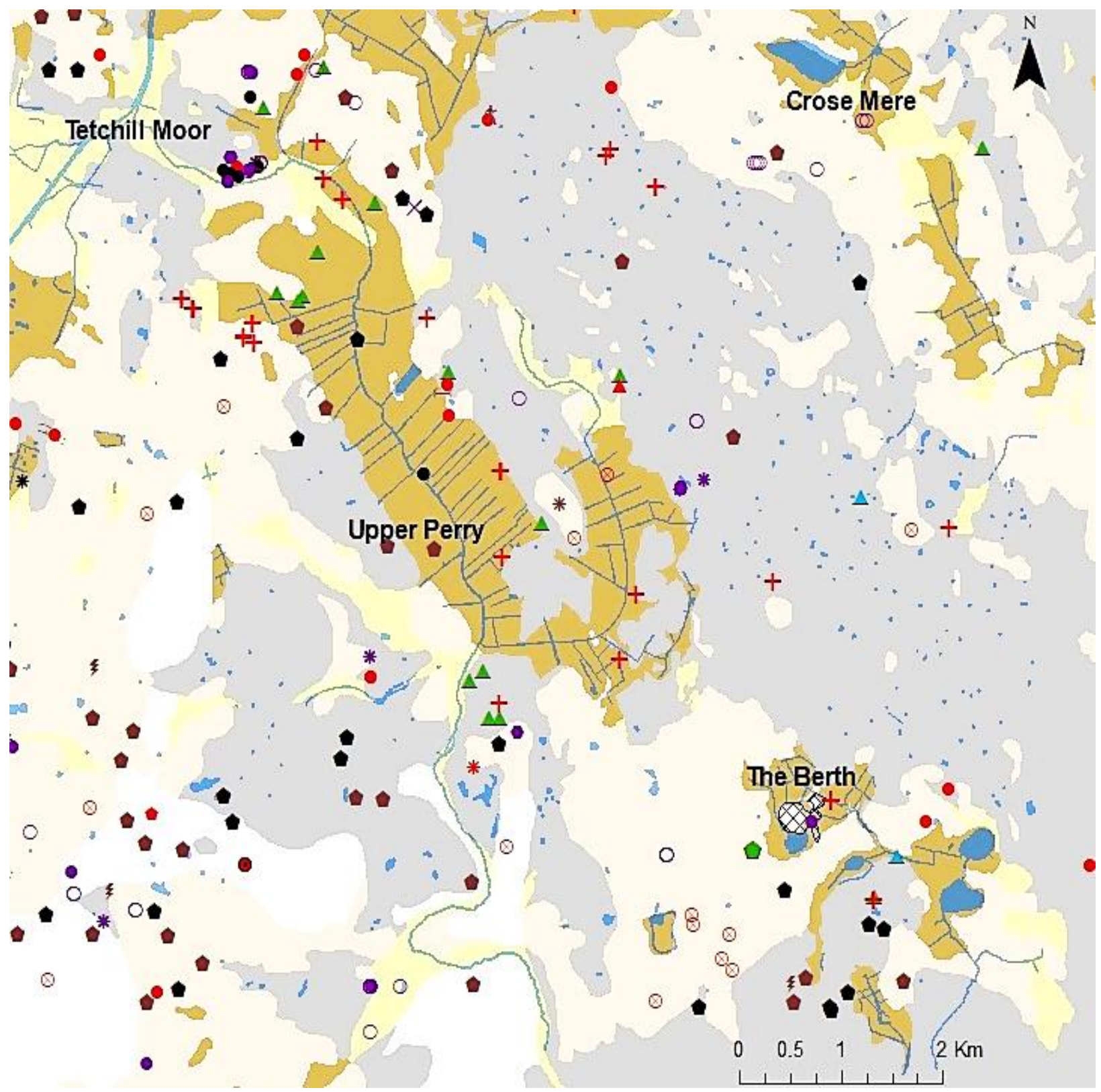

$\begin{array}{cccccccccc}\mathbf{\Delta} & \text { lithic } & - & \text { metalwork } & \smile & \text { canoe } & \mathrm{X} & \text { marching camp } & \otimes & \text { ring-ditch } \\ + & \text { burnt mound } & N & \text { pit alignment } & * & \text { artefact } & 0 & \text { stone circle } & * & \text { brooch/ring } \\ - & \text { ceramic } & K & \text { human remains } & + & \text { fort } & & \text { track way } & & \end{array}$

- crop mark/enclosure/field system

Period Prehistoric/Mesolithic Neolithic Bronze Age

Superficial Geology alluvium fluvio/lacustrine glacial deposits till peat river terrace

Fig. 6-7 The Berth/Upper Perry - all sites; superficial geology (BGS 1:50000; Dec 2017); Shropshire HER (May 2014); PAS (July 


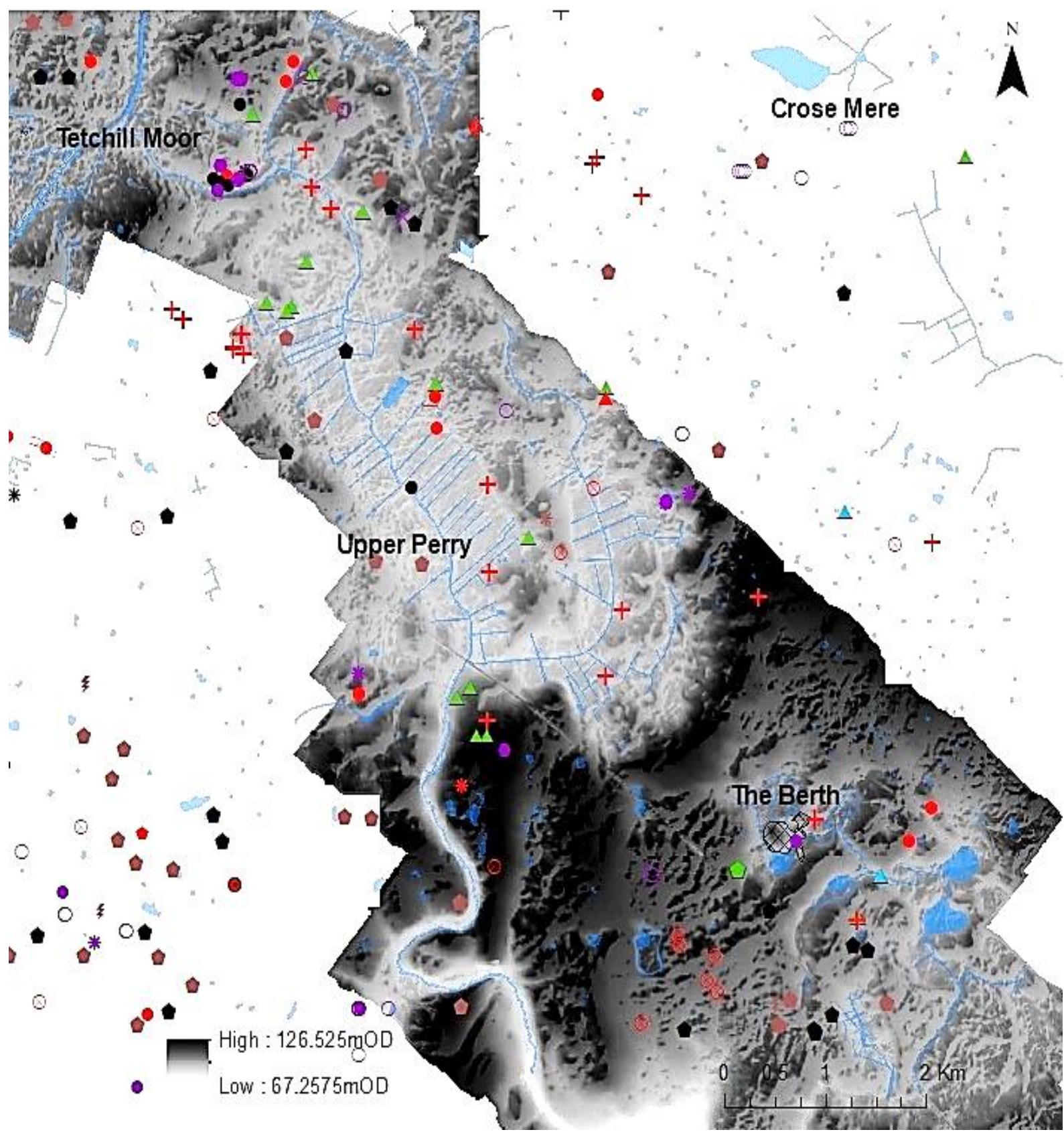

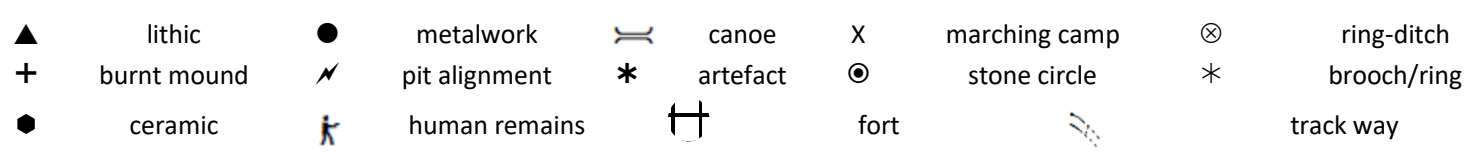

- crop mark/enclosure/field system

O

coin/coin hoard

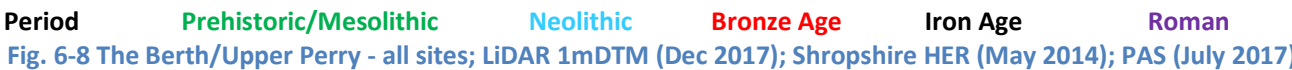
Undated 


\subsubsection{The Berth/Upper Perry - Prehistoric/Mesolithic/Neolithic (Fig.} 6-9)

There are eighteen records of early prehistoric lithic finds at the Berth and along the Upper Perry river valley, representing a wide chronology. Some deposits favour slightly higher ground whilst others were found along and south of the Tetchill Brook and around Wykey Weir. The scattering along the Upper Perry, together with a similar scattering on the Weald Moors, indicates that these low-lying reed-beds, peat moors and river courses were well utilised in early prehistory.

There has been limited recovery of Mesolithic, Neolithic and early Bronze Age lithics from across Shropshire and evidence has been confined to lithic scatters on sandstone outcrops such as at Nesscliffe (Leah et al., 1998:120). However, recent recoveries are changing this pattern. Whilst the Early Mesolithic lithic scatter near Wykey Weir (HER 31696) (Leah et al., 1998:142) still represents something of a rarity, it was matched by an assemblage, comprising Early Mesolithic, Mesolithic and Bronze Age items, found near Newport just outside the Weald Moors (HER 21902). A substantial assemblage, suggesting a flint working site, was also recovered from the summit of Grinshill, circa12km east of the Upper Perry (HER 4726). These finds are part of a growing body of evidence suggesting that hunter/gather activity was more prevalent on the North Shropshire Plain than previously thought. Although low in number, the finds along the Upper Perry suggests the river valley was a routeway and/or hunting place for Mesolithic hunter/gatherer communities.

Of the two Neolithic axes found in the area, one was recovered from a drainage ditch just south of the Berth and the other at the interface of the alluvium and mineral soils, north of the Berth; several more have been recovered slightly further north (Woodward, 2007:Fig. 12.2). Although there is always the possibility of accidental loss, given the highly ritualised treatment in the distribution of Neolithic axes and their frequent connection with causewayed enclosures and burial sites, most are considered to be deliberate ritualised depositions (Bradley, 1990:64-75; Whittle, 2009:89-90). Around the 


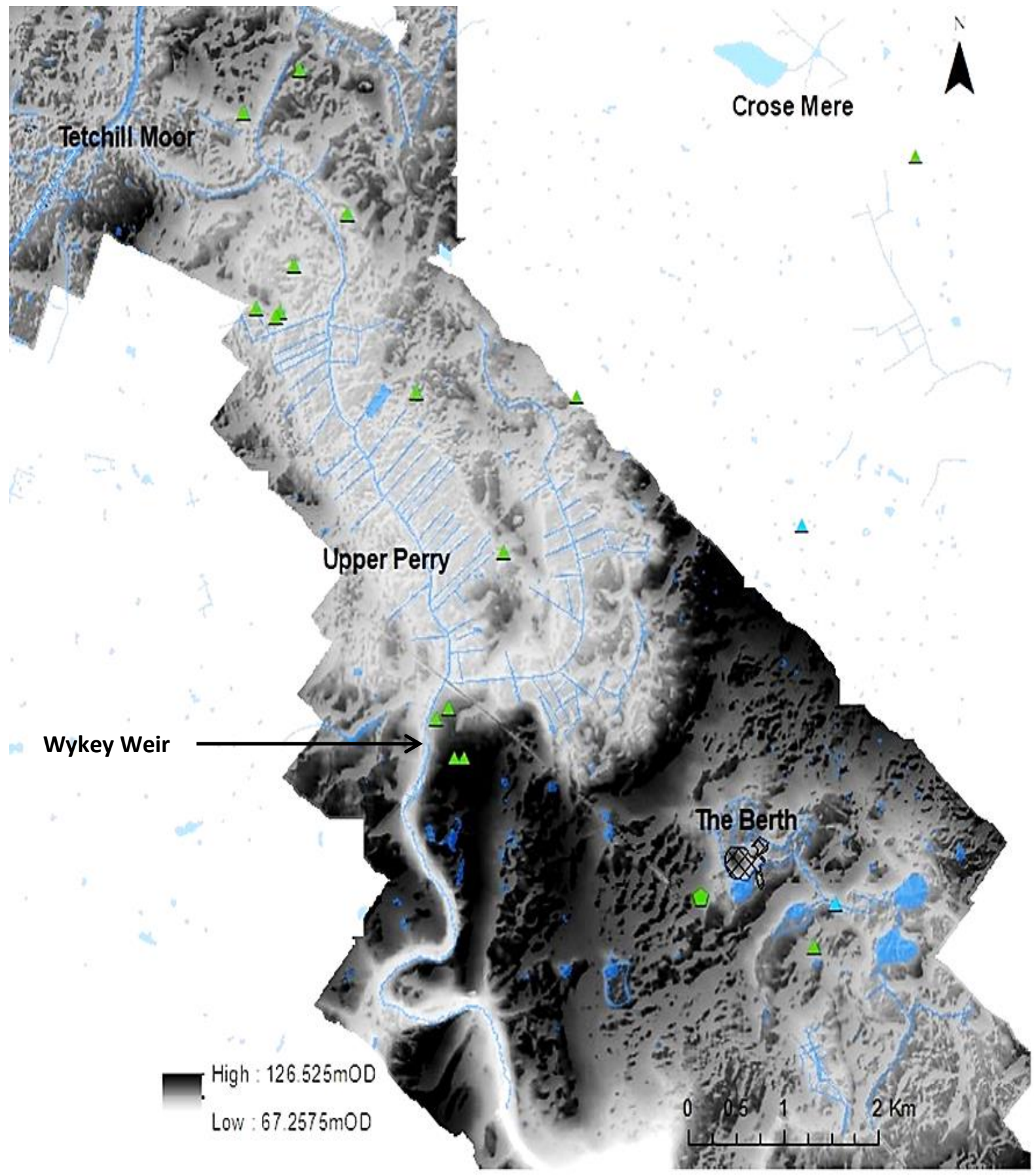

$\Delta$ lithic crop mark/enclosure/field system

Fig. 6-9 The Berth/Upper Perry - Prehistoric/Mesolithic/Neolithic 
Berth/Upper Perry, the axes appear to have been placed at the edge of the peat with no intention of retrieval.

The enclosure immediately west of the Berth is classified as Prehistoric in the HER (HER 4923). Its curvilinear nature may indicate a Bronze Age date and it could even be Neolithic in origin (Ray, 2007); given its position between the Berth and the Bronze Age cemetery, it could also indicate the remains of a ring-ditch (see below).

\subsubsection{The Berth/Upper Perry- Bronze Age (Fig. 6-11)}

A considerable increase in activity is evident across the Upper Perry valley mire during the Bronze Age. Seventy eight sites/findspots are recorded comprising burnt mounds, metalwork deposits, and funerary monuments.

Thirty-one burnt mounds are documented; notwithstanding some duplication in the records (Leah et al., 1998), such a concentration is significant (Bayliss, 1991; Ehrenberg, 1991). Burnt mound sites span a wide chronology from the Neolithic to the Medieval (Ó'Néill, 2009; Kenney, 2012). However, they are generally considered a Bronze Age phenomenon (Ehrenberg, 1991; Hodder and Barfield, 1991), hence their inclusion here. The only excavated example in North Shropshire is from Rodway on the Weald Moors (where there is a similar concentration of burnt mound sites - see Fig. 5-21), which returned a Middle Bronze Age date and a possible rubbing stone which was suggested as a ritual object (Hannaford, 1999).

Burnt mounds are the detritus created after hot stones were placed in a trough to heat water. Their purpose is much debated (Bayliss, 1991; Hodder, 2002; Ó'Néill, 2009; Yates and Bradley, 2010), with hypotheses ranging from the domestic (cooking) to the industrial (leather treatment; fulling; salt extraction) to the ritualistic (feasting and ritual saunas (Barfield and Hodder, 1987; Hodder and Barfield, 1991)). Salt evaporation (see Chapter 5 ) is also a possibility. Hot water technology requires the proximity of a watercourse and many examples, including those from the Weald Moors and the Upper Perry, are found at the interface of the peat with mineral soils. 
Two burnt mounds are found close to the Berth, one of which lies next to the small enclosure (Fig. 6-10) and 50m from Berth Stream; the watercourse may have been closer in prehistory. An excavation of this site would be beneficial on several counts identifying the purpose for the burnt mound per se, possibly highlighting some aspect of the Berth's functionality, and establishing a date for activity at the Berth preceding the construction of the Iron Age monument. The other burnt mound lies close to Birchgrove Pool and is unexplored.

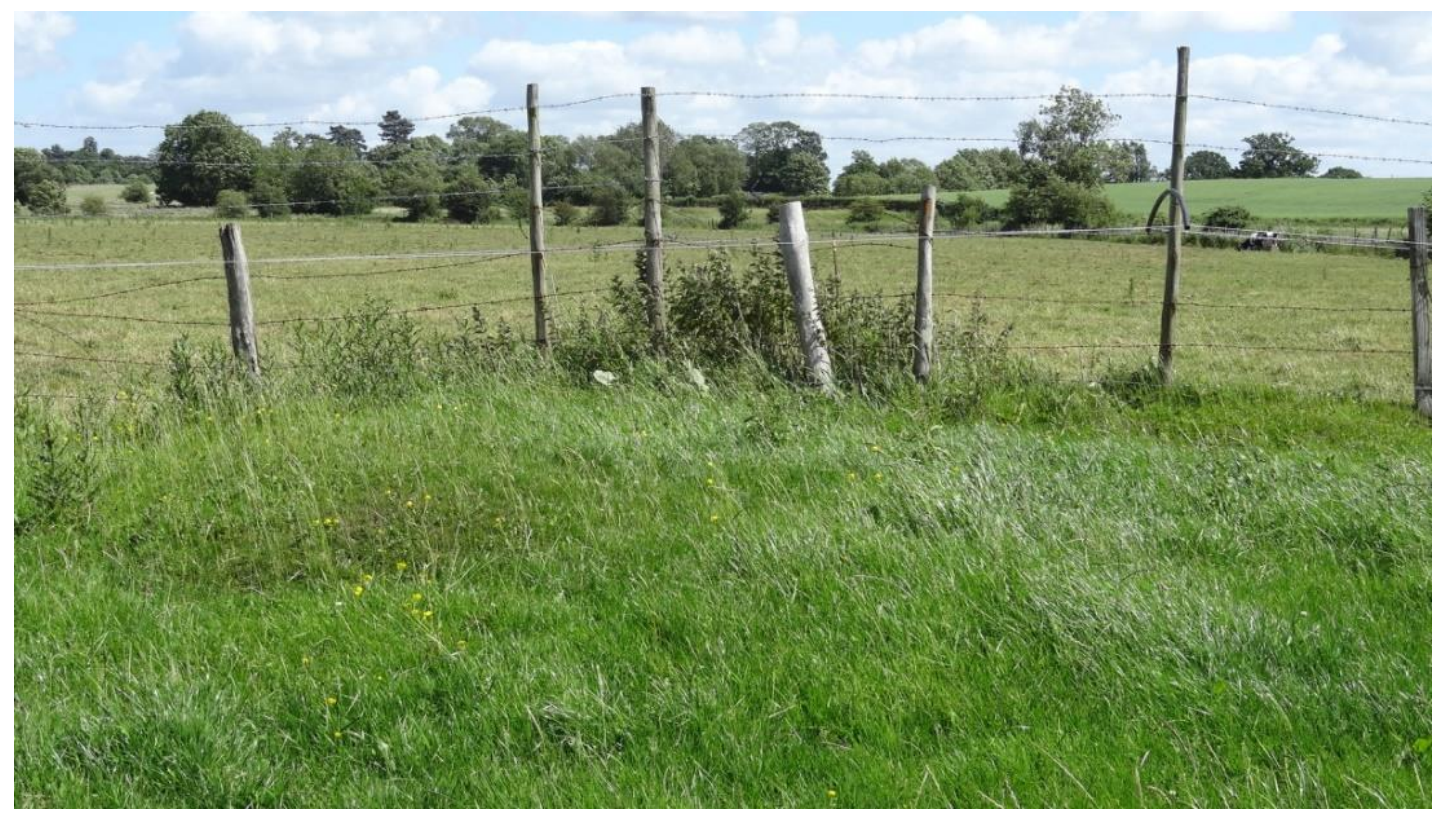

Fig. 6-10 Unexcavated burnt mound adjacent to the Berth's small enclosure (Norton 2017)

Burnt mound concentrations frequently correlate with the ritualised deposition of metalwork (Halsted, 2007). North Shropshire lies within the North Wales region for the deposition of metalwork in watery places (Wait, 1985:48), and during the Late Bronze/ Early Iron Age, this activity was often associated with mortuary practices (Bradley, 1990:170-1). There are twenty five instances of metalwork deposition recorded in the Berth/Upper Perry area. These instances are notable for both their quantity and quality, with a range of weapon types including socketed axes, daggers and blades; two of the most notable recoveries are the Hordley Rapier (Mid-Late Bronze Age and a possible 
Irish import (Burgess, 1981) (HER2647)) and the Bagley Shield (HER900; Yetholm type, circa1200-800BC; now lost). Not all of these finds came directly from water (cf. Bradley, 1990), and there is a concentration from the peat/alluvium around Tetchill Moor (see 6.2.5 below). However, these locations should be treated with caution as the river valley has been subject to drainage as the LiDAR data shows (Fig. 6-11) (see also Chapter 5). Two metalwork items were recovered south-east of the Berth - a palstave and a dagger. These finds appear to have been placed at the peat interface, possibly in a watery context, and are likely to be of a ritualised nature (Bradley, 1990; Yates and Bradley, 2010).

If the correlation between burnt mounds and metalwork deposition is positive, the opposite is often true of settlement (Halsted, 2007). With two possible but unconnected exceptions (a circular enclosure and two spindle whorls), there is no evidence for Bronze Age settlement in the Berth/Upper Perry landscape. A non-domestic landscape is further evinced by nineteen funerary monuments (ring-ditches/barrows). The Bronze Age cemetery at Baschurch, less than $2 \mathrm{~km}$ west of the Berth (HER2451), comprises the remains of eight bowl barrows and is the most important of its kind in the area. The barrows were contiguous with associated linear features, which may have defined blocks of land, and with a number of pits which respect the barrow formation (Appleton-Fox, 2002). The cemetery is now severely truncated. A possible 'half-henge' was also recorded (Appleton-Fox, 2002) and several more truncated barrows were found $0.5 \mathrm{~km}$ to the north, adjacent to Boreatton Moss. This was clearly an important place in the Bronze Age of North Shropshire, where ancestral memory was kept alive and land claims established through creating highly visible monuments (Carver, 1991:6). The Berth's small enclosure may also contain a ring-ditch although the data have been disputed (Gaffney, 1995; Smalley, 2011); there would be a stronger case for this if the 


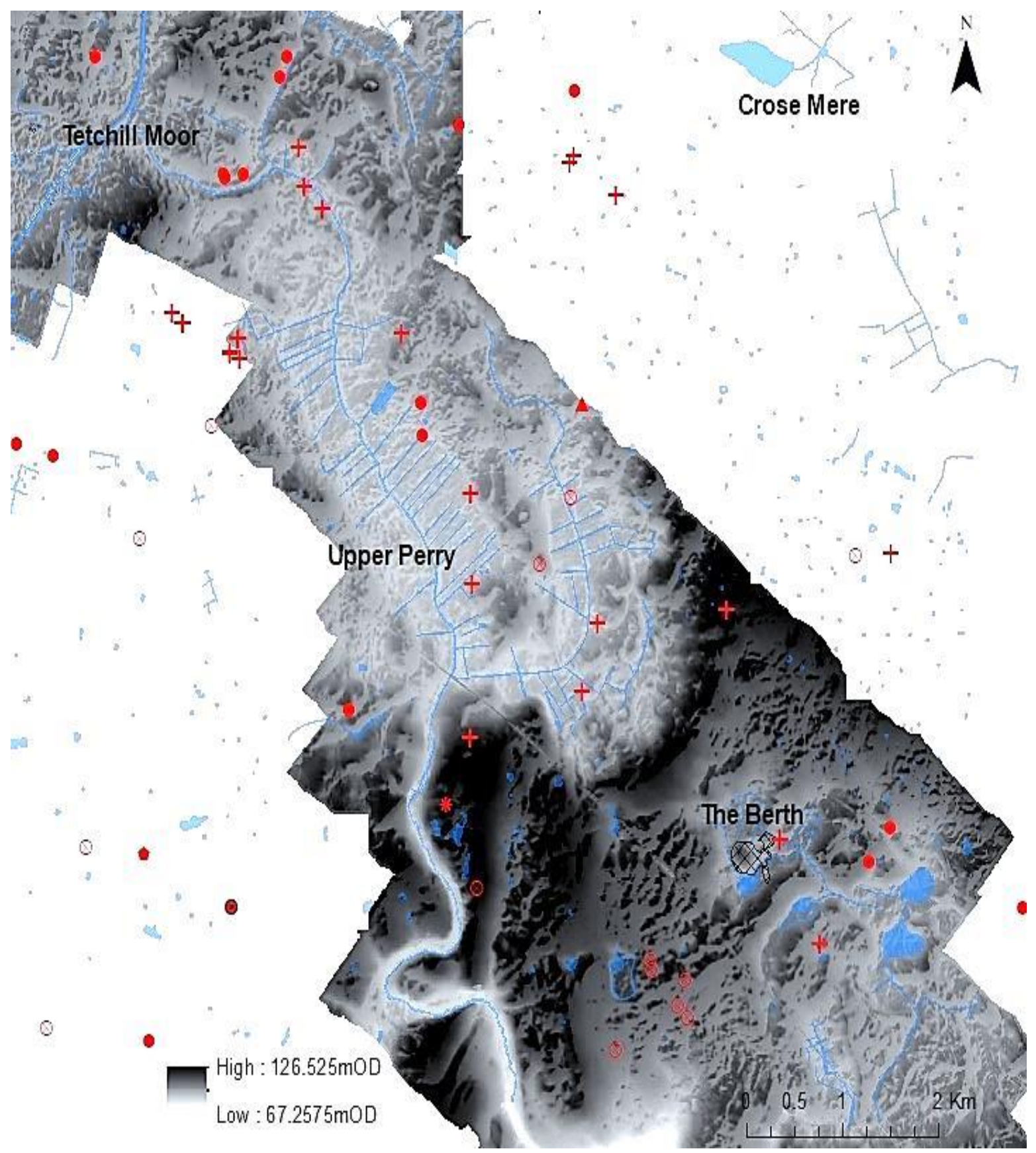

- lithic metalwork $\otimes$ ring-ditch/burial $\odot \quad$ stone circle

+ burnt mound * artefact $\square$ fort crop mark/enclosure/field system

Fig. 6-11 The Berth/Upper Perry - Bronze Age 
prehistoric enclosure to the immediate west proved to be a ring-ditch also (see above). A number of scattered funerary monuments lie to the west of the Perry, together with a possible stone circle (destroyed) on the higher ground to the west of the valley (Robin Hood's Chair; HER 854).

Each of these site-types has been linked with the developing process of land division and land tenure (Buteux and Hughes, 1995; Garwood, 2007a:154) which began during the Bronze Age. The collective archaeological evidence suggests that this area was used for specific purposes - burial, ceremonial activities and ritual deposition - rather than for settlement. Its Bronze Age signature - burnt mounds, metalwork deposition, barrows and ring-ditches - is almost identical to that of the Weald Moors.

\subsubsection{The Berth/Upper Perry- Iron Age/Undated (Fig. 6-12)}

The Iron Age landscape that gave rise to the Berth is evidenced by enclosures and field systems. These are mainly found on the slightly higher ground away from the peat; however the evidence is exclusively from cropmarks, which in turn are dependent on soil type, therefore the apparent distribution may be misleading. Together with a number of linear features and field systems, this apparent domestication stands in sharp contrast to the Bronze Age landscape, and the two maps show limited evidence of overlap (Fig. 6-11; Fig. 6-12). As the land became more settled, people established their land tenure on more solid ground, possibly in the teeth of a worsening climate (Lamb, 1981; Barber and Coope, 1987; Barber et al., 2003). The lack of enclosure/cropmarks and the location of an (undated) canoe to the east of the Perry may indicate that this ground was too wet to farm, although the apparent emptiness extends onto the mineral soils.

Concentrations of enclosures/field systems lie to the north and west of the Perry, and to the south of the Berth. The Berth stands out as the largest monument in the area. Its closest neighbours, a group of small enclosures and several field systems, lie to the south of Birchgrove Pool. The extent and positioning of these cropmarks in relation to 
the Berth is shown, together with the Baschurch cemetery, as polygons in Fig. 6-13; this degree of activity contrasts with the 'empty' areas to the north, east and further south. The closeness of these settlements to the Berth may mean that it acted as a dedicated refuge or ceremonial focus for this community. The factors relating to the scale of the Berth's influence are discussed in Chapter 9.

Further north, metalwork deposition continued at the confluence of the Tetchill Brook and the River Perry. Deposits include a bracelet, a fob and a brooch. Iron Age artefactual finds elsewhere in the area include a cosmetic mortar, a quernstone, and a quartz touchstone.

Enclosures and linear features recorded as 'undated' have been included pragmatically with this chronology, albeit that they may not all represent prehistoric settlement activity and land division (Leah et al., 1998:37). Three pit alignments are present in the Upper Perry/Berth region. In similar vein to linear ditches and cross-ridge dykes, their chronology and function is poorly understood, but all three site-types are generally associated with Late Bronze Age/Iron Age land division (Wigley, 2002; Cunliffe, 2005). They frequently show signs of re-cutting and maintenance, often interpreted as evidence for communal activity within a society where land division relied on social cooperation (Wigley, 2002; 2017b). The example south of the Berth may suggest a boundary to the western edge of an enclosure/field system cluster reinforcing a boundary already suggested by the Bronze Age cemetery.

Two trackways are recorded to the west of the river, although not on peaty ground as might be expected. Although bog bodies are recorded east of Tetchill Moor, the HER coordinates are misleading, and refer to those found in Whixall Moss (see Chapter 5). 


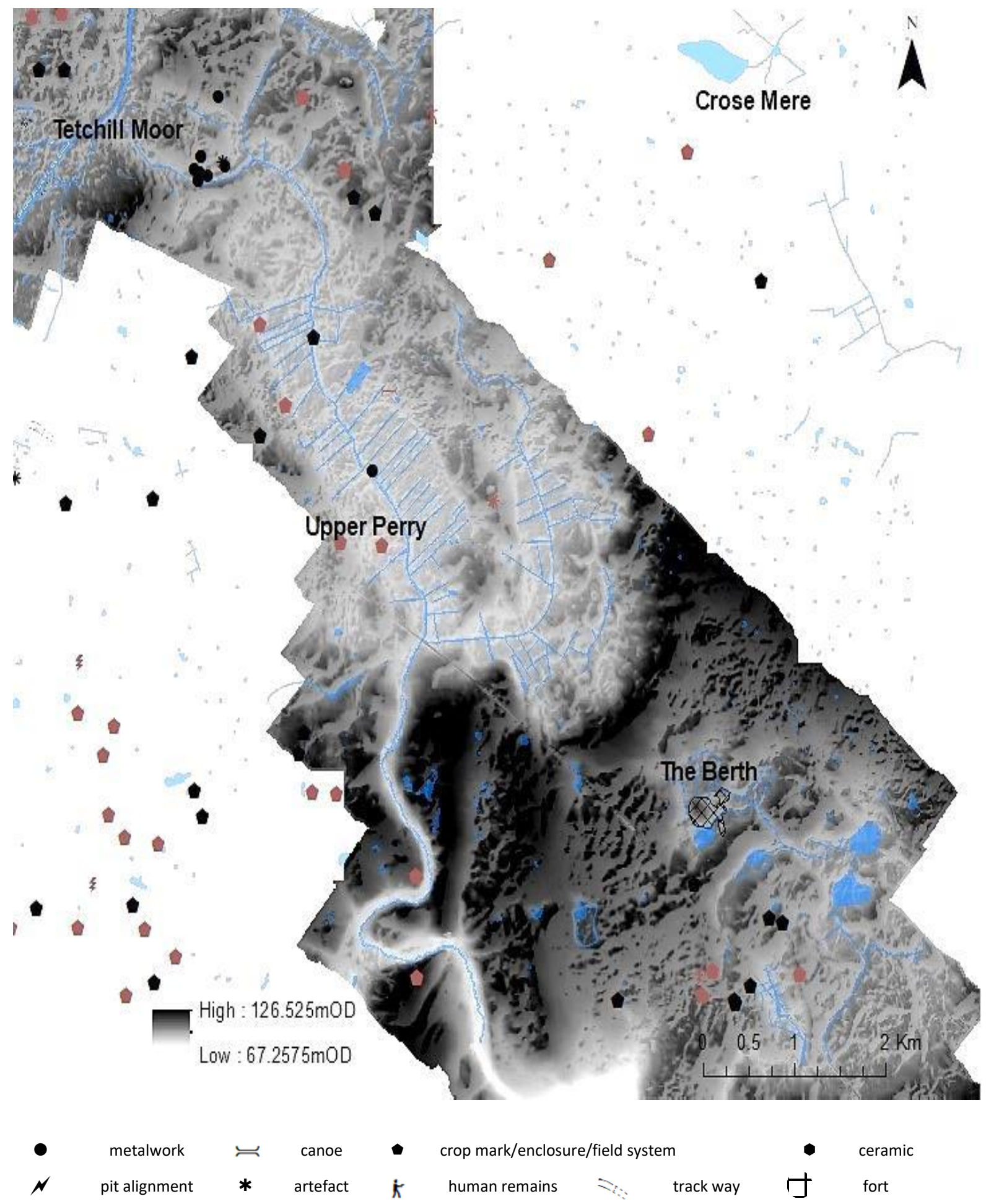

Fig. 6-12 The Berth/Upper Perry - Iron Age/Undated 

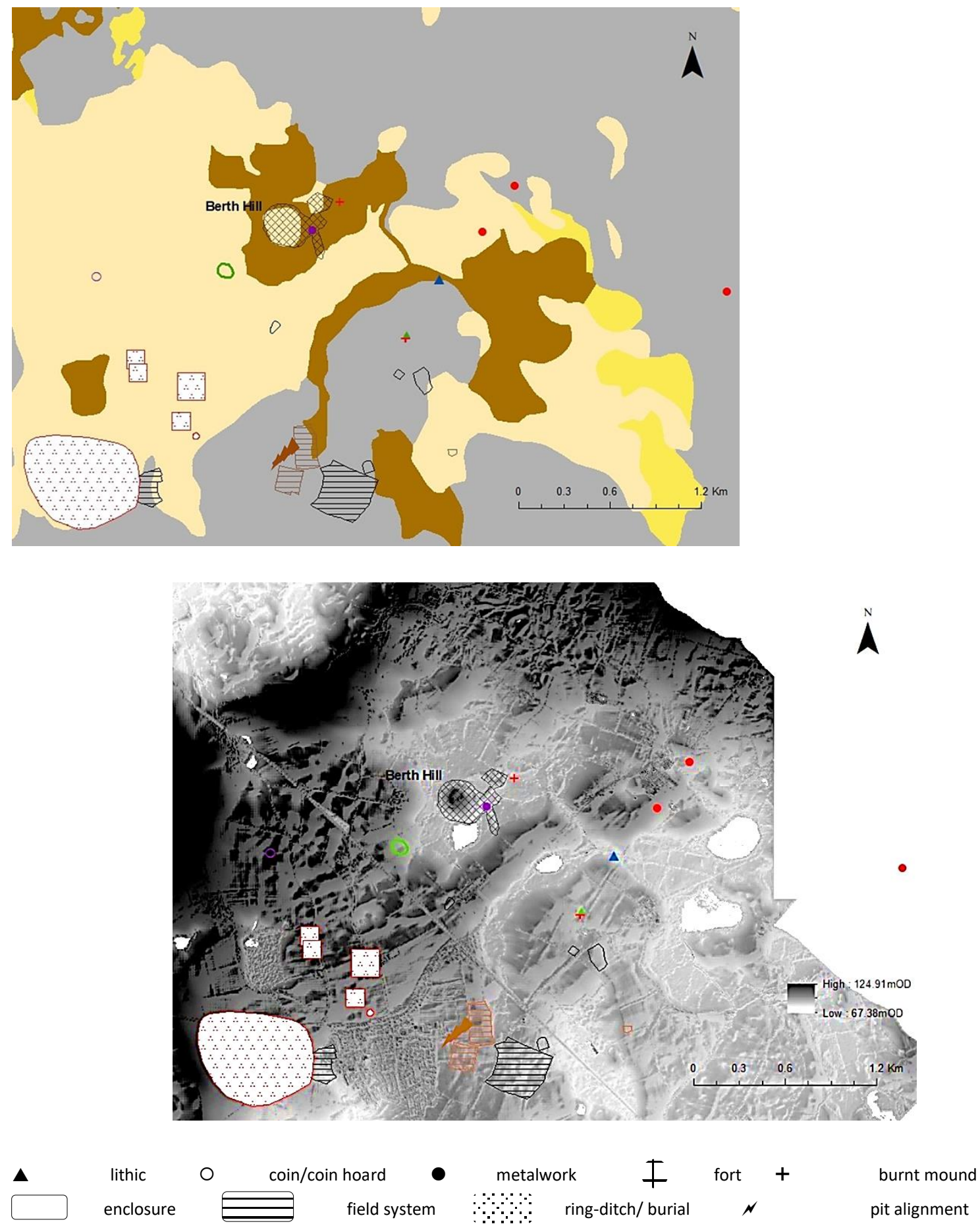

Period Prehistoric/Mesolithic Neolithic Bronze Age Iron Age Undated

\begin{tabular}{l|llllll} 
Superficial geology & alluvium & fluvio/lacustrine glacial deposits & till & peat & river terrace
\end{tabular}

Fig. 6-13 The Berth - cemetery, pit alignment, enclosures and field systems 


\subsubsection{The Berth/Upper Perry - Roman (Fig, 6-14)}

Evidence for activity in the Roman period around the Upper Perry and the Berth includes two (possible) military camps, a number of coins/coin hoards, ceramics and artefacts. All evidence arises from marginal areas, and the valley mire itself is almost empty of activity during the Roman occupation with the collective evidence suggesting a predominantly 'working environment'. However, ritualised deposition continued at the Tetchill Brook, showing that this particular place sustained its special status. Artefacts from elsewhere in the area include brooches, a curse tablet, a spindle whorl, and a bell clapper. A concentration of Roman coinage has been found around and west of Ruyton-XI-Towns, and it has been suggested that the Iron Age enclosures in this area may mask a possible Roman villa (HER689).There is evidence for use of the Berth during the Early/Mid-Roman period, although it is somewhat contradictory. Three sherds of Severn Valley ware were recovered by Gelling (discussed above - see 6.1 and Appendix 2) possibly suggesting low-level domestic activity. However, the deposition of the Berth Cauldron (Fig. 6-5) implies a different dimension. The Cauldron conforms in shape to Joy's 'Group 1 - projecting-bellied cauldrons', dated between the midfirst to the second-century $A D$, and its manufacturing technique, spun from a single piece of copper alloy, was in use around this time (Joy, 2014:6). These types of cauldrons are distributed throughout northern England and Ireland (and in north-west Norfolk) and three copper-alloy sheet fragments from this type formed part of the Llyn Cerrig Bach hoard (Joy, 2014:27-28). It is presumed that cauldrons were used in the preparation and serving of food and drink at 'redistributive, life-event and/or religious ceremonies' (Joy, 2014:17) which may account for why cauldrons were seen as appropriate objects for deposition. The Berth Cauldron would have held approximately 50 litres. It lacks rims and handles, suggesting that it may have been decommissioned before deposition (Joy, 2014:16). Its place of recovery has always led to an assumption that it was placed in water, and this assumption conforms with Joy's findings that Group 1 cauldrons were predominantly recovered from watery contexts (Joy, 2014:4).The dates for the Severn Valley ware and the Cauldron are quite specific, indicating that the Berth was in use, or perhaps re-used, during the first-second century AD. The La Tène III brooch found as part of the Gelling excavations suggests the earlier rather than 
the later part of this date range (cf. Haselgrove, 1997), and the Roman glass bead recovered from Berth Hill may also support this conclusion.

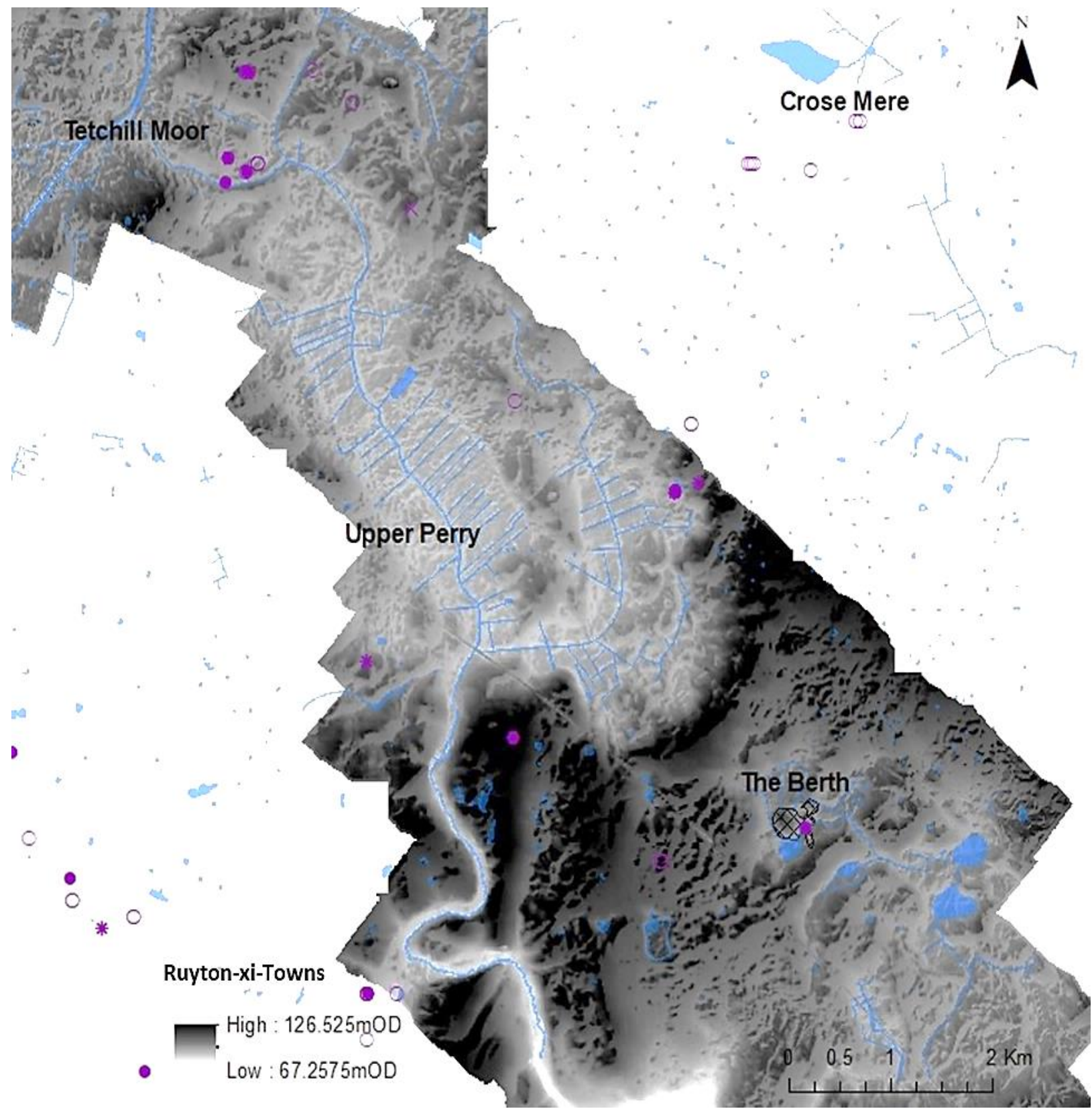

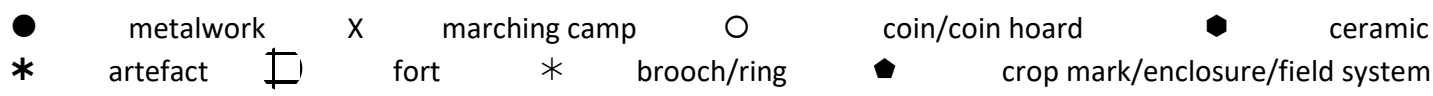

Fig. 6-14 The Berth/Upper Perry - Roman 


\subsubsection{Tetchill Brook (Fig. 6-15)}

There is no outstanding topographical reason why the Tetchill Brook and the field immediately west of its confluence with the River Perry should be favoured as a special place, but it clearly was. Twenty-two artefacts have been recovered from one field alone. The finds include Bronze Age metalwork (a bracelet and a faceted axe) and Iron Age artefacts (a toggle, a swan-necked pin, a sword guard and point, a bracelet and a La Tène I brooch, as well as a terret and other harness fittings). Deposition continued throughout the Roman period, evidenced by two brooches, a vessel, some casting waste, and numerous coins which span a date range from AD98 to AD260. LiDAR data indicate that the field contains a palaeochannel, suggesting that deposits were placed into a watery environment. Further north along the Tetchill Brook, other finds include the Hordley rapier and more Roman coins and artefacts.

The field is topographically undistinguished in the wider landscape, and its only notable aspect is that it lies at a river confluence, a recurring theme in ritual deposition (e.g. Fredengren, 2011). As far as this study is concerned, the site is equidistant $(7 \mathrm{~km})$ from several of the sites reviewed in this thesis - Stocketts Enclosure, Whittington/Oswestry and the Berth - but this does not mean that it was material to any of them. It is unrelated to places of burial and nothing indicates that it was highlighted or made visible in prehistory; whether it was made special by virtue of being hidden is unknown. However, whilst spaces may be defined in terms of natural topography, places are defined by the activities conducted within them (Jones, 1998:318), and this lack of prominence is directly in line with Fontijn's conclusions regarding the importance of 'invisible' places in the wider landscape (Fontijn, 2007).

The deposits at the Tetchill Brook were meaningful acts. As suggested by Fontijn (2002), such a concentration of artefactual evidence suggests a place, in this case a field and river confluence, which was retained as special in the memory of those who dwelt here and which was passed down the generations for over 1,000 years. 


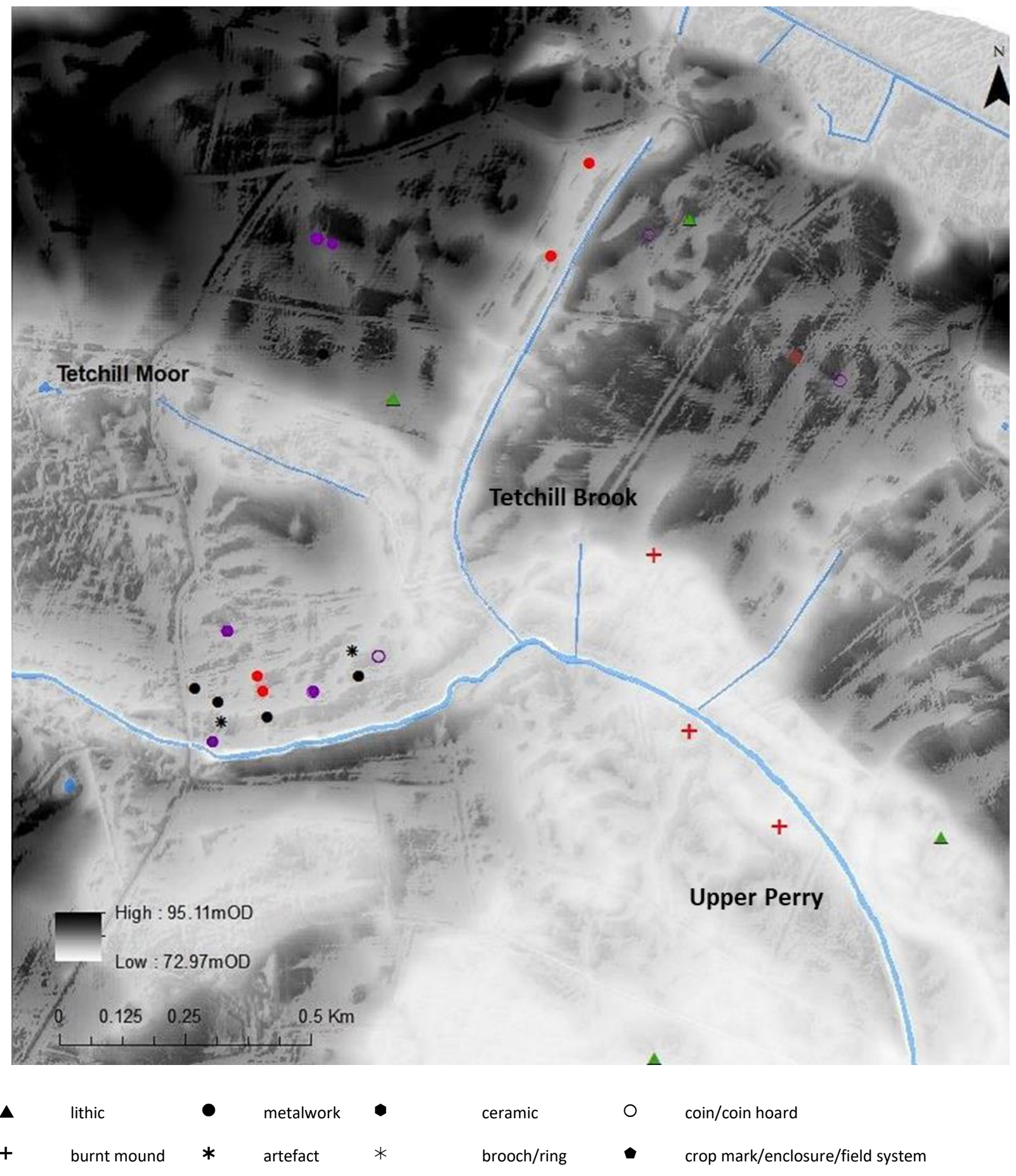

Period Prehistoric/Mesolithic Neolithic Bronze Age Iron Age Roman Undated

Fig. 6-15 Tetchill Brook - depositionary evidence (NB. Findspots overlap) 


\subsection{The Berth - a 'line-of-sight' analysis}

So far, this investigation has concentrated on the archaeological landscape surrounding the Berth and by extension, the Upper Perry river valley. However, the Berth's role in the wider landscape may have been material to the siting of such a singular monument; whether the Berth could be seen, and what could be seen from it, may have been important to those who created it.

Studies indicate that visual perception is the principal means by which humans relate to the world (Punter 1982, in Chapman, 2006) and intervisibility is well documented as an interpretive tool in landscape research at both a practical and a symbolic level (Thomas, 1993; Tilley, 1994; 2010). Visual perception relates to both natural and anthropogenic phenomena, and is of equal relevance whether based on the viewing location, the location being viewed, or the co-visibility between monuments and natural phenomena (Llobera, 2007). Assessing intervisibility is greatly facilitated by the use of surface analysis tools within GIS, which can be used to create simple line-of-sight or complex viewshed models (e.g. Ebert, 2004; Chapman, 2006). Whilst line-of-sight models are binary and consider intervisibility between points, viewshed analysis calculates that which is visible or hidden, usually in a $360^{\circ}$ circle, from a given location (Wheatley, 1995; Wheatley and Gillings, 2000). Both types of survey enable the modern viewer/archaeologist to estimate intervisibility from a chosen location, and by implication, what was potentially important to those who stood in the same location or travelled the same path. There are many examples of how unfolding viewsheds may have held symbolic importance in prehistory (see Chapter 4).

However, intervisibility analysis makes some broad assumptions, and criticisms are many and varied (e.g. Ebert, 2004). Whereas the 'bare bones' of the natural environment are likely to remain the same (Tilley, 1994), other landscape features are subject to change through time. Monuments and significant places may become invisible; for example, the Baschurch cemetery near the Berth may have been a prominent in prehistory but is now only visible as crop-marks. The presence or absence of vegetation may mask or reveal viewsheds or lines-of-sight (e.g. Chapman and Gearey, 2000), either in modern times or in the past; perhaps a prominent tree 
held symbolic resonance (Connolly and Lake, 2006:230). Many intervisibility analyses assume that monuments were in use contemporaneously but this may not be the case. To a degree, all these problems can be overcome by using multiple variables within a GIS to repeat the modelling experiments (Lake, 2007). However there is no guarantee that what appears important to a modern archaeologist had any relevance to someone living in prehistory. It must also be remembered that, in a multi-sensory world, total reliance on sight may be misleading (Watson and Keating, 1999; Llobera, 2007; Lake, 2007). Occasionally, the models created can simply be wrong; this is illustrated below.

Hillforts are widely regarded as the major visible field monument of the Iron Age (e.g. Cunliffe, 2006; Harding, 2012). Given their prominent locations and their range of possible functions (see Chapter 2), intervisibility with the surrounding landscape, seeing and being seen, clearly mattered, therefore using GIS as an aid to hillfort interpretation is particularly appropriate (e.g. Bedwin et al., 1980; Lock and Harris, 1996; Hamilton and Manley, 2001; Driver, 2007). Many of the Iron Age fortifications of North Shropshire and the Welsh Marches are visually prominent and share intervisibility with each other. One has only to stand on top of the Wrekin to realise the number of Iron Age hillforts which are in view. At lower elevation, Brown suggested that Old Oswestry occupied a strongly strategic position at the confluence of several Welsh valleys with the North Shropshire Plain, making use of extensive lines-of-sight (Brown, 2008).

This places the Berth (and other marsh-forts) in an unusual position. Lying at the 80-85mOD contour in a wetland depression, the Berth's architecture is monumental but hidden. However, Berth Hill provides an unusually flat $360^{\circ}$ viewing platform from which to survey the surrounding landscape (Fig. 6-16). Such a combination could produce a 'best of both worlds' scenario - a fortification within a hidden or sheltered environment combined with a high viewpoint from which to assess, or communicate with, others in the vicinity. Hence, developing an understanding of the places that could be viewed from the Berth may provide 
the basis for discussion regarding its interconnectedness with prominent places and hillforts across the North Shropshire Plain.

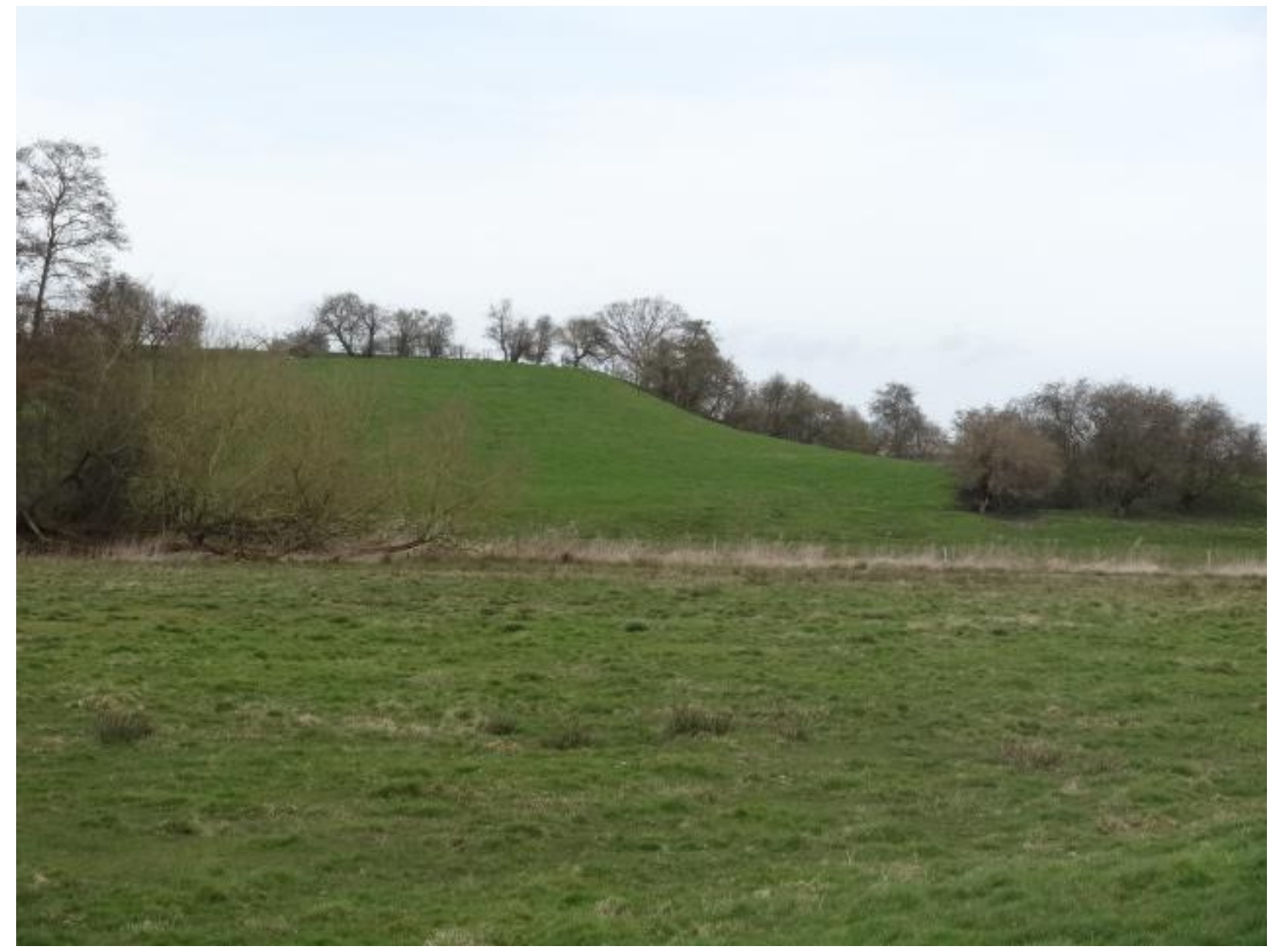

Fig. 6-16 Berth Hill, seen from Berth Pool (Norton, 2014)

An experimental line-of-sight model was built in ArcGIS to assess the Berth's intervisibility with other prehistoric monuments and uses the summit of Berth Hill as the viewing point (97mOD spot height); the results were tested through personal observation/site visits (for Methodology, see 3.2.7). The model (Fig. 6-17) indicates that Berth Hill has a direct line-ofsight relationship with several hillforts - The Wrekin, The Burgs, Bury Walls, and The Breiddin are highlighted. These were all confirmed empirically except for The Burgs, which although closer than the Wrekin or the Breiddin, is indistinct even in good weather, and illustrates the obvious fact that distance decreases visual impact unless the location viewed is outstanding 
(Maschner, 1996, cited in Ebert, 2004). The GIS results also indicate that the visual relationship with Nesscliffe hillfort is 'interrupted' in its final stages and this too was borne out empirically. The wooded slopes occupied by Nesscliffe are visible from Berth Hill, but the fort is orientated north towards Old Oswestry; in order to see the Berth, you need to look round a corner. The model indicated no intervisibility with important low-level sites in the immediate vicinity (for example, the Bronze Age cemetery or the Upper Perry/Tetchill Brook), nor with Old Oswestry hillfort, or potential marsh-forts (also confirmed by observation). However, observation suggests that more sites are visible than the model indicates, including Llanymynech and several of the hillforts close to the Breiddin (Fig. 6-19). The line-of-sight relationships decrease dramatically when modelled from the 80mOD contour (Fig. 6-18); only the Wrekin continues to be visible, and this was corroborated on several site visits.

However, these results do not entirely agree with an existing GIS-based line-of-sight analysis, which looked at intervisibility between the hillforts of the Welsh Marches and across the Cheshire Plain (Matthews, 2014). Matthews concluded that only three hillforts shared visibility with the Berth - Bury Walls, the Breiddin and Nesscliffe (Fig. 6-21). Matthews' model cannot 'see' the Burgs or the Wrekin, perceive the nuanced relationship with Nesscliffe, or acknowledge sites visible from the summit of Berth Hill, such as Llanymynech. These discrepancies may be accounted for by selecting a different viewing height, or by small inaccuracies in the viewing points, or by simply moving around, and, due to the Berth's lack of public access, Matthews was unable to verify his lines-of-sight by site visit (pers.comm. D. Matthews).

Whilst these analyses illustrate that ground truthing is as important in desk-based GIS modelling as it is in all archaeological research, a more positive conclusion can be drawn. Both models emphasise the Berth's isolation in relation to other Iron Age fortifications in the North Shropshire area. With the exception of Nesscliffe (6km distant), the area's major hillforts (Old Oswestry; Bury Walls; The Burgs; The Breiddin; The Wrekin) lie 15km or more from the Berth. The area to the north is empty. This spatial patterning gives the Berth a feeling of separateness 
and possibly, territorial importance or control. Given their low-lying locations, it is unsurprising that the Berth does not share intervisibility with Wall Camp (25km east). Wall Camp is similarly isolated and inconspicuous in its immediate surroundings, but unlike the Berth, there is no higher ground from which to view the surrounding landscape; it shares intervisibility only with the Wrekin.

The Berth did not promote its status through the prominence of its fortifications and it is unlikely that it demarcated its territory by visual dominance. Although Berth Hill may have been visible when looked towards from high vantage points surrounding the North Shropshire Plain (e.g. Fig. 6-20), the lower-lying fortifications were largely hidden. It is not known whether the summit of Berth Hill was occupied or whether it was used as a platform to view the surrounding landscape. The Roman glass bead (see above) suggests that the summit may have had some significance although this evidence is minimal.

The intervisibility model put forward in this case study focusses on a single, simple, dynamic the visual interconnectedness between the Berth and Iron Age hillforts in the vicinity. Making sense of such visual patterns is in its early stages and this experiment is not put forward as a rigorous model. However, it does show that, from the vantage point of the summit of Berth Hill, the Berth marsh-fort had a visual relationship with many of the major monuments in the surrounding area despite its obscure, wetland location. It also emphasises the importance of corroborating desk-based modelling with site visits. 


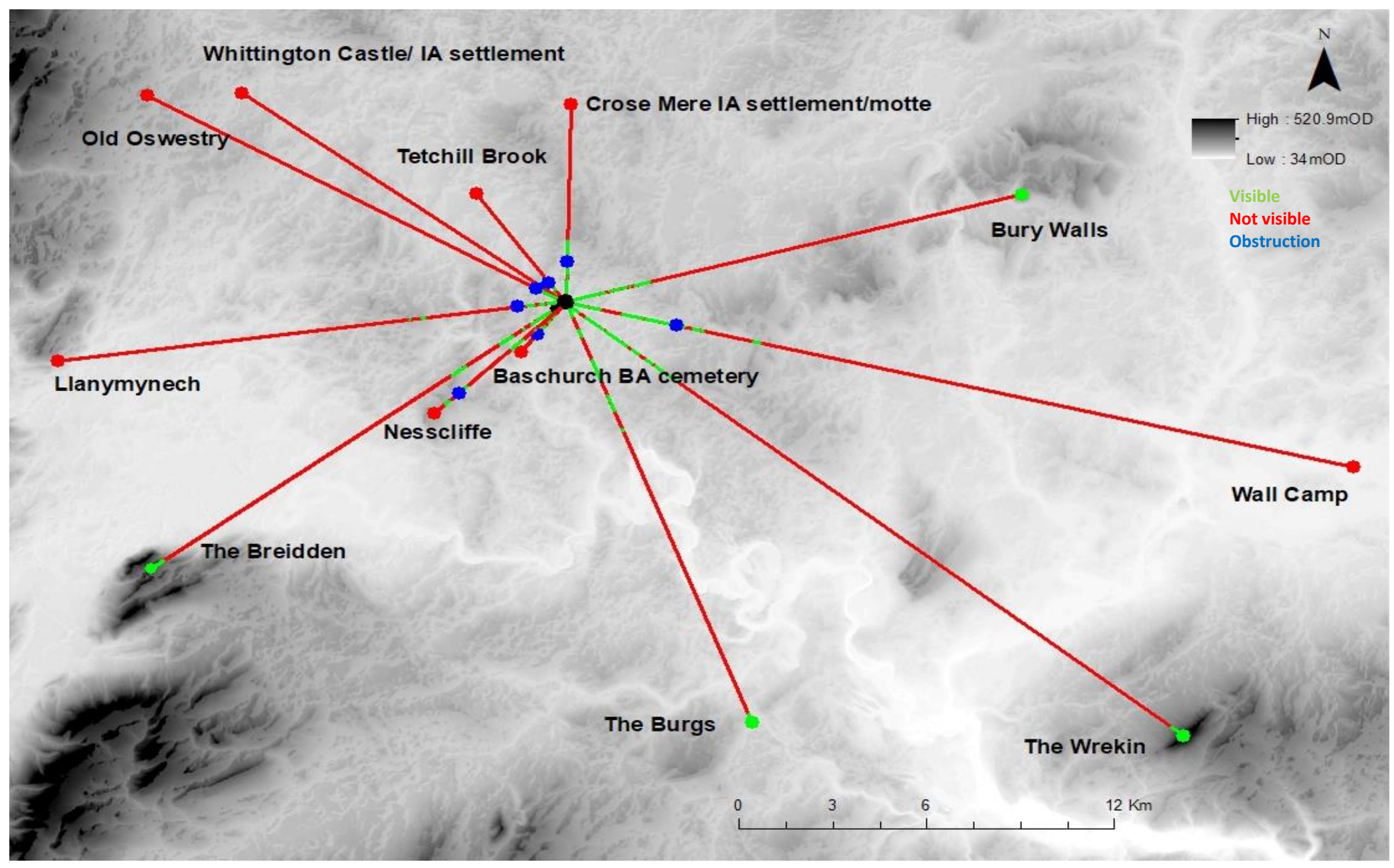

Fig. 6-17 The Berth - Line-of-sight analysis; 97mOD (Edina Digimap; 2m LiDAR; Historic England 20150925_ScheduldMonument.shp) 


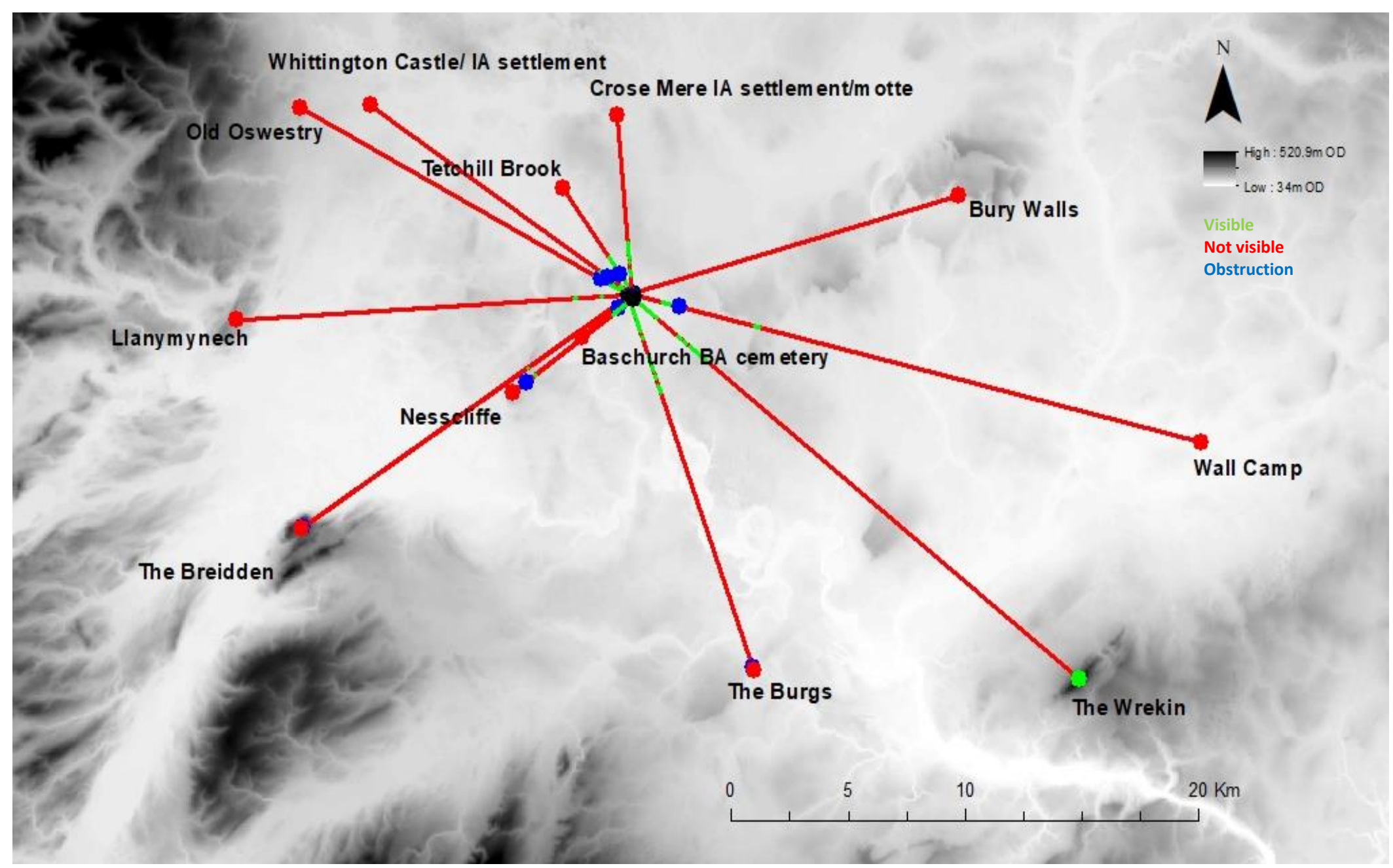

Fig. 6-18 The Berth - Line-of-sight analysis; 80mOD (Edina Digimap; 2m LiDAR; Historic England 20150925_ScheduldMonument.shp) 
Chapter 6-The Berth and Upper Perry - macro-scale landscape analysis

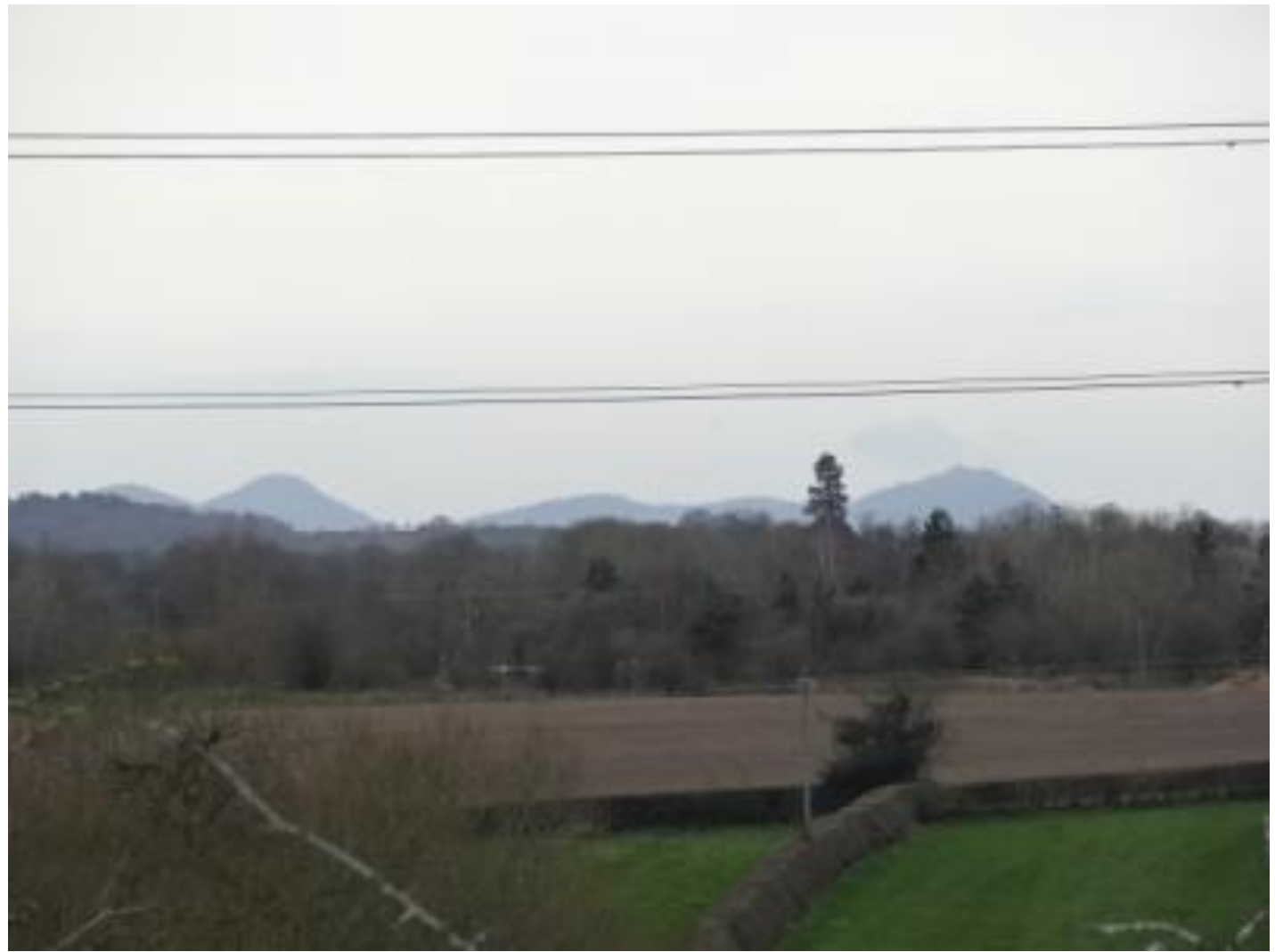

Fig. 6-19 The view from the summit of Berth Hill looking west. From left, the wooded slopes of Nesscliffe, the hillforts surrounding Cefn-y-Castell, and the Breiddin (right) (Norton, 2014)

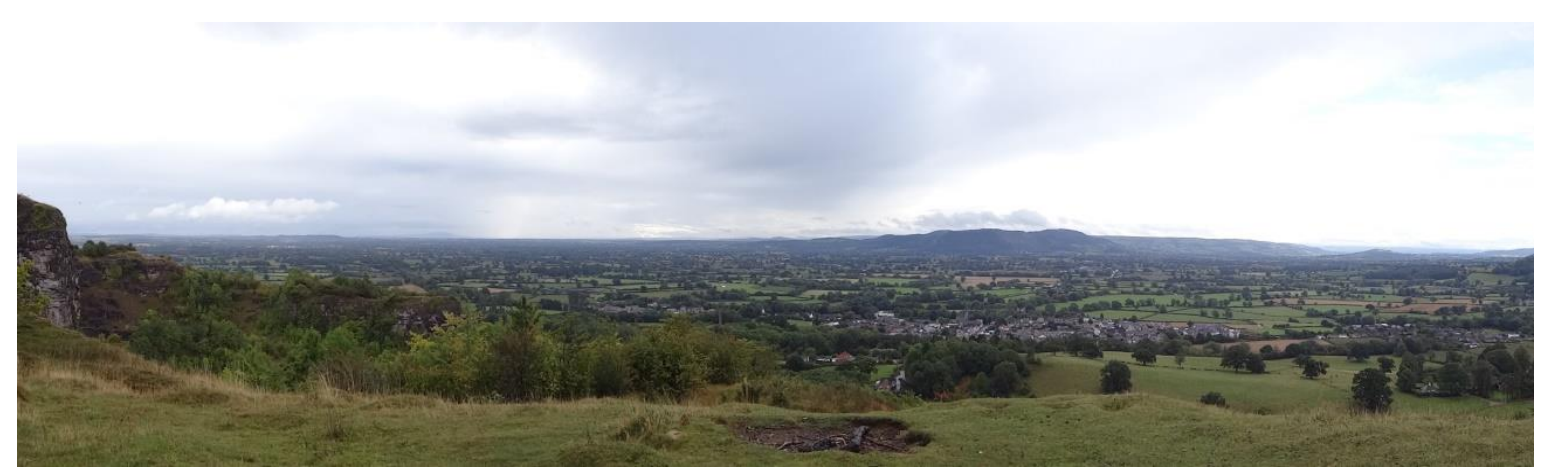

Fig. 6-20 The North Shropshire Plain viewed from Llanymynech, looking east towards the Berth (Norton, 2016) 


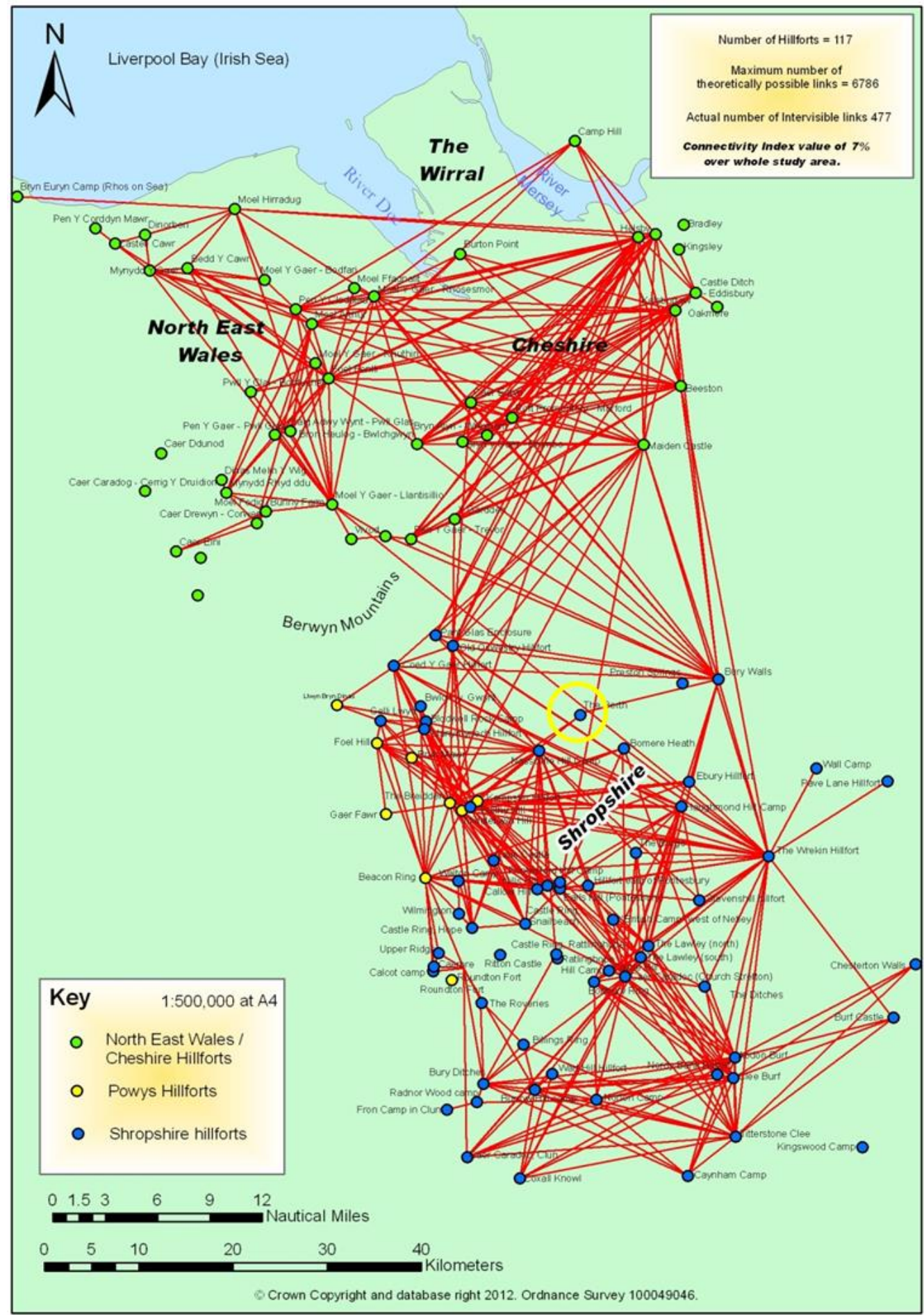

Fig. 6-21 Hillforts intervisibility (Matthews, 2014: Fig. 1) with the Berth highlighted 


\subsection{Summary}

Whilst acknowledging that the complexities of interpreting prehistory cannot be reduced to a simple set of diagrams, a study such as this represents an important stage in the landscape analysis at the Berth. By combining a wide range of data (topographical, LiDAR, HER and PAS records) within a GIS, the resulting multi-chronological model illustrates how the Berth's regional landscape was utilised and reinterpreted through time. Evidence for usage during the Mesolithic is emphasised by the recovery of an important lithic assemblage at Wykey Weir, and during the Neolithic by two stone axes, both possibly the result of ritual deposition. The Bronze Age landscape shows increasing signs of enculturation, as evidenced by funerary monuments and metalwork deposition. When combined with the numerous burnt mounds, this reinforces the Upper Perry and the area around the Berth as a non-domestic, possibly ritualised landscape.

The Iron Age landscape evinces a profound change in landuse, and evidence of settlement dominates the record. The proliferation of cropmarks indicates a farming community who avoided the wetland and the valley bottom in favour of higher, more free-draining ground. The avoidance of wetter areas may have been a pragmatic, deterministic response to climatic worsening from circa 1000BC; however, the actual impact of these conditions on everyday living is unclear and hard to determine. An attempt has been made to quantify the issue by estimating whether poor climate affected population decline in early first-millennium BC Ireland, through a collation of the radiocarbon dates associated with human activity (Armit et al., 2014); the study concluded that the population numbers remained stable, and the impact was minimal. Similarly, human response to environmental change at Goldcliff suggests that people adapted to and extracted the benefits from changing climatic conditions rather than make wholesale alterations to their lifestyle (Bell and Neumann, 1997). This may also be true of the Upper Perry.

Avoiding the valley mire during the Iron Age and into the Roman periods may also illustrate an ongoing respect for the area's symbolic significance. However, the need to deposit treasures or appease deities was ongoing, and these actions became confined to a very small area - the 
confluence of the Tetchill Brook with the Upper Perry, a location which retained its significance for multiple generations.

In spite of its slight topographical separation from the Upper Perry, the landscape around the Berth mirrors each of these archaeological stages. Its history encompasses deposition of axes during the Neolithic, Bronze Age burnt mounds and an association with the Baschurch cemetery. When, during the Iron Age, it was decided to establish the marsh-fort, it became one of the largest monuments on the North Shropshire Plain. It was used discontinuously from the Middle Iron Age into the Roman period, although whether that usage was domestic or non-domestic has yet to be clarified (see 6.1 above, Chapter 9 and Appendix 2). Its proximity to the enclosures immediately to the south might suggest that it functioned as a local refuge, although its size appears out of proportion for the needs of this small community (maximum five enclosures, not necessarily contemporary). Additionally, climatic change would suggest that, if anywhere was going to be wetter at this time, it would be the Berth, and therefore the creation of such a monument in extreme conditions may indicate a significant undertaking by a larger group. If it acted as a ritual centre of some sort, it may have been the focus for the southern Perry valley community, whilst others continued to express their ceremonial/spiritual needs at the Tetchill Brook. Its importance may have been reinforced by its ability to reach out visually from Berth Hill, across the wider landscape.

It is important not to create a pseudo-history for the Berth on the strength of the landscape data alone, and a fuller picture can be drawn only by combining a range of datasets. The Berth's micro-landscape is presented in the following chapters. 


\section{The Berth - stratigraphic sequencing and radiocarbon dating}

$\therefore$ the cyclops eye

Of a tarn...

... The wet centre is bottomless...' (Bogland, Heaney, I972)

Constructing a substantial fortification in a wetland setting would have been a complex task, and the difficulties involved must have been balanced by the potential gains. To understand the challenges and opportunities presented by the Berth's immediate surrounding landscape, an investigation of the underlying topography of the peat basin was undertaken by auger survey and the results mapped spatially using ArcGIS 10.2, and modelled using ArcScene and Strater ${ }^{\circledR}$ software (see 3.2.2.1).

The results are presented in this chapter and form the second section of the Berth case-study. The sedimentary sequence indicates that the basin resulted from a kettle-hole which subsequently became terrestrialised. An upper surface of sands and gravels is surrounded by deep biogenic and minerogenic deposits of peat, silt and shelly marl, reaching depths in excess of $7 \mathrm{~m}$ and resting on a foundation of Late Glacial deposits. Changes in the stratigraphy suggest ways in which the wetland may have facilitated or hampered the construction and occupation of the Berth. The stratigraphic changes are positioned temporally by radiocarbon dating.

This fieldwork has identified a chronologically extensive and hitherto unknown sedimentary archive. The analyses presented here are unlikely to be the last word on the micro-topography of the Berth and should act as a base-line for further palaeoenvironmental and topographic study and future site management. 


\subsection{The Berth - stratigraphic sequence}

\subsubsection{Topography, hydrology and geology}

The marsh-fort was constructed on glacio-fluvial material which intrudes into and is surrounded by a basin of deep, low-lying peat wetland, situated at the $80-85 \mathrm{mOD}$ contour (Fig. 7-1 and Fig. 7-2). The basin itself is surrounded by deposits of boulder clay/till. The Berth's main enclosure encircles the sands and gravels which make up Berth Hill (spot height $=$ 97mOD) whilst the smaller enclosure occupies a spit of gravel which intrudes into the peat from the east. This gravel spit extends towards the main enclosure, and was the site of a short causeway which connected the two structures (Chapman, Smith and Norton, 2017). Berth Pool, a 3ha remnant of the lake which occupied the glacial kettle-hole, is located to the south of Berth Hill. It is fed by natural seepage and a drain which enters from the north, and is emptied from its north-east corner by Berth Stream, which flows east before turning sharply south to join with the outflows of Fenemere, Marton and Birchgrove Pools.

The landscape surrounding the Berth is flat, emphasising the prominence of Berth Hill; this is illustrated in 2D+ in Fig. 7-3. The field locations referred to in the text are shown in Fig. 7-4. The boreholes used in sub-surface modelling are shown in Fig. 7-5 and each is described below. The spacing between each borehole varies between $10 \mathrm{~m}$ and $50 \mathrm{~m}$ depending on the terrain (see Methodology: 3.2.2.1). 


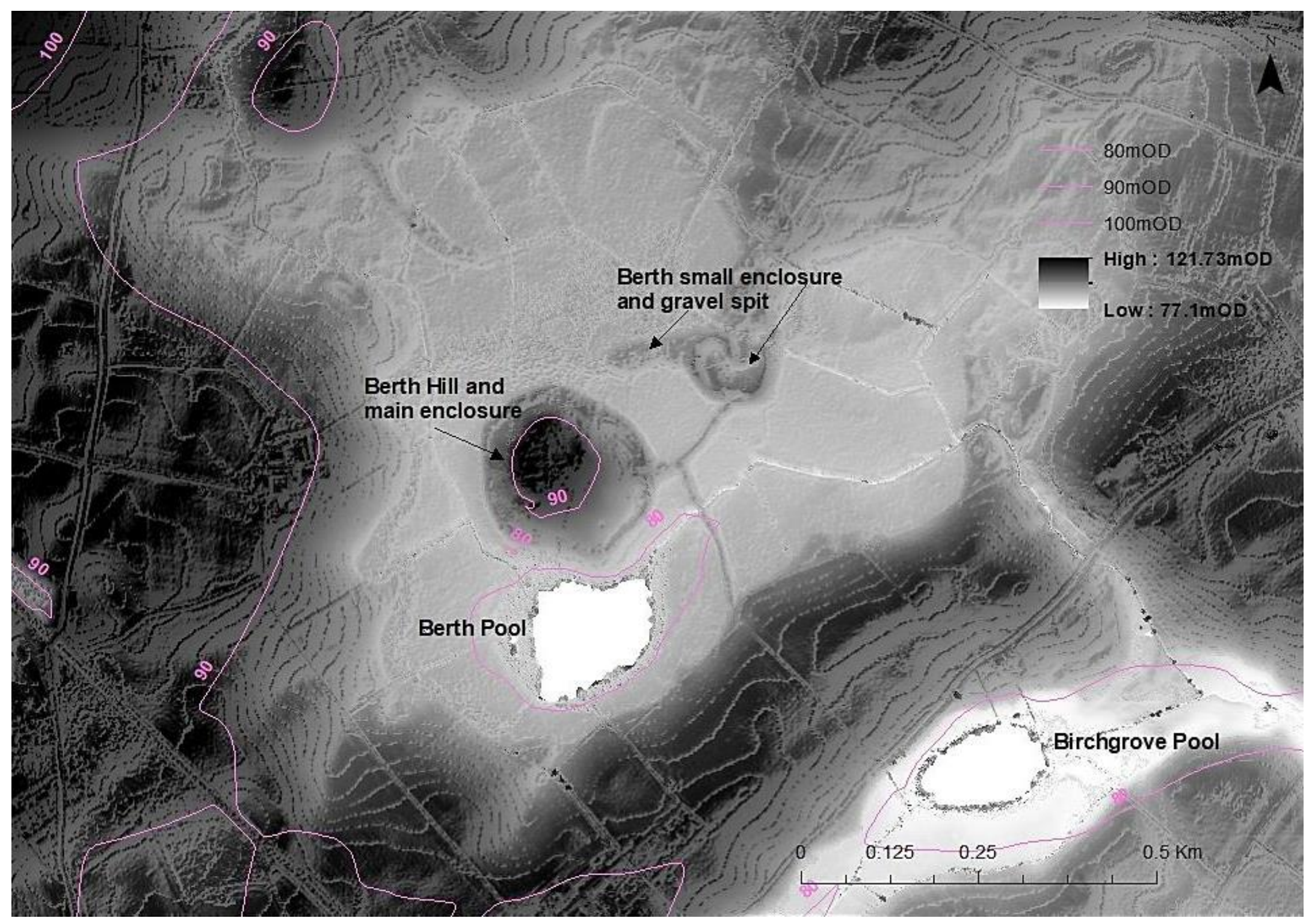

Fig. 7-1 The Berth contour map (LiDAR = 1mDSM $)$ 
Chapter 7 - The Berth - stratigraphic sequencing and radiocarbon dating

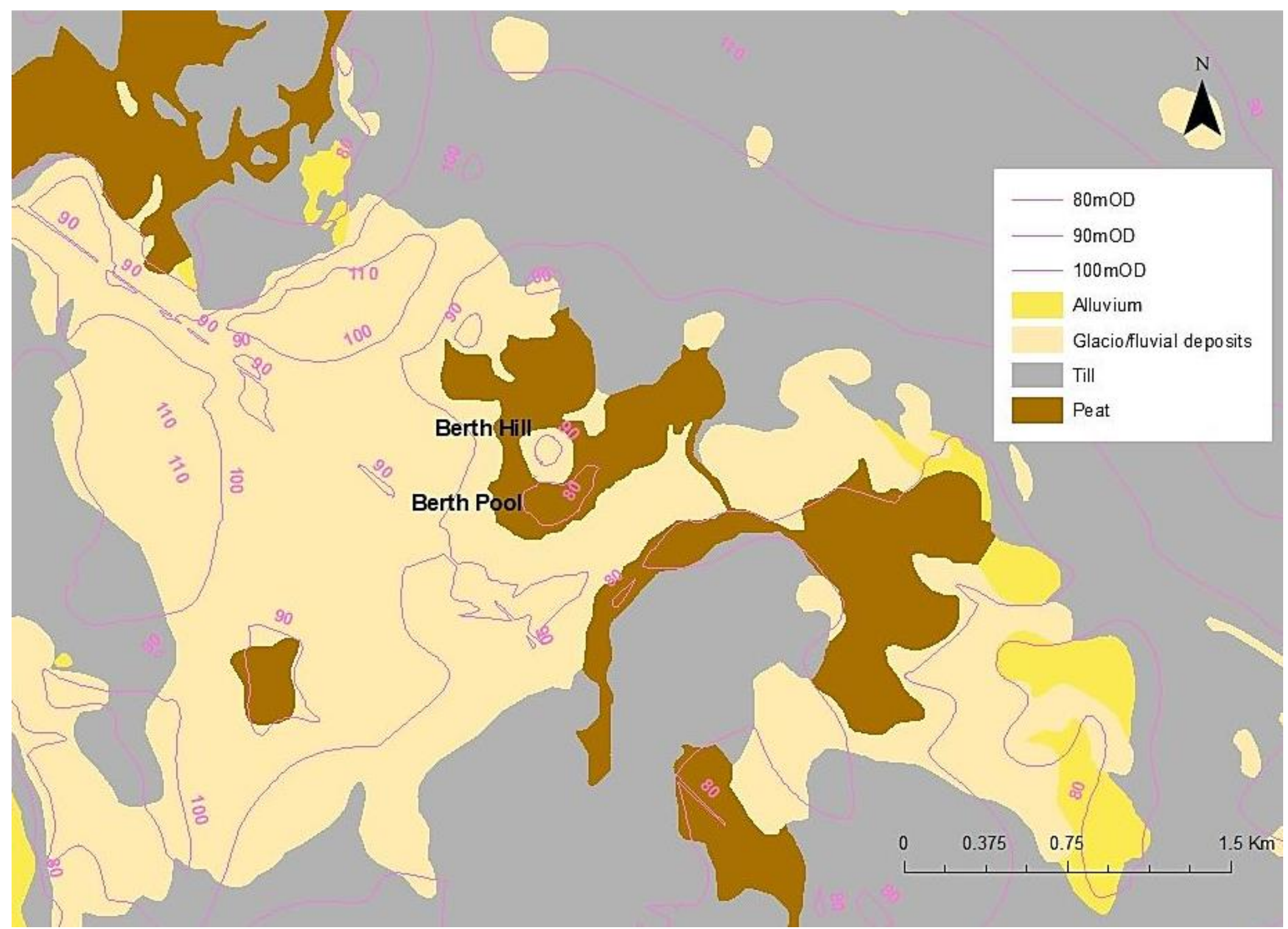

Fig. 7-2 The Berth - superficial geology (BGS 1:50,000) 


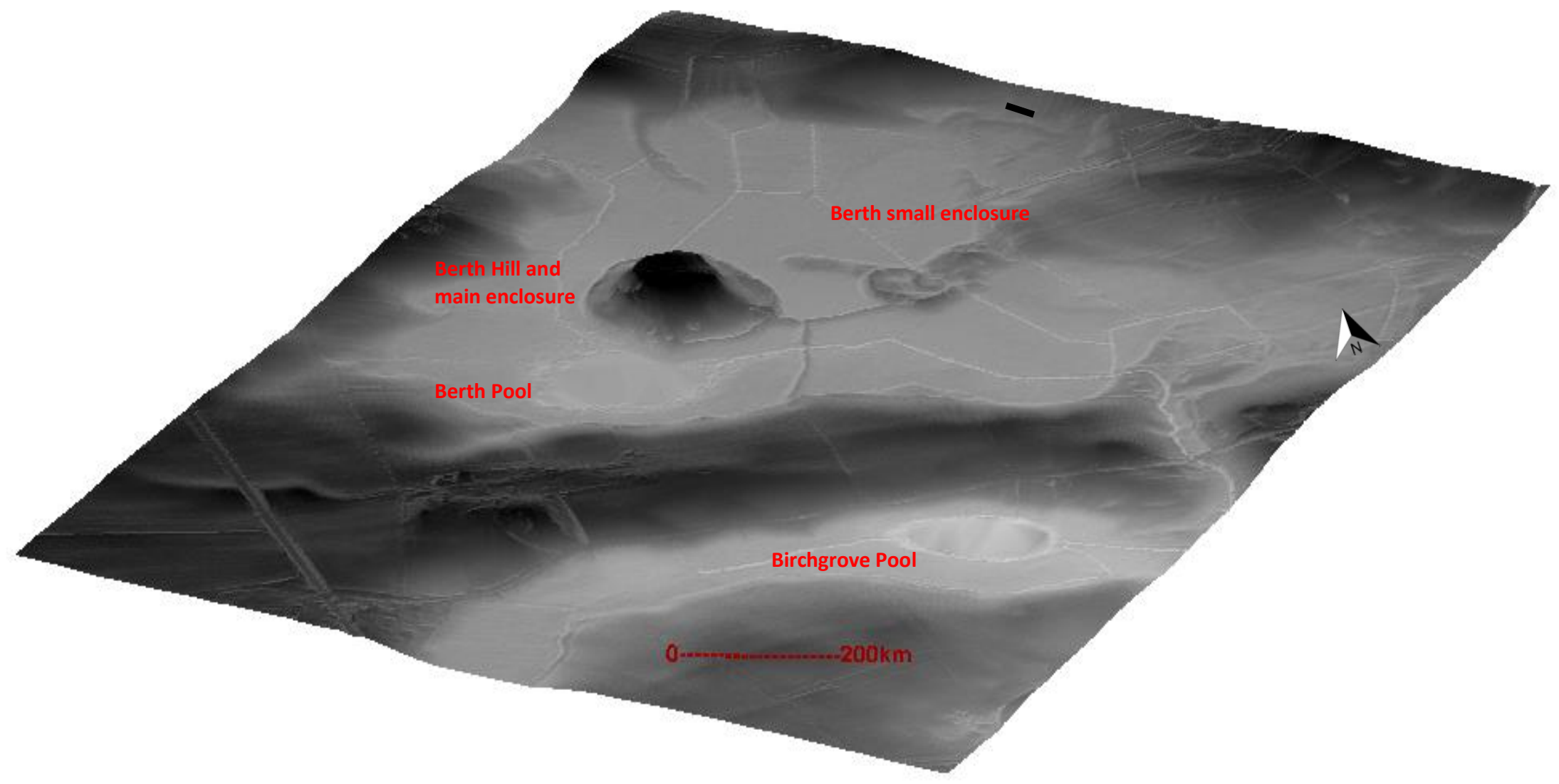

Fig. 7-3 The Berth landscape setting, showing shallow peat basin and the prominent Berth Hill (LiDAR = 1mDTM; Vertical Exaggeration $\times 2$ ) 


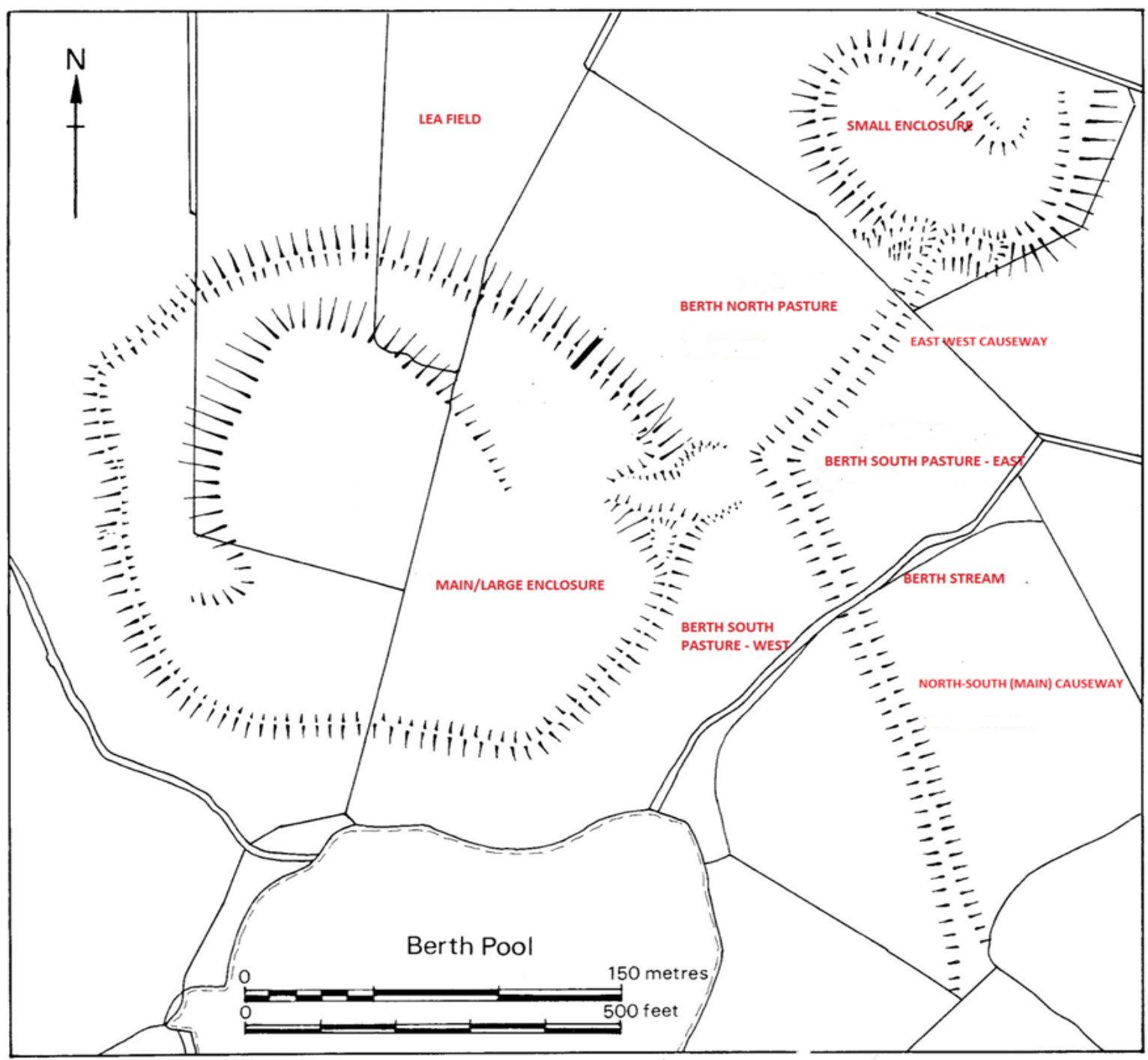

THE BERTH - locations

(map adapted from Morris and Gelling 1991: Fig. 17)

Fig. 7-4 The Berth - field locations 


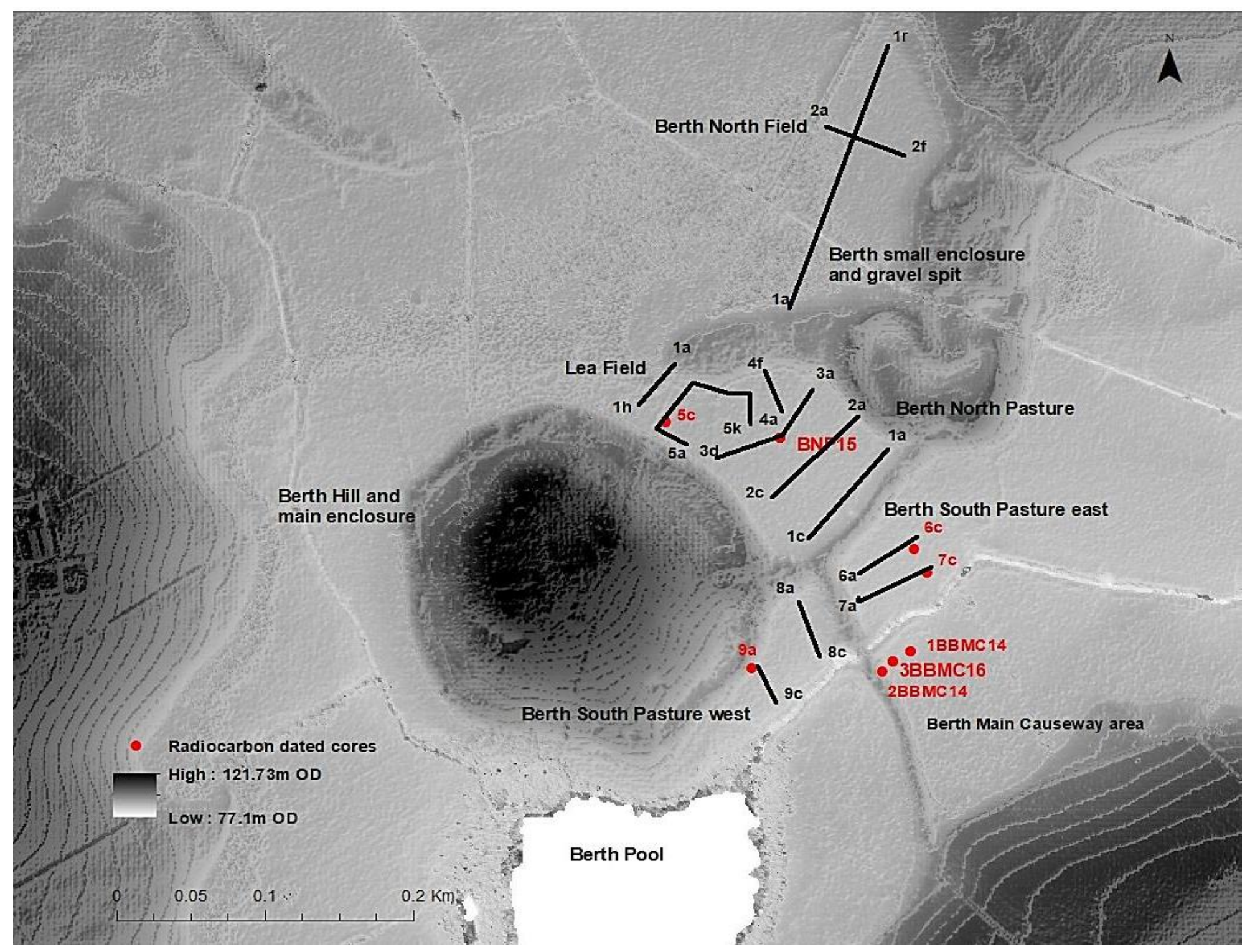

Fig. 7-5 The Berth - 2016 and 2017 coring transects and position of radiocarbon dated cores (LiDAR = 1mDSM) 


\subsubsection{Stratigraphic results}

\subsubsection{Berth North Pasture and Lea Field (Fig. 7-6 - Fig. 7-9)}

Berth North Pasture occupies the land between the large and small enclosures and is of primary importance to understanding the physical relationship between these two structures. Twenty eight cores were taken across this field in five transects (1a-c; 2a-c; 3a-d; 4a-f; 5a-k). An additional core (BNP15), obtained from the centre of the pasture, was used for organic analysis and is discussed in Chapter 8. A further transect of eight cores was taken from the adjacent Lea Field (1a-1h). Together, these cores illustrate the depth and shape of the peat basin between the two enclosures.

Transects 1, 2, and 3 illustrate an area which was open water/reed bed during the early Holocene, and which subsequently developed into woodland. These ecosystems are indicated by extensive deposits of reed and wood peat; the wood peat contains sizeable inclusions. The case for open water is further reinforced by a discontinuous layer of calcareous remains containing shell fragments of water snails (Bithynia sp.) and algal oospores (Chara sp.), occurring between depths of $3 \mathrm{~m}-4 \mathrm{~m}$, occasionally higher (see Core 1c). These species are found mostly in calcium-rich freshwater environments at depths of up to $5 \mathrm{~m}$ and are discussed in Chapter 8.

The underlying shape of the peat basin is not symmetrical but shelves from east to west to form very deep peat deposits close to Berth Hill. For example, Core $5 c$ achieved a maximum depth of $7.7 \mathrm{~m}$ which included a deep $(6 \mathrm{~m})$ layer of wood/reed peat; Core $1 \mathrm{~h}$ in the Lea Field did not reach solid geology and here, the peat deposits may be substantially deeper. The dramatic drop from the side of Berth Hill into the peat is typical of steep-sided kettle-holes, which are often asymmetric in profile (Sinker, 1962; Reynolds and Sinker, 1976; Reynolds, 1979). This buried topographic feature may have aided or emphasised the defences of the Berth's main enclosure. 


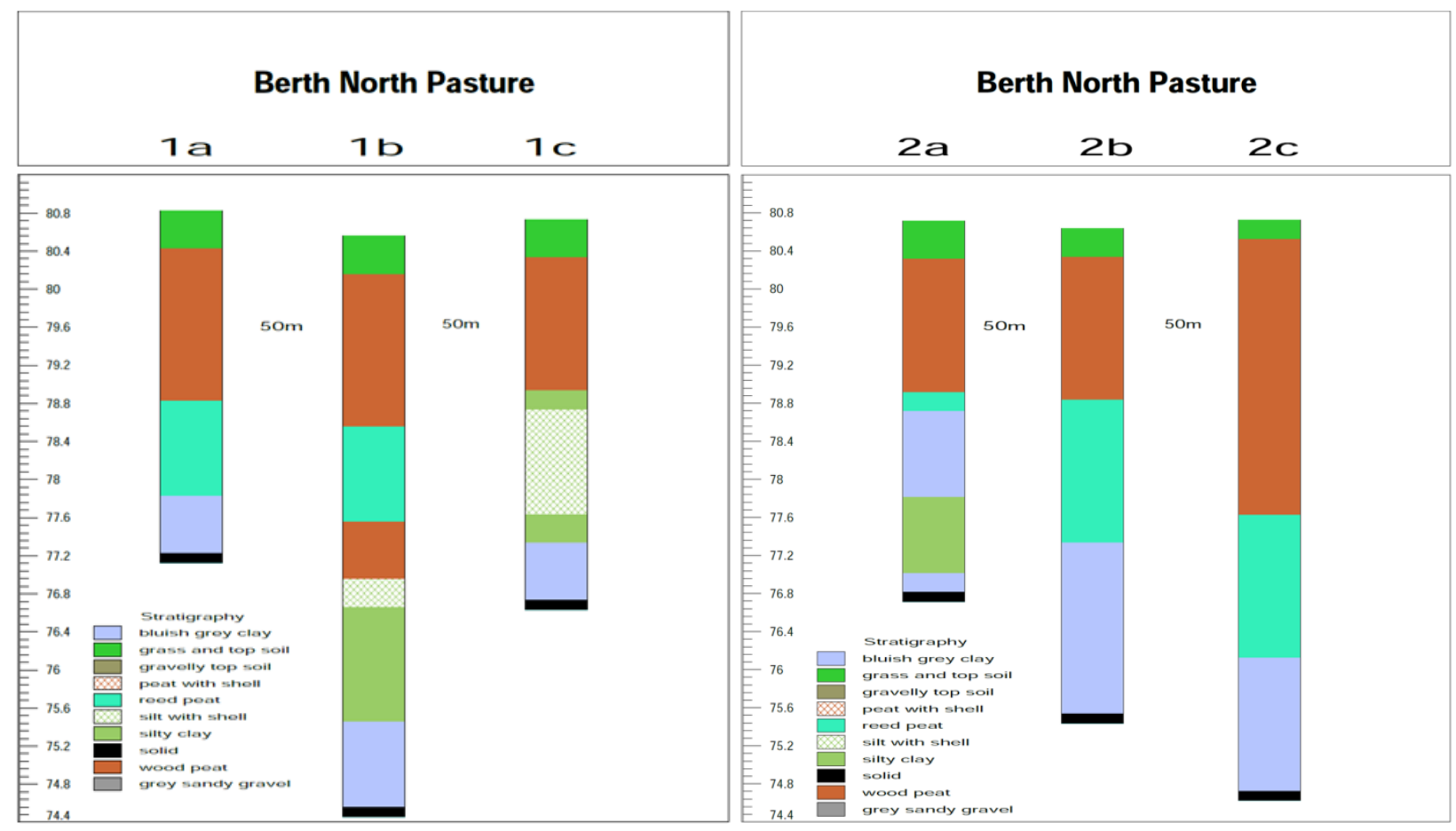

Fig. 7-6 Berth North Pasture - Transects 1 and 2

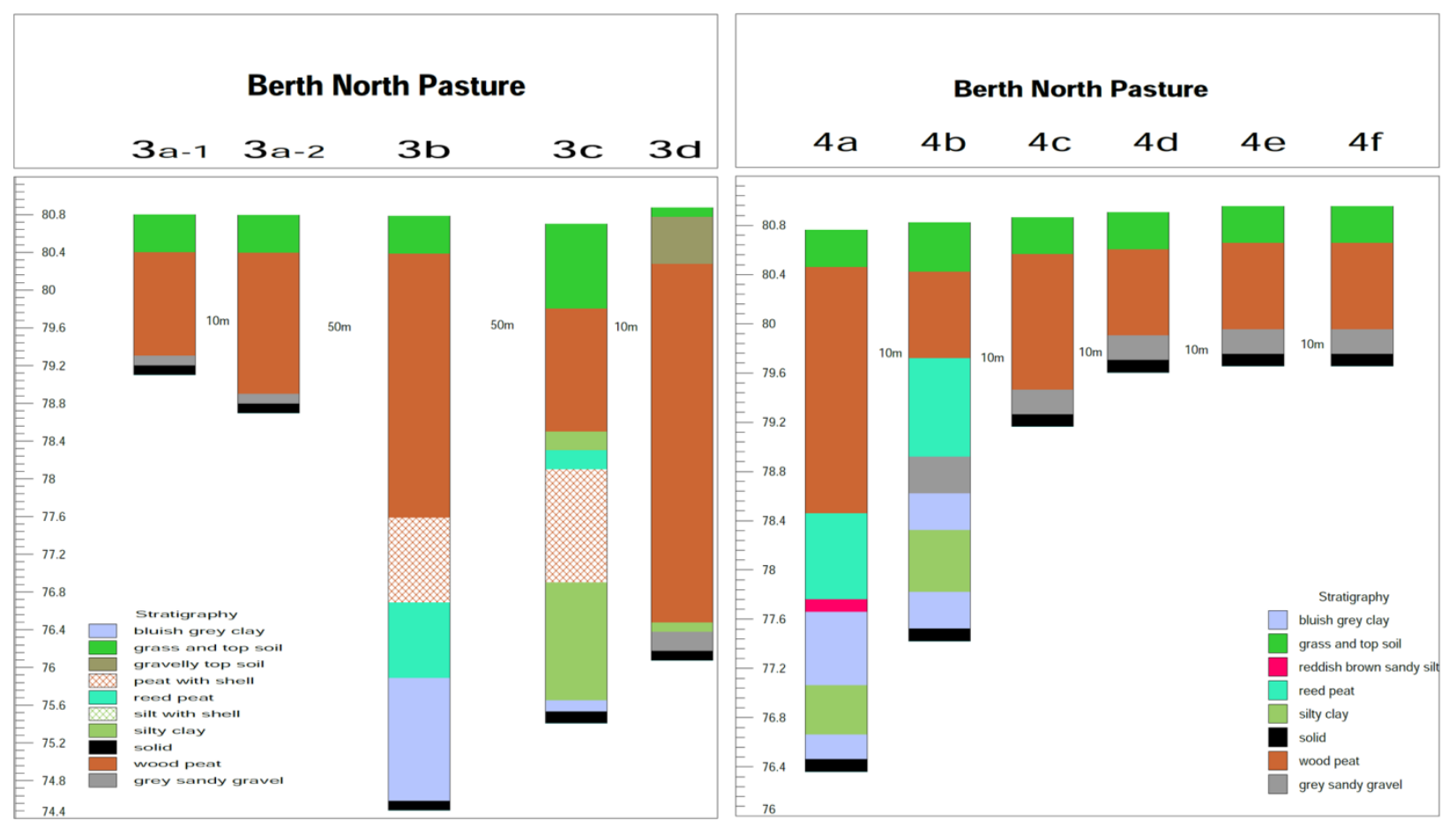

Fig. 7-7 Berth North Pasture - Transects 3 and 4 


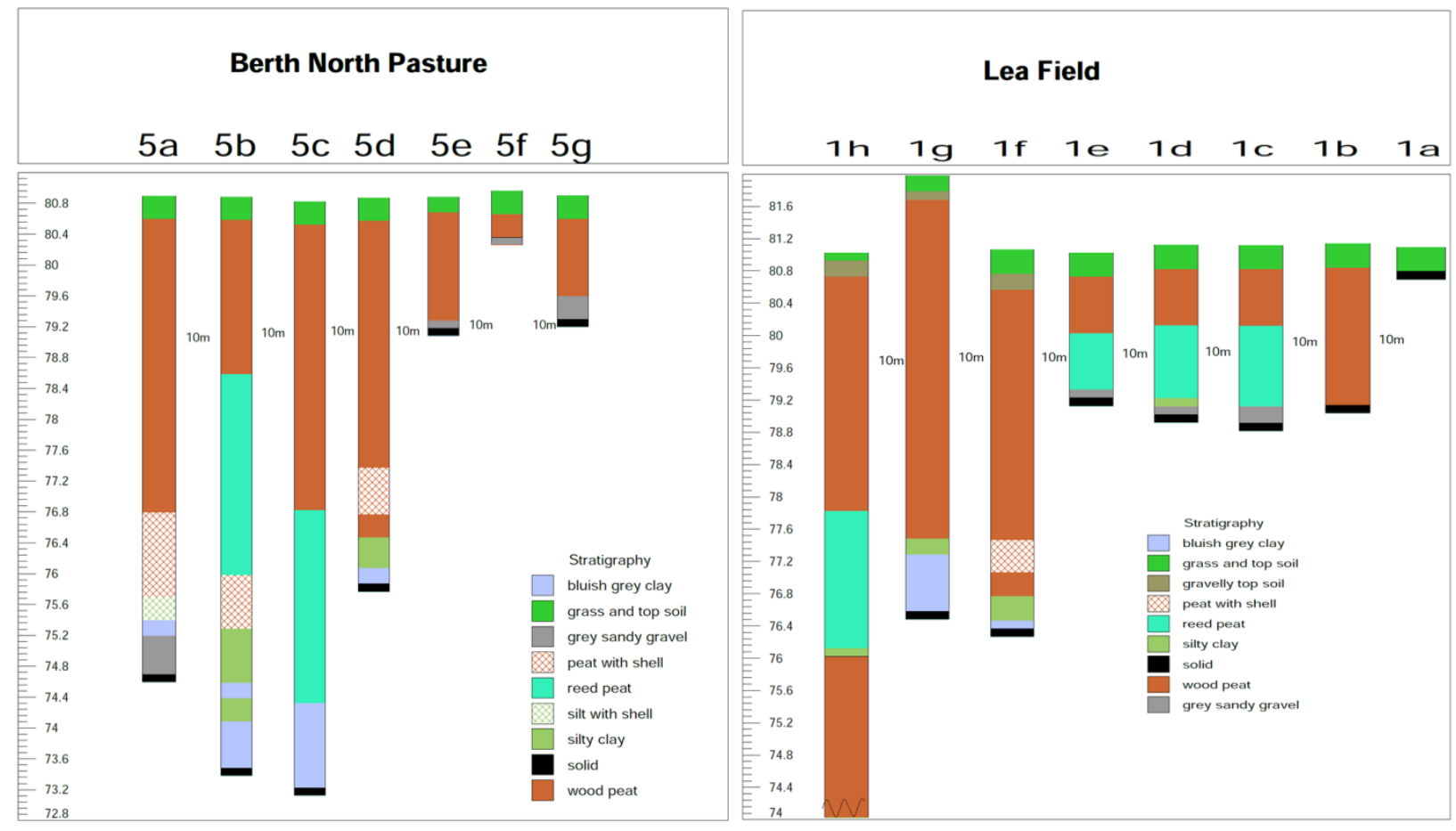

Fig. 7-8 Berth North Pasture - Transect 5a-5g and Lea Field transect

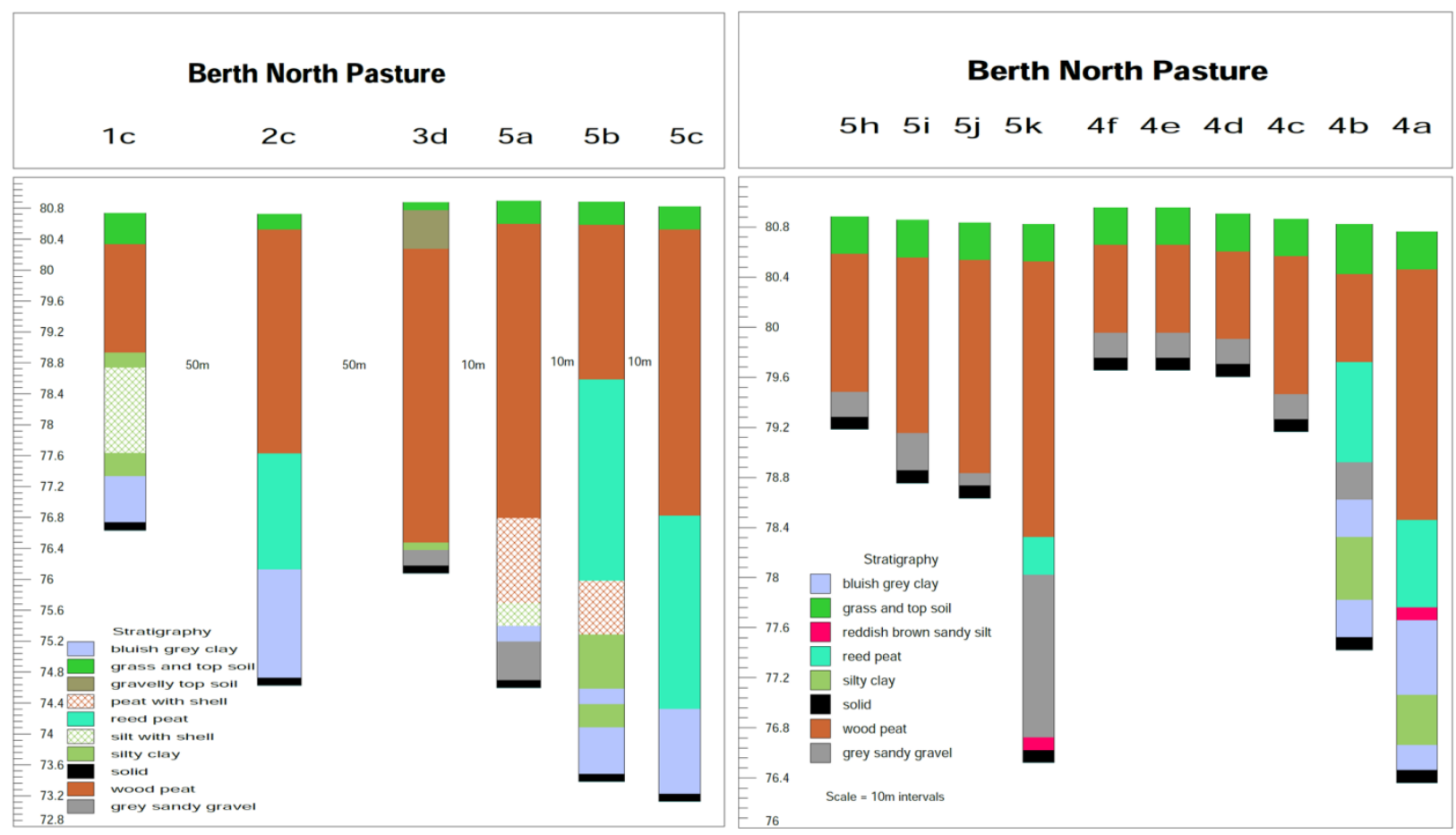

Fig. 7-9 Berth North Pasture - cores illustrating depth bordering the main enclosure (1c-5c) and the drop off from the gravel spit (5h-5k; 4f-4a) 


\subsubsection{Berth South Pasture - East/West (Fig. 7-10; Fig. 7-11)}

The stratigraphy of Berth South Pasture - East (Transects 6a-6c and 7a-7c) presents a similar profile to Berth North Pasture; reed and wood peat rest on layers of clay and silt, which in turn lie on a foundation of sands and gravels. However, here the reed peat and the shelly layers are more extensive, suggesting that this tract of land was open water/reed bed for a longer period. The layers apparent in the blue-grey clay/silt suggest that these may be varve deposits (see also Fig. 7-14) and a discontinuous layer of leached manganese was identified towards the bottom of these cores. The maximum depth achieved was $6.8 \mathrm{~m}$.

Transects 8a-8c and 9a-9c (Berth South Pasture - West) explored the area between the southern ramparts of the main enclosure and Berth Pool. Transect 8 comprised extensive deposits of reed/wood peat with large wood inclusions, a deep shelly layer and bands of glacial clay; this transect also reached a depth of $6.8 \mathrm{~m}$. In Transect 9, Core 9a encountered an impenetrable gravel layer at $3 \mathrm{~m}$ - the glaciofluvial deposits of Berth Hill. By contrast, Cores 9b and 9c failed to reach solid geology; this sharp dropoff into the peat is similar to that encountered alongside the ramparts which border Berth North Pasture. Together with the extensive reed peat and the shallow shell horizon (encountered at $0.7 \mathrm{~m}$ in Core 9b), the results suggest that Berth Pool was previously more extensive and depending on chronology, may have reached the ramparts of the Berth's main enclosure. 


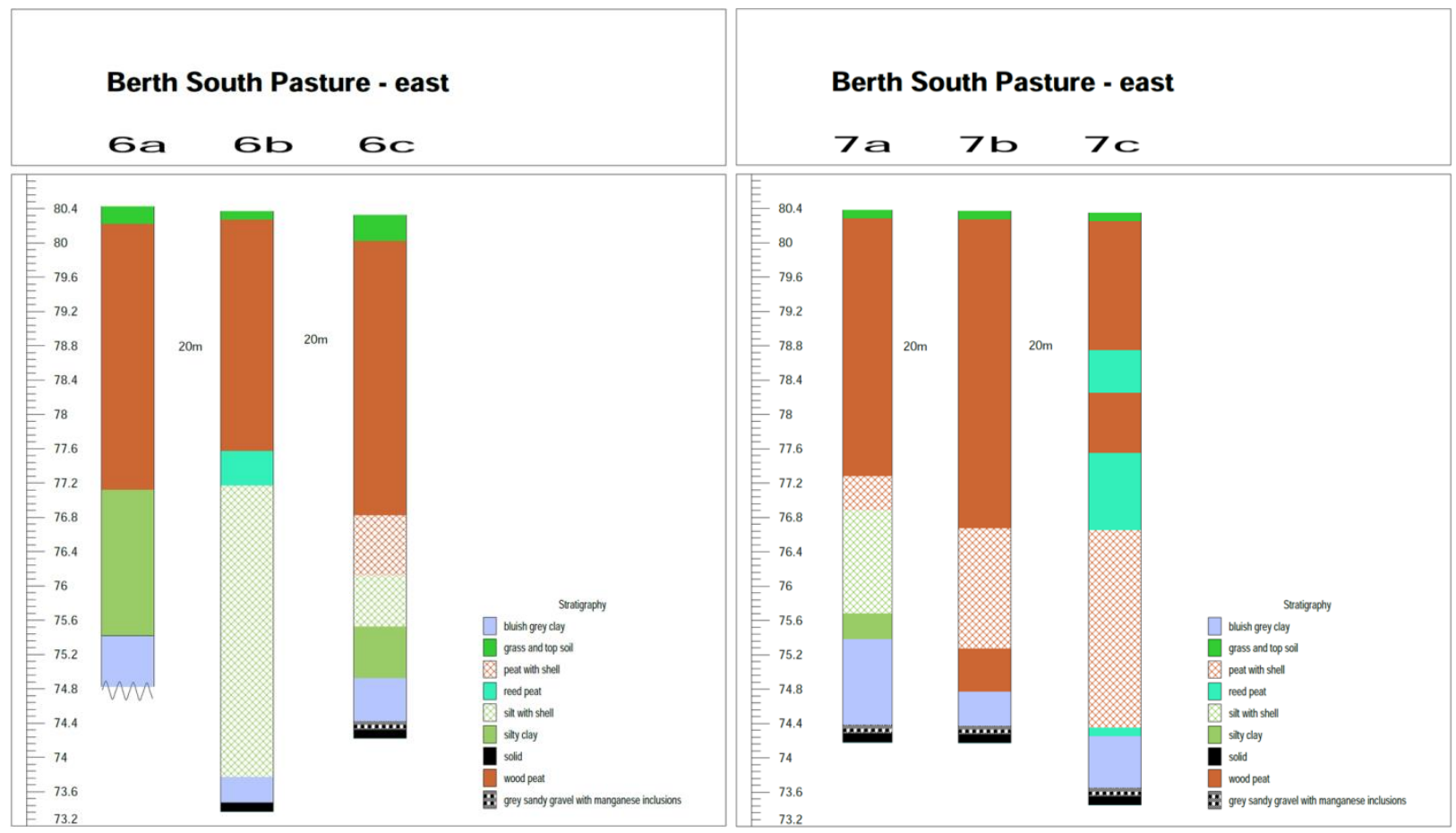

Fig. 7-10 Berth South Pasture - east

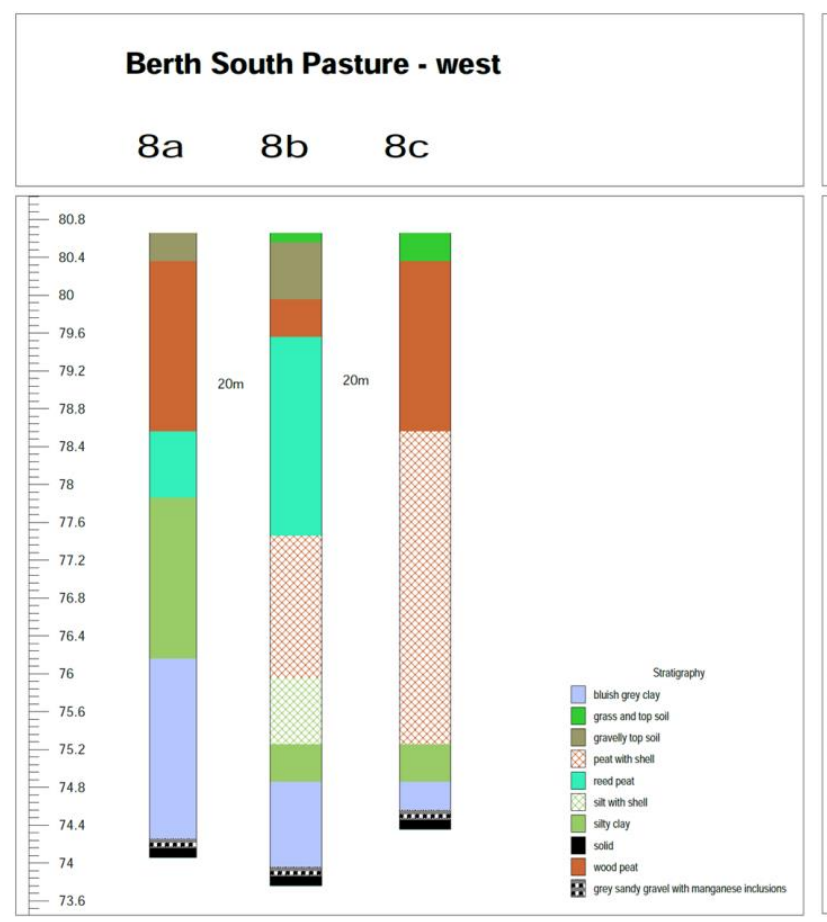

Berth South Pasture - west

$9 a \quad 9 b \quad 9 c$

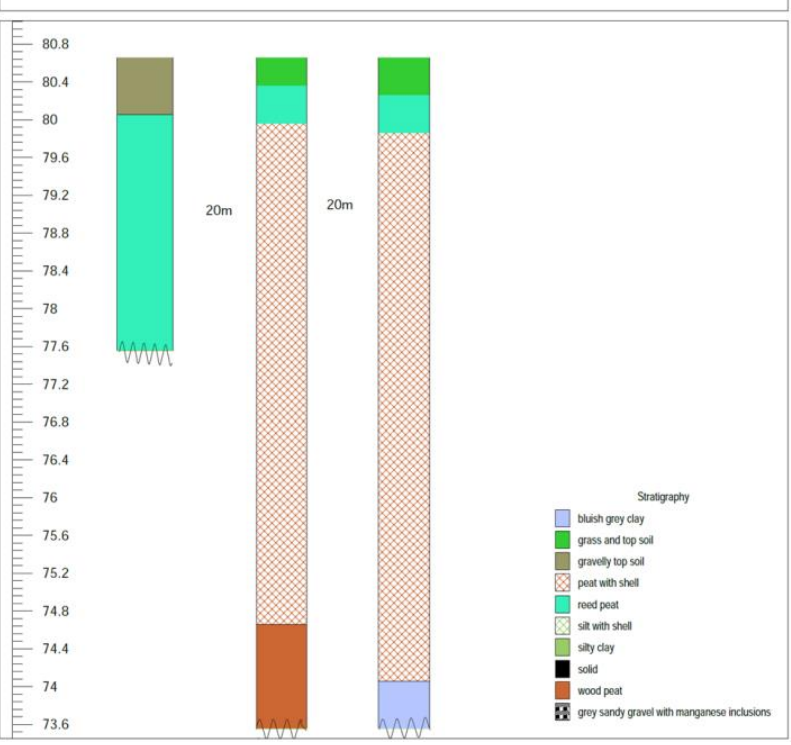

Fig. 7-11 Berth South Pasture - west 


\subsubsection{Berth North Field (north of the small enclosure; Fig. 7-12)}

Investigation of the muddy field north of the gravel spit and small enclosure comprised twenty five cores taken in two intersecting transects (1a-1r, and 2a-2f; see Fig. 7-5). This section of pasture was selected for investigation to ascertain whether the peat basin was as deep here as elsewhere and by inference, whether open water once surrounded both enclosures. The deposits encountered in these transects were mainly wood peat, with occasional shallow layers of reed peat towards the base of several cores. There is a pronounced depth of clay/gravel at the west end of Transect 2 (2a), whilst the eastern end of this transect (2f), approaching the small enclosure, looked like 'made ground'. No shelly deposits were encountered in these cores, therefore it is unlikely that the area had ever been open water; in other words, the kettle-hole and subsequent peat basin did not extend into this area of the Berth's environs.

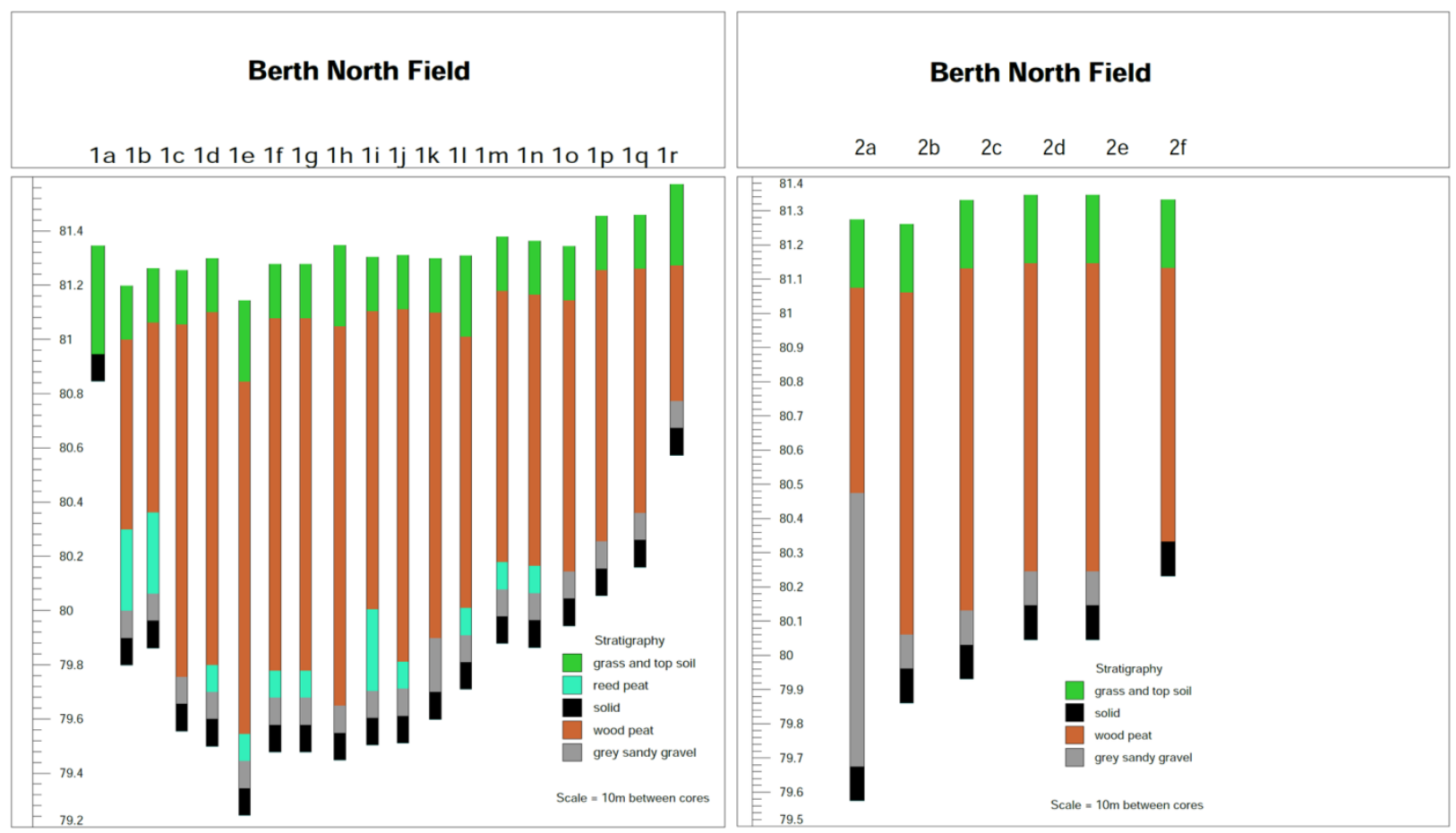

Fig. 7-12 Berth North Field - Transects 1 and 2 


\subsubsection{Berth Main Causeway, south of Berth stream (Fig. 7-13)}

Two cores (1BBMC14/2BBMC14) were taken from south of Berth Stream as a rudimentary transect during early field work, and are included here to illustrate that the sequence of deposits identified in Berth North and South Pastures extends south of Berth Stream - wood peat overlies reed peat and shell which in turn overlies glacial clays. 2BBMC14 was taken from close to the causeway, hence the slight increase in elevation. This suggests that the causeway has fossilised and preserved the underlying peat stratum which did not shrink or deflate to the same degree as more exposed deposits; this factor is further shown in the radiocarbon dating and palaeoenvironmental analysis (see 7.2 and Chapter 8).

3BBMC16 was taken $3 \mathrm{~m}$ east of the main north-south causeway, and provides the same extensive sequence of post-glacial varve deposits as were seen in Berth South Pasture - East. The Late Glacial sequence, including the Windermere interstadial, is particularly well represented (pers.comm. Dr Warren Eastwood) (Fig. 7-14).

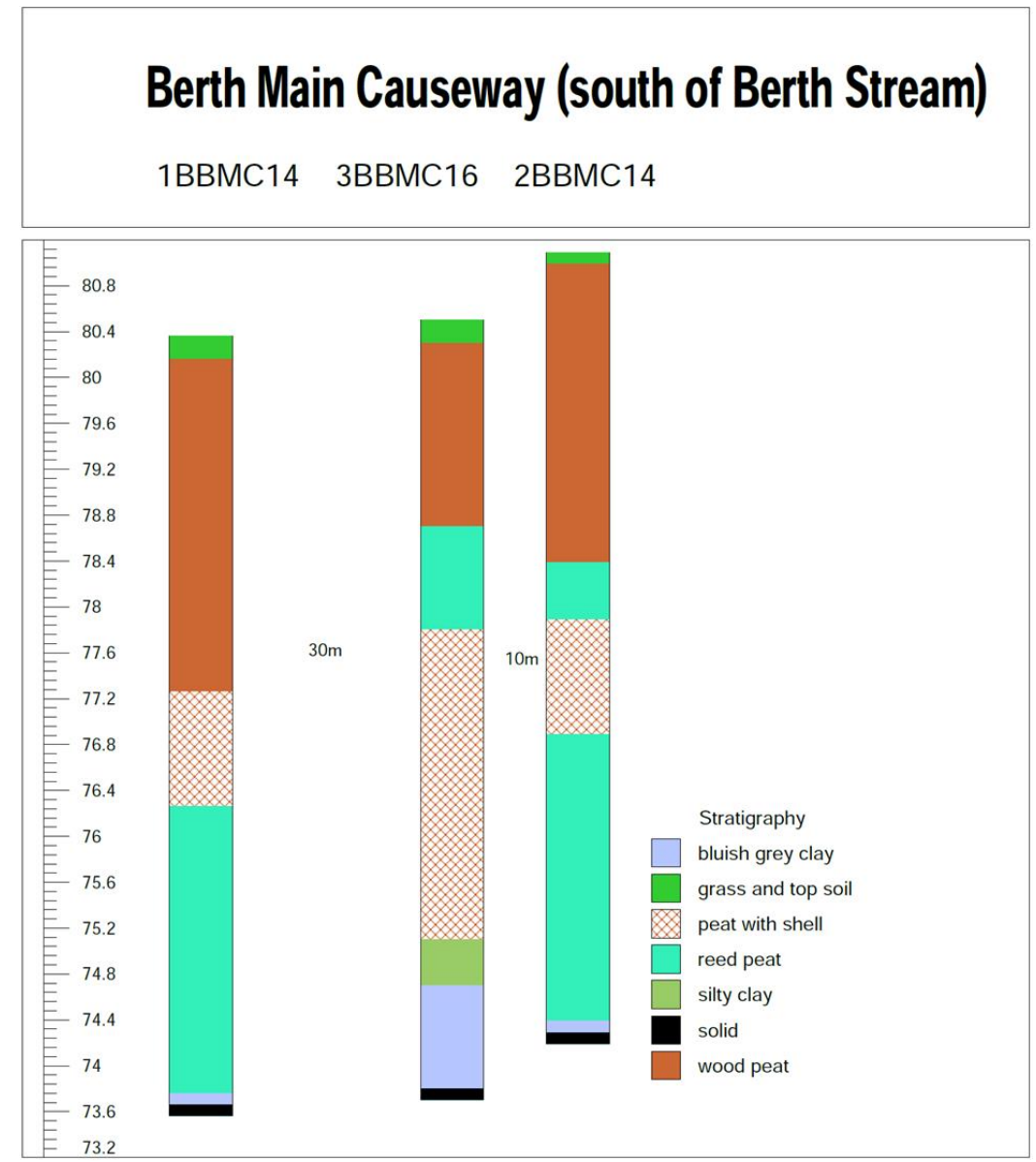

Fig. 7-13 Berth Main Causeway - cores 


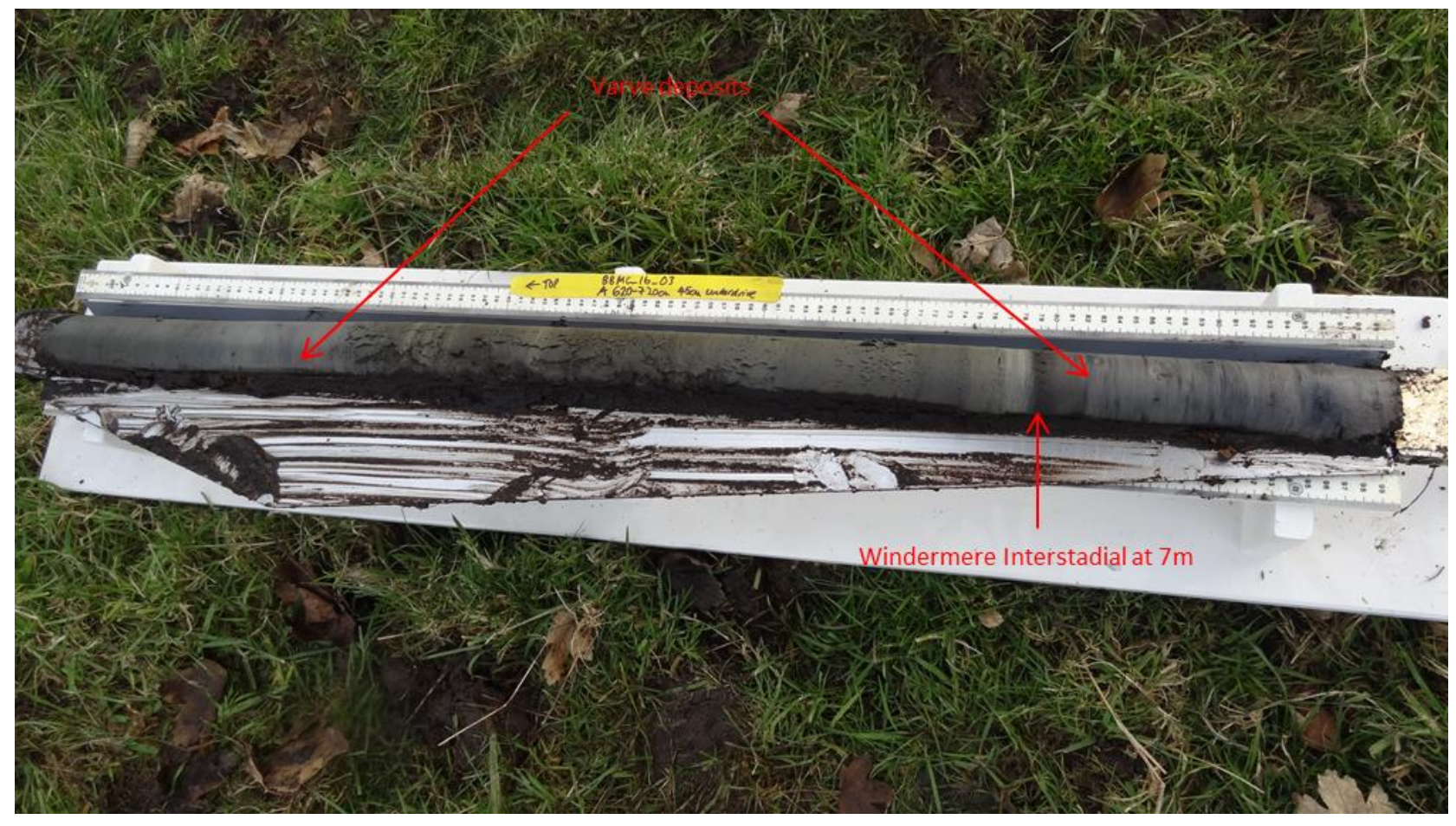

Fig. 7-14 Core 3BBMC16 - Windermere Interstadial (Norton 2016)

\subsubsection{Subsurface modelling - summary}

Although some boreholes failed to reach solid geology and there is disturbance of the top metre of deposits, this auger survey presents a comprehensive picture of the stratigraphy surrounding the Berth. A summary of this stratigraphy is presented in diagrammatic form in Fig. 7-15 and shows the depth of the peat layer especially in relation to Berth Hill.

These results are amalgamated with conclusions from the radiocarbon dating programme and discussed below (see 7.2). 
Chapter 7 - The Berth - stratigraphic sequencing and radiocarbon dating

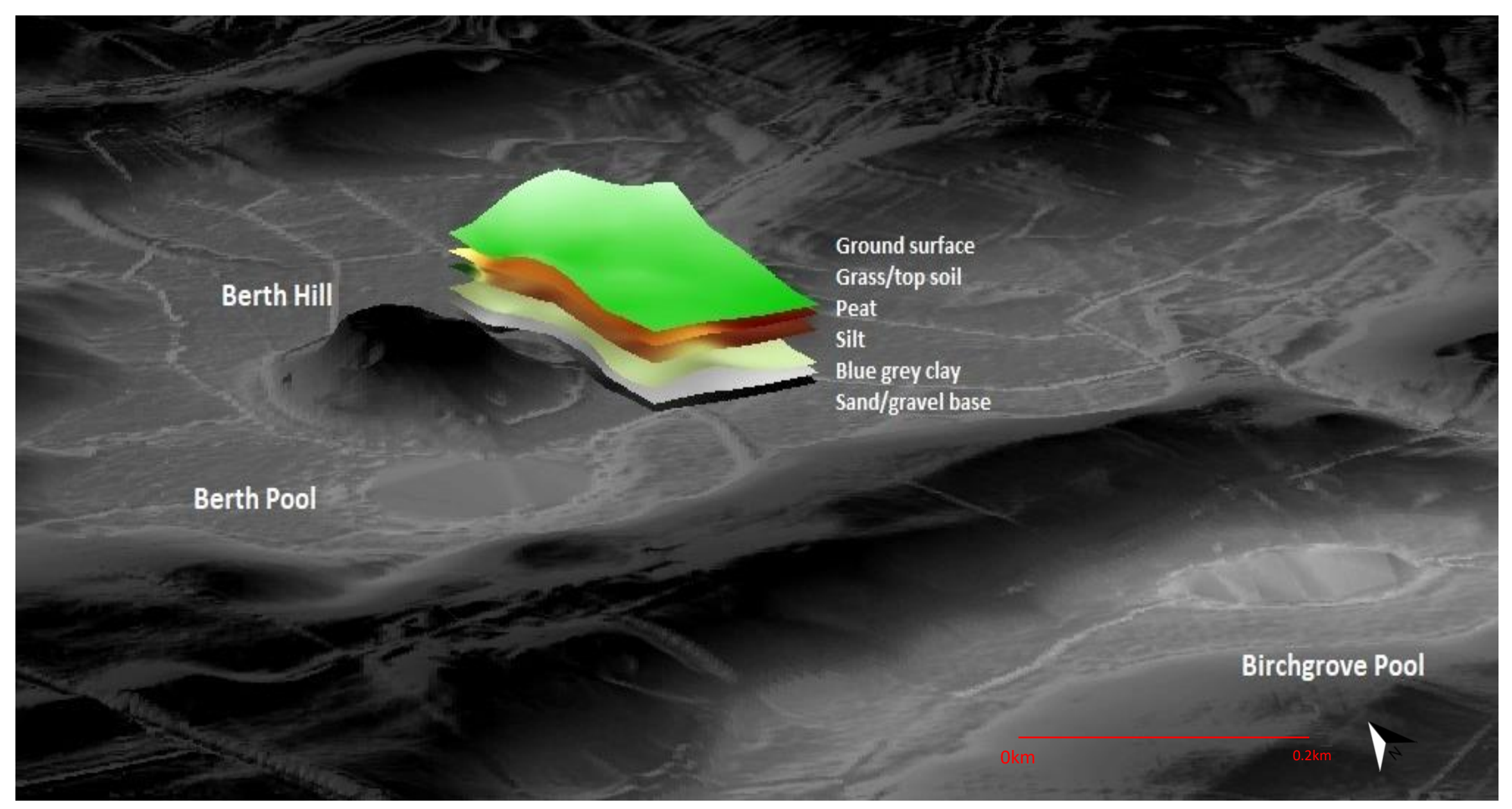

Fig. 7-15 The Berth - 2D+ stratigraphy (LiDAR = 1mDTM; Vertical Exaggeration $\times 2$ ) 


\subsection{The Berth - chronologicall sequence}

A radiocarbon dating programme undertaken for this research has established a lengthy chronology for the litho- and bio-stratigraphic horizons at the Berth. Fourteen determinations were obtained from peat samples taken from the following locations (see also Fig. 7-5):

- Berth Main Causeway

- 1BBMC14 (mid-pasture - two dates)

- 2BBMC14 (next to the causeway)

- 3BBMC16 (between causeway and pasture - two dates)

- Berth North Pasture

- BNP15 - a sequence of five dates between $1 \mathrm{~m}-3 \mathrm{~m}$

○ $5 \mathrm{C}$

- Berth South Pasture
○ $6 \mathrm{C}$
$\circ 7 \mathrm{C}$
$\circ 9 \mathrm{~A}$

Two additional radiocarbon determinations were obtained during excavations in 2016 from deposits underlying the north-south causeway (Trench 1), making a total of sixteen dates. The results are shown in Table 7-1 - Table 7-4, and Appendix 5. 


\begin{tabular}{|c|c|c|c|c|c|c|}
\hline Lab no. & Reference & Depth cm & Service & Material & Conventional Age & 2 SIGMA CALIBRATION (95\% probability) \\
\hline \multicolumn{7}{|c|}{ BETA ANALYTIC, MIAMI - Calibration: OxCal v4.2.4;Bronk Ramsay (2013); IntCal13 atmospheric curve (Reimer et al 2013) } \\
\hline \multicolumn{7}{|c|}{ THE BERTH - MAIN (NORTH-SOUTH) CAUSEWAY AND PASTURE SOUTH OF BERTH STREAM Obtained - August 2014 ; November 2016} \\
\hline 387078 & 1BBMC14 & 170 & AMS & Wood (unident) & $3280 \pm 30 \mathrm{BP}$ & Cal BC 1625 - 1500 (Cal BP 3575 - 3450) \\
\hline 387079 & 1BBMC14 & 325 & AMS & plant material & $4850 \pm 30 \mathrm{BP}$ & Cal BC 3690 - 3540 (Cal BP 5500 - 5490) \\
\hline 387080 & 2BBMC14 & 170 & AMS & Wood (unident) & $2460 \pm 30 \mathrm{BP}$ & Cal BC $765-410 \quad$ (Cal BP $2715-2360)$ \\
\hline 453320 & 3BBMC16-1 & 160 & AMS & plant material & $3870 \pm 30 \mathrm{BP}$ & Cal BC 2465 - 2210 (Cal BP 4415 - 4160) \\
\hline 453321 & 3BBMC16-2 & 180 & AMS & plant material & $3860 \pm 30 \mathrm{BP}$ & Cal BC 2460 - 2205 (Cal BP 4410 - 4155) \\
\hline \multicolumn{7}{|c|}{ THE BERTH - BERTH NORTH PASTURE Obtained - June 2016} \\
\hline 450200 & Berth $20165 c$ & 120 & AMS & Wood (unident) & $3850 \pm 30 \mathrm{BP}$ & Cal BC $2460-2205$ (Cal BP 4410 to 4155 ) \\
\hline \multicolumn{7}{|c|}{ THE BERTH - SOUTH PASTURE EAST/WEST Obtained - June 2016} \\
\hline 450202 & Berth 2016 6C & 220 & AMS & Wood (unident) & $5460 \pm 30 \mathrm{BP}$ & Cal BC 4350 - 4260 (Cal BP 6250 to 6210 ) \\
\hline 450201 & Berth $20167 C$ & 240 & AMS & Wood (unident) & $3310 \pm 30 \mathrm{BP}$ & Cal BC 1660 - 1505 (Cal BP 3610 to 3455) \\
\hline 450199 & Berth $20169 \mathrm{~A}$ & 180 & AMS & Wood (unident) & $3510 \pm 30 \mathrm{BP}$ & Cal BC 1915 - 1745 (Cal BP 3865 to 3695) \\
\hline \multicolumn{7}{|c|}{ POZNAN LABORATORIES, POLAND Calibration: OxCal v4.2.4 Bronk Ramsay (2013): r:5 IntCal13 atmospheric curve (Reimer et al 2013) } \\
\hline \multicolumn{7}{|c|}{ THE BERTH - BNP 15 - NORTH PASTURE Obtained - May 2015} \\
\hline Poz-77442 & The Berth BNP $15(2)(1 \mathrm{~A})$ & $100-110$ & AMS & Alder (cone) & $6120 \pm 40 \mathrm{BP}$ & Cal BC $5209-4953$ \\
\hline Poz-77444 & The Berth BNP 15 (2) (2A) & $140-150$ & AMS & Wood (unident) & $7060 \pm 50 \mathrm{BP}$ & Cal BC $6032-5837$ \\
\hline Poz-77445 & The Berth BNP $15(2)(3 \mathrm{~A})$ & $160-170$ & AMS & Alder (seed) & $7280 \pm 90 \mathrm{BP}$ & Cal BC $6366-6002$ \\
\hline Poz-77446 & The Berth BNP 15 (2) (4A) & $180-190$ & AMS & Alder (seed) & $6950 \pm 100 \mathrm{BP}$ & Cal BC $6010-5664$ \\
\hline Poz-77546 & The Berth BNP 15 (2) (5A) & $290-300$ & AMS & N.marina (seed) & $8710 \pm 50 \mathrm{BP}$ & Cal BC $7938-7597$ \\
\hline \multicolumn{7}{|c|}{ QUEEN’S UNIVERSITY, BELFAST - Calibration: OxCal v4.2.4;Bronk Ramsay (2013); IntCal13 atmospheric curve (Reimer et al 2013) } \\
\hline \multicolumn{7}{|c|}{ THE BERTH - 2016 EXCAVATION BENEATH TRENCH 1; NORTH-SOUTH CAUSEWAY STRUCTURE Ｏbtained - June 2016} \\
\hline UBA-32479 & Trench 1 & $\mathrm{n} / \mathrm{a}$ & AMS & $\begin{array}{l}\text { Carbonized wood } \\
\text { (larch?) }\end{array}$ & $2141 \pm 25 \mathrm{BP}$ & Cal BC 351- 61 \\
\hline UBA-32480 & Trench 1 & $\mathrm{n} / \mathrm{a}$ & AMS & $\begin{array}{l}\text { Carbonized wood } \\
\text { (larch?) }\end{array}$ & $2266 \pm 30 \mathrm{BP}$ & Cal BC 398-210 \\
\hline
\end{tabular}

Table 7-1 The Berth - radiocarbon results; August 2014; January 2016; June 2016; November 2016 (highlighted dates = possible anomalies) 


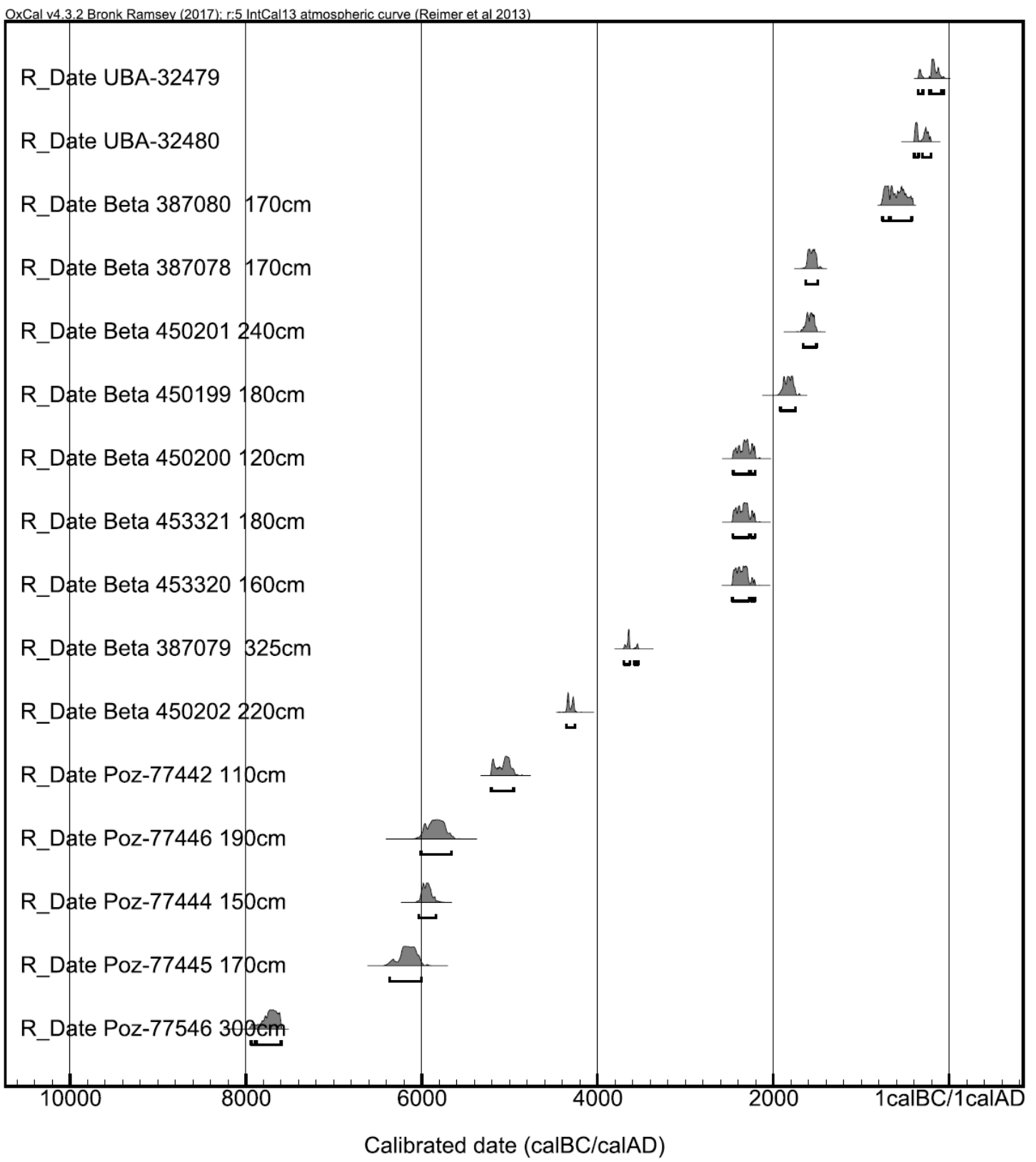

Table 7-2 The Berth - chronological multi-plot of radiocarbon dates

\subsubsection{Chronological coverage and reliability}

Collectively, the dates cover a depth of $2.15 \mathrm{~m}$ and span 6250 years of deposition (Table 7-2). Although the chronological sequence appears to be a straightforward, when arranged 
stratigraphically and spatially, these data fall into two parallel groups (blue and red groups in Table 7-3 below). The blue group depicts the BNP15 sequence, whilst the red group depicts the remaining dates (5c; 6c; 7c; 9a; 1BBMC14-1 and 2; 2BBMC14; 3BBMC16-1 and 2). The deposits from BNP15 are substantially older than elsewhere. Both groups contain anomalies.

BNP15 provides chronological evidence for ancient deposits dating from the early Holocene. The sequence includes one date that appears too 'young' (Poz-77446; 6950 $100 \mathrm{BP}$ ). Reverses are not unusual when dating complex sequences (e.g. Bartley and Morgan, 1990:184; Howard et al., 2016:37). Causes can include laboratory-based contamination or the selection of varying types of organic material; however, the processes adopted by this research took care to avoid these errors. Reverses can also stem from natural causes, such as an in-wash of organic material or distortions in ${ }^{14} \mathrm{C}$ measurements caused by a 'reservoir effect' where ${ }^{14} \mathrm{C}$ is retained differentially in aquatic (usually marine) contexts (e.g. Blaauw et al., 2004; Piotrowska et al., 2011; Philippsen, 2013). However, the stratigraphy encountered at the Berth is undynamic, with no evidence for palaeochannels or intrusive material. Therefore the reason for the reverse is likely to be taphonomic - a 'younger' seed was taken down to a lower stratigraphy by rootlets or burrowing organisms (e.g. Birks, 1982; Howard et al., 2016). The stratigraphic proximity of Poz-77446 with those that flank it may also indicate a lack of true age difference, and its unreliability is emphasised by a large standard deviation of \pm 100 years. Therefore as a precaution, Poz-77446 has been discounted.

The remaining dates (red group) do not form a sequence. They were recovered from similar depths across the peat basin, illustrate a younger chronology and also contain anomalies. Beta 450202 (6c; 220cm; $5460 \pm 30$ BP) appears to be too old whilst Beta 453201 (7c; $240 \mathrm{~cm}$; $3310 \pm 30 B P$ ) may be too young. These samples originated in Berth South Pasture - East; they were in close proximity and at a similar stratigraphic level. Their discontinuity may suggest that the deposits in Berth South Pasture are unreliable, perhaps due to its previous lacustrine nature. Beta 450200 (5c; $120 \mathrm{~cm} ; 3850 \pm 30 \mathrm{BP})$ is also anomalous; it does not fit with either the BNP15 sequence or with other dates across the peat basin. Core $5 \mathrm{c}$ is located at the short 
crossing point between the gravel spit and the main enclosure, ground which may have been disturbed by the putative causeway or by natural drainage (see below). Finally, Beta 453320 (3BBMC16; $160 \mathrm{~cm} ; 3870 \pm 30 \mathrm{BP}$ ) appears to be possibly too old, and perhaps a safer option is to rely on its proximal counterpart from the same core (Beta $453321 ; 180 \mathrm{~cm} ; 3860 \pm 30 \mathrm{BP}$ ).

'Perhaps the only way to ensure a robust chronology for any given sequence is through the dating of multiple sediment fractions from selected horizons' (Howard et al., 2016:38). As was found in the Suffolk River Valleys Project, a clear sequence with no reverses or anomalies is not always achievable given the stratigraphic formation of many wetland sites. Notwithstanding these anomalies, the dating programme at the Berth has produced informative results. A revised grouping minus the anomalies is presented in Table 7-4; whilst dismissing these anomalies reduces the available data, the resulting discussion is based on firmer ground. The implications of each of these results are discussed below.

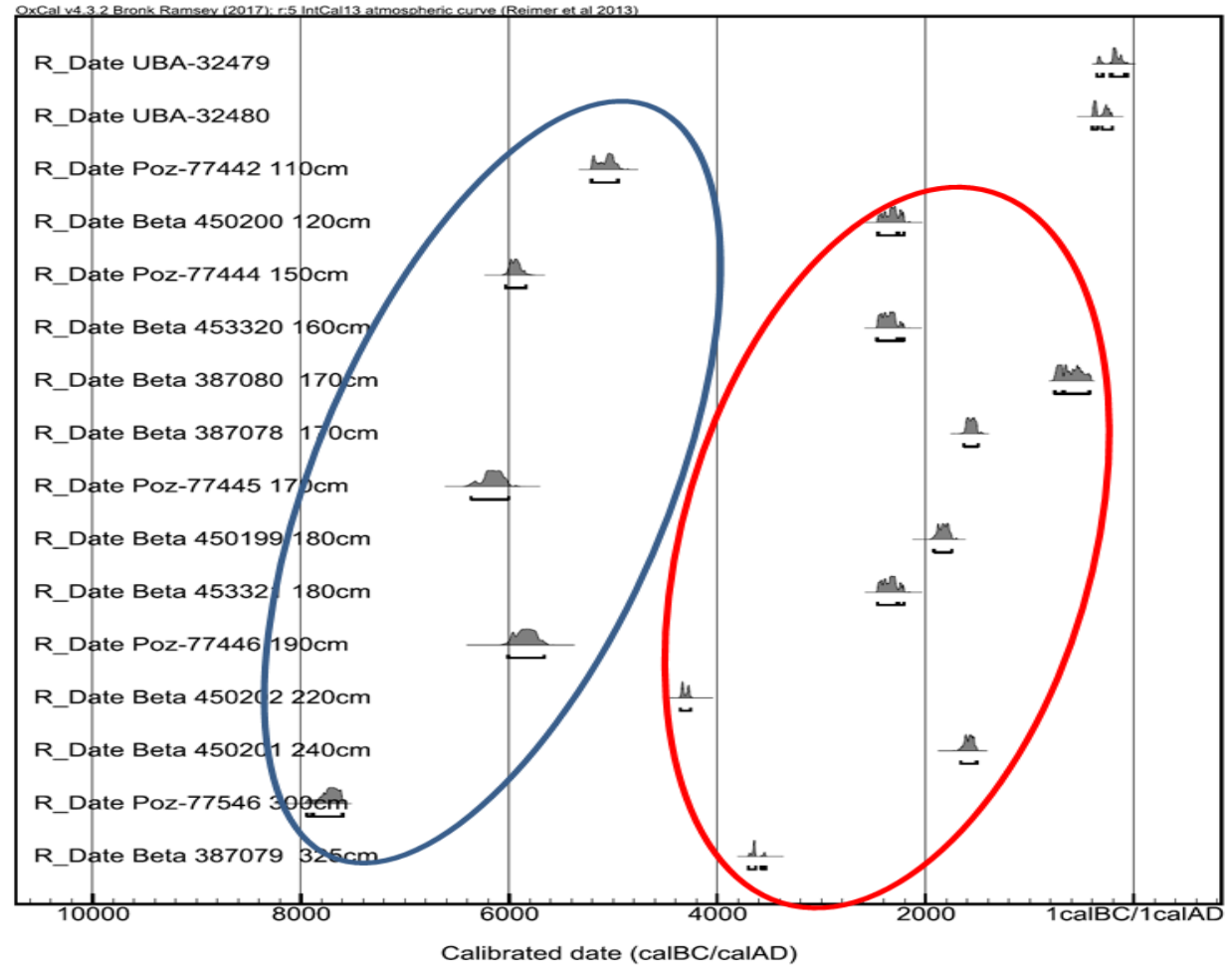

Table 7-3 The Berth - radiocarbon dates grouped by depth and age 


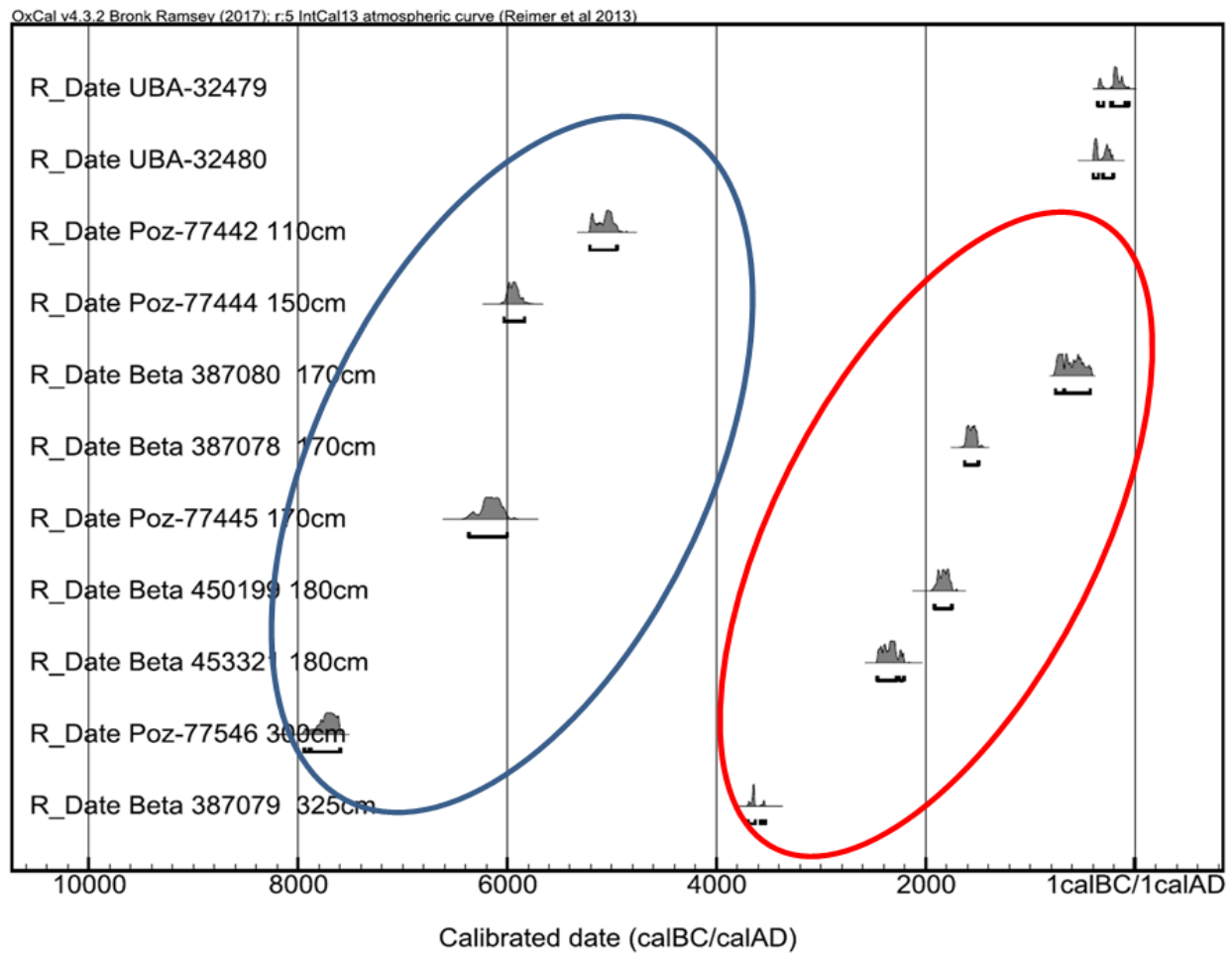

Table 7-4 The Berth - radiocarbon dates minus anomalies

\subsection{Stratigraphic summary and cross-correlation of peat deposits}

The results of the auger programme demonstrate that the sub-surface topography surrounding the Berth is based on a layer of Late Glacial minerogenic dark grey sand/gravel which varies in thickness. The gravel is overlain by deposits of laminated blue-grey clay (possibly varves) containing limited amounts of organic matter. The occasional black stripes towards the base of this layer are interpreted as leached manganese, indicating ongoing percolation throughout the deposits. They appear only in the area south of the east-west causeway and possibly indicate that this area was a sump. Evidence of the Windermere interstadial is visible in several cores. These findings correspond with the Late Glacial sequences found elsewhere in the Shropshire meres (Reynolds, 1979).

The clay-bands are overlain by olive-grey silt with occasional fibrous inclusions, and then by wood and reed peat. In this sequence, wood peat normally follows reed peat, but occasionally, 
these layers are interleaved, suggesting a semi-terrestrialised environmental mosaic leading to spatial and temporal differences in site sedimentation. The stratigraphic pattern demonstrates a predictable hydroseral succession - open water was gradually terrestrialised as organic deposits accumulated and the ground was colonised by plants favouring drier conditions. The plant macrofossils are discussed in detail in Chapter 8, and indicate that the reed-bed was predominantly Cladium mariscus (great fen-sedge/sawsedge) rather than Phragmites australis (common reed) suggesting that more calcareous conditions prevailed (Conway, 1942; Reynolds and Sinker, 1976; Reynolds, 1979). Sizeable wood inclusions were identified below a depth of $1 \mathrm{~m}$ which included macrofossils of alder and oak (pers.comm. Dr Wendy Smith), suggesting that the wood peat was derived from fen woodland. Although a few plant taxa identified in the plant macrofossil analysis suggest acid bog (see 8.1.3.4), the terrain never achieved raised bog/ombrogenous status, unlike similar meres and mosses on the ShropshireCheshire Plain, for example Lindow Moss in Cheshire and Whattal Moss near Crose Mere (Reynolds, 1979). The causes probably lie in a combination of the steep-sided nature of the basin topography coupled with natural seepage which allowed the bog to drain slowly (Gorham, 1957). There is no evidence for in-wash, palaeochannels or a depositionary hiatus, suggesting a low-energy, autochthonous environment and a stratigraphy which for the most part has remained undisturbed since deposition.

It has not been possible to date peat initiation through this study. However if the deep peats found in Core 5c (Berth North Pasture; 6.4m) are compared to the Age:Depth Profile discussed in Chapter 8 (Fig. 8-3), a date of circa 9000BP seems reasonable and would be in line with peat initiation at Wem Moss circa 9500BP (Hardy, 1939; Reynolds, 1979:151). In Berth North Pasture, peat accumulation appears to cease after circa 6120 \pm 40 BP (Poz-77442) at a depth of $1 \mathrm{~m}$, although this date may be unreliable as the top $1 \mathrm{~m}$ of deposits is highly disturbed. South of Berth Stream, peat was still accumulating circa $3280 \pm 30$ BP (Beta-387078) at a depth of $170 \mathrm{~cm}$. 
The Holocene peat sequence is therefore incomplete across the site and the results are discontinuous across the basin. There could be multiple explanations. The peat may have undergone shrinkage or deflation, and eye-witness accounts from the early nineteenthcentury reported that the (post-medieval?) causeways showed only as parch-marks (Buckler, 1787 - 1897; Hartshorne, 1841; Appendix 3); however, this is anomalous and would require the (then) recently created causeways to be embedded into the peat (see below). Peat cutting, drainage and/or erosion may also have affected the current ground level; additionally and notwithstanding the wet nature of the ground, the area may have been ploughed. The radiocarbon dates suggest that peat loss is greater in Berth North Pasture than in Berth South Pasture or south of Berth Stream. This could be explained by water funnelling through the gap between the gravel spit and Berth Hill, which is dammed (in modern times at least) by the east-west causeway, and argues for erosion as the main cause of peat loss (Fig. 7-16; Fig. 7-17). The water eventually seeps underneath this causeway and into Berth Stream.

The radiocarbon determinations returned three Iron Age dates and all are associated with the north-south causeway. 2BBMC14 (adjacent to the causeway and south of Berth Stream) produced a date of 2460 $\pm 30 B P$ (Beta 38708; 765-410 cal BC), whilst the fossilised surface

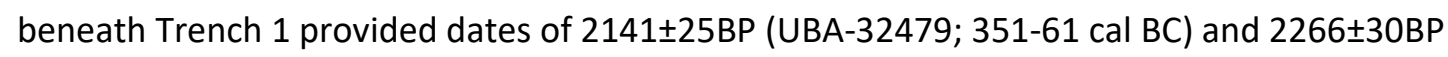
(UBA-32480; 398-210 cal BC). Whilst this was fortuitous from a palaeoenvironmental perspective (see 8.3), the fossilisation of an Iron Age surface beneath an apparently postmedieval structure requires explanation. The peat may have ceased to accumulate after alder clearance circa AD400 (see Twigger, 1988, Chapter 8) and the wider area may have been open pasture from the Anglo-Saxon period onwards. In building the causeways, the land may have been coincidentally levelled down to the Iron Age stratigraphy. A further suggestion is that the causeway is located on naturally firmer ground towards the edge of Berth Pool, although there is nothing in the superficial geology to support this. None of these explanations is wholly convincing, and the search for additional evidence continues. Nevertheless, an Iron Age surface is preserved beneath the post-medieval causeways which appears to have been lost elsewhere in the Berth's pastures. 


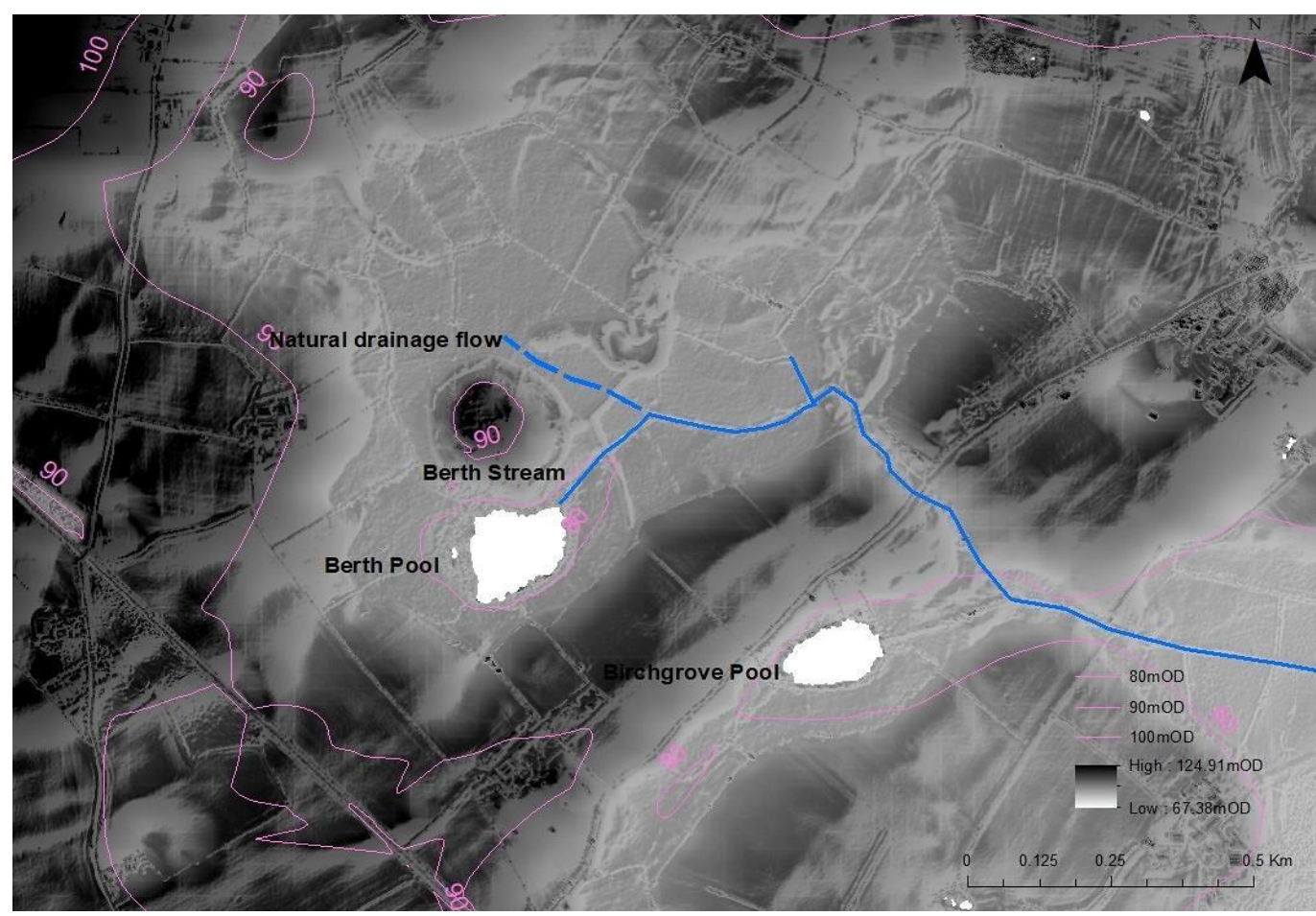

Fig. 7-16 Natural water flow from north to south showing the water course (dotted line) across Berth North Pasture (LiDAR = 1mDSM)

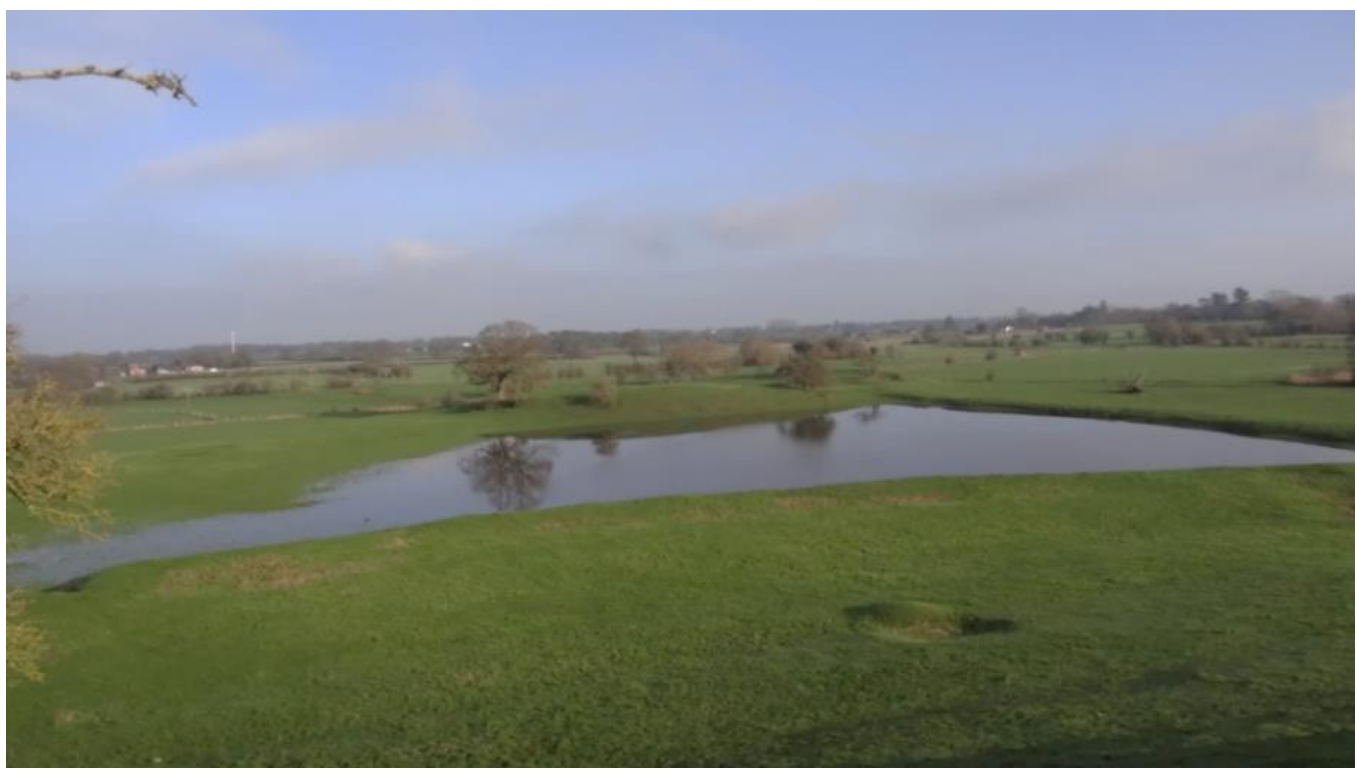

Fig. 7-17 Looking towards the small enclosure across Berth North Pasture; the east-west causeway acts as a dam in wet weather (Norton, 2016) 


\subsection{Hydrological change and the extent of Berth Pool}

Despite an imaginative reconstruction found on the Megalithic Portal (Fig. 7-18), there is no evidence that the Berth's fortifications were ever completely surrounded by open water. However, the stratigraphy suggests that Berth Pool was more extensive in the past.

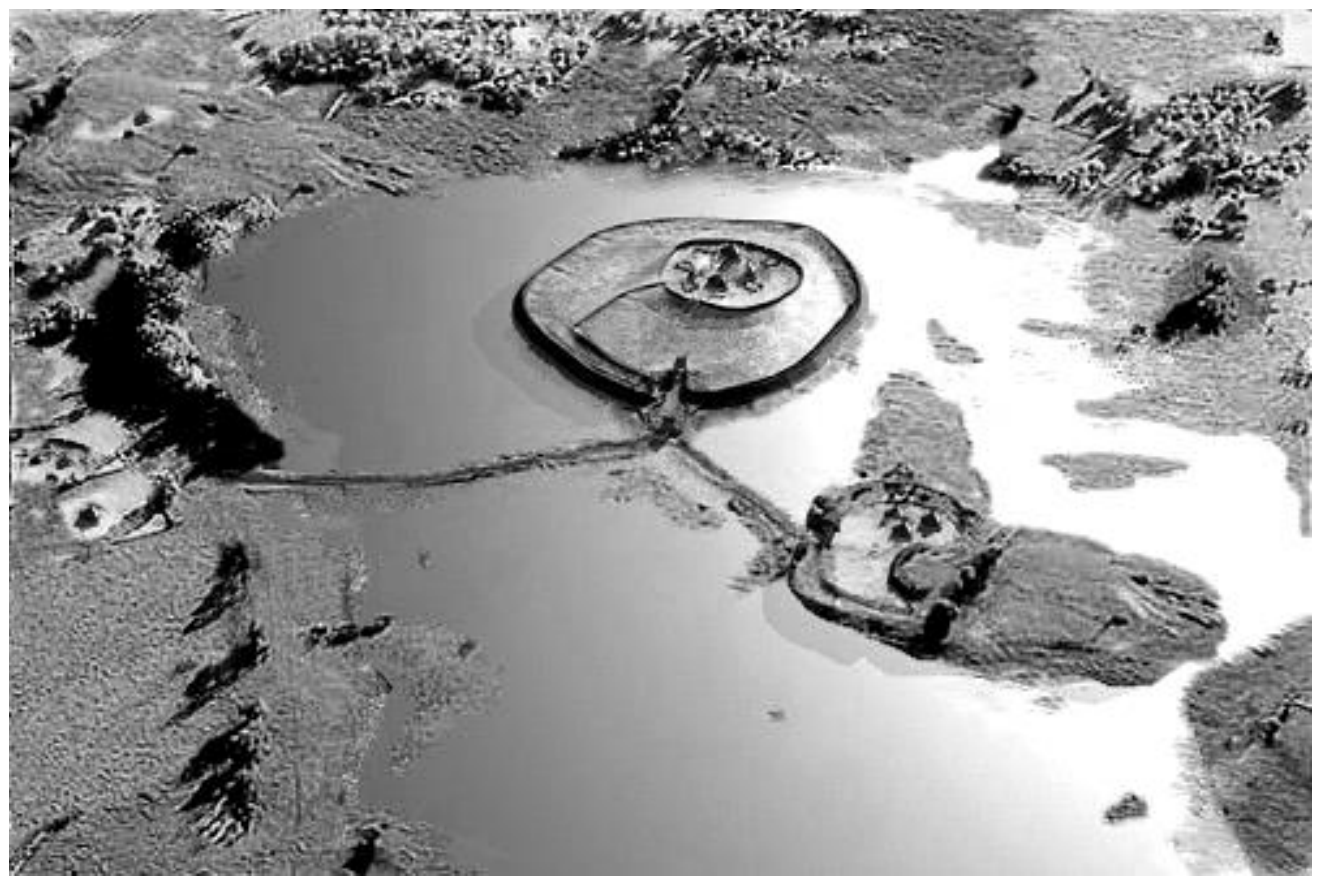

Fig. 7-18 The Berth as depicted on the Megalithic Portal

http://www.megalithic.co.uk/modules.php?op=modload\&name=a312\&file=index \&do=showpic \&pid=9602

The evidence for hydrological change around the North Shropshire meres in later prehistory is complex. Prior to the Iron Age, lake levels were apparently lower, rising during the Iron Age in line with climatic worsening (Farr et al., 1991). At Ellesmere, $11 \mathrm{~km}$ north of the Berth, the rise is thought to have been several metres (Hamlin, 1988; Farr et al., 1991), and increased wetness has been identified elsewhere in North Shropshire, for example, at Top Moss (2195 $\pm 50 B P ; O x A-6640)$ (Leah et al., 1998:180).

Berth Pool is a 3ha remnant of the original Late Glacial kettle-hole. Historically, its size, shape and drainage appear constant (see Appendix 3). The earliest map of the site (1731; Shropshire Archive 6000/17389) shows a inflowing channel from the north-west, and an outflow - Berth 
Stream - which flows east, before turning sharply south to join the War Brook and, ultimately, the River Severn. Both formed part of a natural drainage pattern, perhaps of swampy channels, which has been enhanced in modern times. Although Berth Pool is omitted from the 1752 Roque map (Shropshire Archive 552/8/916), there is no evidence that it was ever drained. The level was lowered by $2^{\prime} 8$ 'in 1809 , but was promptly restored when this became a dispute between interested parties (Shropshire Archive 6000/17409). Over time, the creation of the causeways has interrupted the natural drainage and Gelling described the north-south causeway as possibly acting as a dam (Guilbert et al., 1977), in similar vein to the east-west causeway described above.

Whether Berth Pool was the same shape or size in prehistory has profound implications for the way in which the marsh-fort was accessed, and proxy evidence for hydrological change can be derived from the reed peat and shell deposits (see Fig. 7-6 - Fig. 7-13). These indicate that at one point, open water was extensive, albeit variable, across Berth North Pasture. The shell horizon lies at a depth of $2.0 \mathrm{~m}-4.1 \mathrm{~m}$ and environmental analysis indicates that this area was terrestrialised circa 7000BP (see Chapter 8) - in other words, the area between the main and small enclosures had not been open water since the early-mid Holocene. However, in Berth South Pasture - West, Transects 8 and 9 indicate a much shallower shell horizon $(0.7 \mathrm{~m}$ from the surface in Cores 9b and 9c) suggesting that, in later chronology, Berth Pool was more extensive and its previous dimensions could be inferred from the 80mOD contour (Fig. 7-19). The evidence for open water does not extend as far as Berth North Field.

This proxy evidence for more extensive open water has two possible implications. Firstly, the Berth Cauldron was recovered from the junction of Berth Stream with the current north-south causeway during stream clearance in 1906 . If the $80 \mathrm{~m}$ contour suggests the pool's limit when water levels were higher (Fig. 7-19), the Berth Cauldron could have been deposited at the lake shore, which may have been accessed from the main enclosure's south-east 'entrance'.

Secondly, if Berth Pool were more extensive, access to the site from the south may have been across open water. 


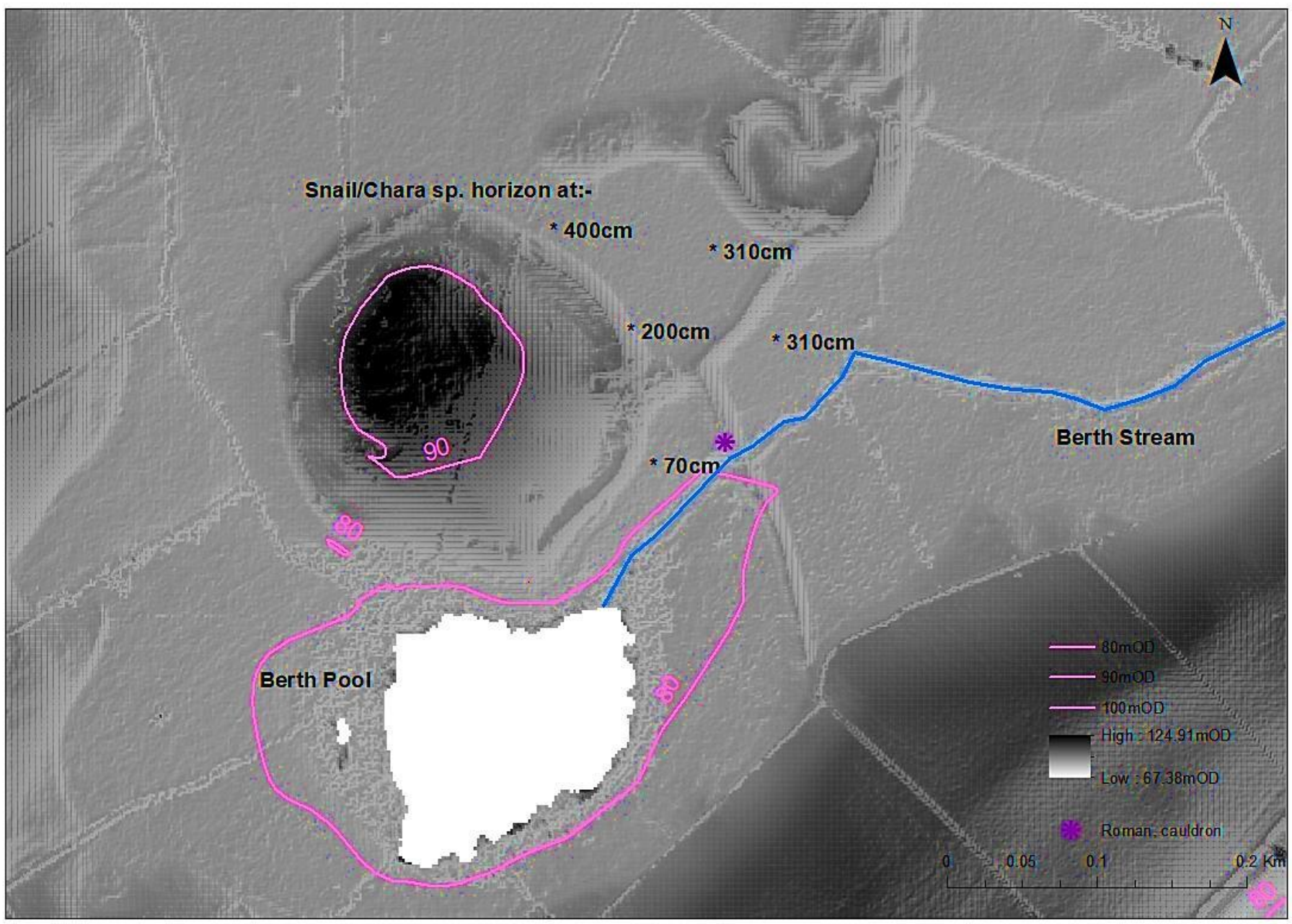

Fig. 7-19 Berth Pool; contour and variations in the snail/Chara horizon (LiDAR 1mDSM) 


\subsection{Summary}

The sedimentary sequence presented here covers the Late Devensian glaciation and part of the Holocene, and provides information about the depth and shape of the peat basin, peat accumulation, the extent of open water and the preservational environment. The complex interplay of stratigraphic elements is supported by radiocarbon dating. The issues arising centre mainly on the wetness of the surrounding marsh, access to the Berth's main enclosure and changes in the extent of Berth Pool.

The stratigraphy surrounding the Berth comprises a sand/gravel base overlain by layers of blue-grey clay, olive-grey silt, wood peat interleaved with reed peat both of which contain large wood inclusions, topped with a grass/top-soil layer, to a depth exceeding $7 \mathrm{~m}$ in places. The most extensive individual layers were of wood peat. The changing stratigraphy indicates hydroseral succession and terrestrialisation of the kettle-hole and this conclusion is supported by the palaeoenvironmental analysis (see Chapter 8 ). Peat initiation appears to date from the early Holocene (circa 9000BP), but when and whether it stopped growing is less clear. It was still accumulating during the Middle Bronze Age, but the uppermost layers, certainly in Berth North Pasture, either did not develop or have been lost through erosion. The stratification also shows that the Berth's main enclosure was located on the edge of a dramatic drop-off into the peat basin and this buried topographic feature may have been incorporated into the construction strategy.

The surrounding wetland would have presented challenges to those who built, accessed and occupied the marsh-fort. Whilst the small enclosure would have been accessible from the east in most weather conditions across more solid glacio-fluvial deposits, the main enclosure would have been cut off by the surrounding wetland especially during poor weather, and access problems would have been exacerbated by the climatic fluctuations of the first-millennium BC. The extreme wetland topography which surrounds the Berth naturally raises questions concerning site access and the chronology of the existing causeways. There are currently four strands of evidence which need to be reconciled. Firstly, excavation of the causeways and comparison with other local and similar structures has indicated that they are post-medieval 
with no underlying prehistoric structure, and were used to facilitate gravel extraction (Chapman, Smith and Norton, 2017; Blockley and Shaw, unpublished, see 6.1). However and secondly, this does not fit comfortably with nineteenth-century eye-witness accounts describing the causeways as parch-marks, nor with the fossilised Iron Age surface located beneath the stone structure of the north-south causeway, and substantial stone causeways across wetland have been identified at many crannogs (for example, at Loch Baravat Dun on the Isle of Lewis). Thirdly, a putative third causeway has been identified crossing the shortest distance across the bog, which linked the small enclosure to the main enclosure at its northeastern 'corner' and led to a newly identified entrance in the main enclosure ramparts. Fourthly, a shelly layer in the stratigraphy acts as a proxy measure for estimating the previous shape and size of Berth Pool, and shows that it was larger and extended across the southern edge of Berth Hill earlier in the Holocene. This could suggest that access to the main enclosure was from the south across open water, and may indicate that the Berth Cauldron was deposited not into Berth Stream, but onto the shores of an enlarged Berth Pool.

These strands of evidence - the post-medieval causeways, the underlying Iron Age deposits, the identification of an alternative means of accessing the main enclosure by a third causeway, and the previous extent of Berth Pool - illustrate that a greater understanding is required of the Iron Age stratigraphy which surrounds the Berth. Collectively however, they support a conclusion is that accessing the Berth would have been a formalised event which negotiated the surrounding wetland and may have involved votive deposition. The implications for this conclusion are discussed in Chapter 9. 


\section{The Berth - Palaeoenvironmental Reconstruction}

The third and final stage of the Berth landscape and environmental case-study uses data from three separate multi-proxy palaeoenvironmental analyses to reconstruct the prehistoric landscape immediately surrounding the Berth marsh-fort:

i. BNP15 - analysis of a 5m core taken from the peat deposits in Berth North Pasture, covering the Late Glacial to Mid-Holocene period

ii. 3BВMC16 - analysis of three Early Bronze Age peat deposits from pasture close to the north-south causeway and south of Berth Stream (Kang, 2017)

iii. Trench $1-\mathbf{0 - 2 0} \mathrm{cm}$ - analysis of silty material of Middle-Late Iron Age date recovered during excavation of the north-south causeway, close to the Berth's south-east entrance (Norton in Chapman, Smith and Norton, 2017)

These results are described in turn, and amalgamated with an earlier palynological study from Berth Pool (Twigger, 1988) to create a temporal and spatial evolutionary record of mire-basin development covering an almost complete Holocene sequence, the only gap occurring circa 5250-6000BP (Table 8-1). The narrative describes periods of climatic and environmental change, illustrates the dynamics of Late Glacial plant colonisation, charts the establishment and development of woodland and grassland, examines the processes associated with terrestrialisation and hydroseral succession, and compares the emerging sequence with others regionally, notably Crose Mere (Beales, 1980) and King's Pool Staffordshire (Bartley and Morgan, 1990), and nationally. 


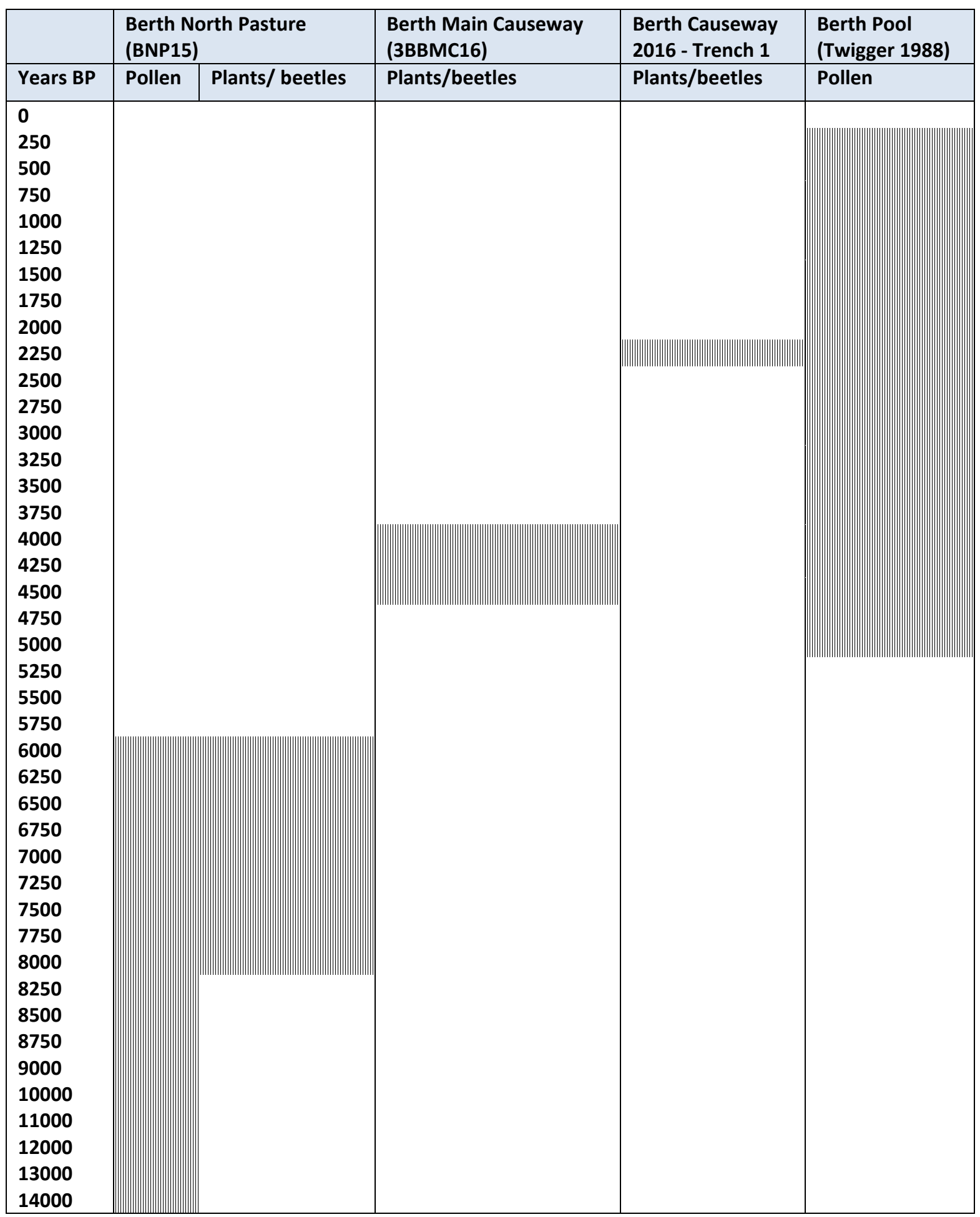

Table 8-1 -The Berth - Holocene palaeoenvironmental data; chronological coverage and overlap 
The area around the Berth may have been utilised sporadically from the Mesolithic onwards, but the period of direct interest to this thesis is the Iron Age when the marsh-fort was known to be occupied. This palaeoenvironmental analysis draws on multiple proxies to establish a 'plausible' landscape - the likeliest scenario for the landscape surrounding the Berth in the absence of an historic record (sensu Caseldine et al., 2008) - in which to situate an Iron Age marsh-fort. The methodology for obtaining and processing all samples is described in Chapter 3 , and the results are supported by radiocarbon dating (see Chapter 7). Presentation of the results is in tabular and graph format with accompanying diagrams and text. For full species lists, see Appendix 7.

\subsection{BNP15 - Berth North Pasture- stratigraphy and taphonomy} A peat core measuring in excess of $5 \mathrm{~m}$ was obtained from Berth North Pasture and used to reconstruct the Berth's palaeolandscape (BNP15). The stratigraphy mirrors that elsewhere in Berth North Pasture (see Chapter 7 and Fig. 8-1) - wood and reed peat interleaved with silt resting on Late Glacial sands and gravels; the core included a deep layer of calcareous remains. The whole core was used for palynological analysis and the creation of an Age:Depth profile of sedimentary deposition (undergraduate dissertation; R. Eastwood (2016), under the supervision of Dr W. Eastwood, University of Birmingham;

Fig. 8-2; Fig. 8-3). Levels $1 \mathrm{~m}-3 \mathrm{~m}$ were analysed personally for plant macrofossil and beetle remains.

Taphonomically, BNP15 comprises natural sediments which have been exposed to 'soil animals' (worms and beetles) and chemical processes (sensu Murphy and Wiltshire, 1994). The soils of the West Midlands tend towards acidity (Greig, 2007:39), preserving pollen but destroying plant macrofossils and bone (Dincauze, 2000:348). However, at the Berth, peat developed in contact with groundwater creating a less acidic fen-carr environment (Burnham and Mackney, 1964:108). Pollen, insects and plant macrofossils were present in abundance, although there was a degree of variability throughout the core. For example, the upper sections $(100-130 \mathrm{~cm})$ were disturbed, with roots through both plant and beetle remains; fresh 
midge larvae at $110-120 \mathrm{~m}$ provided a further indication of turbation or poaching. At $120-$ $130 \mathrm{~cm}$, robust remains survived although some Alnus sp. (alder) seeds were noticeably small.

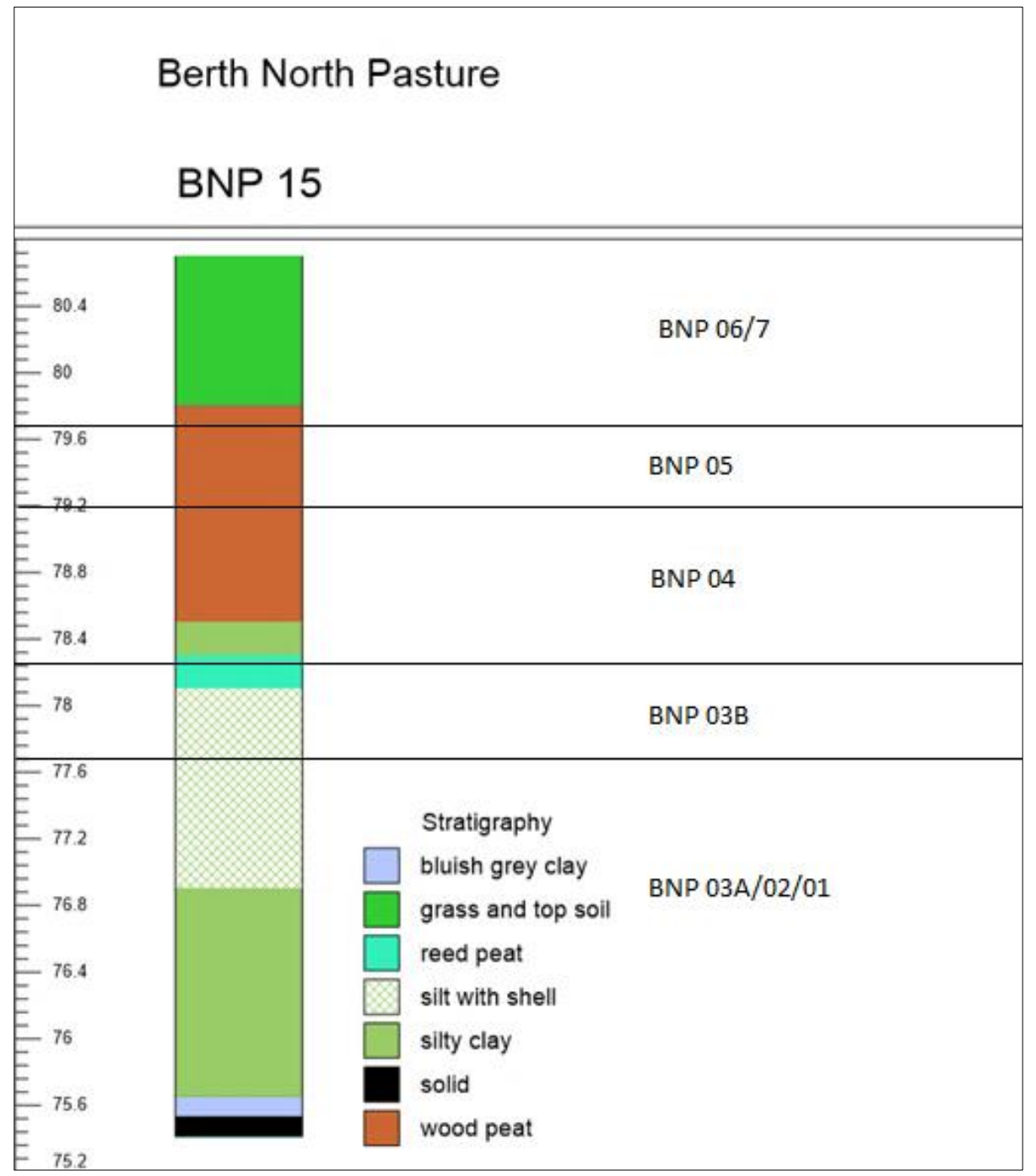

Fig. 8-1 Berth North Pasture - BNP15 - stratigraphy annotated with pollen zones

This could reflect the position of an individual seed within the fruiting cone (smaller seeds towards the top); alternatively, the seeds may have been deposited in oxygenated conditions before being composted and pushed down into anaerobic conditions. However, small size was a recurring theme amongst some alder seeds throughout BNP15 and may be caused by high mineral content or brackish conditions (pers. comm. Dr Wendy Smith). 
As a general rule, preservation improved with depth; for example, at $160-170 \mathrm{~cm}$, some Carex sp. (sedge) seeds retained their urticle (outer casing) and some Betula spp. (birch) seeds retained their wings, indicating that the peat was forming in a steady and undisturbed manner. Preservation continued to be good as low as $260-270 \mathrm{~cm}$ although at this depth, many sub-fossils were affected by compaction leading to fragmentation and squashing. At 290$300 \mathrm{~cm}$, the deterioration of the plant remains reflected the slow process of decay (or, possibly, a period of drying out). Collectively, the taphonomy suggests gradual peat formation and deposits which had been undisturbed for millennia. BNP15 produced plentiful plant macrofossil remains and a Coleopteran assemblage of 635 MNI (Minimum Number of Individuals), of which 567 (89\%) were allocated to habitat group. The results from each proxy have been combined and are described in the following phases:

\begin{tabular}{|l|l|l|l|l|l|l|}
\hline Phase & Depth & Approx. period & $\begin{array}{l}\text { Conventional } \\
\text { radiocarbon dates }\end{array}$ & \multicolumn{2}{|c|}{ Proxy } \\
\hline & & & Pollen & $\begin{array}{l}\text { Plant } \\
\text { macrofossil }\end{array}$ & Coleoptera \\
\hline $\begin{array}{l}\text { BNP-01, } \\
\text { 02 \& 03A }\end{array}$ & $300-500 \mathrm{~cm}$ & $\begin{array}{l}\text { circa 13000- } \\
8750 \mathrm{BP}\end{array}$ & & $\checkmark$ & & \\
\hline BNP-03B & $250-300 \mathrm{~cm}$ & $\begin{array}{l}\text { circa } 8750- \\
8300 \mathrm{BP}\end{array}$ & $\begin{array}{l}8710 \pm 50 \mathrm{BP}(290- \\
300 \mathrm{~cm})\end{array}$ & $\checkmark$ & $\checkmark$ & $\checkmark$ \\
\hline BNP-04 & $150-250 \mathrm{~cm}$ & $\begin{array}{l}\text { circa 8300BP- } \\
7100 \mathrm{BP}\end{array}$ & $\begin{array}{l}6950 \pm 100 \mathrm{BP}(180- \\
190 \mathrm{~cm}) * * \\
7280 \pm 90 \mathrm{BP}(160- \\
170 \mathrm{~cm})\end{array}$ & $\checkmark$ & $\checkmark$ & $\checkmark$ \\
\hline BNP-05 & $\begin{array}{l}120-150 \mathrm{~cm} \\
\text { circa 7100- } \\
6500 \mathrm{BP}\end{array}$ & $\begin{array}{l}7060 \pm 50 \mathrm{BP}(140- \\
150 \mathrm{~cm})\end{array}$ & $\checkmark$ & $\checkmark$ & $\checkmark$ \\
\hline BNP-06/7 & $\begin{array}{l}100-120 \mathrm{~cm} \\
\text { (pollen } \\
\text { analysed to } \\
45 \mathrm{~cm})\end{array}$ & $\begin{array}{lll}\text { circa 6000BP - ? } \\
6120 \pm 40 \mathrm{BP}(110- \\
100 \mathrm{~cm})\end{array}$ & $\checkmark$ & $\checkmark$ & $\checkmark$ \\
\hline
\end{tabular}

Table 8-2 BNP15 - Proxy analysis and chronological phases (NB **reversed date) 
Chapter 8 - The Berth - palaeoenvironmental reconstruction

A chronological summary of the main plant macrofossil species is presented in Table 8-3. 


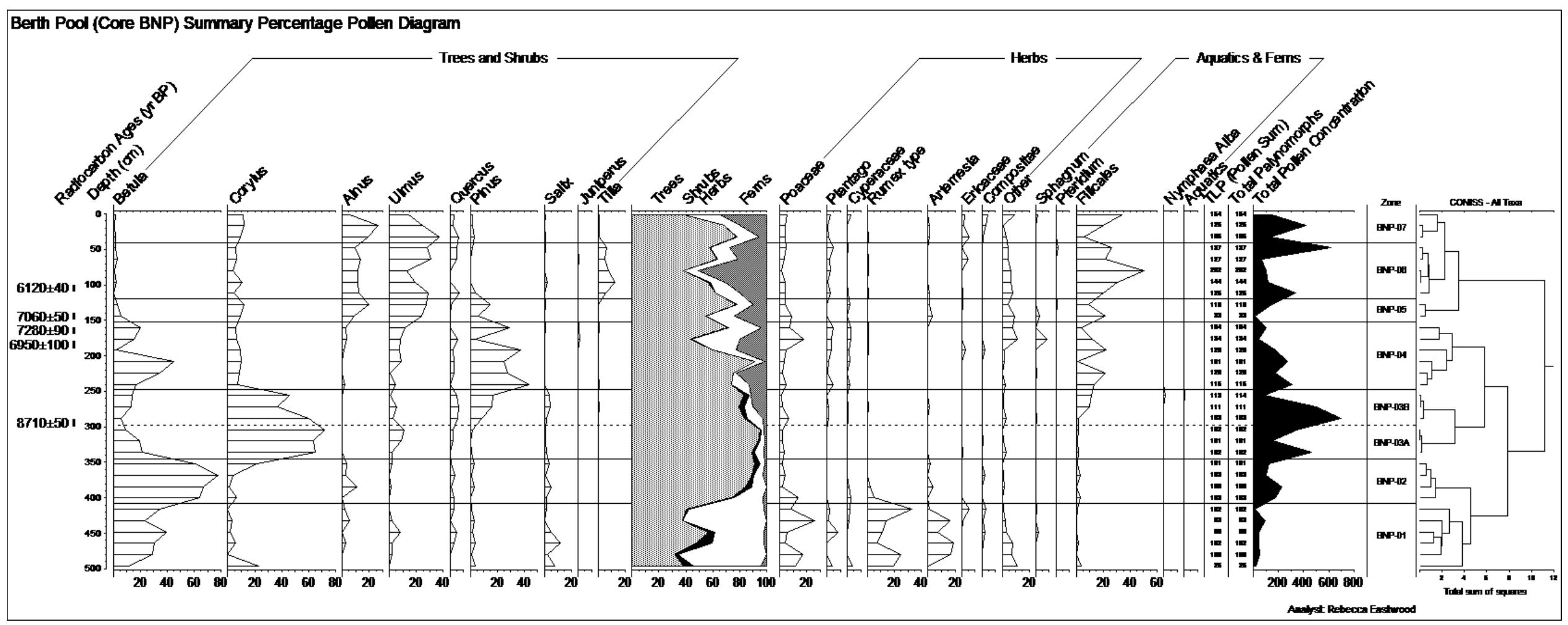

Fig. 8-2 BNP15 - Pollen analysis (R. Eastwood 2016; undergraduate dissertation) 
Age (yr BP)

$0 \quad 1000 \quad 2000 \quad 3000 \quad 4000 \quad 5000 \quad 6000 \quad 7000 \quad 8000 \quad 9000 \quad 100001100012000130001400015000$

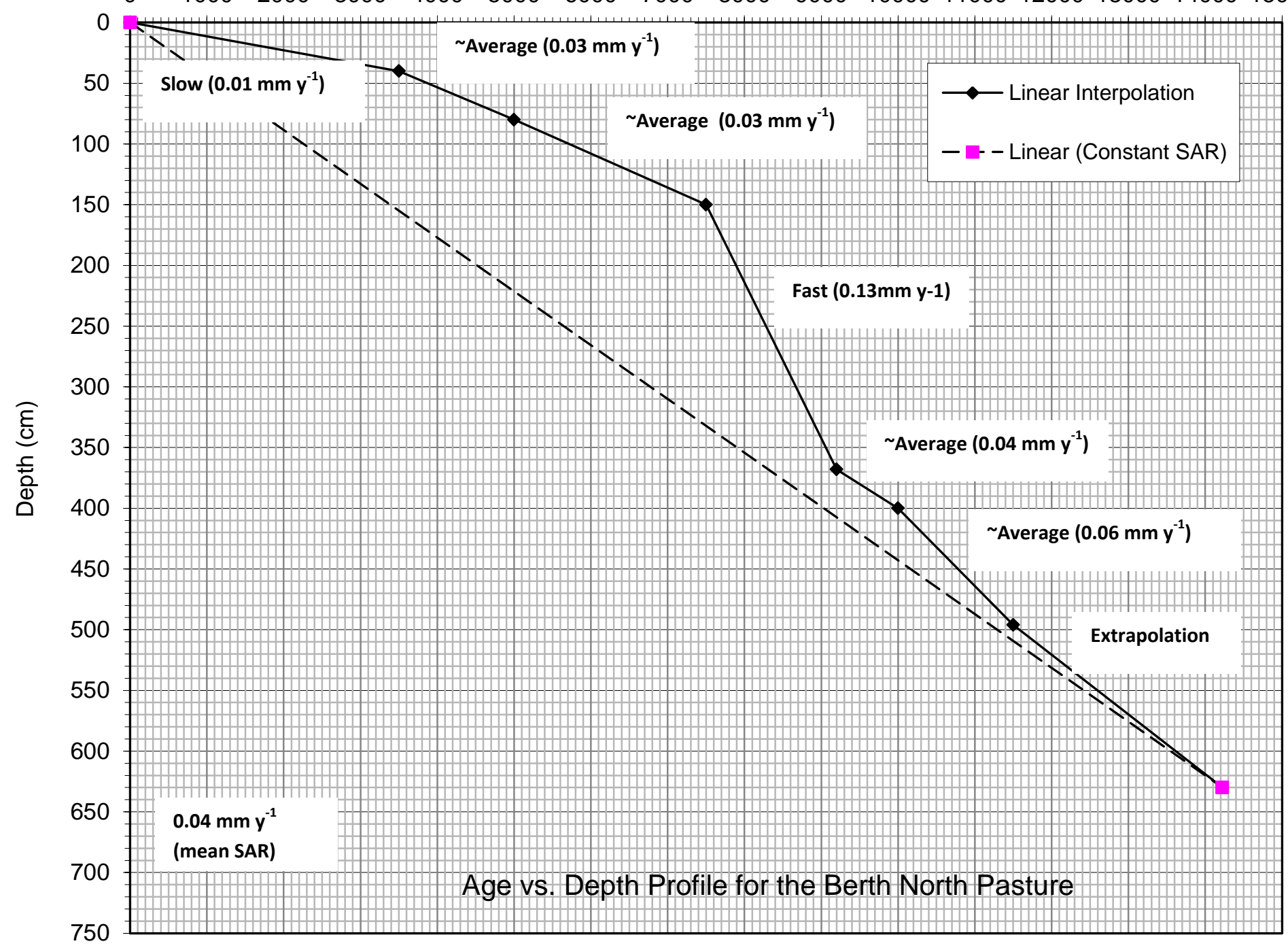

Fig. 8-3 The Berth - Age:Depth profile (Source: Dr W. Eastwood; R. Eastwood) 
Chapter 8 - The Berth - palaeoenvironmental reconstruction

\begin{tabular}{|c|c|c|c|c|c|c|c|c|c|c|c|c|c|c|c|c|c|c|c|c|}
\hline & Betula & Alnus & Fraxinus & $\begin{array}{l}\text { Populus } \\
\text { Pos }\end{array}$ & Corylus & Salix & $\begin{array}{l}\text { Pinus } \\
\end{array}$ & $\begin{array}{l}\text { E. } \\
\text { cannabium }\end{array}$ & $\begin{array}{l}U . \\
\text { dioica }\end{array}$ & $\begin{array}{l}\text { F. } \\
\text { ulmaria }\end{array}$ & Carex & $\begin{array}{l}\text { mariscus } \\
\text { mal }\end{array}$ & $\begin{array}{l}N . \\
\text { marina }\end{array}$ & $\begin{array}{l}N . \\
a l b a\end{array}$ & Chara & Bithynia & Fish & charred & Ecosystem & $\begin{array}{l}\text { Dates } \\
\text { BP }\end{array}$ \\
\hline & \multicolumn{7}{|c|}{ Trees and shrubs } & \multicolumn{3}{|c|}{ Tall, damp herbs; nettle } & \multicolumn{2}{|c|}{ Sedges } & \multicolumn{5}{|c|}{ Aquatics } & & & \\
\hline $\begin{array}{l}100- \\
110\end{array}$ & & & & & & & & & & & & & & & & & & & \multirow{2}{*}{$\begin{array}{l}\text { Alder-carr; sedge; } \\
\text { nettle }\end{array}$} & \multirow{2}{*}{$\begin{array}{l}6120 \pm \\
40 \mathrm{BP} \\
(100- \\
110 \mathrm{~cm})\end{array}$} \\
\hline $\begin{array}{l}110- \\
120\end{array}$ & & & & & & & & & & & & & & & & & & & & \\
\hline $\begin{array}{l}120- \\
130\end{array}$ & & & & & & * & & & & & & & & & & & & & \multirow{3}{*}{$\begin{array}{l}\text { Alder and sedge } \\
\text { with some birch } \\
\text { and nettle. } \\
\text { Woodland less } \\
\text { varied; Noticeable } \\
\text { change }-150 \mathrm{~cm}\end{array}$} & \multirow{3}{*}{$\begin{array}{l}7060 \pm \\
50 \mathrm{BP} \\
(140- \\
150 \mathrm{~cm})\end{array}$} \\
\hline $\begin{array}{l}130- \\
140\end{array}$ & & & & & & & & & & & & & & & & & & & & \\
\hline $\begin{array}{l}140- \\
150\end{array}$ & & & & & & $*$ & & & & & & & & & & & & & & \\
\hline $\begin{array}{l}150- \\
160\end{array}$ & & & & & & 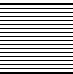 & & & & * & & & & & & & & & \multirow{3}{*}{$\begin{array}{l}\text { Period of greatest } \\
\text { tree variety (and } \\
\text { cover?). Alder } \\
\text { well established; } \\
\text { damp meadows }\end{array}$} & \multirow{10}{*}{$\begin{array}{l}7280 \pm \\
90 \mathrm{BP} \\
(160- \\
170 \mathrm{~cm}) \\
\\
6950 \pm \\
100 \mathrm{BP} \\
(180- \\
190 \mathrm{~cm})\end{array}$} \\
\hline $\begin{array}{l}160- \\
170\end{array}$ & & & & & & 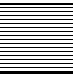 & & & * & & & & & & & & & & & \\
\hline $\begin{array}{l}170- \\
180\end{array}$ & & & & & & 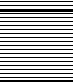 & & & & & & & & & & & & & & \\
\hline $\begin{array}{l}180- \\
190\end{array}$ & & & & & * & 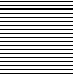 & & & & & & & & & & & & & \multirow{7}{*}{$\begin{array}{l}\text { Area still damp } \\
\text { but perhaps } \\
\text { slightly drier. Less } \\
\text { open water (see } \\
\text { Beetles) } \\
\text { Birch and pine } \\
\text { with tall sedge } \\
\text { and herb }\end{array}$} & \\
\hline $\begin{array}{l}190- \\
200\end{array}$ & & & & & & 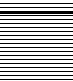 & & & & & & & & & & & & & & \\
\hline $200-$ & & & * & & & 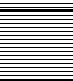 & & & $*$ & & & & & & & & & & & \\
\hline $\begin{array}{l}210- \\
220\end{array}$ & & & & & & 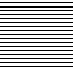 & & & & & & & & & & & & & & \\
\hline $220-$ & & $*$ & & & & 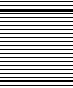 & & & & & & & & & & & & & & \\
\hline $\begin{array}{l}230- \\
240\end{array}$ & & & & & & 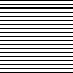 & & & & & & & * & & & & & & & \\
\hline $240-$ & & & & & & $\frac{15}{20}$ & & & & & & & & & & & & & & \\
\hline $\begin{array}{l}250- \\
260\end{array}$ & & * & & & & 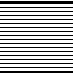 & $*$ & & * & & & & & & * & & * & & \multirow{5}{*}{$\begin{array}{l}\text { Open deep water } \\
\text { surrounded by } \\
\text { Birch forest with } \\
\text { some Pine and } \\
\text { Willow; tall } \\
\text { sedges and herbs } \\
\text { (E. cannabium). } \\
\text { Charring. }\end{array}$} & \multirow{4}{*}{$\begin{array}{l}\text { Change } \\
\text { at } \\
250 \mathrm{~cm} \\
\text { circa } \\
8300 \mathrm{BP}\end{array}$} \\
\hline $\begin{array}{l}260- \\
270\end{array}$ & & & & & & & * & & & & & & & & & * & * & & & \\
\hline $\begin{array}{l}270- \\
280\end{array}$ & & & & & & & * & & & & & & & & & & $*$ & & & \\
\hline $\begin{array}{l}280- \\
290\end{array}$ & & & & & & * & $*$ & & & & & & & & & & $*$ & & & \\
\hline $\begin{array}{l}290- \\
300\end{array}$ & & & & & & & $*$ & & & & $*$ & & & & & & $*$ & & & $\begin{array}{l}50 \mathrm{BP} \\
(290- \\
300 \mathrm{~cm})\end{array}$ \\
\hline
\end{tabular}

Table 8-3 BNP15 - Plant macrofossils - arboreal species plus selected herbs/sedges/aquatics ( ${ }^{*}=$ present) 


\subsubsection{BNP 01, 02, 03A - 500-300cm- Late Glacial/Early Holocene - circa 13000-8750BP} (Fig. 8-4)

BNP 01-03A relies on palynological analysis alone to reconstruct the Berth's landscape and ecology during the Late Glacial/Early Holocene periods, where a succession of warmer and colder periods enabled colonisation of the tundra environment by open habitat species of low-competitive ability; these in turn were succeeded by woodland (Roberts, 1998).

BNP 01 spans the Late Glacial interstadial/Younger Dryas stadial, circa13-10kaBP (Dinnin and Caseldine, 2014). The environment comprised Betula-based (birch) woodland with some Corylus (hazel) and Salix (willow); Pinus (pine) and Quercus (oak) were limited. These arboreal species existed within a community of grasses and herbaceous plants. Birch is a pioneer species of low canopy cover, colonising areas of scree/gravel and edaphically unsuitable environments such as peat bog and fen. It reached its rational limit across the British Isles circa 10000-9500BP (Birks, 1989). Hazel arrived slightly later (circa 9500-8000BP) (Birks, 1989), indicating that BNP-01's stratigraphy formed before the hazel maximum. Birch is not identified to species in most pollen diagrams, but of the three possible choices, downy birch (B. pubescens) is the most likely. It inhabits wetter soils and grows in more northerly locations than silver birch ( $B$. pendula) (Atkinson, 1992), whilst dwarf birch (B.nana) inhabits tundra environments and favours rocky soils (de Groot et al., 1997). However, these species hybridise (Bartley, 1962; Atkinson, 1992) and accurate discrimination is only possible by analysis of selected morphological characteristics, for example, stomatal length (Atkinson, 1992:838). A visual examination of birch seeds and bracts in samples $250-300 \mathrm{~cm}$ confirmed that downy birch is the species represented here; silver birch was an unconvincing possibility in a small number of cases and dwarf birch was not present - see 8.1 .2 below.

The pollen diagram suggests that conditions favoured the expansion of birch (Fig. 8-4). The North Shropshire Plain contains an unusually high percentage of south-facing slopes (Beales, 1980) which together with extensive deposition of fluvio-glacial sands and gravels (Toghill, 1990:171) would have provided ideal ecological conditions for the development of a Willow-Birch-Common Reed (Salix cinereaBetula pubescens-Phragmites australis) woodland community (W2) (Rodwell, 1991a). These landscape features may account for the persistence of birch throughout the earlier Holocene and into modern times (Barber and Twigger, 1987:225; Atkinson, 1992:842).

At this stratigraphic depth and with pollen values of $20-40 \%$, birch is a strong indicator of rapid climatic amelioration, and is consistent with evidence for climatic change across the Severn valley circa 13,000BP (analysis based on Coleoptera, Barber and Coope, 1987:203). Birch also reduces soil acidity and enables a 
conversion of soils to mull humus enabling grassland to flourish (Bennett, 1989; Mitchell, 1990). This can be seen in the high values for both Artemisia (mugwort) and Rumex (dock). Artemisia is a dual indicator. Its appearance together with Rumex later in the Holocene may indicate human impact and an opening-up of the landscape; however, its appearance in pre-Holocene sequences indicates steppic conditions. In terms of ecological chronozones, BNP 01 represents Iversen's pre-temperate protocratic phase of post-glacial development (Iversen, 1958) - a cold, dry, open environment, with shrubby herbaceous plants and some trees.

Findings from nearby palynological studies (Crose Mere, Shropshire and King's Pool, Staffordshire) for the equivalent chronozone support these findings. Crose Mere covers $17 \mathrm{ha}$ and lies $7 \mathrm{~km}$ due north of the Berth; it is the site of the possible marsh-fort of Stocketts Enclosure (see 5.3.4). Beales' analysis of deposits taken from the mere (Beales, 1980) provided a standardised sequence for Late Glacial/Holocene ecological development which is of regional and national importance (Fig. 8-5). At chronozone CMCP1-3

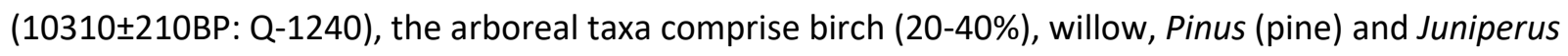
(juniper). Herb pollen exceeds 50\% with high values for both Artemisia and Rumex; grasses (Poaceae/Gramineae) exceed 30\% (Beales, 1980:139). King's Pool (now drained) was situated in a topographically low basin in central Stafford, 50km east of the Berth (Bartley and Morgan, 1990) (Fig. 8-6; Fig. 8-7). This $21 \mathrm{~m}$ sequence was subject to depositional hiatus and several of the radiocarbon dates are compromised due to in-wash, making it less reliable than Crose Mere. However, birch, pine and hazel are present during this period (chronozone ST1-3) and values for Artemisia and Rumex are equivalent to those at the Berth (Bartley and Morgan, 1990:185). The Berth exhibits a more varied range of arboreal taxa than either Crose Mere or King's Pool at this stage, including values for Alnus (alder), Quercus (oak) and Ulmus (elm). This may indicate different rates of arboreal expansion across a comparatively small spatial divide or alternatively, more favourable conditions, although radiocarbon analysis for this section of the Berth's pollen record would be needed before this could be confirmed.

There is a noticeable dip in the Berth's arboreal pollen (AP) at $432 \mathrm{~cm}$, together with a corresponding rise in herb-rich grassland. These changes reflect a return to the steppic conditions of the Younger Dryas stadial (circa 11-10ka BP) (Dinnin and Caseldine, 2014). Crose Mere and King's Pool show a similar downturn in arboreal species.

The warming that followed the Younger Dryas (BNP 02/3A) saw a return to a landscape dominated by birch $(80 \%$ AP; $370 \mathrm{~cm})$ and hazel $(70 \%$ AP; $350 \mathrm{~cm})$. Hazel prefers calcareous and poorly drained soils (Bennett, 1989) and only behaves as an understorey taxon when outcompeted for light by taller species, at which 
point it stops producing pollen (Spikins, 2000:221; Rackham, 2004:68). By circa 10,000BP, hazel had become the dominant taxon at the Berth, synchronous with its development as a major tree-shrub across North Shropshire (Twigger and Haslam, 1991:744). The rise in hazel corresponded with a rise in elm circa 9000BP (10\%AP at $325 \mathrm{~cm}$ ). Whilst elm was never abundant in England (Bennett, 1989), it was well established by 9000BP (Birks, 1989:511), and increases in hazel and elm were often synchronous (Bennett, 1983:477). As the tree canopy thickened and light levels reduced at the Berth, birch experienced a marked decline. Oak was present albeit with low values (5\%), and collectively, these arboreal species mark the inception of thermophilous woodland. Grasses and herbaceous plants also reduced $(<10 \%)$ and although non-arboreal poll (NAP) pollen tends to be underrepresented in pollen diagrams (Sugita et al., 1999), the circumstances suggest that the reduction was real. Alder is represented at the Berth from the Late Glacial onwards in fluctuating and modest amounts.

The rise in hazel has parallels both at King's Pool (80\% AP in ST4; 9650 $\pm 40 B P ;$ WAT-399), and Crose Mere

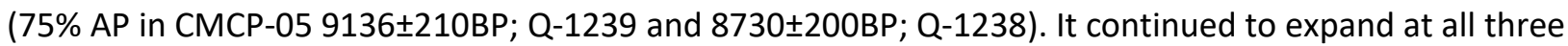
sites until overtaken by mixed woodland (Urwald or wildwood). This pattern was consistent across the majority of England, Ireland and Wales (Birks, 1989:508).

BNP-02/03A represents the period of greatest woodland cover at the Berth (AP 80-97\%) - the Mesocratic phase of post-glacial development, where biomass was at its greatest (Iversen, 1958). Sedimentary deposition and peat growth, which had been average up to this point $(0.06 \mathrm{mmy} 1-0.04 \mathrm{mmy} 1)$ began to accelerate (Fig. 8-3). 


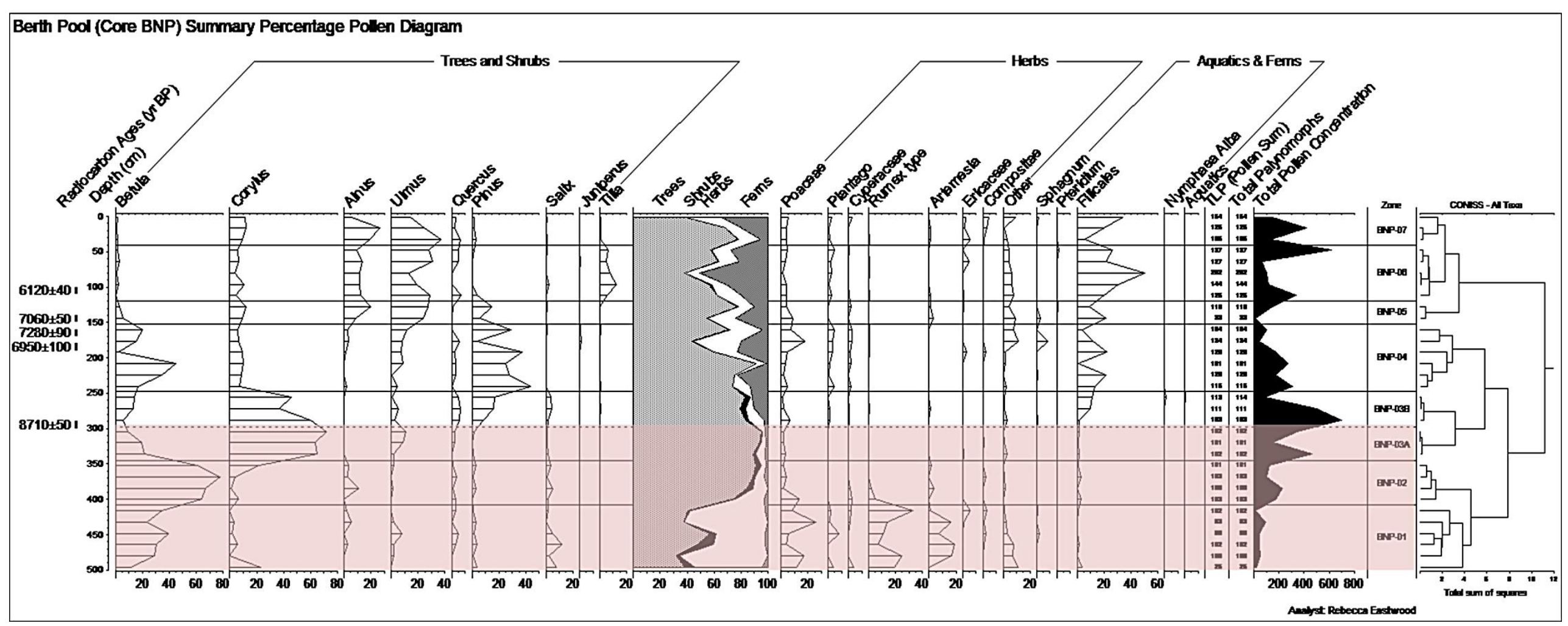

Fig. 8-4 BNP-01, 02, 03a - pollen 


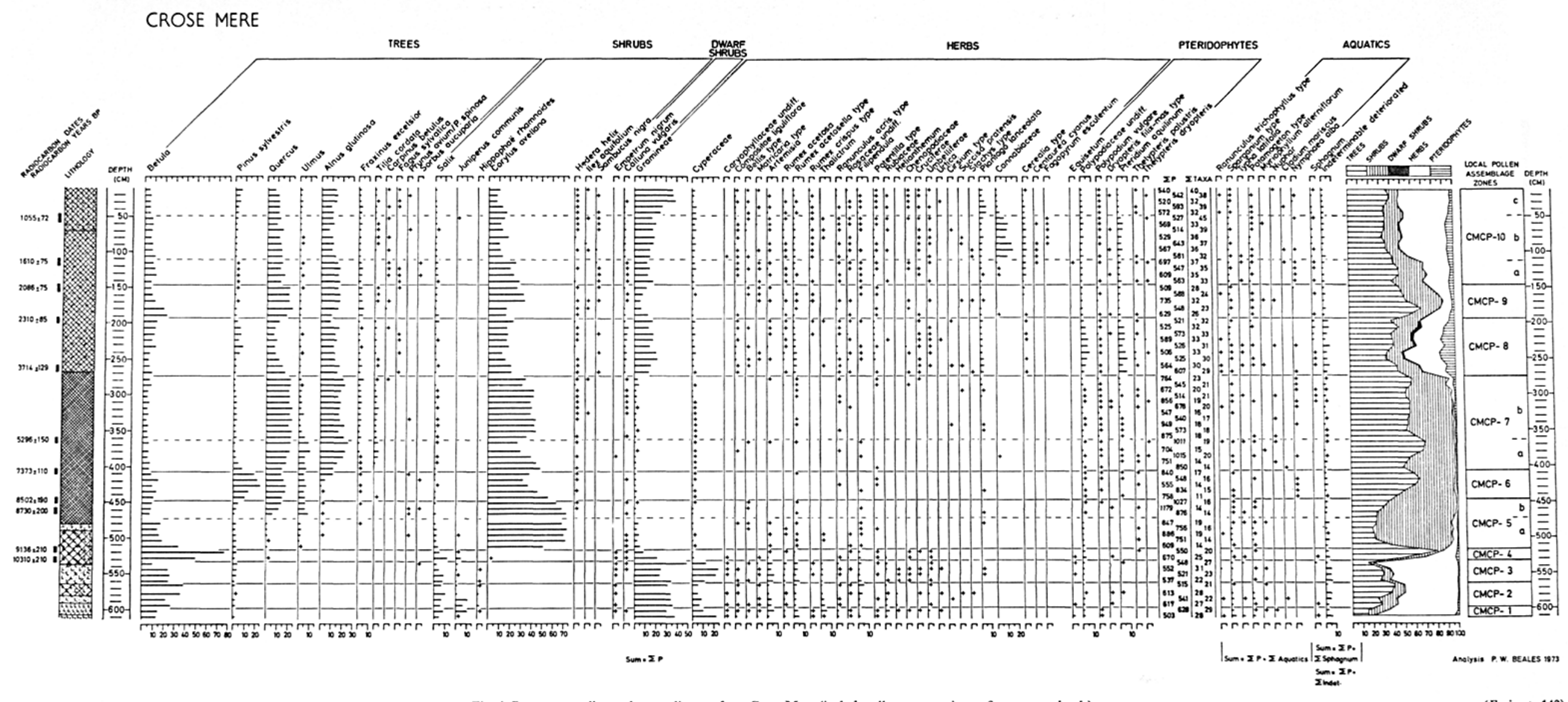

Fig. 4. Percentage pollen and spore diagram from Crose Mere (includes all taxa occurring at five or more levels).

Fig. 8-5 Crose Mere (Beales, 1980) 


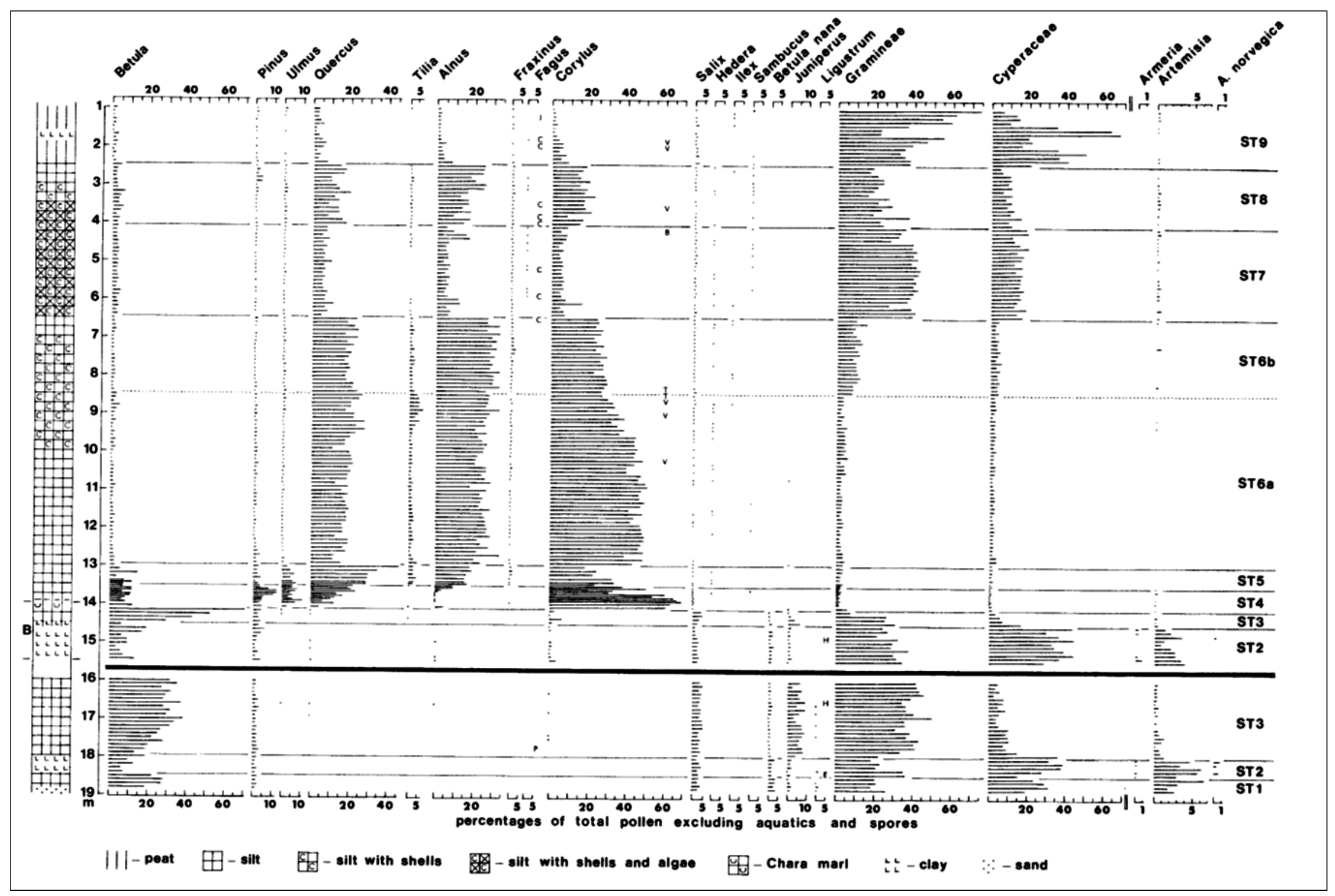

Fig. 8-6 King's Pool, Staffs (Bartley and Morgan, 1990) 


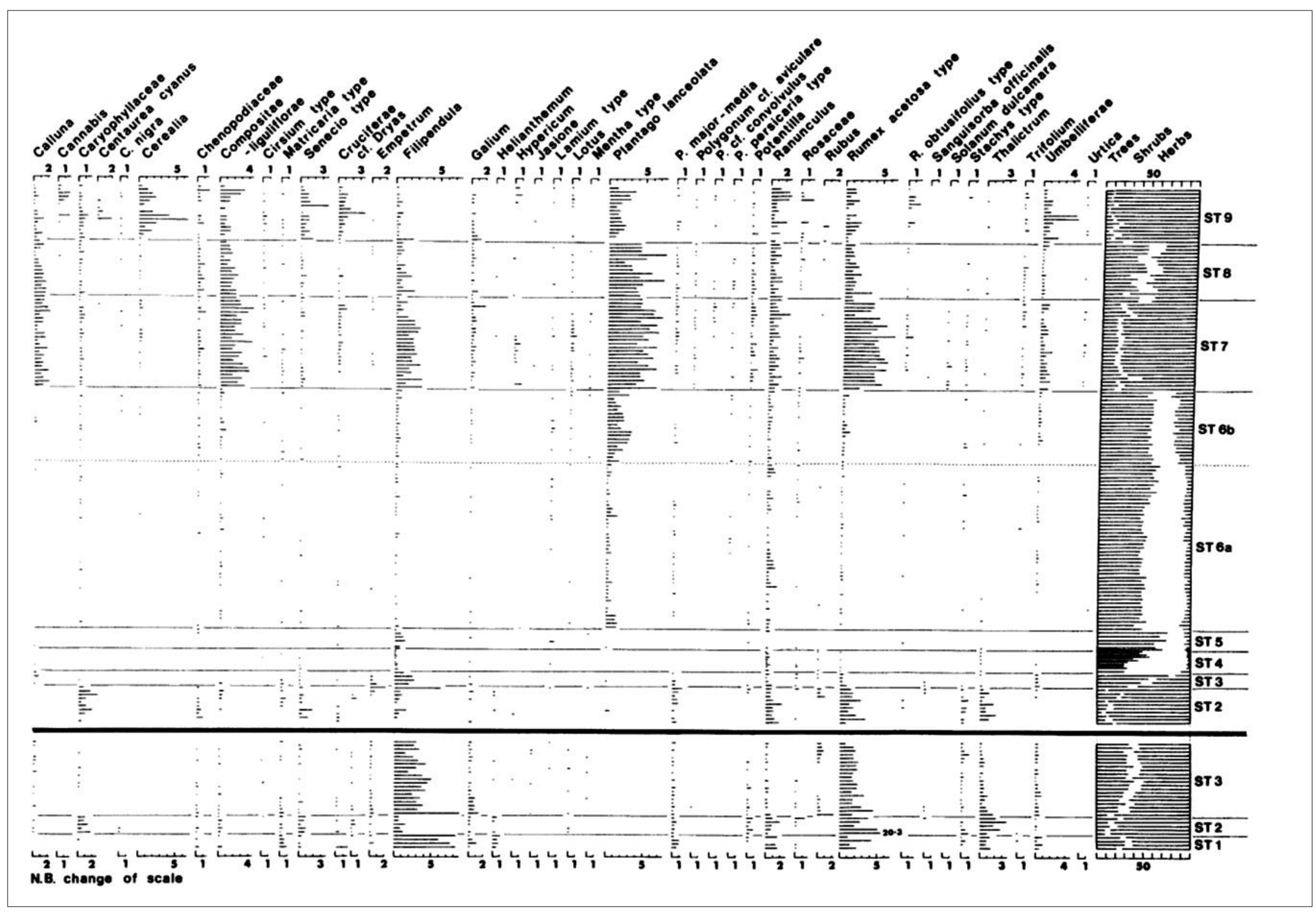

Fig. 8-7 King's Pool, Staffs (Bartley and Morgan, 1990) (cont.) 


\subsubsection{BNP-03B; 300-250cm - Boreal climatic period - circa 8750-8300BP (Fig. 8-8 and} Fig. 8-9)

BNP-03B covers a period of circa 450 years of increasingly warm, dry conditions and lowering water levels during which dense woodland continued to dominate the Berth's landscape. The Age:Depth profile records an accelerated rate of peat deposition (0.13mmy1) commensurate with increased vegetation cover (Fig. 8-3).

\subsubsection{The arboreal landscape}

By BNP-03B, the peat basin surrounding the Berth was densely wooded (80-96\%AP). This is shown by rises in oak and elm, and to a lesser extent Tilia (lime), species which form the major components of ancient woodland. Pine probably occupied drier areas. Oak and elm show roughly equal values (10-15\%), but as the pollen production rate of oak is about twice that of elm (Bennett, 1983), oak was likely to be the dominant species. Although it can achieve a height of $30-40 \mathrm{~m}$, elm rarely dominates the forest canopy, preferring to form mixed stands with oak and ash (Parker et al., 2002:3). There are no plant macrofossils for these taxa; however Luzula sp. (wood sedge), which can often be indicative of oak woodland (Tittensor and Steele, 1971), is present in the plant remains at this level. From the beetle assemblage, Rhynchaenus cf. quercus is found in deciduous woods, especially stands of oak (Koch , 1992) and Scolytus scolytus (the elm bark-beetle) is a primary coloniser on elm, typically inhabiting clearings, isolated copses or single trees rather than dense stands (Girling and Greig, 1985; Parker et al., 2002:26).

Pine values rise from 5\%-35\%. Pine is a high pollen producer with palynomorphs which are readily airborne, hence it can be overrepresented in pollen diagrams (e.g. Twiddle, 2012). However, the plentiful plant remains, including whole pine catkins, suggest that pine trees were close to the core site. The beetle evidence for pine is more equivocal. Orthoperus atomus (at $270 \mathrm{~cm}$ ) has been associated with the mouldy litter in coniferous forests, but it can be found in many damp environments (Bowestead, 1999, and Duff, 1993 in Buckland and Buckland, 2006). Pine requires plenty of light and freely draining soils (Walker, 1955; Carlisle and Brown, 1968) and would have found ideal conditions on the sands and gravels of Berth Hill. Its spread throughout the British Isles attained its highest frequency circa 8000-7000BP (Carlisle and Brown, 1968:298; Birks, 1989). In modern times it frequently occurs with stands of birch, usually on north-facing slopes. Susceptible to fire (Carlisle and Brown, 1968:281), it may be no coincidence that its presence is consistent with charred plant remains at $280 \mathrm{~cm}-250 \mathrm{~cm}$ (see Table $8-3$ ). 


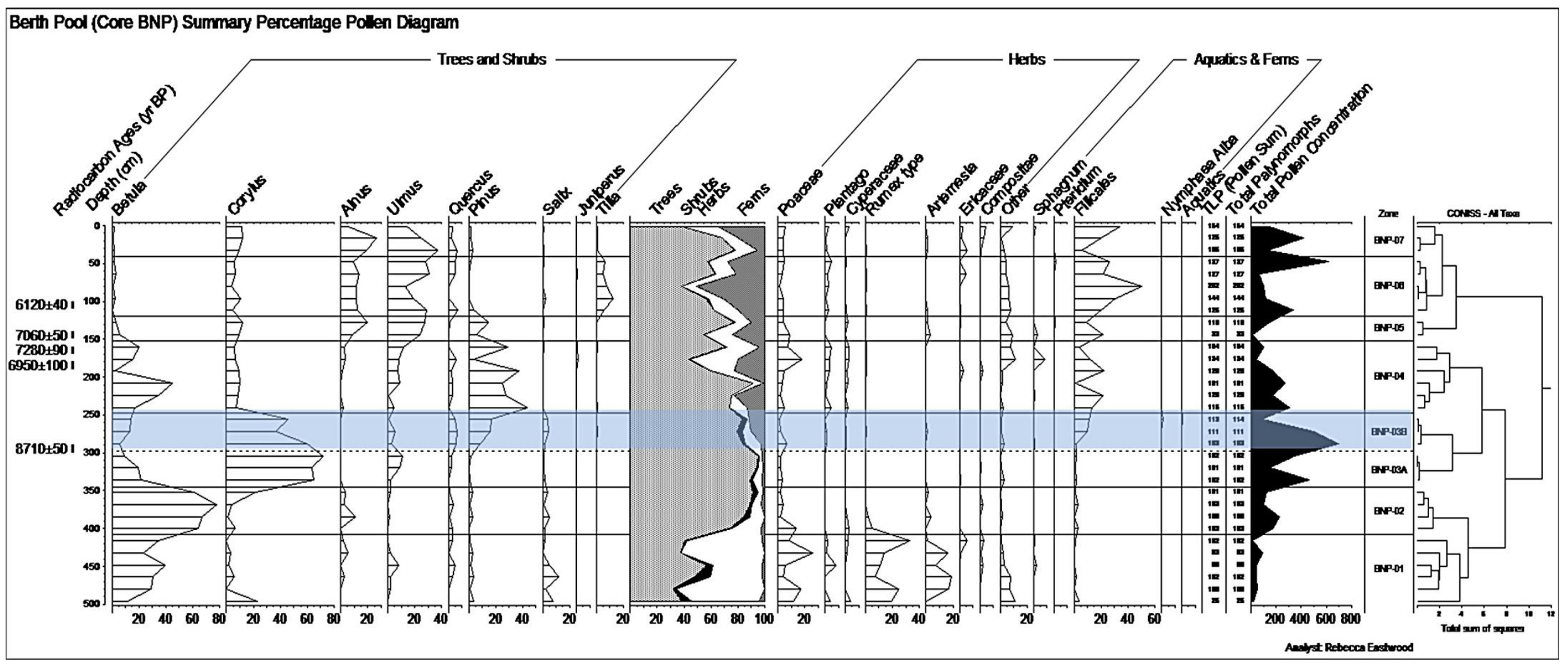

Fig. 8-8 BNP-03B - 300-250cm - Pollen 

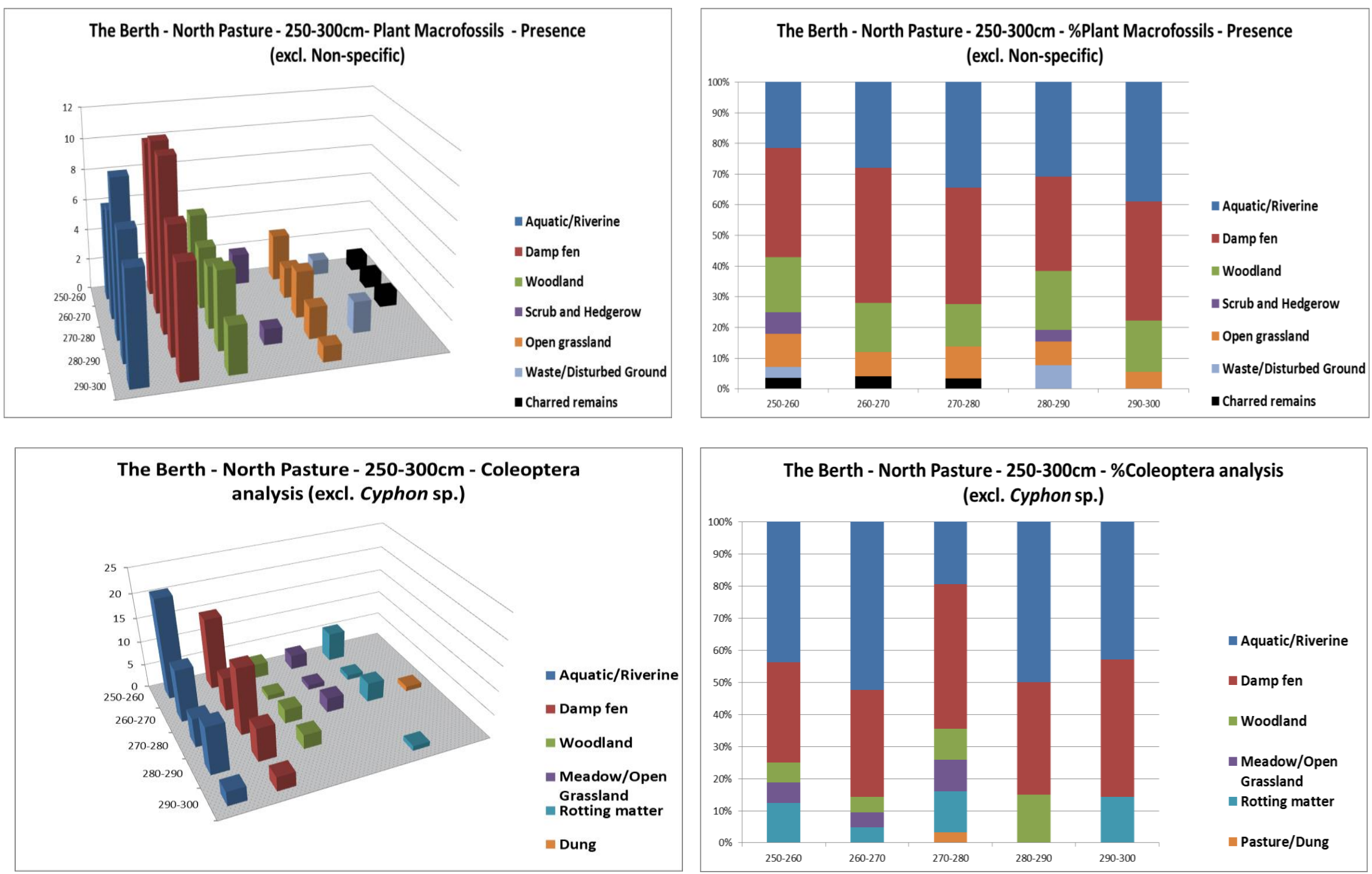

Fig. 8-9 BNP-03B -300-250cm - Plant Macrofossil and Coleoptera 
The woodland was initially dominated by hazel (50\%); however, despite its abundance in the pollen record, the plant remains contribute only two fragments of hazelnut shell $(250 \mathrm{~cm} ; 180 \mathrm{~cm})$ suggesting that it may not have been a primary species at the core site. Its reduction to $<30 \%(250 \mathrm{~cm})$ was synchronous with rises in oak, elm, lime and pine; these Urwald species would create dense canopy cover in which hazel became an understorey species. The canopy had gaps however, as evidenced by recurring high values for Filicales (ferns), and reductions in AP were mirrored by rises in ferns throughout the entire sequence. Whether this and the presence of fire were attributable to human intervention is discussed below.

Birch is super-abundant in the plant remains but the pollen signature is weaker (10-25\%). Birch seed production is high (if variable) (Atkinson, 1992:854) but, although winged, seeds rarely fall more than 40-50m from the parent plant (Atkinson, 1992). Therefore the difference is likely to reflect the spatial zoning represented by each proxy and birch was likely to be close to the sample site. The nut weevil Curculio cf. rubidus (now uncommon in Britain; UKRDB) is associated with birch saplings and is tied to woodland; it is found at $270 \mathrm{~cm}$. Willow is present in both pollen and plant macrofossil analysis (as capsule fragments and buds) suggesting wetter ground. Potentially this is grey willow (Salix cinerea), but species are hard to separate due to frequent hybridisation (Dickson, 1970:247). Eusphalerum primulae is present at this level in the beetle assemblage, and although it is primarily a grassland species, it can be found on willow catkins (Atty, 1983 in Buckland and Buckland, 2006). Alder is scarce in both plant remains and pollen, notwithstanding that it was present and locally abundant from Wales to the Thames estuary by $8200 B P$ (Birks, 1989:515).

It is generally accepted that the presence of woodland beetles reflect the immediate biosphere (e.g. Dinnin and Sadler, 1999). Robinson estimated that woodland was near to the sample site when species represented 15\%-20\% of terrestrial taxa (Robinson, 1991; 2000) and Kenward, Smith and Whitehouse have all argued that that the proportion of arboreal taxa decline sharply as distance from woodland increases (Smith and Whitehouse, 2005; Whitehouse, 2006; Kenward, 2006). In BNP-03B, woodland taxa fluctuate (Fig. 8-10). A total absence at the deepest layer of the sample $(290-300 \mathrm{~cm})$ may suggest that, notwithstanding the pollen analysis, Urwald was still developing. However, the remaining levels average around $18 \%$. Although MNI at each level is small (between one and three individuals) and therefore percentages should be treated with caution, individual species indicate the close proximity of a range of woodland habitats - living trees in dense forest, woodland margins and decaying material accumulating on the forest floor (Coarse Woody Debris/CWD) (Smith and Whitehouse, 2005:155). Species include 
Strophosoma cf. capitatum (polyphagous on deciduous and coniferous trees), Agriotes cf. pallidulus (woodland margins in open deciduous forest) and Ochina ptinoides (on dead and dry ivy). The CWD biozone is indicated by Orthoperus atomus and Dryophthorus corticalis. D. corticalis is an important indicator of ancient woodland (Robinson, 2001:127). It was recovered from, inter alia, Mesolithic deposits at Runnymede Bridge (Robinson, 2000) and West Heath Spa, Hampstead (Girling, 1990), the Neolithic Sweet Track on the Somerset Levels (Girling, 1984) and a Bronze Age site at Thorne Moors (Buckland, 1979). It is one of several species which depend on decaying forest material that suffered reduction or extirpation as their habitat declined; these reductions were at their greatest circa 50003000 cal BP (Whitehouse, 2006; Buckland and Buckland in Duff, 2012) reflecting increased woodland clearance. It is now rare (UKRB1) in the British Isles and found only in Windsor Great Park.

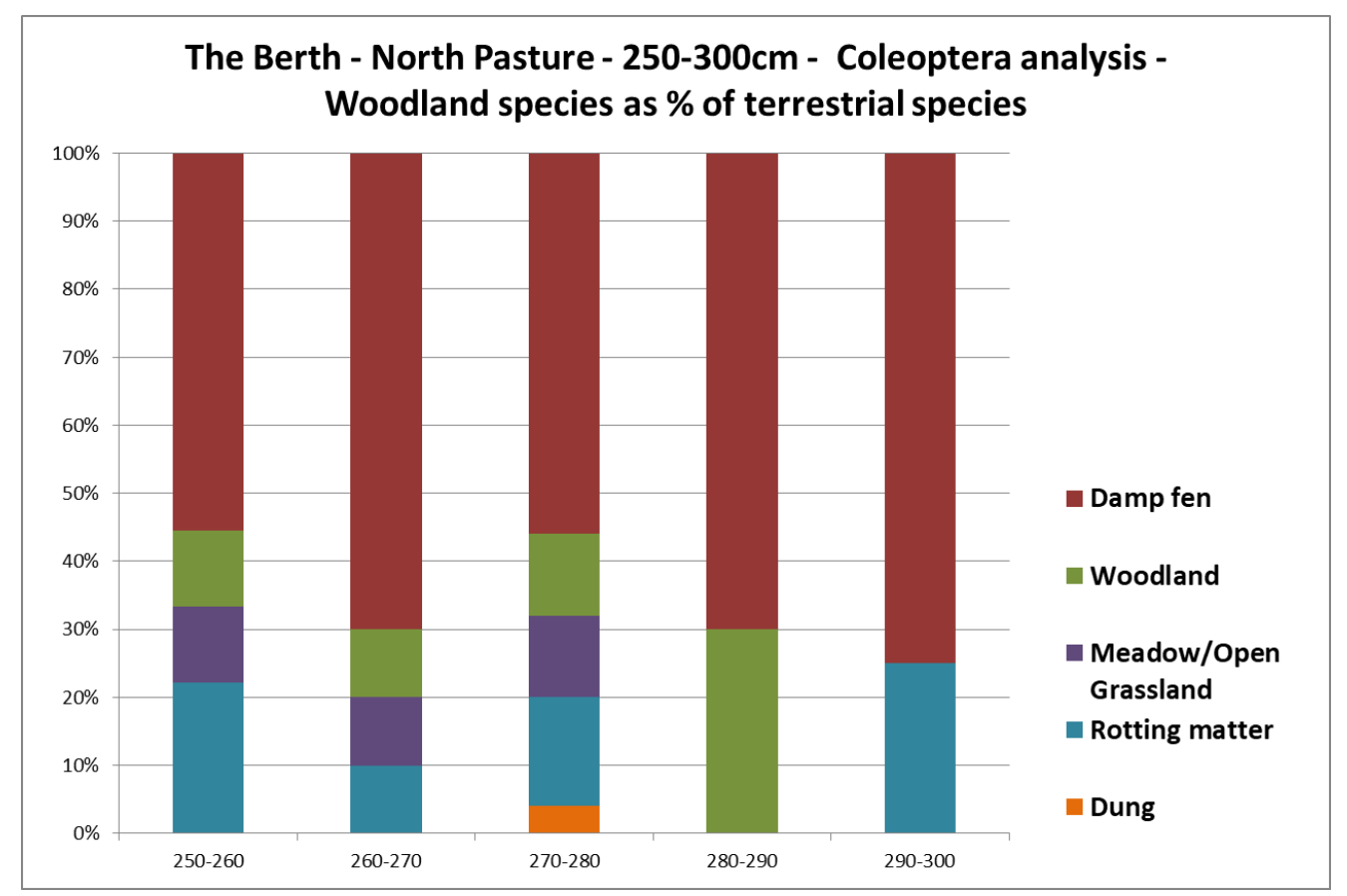

Fig. 8-10 BNP-03B -300-250cm - Woodland Coleoptera expressed as percentages of terrestrial taxa

Macroscopic charred plant remains (unidentified) occur between $280-250 \mathrm{~cm}$, circa 8300BP. They may relate to natural burning of pine forest from fire strike, but could also relate to human manipulation of the wetland during the early Mesolithic as part of a wider subsistence strategy. 


\subsubsection{Open water/waterside}

Plants representing open water are poorly represented in the BNP-03B pollen diagram; this is not unusual as many open water taxa pollinate underwater (Huang et al., 2001) and/or produce pollen in limited amounts (Zhao et al., 2006). However, open water/waterside taxa dominate the plant and beetle remains (Fig. 8-9). The extent, depth and flow of the aquatic environment can be gauged from individual species.

Nymphaea alba (white water lily) is found in Quaternary deposits as early as the Windermere interstadial, colonising still or slow moving, slightly acid or brackish water across British Isles, at depths of between $0.5 \mathrm{~m}-3 \mathrm{~m}$ (Heslop-Harrison, 1955). It has a slight presence in the pollen diagram and is plentiful in the plant macrofossil analysis. The beetle Donacia crassipes (Family Chrysomelidae) feeds on its leaves as an adult and on its roots as larvae and is present in this section of the beetle assemblage. Water lilies are frequently associated with Phragmites australis (common reed) and indicate a water depth greater than 1m (Heslop-Harrison, 1955; Haslam, 1972); however, P.australis is infrequently represented in these plant remains. Najas marina (holly leaved naiad) is a summer annual of lakes around 1.40m deep (Mason and Bryant, 1975:72); it is super-abundant at this level as a macrofossil but absent from the pollen diagram. This taxon flourished in the Boreal/Early Atlantic (Walker, 1955) and persisted in open water habitats until overtaken by hydroseral succession (e.g. at Hockham Fen, Godwin and Tallantire, 1951:298). This trajectory is shown in the Berth's plant remains (see Table 8-2). Its modern range is now restricted to East Anglia.

A range of algae, snails and faunal remains add to the picture. The oospores of Characeae (algae/stoneworts) and the opercula of Bithynia sp. (freshwater snails) were both super-abundant at this level. Chara sp. is often found in clear, hard-water lakes between $0.5 \mathrm{~m}$ and $7 \mathrm{~m}$ deep (Roden and Murphy, 2013), particularly in waterbodies formed in pioneer conditions (Mauquoy and van Geel, 2007:2324). Bithynia sp. inhabits still or slow-moving water up to $5 \mathrm{~m}$ deep (Macan, 1960; Morley et al., 2004) with a high mineral content and a pH of 6.6-8.4. The case for open water is further reinforced by Daphnia ephippia (the eggs of water-fleas) and fish scales. The fish scales were not identified to species, but pike and ruffe inhabit slow moving freshwater, and tench patrol the margins of lily beds (http://www.fish-uk.com/species perch.htm ${ }^{5}$ ). Perch, roach, pike and eel are more or less ubiquitous to the North Shropshire meres (Reynolds, 1979:105) and may have been a valuable food source.

\footnotetext{
${ }^{5}$ Accessed February 2017 
The aquatic perennial Menyanthes trifoliata (bogbean) $(270 \mathrm{~cm} ; 210 \mathrm{~cm})$ occupies shallow ponds, fens, bogs and marshes. It is often associated with other species favouring water/damp conditions such as Phragmites, and was an abundant species during the Late Glacial (Hewett, 1964). Callitriche (waterstarwort) (240-250cm), Potamogeton (pondweed) and Typha (bulrush/reedmace) (both present throughout BNP-03B) all suggest a range of watery substrates from open water to wet mud (Croft and Preston, 2014).

Reconstruction of past environments relies on how well plant macrofossil remains reflect plant communities over any given spatial area (Birks, 2001). A study at Green Plantation Lake, Norfolk (Zhao et al., 2006) found that the plant remains of Potamogeton spp. and Zannichellia palustris (present at $200 \mathrm{~cm}$ ) were good representatives of local (patch-scale) vegetation, whereas Characeae oospores, because of their tendency to be eaten and distributed by wildfowl, represented a wider area. The conclusion was that concentrations of aquatic plant remains were found close to the source of plant dominance, representing a $20-30 \mathrm{~m}$ radius. Extrapolations of these findings suggest that, for the Berth circa $8700 \mathrm{BP}$, deep open water (between $0.5-7 \mathrm{~m}$ ) covered the sample site or occupied pools close by. Coleoptera which reflect still or slow moving water are numerous in this assemblage and include Gyrinus sp. (whirligig beetles), Hygrotus inaequalis, Porhydrus lineatus, Hydrobius fuscipes, Limnebius sp. and Tanysphyrus lemnae (monophagus on duckweed). In addition to D. crassipes (mentioned above), several other phytophagous species indicate their preferred host plants, specifically Donacia marginata (on aquatic plants such as Sparganium) and Corylophus crassidoides (on fallen reed stems). Evidence for moving water is limited to three possible candidates - Hydraena riparia (Hansen, 1987; Koch , 1992) and two Elmid (riffle) beetles, Riolus subviolaceus and Oulimnius spp. - however, all three taxa can occur in murkier, stiller waters (Friday, 1988; Koch , 1992; Smith, 2000; Elliott, 2008). Cyphon sp. is abundant throughout the entire assemblage and has been removed from all calculations to avoid distorting the results; however it contributes to the analysis by reinforcing watery/damp conditions, and is particularly associated with peaty pools and streamside vegetation.

Carex (sedge) and Cladium mariscus (great fen sedge/saw-sedge) are both dominant in the plant macrofossil assemblage and indicate tall (up to $2 \mathrm{~m}$ ) reedy swamp surrounding open water. C.mariscus thrives in calcium-rich/nutrient-poor shallow water. It is a strong indicator of the reed swamp phase of hydroseral succession (Conway, 1942; Hughes and Barber, 2003) and is integral to Rodwell's S2 plant community (Rodwell, 1995). The species decreases when overshadowed by swamp woodland (Conway, 
1942:213), and this pattern is reflected at the Berth - it declines abruptly with the beginning of the alder rise circa 8000BP (230cm; BNP-04).

A range of beetles indicate the terrestrial/aquatic margin, where open water gives way to marsh (Cercyon tristis; Coelostoma obiculare; Limnobaris cf. $t$-album (on Carex and Juncus); Notaris acridulus (on sweet grass (Glyceria)). Peat bog is evidenced by several species, for example Agabus affinis, whilst Pterostichus diligens can suggest damp woodland with a peat substrate.

Several plant and beetle species exhibit a degree of halotolerance, for example, $P$. australis and Melilotus (250cm) (Squires and Ayoub, 1992:135), Bembidion doris, Laccobius sinuatus and Enochrus melanocephalus. This can be explained by the high calcium/ion content of many of the North Shropshire meres (Sinker, 1962:104) including the Berth.

\subsubsection{Damp and dry grassland and meadow}

The percentage for herb/grassland pollen is low $(<5 \%)$, which, when combined with the plant macrofossil evidence, suggests that this environmental patchwork included only limited damp or dry grassland. Damp areas are suggested in the plant remains by Eupatorium cannabium (hemp agrimony) and Lycopus europaeus (gypsywort), both of which are present throughout the BNP15 core. Species indicating drier grassland include docks and sorrels (Rumex sp.), clover (Melilotus/Trifolium) and grasses (Poaceae). Beetle fauna also reflect areas of drier, more open land, namely Scymnus frontalis and Barynotus obscurus, but numbers are low. Only one sclerite in this sample indicates dung (Aphodius sp.) and no conclusions can be drawn from its presence.

\subsubsection{BNP-O3B Summary}

The environment which developed at the Berth during the early Holocene illustrates an environmental mosaic of thermophilous forest, open water, reed-bed and damp and dry grassland. This period contrasts with Beales' LPAZs CMCP-5/CMCP-6 (part) at Crose Mere where pine pollen is between 10$25 \%$, oak is consistently $>15 \%$, alder $<10 \%$, hazel $30-60 \%$, and herb pollen $<2 \%$ (Beales, 1980:140). At King's Pool, the forest canopy was dominated by oak (10\%) with a hazel understorey (15\%) (Bartley and Morgan, 1990:184). A modern sketch of Sweat Mere, adjacent to Crose Mere, provides a suggestion for the environmental mosaic which prevailed at the Berth around this time (Fig. 8-11). 


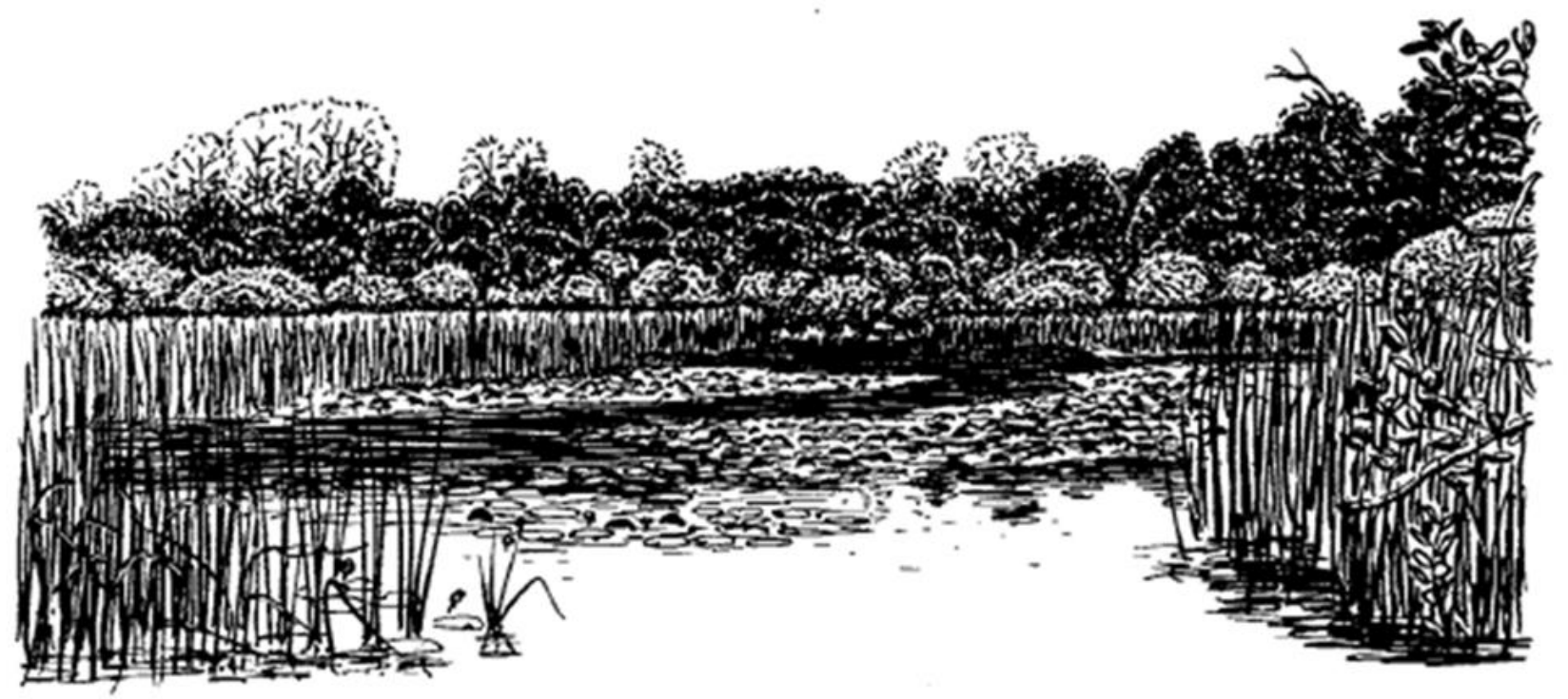

Fig. 8-11 Ecological sketch of Sweat Mere (Sinker, 1962:116)

\subsubsection{BNP-04 - 250-150cm - Boreal/Atlantic transition - circa 8300BP - 7100BP}

(Fig. 8-12; Fig. 8-13)

BNP-04 covers roughly 8300BP-7100BP, incorporating the transition from the warm, dry climate of the Late Boreal to the wetter Atlantic period and illustrating an ecological pattern of marked fluctuations in tree cover and increased floral variety. Vegetation continued to be lush and plentiful as illustrated by the fast rate of sedimentary deposition (0.13mm y-1; 8200BP - 7500BP; Fig. 8-3), which slowed towards the end of this period. The two radiocarbon dates available here record a reverse - $7280 \pm 90 \mathrm{BP}$ at 160 $170 \mathrm{~cm}$ (Poz-77445) and 6950 $\pm 100 \mathrm{BP}$ (Poz-77446) at 180-190cm. The possible causes are discussed in Chapter 7, and Poz-77446 has been discounted as a precaution.

\subsubsection{The arboreal landscape}

BNP-04 begins with a decrease in arboreal pollen $(240 \mathrm{~cm} ; 80 \%)$, synchronous with the short, cold phase known as the '8200BP event'. The thawing of the Laurentian ice sheet caused a 200-300 year period of cooler, drier conditions across the North Atlantic and Northern Europe, resulting in poorer summer growing conditions, fluctuating pollen and reductions in the rate of peat deposition (Spurk et al., 2002:711), although floral diversity continued to increase (Alley and Ágústsdóttir, 2005). Following the 8200BP event, arboreal pollen values at the Berth returned to those seen previously (95\%) with species which tolerate colder conditions - birch and pine - demonstrating the most dramatic increases; this abundance is reflected in the plant macrofossils. 
Pine reached its maximum at the Berth during this phase (45\%) with values higher than either Crose Mere (<20\%) or King's Pool (30\%); perhaps the sands/gravel outcrops that surround the Berth's peat basin offered more suitable growing conditions. Pine expansion at the Berth is commensurate with a decline in hazel and the expansion of alder. This recognised vegetational sequence is reflected across the north-west lowlands, for example, in Shropshire, at Whattal Moss, Wem Moss and Church Stretton (Beales, 1980:149). Hazel never recovered its former profile and continues throughout the remainder of the BNP sequence as an understorey taxon; this pattern has parallels elsewhere, both locally at Crose Mere (Beales, 1980), and across England, for example at Hockham Mere in Norfolk (Bennett, 1983:479). Pollen values are low for oak, but increases are apparent for lime and elm. Lime is found at low altitudes across a wide range of soil types; it favours the stagnogleic brown soils and peaty loams which predominate around the Baschurch area (Crompton and Osmond 1954; Bennett, 1989; Pigott, 1991). Low pollen values for lime are typical, given its poor rate of production and its entomophilous method of distribution (Pigott, 1991); nor are there any plant macrofossils or obligate beetle taxa (such as the lime bark-beetle, Ernoporicus caucasicus) at the Berth to reinforce lime's presence. Nevertheless, lime was an important component of primary woodland, and the low values seen here are likely to be a misrepresentation. The repeated fluctuations in lime pollen which are seen across the British Isles during the Early-Mid Holocene are usually associated with climatic change; however fluctuations later than circa 5000BP are principally associated with anthropogenic impact (Grant et al., 2011). This broad pattern is reflected across North Shropshire (Twigger and Haslam, 1991).

The plant macrofossil remains provide the only indications of the presence of poplar (Populus) and ash (Fraxinus). Poplar $(200 \mathrm{~cm} ; 160 \mathrm{~cm})$ is frequently found in early Holocene deposits, and depending on species, its presence may suggest slightly drier soil (van Geel et al., 1980; Mauquoy and van Geel, 2007:2324). Ash is a poor pollen producer (Bradshaw, 1981), but its presence is indicated by an ash-key found at $200 \mathrm{~cm}$ and by the ash bark-beetle, Leperisinus varius, present at $230 \mathrm{~cm}$, circa $8100 \mathrm{BP}$. In conjunction with evidence from Crose Mere (Beales, 1980:147), this suggests that ash was established in North Shropshire well before the accepted dates for its expansion across the British Isles, between 70006000BP (Birks, 1989:517), and reinforces Birks' conclusion that determining tree arrival and disbursement from pollen alone can be unreliable (Birks, 1989:526).

Alder begins to increase during BNP-04 (from around $200 \mathrm{~cm}$ ), and this is reflected across all proxies. Alder was present across the British Isles throughout the Late Glacial and expanded between 70006000BP, colonising alluvial and peat soils in major river valleys and wetlands (Bennett, 1989; Birks, 
1989:515). Its expansion is diachronous and appears to be controlled by a combination of sporadically wet conditions, episodic flooding, competition from other species, and suitability of soils (McVean, 1953; Beales, 1980:148; Brown, 1997; Allen and Waddington, 2007); anthropogenic impact has also been cited (Barber and Twigger, 1987:227; Twigger and Haslam, 1991:745). Pollen analysis indicates that alder was an intermittent background presence at the Berth from the Late Glacial onwards and its expansion from circa 7900BP $(200 \mathrm{~cm})$ parallels that locally at Crose Mere (see Fig. $8-5)$ and more widely across the West Midlands (e.g. Brown, 1988). Its growing presence is also visible in the plant macrofossil and beetle analyses. Dryocoetinus alni $(210 \mathrm{~cm}$ and $150 \mathrm{~cm})$ and Rhynchaenus $\mathrm{cf}$. testaceus $(170 \mathrm{~cm})$ are two of comparatively few beetles obligate on alder (Girling in Musson et al., 1977; Kennedy and Southwood, 1984; Girling, 1985:15; Bullock, 1992). D. alni was synchronous with the alder rise at Bole Ings in the Trent Valley (Dinnin, 1997), whilst $R$. testaceus (RDB2) was found on alder-dominated floodplain at Mingies Ditch, Oxfordshire (Robinson, 1993) and at the Neolithic site at Croft, on the River Soar, Leicestershire (Smith et al., 2005). The alder rise exemplifies how the nature of the woodland changed at the Berth between $200-150 \mathrm{~cm}$, and reflects the wetter and more oceanic climate which prevailed following Britain's separation from Continental Europe (e.g. Fitch, Gaffney and Thomson, 2007).

Plant and beetle proxies provide continuing evidence for areas of undisturbed, drier woodland. Pine as a host taxon is indicated by Dryophilus pusillus $(220 \mathrm{~cm})$, Rhyncolus ater $(220 \mathrm{~cm})$, Pityophthorus cf. pubescens and Pityogenes cf. chalcographus $(180 \mathrm{~cm})$. Strophosoma cf. melanogrammum /captitatum, Athous haemorrhoidalis and Anobium spp. $(220 \mathrm{~cm})$ are found in ancient and mixed woodland and woodland margins. Rhynchaenus spp. - 'leaf miner/leaf roller' beetles which live on a range of arboreal foliage - is also a regular presence throughout this section. High forest and decaying wood are indicated by Ptiliidae indet $(220 \mathrm{~cm})$, cf. Hylecoetus dermestoides $(190 \mathrm{~cm})$, Clambus spp. $(180 \mathrm{~cm})$, and Euplectus decipiens (170cm). A wood-boring Cerambycid (Grammoptera spp.) is present at $180 \mathrm{~cm}$. Curculio cf. villosus $(170 \mathrm{~cm})$ is associated with oak galls and acorns whilst Crepidodera fulvicornis $(220 \mathrm{~cm} ; 170 \mathrm{~cm})$ is oligophagous on poplar and willow. The percentages of woodland species are similar to those seen in BNP-03B suggesting that the overall proximity of woodland changed little (see Fig. 8-14). 


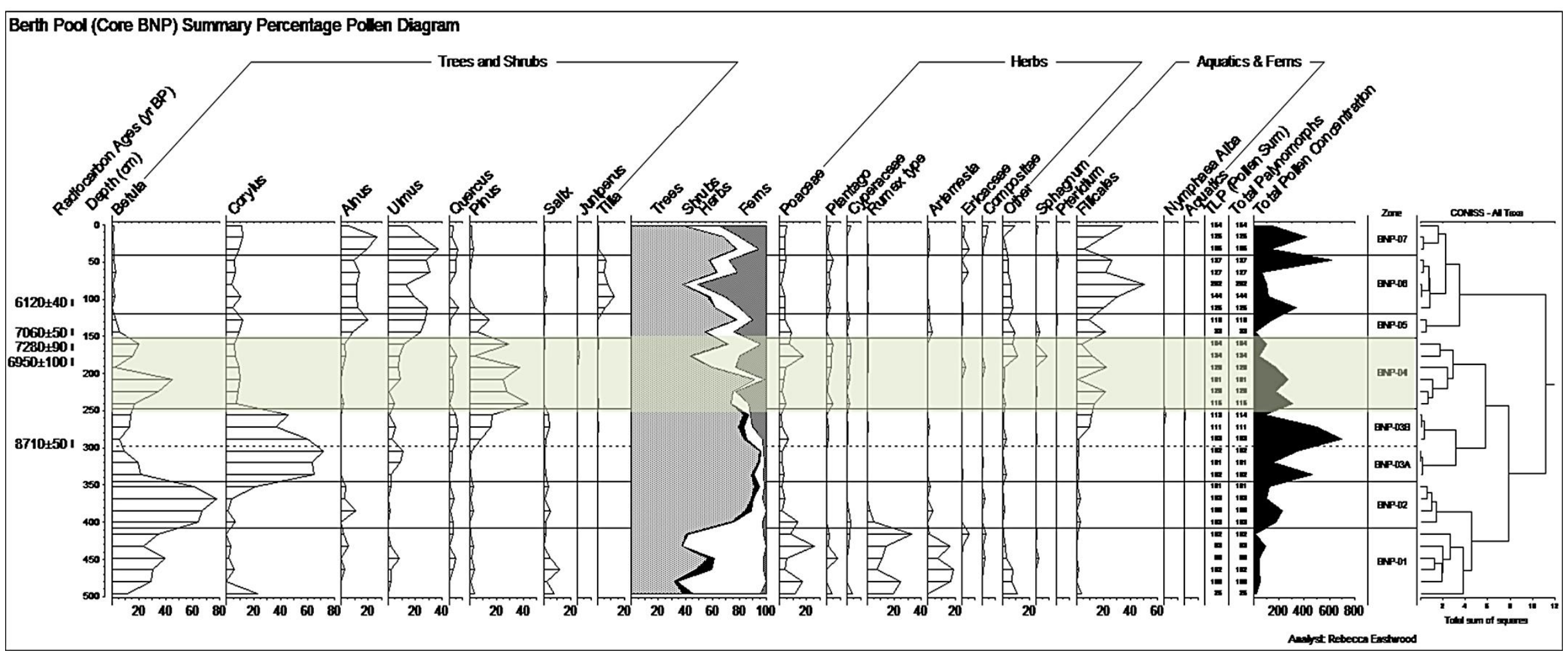

Fig. 8-12 BNP-04 -250-150cm - Pollen 

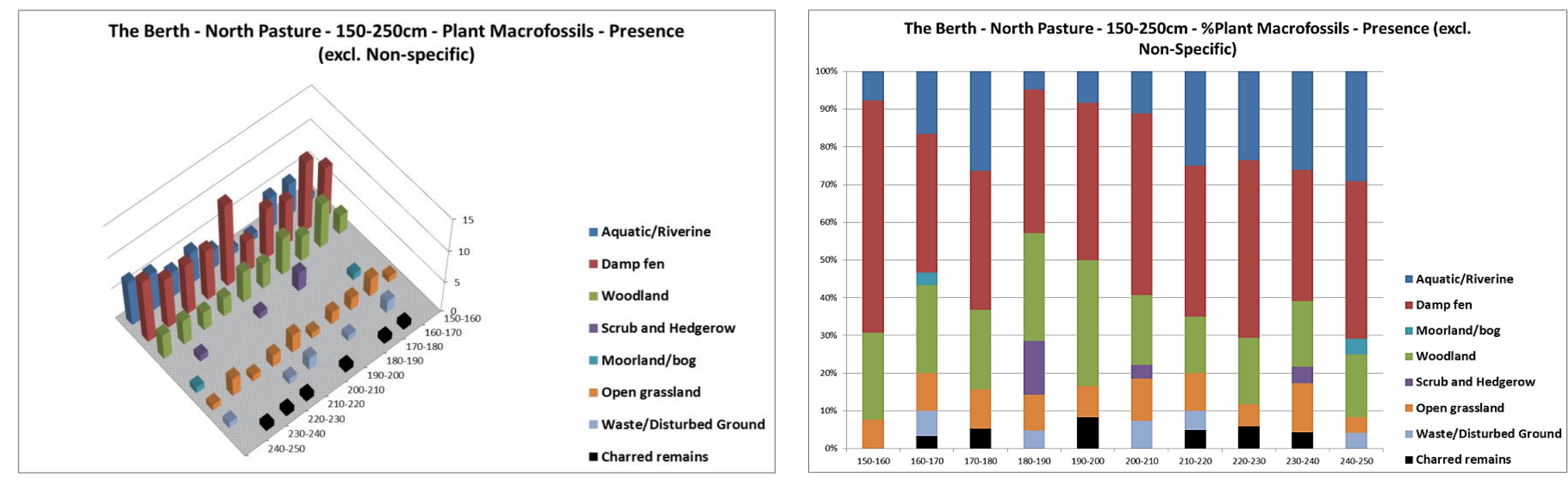

The Berth - North Pasture - 150-250cm - Coleoptera analysis (excl. Cyphon sp.)
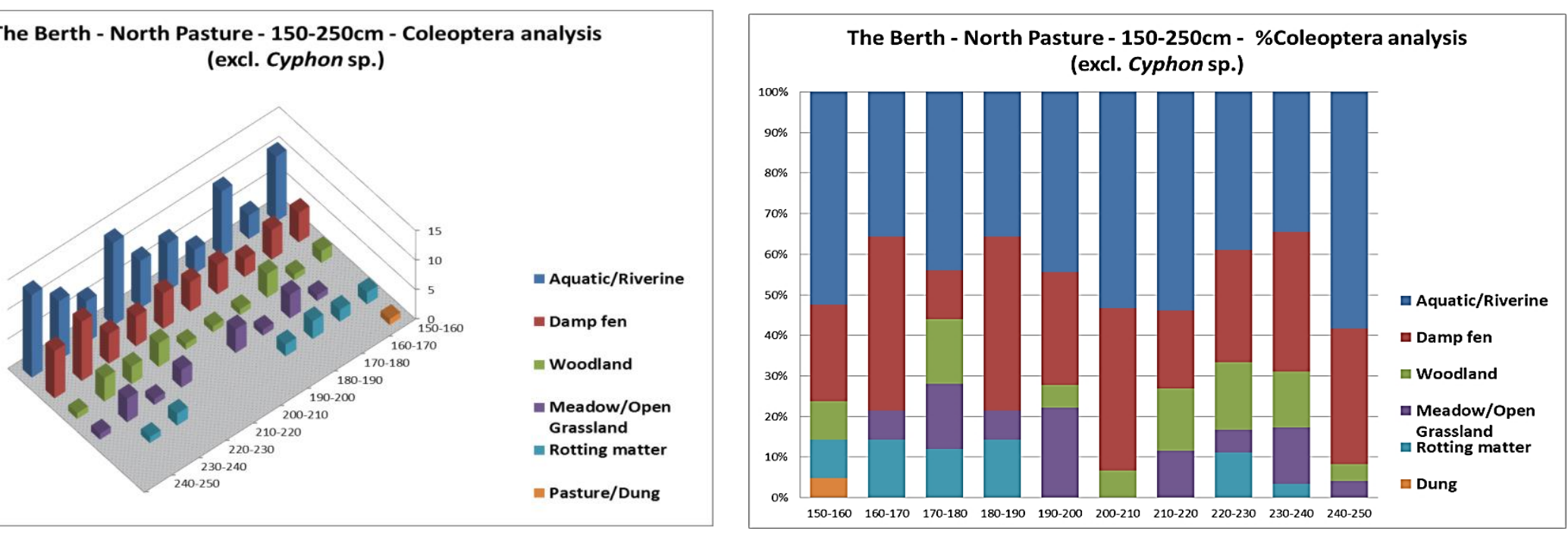

Fig. 8-13 BNP-04 - 250-150cm - Plant macrofossil and Coleoptera 
However, a sharp decline in arboreal pollen is noticeable at $175 \mathrm{~cm}$, due mainly to falls in birch and then pine, and commensurate with rises in Poaceae and Sphagnum (see 8.1.3.3 below). Woodland Coleoptera are absent at roughly the same time. This decline may suggest increasingly wet conditions, although early anthropogenic clearance is also a possibility and charred plant remains (unidentified) are abundant at this time. Birch and pine recover, but $160 \mathrm{~cm}$ marks the start of a downward trend for both species as they are overtaken by alder and elm. Notwithstanding these fluctuations in arboreal taxa, all proxies indicate that Urwald forest continued as the predominant ecosystem throughout BNP-04, but with increasingly open and damp areas. This eventually gave way to domination by alder and elm which lasted for the remainder of the BNP15 sequence.

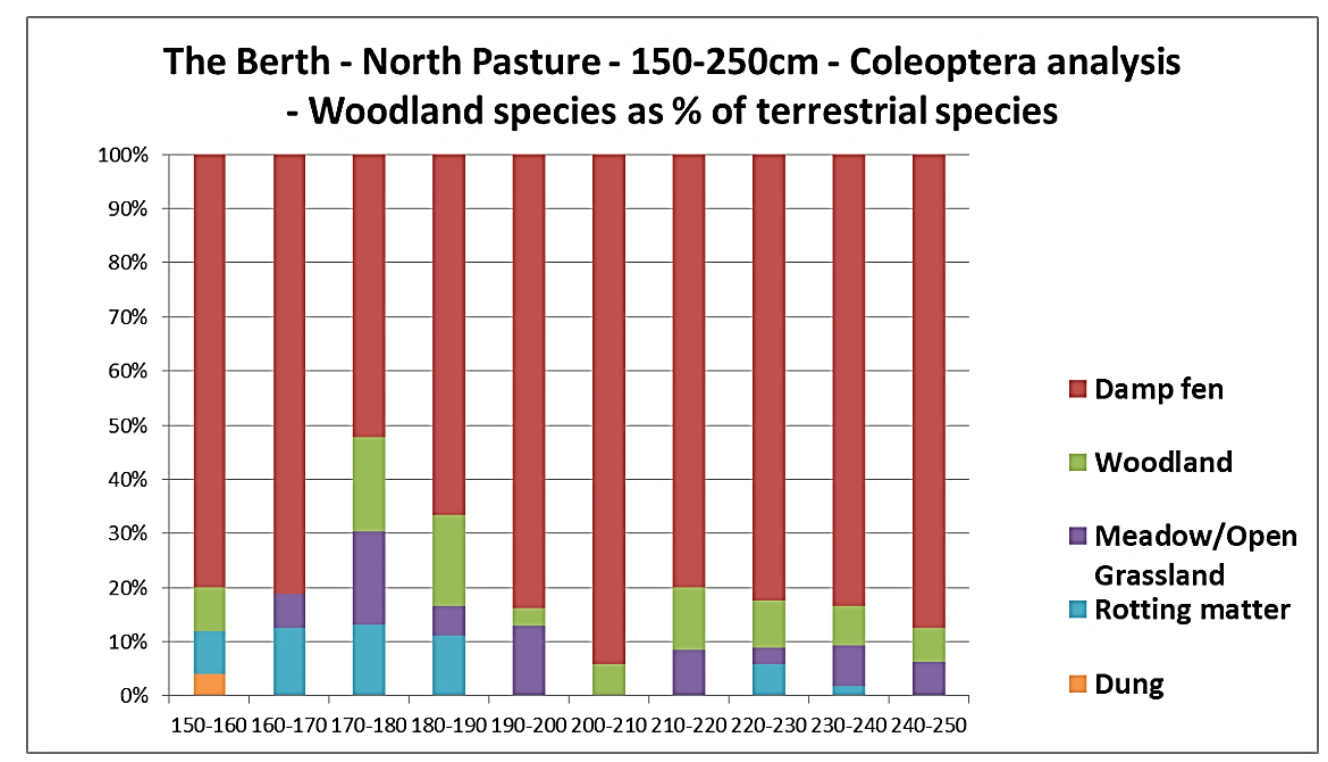

Fig. 8-14 The Berth $150-250 \mathrm{~cm}$ Woodland Coleoptera expressed as percentages of terrestrial taxa

\subsubsection{Open water/waterside}

Throughout BNP-04, indications of open water gradually decline across all proxies. Whilst aquatic plant taxa are predictably absent from the pollen analysis, they also decline in the plant macrofossil remains; for example, N. alba and N.marina occur only occasionally. However, Potamogeton, Callitriche, Z.palustris and M.trifoliata continue to be present, and indicate a range of water depths from shallow to moderate (Croft and Preston, 2014). The shelly remains of Chara sp. and Bithynia sp. are absent but Daphnia ephippia are still found. Together this suggests that pools were infilling and becoming shallower.

Coleoptera reflect this change. Whilst species from aquatic and damp fen environments dominate the beetle remains (Fig. 8-13), fewer taxa are associated with open water and more are associated with 
peaty pools. The whirligig beetle Gyrinus is now occasional rather than ever-present. A mixture of still and running water is indicated by Hydraena riparia, Hydraena cf. rufipes, Hydraena testacea, and Ochthebius minimus. Peaty pools are suggested by Agabus affinis, Hygrotus inaequalis, cf. Dryops sp., Hydroporus elongatulus and Hydroporus scalesianus. H. scalesianus is now rare (RDB2) and, together with H.elongatulus, suggests the eutrophic conditions of a fen-carr environment. H. scalesianus is also associated with Sphagnum moss (Foster, 2010), as is Enochrus affinis $(170 \mathrm{~cm})$ (Whitehouse in Plunkett et al., 2009:272), and both support the presence of Sphagnum recorded in the pollen analysis (see 8.1.3.3 below).

Reed-bed is represented by an abundance of plants and Coleoptera. C. mariscus, Phragmites (limited), Sparganium and Typha would have created a tall screen around dwindling pools. Typha in particular indicates little or no water movement (e.g. Grace and Wetzel, 1981), and its seeds were found regularly in small numbers throughout the plant macrofossils. Glyceria (sweet-grass) was found at $220 \mathrm{~cm}$ and $160 \mathrm{~cm}$, recognisable as tough opaque fruits with long hilum (Dickson, 1970:239), although its oligophage, $N$. acridulus, was not present in the beetle assemblage.

Carex pollen (Cyperaceae) begins to increase during BNP-04; however Carex seeds were present in abundance at all levels of the plant macrofossil assemblage. Carex is an indicator of damp ground and forms an essential component of the reed-bed. However, if refined to individual species, the results are more informative. Preservation at level $160-170 \mathrm{~cm}$ was sufficiently good (see 8.1 above) to facilitate an in-depth study of the Carex specimens, which was undertaken with reference to the plant collection held by Historic England's Environmental Archaeology Dept., Fort Cumberland. The results show a range of sub-species which reflect the environmental patchwork. C. paniculata (greater tussock-sedge) and $C$. acutiformis/riparia/pseudocyperus (pond-sedge) indicate the herbaceous flora of alder/birch woodland (Wheeler, 1980:771) whilst C. Hirta (hairy sedge) is associated with slightly drier, rich-fen meadow communities (Wheeler, 1980:763). C. Hostiana (tawny sedge) is found in meadows and marshes, and $C$. Sylvatica (wood-sedge) occupies the edge of ancient woodland. All prefer base-rich waters, and their varying heights (C. Hirta grows to around $60 \mathrm{~cm}$, whilst $C$.paniculata/C.acutiformis exceeds $1 \mathrm{~m}$ ) indicate the successive floral zones which formed part of the ecosystem.

The water's edge community is further reinforced by numerous beetle species. Ground beetles (Caribids) include Elaphrus lapponicus and Pterostichus gracilis and suggest a range of damp places from woodland to marshy grassland. Water beetles (Hydrophilids) include Cercyon tristis, Helophorus brevipalpis and Chaetarthria seminulum, all indicating the vegetation around peaty pools. Curculionids (weevils) which favour damp environments include Limnobaris t-album which is found on Carex, and 
Sitona cambricus. Several Chrysomelids, for example Plateumaris bracatta (on P.australis) and Plateumaris cf. rustica, are further indicators of these vegetation-rich waters.

\subsubsection{Damp/dry grassland and meadow}

Pollen values for grasses and herbs rise noticeably around 7200BP $(175 \mathrm{~cm})$, synchronous with a decline in AP to $40 \%$, indicating a more open landscape which lasted for several hundred years.

The plant remains indicate that the grassland was predominantly damp, and include the (ever-present) E. cannabium and L. europaeus, together with Cicuta virosa (cowbane, rare in modern times outside of East Anglia), Silene flos-cuculi (ragged robin), and (cf.) Alchemilla (lady's mantle). Plantago is not identified to species in the pollen diagram; however, the plant macrofossils record P.major/media at this level, indicating disturbed, damp ground. The presence of the tall fen-herb Filipendula ulmaria (meadowsweet) mirrors the rise of alder and both contribute to Rodwell's Alder/Greater tussock-sedge plant community (W5), which develops in topogeneous mires and valley fens (Rodwell, 1991a:30). Filicales (ferns) were not identified to species in the pollen diagram and do not feature in the plant macrofossils, but Athyrium filix-femina L. (Roth) (lady's fern) and Thelypteris palustris Schott (marsh fern) are also associated with this community; both favour damp conditions, with T.palustris preferring slightly drier, more open situations. Collectively, these species form classic fen-carr which may eventually become swamp.

The fen peats that surround the Berth are not strongly acid (pH 5.5 or higher) (Sinker, 1962; Burnham and Mackney, 1964:108; Reynolds, 1979); however, several factors suggest that areas of the Berth's environs achieved acidic conditions. Juniper, Ericaceae and Sphagnum are present from $200 \mathrm{~cm}$ onwards; bryophytes (mosses and liverworts) are limited in the plant macrofossils but are indicated by some Coleoptera, for example Bryaxis sp. and Brachygluta sp. More convincingly, fragments of cf. Scheuchzeria palustris (Rannoch rush) were identified at $160 \mathrm{~cm}$ and $140 \mathrm{~cm}$. This is a species of basepoor habitats and acid pools and is now rare across the British Isles (extant only on Rannoch Moor - Fig. 8-15). It was noted within the last century in the North Shropshire wetlands, for instance at Clarepool Moss, where it was eliminated during a brief dry phase (Sinker, 1962:120), and at Wem Moss, where it survived in one of the wet Sphagnum pools (Slater, 1972). However, species such as Eriophorum angustifolium (cottongrass), Trichophorum caespitosum (deergrass) and Drosera sp. (sundews) (Slater, 1972:96) are absent from the Berth, suggesting that raised (ombrotrophic) bog conditions were never fully achieved. The failure to achieve ombrotrophic status may relate to the combination of minerotrophic soils and groundwater drainage, but causes can also include burning (Walker, 1970:114; Slater, 1972), and charred plant remains occur regularly at this level (Table 8-3). 
The existence of drier meadow-type conditions at the Berth is only arguable when all proxies are combined. Artemisia and Rumex each have a small presence in the pollen record but are absent from the macrofossils. Plant remains include Solanum sp. (nightshade), and some Carduus/Cirsium, although these species tolerate a wide variety of conditions. Some meadowland beetles are also present - Athous haemorrhoidalis, Athous bicolor, Cantharis cf. livida, Rhagonycha lignose, Apion spp. and Neliocarus (Strophosoma) faber. Aphodius cf. sphacelatus/prodromus is the single representative of dung.

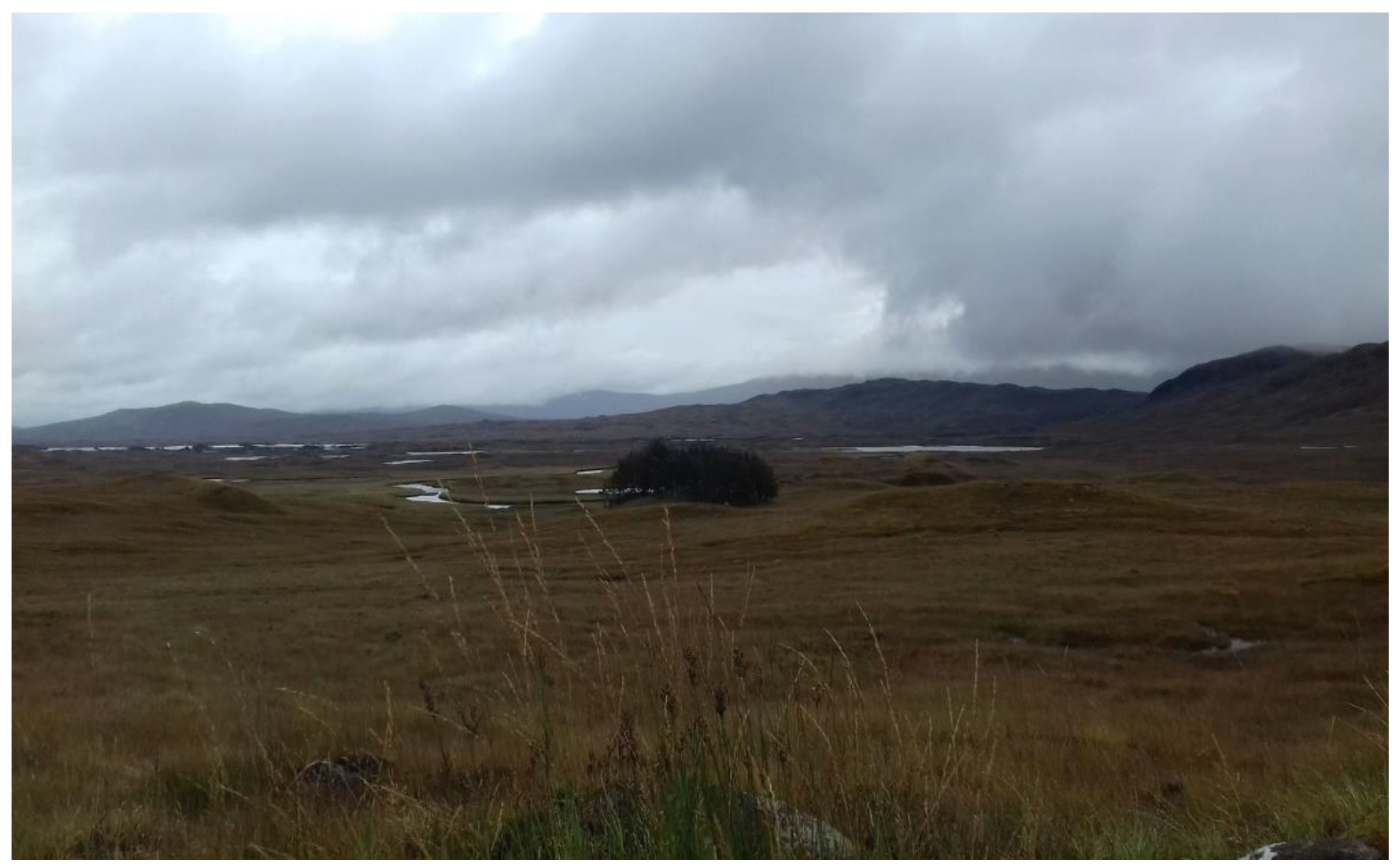

Fig. 8-15 Rannoch Moor (Norton, 2017)

\subsubsection{250-150cm Summary}

BNP-04's pollen record indicates that dense mixed woodland peaked at $210 \mathrm{~cm}(90 \%$ AP). Thereafter, gaps occur, occupied by ferns, shrubs and grassland. The pollen profile is corroborated by the plant macrofossil and beetle remains which add detail in terms of species. This environmental mosaic blended dense woodland with open water, reed-bed, damp fen, and grassland.

The changes in vegetation at the Berth during BNP-04 illustrate a classic hydroseral succession (Sinker, 1962; Walker, 1970). The process begins as open water is colonised by pondweed and waterlilies. Their remains fall to join the basal silt, allowing bottom rooted plants (Sparganium; $P$. australis) to become established. The accumulating organic platform grows to mean water level, providing habitat for flora which prefer slightly drier conditions such as Carex. Eventually, the platform becomes sufficiently stable 
to support trees (willow and alder), forming a fen-carr environment of wet woodland (Fig. 8-16). As they die, they feed the organic remains in an ongoing cycle. What happens next depends on climate (increasing/decreasing rainfall) and topography (shallowness of the mere and the steepness of its sides) (Sinker, 1962; Reynolds, 1979). The peat growth may become separated from ground water sources and develop into a raised (ombrotrophic) bog fed exclusively by rain-water. At this point, the flora changes, with acid-loving species (Sphagnum) replacing fen-carr. The hydroseral succession recorded at the Berth stops short of ombrotrophic status, unlike other areas in the North Shropshire wetlands. Fenn's/Whixall Moss is the most obvious example (see Chapter 5); today, it is considered to be the southern limit for raised bog in England, although several raised bogs further south (for example, Bomere Pool) have been lost in the past 200 years (Sinker, 1962:134).

The development of a complex woodland mosaic at the Berth is reflected locally and regionally. At Crose Mere circa 8500BP (8502 \190BP Q-1237; LPAZ CMCP-6), values for pine, oak and other broad-leaved woodland taxa rise, with a commensurate decline in understorey species (specifically hazel). From circa

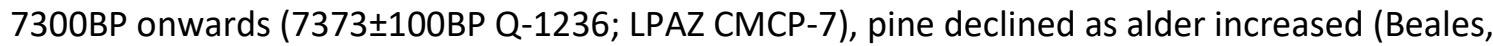
1980:148). Although different arboreal species dominate at different times, tree cover continued at Crose Mere until (anthropogenic) clearance and a marked rise in Poaceae/Gramineae are seen in the early Bronze Age (3714 $\pm 129 B P$ Q-1234). King's Pool shows the same broad pattern (Bartley and Morgan, 1990). Summarising the vegetational Holocene sequence for North Shropshire, Twigger and Haslam concluded that a broad-leaved woodland of oak, pine, lime and elm was well established by circa 8000BP (1991:744). This stable ecosystem was reflected across the English Midlands by the midHolocene, limiting soil erosion, and incorporating a mosaic of environments where different species gained dominance depending on slope orientation, hydrological and edaphic conditions (Brown and Barber, 1985; Greig, 2007).

Charred plant remains were plentiful at the Berth throughout BNP-04. The causes may be natural, for example, a combination of lightning strike and flammable pine (e.g. Whitehouse, 2000; 2004; Boswijk and Whitehouse, 2002; Smith et al., 2010). However as Buckland concluded when analysing the insect remains from Thorne Moors (1979:13), it is unlikely that fire would run easily through fen-carr woodland, and human manipulation of the environment, or even camp fires, should not be ruled out. Charred remains reduce but do not disappear from the area when pine is absent, after circa 6500BP. 

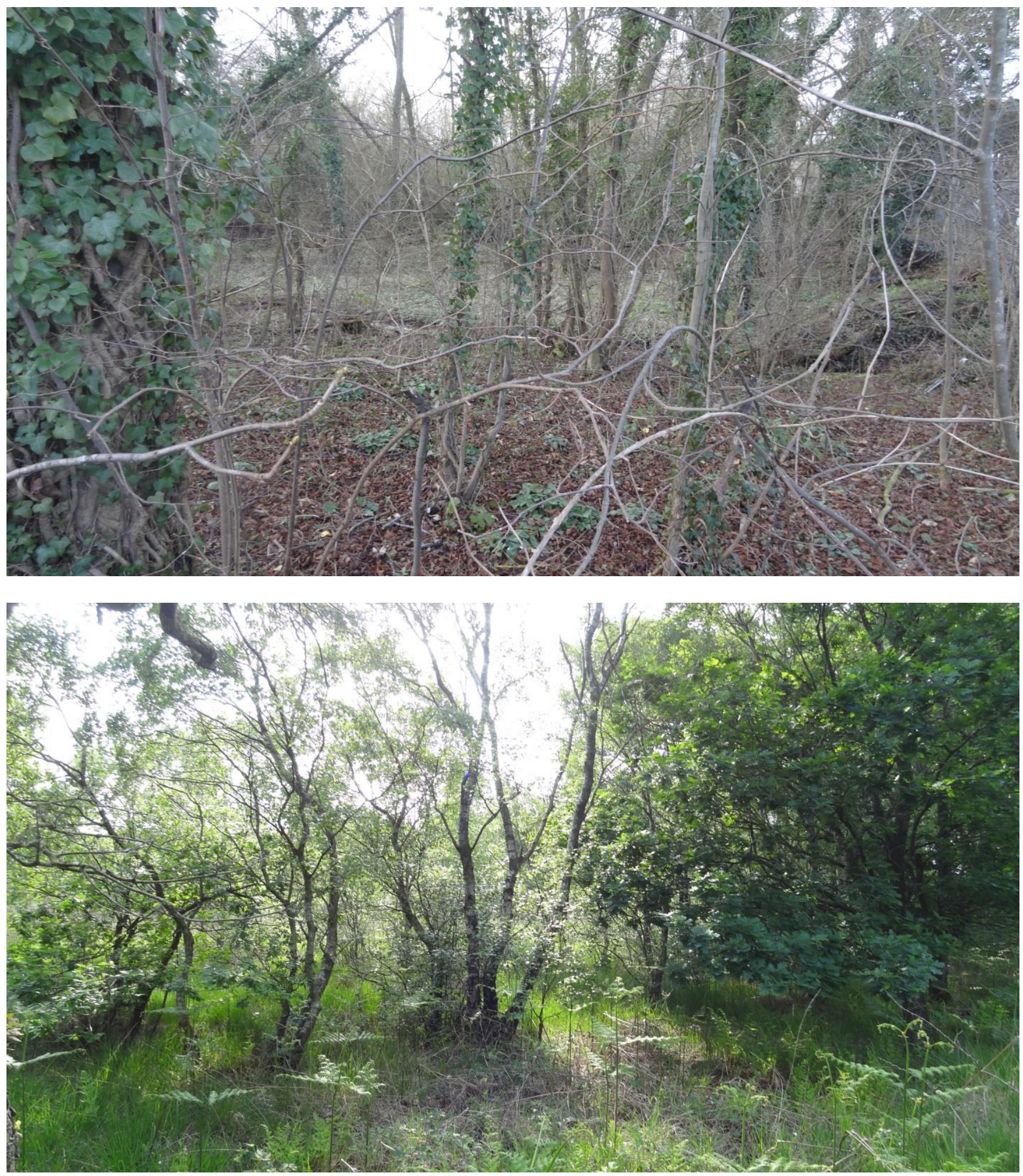

Fig. 8-16 Examples of alder-carr in Worcestershire (top) and at Fenn's/Whixall Moss (bottom) (Norton, 2016) 


\subsubsection{BNP-05 - 150-120cm - Atlantic climatic period - circa 7100-6300BP (Fig. 8-17 -}

Fig. 8-18)

The warm and wet climate of the Atlantic period continued throughout BNP-05. Arboreal pollen values fluctuated between $60-80 \%$, indicating plentiful forest but with noticeable clearances occupied by grasses and ferns (15-20\%). The rate of sedimentary deposition reflected the changes in botanical composition dropping to an average rate of $0.03 \mathrm{mmy}^{1}$ (see Fig. 8-3).

\subsubsection{The arboreal landscape}

Woodland composition changed during BNP-05 with elm (30\%) and alder (20\%) becoming increasingly dominant. Alder also dominated the plant macrofossil assemblage, although there were no macrofossils for elm. Pine fluctuated and declined. Initially oak appeared to be absent, but recovered to 5\%AP; lime values were similarly low. This combination of taxa reflects colonisation of the differing topographical zones around the Berth's environs. Alder would favour the wetter areas, and its rise at the Berth is synchronous with its expansion in the River Perry catchment, $6 \mathrm{~km}$ to the north-west, which signalled a major change in floodplain vegetation (Brown, 1990:42) (see Chapter 6). Elm can inhabit floodplains, but is usually found in drier woodland (e.g. Batchelor et al., 2014). Its domination over oak at the Berth may result from local edaphic conditions, as elm out-competed oak on the less fertile brown earths that make up the Berth's superficial geology (Burnham and Mackney, 1964; Crompton and Osmond 1954). There is evidence for willow in both pollen and plant macrofossil proxies; hazel is only represented by pollen (10-15\% AP). Hazel understory can fringe alderwoods in valley mires and these species most likely coexisted (Rackham, 2004). Scrub and woodland edge are indicated by Moehringia trinervia (threenerved sandwort) (Greig, 1994:14) and Dipsacaceae indet (teasel).

Woodland beetles indicate a reduced species set, and are limited to Dorytomus cf. longimanus (often on willow) and Agathidium spp., which is saproxylic on bark fungus and tree stumps of various species. Woodland beetle MNI is low (ones and twos), therefore the percentages indicated as woodland species in Fig. 8-19 may overstate the case.

By the end of this phase, pine and birch had diminished markedly; this is reflected in the plant remains.

\subsubsection{Open water/waterside}

Still or slow moving watery conditions were an ongoing component of the environmental mosaic, indicated by plant species such as Alisma plantago-aquatica (water-plantain), Typha, Juncus effusus (soft-rush), and Carex, all of which occur in waterside/wet mud/damp conditions rather than open water. The single Chara oospore in the plant remains may be out of place. Some Daphnia ephippia and several Foraminifera (single celled, amoeba-type organisms which reflect non-acidic, brackish 
conditions) complete the set. Gradual terrestrialisation is reflected by the beetles, with a predominance of species requiring stagnant pools and damp waterside-Hydraena testacea, Agonum gracile, Cercyon sternalis (fen ponds), Ochthebius spp. Donacia marginata indicates a range of water-plants including Typha. The rotting detritus that forms an essential element of waterside and fen is suggested by Corylophus crassidoides, Tachinus spp. and Orthoperus spp. Several taxa indicate damp moss Pselaphids Rybaxis spp., Brachygluta spp., Bryaxis curtisii, and Anotylus rugosus - confirming the continued presence of some bog and heath, which is also indicated by a small amount of Sphagnum pollen. Euaesthetus cf. bipunctatus suggests alder-carr and other damp places.

\subsubsection{Damp/dry grassland and meadow}

Grass and herb pollen remain constant at $10 \%$, although values for Poaceae decrease slightly. The plant remains provide evidence for increasingly open, damp/dry grassland - Ranunculus sp. ( $R$. acris/repens/bulbosus meadow/creeping buttercup), L.europaeus and E.cannabium, together with a single seed of cf. Poa annua (annual meadow-grass). Ground disturbance is suggested by rising values for Artemisia in the pollen record and Urtica dioica (nettle) in the plant remains. Nettle colonises nutrient rich soils, and may have benefited from fire disturbance as evidenced by more charred plant remains $(120 \mathrm{~cm})$. Together with alder, nettle creates Alnus-Urtica wet woodland (W6) (Rodwell, 1991a:33) and associated species - Rubus (bramble), Ranunculus repens (creeping buttercup,150cm) and poisonous Solanum dulcamara (woody nightshade or bittersweet, $120 \mathrm{~cm}$ ) - are all present in the plant assemblage. Coleoptera are few and grassland species are limited to a small number of clover weevils (Sitona spp.). Ericaceae supplies a small amount of pollen, indicating some continuation of heath-like conditions.

\subsubsection{150-120cm Summary}

By BNP-05 (circa 7100-6300BP), the period of greatest arboreal variety and density was over. The environmental mosaic prevailing at this time continued to blend wet woodland with some open water, reed-bed, drier grassland and possibly some heath. This mixed landscape may have been more attractive to people than the monolithic woodland at other locations such as Crose Mere and King's Pool, as suggested by the charred plant remains locally and by Mesolithic activity along the Upper Perry (Chapter 6). 


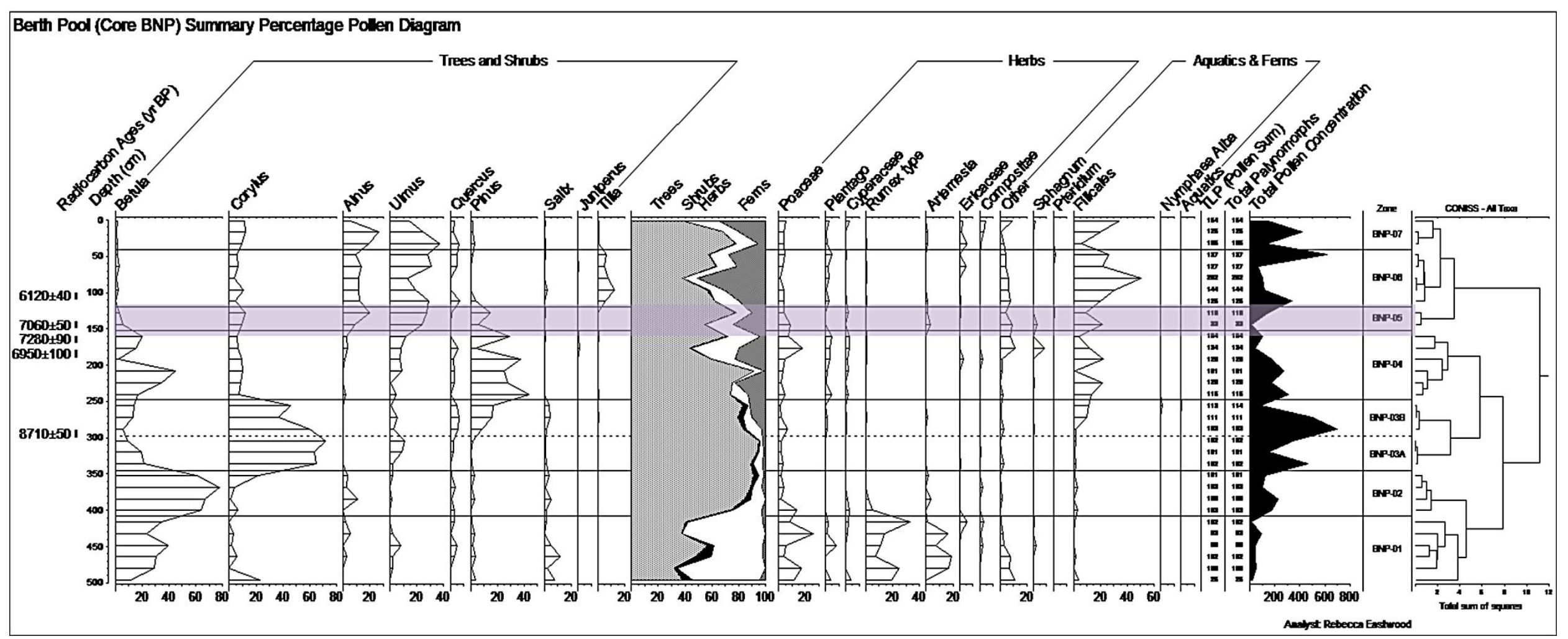

Fig. 8-17 BNP-05 -150-120cm- Pollen 

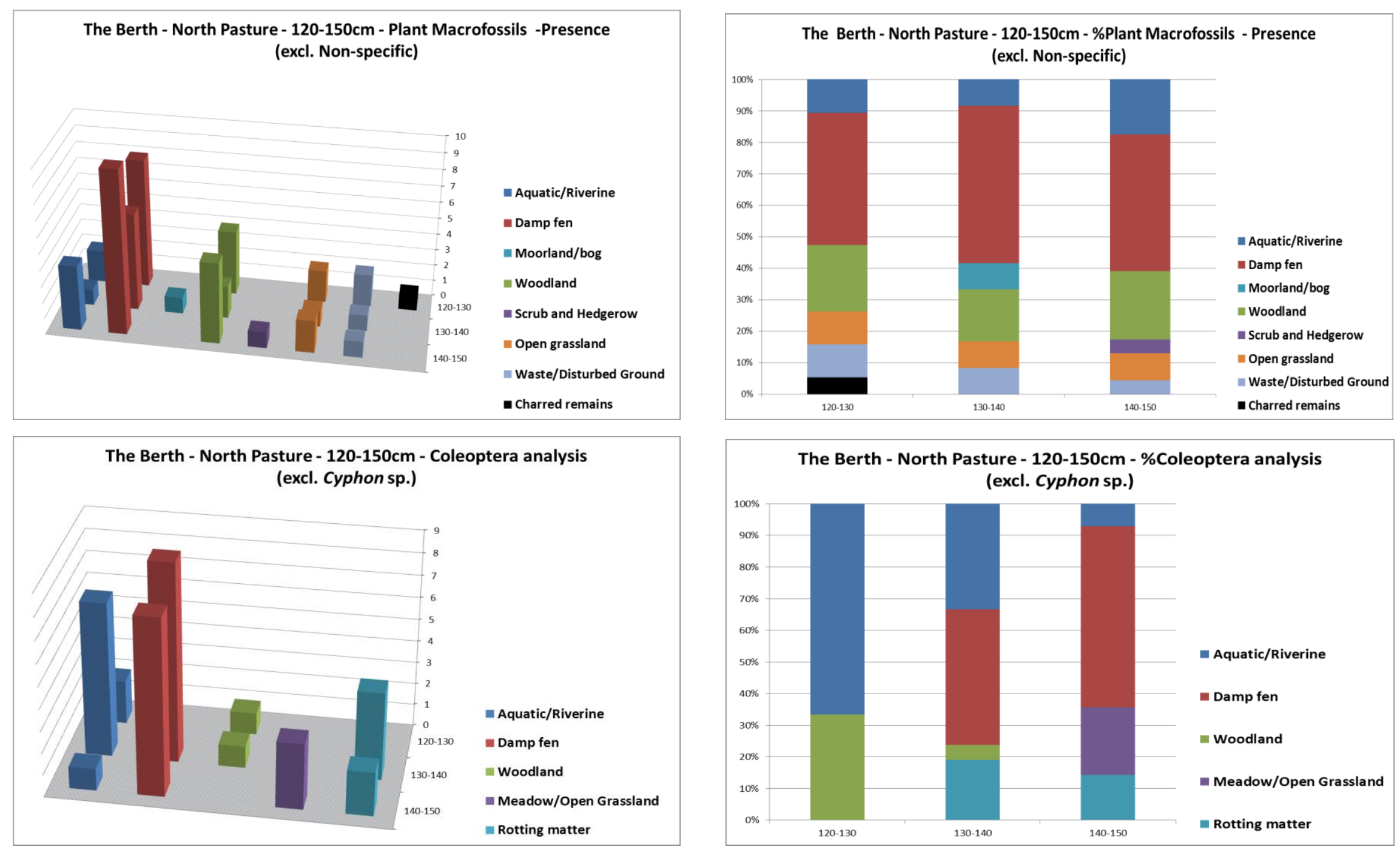

Fig. 8-18 BNP-05 150-120cm - Plant macrofossil and Coleoptera 


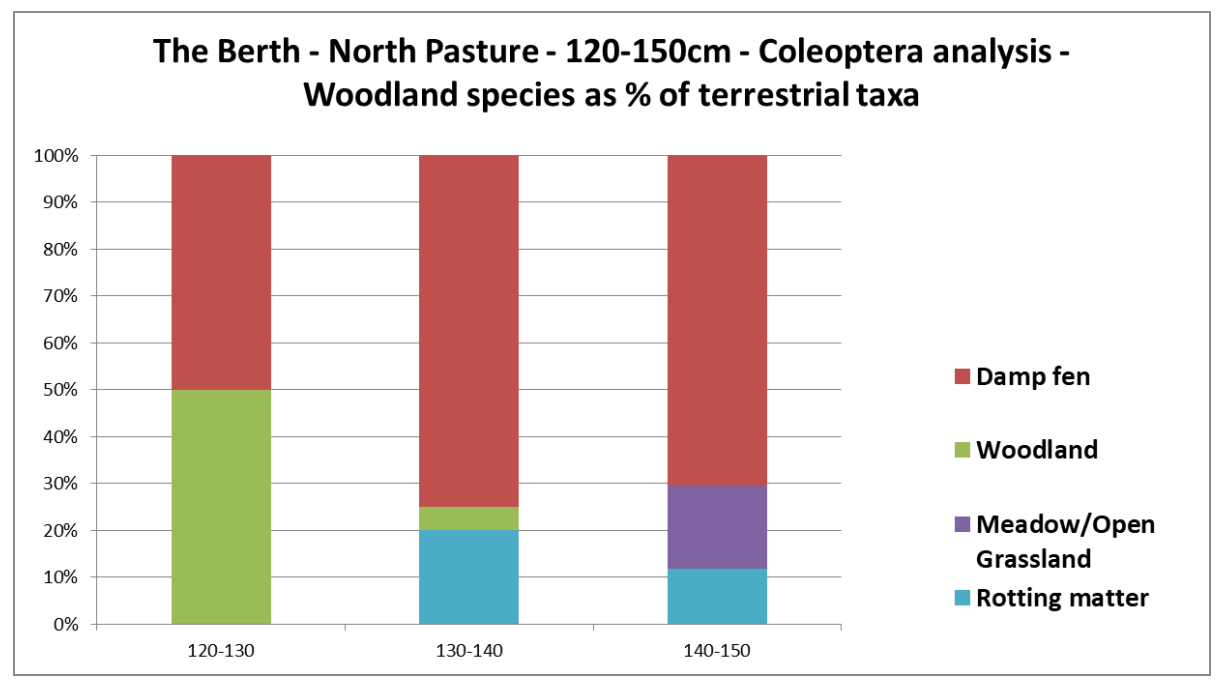

Fig. 8-19 The Berth $120-150 \mathrm{~cm}$ Woodland Coleoptera expressed as percentages of terrestrial taxa

\subsubsection{BNP 06/07 - 120-0cm - Atlantic/Sub Boreal - circa 6300-5000BP (?) (Fig. 8-20; Fig. 8-21)}

The final section of the BNP sequence has been analysed in two parts. BNP-06 $(120-100 \mathrm{~cm})$ was analysed for pollen, plant and beetle remains. However, the sediments showed signs of stratigraphic disturbance with roots through seeds, and plant macrofossil and insect remains were few, hence BNP07 (100 - 0cm) was analysed for pollen only. Hence, the data in BNP-06/07 may be incomplete and are here treated with caution. A radiocarbon date of $6120 \pm 40 \mathrm{BP}(\mathrm{Poz}-77442)$ was returned at $100 \mathrm{~cm}$ and is synchronous with the early elm decline (Parker et al., 2002; Clark and Edwards, 2004).

An uncritical extrapolation of the top $100 \mathrm{~cm}$ of sediment suggests that it encompasses a chronology from the early Neolithic to the present day and assumes a rate of sediment accumulation which slows considerably and/or stops (Fig. 8-3). This is possible, and peat growth can cease if there are changes in drainage, water table, climatic conditions or vegetation; alternatively, the top-most layer of peat, encompassing all or part of the last 5000 years, has eroded or deflated (see Chapter 7). Collectively this suggests that erosion and rather than a cessation of peat growth is the more likely scenario.

\subsubsection{The arboreal landscape}

BNP-06/07 was a period of arboreal fluctuations. Initially, the woodland comprised elm (25\%) and alder (10\%), with some oak (5\%). Lime increased initially and then decreased markedly (10-0\%). Hazel maintained a constant $10 \%$, whilst pine and birch were insignificant. The marked drop in arboreal pollen at $80 \mathrm{~cm}$ was driven by a sharp reduction in elm, and ferns increased accordingly. Values for Ericaceae were higher than previously, whilst at the same time juniper increased. As a primary coloniser, juniper is present in the British Isles from 9500BP. It features sporadically $(<5 \%)$ at the Berth from circa7200BP. 
Ferns, Ericaceae and juniper are intolerant of shade (Thomas et al., 2007), and make a strong case for openings in the forest canopy. The plant macrofossils confirm that alder was plentiful, although Glechoma hederacea (ground ivy) and Fragaria vesca (wild strawberry) also indicate scrub and the woodland edge. There are no woodland beetle fauna. The pollen sequence ends with decreases in both alder and elm whilst the remaining arboreal taxa maintained their percentages. Charred plant remains were once again present in the plant macrofossil assemblage.

Throughout the BNP sequence, values for oak do not exceed $5 \%$, and notwithstanding some beetle fauna which are obligate on oak, there are no plant remains. Therefore oak may not have been a major component of the Berth's woodland, the eutrophic soils offering better conditions for competitors such as lime and elm (see 8.1.4.1 above) (Bennett, 1989). Lime was a major forest species across southern England by 7500BP, spreading to the Midlands by circa 7000BP (Birks, 1989), and its trajectory throughout the Holocene follows a series of declines and regenerations (Grant et al., 2011). Lime does not grow well on permanently wet soils and fluctuations from circa 7300BP are attributed to the climatic changes of the warm and wet Atlantic period; however, after circa 6000BP declines are considered to be the result of anthropogenic clearance (Grant et al., 2011:400). Looking at data from Crose Mere (Beales, 1980) and the Mid-Shropshire wetlands (Twigger, 1988), Grant et al concluded that the lime decline in North Shropshire (circa 3900-2900BP) was anthropogenic in origin (Grant et al., 2011:400). Notwithstanding the potential unreliability of BNP-06/07, the lime decline at the Berth precedes these events by some margin and its rise and fall during BNP-06/07 may signpost one of the earliest fluctuations, climatic or anthropogenic, in the area. Although lime readily regenerates as coppice when felled, it does not grow well from seed in a canopy environment, and eventually, trees fail (Pigott, 1991:1158). By circa 1700BC, after several cycles of decline and regeneration, lime was virtually absent from the North Shropshire landscape (Twigger and Haslam, 1991:747).

The second major alteration to the forest canopy during the Holocene was the elm decline, the start of which is potentially visible at the Berth. The catastrophic decline of elm populations across the British Isles and parts of northern Europe is a well-documented phenomenon (Parker et al., 2002). In Britain, the mean average date for elm decline, calculated from a total of 139 dates from across Britain is 5036 $\pm 247 \mathrm{BP}$ (Parker et al., 2002:28) and delimits the boundary between the Atlantic and SubBoreal periods; it was rapid, abrupt and without clear regional differences (Parker et al., 2002:9). The causes are debated (e.g. Ten Hove, 1968; Bennett, 1989; Parker et al., 2002; Clark and Edwards, 2004) and variously attributed to climatic change (towards more continental conditions), anthropogenic clearance 
of woodland, and disease (attack by the ascomycete fungus Ophiostoma (Ceratocystis) ulmi (Buisman) with Scolytus scolytus as the vector (Girling and Greig, 1985; Parker et al., 2002:21)). The decline at Crose Mere is dated 5296 $\pm 150 \mathrm{BP}$ (Q-1235), fragmenting the canopy and allowing a rise in ash trees; the accompanying low levels of cereal crops (Cerealia) have been interpreted as early agriculture (Beales, 1980:152). At the Berth, the elm population fell from a high of $35 \%$ at $40 \mathrm{~cm}$ to $10 \%$ by the end of the Berth's sequence, suggesting a decline in elm from circa 5000BP, consistent with the regional and national pattern.

\subsubsection{Grassland and open water}

Despite the fluctuations in arboreal pollen, non-arboreal pollen maintains a constant $15 \%$, with species including Poaceae, Plantago, Rumex and Artemisia, some Asteraceae (Compositae) and Ericaceae.

Plantago sp. is a regular presence throughout the BNP15 sequence. This wide genus colonises disturbed, open ground, and P.lanceolata (ribwort plantain) is particularly linked with anthropogenic activity (Edwards, 1979:256; 1999; Behre, 1981:229); it was recorded at Crose Mere alongside slight evidence for cereal crops (see above). However, the Plantago species identified in the macrofossils at the Berth are Plantago major (greater plantain) $(290 \mathrm{~cm} ; 100 \mathrm{~cm})$ and P. cf. media $(170 \mathrm{~cm})$, neither of which suggest anything other than damp disturbed ground, and there is no evidence for agriculture at the Berth (agricultural weeds or Cerealia pollen) throughout the prehistoric sequences.

Others within the plant macrofossil assemblage requiring a damp habitat include cf. Thyselium palustre (milk parsley) and E. cannabium. More aquatic conditions are suggested by Ranunculus cf. aqualitis (common water crowfoot), Sagittaria/Alisma, and Sparganium cf. erectum (branched bur-reed). Carex is ever-present. The (very few) beetle fauna confirm the damp setting - Ceutorhyncus spp., cf. Sitona spp., Cyphon spp. and Aquatic Cercyon spp. The environment suggested by these species is one of peaty pools; there was also a single Chara sp. oospore, and a small number of Foraminifera.

\subsubsection{120-100cm Summary}

As the BNP sequence ended, stands of alder-carr interspersed with damp/dry grassland and peaty pools were firmly established as the predominant floral community across the Berth's peat basin. The pollen record provides evidence for declines in both elm and lime, both of which reflect the regional and national pattern. Charred plant remains were a frequent occurrence at this time. 


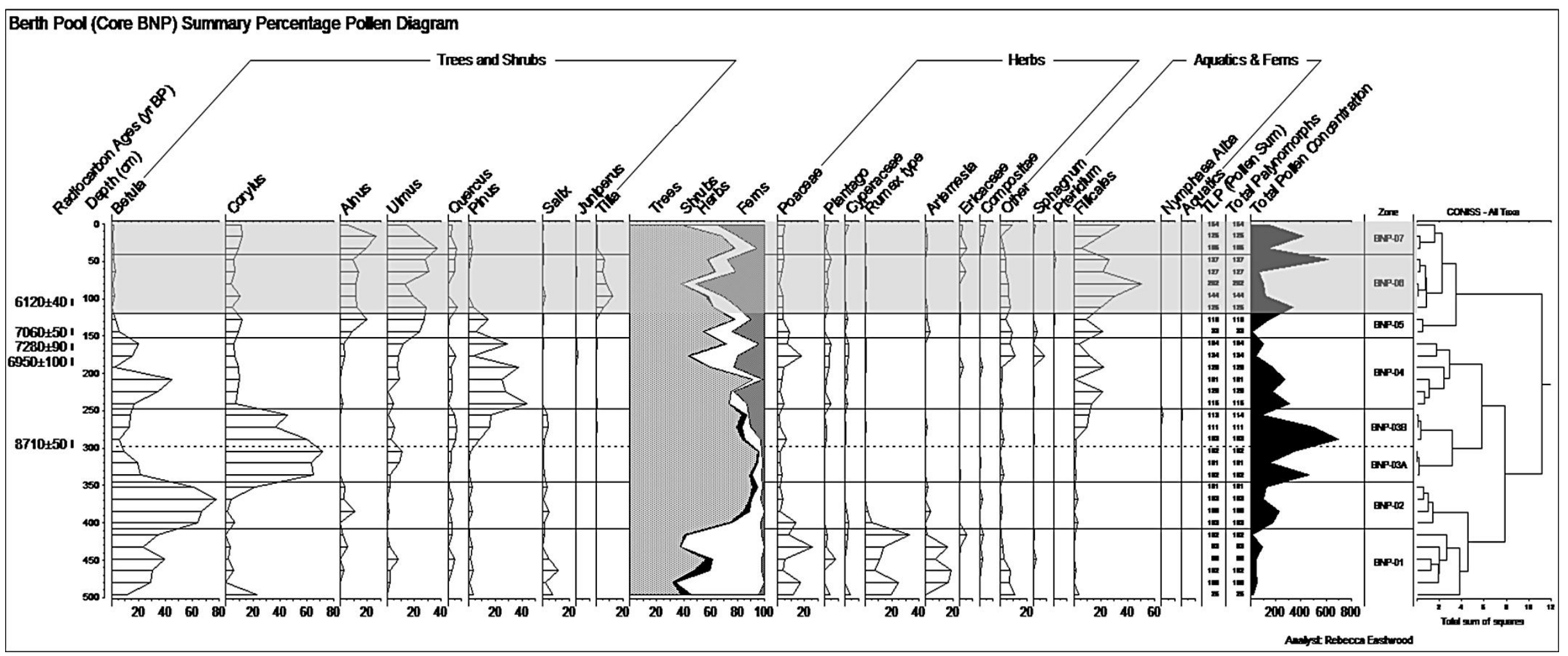

Fig. 8-20 BNP-06/07-120-0cm -Pollen 

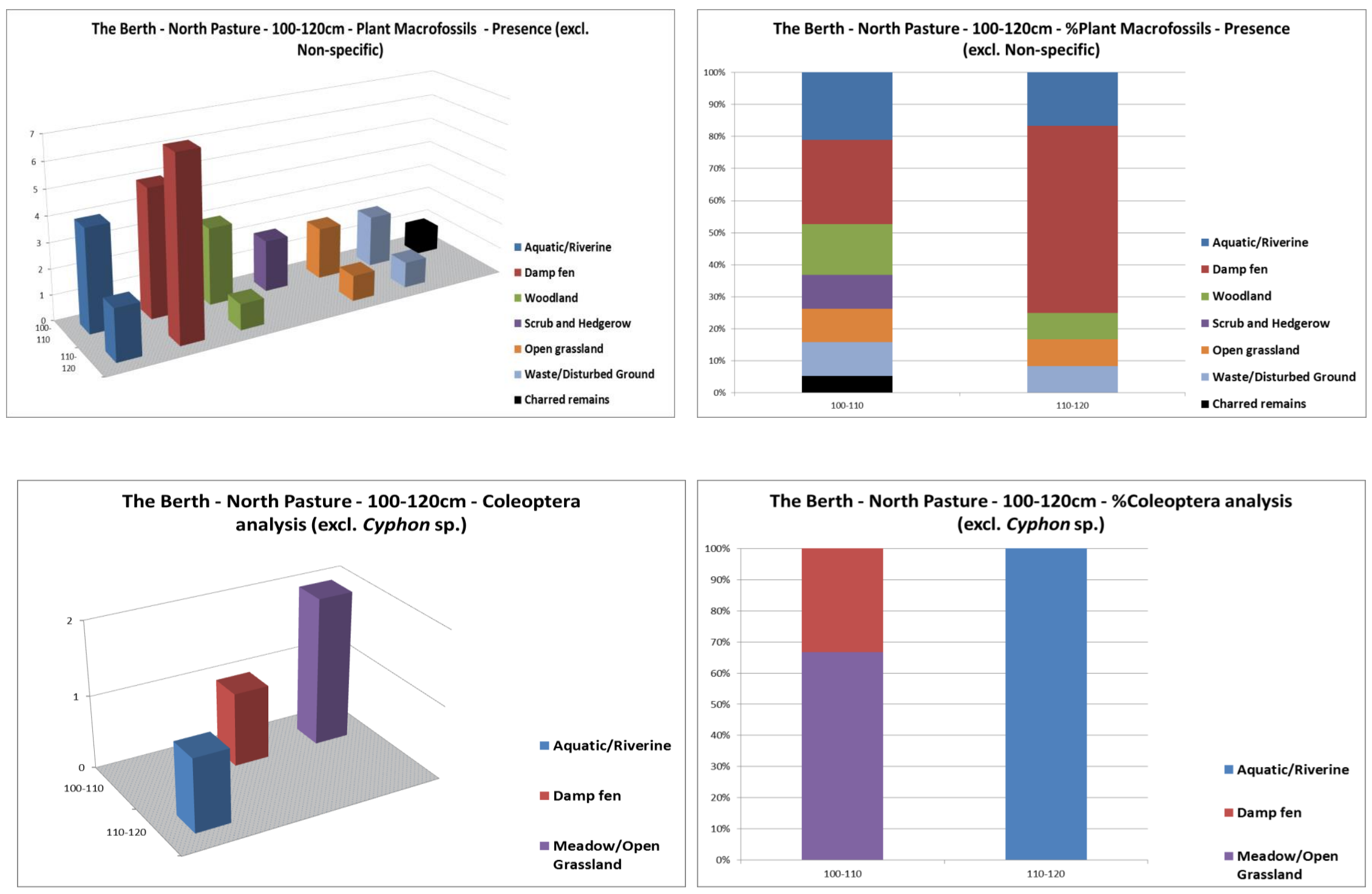

Fig. 8-21 BNP-06 120-100cm Plant macrofossil and Coleoptera 


\subsubsection{BNP15 - summary; human impact during the early Holocene}

Over a period of circa 8000 years, BNP15's palaeoenvironmental sequence illustrates post-glacial colonisation by primary species (birch, hazel and pine), the emergence of dense-canopy, mixed woodland, gradual terrestrialisation of open water and the development of alder-carr wetland; open grassland rarely exceeded $15 \%$ throughout.

Charred plant remains are present throughout BNP15 at the following levels (see also Table 8-3):

\begin{tabular}{|l|l|}
\hline $280-250 \mathrm{~cm}$ & circa $8500-8300 \mathrm{BP}$ \\
\hline $240-210 \mathrm{~cm}$ & circa $8200-7700 \mathrm{BP}$ \\
\hline $200-190 \mathrm{~cm}$ & circa $7500 \mathrm{BP}$ \\
\hline $180-160 \mathrm{~cm}$ & circa $7400 \mathrm{BP}$ \\
\hline $130-120 \mathrm{~cm}$ & circa $7000 \mathrm{BP}$ \\
\hline $110-100 \mathrm{~cm}$ & circa $6000 \mathrm{BP}$ \\
\hline
\end{tabular}

These remains are broadly synchronous with reductions in arboreal pollen between $280-250 \mathrm{~cm}$ and at $175 \mathrm{~cm}$, especially pine; charred remains at $100 \mathrm{~cm}$ are temporally close to declines in elm, alder and oak around $80 \mathrm{~cm}$. Evidence for plants which take advantage of disturbed ground such as Rumex and Plantago sp. is apparent throughout the pollen assemblage. Collectively, this evidence may suggest deliberate burning of the ecosystem around the Berth by Mesolithic hunter-gatherers.

The relationship between people and the environment during the British Mesolithic was dynamic, complex and sophisticated. From circa 8500BP, burning was used to clear forest and reed-swamp, providing access for both people and animals and optimising both hunting and foraging strategies (Innes et al., 2011). This was originally thought to be small scale (Elias, 2010a), although recent summaries of pollen and beetle evidence have concluded that the degree of environmental manipulation was considerable (Whitehouse and Smith, 2004; Smith and Whitehouse, 2005).

Not all charred remains represent acts of deliberate environmental manipulation. Fires can occur naturally through lightning strikes, especially around flammable pine. However, alder-oak forest is likely to be fire tolerant (Tinner et al., 1999:273), and according to Rackham '(British) native woods will not burn' (2004:69). Fires can also be set accidentally, for example, from cooking (Chambers et al., 1996). But opinion suggests that many instances of burning noted in the palaeoenvironmental record indicate Mesolithic impact (e.g. Simmons and Innes, 1981; 1987). For example, at the emblematic Mesolithic site of Star Carr, microscopic charcoal/'soot' coincided with local vegetational disturbance and the 
expansion of alder (Cloutman, 1988), and at Bonfield Gill, North Yorkshire, regular burning of the vegetation took place both locally and regionally throughout the Atlantic period, ending at the elm decline (Simmons and Innes, 1981).

'With regard to the Later Mesolithic (of northern England).........we suggest that the pollen and charcoal evidence of mid-Holocene woodland disturbance may represent deliberate management of parts of ecosystems to maximize resource potential, probably as part of a conscious economic strategy' (Simmons and Innes, 1987:397).

Charred plant remains occur in early Holocene deposits across the North Shropshire wetlands. At Wolfshead Moss, $6 \mathrm{~km}$ from the Berth, 'a prominent band of charcoal of Mesolithic age' is linked with a decline in pine, a rise in alder and a dip in arboreal pollen (Leah et al., 1998:170). Charred plant remains were identified on the Weald Moors circa 9210 $\pm 40 \mathrm{BP}$ (Beta-341619; Norton, 2016), and charring is evident throughout the sequence at Top Moss (Leah et al., 1998:175 et seq). Conversely, although Crose Mere appears to be a suitably resource-rich area which could have attracted Mesolithic huntergatherers, no charred remains are recorded and the surroundings remained densely wooded until more widespread clearance occurred in the Neolithic, suggesting that areas for clearance were carefully selected rather than random. Whilst the case for environmental manipulation at the Berth during the Mesolithic is not conclusive, it becomes more convincing when linked to the local lithics evidence, for example along the Upper Perry and at Grinshill (see Chapter 6). 


\subsection{Berth Main Causeway - 3BBMC16 (Kang, 2017)}

The second set of samples which contribute to the Berth's environmental reconstruction were selected from the pasture east of Berth Main Causeway, $3 \mathrm{~m}$ east of the north-south causeway and $10 \mathrm{~m}$ south of Berth Stream (3MBBMC16). Samples were taken from peat deposits at depths of 130$140 \mathrm{~cm}, 150-160 \mathrm{~cm}$, and $170-180 \mathrm{~cm}$ and analysed for plant macrofossil and Coleopteran remains (Kang, 2017) (NB. Palynological analysis is pending). Sample selection and processing is described in Chapter 3; the stratigraphy is discussed in Chapter 7 and shown in Fig. 8-22. No taphonomic notes are available. The wood samples selected for radiocarbon dating returned an Early Bronze Age date

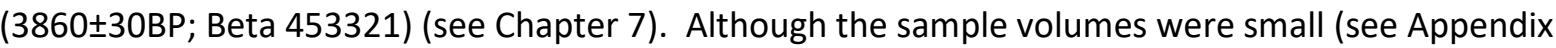
6), the results obtained from each proxy were consistent. The Coleopteran assemblage provided 71 MNI of which 58 (81\%) were allocated to a simplified set of habitat groupings (see Fig. 8-23). Appendix 7 provides a full species list.

In the earliest part of the sequence $(180-170 \mathrm{~cm})$, alder and birch dominate the plant macrofossil evidence indicating wet alder-carr woodland; supporting evidence also comes from lower strata plants (Caltha palustris (marsh marigold), Alisma gramineum (water plantain) and E.cannabium). There is little beetle evidence to confirm woodland (Cantharis spp. - one sclerite). In the second sample $(160-150 \mathrm{~cm})$, woodland decreased but alder continued to dominate, and was accompanied by llex (holly) and infrequent birch. In the later sample $(130-140 \mathrm{~cm})$, there is evidence for some ash and possibly oak; alder reduced and birch was eradicated, suggesting that the woodland was more mixed and the landscape became drier; scrub/hedgerow is suggested by Rubus sp. (blackberry/raspberry) although these species are generally non-specific. Mixed woodland was also reflected in the beetle assemblage, with species including Agelastica alni (on alder), Grynobius planus and Rhyncolus chloropus/ater (both on decaying wood) and Throscus sp. Grassland plants (Poaceae sp. and various Asteraceae) were indicated by the chafer, Phyllopertha horticola. This meadowland pest lives on the leaves of deciduous trees as an adult, but in its larval stages, it lives on the roots of cereal, grass and clover (e.g. Hann et al., 2015). There are no dung beetles to suggest that the area was grazed.

In addition to woodland, an ecosystem of pools and reed-bed is reflected throughout all three samples, indicated by M. trifoliata (bogbean) and Potamogeton sp., with abundant Carex. This environment is further confirmed by the beetles Noterus clavicornis (inhabiting ditches and ponds), Limnobaris pilistriata (on sedge), Oodes gracilis and Chaetarthria seminulum (both inhabiting water's edge vegetation), Donacia sp. and numerous Helodidae (marsh beetles). The presence of Donacia 
crassipes may indicate open water (it is frequently associated with white waterlily) although this species can be found in other watery habitats.

These samples pick up the environmental narrative from the BNP15 sequence after a gap of around 1200 years. The earlier samples $(180-170 \mathrm{~cm} ; 160-150 \mathrm{~cm})$ continue to reflect the mosaic of damp deciduous woodland dominated by alder-carr and reed-bed, seen in BNP-06/07. Later, perhaps by the Middle Bronze Age (130-140 cm), grassland increased, alder-carr decreased and woodland became more mixed, which could suggest an environment subject to (periodic) clearance. This would be consistent with results from Crose Mere, where the equivalent chronozone (CMCP8; $3714 \pm 129 \mathrm{BP}$ ) indicates a substantial fall in arboreal pollen, rises in grassland species and an opening of the fen-carr environment (Beales, 1980:152); Beales considered this to the first of several clearance phases and one of the earliest in north-west England (Beales, 1980:156). 


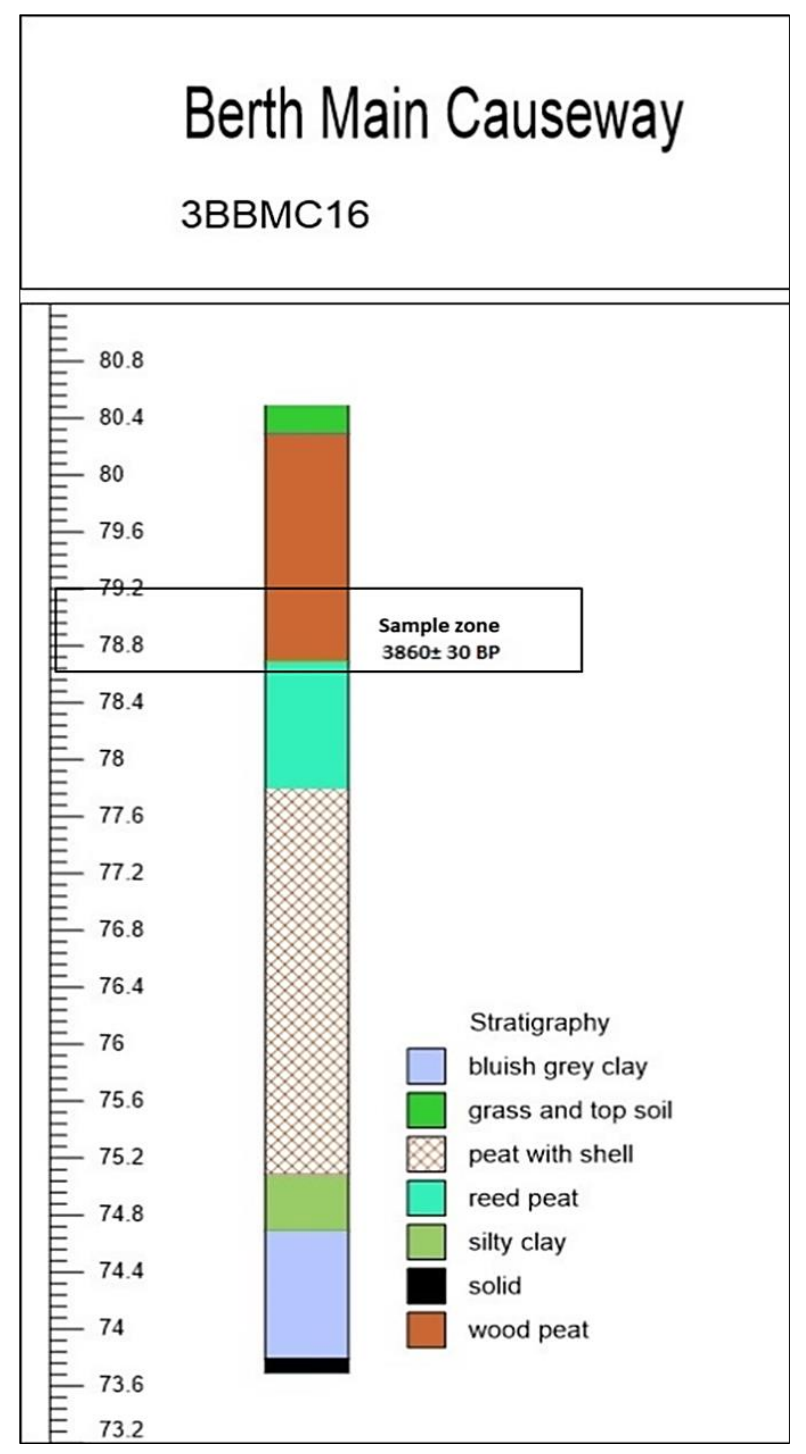

Fig. 8-22 3BBMC16 - Stratigraphy and dating

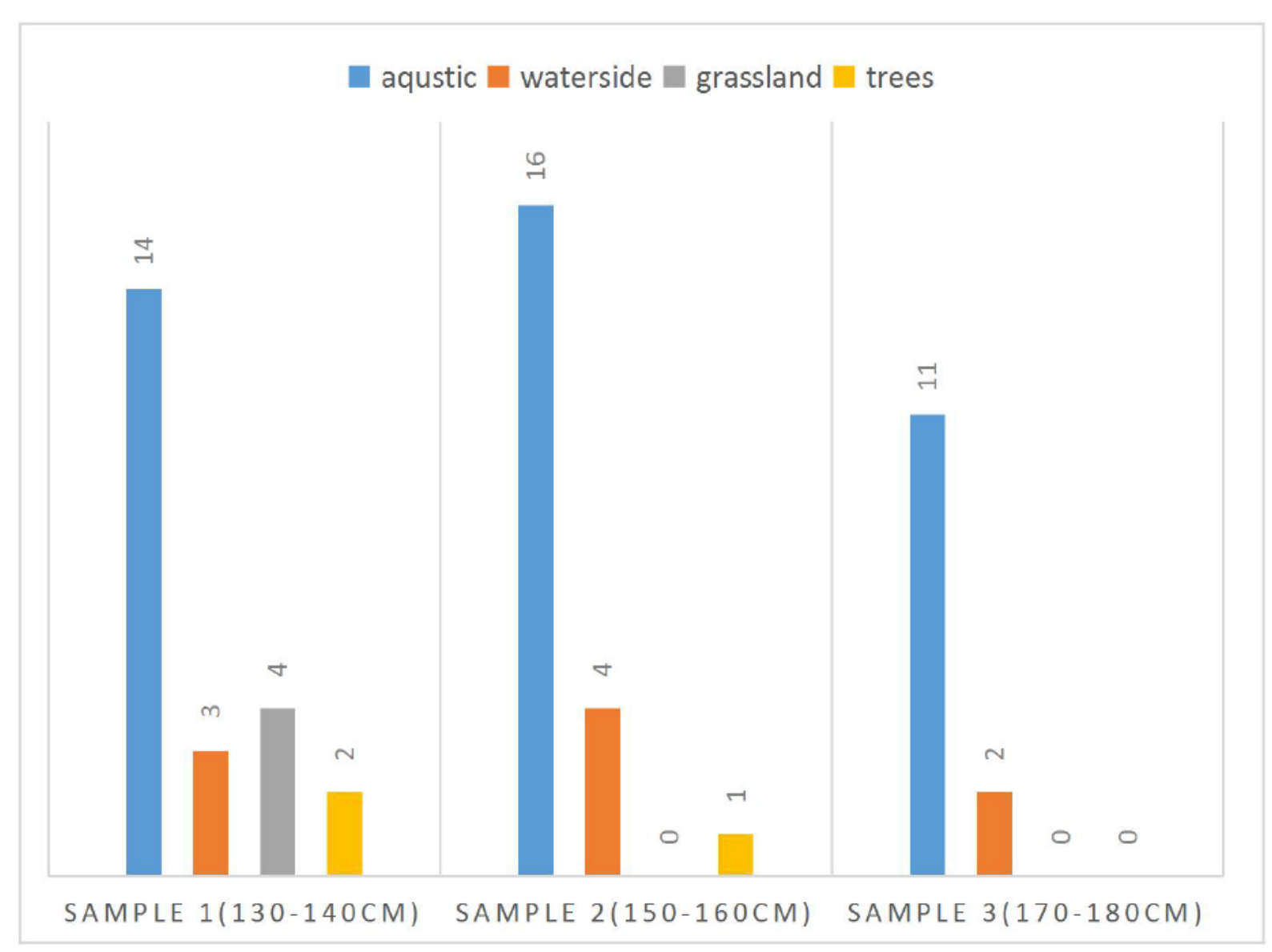

Fig. 8-23 3BBMC16 - Coleoptera - habitat groupings (Kang, 2017: Table 6) 


\subsection{Berth Excavation 2016 - Trench 1 - 0-20cm (Fig. 8-24)}

Excavations to establish the provenance of the Berth's causeways were undertaken during 2016 (Chapman, Smith and Norton, 2017) (see Chapters 3, 6 and 7), and provided material for plant macrofossil and Coleopteran analysis. Organic sediments comprising silty peat, with fine grey sand and some stones, were recovered from the interface of the causeway stone with the underlying peat, at depths of $0-10 \mathrm{~cm}$ and $10-20 \mathrm{~cm}$. Given their positioning beneath a built structure, it is uncertain whether these assemblages are archaeological or natural.

In Trench 1, the causeway stone had fossilised the underlying sediments and preservation was generally good. Seeds were whole and unabraded although Coleoptera were fragmented. However, although the construction was similar in the east-west causeway, Trench 2 returned no organic material except for some charred plant remains; this may be the result of the drainage pattern and consequent erosion across Berth North Pasture (see 7.3). Preservation was poor in Trench 3 where the causeway was more ephemeral, and only robust seeds, such as Sambucus nigra (elder), and fragmented Coleoptera survived.

Two radiocarbon dates were obtained from charred wood taken from Trench 1 (Larch (Larix sp.);

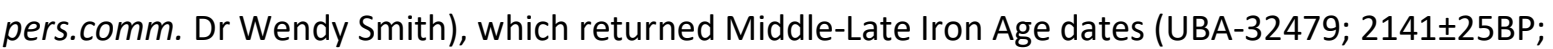
351-61 cal BC and UBA-32480; 2266 $\pm 30 B P ; 398-210 \mathrm{cal} \mathrm{BC).} \mathrm{Analysis} \mathrm{of} \mathrm{these} \mathrm{deposits} \mathrm{therefore}$ reflects the ecological environment which prevailed at the time of the Berth's occupation but raises anomalies regarding the contemporaneity of the stone structures and the underlying surface (see 7.3 and 7.5).

Trench 1 was the only deposit to return both viable organic samples and a reliable radiocarbon date, and these results form the third dataset presented in this thesis. The samples did not yield large quantities of remains and although layers $0-10 \mathrm{~cm}$ and $10-20 \mathrm{~cm}$ were processed and analysed separately, they are considered here as a single unit with any differences highlighted. The Coleopteran remains produced 58 sclerites in the upper sample $(0-10 \mathrm{~cm})$ and 83 sclerites in the lower sample $(10-20 \mathrm{~cm})$, of which $91 \%$ and $83 \%$ respectively were allocated to a habitat group.

\subsubsection{The arboreal landscape/damp fen}

The plant remains produced large quantities of alder (seeds and catkins), some willow and wood sorrel (Oxalis acetosella). The Coleoptera are less precise and simply reflect shady wet ground (Pterostichus nigrita, P. strenuous and Orthoperus cf. brunnipes), although Throscus sp. (one sclerite) suggests a more heavily wooded environment. There are also indications of scrub and hedgerow in the form of bramble (Rubus sp.) and common elder (Sambucus nigra) (Atkinson and Atkinson, 2002) 
which is linked with disturbed ground and, tentatively, with human habitation (Godwin, 1975:336; Twigger, 1988:225). When combined with nettle (see below), these species are typical of the Alnus glutinosa- Urtica dioica woodland community W6/ Sambucus nigra sub-community W6d (Rodwell, 1991a: 91-101), which suggests a species-poor habitat of closed-canopy, multi-stemmed trees on eutrophic moist-to-wet soils. It also represents a seral development from a wetter Salix-BetulaPhragmites woodland (Rodwell, 1991a:96) - in other words, the environment had become drier. It is reasonable to conclude that alder-carr and scrub were close to the Berth at the time of its occupation with denser woodland at a distance.

Charred plant remains (wood, not seeds) were present in the assemblage, which, given the damp nature of the surrounding terrain and the proximity of the Berth fortifications, is quite likely to relate to human activity. As alder is known to produce charcoal of high quality (McVean, 1953:465), charred wood may be connected with on-site metalworking and two (possible) crucibles were recovered by the Gelling excavation (Appendix 2).

\subsubsection{Open water/marginal plants}

Plant species which inhabit still, open water (Lemna sp. (duckweed), Potamogeton (pondweed) and Z.palustris (horned pondweed)) were present in the assemblage suggesting that Berth Pool was more extensive and closer to the causeways than in modern times. A zone of tall reed-bed is suggested by Glyceria sp. and abundant Carex sp. Cladium mariscus is present but limited to one seed; this taxon, super-abundant earlier in the Berth's environs, is shade intolerant (Conway, 1942) and this sparse evidence suggests that the species retained a slim presence as bush and scrub took over. The reed-bed is further reinforced by the beetle remains. Plateumaris braccata and Donacia clavipes are both monophagous on P. australis (common reed, although P.australis was absent from the plant macrofossils). The Erirhinid Notaris acridulus suggests that Glyceria found in the plant macrofossils is G. maxima (reed sweet-grass). Lower strata marginal plants include Rorippa sp. (yellow-cress) and Nasturtium officionale (water-cress), both of which provide a habitat for the Chrysomelid Phaedon cochlearidae. The interface between the reed-bed and more extensive areas of sedge is reinforced by the ground beetle, Blethisa multipunctata.

The remaining aquatic/waterside Coleoptera indicate the still, slow moving, muddy waters of damp fen, marsh and riverbank. Species include Cymbiodyta marginella, Coelostoma orbiculare, Agabus sp. (aquatic) and Dryops sp. (Foster and Friday, 2011; Foster et al., 2014). Water-scavenger beetles (Helophorideae - five sclerites) are consistent with ephemeral pools and short lived ponds/puddles, as are Hydroporus sp. (Foster and Friday, 2011; Foster et al., 2014). Hydroporus melanarius is the only beetle to suggest a bog/heathland environment and is associated with Eriophorum sp. (cotton 
grass) and Sphagnum moss, which obviously clung on in some areas. The only Elmid beetle in this assemblage - Oulimnius spp. - is tolerant of slower moving water (Smith, 2000; Greenwood and Smith, 2005:60; Elliott, 2008).

Slightly drier ground is indicated by plant remains such as Ranunculus Subgen. Batrachium (water crowfoot), R. sceleratus (celery leaved buttercup), Hydrocotyle vulgaris (marsh pennywort), Oenanthe crocata (hemlock water-dropwort), Apium graveolens (wild celery, which also tolerates brackish waters), Cicuta virosa (cowbane) and Juncus (effusus-type) (common or soft rush). However, Eupatorium cannabium and Lycopus europaeus, present throughout the Holocene sequence until the Early Bronze Age, were absent from this chronology. The causes may be legion, however, grazing may have played a part.

\subsubsection{Damp and dry grassland}

More open, drier grassland is signified by a range of plant taxa, for example, Poaceae sp., Aphanes arvensis (parsley-piert, sometimes related to crops and cultivation (Greig, 1994:8)), Persicaria lapathifolia (pale persicaria) and Polygonum aviculare (knotgrass). Disturbed, nutrient-rich ground is represented by plentiful Urtica dioica (common nettle) and Hyoscyamus niger (henbane). Nettle frequently invades areas of bare, eutrophic ground caused by overgrazing, poaching, stock feeding, and fires (Natural England, 2007), whilst henbane has been linked with ground manured by cattle (Stace, 2010:573). Species typical of heath and moorland are confined to one possible seed from Myrica gale (bog myrtle) and several Linum catharticum (fairy flax); the latter species is also a weed associated with calcareous grassland (Wheeler, 1980; Ciaraldi, 2009:257).

Drier, more open land (grassland or meadow) is confirmed by the scarab beetles Phyllopertha horticola (see 3BBMC16 above) and Hoplia philanthus. Species which feed on cruciferous plants include Chaetocnema concinna which feeds on P. aviculare (see above) and grassland is further evidenced by Apion sp. (weevils, many of which feed on clover), Mecinus pyraster and Alophus triguttatus. Elateridae (Click beetles) are represented by one sclerite - Ctenicera pectinicornis; the larvae feed on roots in grassland and it is one of two species (the other being Xylodromus concinnus, see 8.3.4) which imply the presence of hay meadow. Nedyus quadrimaculatus reinforces the presence of nettle. A number of Staphilinids (Phylodrepa sp., Anotylus complanatus and Philonthus sp.) indicate rotting vegetation.

A range of dung beetles confirm that the area was used as pasture by grazing herbivores. Aphodius sp. are found on most cow-pats (e.g. Osborne, 1988:724) and up to 100 individuals can be present on one dropping (Robinson, 1983:31). Several different species can occupy the same ground, and are represented here by $A$. fimentarius and $A$. prodromus, albeit that the latter is known from rotting 
plant matter as well as dung (Kenward, 1978:31). Geotrupes spp. (one sclerite) is restricted to the dung of large herbivores (Robinson, 1983:30). Cercyon impressus and Megasternum concinnum have similar habits.

There is no evidence for cereal or arable crops.

\subsubsection{Human habitation}

Significantly, the Coleopteran assemblage includes taxa which are often associated with human habitation, specifically Ptinus fur (one sclerite) and Anobium punctatum. The 'spider beetle' $P$. fur is found in the decaying, mouldy vegetation or waste associated both directly and indirectly with buildings (Koch , 1992; e.g. Kenward and Hall, 1995), and Kenward (1997) regards this species as strongly synanthropic. A. punctatum (common woodworm) is mostly known for infesting timbers in human settlement (e.g. Kenward and Large, 1998; Elias, 2010b), although its origins lie in decaying trees in woodlands, and it has been recovered from several natural rather than anthropogenic prehistoric deposits such as the Somerset Levels (Girling, 1985:13). It attacks alder especially when the wood is dry (Girling, 1985:15). X. concinnus (one sclerite - see above) is found in hay stacks, corn mills, straw barns, stalls, and dry, mouldy plant matter, although it can also occur in dry grassland in sheltered places such as hedgerows (Smith, 1998). It is included as a synanthropic species in terms of its usual proximity to human activity (e.g. Smith, 1998; Smith, 2009:270) but may not always be a house dweller (Kenward, 1978:28). Whilst each of these species originates in natural habitats, collectively they reflect a human presence, either in the form of settlement or structures nearby, or the spreading of human detritus and agricultural waste. 

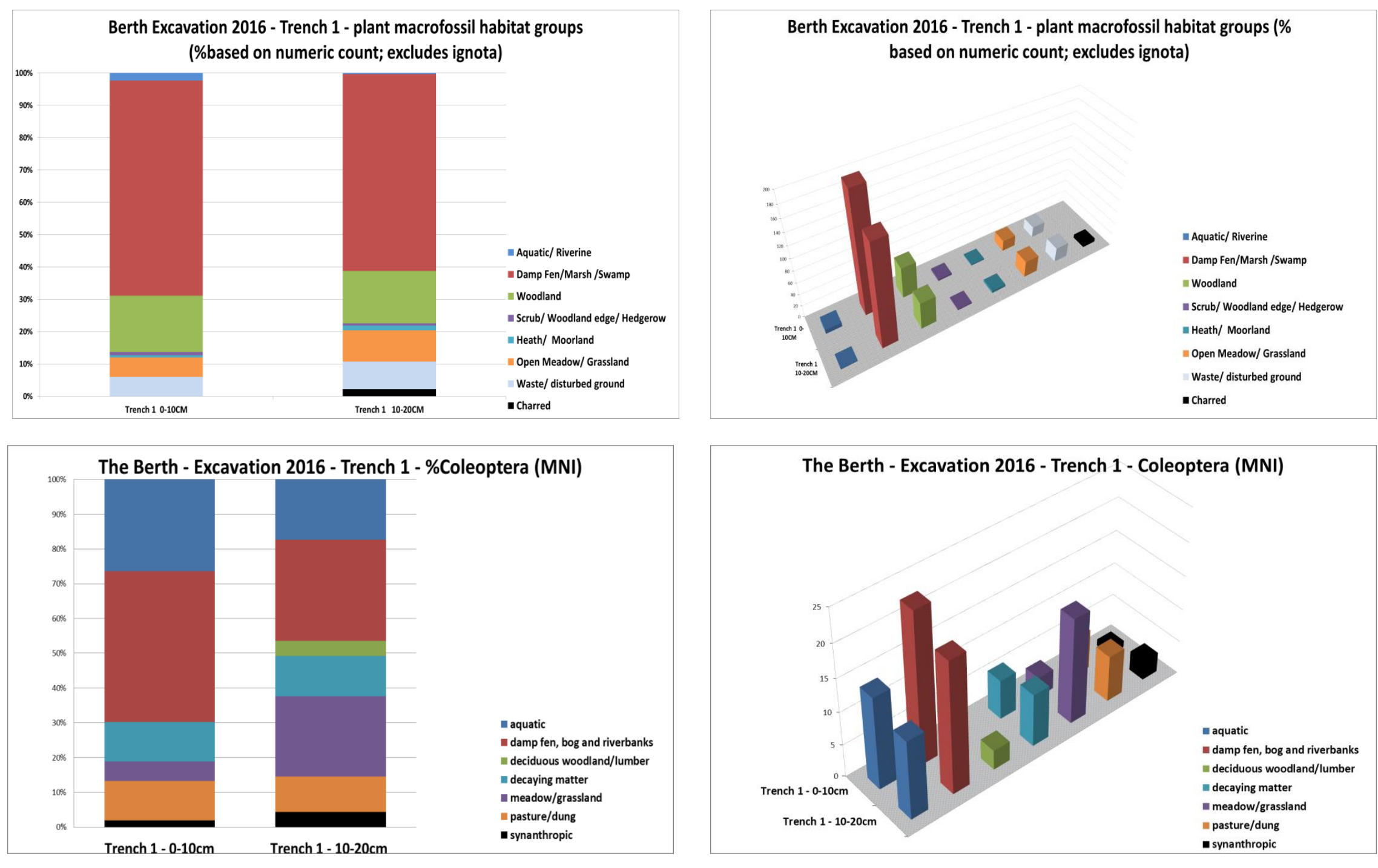

Fig. 8-24 The Berth - plant macrofossil and Coleoptera remains - Trench 1 


\subsubsection{Berth Trench 1 - Summary}

The ecosystem which surrounded the Berth at the time of its usage combined alder-carr woodland with, on the one hand, open or slow-moving water and reed-bed, and on the other, more open damp and dry areas of pasture; there is no evidence for the cultivation of arable crops. Accessing the Berth marsh-fort through this combination of alder, elder, reedy marshy ground and open water would have been difficult and it would have been important to know the safest pathways.

Occupation of the site is not evident from the plant remains; however a human presence is implied by both synanthropic and dung beetles. The small number of beetles associated with human habitation - P. fur, A. punctatum and X. concinnus - are far from being a 'house fauna' (sensu Carrott et al., 1994; Carrott and Kenward, 2001:890), and each can be found in natural deposits. However, each species has adapted to take advantage of the conditions made available by human habitation and land management. They are 'culture-favoured' (Smith et al., 2000), and collectively their presence here implies more than chance inclusion (Kenward and Hall, 1995). X.concinnus is also a possible indicator of hay, as is C.pectinicornis. Hay is normally a crop of low nutrient land with a very specific flora and fauna which are not seen here (Kenward and Hall, 1997; 2000), and as both taxa can be identified with less specific environments, the signature for hay, or for the Berth as a 'mowing meadow', is unproven (Conway, 1942; Rodwell, 1995:S24, Swamp and Tall Fen). Dung beetles are frequently interpreted as synanthropic indicators, as conditions for grazing are largely developed and managed by humans (Kenward, 1997:18). Species favouring dung comprise 16\% of terrestrial fauna, and a tentative calculation made against a modern analogue suggests that the herd size was 'large' or 'dense' (Smith et al., 2010:225).

Both plant and insect proxies indicate that the environment changed during the timespan encompassed by the samples $(0-10 \mathrm{~cm} ; 10-20 \mathrm{~cm}$ ) (see Fig. 8-25). Watery areas increased as open ground and grassland decreased - an indication perhaps of one of several periods of increased wetness around the Middle-Late Iron Age (e.g. Hughes et al., 2000; Barber et al., 2003).

In summary, the environment surrounding the Berth marsh-fort at the time of its usage comprised damp wet fen, with areas of open water, reed-bed and some drier ground used as pasture; access may have required specialist knowledge. Whatever the purpose - (wet) summer grazing for cattle, coppicing, producing charcoal - this was an environment managed by people. 

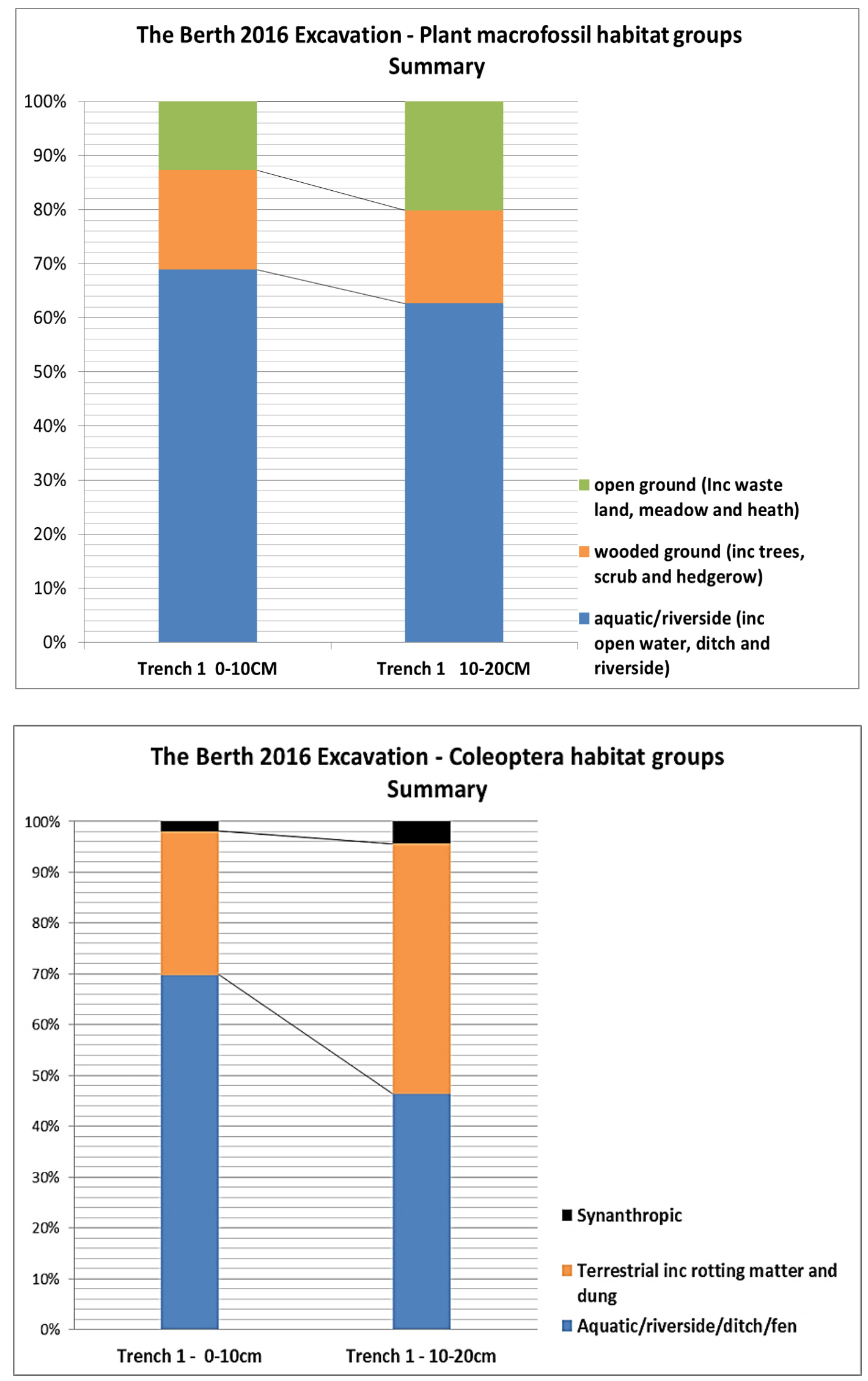

Fig. 8-25 Berth Trench 1 - comparison between plant macrofossil and Coleoptera samples 


\subsection{Berth Pool (Twigger, 1988)}

The datasets summarised so far provide a narrative which runs through the Holocene, concluding with a reconstruction of the environment surrounding the Berth at the time of its occupation. These results are next compared with a palynological analysis of six wetland sites in Mid-Shropshire (Twigger, 1988) - Fenemere, Marton Pool, Birchgrove Pool, Boreatton Moss, New Pool and Berth Pool (see Fig. 8-26) - which chronologically cover circa 5400BP -AD1900 (Fig. 8-27. NB. These dates are expressed as ' $b c$ ', indicating these are uncalibrated 'historical' dates (Renfrew and Bahn, 2000:139); for the purposes of this analysis, they have been converted to dates BP). This palynological sequence fills in some gaps and links together the results presented by BNP15, 3BBMC16 and Berth Excavation 2016, Trench 1.

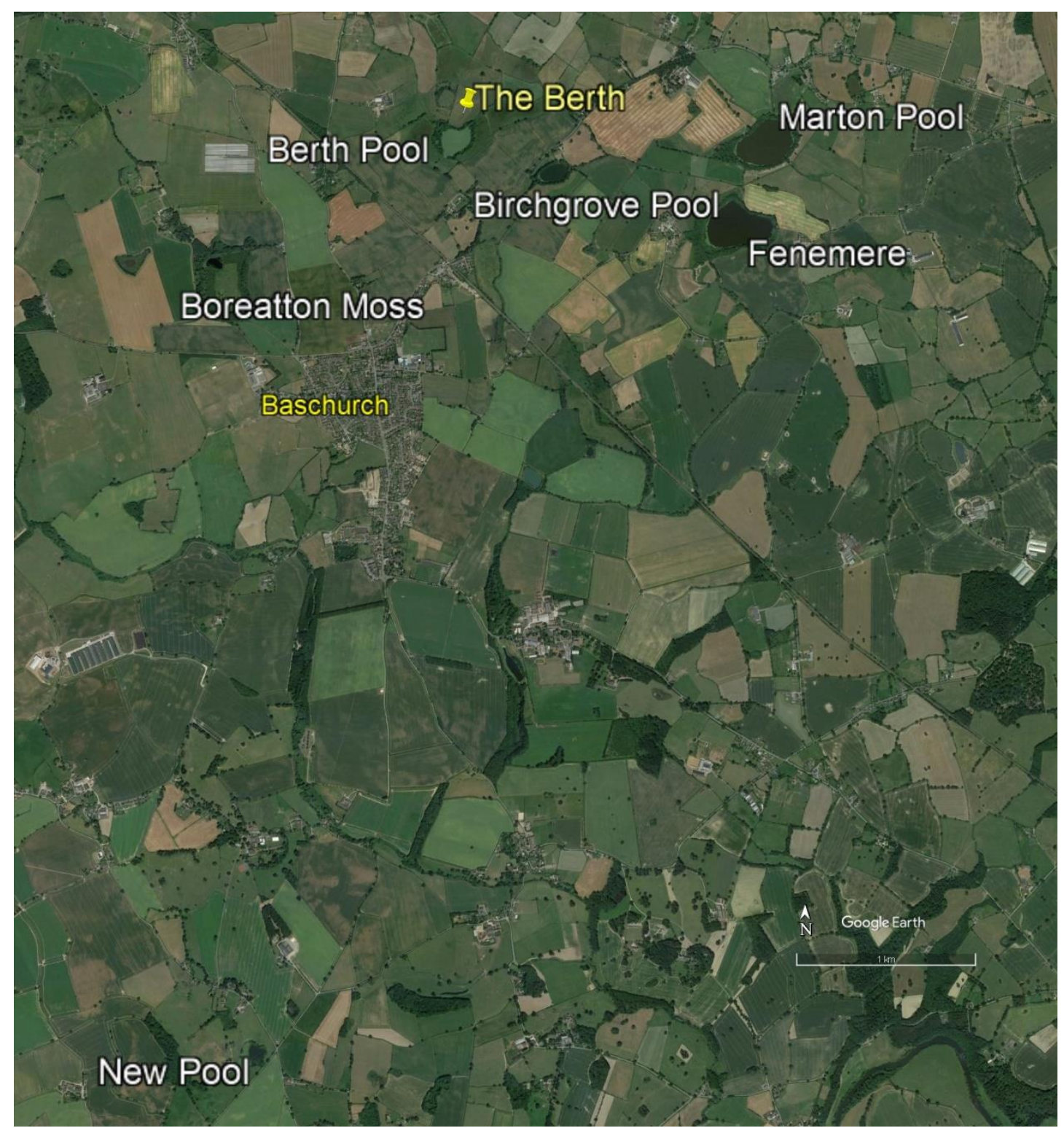

Fig. 8-26 Mid-Shropshire meres investigated by Twigger (Twigger, 1988) (Google Earth; September 2017) 
Twigger summarised his findings across fourteen chronozones (B1-B14). The longest sequence, taken from Berth Pool, spanned circa 4800BP to AD1900 (see Fig. 8-28). Chronozones B2-B10 have been compared with samples 3BBMC16 and Trench 1 and provide a palynological overview of the wider environs around the Berth which complements the analysis from the plant macrofossil and insects. The spatial zones covered by each proxy are discussed below and Twigger concluded that the dominant taxa at Berth Pool came from plants growing within a $150-200 \mathrm{~m}$ radius (Twigger, 1988:357).

During the Late Neolithic to the Middle/Late Bronze Age (B2-B6; circa 4800-3200BP), a dense deciduous woodland surrounded Berth Pool consisting of birch, lime, elm, ash and yew (Taxus) with alder and oak, and a prominent understorey of hazel; pine was sparse. Open areas of grassland (Gramineae/Poaceae) and heath (Ericaceae) were limited. Open water and marginal environments are indicated by, for example, Sparganium/Typha sp. and Nymphaceae. Twigger's chronozone B2/3 equates roughly with the macrofossil analyses for 3BBMC16 (see 8.2) (Kang, 2017). Although the plants and beetles place greater emphasis on alder-carr/open water species and there are inconsistencies in the arboreal taxa, the increase in grassland is mirrored in both analyses.

B2-B6 suggests a landscape of low-level human exploitation and small scale clearances with limited erosion of forest soils around Berth Pool, Fenemere, Birchgrove and Marton Pools (Twigger, 1988). However, Boreatton Moss exhibits a slightly different profile (B5, circa 4000BP). Reductions in elm and lime coincide with increases in grass and herb pollen, the flooding of the moss surface, and a rise in agriculture (Twigger, 1988; Twigger and Haslam, 1991:748). The development of land for early arable farming has been linked with the location of Bronze Age round barrow cemeteries in North Shropshire (Garwood, 2007a), and it is probably no coincidence that the Baschurch barrow cemetery is located near to Boreatton Moss (see Chapter 6).

The ecology around the Berth changed at the beginning of chronozone B7 (Mid-Late Bronze Age circa 3200BP). Whilst arboreal pollen remained roughly constant, grasses increased and alder declined, suggesting an increasingly open environment. This pattern is mirrored at Fenemere, where short-lived reductions in arboreal pollen were accompanied by rises in grasses and herbs; this pattern can also be seen at Whixall Moss (Turner, 1964) and at Crose Mere (Beales, 1980).

A period of dramatic and intensive woodland clearance began circa 2800BP (B8), contemporary with widespread clearance along the Severn and Avon valley catchments and marked by an increase in soil erosion (Shotton, 1978a; Brown and Barber, 1985; Brown, 1990; 1999; Maddy et al., 1995). Twigger and Haslam estimated that around a third of woodland was cleared across North 
Shropshire, increasing to around three-quarters in some localities (Twigger and Haslam, 1991:750). This period also coincides with rampart construction at some early hillforts in the northern Welsh Marches such as the Breiddin (Musson et al., 1991).

Of the meres analysed by Twigger, clearance was most marked at Berth and Birchgrove Pools. At the Berth, all arboreal/shrub species, including hazel, declined; arboreal pollen, a constant $60 \%$ throughout the earlier part of the sequence, fell to $25 \%$ (compared with $40-50 \%$ at Fenemere). Grasses and open habitat indicators represented by P.Ianceolata, Liguliflorae/Cichorioideae (weeds, such as dandelions), and Cruciferae/Brassicaceae (cabbage; cress) increased accordingly. It is tempting to relate this evidence to the first of three phases of human occupation at the Berth (Gelling, 1962/5; Gelling, 1964); however, Morris indicated that the Cheshire briquetage found throughout the Berth's occupation layers (the only datable material) came from a later phase of briquetage distribution (Morris, 1985). Further investigation is required.

B9 (circa 2600-2400BP) saw a resurgence in woodland cover, suggesting a reduction in land use intensity across the area. At Fenemere, whilst grasses and bracken decreased, birch, lime, alder and pine increased although oak continued to decline. This was not uniform, however. Berth and Birchgrove Pools maintained the openness seen in B8 and, significantly, this continued at the Berth (with minor fluctuations) into the post-medieval period.

Successive waves of clearance took place across North Shropshire during chronozone B10, circa 2400-2050BP (Middle-Late Iron Age); for example, at Fenemere, whilst percentages for arboreal pollen fluctuated between $40-50 \%$, herb/heath pollen rose to $30-40 \%$ and included taxa associated with arable or pastoral farming (P.lanceolata and Rumex). The B10 pollen profile from Fenemere correlates with Crose Mere (CMCP8; Beales, 1980) indicating a similarly high level of human activity across the wider area. By the end of this period (immediately preceding the Roman conquest), more than half the woodland in the Baschurch area had been cleared (Twigger and Haslam, 1991:753). The objective of these repeated clearances was the development of agricultural land and the construction of hillforts, settlements and enclosures. Old Oswestry and Bury Walls hillforts were enhanced around this time, and although no radiocarbon dates are available, these elaborations are contemporary with 'developed hillforts' in Wessex (Cunliffe, 2005). However, evidence from the Breiddin is mixed. Rampart construction recommenced and round houses were built circa 300BC (Musson et al., 1991:179-192), demonstrating renewed and intensive human occupation, but the palaeoentomological evidence from Breiddin's Buckbean Pond suggests only a continuance of grazing (Musson et al., 1977; Buckland et al., 2001): 
'Despite the remains of four post structures close to the pond and of roundhouses and associated deposits in the vicinity, both flora and insects indicate a quiet natural pond with little disturbance other than casual grazing by animals. This "evidence of absence" does not square with the archaeological evidence which is here interpreted as deriving from human activity which was neither permanent nor intensive.' (Buckland et al., 2001)

Chronozone B10 corresponds with the macrofossil analysis for Berth Trench 1 (see 8.3). There are no contra-indicators, and the benefits of a multi-proxy approach can be seen in the extra detail provided. Alder, willow and elder are present across all proxies, although oak is present only in the pollen spectrum. Although woodland was allowed to regenerate slightly around Berth Pool (arboreal pollen increased from $18-25 \%$ and is potentially reflected in the macrofossils), tree cover was still less than at other meres. The palynological evidence for cereal production is slight (there is no evidence in the macrofossils) leading Twigger to conclude that land use was predominantly pastoral (Twigger, 1988:274-5); this is supported by the beetle evidence. Although open water and swamp dominate the plant and coleopteran remains, these taxa are predictably limited in the pollen analysis. Analysis of the pottery from Gelling's excavation indicates this as a period of occupation at the Berth (Morris and Gelling, 1991). If accurate (no radiocarbon dates were obtained), this study indicates that occupation took place within an ecosystem of alder-carr swamp, with drier areas used mainly for pastoral farming; therefore accessing the fort may have been difficult, and its visibility may have been obscured. The pollen profile at Berth Pool during B10 is similar to that of Birchgrove Pool, and these are the only localities in Twigger's analysis which share evidence of human habitation (enclosures and field systems) during the Iron Age; the relationship between these sites is explored in Chapter 9.

Woodland recolonised the cleared land between circa 2050BP and 1900BP (B11), with increases in arboreal pollen at Fenemere, Marton and Birchgrove Pools (particularly oak and birch), and a decrease in grasses. The woodland around Birchgrove Pool was allowed to regenerate with the likely abandonment of its enclosures and field systems. (At Crose Mere, cereal crops and ruderals increased significantly around this time). This pattern of clearance and regeneration may mirror the repeated climatic fluctuations which occurred during the Iron Age, noted in proxy indicators such as speleothems and bog surface wetness records (Lamb, 1981; Hughes et al., 2000; Charman et al., 2001; Barber et al., 2003). Coupled with an influx of Roman invaders, the unpredictability of the climate and increased peat growth (Twigger and Haslam, 1991:752-3) may have led to a displacement of people, land abandonment, and ultimately tribal reorganisation. In the teeth of this 
perfect storm and in contrast to the other meres, the comparatively open environment around the Berth remained constant, suggesting maintenance and perhaps ongoing usage of the marsh-fort.

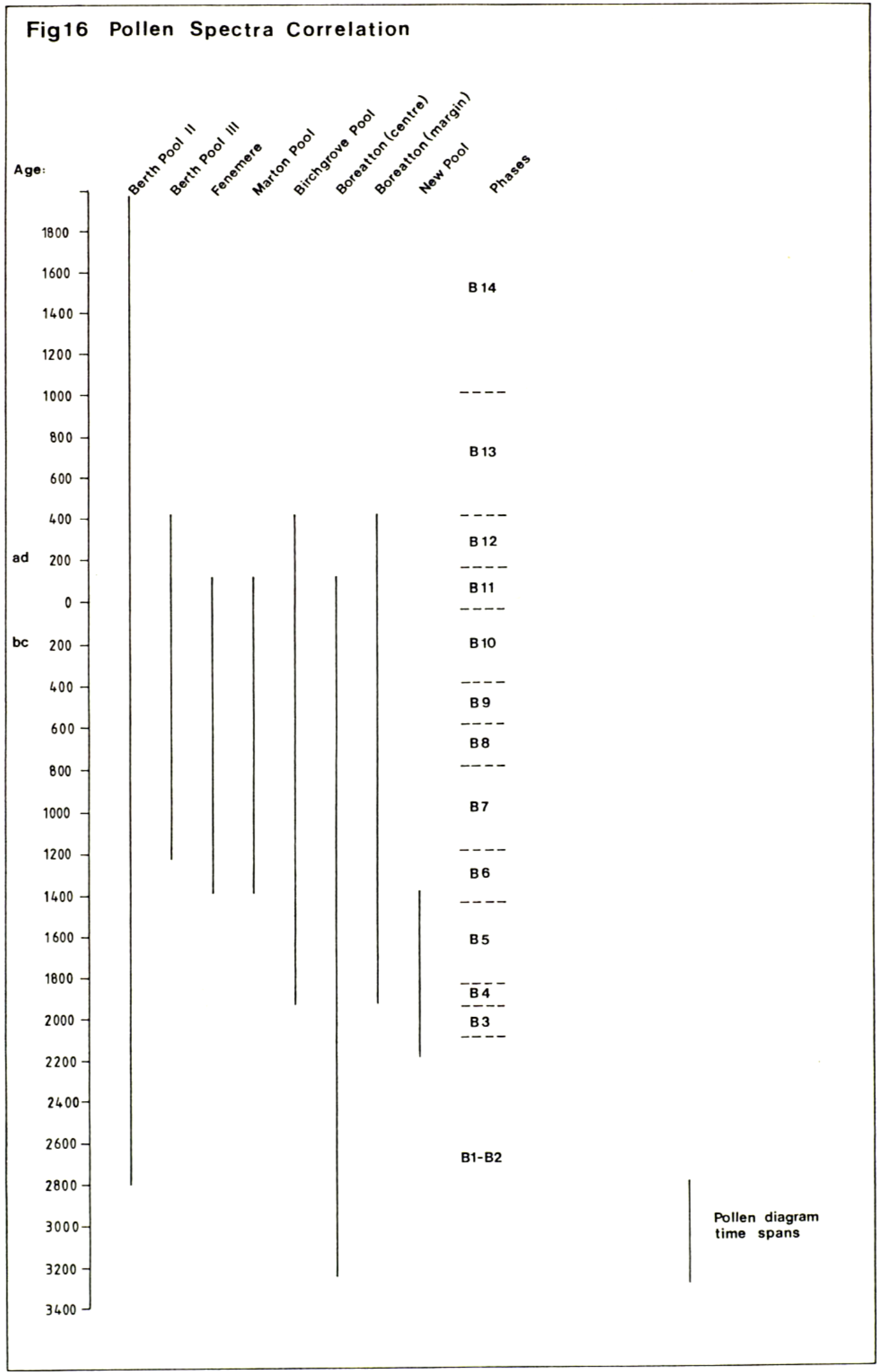

Fig. 8-27 North Shropshire meres - radiocarbon dating (uncalibrated dates bc) (Twigger, 1988) 


\section{BERTH POOL ॥}

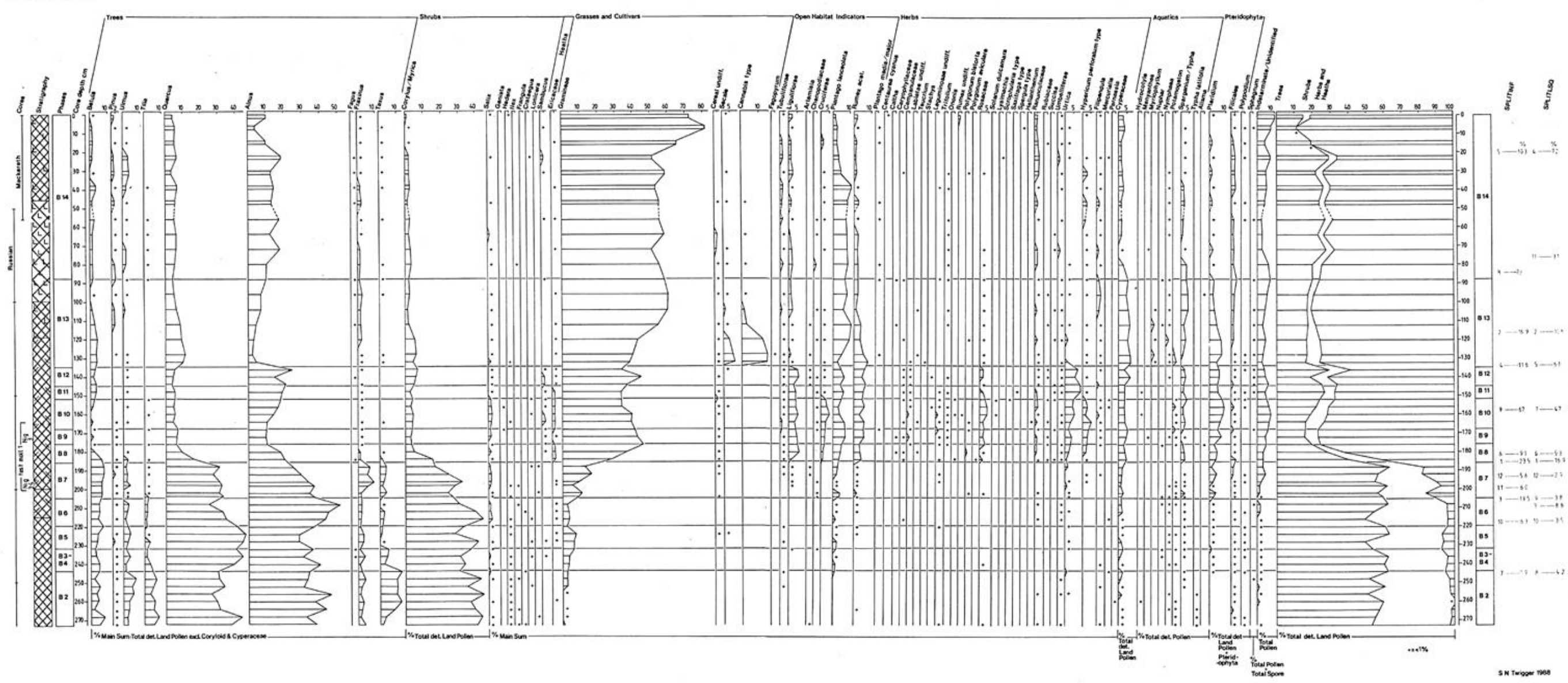

Fig. 8-28 Berth Pool II - pollen analysis (Twigger, 1988) 
Clearance recommenced around the North Shropshire meres between circa 1900BP-1600BP (B12), and the early part of this phase may correlate with deposition of the Berth Cauldron. Whilst the Berth's woodland cover continued at around $20 \%$, there was a noticeable spike in arboreal pollen, attributable to a rise in alder, perhaps an indication that the Berth was a less used during the later Roman period.

A rapid and major change in land use occurred at the Berth around 1600BP-1240BP (B13) (the other meres do not cover this period). Alder was much reduced and elder was eradicated. This mirrors Brown's study of the Upper Perry, 3km west of the Berth (1990), which concluded that the floodplain was only finally deforested circa 1600-1400BP. The damper areas around the Berth may have been cleared for the cultivation and processing of hemp. Flax/hemp and rye were important Anglo-Saxon crops (Godwin, 1967; French and Moore, 1986; Stead, 1991) and the Berth's pollen profile shows significant increases in both species. The Cannabis type pollen present here is thought to be Cannabis sativa L. (hemp) (Twigger, 1988:330), although its pollen is difficult to distinguish from common hop, Humulus lupulus L. Hemp grows well on wet alluvial soils, although the smell associated with hemp-retting often precludes processing close to human occupation (e.g. Andresen and Karg, 2011). Although Anglo-Saxon arable crops were predominantly wheat and oats, Secale cereale (rye) was useful as winter cereal and grown on poorer wetter soils (Banham and Faith, 2014). Rye was present (along with other cereal crops) as a continuous low level pollen curve from the Late Bronze Age onwards throughout the North Shropshire meres (Berth Pool II, B7), but its cultivation assumed prominence at the Berth after 1600BP; there is also intermittent evidence for Fagopryum esculentum (buckwheat) (Twigger,1988:330). Both hemp and rye indicate that the location of the Berth was used but maybe not occupied during Anglo-Saxon times.

In summary, Twigger's analysis shows that the Berth and the North Shropshire meres underwent successive woodland clearance interspersed by phases of regeneration throughout prehistory and into the Anglo-Saxon period. Significantly, woodland surrounding other meres went through phases of clearance and regeneration during the Iron Age, but the Berth remained comparatively clear from circa 2800BP onwards, signifying community effort and its long term importance to the local population. 


\subsection{The Berth - Palaeoenvironmental Reconstruction - spatial coverage and landscape evolution}

The multi-proxy landscape reconstruction detailed in this chapter describes ecological change around Berth Pool throughout the Holocene.

\subsubsection{Spatial coverage}

As pollen, plant macrofossil and beetle remains disperse differently, they provide information at varying spatial levels. Whilst these differences have been alluded to throughout this thesis, they have not been discussed in detail.

The dispersal radius for pollen varies according to the size and nature of the catchment; it is frequently calculated as circa 200m (Jacobson and Bradshaw, 1981; Fossitt, 1994) although a large lake $500-750 \mathrm{~m}$ in diameter can provide a pollen signature for an area up to $1 \mathrm{~km}$ radius (Birks and Birks, 2011). Berth Pool is circa $200 \mathrm{~m}$ in diameter and covers 2.9ha. Twigger's research estimated a radius for modelling pollen rain between $150-200 \mathrm{~m}(1988: 169,357)$ and assumes that Berth Pool maintained its current size throughout the Holocene; the larger pool size postulated in Chapter 7 would increase this area. Assuming a similar dispersal radius for pollen from sample BNP15, the combined pollen analysis covers both the peat basin and the areas of better drainage around the small enclosure and Berth Hill (Fig. 8-29).

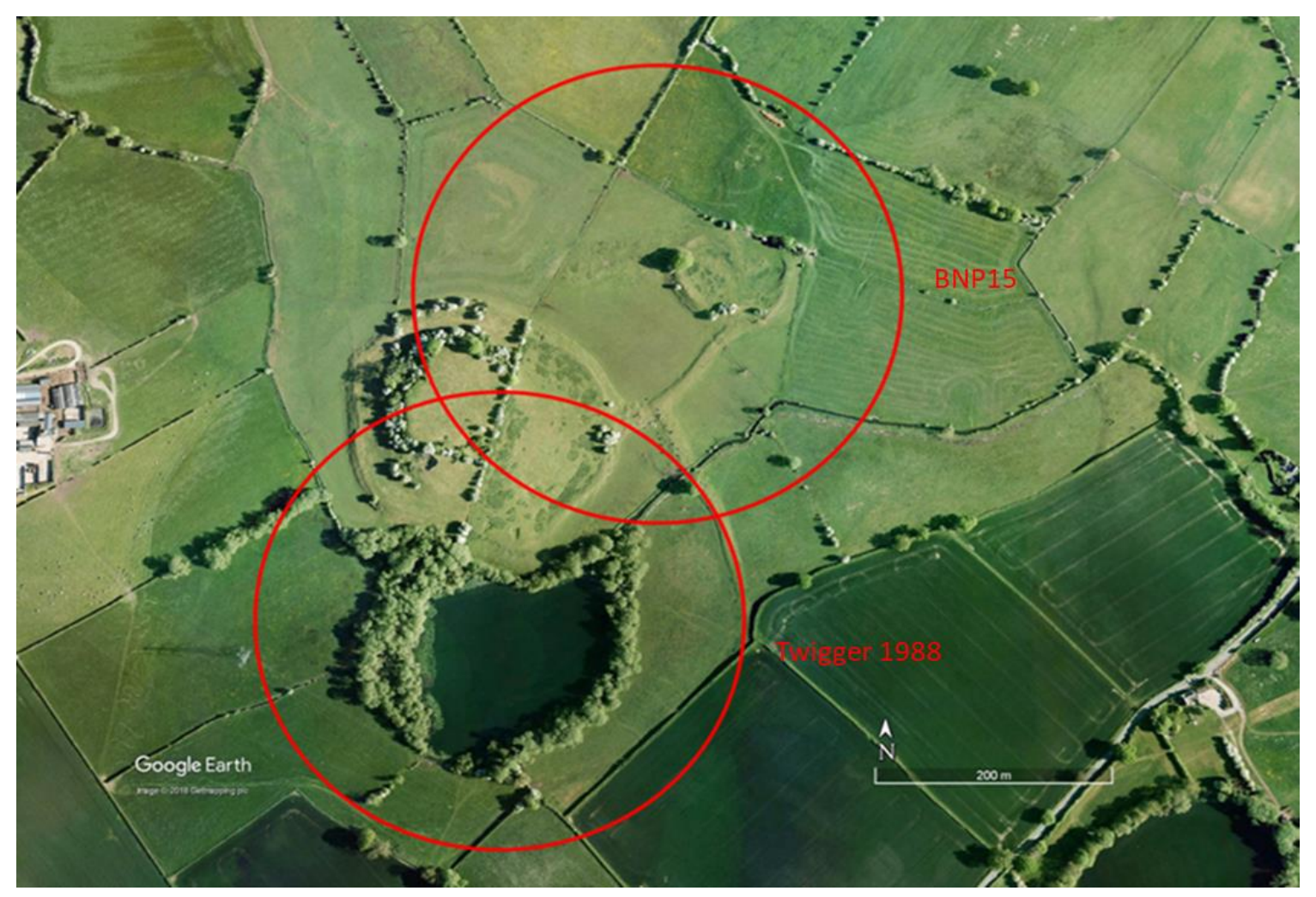

Fig. 8-29 The Berth - pollen distribution and overlap (BNP15; Twigger, Berth Pool 11)(Google Earth; June 2017) 
The plant macrofossil record depends on the production and dispersal characteristics of the species present but generally the catchment is considered to be approximately $40-50 \mathrm{~m}$ radius from the core site (see Chapter 3). The depositional environment was stable, with no obvious streams/rivers to introduce allochthonous remains. Wind dispersal may have had an impact, however most seeds do not travel far especially where shelter is afforded by other vegetation (Bell et al., 2000:213). By combining all the plant remains from all the assemblages in this analysis (Fig. 8-30), a spatial and temporal reconstruction can be created which traces the development of an environmental mosaic which was constant from circa 9000BP but became more open from circa 2600BP.

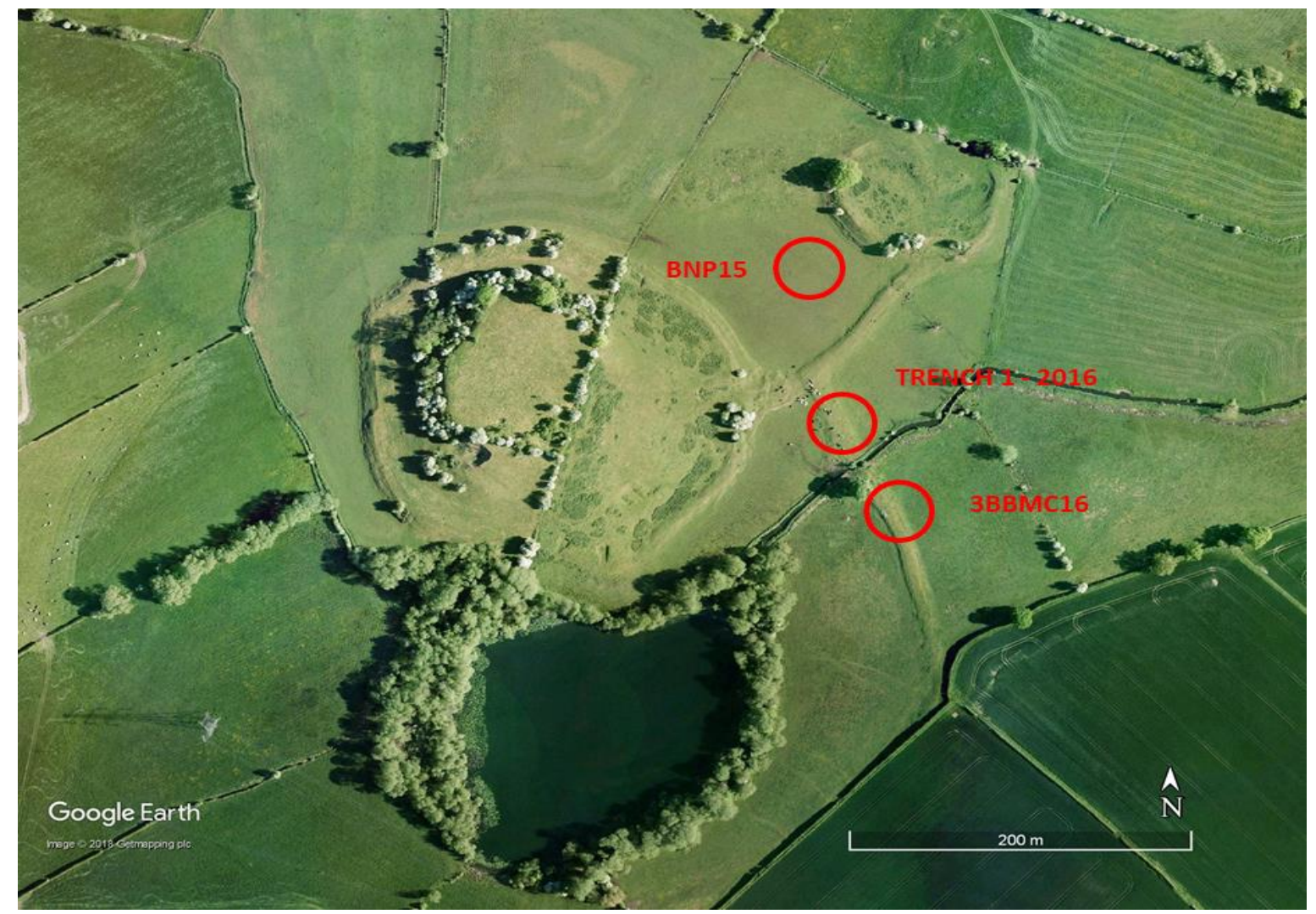

Fig. 8-30 The Berth - plant macrofossil distribution - BNP15; 3BBMC16 and Trench 1 (Google Earth; June 2017)

Although each species exhibits a personalised habitat signature, Coleoptera generally span the spatial difference between pollen and plants, and the consensus is that beetles from natural depositions are a faithful reflection of the surrounding area (Kenward, 1975; Smith et al., 2010). The Coleoptera discussed in this chapter add detail and provide no contra-indicators to suggest anything other than hydroseral succession from ancient woodland with open water and reed-bed to aldercarr with areas of grassland. The synanthropic species present in sample Trench 1 provide the only evidence for the presence of people. 


\subsubsection{Summary - The Berth - Landscape evolution throughout the Holocene} Covering the Late Glacial to the early Anglo-Saxon period, these studies present a sequence which highlights periods of climatic oscillation, the replacement of tundra-type vegetation by thermophilous woodland, declines in both lime and elm, decreases in open water, hydroseral succession and the rise of fen-carr, across an area of circa 40ha.

The pollen record illustrates a post-glacial succession of birch, hazel and pine, with forest climax between 9500-8300BP. As forest cover altered, gaps were colonised by ferns rather than by any noticeable extension of open, drier grassland. The aquatic and damp-fen taxa prominent in the plant remains illustrate calm, open water around 1.5m deep; whether this was a single lake (a large body of water of which Berth Pool is now a remnant), or multiple pools is unclear. As the area became increasingly terrestrialised circa 7100BP, alder-carr formed the main ecosystem, pocketed with peaty water, tall reed-bed, and damp grassland; ombrotrophic conditions did not develop to any great extent. This environmental mosaic was more prominent at the Berth than at Crose Mere and King's Pool where forest cover was denser and more prolonged. Charred plant remains were evident at the Berth and may indicate the manipulation of forest cover and reed bed during the Mesolithic and Neolithic periods.

Tree cover fluctuated from the Late Bronze Age onwards suggesting anthropogenic clearance associated with farming and settlement, although alder-carr remained the dominant ecosystem throughout the first-millennium BC. This was the environment chosen in which to build the Berth. During its occupation, the surrounding ecosystem was used for pasture and as a possible source of charcoal. Although wet woodland continued, Berth Pool was the only one of the Mid-Shropshire meres to maintain a degree of woodland of clearance throughout the Iron Age and into the AngloSaxon period. Evidence for arable farming is inconclusive, although rye and hemp were grow circa 1600BP.

This study has created a temporal and spatial framework of palaeoenvironmental evolution at the Berth. Whilst landscape reconstruction can only ever estimate reality, these conclusions are given weight by the use of multiple proxies, turning a 'plausible' into something approaching a 'faithful' reconstruction (Caseldine et al., 2008). The implications for those who used this land during later prehistory and its similarities to Sutton Common are discussed in Chapter 9. 


\section{Assessing marsh-forts - discussion and conclusions}

"We arrive many millennia after the heat and urgency of daily life has cooled and cast a retrospective view over the landscape' (Gosden and Lock, 1998:4)

The aim of this thesis is to assess marsh-forts as a separate phenomenon within Iron Age society through an understanding of their landscape context and palaeoenvironmental development (see 1.3.1). This research has identified a group of sites nationally which could be classified as marshforts, compared them against the Sutton Common hypothesis and reconstructed the local palaeoecological landscape of one site in particular - the Berth in North Shropshire.

This chapter begins with a detailed comparison of Sutton Common and the Berth, highlighting similarities and differences in functionality, morphology, chronology and material culture. In line with the thesis objectives (see 1.3.2), the conclusions seek to answer questions concerning whether marsh-forts were a local adaptation to topographical circumstance and/or whether wetlands were a deliberate choice in which to establish an important community monument. Using the insights obtained, this chapter concludes by proposing a functional paradigm for marsh-forts which can be used in further studies.

\subsection{The Berth and Sutton Common - a comparison}

Investigations at the Berth lag some way behind those at Sutton Common and there are gaps in the data that have yet to be filled. Nevertheless, the following comparison illustrates the similarities between these sites. As the Berth and Sutton Common were located $150 \mathrm{~km}$ apart, this raises important questions about the universality of the marsh-fort site-type.

\subsubsection{The palaeolandscape}

Palaeoenvironmental analysis has enabled the reconstruction of an almost complete Holocene sequence at the Berth and established the longue durée of its landscape development. In summary, following the Devensian glaciation, thermophilous mixed woodland and reed-bed gradually colonised the peat basin, developing into oak and alder-carr woodland with peaty pools and some tall-herb grassland. Human presence is potentially signalled by burning of the reed-bed during the Mesolithic; thereafter, apart from the undated burnt mound, there is no indication of human presence until the building of the Berth fortification during the Middle Iron Age.

Woodland clearance from the Bronze Age onwards is usually linked with increased farming and settlement. Anthropogenic woodland clearance was noticeable around the Berth from circa 3200BP, 
but became more marked circa 2600BP with declines in hazel, ash, alder, oak and birch. Based on small amounts of cereal-type pollen, Twigger concluded that sporadic arable production was ongoing at the Berth from the Late Bronze Age and throughout the first-millennium BC. However, the pollen signature is muted and there is no supporting evidence from either the plant macrofossil or beetle remains. There is greater evidence for the land being used as pasture for grazing animals, particularly during the Iron Age; charred plant remains from this period may also suggest charcoal production, which would fit with the evidence for metalworking (see below). Arable crops were not grown to any great extent until the final clearance of alder circa 1600BP. This environmental profile reflects the same 'discontinuous process to arable' seen elsewhere in North Shropshire (Haslam, 2003:28) and in many prehistoric wetlands (e.g. Van de Noort, 2004), including Sutton Common.

It is tempting to conclude that the reason for clearance at the Berth was to build the marsh-fort, although the facts are slightly more complex. Firstly, felling was synchronous around all the MidShropshire meres from circa $2800 \mathrm{BP}$, suggesting that clearance at the Berth was one event amongst many. Secondly, the earliest datable evidence from the Berth is Cheshire VCP, providing a terminus post quem of the fifth-century BC (Morris, 1985), and placing woodland clearance at Berth Pool a minimum of 100 years earlier than marsh-fort construction. The Berth's ramparts are uni-/bivallate which may support an earlier construction date, but they appear to be of dump construction which would place them later. Hence, no firm conclusions regarding the Berth's origins can be reached until a more robust chronology is obtained.

A comparatively open environment of wet alder-carr, some oak, peaty pools and grassland was maintained around the Berth for the remainder of the first-millennium $B C$, in contrast to the other Mid-Shropshire meres where denser woodland was allowed to recover. The implication is that the Berth was sufficiently important to the community to invest in the ongoing maintenance of its surroundings, a level of upkeep that continued into Roman times.

The Berth has been proposed as an alternative administrative centre to Viroconium following the Roman departure, and/or as a stronghold for emerging local warlords, both of which suggest a site of some status (Trinder, 1983:22; Gelling, 1992:25; White, 2002). However, the pollen record argues against this. Following the alder clearance, the land was used for growing Secale sp. (rye) and Cannabium sp. (hemp), and oak was allowed to regenerate; the smell from flax retting may have precluded occupation.

The Berth shares similarities in its palaeolandscape with Sutton Common, where the prevailing environment was also one of cleared woodland and open grassland from the Early Iron Age onwards 
(Van de Noort et al., 2007:58-67). Oak was not present in the immediate surroundings, although, significantly, oak timbers were used to create the monument's palisade, perhaps adding to its status (Van de Noort et al., 2007:176). Like the Berth, the surrounding landscape was used for pasture prior to the Roman period, after which there is more evidence for arable farming.

\subsubsection{Topography and location}

'Features in the natural landscape may be held to have provided a symbolic resource of the utmost significance to prehistoric populations' (Tilley, 1994:24).

The Berth is surrounded by an unusual combination of natural features that may have marked the location as special. The ramparts of the main enclosure surround the prominent if low-lying Berth Hill, which rises $17 \mathrm{~m}$ above the surrounding waterscape (at $80-85 \mathrm{mOD}$ ), with Berth Pool at its foot. The wetland would have offered resources (fishing, wildfowl, summer grazing), a defensible location and a place for the ritual and ceremonial activity associated with watery places during the Iron Age. The flat summit of Berth Hill afforded $360^{\circ}$ intervisibility across much of the North Shropshire Plain, providing a possible strategic viewing platform from which several surrounding hillforts, including the Wrekin and the Breiddin, could be seen. The summit would have been visible above the later prehistoric alder-carr woodland, but the ramparts surrounding the main enclosure, the small enclosure and the peat basin would be screened and made inaccessible by the surrounding vegetation and marsh. The summit is naturally suggestive of a ceremonial platform, perhaps sharing a similar significance to the Bronze Age barrow complexes discussed by Fontijn (2007:71); it is not known whether the summit has been artificially levelled.

Potentially, the Berth is contemporary with the Birchgrove enclosures and the adjoining field systems, $1 \mathrm{~km}$ to the south. Both marsh-fort and settlement appear to reference a pre-existing boundary indicated by the nearby pit alignment and Bronze Age cemetery, which could delineate both symbolic and economic land division (cf. Chadwick, 1999; Robbins, 1999; Wigley, 2002; Garwood, 2007a). Such proximity has been noted between hillforts, linear ditches and clusters of smaller enclosures elsewhere in the Welsh Marches (Wigley, 2017b). The Berth's location and surrounding archaeology could therefore suggest a local, communal monument - defensive, economic and/or ceremonial - which was created and controlled by a settled population who lived around Fenemere, Berth and Birchgrove Pools and had a previous connection to the Bronze Age cemetery.

However, the Berth's size and complexity suggests a relationship with the wider area, in particular with the Upper Perry, replete with barrows, metalwork deposition and burnt mounds. The Berth is located on the edge of this vernacular landscape, and the archaeological record is a reflection of the 
cultural character of those who occupied the land throughout the longue durée. The creation of Berth may suggest the consolidation of that broader territory once the agricultural revolution of the Iron Age came about.

By contrast, Sutton Common occupies a sand dune in the flatlands to the west of Thorne and Hatfield Moors, between $2 \mathrm{~m}-5 \mathrm{mOD}$. The dune is surrounded by peat wetland, with the open water of Shirley Pool lying to the east. The landscape is undistinguished and there is no highpoint from which to survey the surrounding land. The brick-work field systems which surround Sutton Common are bisected by the first-century AD Roman Road at Austerfield and are therefore potentially Iron Age in date (Van de Noort et al., 2007:166-170), however, the area is largely aceramic and dating evidence is elusive. Chadwick suggested that the monument was little more than a point of community focus (Chadwick, 2010:1048), although this bland dismissal could be levelled at many sites. Sutton Common's hinterland does not compare to the Berth/Upper Perry's rich archaeological heritage.

The closest potential marsh-fort to the Berth is Stocketts Enclosure, which lies $7 \mathrm{~km}$ to the north, but the most likely candidate - Wall Camp - is $25 \mathrm{~km}$ to the east, suggesting a separate area of influence. Several marsh-fort candidates of varying size lie within a $4-10 \mathrm{~km}$ radius of Sutton Common. Each contains features that are out of the ordinary, although issues of interaction with other sites remain unexplored. Perhaps a group of interacting marsh-forts is more likely in South Yorkshire (or even East Anglia) than in the North Shropshire wetlands.

\subsubsection{Size, morphology, access and orientation}

The Berth covers 8ha (Historic England Scheduled Area, including causeways) and is the largest Iron Age monument within a $15 \mathrm{~km}$ radius - not quite the small, low-lying, wetland enclosure described by Wigley (2002:219). Its morphology comprises two enclosures connected across marshy ground. The earthworks of the main enclosure comprise a uni-/bivallate rampart with an internal ditch; the antiquary Sir Richard Colt Hoare noted that this arrangement was similar to a henge (Buckler, 1787 1897), although more practically, the ditch may simply result from quarrying for the rampart. The rampart was faced with large stones, perhaps to accentuate the monument's visibility (for example, as suggested by Bowden (2005:24) at Midsummer Hill on the Malverns) or possibly as a protection against flood (Guilbert et al., 1977), and may have been palisaded (see below). The current working hypothesis is that the upstanding causeways that cross the marsh are post-medieval, notwithstanding Iron Age dates obtained from the fossilised sub-surface (Chapman, Smith and Norton, 2017) (see 7.5); a newly-identified third causeway appears to have connected the smaller 
enclosure to an entrance in the north-east section of the main enclosure's ramparts. A larger, inturned 'entrance' to the main enclosure faced south-east (see below).

In each of these aspects - size, morphology and orientation - the Berth and Sutton Common are strikingly similar. Sutton Common is the largest monument its locale (6ha), and considerably larger than the other suggested marsh-forts nearby (see 0); the nearest hillfort - Barwick-in-Elmet - lies $30 \mathrm{~km}$ north-west. Its morphology comprises dual enclosures connected by a monumental causeway across the relic palaeochannel of the Hampole Beck. On the eastern side of the large enclosure, the wetland was accessed via a monumental gateway. The fortifications were mainly univallate and faced in part with limestone walling which, together with the surrounding palisade, would make a visual impact in the flat landscape. Anomalies in the fortifications, for example the wide spacing of individual palisade timbers, suggest this was not a defensive site (Van de Noort et al., 2007:109-113).

Access and orientation were symbolically linked in later prehistory. Hillfort entrances were frequently east-west orientated (e.g. Hill, 1995; Cunliffe, 2005), and entrances to domestic roundhouses often faced east (Fitzpatrick, 1994; Oswald, 1997). For marsh-forts, access and orientation were complicated by the need to negotiate the surrounding wetland and possibly to maximise their symbolic features, and understanding how these structures were approached is crucial when interpreting functionality. Based on its lack of domestic evidence and the presence, during its final phase, of carefully curated human remains, Sutton Common has been interpreted as a sacred, wetland-encircled dune of enduring social identity and shared memory (Van der Noort et al., 2007:175-185). This functionality is emphasised by the proposal of a 'proper' approach route (Chapman, 2000). Proceeding west to east, the route entered the annex (Enclosure B) at the southwest corner before proceeding along and around Enclosure B's ramparts and crossing a substantial causeway into the western rampart of Enclosure A. A monumental gateway in the eastern ramparts of Enclosure A accessed another possible causeway which led across wetland towards Shirley Pool.

A similar access route, which was both practical and possibly formalised, can be proposed for the Berth's main enclosure. Assuming that the upstanding causeways are post-medieval, the practical approach appears to be via the drier land to the east, through the 'annex' of the small enclosure, and across the marsh via the north-east causeway to enter the main enclosure. What happened next would depend on what was considered the ultimate destination, which may have been any part of Berth Hill, including its flat-topped summit. However, if the route continued along the ramparts, the destination was possibly the south-east 'entrance', which accessed the surrounding marsh or an enlarged Berth Pool. Therefore, this entrance appears redundant for normal access and looks 
increasingly like a point of deposition; however, it would be an entry point if access to the main enclosure was across an enlarged Berth Pool.

Whilst these descriptions of access and morphology suggest similarities, the Berth requires further investigation. The main points of difference lie in the nature of the causeways and the south-east gateway. Sutton Common's causeway was no mere track but a monumental structure in its own right, as was its monumental east-facing gateway. As yet, neither feature has been discovered at the Berth but these discrepancies may be overturned. This also assumes a 'template' for ritual architecture and activity around marsh-forts which may be far from the case.

\subsubsection{Site usage - features and finds}

Whilst this research has centred on the palaeoenvironmental and landscape analysis of the area surrounding the Berth, it is important to integrate these investigations with the archaeological and cultural data in order to produce a rounded picture of past living (e.g. Mithen, 1999). The features and finds evidence presented here is derived principally from Gelling's investigations (Gelling, 1962/5; 1964; Gelling and Stanford, 1965 (1967); Morris and Gelling, 1991) and has been summarised in Appendix 2; however the Gelling record is incomplete and at times confusing, and it is hoped that further research will add to the following analysis.

The archaeological features include three separate levels of 'occupation' separated by sterile layers, numerous postholes, two floors and a cobbled surface; there is no suggestion that the site was used seasonally. The postholes were interpreted as domestic structures, one of which was placed typologically at the end of the Roman period (Gelling, 1964). However, some postholes were large enough for palisade timbers whilst others appeared to be lined with stone blocks, and Gelling was excavating at a time when four- and six-post structures were still interpreted as houses. No domestic buildings were found at Sutton Common, but the 150+ four- and six-post structures in Enclosure A were interpreted as grain stores with possible ancestral and ceremonial associations (Van de Noort et al., 2007).

Domestic activity at the Berth is indicated by finds of pottery and two spindle whorls. Cheshire VCP is found extensively but not ubiquitously in enclosure and hillfort sites across North Shropshire, Cheshire and North Wales. It was recovered from all three layers at the Berth and confirms that salt was an important commodity; assuming it was used for meat preservation, this could indicate that a meat surplus from the surrounding area was controlled by the marsh-fort. Control of surplus in an agricultural economy equals wealth and power (Chapman and Buteux 2009:126), and reinforces the Berth's standing in the surrounding social hierarchy. The remaining ceramics confirm that the Berth 
had connections along the Severn Valley during its later chronology. Whilst spinning may also have been an on-site activity, two spindle whorls are hardly conclusive evidence.

The remaining finds incorporate metalwork, a Roman glass bead and some organic remains. The metalwork from Gelling's excavations is un-curated; some evidence exists only in photograph or as records in Gelling's site diaries. Consequently, interpretation is difficult. If all the evidence is combined, the metalwork finds comprise agricultural implements, blades and daggers, currency bars and a chain, in addition to the Berth Cauldron. The agricultural implements could indicate a farming economy although the palaeoenvironmental record argues against this; a quern fragment was also recorded although this is now lost. Two, possibly three, currency bars were recorded in photograph although their original location is unknown. A La Tène III brooch was found in the uppermost occupational layer. Two (possible) crucibles were recorded amongst the ceramic finds, suggesting on-site metalworking of bronze, an activity often associated with specialist or high-status sites (for example, at Danebury; Cunliffe 1995:67). If the wetlands surrounding the Berth functioned as a place of ritual deposition during the Iron Age, this may have gained a sense of urgency at the time of the Roman invasion, and the votive offering of the Berth Cauldron may embody such concerns; alternatively, it may represent something more positive such as feasting (Joy, 2014) and could be connected with the nearby burnt mound. The 'slave chain' found by Jenks (now lost) was probably a cauldron suspension chain (Manning, 1983), although connecting it directly to the Berth Cauldron might push the evidence too far. The presence of the Cauldron reinforces the Berth's importance as a high-status site. A Roman glass bead was a chance find from the summit of Berth Hill, but others are referred to in Gelling's diaries. Animal bones and organic remains were also referred to by Gelling but, unsurprisingly, none are present in the archive. A handful of (possible) spelt wheat (Triticum spelta) is shown in one photograph, and whilst this may correlate with the agricultural implements, there is no evidence for spelt in the palaeoenvironmental record.

Whilst these items may have resulted from accidental loss or the detritus left after the site was abandoned, the archaeological record is increasingly seen to result from items that were deliberately placed or left (Schiffer, 1972). The items found at the Berth do not yet constitute the structured deposition frequently found on other Iron Age sites (e.g. Hill, 1995b), but investigation is still in the early stages. Currency bars and other metalwork items are regularly interpreted as foundation deposits or deposits made when a structure/enclosure was renewed, changed its function, or was ceremonially 'closed' (e.g. Hingley, 1990; Brück, 1999:334). Brooch finds are now considered more as deliberate deposits rather than accidental losses (Haselgrove, 1997). Deposits of organic remains are increasingly interpreted less as storage and more as fertility offerings to 
chthonic deities (e.g. van der Veen and Jones, 2006; Livarda et al., 2018), and this may also apply to the deposition of agricultural implements (Piggott, 1953; Bradley, 2000; Bradley, 1990).

There was a lack of distinction between domestic and ritual practice during the Iron Age. Ritual activity shifted away from the visually dominant monuments of the Bronze Age and became interwoven with everyday life (e.g. Hill, 1995a; 1995b; Barrett, 1999a; 1999b; Bradley, 2005; Joy, 2011). Society became overwhelming concerned with fertility and security (Barrett, 1988; 1989; Bradley, 1991; Bradley and Yates, 2007), and deposition in watery places became a regular practice (e.g. Wait, 1985; Bradley, 1990). The bulk of the finds from the Berth, including the La Tène III brooch, were found in the upper layer, suggesting the Berth may have developed as a place of ritual deposition during the Later Iron Age/Early Roman periods. This chronology correlates with the Cauldron and suggests that emphasis may have shifted towards using the monument as a predominantly ritual location when times were difficult and dangerous. Alternatively, we may be seeing the incorporation of new people - perhaps early Roman settlers - into an existing social system as they 'paid tribute' at an important indigenous site (Barrett, 1999a), and many Iron Age deposition sites developed as cult sites during the Roman period (Fontijn, 2002).

The finds record from the Berth, although sketchy, is more impressive than that from Sutton Common which comprises a few undiagnostic ceramic sherds, a possible wheel and ladder, quern fragments, an antler weaving comb, a fragment from a gold ingot/bracelet, and glass beads, some of which were produced on site and some imported. However, Sutton Common is notable for its cremated human remains, which were carefully placed in 'mortuary rings', often with charred plant remains (Van de Noort et al., 2007:161-165); this practice is unique to Sutton Common. No human remains have been recovered from the Berth; animal remains were recovered from both sites. No single item as impressive as the Berth Cauldron has been recovered from Sutton Common, but as far as is known, no recoveries have been made from Shirley Pool.

\subsubsection{Chronology}

The Berth and Sutton Common are chronologically similar. The Berth's chronology derives from the stratified finds record and spans the Middle Iron Age into possibly the later Roman era. However this applies to the main enclosure only. Geophysical prospection has suggested that the small enclosure contains a ring-ditch (Gaffney, 1995); if proven, the small enclosure may precede the main enclosure by many centuries and provide the Berth with a Bronze Age past. Sutton Common also contains a Bronze Age funerary monument (Van de Noort et al., 2007:56-58). The palisades for the main enclosure have been precisely dated to the Middle Iron Age although use of the marsh-fort itself was very short lived. The site was 'closed'/abandoned during the Late Iron Age. 
Whilst the Berth may span a longer chronology than Sutton Common, both sites are marked by periods of disuse and apparent abandonment. Return and reoccupation has been recognised at sites other than marsh-forts and offers an insight into the social complexities of the time.

Explanations range between '...opportunistic reoccupation of existing sites during periods of political insecurity, to more opaque considerations of ancestry, legacy, tradition, and identity.' (Lenfert, 2013:136). Although referring to crannogs, Cavers considered that "...occupation of (ancient islet) sites must have been a very deliberate undertaking, designed to create a tangible connection to the past." (Cavers, 2006:146 cited in Lenfert, 2013:138). Alternatively put, reuse may be simply practical, or, more humanistically, an indication of the persistence of social memory and a connection with the ancestral landscape (e.g. Giddens, 1984; Rowlands, 1993; Schama, 1995). The intervals between periods of occupation can also be instructive. For example, separate periods of occupation at Segsbury hillfort were '...the result of continuous and repeated forms of action in the one place over a relatively brief period of time...' (Gosden and Lock, 1998:9); conversely, at the multiphase hilltop enclosure of Rams Hill, lengthy intervals between periods of use indicate '...an underlying continuity of human memory ...' (Gosden and Lock, 1998:8) sustained across multiple generations.

The intervals separating phases of activity at the Berth are not known. However, throughout the Iron Age, people maintained the monument free from woodland cover, moved away and came back to reoccupy, renew or reuse. This important monument was a resilient component in the social consciousness of those living in the North Shropshire wetlands. Its repeated usage reflects similar social practice at the Tetchill Brook on the Upper Perry, where deposition spanned the Bronze Age and into the Roman era.

\subsubsection{Positioning the Berth and Sutton Common in time and space}

The Berth does not benefit from the extensive excavations undertaken at Sutton Common and the fragmentary nature of the evidence is like looking at Stonehenge through a keyhole. Nevertheless, it is possible to suggest a life-history for the site which can be refined by future research.

The Berth was situated within a complex landscape of larger upland and lowland settlements. The wetlands surrounding the Mid-Shropshire meres were populated but not overrun with enclosures; therefore the location surrounding Berth Hill was a deliberate choice from which to control economic resources, and/or as a specialist site, a place of refuge or a ritual/spiritual hub. During the Middle/Late Iron Age, the surrounding landscape was used for grazing livestock, probably cattle. The Berth's size and finds record suggest that it was at the top of a social hierarchy of sites in the immediate area, with likely connections to the nearby enclosures and field systems and possibly to 
the landscape of the Upper Perry. Its discontinuous use demonstrates a society which '...orientated (its) actions in the present with the past in mind ...' (Gosden and Lock, 1998:2).

Assuming interpretation of the Gelling archive is accurate, functionality at the Berth may have changed during the Later Iron Age/Early Roman period, with a range of finds suggesting ritualised deposition. Although '...not everything on an Iron Age site is explicable as 'ritual'...' (Haselgrove, 2001b), the evidence at the Berth during this period looks persuasive. This change may represent a reinvention of the monument, reflecting the fundamental social changes ongoing during the Late Iron Age which were brought into sharp focus by the Roman incursion. The finds record culminates with the votive offering of the Berth Cauldron, although whether this marks some element of site closure is speculative. The Berth may have originated as a domestic site and 'acquired' a ritual importance, a pattern possibly reflected at Sutton Common. However, in order for the changes at both sites to come about, they must have been held as special, and memorialised across the generations.

\subsection{Marsh-forts in North Shropshire}

One question which prompted this research was whether the Berth was one of a group of marshforts which existed in North Shropshire. Eight sites were examined, of which three warrant further consideration - the large, multivallated wetland enclosure of Wall Camp on the Weald Moors (Group 1), Stocketts Enclosure and Whittington (both Group 2 - see 5.4); of these, Wall Camp shares most similarities with the Berth and Sutton Common.

Like the Berth, the topographical evidence suggests that all these sites were positioned to control wetland. Wall Camp was surrounded by marshland, with possible causeways facing east and southeast which accessed deeper wetland, and was the largest structure on the Weald Moors. Stocketts Enclosure occupied a tongue of solid land that controlled access to Whattal and Sweat Mosses and overlooked Crose Mere. Whittington lies at the confluence of several streams, although the natural drainage pattern is confused by a combination of the medieval castle and modern building. Stocketts Enclosure is considerably smaller than Wall Camp and Whittington, which could suggest a different functionality.

Palaeoenvironmental and archaeological information for these sites is limited. The only reliable palaeoenvironmental evidence comes from Crose Mere which is overlooked by Stocketts Enclosure (Beales, 1980). This is reviewed in Chapter 8 and shows repeated woodland clearance from the Late Bronze Age onwards. Cereal crops and ruderals increased circa 2000BP, suggesting arable use of the 
surrounding land during the Late Iron Age/Early Roman period. Palaeoenvironmental evidence from Wall Camp is only available for the Mesolithic period and reflects the surrounding fen-carr ecology.

There is very limited excavational evidence from Stocketts Enclosure and whilst several finds could be interpreted as ritual deposition, this conclusion is tentative at best. Wall Camp however, benefited from an excavation of the interior, which provided a Middle/Late Iron Age date (Bond, 1991) and evidence of round-houses and a possible midden. Because of its unusual morphology and location, Wall Camp has also been suggested as a place of ritual activity (Malim and Malim, 2010) and this may be reinforced by the recovery of the Telford torc from nearby wetland. No evidence is available for Whittington.

Limited information can be gleaned from the wider archaeological landscapes that surround Stocketts Enclosure and Whittington. However, Wall Camp was central to an extensive area of marshland with a rich Bronze Age heritage, notable for its multiple ring-ditches, burnt mounds and metalwork deposition, and this archaeological signature has clear similarities with the Upper Perry. The Iron Age landscape surrounding Wall Camp is much quieter; enclosures and field systems were concentrated along the River Tern, $6 \mathrm{~km}$ distant from Wall Camp, leaving the marsh-fort isolated but perhaps reinforcing its special status.

Wall Camp and the Berth are similar monuments, $25 \mathrm{~km}$ apart, which share a chronology, some morphological features, a wetland setting and a material culture. Cheshire VCP from both marshforts suggests a primary role in animal husbandry and stock management, perhaps controlling the lush summer grazing afforded by the surrounding wetland. Interpreting Wall Camp and the Berth simply as enclosures in a pastoral environment would be straightforward were it not for their monumentality and size, the apparent formality of access across marsh towards deeper water, and a number of specialised finds. These monuments appear to be communal centres sited in extreme wetland, each with a discrete hinterland, utilised for a variety of functions including ritual activities, by those living in the surrounding area.

The sites mentioned here do not provide sufficient information to establish whether the marsh-forts of North Shropshire acted as a group; this would require evidence of function and chronology that is not available. However, both Wall Camp and the Berth indicate that they were prime sites in their locales and may reflect the kind of settlement patterning suggested for upland hillforts in both the Welsh Marches and Wessex (Wigley, 2002; Cunliffe, 2005; 2006). 


\subsection{Marsh-forts in England and Wales - supra-regional perspectives and}

\section{themes}

The gazetteer discussed in this thesis was compiled from a range of sites whose topographical location had originally suggested that they were marsh-forts. These were then assessed against the following criteria derived from the Sutton Common model:-

1. large size (cf.

Jackson,1999; 3.1ha-6ha)

4. Middle/ Late Iron Age site chronology
2. Marshland/ wetland location

5. Lengthy landscape chronology; discontinuity of monument use
3. Monumentality of fortifications /unusual morphology

6. Localised woodland clearance/ pasture; possible field systems in the wider landscape

7. non-domestic, possibly ceremonial or ritual use

Sites were deemed to be potential marsh-forts if they fulfilled four out of the seven criteria and have been grouped as follows (see 4.3 and 5.4 ):

Group 1. Marsh-forts in the Sutton Common model, used for non-domestic/ritual purposes

Group 2. Potential marsh-forts similar to Sutton Common, which may also have been used for non-domestic/ritual purposes

Group 3. Low-lying, monumental, marshland sites which possibly exercised a controlling function (economic, territorial, ritual) across the surrounding wetland landscape, but where evidence is principally domestic

A residual group (Group 4; 50\% of the gazetteer sites) had insufficient similarities or too poor a dataset to allow classification.

Evidentially, all the sites reviewed share a wetland setting, be it marshland, riverside, low knolls overlooking marsh, or lakeshore. However, for many of the Group 4 sites such as Tharston or Boney's Island, topography was the only reason for their original inclusion; other Group 4 sites, such as Pave Lane, Peckforton or Hetha Burn West, appear to be defended enclosures that utilised the surrounding wetland as a practical resource, perhaps in conjunction with a larger hillfort nearby. However, for sites more closely aligned to the marsh-fort criteria (Groups 1-3), their wetland locations appear to combine a range of benefits - access to resources, defence, control of marginal 
areas, a setting for ceremonial activities - that inform their functionality. All of these functions are possible with or without settlement activity and none are mutually exclusive. Their locations appear to be deliberate choices in which to site substantial, significant monuments which acted as communal foci, or if interpreted more hierarchically, from which to exercise territorial control. Although each of these functions occurs in hillforts, these sites suggest a propensity to occur in combination in marsh-forts. At sites where the evidence is greatest, marsh-forts could be interpreted as playing a central role in all aspects of the social fabric of the surrounding community economic, territorial and/or ceremonial - with wetland at the core of their purpose and functionality.

\subsubsection{Economic control}

Economic control takes many forms - control of surrounding agricultural land and its produce as part of a settlement hierarchy, control of specialist skills and resources and control of access - and whereas all may have been equal in an egalitarian society, it is more suggestive of a social hierarchy existing in a settled landscape.

The palaeoenvironmental evidence - for example, from the Berth, Oakmere, Sutton Common, Arbury and others in Fenland including Tattershall Thorpe, Stonea Camp, Wardy Hill and Borough Fen - suggests that many marsh-forts were sited in areas cleared of woodland and surrounded by pasture, placing them at the centre of a pastoral economy. Whilst division of Iron Age farming practice into agriculturalists and pastoralists was largely overturned by research at the Iron Age/Roman riverside settlements at Farmoor (Lambrick and Robinson, 1979), few marsh-forts indicate an environment used for arable production. The pastoral economy at the Berth and Wall Camp is further suggested by the presence of briquetage. Clearance would also have given the marsh-fort physical prominence in a flat landscape (for example, Arbury, Stonea Camp, and Sutton Common).

Specialist functionality is notable at some sites, for example the Berth (metalworking), Arbury (leatherworking) and Sutton Common (glass working). Such specialisms also feature in hillforts and in lake villages, for example, metallurgy at Danebury and Little Solsbury, Somerset, and glass manufacture at Meare. Whilst these activities do not differentiate marsh-forts, they may suggest a degree of control of the surrounding occupied lands.

For sites such as Warham and Bloodgate Hill, a riverside location enabled control over the movement of people, produce, or goods; Cherbury and the valley-forts along the Thames no doubt used the river in a similar way. For each site, the river provided a defensive boundary and a means of transport. Tattershall Thorpe occupied a strategic point on the River Bain between the River Witham 
and the Iron Age coast, controlling the surrounding pastureland; as a remote possibility, it may even have regulated access to the depositionary causeway at Fiskerton.

Locating marsh-forts within settled landscapes of field systems and enclosures requires more research, notwithstanding Chadwick's analysis of lowland South Yorkshire (Chadwick, 2010). At the Berth, the enclosures and field systems lie within $1 \mathrm{~km}$, whilst those on the Weald Moors are $6 \mathrm{~km}$ distant suggesting a different kind of relationship. In his landscape study of the Welsh Marches, Wigley concluded that hillforts were not generally situated alongside settlement or other cropmarks (Wigley, 2002) indicating long-term morphological changes in land tenure; however marsh-forts in the Welsh Marches may present a different scenario.

These economic factors lend weight to some marsh-forts as potentially high-status sites at the apex of a social hierarchy, dominating the surrounding wetland; Wardy Hill for example, has been specifically suggested as a chiefly centre (Evans, 2003). The economic and social control exerted by marsh-forts may however have been a local affair, and Hall and Coles found it difficult to envisage any kind of social hierarchy existing across the wide distances and difficult terrain of Fenland (Hall and Coles, 2014:103). Additionally, as many marsh-fort sites lack domestic evidence, control may not be synonymous with centralised settlement.

Notwithstanding the evidence of glass working, one site which may not have exercised economic control over its surroundings is Sutton Common, which has been interpreted as a communal, symbolic monument used by the wider community (Van de Noort, 2004:69); the presence of multiple human remains curated in mortuary rings may also indicate that Sutton Common was at an extreme end of the marsh-fort continuum.

\subsubsection{Landscape patterning and boundary control}

Landscape patterning surrounding marsh-forts can be considered at regional and/or local level. Marsh-forts have been proposed as territorial markers in frontier locations, delineating neutral ground between socio-political groups, or acting as boundaries between smaller local or kinship groups (Davies et al., 1992; Parker Pearson and Sydes, 1997; Chadwick, 2010). Neutral territory suggests locations where opposing forces might meet or where social ceremonies could be enacted. Later Iron Age oppida, represented here by Salmonsbury and Abingdon, the Vineyards, are increasingly seen as occupying marginal areas where settlement had been sparse, perhaps reusing a site, seasonally or for ceremonial functions, which held significance in earlier times (Moore, 2006:79). The grouping and distribution of marsh-forts in eastern England may suggest the control of tribal borderlands, in particular between the Catuvellauni and (from north to south), the Brigantes, the Iceni, and the Trinovantes. The other potential group of marsh-forts - on the 
Shropshire/Cheshire Plain - lies firmly within the territory of one tribe, the Cornovii. However, this association links an Iron Age phenomenon with tribal units which may have been a Roman imposition (e.g. Wigley, 2001; Moore, 2011) and cannot be substantiated further. Marsh-forts may therefore have been a culture-specific phenomenon, peculiar to those who knew the value and symbolism of occupying and controlling wetland.

The location of several sites suggests an association with a hillfort neighbour - for example, Arbury and Wandlebury, Hetha Burn West and Great Hetha, Whittington and Old Oswestry, and Oakmere/Peckforton and the hillforts along the Cheshire Ridge (e.g. Leah et al., 1997) - and this may reflect a sharing or separation of functionality. This phenomenon has also been proposed for pairs or groups of hillforts (e.g. Dorling et al., 2017).

\subsubsection{Control of ceremonial and ritual practice - waterscapes as place of votive deposition}

It is impossible to separate the waterscapes occupied by marsh-forts from ritual or ceremonial activity.

'The archaeological evidence (from the Humber Wetlands) suggests that wetlands were a foci of ritualised activities ... predominantly mires, or peat-producing wetlands, rather than the minerogenic wetlands or the waterbodies themselves....Before artificial drainage, these mires formed uncultivatable and intractable landscapes, unsuited for agriculture and difficult to travel through. The association of such landscapes with the realm of the gods or spirits contrasts with the association of the minerogenic wetlands with farming and industrial activities.' (Van de Noort, 2004:106).

Such liminal places epitomise the 'wetland paradox' (Van de Noort, 2004:166-170) - economically valuable, separate from everyday activity, ambiguous, seemingly harmless but treacherous for the unwary, associated with wilderness, social rebirth and regeneration. They may have offered a portal, a bridge between two worlds, the space between the wet and the dry where rituals were enacted, offering the prospect of '...active, perceptual engagement of human beings with the constituents of their world...'(Ingold, 1992:42); such places continue to be regarded as socially marginal even in modern times, as demonstrated by novels such as Graeme Swift's Waterland (Swift, 1984).The marsh-forts that most closely match the Sutton Common model, and Van de Noort's description, have a greater association with peatlands than with riverside locations. Their locations are as topographically extreme as some hillforts, and one function of marsh-forts may have been to exercise control over the ritual activity associated with wetlands. 
Identifying ceremonial or ritual behaviour has long been problematic in archaeological practice (Hawkes, 1954; Evans, 1998), but is at its most observable in votive deposition (especially of metalwork), funerary remains, and the presence of shrines. Of these lines of evidence, votive deposition is most strongly associated with wetlands during the Iron Age. Deposition was an act of reciprocity between worlds (Fontijn, 2002:269), favouring natural, watery places as well as remote or peripheral locations, and there is considerable overlap between the sites highlighted in this thesis and the depositionary zones highlighted by Wait (1985) (Fig. 9-1). Whilst evidence for direct deposition is not apparent at many marsh-fort sites, they may have controlled access to places of deposition nearby - Sutton Common to Shirley Pool, the Berth to Berth Pool, Wardy Hill to the wetland 'bay' at Coveney, and Wall Camp to the peat bog of the Weald Moors. Those accessing special places may have been required to cross the numinous element of water in order to deposit valued items, and causeways feature in the architecture of many sites.
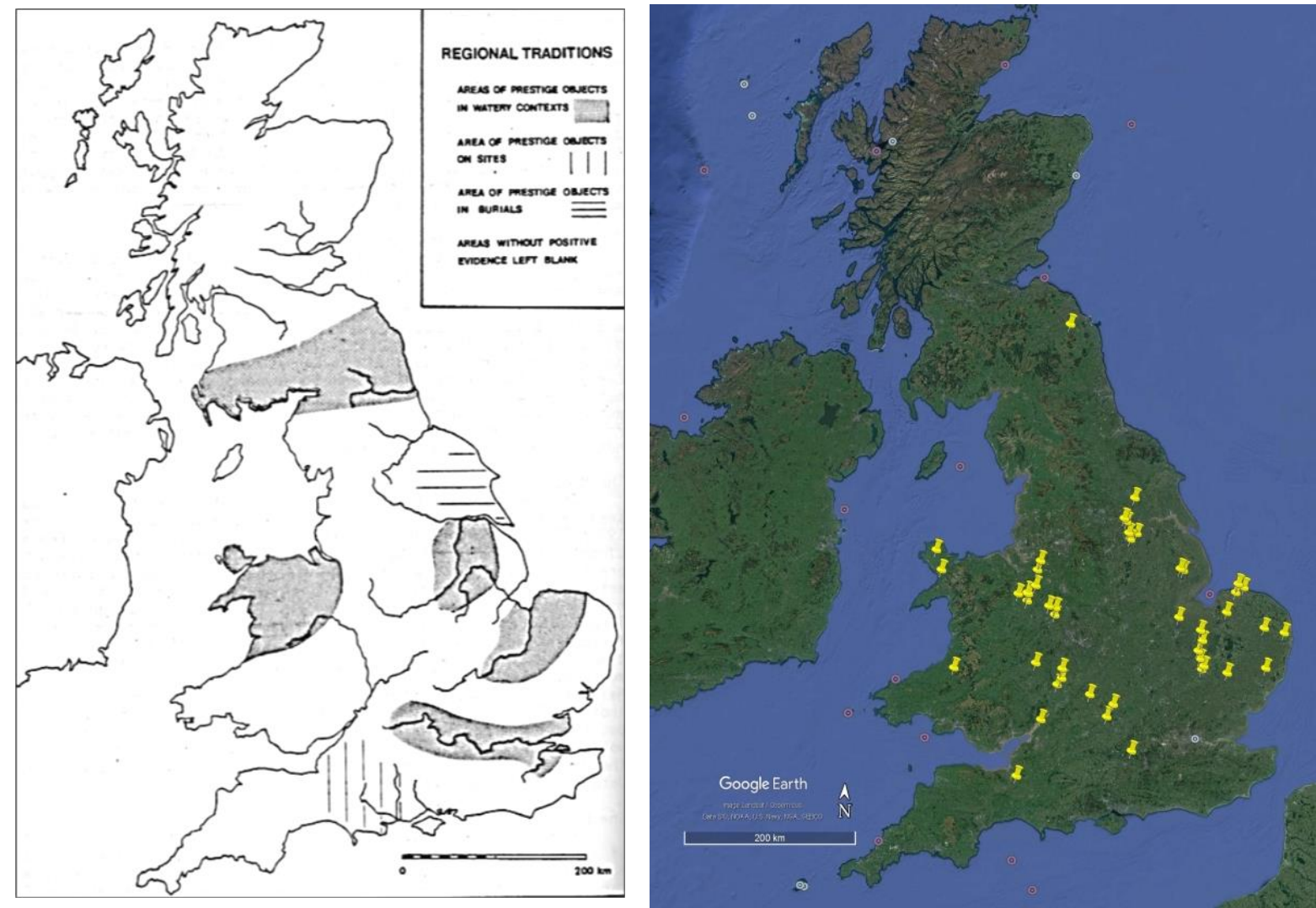

Fig. 9-1 Regional traditions of metalwork deposition in the Iron Age (Wait, 1985:Fig. 2.13) and marsh-fort locations (Google Earth; April 2018)

Many of the marsh-forts in this sample evince a lengthy chronology that preceded the Iron Age Cherbury, Stonea Camp, Sutton Common, and Wardy Hill to name but a few. This may simply indicate locations that were, over time, recognised as important centres for controlling the surroundings and providing a good living. However, landscapes of deposition were also landscapes of memory (Fontijn, 2002:260) and several (Sutton Common, Holkham, the Berth, possibly Wall 
Camp) show that usage was discontinuous and that memory, spanning chronological gaps, was passed down through the generations. Sutton Common showed that usage was different at different times, suggesting that use of the monument was reinvented during its history; this may also be true of the Berth.

Although not always associated with defined burials, human remains are not unusual finds in either marsh-fort or hillfort contexts. Of the marsh-forts reviewed in this thesis, they were recovered from Arbury, Burgh, Holkham, Stonea Camp and Wardy Hill. Sutton Common is unique in this survey as the only marsh-fort to evince cremated human remains in quantity, specifically placed and clearly ritualistic in nature. Animal remains are also common on both hillfort and marsh-fort sites; for example, the defleshed horse's skull at Borough Fen may be a foundation deposit.

It seems a short step to link ceremonial activity with feasting, and the Berth Cauldron presents evidence for this activity. However, with the exception of Aslockton (Chadwick, 2010:372), it is unique amongst the sites reviewed. Charred grain deposits have also been linked to feasting activity (van der Veen and Jones, 2006), and these accompanied some of the mortuary deposits at Sutton Common.

\subsection{Conclusions}

The purpose of archaeological research is to extract meaning and understanding from the data available and so provides an interpretation of past events and actions (Barrett, 1988; 1999a). One of the aims of this thesis was to construct a site narrative for marsh-forts and to start the process of interpretive discourse so that they might be better understood (see 1.3). This research has shown that, like hillforts, marsh-forts were a multi-faceted phenomena, variable across space and time, and exist on a spectrum.

This thesis began by outlining the central problem associated with marsh-forts - sizeable monuments, architecturally similar to hillforts, located in wetland, which did not adhere to one of the major tenets of hillforts - visibility. Despite the importance of wetlands to Iron Age society and notwithstanding the palaeoenvironmental resources that their settings could offer, these monuments have been overlooked in archaeological research. Knowledge was restricted to one example - Sutton Common - which combined size, monumental architecture and an extreme wetland setting with non-domestic evidence that suggested periodic ritual use by a (local) community.

Sutton Common was not alone. Other Iron Age wetland monuments across England and Wales evince similar although not always identical characteristics. Some show a greater propensity for 
ritualised metalwork deposition which is not apparent at Sutton Common, and others suggest a greater degree of interaction within a socially structured landscape. Of all the sites reviewed, the Berth is the closest comparator, and, notwithstanding its lack of human remains, the similarities are striking.

The Berth and Sutton Common are 150km apart and one of the questions posed the beginning of this thesis was whether marsh-forts were culture-specific, convergent or universal. The evidence suggests that they are unlikely, on topographical grounds alone, to be universal and are manifestly environmentally contingent. They appear to be a convergent phenomenon: -

'If there are limited ways to adapt to a given environmental circumstance, then we would expect (species) occupying similar environments to convergently evolve the same adaptions, and that's exactly what happens.' (Losos, 2017:5).

In exploring whether human evolution was predictable and repeatable, Losos concluded that both sets of forces - the random and the predictable - give rise to what we call history, and that '...convergent evolution usually results from the conjunction of a limited number of optimal solutions ... development, and ecology funnelling adaptation in the same direction.' (Losos, 2017:334). This may be the lesson to take away from the marsh-fort phenomenon.

In order to understand marsh-forts better we must set them in their landscape context and this research has highlighted the meagre evidence available for the communities who utilised lowlands and wetlands during the Iron Age. The creation of hillforts reworked the structure of certain regions in the Iron Age landscape, redefining the concept of land tenure for upland living. Marsh-forts may have acted similarly but in different topographic locations and with different rules.

\subsection{Marsh-forts - a theory}

'The failure to develop low and middle-range theory in archaeology has much to do with the doubts held by archaeologists as to whether it is really needed at all' (Murray and Walker, 1988:285).

This section fulfils the final objective outlined in the introduction to this thesis.

A robust understanding of any archaeological phenomenon requires the construction of a theory, without which, according to Murray and Walker, archaeological argument rarely rises above the eclectic (1988:285). Systematic observation and research of the evidence lead to a hypothesis, which is tested to provide an explanation - a theory - of a past phenomenon, capable of being re-tested and either proven or overturned. Without a systemic approach, the interpretation of prehistoric phenomena can deteriorate into guesswork. 
Research into marsh-forts is probably not yet at the theoretical stage. Nevertheless, as a step along that road, this thesis has drawn together a body of evidence from a number of Iron Age sites and compared their features to the only acknowledged marsh-fort - Sutton Common. As a consequence, marsh-forts can be seen as:

- Middle-Late Iron Age monumental structures defined by their wetland locations, which exercised control - ceremonial, ritual, territorial and possibly economic - over the surrounding waterscape, often as the largest fortification for many miles.

- fulfilling a community function as places where a range of socially cohesive activities were enacted, from the gathering of stock to the curation of human remains to the deposition of treasured goods, possibly acting as a bridge between depositionary sites and ritual enclosures

Their 'specialness' may have been retained in collective memory and spanned the generations. They were 'hillforts' in extreme topography, fulfilling many of the same functions but serving the community differently with more emphasis on ceremonial and ritual activities. Whilst Sutton Common has been used throughout this thesis as the hypothesis, this final review has demonstrated that it is unique in several respects and that other sites, perhaps the Berth and Wall Camp appear to share greater functional, chronological and landscape patterning. Perhaps Sutton Common is the most singular marsh-fort of all. 


\section{Future Research}

It is appropriate to identify aspects of this work which could have been approached differently or could have been investigated in greater detail. This chapter reviews these issues and aims to act as a stimulus for further research.

\subsection{The Berth}

Of all the marsh-forts studied in this thesis, the Berth offers the closest match to Sutton Common and, notwithstanding two untested examples in Wales, is the most westerly of its genre. Its size, wetland setting and complexity, together with the deposition of the Berth Cauldron, suggest this was an important place in the later prehistory of North Shropshire.

Despite being subject to sporadic excavation, schematic mapping (maps by both Tyler and Smithson are held in the HER) and television interest (Schofield's Quest, 1995, Michael Hurll Television), the Berth is under-researched. As a minimum, the site requires a thorough topographical survey. The 1960s excavations concentrated on the main enclosure and were never published, leaving an obvious gap. A review and analysis of the artefacts is outstanding and it would be a bonus if the missing items such as the currency bars and the chain could be located. Re-excavation of the main enclosure should be a priority to establish usage and chronology; in particular, the extent and nature of the structures found by Gelling should be revisited. The current dating strategy is reliant on a fifty year-old ceramic analysis; good though it is, a thorough approach to dating individual occupational layers is needed. The small enclosure has been subject to geophysical investigation only (Gaffney, 1995; Smalley, 2011). Whilst a number of anomalies were identified including possible wooden structures and a ring-ditch, no ground truthing was undertaken and its function and chronology remain unclear. Investigating the burnt mound between the two enclosures may indicate whether the peat basin was in use before the Iron Age.

The palaeoenvironmental investigation in this thesis provides an almost complete Holocene sequence. Whilst it has addressed a percentage of the area surrounding the monument, there may be additional pockets in the peat which hold Iron Age material. Bayesian modelling of the radiocarbon dating sequence would also produce a more robust chronology for peat development and the extent of open water surrounding the Berth's two enclosures. For obvious reasons, this thesis has focussed on the Iron Age, but the presence of charred organic remains may suggest Mesolithic or Neolithic use of the reed-bed and wet woodland. 
Whilst recent excavational evidence indicates that the upstanding causeways are post-medieval, the underlying deposits have been dated to the Iron Age; this conundrum remains substantially unresolved. However, this excavational evidence does not preclude an access route into the main enclosure from a north-eastern causeway, offering the possibility of a processional route into, around and through the main enclosure. A viewshed analysis could produce a series of 'reveals' similar to those undertaken at Sutton Common (Chapman, 2000).

Much could be achieved at the Berth through the medium of non-invasive archaeology. Geophysical prospection of the unusually flat summit of Berth Hill may ascertain whether it had been artificially flattened and/or used for occupation. Positive magnetic anomalies could indicate areas used for metalworking. Metal detecting, especially near Berth Pool, could be of value in finding additional deposited metalwork.

Each piece of investigation would help to fill in the jigsaw of how the marsh-fort functioned and its status within the later prehistoric community of North Shropshire.

\subsection{Marsh-forts in North Shropshire}

The Berth's wider landscape potential remains largely untapped and the archaeology of the Upper Perry presents numerous opportunities for investigation. Whilst this valley mire was a place of ritual deposition during the Bronze Age, this thesis has proposed that, during the Iron Age, ceremonial focus shifted south to the Berth. Investigation of the deposition site at Tetchill Brook could be revealing especially if additional coeval Iron Age material was identified, offering the possibility of dual areas of ritual practice on the North Shropshire Plain. There is a lack of recent research and the absence of a comprehensive synopsis of hillfort chronology, morphology and social impact for northern Shropshire, and the interactions between the Berth and the surrounding hillforts also warrants further exploration. The land to the south and east of the Berth which includes the enclosures of Preston Springs and Bomere Heath appears comparatively empty but has not been explored in detail.

The Berth and Wall Camp may have acted as local centres of control during the Middle/Late Iron Age but Wall Camp has been subject to less investigation than the Berth. This project has established that Wall Camp's palaeoenvironmental archive is damaged but not extinguished, and areas to the east of the camp may provide organic material contemporary with the marsh-fort. Its morphology is potentially as interesting as that of the Berth, with ramparts of phased construction and at least one causeway leading to a deeper wetland. The 1980's excavation (Bond, 1991) identified features which suggest domestic usage, but the scale of the monument appears out of proportion with the scale of 
the settlement, and existed on the Weald Moors in isolation from other Iron Age enclosures. Whilst Wall Camp may have functioned as a stock corral, this does not preclude a separate function.

Of the other potential marsh-fort sites in North Shropshire, Whittington and Stocketts Enclosure are medieval fortifications built on Iron Age foundations and their locations suggest that they controlled the surrounding wetland. The other sites identified in this thesis are less convincing but, building on The Rounds Mounds Project (Leary, 2017), the motte-and-bailey castles of Pan Castle and Belan Bank may also contribute valuable information. If collectively these sites represent a group of marshforts, it would be valuable to establish whether their chronology was synchronous and their functionality shared.

\subsection{Marsh-forts across England and Wales}

The selection criteria adopted by this thesis are adequate as a first pass, but greater complexity is required in order to predict future marsh-fort sites and examine those identified in more detail.

The approach to investigating marsh-forts nationally should take advantage of the unparalleled opportunities offered for palaeoenvironmental research and landscape analysis. Micro-scale landscape studies have evolved to see landscape as a process rather than a static entity, reflecting technological change and climatic deterioration, loss of fertility and soil erosion, peat growth, shifts in forest margins and river courses, and increased/decreased flooding. These changes may have been gradual and cumulative, or dramatic and catastrophic. Further study could address these issues through palaeotopographical study and multi-proxy palaeoenvironmental analysis. Macro-scale landscape analysis could address question such as territorial influence, land tenure and settlement patterns, morphology and ritual affinities which have only been touched on in this thesis. The geographical scope could extend to cover Scotland and look for parallels on Continental Europe.

The ultimate aim should be to build on the research in this thesis to develop a rich, detailed and testable narrative for the life and death of a marsh-fort, its daily life and practice, its relationships with previous and contemporary monuments and its contribution to the ongoing debate regarding the distinction between ritual and domestic practice in Iron Age Britain.

\subsection{Conclusions}

If Sutton Common fulfilled a specialised role as it appears to have done, others may have functioned similarly, but as Robbins pointed out, it is only through interpretive discourse that a 'past' emerges (Robbins, 1999:43). This thesis began with the observation that marsh-forts are a neglected monument class which, because of their topographical situation and aided by their palaeoenvironmental archive, have the potential to expand knowledge of Iron Age societal 
structures. It is hoped that the research presented in this thesis shows marsh-forts as a cohesive site-type, and acts as a spring board for further research. 


\section{BIBLIOGRAPHY}

Aalbersberg, G. and Brown, T. 2011. 'The Environment and Context of the Glastonbury Lake Village: A Re-assessment', Journal of Wetland Archaeology 10 (1), 136-151.

Alcock, L. 1965. 'Hillforts in Wales and the Marches', Antiquity 39 (155), 184-195.

Allen, P. and Waddington, C. 2007. Pollen Analysis from Lanton Quarry, Northumberland. ARS Ltd. Report 18.

Allen, T.G. 1993. Abingdon Vineyard Area 3. Summary report of excavations and statement of potential Oxford Archaeological Unit.

Alley, R.B. and Ágústsdóttir, A.M. 2005. 'The 8k event: cause and consequences of a major Holocene abrupt climate change', Quaternary Science Reviews 24, 1123-1149.

Anderson, A. 1991. 'The chronology of colonization in New Zealand', Antiquity 65 (249), 767-795.

Andresen, S.T. and Karg, S. 2011. 'Retting pits for textile fibre plants at Danish prehistoric sites dated between 800 b.c. and a.d. 1050', Vegetation History and Archaeobotany 20, 517-526.

Andrews, G., Barrett, J.C. and Lewis, J.S.C. 2000. 'Interpretation not record: the practice of archaeology', Antiquity (74), 525-530.

Appleton-Fox, N. 2002. Ruyton Road, Baschurch, Shropshire, A Report on an Archaeological Assessment and Field Evaluation. Marches Archaeology Series. Report 240.

Arkell, W.J. 1939. 'The site of Cherbury Camp', Oxoniensia IV, 196-197.

Armada, X. and Moore, T. 2011. Atlantic Europe in the first millennium BC: crossing the divide. Oxford.

Armit, I. 2011. 'Violence and society in the deep human past', The British Journal of Criminology 51 (3), 499-517.

Armit, I. 2007. 'Hillforts at War: From Maiden Castle to Taniwaha Pā', Proceedings of the Prehistoric Society 73, 25-37.

Armit, I., Swindles, G.T., Becker, K. et al. 2014. 'Rapid climate change did not cause population collapse at the end of the European Bronze Age', http://www.pnas.org/content/pnas/111/48/17045.full.pdf (accessed January 2018).

Aston, M. 1985. Interpreting the landscape: landscape archaeology in local studies. London.

Atkinson, D. 1942. Report on excavations at Wroxeter (the Roman city of Viroconium) in the County of Salop 1923-1927. Oxford.

Atkinson, M.D. 1992. 'Betula Pendula Roth (B. Verrucosa Ehrh.) and B. Pubescens Ehrh', Journal of Ecology 80 (4), 837-870.

Atkinson, M.D. and Atkinson, E. 2002. 'Sambucus nigra L.', Journal of Ecology 90 (5), 895-923.

Auden, J.E. 1918. Shropshire. 2nd ed. London.

Bagshaw, S. (1851) 'History, gazetteer, and directory of Shropshire'. Sheffield.

Bailey, G. 2007. 'Time perspectives, palimpsests and the archaeology of time', Journal of Anthropological Archaeology 26 (2), 198-223.

Bailey, G. 1981. 'Concepts, Timescales and Explanations in Economic Prehistory' in A. Sheridan and G. Bailey (eds.), Economic Archaeology: Towards an Integration of Ecological and Social Approaches BAR 96, Oxford. 97-117. 
Baker, J.A. 1967. The Peregrine. London.

Balaam, N.D., Smith, K., Wainwright, G.J., et al. 1982. 'The Shaugh Moor Project: Fourth Report - Environment, Context and Conclusion', Proceedings of the Prehistoric Society 48, 203-278.

Banham, D. and Faith, R. 2014. 'Anglo-Saxon Farms and Farming', http://www.oxfordscholarship.com/view/10.1093/acprof:oso/9780199207947.001.0001/acprof-9780199207947 (accessed October 2017)

Barber, J.W. and Crone, B.A. 1993. 'Crannogs; a diminishing resource? A survey of the crannogs of southwest Scotland and excavations at Buiston Crannog', Antiquity 67 (256), 520-533.

Barber, K.E. 1982. 'Peat-bog stratigraphy as a proxy climate record' in Harding, A.F.(ed.) Climatic change in later prehistory Edinburgh. 103-113.

Barber, K.E., Chambers, F.M. and Maddy, D. 2003. 'Holocene palaeoclimates from peat stratigraphy: macrofossil proxy climate records from three oceanic raised bogs in England and Ireland', Quaternary Science Reviews 22 (5-7), 521-539.

Barber, K.E., Chambers, F.M., Maddy, D., and Stoneman, R. 1994. 'A sensitive high-resolution record of late Holocene climatic change from a raised bog in northern England'. The Holocene (4.2), 198-205.

Barber, K.E. and Coope, G.R. 1987. 'Climatic history of the Severn Valley during the last 18,000 years', in K.J. Gregory, J. Lewin and J.B.Thomes (eds.), Palaeohydrology in Practice Chichester. 201-216.

Barber, K.E. and Twigger, S.N. 1987. 'Late Quaternary Palaeohydrology of the Severn Basin', in K.J. Gregory, J. Lewin and J.B.Thomes (eds.), Palaeohydrology in Practice Chichester. 217-250.

Barfield, L.H. and Hodder, M. 1987. 'Burnt mounds as saunas, and the prehistory of bathing', Antiquity 61 (233), 370-379.

Barker, P. 1973. Excavations on the site of the baths basilica at Wroxeter (Viroconium Cornoviorum) 1966-1973: an interim report. Birmingham.

Barker, P., Haldon, R.A. and Jenks, W.E. 1991. Prehistory in Lowland Shropshire: Excavations at Sharpstones Hill near Shrewsbury 1965-1971. Transactions of the Shropshire Archaeological and Historical Society LXVII, 15-57.

Barrett, J.C. 1999a. 'Chronologies of Landscape', in Ucko, P.J. and Layton, R. (eds.) The Archaeology and Anthropology of Landscape. London. 21-30.

Barrett, J.C. 1999b. 'The Mythical Landscapes of the British Iron Age', in Ashmore, W. and Knapp, A. (eds.) Archaeologies of landscape: contemporary perspectives. Oxford. 253-265.

Barrett, J.C. 1994. Fragments from antiquity: an archaeology of social life in Britain 2900-1200 BC. Oxford

Barrett, J.C. 1989. 'Food, gender and metal: questions of social reproduction', in Stig-Sørensen, M. and Thomas, R. (eds.), The Bronze Age-Iron Age transition in Europe: aspects of continuity and change in European societies C.1200-500 B.C. Oxford. 304-320.

Barrett, J.C. 1988. 'Fields of Discourse: Reconstituting a Social Archaeology', Critique of Anthropology 7, 5-16.

Bartington Instruments 2007. 'Grad 601 Cherbury Camp, Charney Bassett', http://www.bartington.com/Literaturepdf/Case\%20Studies/Grad601\%20in\%20Archaeology\%20\%20Cherbury\%20Camp\%20-\%20Charney\%20Bassett.pdf (accessed June 2017).

Bartley, D.D. 1962. 'The Stratigraphy and Pollen Analysis of Lake Deposits near Tadcaster, Yorkshire', New Phytologist 61 (3), 277-287.

Bartley, D.D. and Morgan, A.V. 1990. 'The palynological record of the King's Pool, Stafford, England', New Phytologist 116 (1), 177-194. 
Batchelor, C.R., Branch, N.P., Allison, E.A., Austin, P.A., Bishop, B., Brown, A.D.; Elias, S.A., Green, C.P., and Young, D.S. 2014. 'The timing and causes of the Neolithic elm decline: New evidence from the Lower Thames Valley (London, UK)', Environmental Archaeology 19 (3), 263-290.

Bayliss, P. 1991.'Some Shrosphire Burnt Stone Sites', in Hodder, M. and Barfield, L.H. (eds.) Burnt mounds and hot stone technology: papers from the Second International Burnt Mound Conference, Sandwell, 12th-14th October 1990. West Bromwich, 21-25.

Beales, P.W. 1980. 'The late Devensian and Flandrian vegetational history of Crose Mere, Shropshire', New Phytologist 85, 133-161.

Bedwin, O., Rudling, D., Hamilton, S., Drewett, P. and Petzoldt, K. 1980. 'Excavations at Chanctonbury Ring, Wiston, West Sussex 1977', Britannia 11, 173-222.

Behre, K. 1981. 'The interpretation of anthropogenic indicators in pollen diagrams', Pollen et spores 23, 225-245.

Behre, K. 1992. 'The history of rye cultivation in Europe', Vegetation History and Archaeobotany 1, 141-156.

Bell, M. Caseldine, A. and Neumann, H. 2000. Prehistoric intertidal archaeology in the Welsh Severn Estuary. York.

Bell, M. and Neumann, H. 1997. 'Prehistoric Intertidal Archaeology and Environments in the Severn Estuary, Wales', World Archaeology 29 (1), 95-113.

Bender, B. 1998. Stonehenge: making space. Providence RI and Oxford.

Bender, B. 1993. 'Landscape - Meaning and Action', in Bender, B. (ed.) Landscape: politics and perspectives. Providence RI and Oxford. 1-17.

Bender, B. 1993. Landscape: politics and perspectives. Providence RI and Oxford.

Bender, B., Hamilton, S. and Tilley, C. 1997. 'Leskernick: Stone Worlds; Alternative Narratives; Nested Landscapes', Proceedings of the Prehistoric Society 63, 147-178.

Bennett, K.D. 1989. 'A provisional map of forest types for the British Isles 5000 years ago', Journal of Quaternary Science 4 (2), 141-144.

Bennett, K.D. 1983. 'Devensian Late-Glacial and Flandrian vegetational history at Hockham Mere, Norfolk, England', New Phytologist 95 (3), 457-487.

Berggren, G. 1969. Atlas of seeds and small fruits of Northwest-European plant species. Part 2, Cyperaceae. Stockholm.

Bersu, G. 1940. 'Excavations at Little Woodbury, Wiltshire', Proceedings of the Prehistoric Society 6, 30-111.

Bevan, B. 1999. Northern Exposure: interpretative devolution and the Iron Ages in Britain. Leicester.

Binford, L.R. 1964. 'A Consideration of Archaeological Research Design', American Antiquity 29 (4), 425-441.

Binford, L.R. 1962, 'Archaeology as Anthropology', American Antiquity 28 (2), 217-225.

Binford, L.R. and Binford, S.R. 1968. New perspectives in archeology. Chicago.

Birks, H.H. 2001. 'Plant macrofossils' in Smol, J.P. Birks, H.J.B. and Last, W.M. (eds.) Tracking environmental change using Lake Sediments Volume 3: Terrestrial, Algal, and Siliceous Indicators. Amsterdam, 49-74.

Birks, H.H. 2003. 'The importance of plant macrofossils in the reconstruction of Lateglacial vegetation and climate: examples from Scotland, western Norway and Minnesota, USA', Quaternary Science Reviews 22, 453-473. 
Birks, H.H. and Birks, H.J.B. 2011.' Introduction to Quaternary Palaeoecology', http://www.uib.no/filearchive/quatpalaeo_intro.pdf 2017 (accessed Junne 2017).

Birks, H.H. and Birks, H.J.B. 2005. 'Reconstructing Holocene climates from pollen and plant macrofossils', in Mackay, A. (ed.) Global change in the Holocene London. 342-357.

Birks, H.H. and Birks, H.J.B. 2006. 'Multi-proxy studies in palaeolimnology', Vegetation History and Archaeobotany 15 (4), 235-251.

Birks, H.J.B. 1982. 'Mid-Flandrian forest history of Roudsea Wood National Nature Reserve, Cumbria', New Phytologist 90 (2), 339-354.

Birks, H.J.B. 1989. 'Holocene Isochrone Maps and Patterns of Tree-Spreading in the British Isles', Journal of Biogeography 16 (6), 503-540.

Blaauw, M., van der Plicht, J. and van Geel, B. 2004. 'Radiocarbon dating of bulk peat samples from raised bogs: nonexistence of a previously reported 'reservoir effect'?', Quaternary Science Reviews 23 (14-15), 1537-1542.

Blockley, M. and Shaw, M. Caldon Low Early Railways Project. (unpublished).

Bond, D. 1991. 'An Excavation at Wall Camp, Kynnersley', Transactions of the Shropshire Archaeological and Historical Society LXVII, 98-105.

Boswijk, G. and Whitehouse, N.J. 2002. 'Pinus and Prostomis: A dendrochronological and palaeoentomological study of a mid-Holocene woodland in eastern England.' The Holocene 12 (5), 585-596.

Bourdieu, P. 1977. Outline of a theory of practice, trans R. Nice. Cambridge.

Bourke, J.B. Brothwell, D.R. and Stead, I.M. 1986. Lindow Man: the body in the bog. London.

Bowden, M. 2006. “Guard Chambers': an Unquestioned Assumption in British Iron Age Studies', Proceedings of the Prehistoric Society 72, 423-436.

Bowden, M. 2005. The Malvern Hills: an ancient landscape. London.

Bowden, M. and McOmish, D. 2012. 'A British Tradition? Mapping the Archaeological Landscape', Landscapes 12 (2), $20-40$.

Bowden, M. and McOmish, D. 1989. 'Little Boxes: More about hillforts', Scottish Archaeological Review 6, 12-16.

Bowden, M. and McOmish, D. 1987. 'The required barrier', Scottish Archaeological Review 4, 76-84.

Bradford, J.S.P. 1951. 'Excavations at Cassington, Oxon, 1947', Oxoniensia XVI (1)

Bradford, J.S.P. 1940. 'The excavations at Cherbury Camp,1939', Oxoniensia V, 13-20.

Bradley, R. 1987. 'Stages in the Chronological Development of Hoards and Votive Deposits', Proceedings of Prehistoric Society 53, 351-362.

Bradley, R. 1990. The passage of arms: an archaeological analysis of prehistoric hoards and votive deposits. Cambridge.

Bradley, R. 1991. 'The pattern of change in British prehistory', in Earle, T. (ed.) Chiefdoms: Power, Economy and Ideology. Cambridge. 44-70.

Bradley, R. 2000. An archaeology of natural places. London.

Bradley, R. 2005. Ritual and domestic life in prehistoric Europe. London. 
Bradley, R. and Yates, D. 2007. 'After Celtic Fields: the social organisation of Iron Age agriculture', in Haselgrove, C. and Pope, R. (eds.) The Earlier Iron Age in Britain and the Near Continent Oxford. 94-102.

Bradshaw, R.H.W. 1981. 'Modern Pollen-Representation Factors for Woods in South-East England', Journal of Ecology 69 (1), 45-70.

Britnell, W.J., Britnell, J., Darvill, T., Greep, S., Healey, E., Howard, H., Jones, G., Jones, G., Keeley, H.C.M., Milles, A., Morgan, G.C., Morris, E., Spratling, M.G., Webster, J. and Webster, P.V. 1989.'The Collfryn Hillslope Enclosure, Llansantffraid Deuddwr, Powys: Excavations 1980-1982', Proceedings of the Prehistoric Society 55, 89-134.

Britnell, W.J. and Earwood, C. 1991. 'Wooden Artefacts and other worked wood from Buckbean Pond', in Musson, C.R. Britnell, W.J. and Smith, A.G. (eds.) The Breiddin Hillfort: a later prehistoric settlement in the Welsh Marches. London. 161172.

Broström, A., Nielsen, A.B., Gaillard, M.J. 2008. Pollen productivity estimates of key European plant taxa for quantitative reconstruction of past vegetation: a review. Vegetation History and Archaeobotany, 17, 461-478.

Brown, A.G. 1988. 'The palaeoecology of Alnus (alder) and the Postglacial history of floodplain vegetation. Pollen percentage and influx data from the West Midlands, United Kingdom', New Phytologist 110 (3), 425-436.

Brown, A.G. 1990. 'Holocene floodplain diachronism and inherited downstream variations in fluvial processes: A study of the river Perry, Shropshire, England', Journal of Quaternary Science 5 (1), 39-51.

Brown, A.G. 1991. 'Hydrogeomorphological changes in the Severn basin in the last 15,000 years: Orders of change in a maritime catchment', in Starkel, L. Gregory, K.J. and Thornes, J.B. (eds.) Temperate palaeohydrology: fluvial processes in the temperate zone during the last 15000 years Chichester. 147-169.

Brown, A.G. 1997. Alluvial geoarchaeology : floodplain archaeology and environmental change. Cambridge.

Brown, A.G. 1999. 'Characterising prehistoric lowland environments using local pollen assemblages', Journal of Quaternary Science 14 (6), 585-594.

Brown, A.G. 2008. 'The Bronze Age climate and environment of Britain', Bronze Age Review; Volume 1. The British Museum.

Brown, A.G. and Barber, K.E. 1985. 'Late Holocene paleoecology and sedimentary history of a small lowland catchment in central England', Quaternary Research 24 (1), 87-102.

Brown, I. 2008. Beacons in the landscape: the hillforts of England and Wales. Oxford

Brown, P. 2003. Whittington Castle Guidebook. Whittington Castle Preservation Trust/English Heritage.

Brown, R.A. 1951. Baschurch; a brief survey of its history and more interesting features. Shropshire Archives XLS5057.

Brück, J. 1999. 'Ritual and rationality: some problems of interpretation in European archaeology', European Journal of Archaeology 2 (3), 313-344.

Brück, J. 2000. 'Settlement, Landscape and Social Identity: The Early-Middle Bronze Age Transition in Wessex, Sussex and the Thames Valley', Oxford Journal of Archaeology 19 (3), 273-300.

Buckland, P.I. 2000. An Introduction to Palaeoentomology in Archaeology and the BUGS Database Management System. Umeå

Buckland, P.I. and Buckland, P.C. 2006. Bugs Coleopteran Ecology Package (Versions: BugsCEP v7.63; Bugsdata v8.0; BugsMCR v2.02; BugStats v1.22) www.bugscep.com. (downloaded: September 2015).

Buckland, P.C. 1979. 'Thorne Moors: a palaeoecological study of a Bronze Age site : a contribution to the history of the British insect fauna. Occasional Publication No.8 University of Birmingham. 
Buckland, P.C., Parker Pearson, M., Wigley, A., and Girling, M. 2001. 'Is There Anybody Out There? A Reconsideration of the Environmental Evidence from the Breiddin Hillfort, Powys, Wales', The Antiquaries Journal 81, 51-76.

Buckler, J. 1787 - 1897. Buckler Drawings: Shropshire: Views: 182. British Library Collection.

Budd, P. and Taylor, T. 1995. 'The Faerie Smith Meets the Bronze Industry: Magic Versus Science in the Interpretation of Prehistoric Metal-Making', World Archaeology 27 (1), 133-143.

Bulleid, A. 1968. The lake villages of Somerset. 6th ed. Glastonbury.

Bullock, J.A. 1992. 'Host plants of British beetles: a list of recorded associations', The Amateur Entomologist 11a. Brentwood.

Bunting, M.J., Gaillard, M., Sugita, S., Middleton, R., Broström, A. 2004. 'Vegetation structure and pollen source area', The Holocene 14 (5), 651-660.

Burgess, C. 1981. The dirks and rapiers of Great Britain and Ireland. München

Burnham, C. and Mackney, D. 1964. 'Soils of Shropshire', Field Studies 2 (1), 83-113.

Buteux, S., Gaffney, V., White, R.H., van Leusen, M. 2000. 'Wroxeter Hinterland Project and geophysical survey at Wroxeter', Archaeological Prospection 7 (2), 69-80.

Buteux, S. and Hughes, G. 1995. 'Reclaiming a wilderness: the prehistory of Shropshire', Transactions of the Shropshire Archaeological Society LXX, 159-170.

Butzer, K.W. 1978. 'Toward an integrated, contextual approach in archaeology: a personal view', Journal of Archaeological Science 5 (3), 191-193.

Campbell, I.D. 1999. 'Quaternary pollen taphonomy: examples of differential redeposition and differential preservation', Palaeogeography, Palaeoclimatology, Palaeoecology 149 (1-4), 245-256.

Cantrill, T.C. 1908. 'Geology' in Page, W. (ed.) The Victoria history of Shropshire. Vol. 1 London. 1-46.

Cappers, R.T.J. Bekker, R.M. and Jans, J.E.A. 2006. Digitale Zadenatlas van Nederland. (Digital Seed Atlas of the Netherlands). Groningen Archaeological Studies Vol.4. Zuurstukken

Carlisle, A. and Brown, A.H.F. 1968. 'Pinus Sylvestris L.', Journal of Ecology 56 (1), 269-307.

Carrott, J., Hall, A., Kenward, H. and Large, F. 1994. 'Insect and plant remains from excavations at 16-18 Netherkirkgate, Aberdeen (site code E35): Technical report 94/59.' York.

Carrott, J. and Kenward, H. 2001. 'Species Associations Among Insect Remains from Urban Archaeological Deposits and their Significance in Reconstructing the Past Human Environment', Journal of Archaeological Science 28 (8), 887-905.

Carver, M.O.H. 1991. 'Prehistory in Lowland Shropshire: A Strategy for Lowland Shropshire', Transactions of the Shropshire Archaeological and Historical Society LXVII, 1-9.

Caseldine, C., Fyfe, R. and Hjelle, K. 2008. 'Pollen modelling, palaeoecology and archaeology: virtualisation and/or visualisation of the past?' Vegetation History and Archaeobotany 17, 543-549.

Caseldine, C. and Gearey, B.R. 2005. 'A multiproxy approach to reconstructing surface wetness changes and prehistoric bog bursts in a raised mire system at Derryville Bog, Co. Tipperary, Ireland', The Holocene 15 (4), 585-601.

Cavers, G. 2006. 'Late Bronze Age and Iron Age lake settlement in Scotland and Ireland: the development of the 'crannog' in the north and west', Oxford Journal of Archaeology 25 (4), 389-412. 
Chadwick, A. 1999. 'Digging ditches but Missing Riches? Ways into the Iron Age and Romano-British cropmark landscapes of the north Midlands', in B. Bevan (ed.), Northern Exposure: interpretative devolution and the Iron Ages in Britain. Leicester. 149-172.

Chadwick, A. 2010. Fields for Discourse: Landscape and Materialities of Being in South and West Yorkshire and Nottinghamshire during the Iron Age and Romano-British Periods. A Study of People and Place: PhD Thesis. University of Wales.

Challis, K. 2006. 'Airborne laser altimetry in alluviated landscapes', Archaeological Prospection 13 (2), 103-127.

Chambers, F.M. and Charman, D.J. 2004. 'Holocene environmental change: Contributions from the peatland archive', The Holocene 14 (1), 1-6.

Chambers, F.M., Mighall, T.M. and Keen, D.H. 1996. 'Early Holocene pollen and molluscan records from Enfield Lock, Middlesex, UK', Proceedings of the Geologists' Association 107 (1), 1-14.

Chapman, H. 2006. Landscape archaeology and GIS. Stroud.

Chapman, H. 2003. 'Rudston 'Cursus A' - Engaging with a Neolithic Monument in Its Landscape Setting Using GIS', Oxford Journal of Archaeology 22 (4), 345-356.

Chapman, H. 2000. 'Understanding wetland archaeological landscapes: GIS, environmental analysis and landscape reconstruction; pathways and narratives', in G. Lock (ed.), Beyond the map: archaeology and spatial technologies. Amsterdam and Oxford. 49-59.

Chapman, H. and Buteux, S. 2009. Where Rivers Meet. Council for British Archaeology.

Chapman, H. and Cheetham, J.L. 2002. 'Monitoring and Modelling Saturation as a Proxy Indicator for in situ Preservation in Wetlands-a GIS-based Approach', Journal of Archaeological Science 29 (3), 277-289.

Chapman, H. and Gearey, B.R. 2013. Modelling archaeology and palaeoenvironments in wetlands: the hidden landscape archaeology of Hatfield and Thorne Moors, Eastern England. Oxford.

Chapman, H. and Gearey, B.R. 2013. 'Palaeoenvironments, chronology and perception of landscape in the Neolithic: A case study from Hatfield Moors, England', in R. Schulting and N. Whitehouse, (eds.), Living Landscapes.

Chapman, H. and Gearey, B.R. 2000. 'Palaeoecology and the perception of prehistoric landscapes: some comments on visual approaches to phenomenology', Antiquity 74 (284), 316-319.

Chapman, H., Smith, D.N. and Norton, S.M. 2017. The Berth, Baschurch, Shropshire (SAM 1004770; HER129): Report on the Excavation and Post Excavation Analysis from the Berth, Shropshire 2nd to 18th June 2016. Unpublished Report to Historic England. University of Birmingham.

Chapman, H. and Van de Noort, R. 2001. 'High-Resolution Wetland Prospection, using GPS and GIS: Landscape Studies at Sutton Common (South Yorkshire), and Meare Village East (Somerset)', Journal of Archaeological Science 28 (4), 365-375.

Charman, D.J. 2002. Peatlands and environmental change. Chichester.

Charman, D.J., Caseldine, C., Baker, A., Gearey,B.R., Hatton,J., and Proctor,C. 2001. 'Paleohydrological Records from Peat Profiles and Speleothems in Sutherland, Northwest Scotland', Quaternary Research 55 (2), 223-234.

Cheetham, J.L. 2004. An assessment of the potential for in situ preservation of buried organic archaeological remains at Sutton Common, South Yorkshire. PhD Thesis. University of Hull.

Cherns, L. 2014. 'Taphonomy', in J.A. Matthews (ed.), Encyclopedia of Environmental Change. https://uk.sagepub.com/engb/eur/encyclopedia-of-environmental-change/book237846 (accessed July 2017).

Chippindale, C. 1999. 'Review: Stonehenge: Making Space by Barbara Bender', American Antiquity 64 (2), 387-388. 
Chitty, L.F. 1923-32. 'Sixth Field Excursion: The Berth and Nesscliff Hill', Offa's Field Club Transactions Shropshire Archive; Document Reference XLS20219.

Chitty, L.F. 1927. 'Dug out canoes from Shropshire', Transactions of the Shropshire Archaeological Society X1, 113-133.

Chitty, L.F. 1933. 'Bronze looped palstave from Whixall Moss, North Shropshire', Transactions of the Shropshire Archaeological and Natural History Society 4th Series (17), 73-77.

Chitty, L.F. 1937. 'How did the hillfort builders reach the Breiddin? A Tentative Explanation', Archaeologia Cambrensis (92), 129-150.

Chitty, L.F. 1937/8. 'The Berth', Transactions of the Shropshire Archaeological and Historical Society 49th ed. viii-x.

Chitty, L.F. 1953. 'Bronze Axe Hoard from Preston-on-the-Weald Moors, Shropshire', Transactions of the Shropshire Archaeological Society LIV 1951-1953, 240-254.

Chitty, L.F. 1956 a) 'An Introduction to Shropshire Archaeology', Archaeological Journal 113, 178-185.

Chitty, L.F. 1956 b) 'Report of the Summer Meeting of the Royal Archaeological Institute at Church Stretton in 1956', Archaeological Journal 113 (1), 176-222.

Chitty, L.F. 1992. Lily F. Chitty Collection: catalogue of her archaeological records relating to Shropshire. Shrewsbury.

Chiverrell, R.C. and Thomas, G.S.P. 2010. 'Extent and timing of the Last Glacial Maximum (LGM) in Britain and Ireland: a review', Journal of Quaternary Science 25 (4), 535-549.

Chowne, P., Girling, M. and Greig, J. 1986. 'Excavations at an Iron Age Defended Enclosure at Tattershall Thorpe, Lincolnshire', Proceedings of the Prehistoric Society 52, 159-188.

Ciaraldi, M. 2009. 'The Plant Macroremains - Evidence of Domestic and Industrial Activities at Edgbaston Street, Moor Street, Park Street and The Row', in S. Rátkai and C. Patrick (eds.) The Bull Ring uncovered : excavations at Edgbaston Street, Moor Street, Park Street and the Row, Birmingham, 1997-2001 Oxford. 269-294.

Clapham, A.R. Tutin, T.G. and Moors, D.M. 1987. Flora of the British Isles. 3rd ed. Cambridge.

Clark, G. 1966. 'The Invasion Hypothesis in British Archaeology', Antiquity 40 (160), 297-299.

Clark, S.H.E. and Edwards, K.J. 2004. 'Elm bark beetle in Holocene peat deposits and the northwest European elm decline', Journal of Quaternary Science 19 (6), 525-528.

Clarke, D.L. 1968. Analytical archaeology. London.

Cloutman, E.W. 1988. 'Palaeoenvironments in the Vale of Pickering', Proceedings of the Prehistoric Society 54, 1-58.

Coles, B. 1988. 'Fossil assemblages from the Somerset Levels: the work of Maureen Girling', in P. Murphy, and C. French. (eds.) The Exploitation of Wetlands. Oxford. 5-20.

Coles, B. 2006. Beavers in Britain's past. Oxford.

Coles, B. and Coles, J. 1986. Sweet Track to Glastonbury: the Somerset levels in prehistory. London.

Coles, J. 2001. 'North European bronzes, rock art, and wetlands: Looking for context and relations: A preliminary study', in B.A. Purdy (ed.), Enduring Records: The environmental and cultural heritage of wetlands Oxford, 148-157.

Collis, J. 2010. 'Why do we still dig Iron Age ramparts?' Collection Bibracte 19, 27-36. 
Coles, J. and Minnitt, S. 1995. 'Industrious and fairly civilized' : the Glastonbury Lake village'. Somerset Levels Project and Somerset County Council Museums Service.

Collis, J. 1981. 'A theoretical study of hill-forts', in G. Guilbert (ed.) Hill-fort studies: essays for A.H.A. Hogg. Leicester. 66-76.

Collis, J. 1987. 'Review: Danebury: Anatomy of An Iron Age Hillfort by Barry Cunliffe', Archaeology, 40 (2), 60-72.

Collis, J. 1996. 'Hill-forts, Enclosures and Boundaries', in T.C. Champion and J.Collis (eds.), The Iron Age in Britain and Ireland: recent trends. Sheffield. 87-94.

Collis, J. 2003. The Celts: origins, myths, inventions. Stroud.

Collis, J. 2008. 'The Earlier Iron Age in Britain and the Near Continent; The Later Iron Age in Britain and Beyond; Peer Review Journal', The Antiquaries Journal 88. 434-435.

Conolly, J. and Lake, M. 2006. Geographical Information Systems in Archaeology. Cambridge.

Conway, V.M. 1942. 'Cladium Mariscus', Journal of Ecology 30 (1), 211-216.

Cook, H.F. and Williamson, T. 1999. Water management in the English landscape : field, marsh and meadow. Edinburgh.

Coope, G.R. 1970. 'Interpretations of Quaternary Insect Fossils', Annual Review of Entomology 15 (1), 97-121.

Coope, G.R. 1978. 'Constancy of insect species versus inconstancy of Quaternary environments', in L.A. Mound and N. Waloff (eds.), Diversity of Insect Fauna Symposia of the Royal Entomological Society of London: $9^{\text {th }}$ ed. Oxford. 176-187.

Coope, G.R., Gibbard, P.L., Hall, A.R., Preece, R.C., Robinson, J.E. and Sutcliffe, A.J. 1997. 'Climatic and environmental reconstructions based on fossil assemblages from middle devensian (Weichselian) deposits of the river Thames at South Kensington, Central London, UK', Quaternary Science Reviews 16 (10), 1163-1195.

Coope, G.R., Shotton, F.W., Strachan, I. and Dance, S.P 1961. 'A Late Pleistocene Fauna and Flora from Upton Warren, Worcestershire', Philosophical Transactions of the Royal Society of London. Series B, Biological Sciences 244 (714), $379-421$.

Cooper, A.H. 2002. 'Halite karst geohazards (natural and man-made) in the United Kingdom', Environmental Geology 42, 505-512.

Cosgrove, D.E. 1998. Social formation and symbolic landscape. Madison.

Cosgrove, D.E. and Daniels, S. 1988. The Iconography of landscape: essays on the symbolic representation, design and use of past environments. Cambridge.

Coulson, J.C. and Butterfield, J. 1978. 'An Investigation of the Biotic Factors Determining the Rates of Plant Decomposition on Blanket Bog', Journal of Ecology 66 (2), 631-650.

Crawford, O.G.S. 1928. Wessex from the air. Oxford.

Crew, P. 1995. 'Currency Bars and other forms of trade iron. Archaeology Data Sheet No 8', http://histmet.org/resources/datasheets.html (accessed May 15th 2016).

Croft, J.M. and Preston, C.D. 2014. Aquatic Plants in Britain and Ireland. BRILL.

Crompton, E. and Osmond, D.A. 1954. Memoirs of the Soil Survey of Great Britain. The Soils of the Wem District of Shropshire (Sheet 138). London.

Crone, B.A. 1993. 'Crannogs and Chronologies', Proceedings of the Society of Antiquaries of Scotland 123, 245-254. 
Cunliffe, B.W. 1974. Iron Age communities in Britain: an account of England, Scotland and Wales from the seventh century B.C. until the Roman conquest. London.

Cunliffe, B.W. 1983. Danebury: anatomy of an Iron Age hillfort. London.

Cunliffe, B.W. 2000. The Danebury Environs Programme: the prehistory of a Wessex landscape. Oxford.

Cunliffe, B.W. 2005. Iron Age communities in Britain: an account of England, Scotland and Wales from the seventh century $B C$ until the Roman conquest. London.

Cunliffe, B.W. 2006. 'Understanding hillforts: have we progressed?', in A. Payne, M.Corney, B.W. Cunliffe and N.Burton (eds.), The Wessex hillforts project : extensive survey of hillfort interiors in central southern England London. English Heritage. 151-162.

Cunliffe, B.W. 2013. Britain begins. Oxford.

Cunliffe, B.W. 1991. Iron Age communities in Britain: an account of England, Scotland and Wales from the seventh century $B C$ until the Roman Conquest. London.

Dark, P. 2006. 'Climate deterioration and land-use change in the first millennium BC: perspectives from the British palynological record', Journal of Archaeological Science 33 (10), 1381-1395.

Darvill, T. 1999. 'The historic environment, historic landscapes, and space-time-action models in landscape archaeology', in P.J. Ucko, P.J. and R. Layton (eds.), The Archaeology and Anthropology of Landscape. London. 104-118.

Davidson, J. 1987. The Prehistory of New Zealand. Auckland.

Davies, A.L. and Tipping, R. 2004. 'Sensing small-scale human activity in the palaeoecological record: Fine spatial resolution pollen analyses from Glen Affric, Northern Scotland', The Holocene 14 (2), 233-245.

Davies, J.A. Gregory, T. Lawson, A.J., Rickett R. and Rogerson A. 1992. The Iron Age forts of Norfolk. East Dereham.

de Groot, W.J., Thomas, P.A. and Wein, R.W. 1997. 'Betula Nana L. and Betula Glandulosa Michx', Journal of Ecology 85 (2), 241-264.

De Vleeschouwer, F., Chambers, F.M. and Swindles, G.T. 2010. 'Coring and sub-sampling of peatlands for palaeoenvironmental research', Mires and Peat 7 (1), 1-10.

Devereux, P. 1991 'Three-dimensional aspects of apparent relationships between selected natural and artificial features within the topography of the Avebury complex', Antiquity 65 (249), 894-898.

Dickson, C.A. 1970. 'The Study of Plant Macrofossils in British Quaternary Deposits', in D. Walker and R.G. West (eds.), Studies in the vegetational history of the British Isles : essays in honour of Harry Godwin. London. 233-254.

Dincauze, D.F. 2000. Environmental archaeology: principles and practice. Cambridge.

Dineley, D.L. 1960. 'Shropshire Geology: An Outline of the Tectonic History', Field Studies 1 (2), 86-107.

Dinnin, M. 1997. 'Holocene beetle assemblages from the Lower Trent floodplain at Bole Ings, Nottinghamshire, U.K.', in A.C. Ashworth, P.C. Buckland and J.P. Sadler (eds.) Studies in Quaternary Entomology: an inordinate fondness for insects Chichester. 83-104.

Dinnin, M. and Caseldine, C. 2014. 'Late Glacial Environmental Change', in J. Matthews (ed.), Encyclopedia of Environmental Change Vol 3. https://uk.sagepub.com/en-gb/eur/encyclopedia-of-environmental-change/book237846. 631-632. (accessed May 2017)

Dinnin, M. and Sadler, J.P. 1999. '10,000 years of change: the Holocene Entomofauna of the British Isles', Journal of Quaternary Science 14 (6), 545-562. 
Dinnin, M. and Van de Noort, R. 1999. 'Wetland habitats, their resource potential and exploitation. A case study from the Humber wetlands', in B. Coles, J. Coles, and M.S.Jørgensen (eds.), Bog Bodies, Sacred Sites, and Wetland Archaeology. Exeter. 69-79.

Dobney, K., Hall, A., Kenward, H., and Milles, A. 1992. 'A working classification of sample types for environmental archaeology', Circaea 9 (1), 24-26.

Donovan, S.K. 2002. 'Taphonomy', Geology Today 18 (6), 226-231.

Dorling, P., Ray, K. and White, P. 2017. 'Herefordshire: from the Middle Bronze Age to the Later Iron Age', in D. Hurst (ed.), Westward on the High-Hilled Plains: the Later Prehistory of the West Midlands Oxford. 70-84.

Downman, E.A. 1906. Ancient earthworks of Shropshire. Hill forts, castles etc surveyed and drawn by Edward Andrews Downman. Shropshire Archive: Document reference: 6001/297.

Driver, T. 2007. 'Hillforts and Human Movement: Unlocking the Iron Age Landscapes of Mid Wales', in A. Fleming, and R. Hingley (eds.), Prehistoric and Roman landscapes: Landscape History after Hoskins. Macclesfield. 83-100.

Duff, A. 2012. Checklist of Beetles of the British Isles. Iver.

Duffy, E.A.J. 1953. Coleoptera: Scolytidae and Platypodidae (Handbooks for the Identification of British Insects 5/15). London.

Dunning, G.C. 1931. 'Salmonsbury Camp, Gloucestershire', Antiquity 5, 489-491.

Durno, S.E. 1961. 'Evidence Regarding the Rate of Peat Growth', Journal of Ecology 49 (2). 347-351.

Dyer, J. 1981. Hillforts of England and Wales. Aylesbury.

Earwood, C. 1997. 'Bog Butter: A Two Thousand Year History', The Journal of Irish Archaeology 8 ,25-42.

Ebert, D. 2004. 'Applications of Archaeological GIS', Canadian Journal of Archaeology / Journal Canadien d'Archéologie 28 (2), 319-341.

Edwards, K.J. 1999. 'Palynology and people: observations on the British record', Journal of Quaternary Science 14 (6), 531 544.

Edwards, K.J. 1979. 'Palynological and temporal inference in the context of prehistory, with special reference to the evidence from lake and peat deposits', Journal of Archaeological Science 6 (3), 255-270.

Efremov, L.A. 1940. 'Taphonomy: a new branch of paleontology', Pan American Geology 7, 81-93.

Ehrenberg, M.R. 1991. 'Some Aspects of the Distribution of Burnt Mounds', in M. Hodder and L.H. Barfield (eds.), Burnt mounds and hot stone technology: papers from the Second International Burnt Mound Conference, Sandwell, 12th-14th October 1990. West Bromwich. 41-57.

Elias, S.A. 2010a. Advances in Quaternary Entomology. Vol. 12. Elsevier Science.

Elias, S.A. 2010b. 'The Use of Insect Fossils in Archeology', Developments in Quaternary Sciences 12, 89-121.

Elias, S.A. 2010c. 'The Value of Insects in Paleoecology', Developments in Quaternary Sciences 12, 39-51.

Eliot, T.S. 1979. Four Quartets. London.

Elliott, J.M. 2008. 'The ecology of riffle beetles (Coleoptera: Elmidae)', Freshwater Reviews 1 (2), 180-203.

Ellis, P. 1993. Beeston Castle, Cheshire: Excavations by Laurence Keen \& Peter Hough, 1968-85. English Heritage. 
Ellison, A. and Drewett, P. 1971. 'Pits and Post-holes in the British Early Iron Age: some alternative explanations', Proceedings of the Prehistoric Society 37 (1): 183-194.

Ellison, A. and Harriss, J. 1972. 'Settlement and landuse in the prehistory and early history of southern England: a study based on location models', in D. Clarke (ed.), Models in Archaeology London. 911-962.

English Heritage. 2011. 'Introduction to Heritage Assets: Hillforts', https://www.english-heritage.org.uk/publications/ihahillforts/ (accessed September 2015).

English Heritage. 2011. 'Introduction to Heritage Assets: Oppida', https://historicengland.org.uk/imagesbooks/publications/iha-oppida/oppida/(accessed May 2018).

Evans, C. 2003. Power and island communities: excavations at the Wardy Hill Ringwork, Coveney, Ely. Cambridge.

Evans, C. 1998. 'Historicism, chronology and straw men: situating Hawkes' 'Ladder of inference”, Antiquity 72 (276), 398404.

Evans, C. and Hodder, I. 2006. Marshland communities and cultural landscapes from the Bronze Age to the present day. The Haddenham Project Vol. 2. Cambridge.

Evans, C. and Knight, M. 2002. 'A Great Circle: Investigations at Arbury Camp', Proceedings of the Cambridge Antiquarian Society $\mathrm{XCl}, 23-53$.

Evans, E.E. 1947. 'Bog Butter: Another Explanation', Ulster Journal of Archaeology 10, 59-62.

Farr, K.M., Jones, D.M., O'Sullivan, P.E., Eglington, G., Tarling, D.H and Hedges, R.E.M. 1991. 'Palaeolimnological studies of laminated sediments from the Shropshire-Cheshire meres', Hydrobiologia 214, 279-292.

Fay, M.F. 2011. 'New flora of the British Isles, 3rd ed (Review)', Botanical Journal of the Linnean Society 166 (4), $444-445$.

Ferrell, G. 1995. 'Space and society: New perspectives on the Iron Age of North-East England', in J.D. Hill and C.G.

Cumberpatch (eds.), Different Iron Ages: Studies on the Iron Age in temperate Europe. Oxford. 129-148.

Field, N. and Parker Pearson, M. 2003. Fiskerton: an Iron Age timber causeway with Iron Age and Roman votive offerings : the 1981 excavations. Oxford.

Fisher, C.T. and Thurston, T. 1999. 'Dynamic landscapes and socio-political process: the topography of anthropogenic environments in global perspective', Antiquity 73 (281), 630-631.

Fitch, S., Gaffney, V. and Thomson, K. 2007. Mapping Doggerland: the Mesolithic landscapes of the southern North Sea. Oxford.

Fitzpatrick, A.P. 1984. 'The deposition of La Tène Iron Age metalwork in watery contexts in Southern England', in B.W. Cunliffe and D. Miles (eds.), Aspects of the Iron Age in central southern Britain. Oxford. 178-190.

Fitzpatrick, A.P. 1994. 'Outside in: the structure of an Early Iron Age house at Dunston Park, Thatcham, Berkshire', in A.P. Fitzpatrick and E.Morris, E. (eds.), The Iron Age in Wessex : recent work. Salisbury. 68-72.

Fleming, A. 1999. 'Small scale communities and the landscape of Swaledale (North Yorkshire,UK)', in P.J. Ucko and R. Layton, R. (eds.), The Archaeology and Anthropology of Landscape. London. 65-72.

Fleming, A. 2006. 'Post-processual Landscape Archaeology: a Critique', Cambridge Archaeological Journal 16 (3), $267-280$.

Fletcher, M. and Spicer, D. 1988. 'Clonehenge: an experiment with gridded and non-gridded survey data', in S.P.Q. Ratz (ed.), Computer and Quantitive Methods in Archaeology 1988. Oxford. 309-325.

Fletcher, R. 1992. 'Time Perspectivism, Annales, and the Potential of Archaeology', in A. Knapp (ed.) Archaeology, Annales, and Ethnohistory (New Directions in Archaeology). Cambridge. 35-50. 
Fontijn, D. 2002. Sacrificial landscapes: cultural biographies of persons, objects and 'natural' places in the Bronze Age of the Southern Netherlands, C. 2300-600 BC. Leiden.

Fontijn, D. 2007. 'The Significance of 'Invisible' Places', World Archaeology 39 (1, Viewing Space), 70-83.

Forde-Johnston, J.L. 1962. 'The Iron Age Hillforts of Lancashire and Cheshire', Transactions of the Lancashire and Cheshire Antiquarian Society (72), 9-46.

Forde-Johnston, J.L. 1976. Hillforts of the Iron Age in England and Wales: a survey of the surface evidence. Liverpool.

Fossitt, J.A. 1994. 'Modern pollen rain in the northwest of the British Isles', The Holocene 4, 365-376.

Foster, G.N. 2010. A review of the scarce and threatened Coleoptera of Great Britain Part (3): Water beetles of Great Britain. Species Status. $1^{\text {st }}$ edn. Peterborough.

Foster, G.N. Bilton, D.T. and Friday, L.E. 2014. Keys to the Adults of the Water Beetles of Britain and Ireland: Part 2 (Handbooks for the Identification of British Insects). Vol 4; $5 b$. Shrewsbury.

Foster, G.N. and Friday, L.E. 2011. Keys to the Adults of the Water Beetles of Britain and Ireland: Part 1 (Handbooks for the Identification of British Insects). Vol 4, 5. Shrewsbury.

Foulds, E. M. 2014. Glass Beads in Iron Age Britain: a social approach. PhD thesis. University of Durham.

Fox, C., Sir 1933. The personality of Britain: its influence on inhabitant and invader in prehistoric and early historic times. 2nd ed. Cardiff.

Fredengren, C. 2011. 'Where Wandering Water Gushes - the Depositional Landscape of the Mälaren Valley in the Late Bronze Age and Earliest Iron Age of Scandinavia', Journal of Wetland Archaeology 10 (1), 109-135.

French, C. and Moore, P.D. 1986. 'Deforestation, Cannabis cultivation and Schwingmoor formation at Cors Llyn (Llyn Mire), Central Wales', New Phytologist 102 (3), 469-482.

French, C.A.I. 1988. 'The southwest Fen Dyke survey project', Antiquity 62 (235), 343-348.

Friday, L.E. 1988. 'A key to the adults of British water beetles', Field Studies 7, 1-155.

Frolking, S., Roulet, N.T., Moore, T., Richard, P.J.H., Lavoie, M. and Muller, S.D. 2001. 'Modeling Northern Peatland Decomposition and Peat Accumulation', Ecosystems 4 (5), 479-498.

Fyfe, R., Brown, A.G. and Coles, B. 2003. 'Mesolithic to Bronze Age Vegetation Change and Human Activity in the Exe Valley, Devon, UK', Proceedings of the Prehistoric Society 69, 161-181.

Fyfe, R., Brown, A.G. and Rippon, S. 2004. 'Characterising the late prehistoric, 'Romano-British' and medieval landscape, and dating the emergence of a regionally distinct agricultural system in South West Britain', Journal of Archaeological Science 31 (12), 1699-1714.

Fyfe, R., Woodbridge, J. and Roberts, N. 2015. 'From forest to farmland: pollen-inferred land cover change across Europe using the pseudobiomization approach', Global Change Biology 21 (3), 1197-1212.

Gaffney, C., Gaffney, V., Neubauer, W., Baldwin, E., Chapman, H.P., Garwood, P., Moulden, H., Sparrow, T., Bates, R., Löcker,K., Hinterleitner, A., Trinks, I., Nau, E., Zitz, T., Floery, S., Verhoeven, G. and Doneus, M. 2012. 'The Stonehenge Hidden Landscapes Project', Archaeological Prospection 19 (2), 147-155

Gaffney, V. 1995. 'Baschurch, The Berth (SJ 431238; SA129)', West Midlands Archaeology (38), 48-49.

Gaffney, V. and van Leusen, M. 1995a. 'Extending GIS Methods for Regional Archaeology:The Wroxeter Hinterland Project', http://www.bham.ac.uk/BUFAU/Projects/WH/Lever/ (accessed May 2017). 
Gaffney, V. and van Leusen, M. 1995b. 'GIS, environmental determinism and archaeology', in G. Lock and Z. Stančič (eds.), Archaeology and Geographic Information Systems: a European Perspective. Oxford. 367-382.

Gaffney, V. and White, R.H. 2007. Wroxeter, the Cornovii, and the Urban Process: final report on the Wroxeter Hinterland Project 1994-1997. Volume 1. Researching the hinterland. Portsmouth, Rhode Island.

Gaffney, V. White, R.H. and Goodchild, H. 2007. 'Imagine a city: Wroxeter and its hinterland', in V.Gaffney and R.H. White (eds), Wroxeter, the Cornovii, and the Urban Process: final report on the Wroxeter Hinterland Project 1994-1997. Volume 1: Researching the Hinterland. Portsmouth: Rhode Island. 279-288.

Garrow, D. 2012. 'Odd deposits and average practice. A critical history of the concept of structured deposition', Archaeological Dialogues 19 (2), 85-115.

Garwood, P. 2007a. 'Late Neolithic and Early Bronze Age Funerary Monuments and Burial Traditions', in P. Garwood (ed.) The Undiscovered Country. The Earlier Prehistory of the West Midlands. Oxford. 134-165.

Garwood, P. (ed.) 2007b. The Undiscovered Country. The Earlier Prehistory of the West Midlands. Oxford.

Gearey, B.R., Marshall, P. and Hamilton, D. 2009. 'Correlating archaeological and palaeoenvironmental records using a Bayesian approach: a case study from Sutton Common, South Yorkshire, England', Journal of Archaeological Science 36 (7), 1477-1487.

Gelling, M. 1992. The West Midlands in the Early Middle Ages. Leicester.

Gelling, P.S. 1962/5. 'The Berth, near Baschurch, Shropshire', West Midlands Annual Archaeological News-sheet. 4.

Gelling, P.S. 1964. 'The Berth, Baschurch', West Midlands Annual Archaeological News-sheet. 5.

Gelling, P.S. 1965. 'Excavations at Caynham Camp, near Ludlow: final report', Transactions of the Shropshire Archaeological Society $57,51-100$.

Gelling, P.S. and Stanford, S.C. 1965 (1967). 'Dark Age Pottery or Iron Age Ovens?', Transactions and Proceedings of the Birmingham Archaeological Society 82, 77-91.

Gent, H. 1983. 'Centralized Storage in Later Prehistoric Britain', Proceedings of the Prehistoric Society 49, 243-267.

Gent, H. and Dean, C. 1986. 'Catchment Analysis and Settlement Hierarchy: A Case Study from Pre-Roman Britain', in E. Grant (ed.), Central places, archaeology and history. Sheffield. 27-36.

Gibson, J.J. 1979. The ecological approach to visual perception. London.

Giddens, A. 1984. The constitution of society: outline of the theory of structuration. Cambridge.

Giles, M. and Parker Pearson, M. 1999. 'Learning to Live in the Iron Age: dwelling and praxis', in B. Bevan (ed.), Northern Exposure: interpretative devolution and the Iron Ages in Britain. Leicester. 217-231.

Gillings, M. 2012. 'Landscape Phenomenology, GIS and the Role of Affordance', Journal of Archaeological Method and Theory 19 (4), 601-611.

Gillings, M. 2015. 'Mapping invisibility: GIS approaches to the analysis of hiding and seclusion', Journal of Archaeological Science 62, 1-14.

Gillings, M. and Goodrick, G.T. 1996. 'Sensuous and reflexive GIS: exploring visualisation and VRML', https://doi.org/10.11141/ia.1.2 (accessed March 2017).

Girling, M. 1980. 'The fossil insect assemblage from the Baker Site', Somerset Levels Papers 6, 36-42. 
Girling, M. 1982. 'The effects of the Meare Heath flooding episodes on the Coleopteran succession', Somerset Levels Papers 8, 46-50.

Girling, M. 1984. 'Investigations of a Second Insect Assemblage from the Sweet Track', Somerset Levels Papers 10, 78-91.

Girling, M. 1985. 'An 'old forest' beetle fauna from a Neolithic and Bronze Age peat deposit at Stileway', Somerset Levels Papers 11, 80-85.

Girling, M. 1990. Mesolithic and later landscapes interpreted from the insect assemblages of West Heath Spa, Hampstead, London. Ancient Monuments Labloratory Reports (New Series), 14.

Girling, M. and Greig, J. 1985. 'A first fossil record for Scolytus scolytus (F.) (elm bark beetle): its occurrence in elm decline deposits from London and the implications for neolithic elm disease', Journal of Archaeological Science 12 (5), 347-351.

Glazebrook, J. (ed.) 1997. Research and Archaeology: a Framework for the Eastern Counties Vol 1. Resource Assessment.

Godwin, H. 1934. 'Pollen Analysis. An outline of the problems and potentialites of the method', New Phytologist 33, 325358.

Godwin, H. 1967. 'Pollen-analytic evidence for the cultivation of Cannabis in England', Review of Palaeobotany and Palynology 4 (1), 71-80.

Godwin, H. 1975. The history of the British flora: a factual basis for phytogeography. Cambridge.

Godwin, H. and Tallantire, P.A. 1951. 'Studies in the Post-Glacial History of British Vegetation: XII. Hockham Mere, Norfolk', Journal of Ecology 39 (2), 285-307.

Gorham, E. 1957. 'The Development of Peat Lands', The Quarterly Review of Biology 32 (2), 145-166.

Gosden, C. 1997. 'Iron Age landscapes and cultural biographies', in A. Gwilt and C. Haselgrove (eds.), Reconstructing Iron Age Societies: new approaches to the British Iron Age. Oxford. 303-307.

Gosden, C. and Lock, G. 2007. 'The aesthetics of landscape in the Berksire Downs', in C. Haselgrove and R. Pope (eds.), The Earlier Iron Age in Britain and the Near Continent. Oxford. 279-292.

Gosden, C. and Lock, G. 1998. 'Prehistoric histories', World Archaeology 30 (1), 2-12.

Grace, J.B. and Wetzel, R.G. 1981. 'Phenotypic and Genotypic Components of Growth and Reproduction in Typha Latifolia: Experimental Studies in Marshes of Differing Successional Maturity', Ecology 62 (3), 789-801.

Grant, M.J., Waller, M. and Groves, J.A. 2011. 'The Tilia decline: vegetation change in lowland Britain during the mid and late Holocene', Quaternary Science Reviews 30 (3-4), 394-408.

Greenwood, D.R. 1991. 'The Taphonomy of Plant Macrofossils', in S.K.Donovan (ed.), The processes of fossilization London. 141-169.

Greenwood, M. and Smith, D.N. 2005. 'Changing Fluvial Conditions and Landscapes in the Trent Valley: A Review or Palaeoentomological Evidence', in D.N. Smith, M.B. Brickley and K. Smith (eds.), Fertile Ground: Papers in Honour of Susan Limbrey. Oxford. 53-67.

Gregory, T. 1991. 'Excavations in Thetford 1980-82, Fison Way', East Anglian Archaeology 53.

Gregory, T. and Gurney, D. 1986. 'Excavations at Thornham, Warham, Wighton and Caistor St Edmund, Norfolk', East Anglian Archaeology 30.

Greig, J. 1982. 'Past and present lime woods of Europe', in M. Bell, M. and S. Limbrey (eds.), Archaeological Aspects of Woodland Ecology (Symposia of the Association for Environmental Archaeology 2). Oxford. 232-256. 
Greig, J. 1994. 'A possible hedgerow flora of Iron Age date from Alcester, Warwickshire', Circaea 11 (1), 7-16.

Greig, J. 2007. 'Priorities in Mesolithic, Neolithic and Bronze Age environmental archaeology in the West Midlands', in P. Garwood (ed.), The Undiscovered Country: the earlier prehistory of the West Midlands. Oxford. 39-50.

Grimm, E. 2015. TILIA and TILIA GRAPH. Illinois.

Guilbert, G. 1978. 'Dinorben 1977-8', Current Archaeology 65.

Guilbert, G. 1975a. 'Moel y Gaer, 1973: an area excavation on the defences', Antiquity 49 (194 (2)), 109-117.

Guilbert, G. 1975b. 'Planned Hillfort Interiors', Proceedings of the Prehistoric Society 41, 203-221.

Guilbert, G. Davies, J. Gelling, P.S., Musson, C.R. and Stanford, S.C. 1977. 'A Selection of Hillforts in the N. Welsh Marches, being the itinerary of the 1977 field meeting of the Hillfort Study Group', Hillfort Studies Group.

Gwilt, A. and Haselgrove, C. 1997. Reconstructing Iron Age Societies: new approaches to the British Iron Age. Oxford.

Hall, D. and Coles, J. 2014. Fenland Survey. London.

Hall, S.A. 1981. 'Deteriorated pollen grains and the interpretation of quaternary pollen diagrams', Review of Palaeobotany and Palynology 32 (2), 193-206.

Halsted, J. 2007. 'Bronze Age settlement in Shropshire: research potential and frameworks for settlement studies in the West Midlands', in P. Garwood (ed.), The Undiscovered Country: the earlier prehistory of the West Midlands. Oxford. 166181.

Hamilton, S. and Manley, J. 2001. 'Hillforts, monumentality and place: a chronological and topographic review of first Millennium BC hillforts in south-east England', European Journal of Archaeology 4 (1), 7-42.

Hamlin, A.G. 1988. Ellesmere Historical Town Walk. Ellesmere.

Hammon, A. 2011. 'Understanding the Romano-British-Early Medieval Transition: A Zooarchaeological Perspective from Wroxeter (Viroconium Cornoviorum)', Britannia 42, 275-305.

Hann, P., Trska, C., Wechselberger, K.F., Eitzinger, J. and Kromp,B. 2015. Phyllopertha horticola (Coleoptera: Scarabaeidae) larvae in eastern Austrian mountainous grasslands and the associated damage risk related to soil, topography and management. SpringerPlus, 4 (139).

Hannaford, H. 1999. 'A Bronze Age Burnt Mound at Rodway, Telford', Transactions of the Shropshire Archaeological and Historical Society 74, 67-74.

Hansen, M. 1987. The Hydrophiloidea (Coleoptera) of Fennoscandia and Denmark. Vol. 18 Leiden.

Harde, K.W. 1984. A Field Guide in Colour to Beetles. London.

Harding, A.F. 1982. Climatic change in later prehistory. Edinburgh.

Harding, D.W. 1976. Hillforts : later prehistoric earthworks in Britain and Ireland. London.

Harding, D.W. 2000. 'Crannogs and Island Duns: Classification, Dating and Function', Oxford Journal of Archaeology 19 (3), 301-317.

Harding, D.W. 2004. The Iron Age in Northern Britain: Britons and Romans, Natives and Settlers. London.

Harding, D.W. 2006. 'Redefining the Northern British Iron Age', Oxford Journal of Archaeology 25 (1), 61-82. 
Harding, D.W. 2012. Iron Age hillforts in Britain and beyond. Oxford.

Hardy, E.M. 1939. 'Studies of the Post-glacial history of British vegetation. V. The Shropshire and Flint maelor mosses', New Phytologist 38 (4), 364-396.

Harraway, D.J. 1991. Simians, cyborgs and women: the reinvention of nature. New York.

Hartshorne, C.H.R. 1841. Salopia antiqua: or, An enquiry from personal survey into the 'druidical', military and other early remains in Shropshire and the North Welsh borders: with observations upon the names of places, and a glossary of words used in the county of Salop. London.

Haselgrove, C. 1982. Wealth, prestige and power: the dynamics of late iron age political centralisation in south-east England', in C. Renfrew, C. and S. Shennan (eds.), Ranking, resource and exchange. Cambridge. 79-88.

Haselgrove, C. 1986. 'Central Places in British Iron Age Studies: A Review and Some Problems', in E. Grant (ed.), Central places, archaeology and history. Sheffield. 3-12.

Haselgrove, C. 1997. 'Iron Age brooch deposition and chronology', in A. Gwilt, A. and C. Haselgrove (eds.), Reconstructing Iron Age Societies: new approaches to the British Iron Age Oxford. 51-72.

Haselgrove, C. 2001a. 'Iron Age Britain and its European setting', in J. Collis (ed.), Society and Settlement in Iron Age Europe Sheffield: Actes du XVIIle Colloque de I'AFEAF. Winchester. 37-68.

Haselgrove, C. (ed.) 2001b. Understanding the British Iron Age: an agenda for action: a report for the Iron Age Research Seminar and the Council of the Prehistoric Society. Salisbury.

Haselgrove, C. 2009. 'The Iron Age', in J. Hunter and I. Ralston (eds.), The archaeology of Britain: an introduction from the Upper Palaeolithic to the Industrial Revolution. London. 149-174.

Haselgrove, C. and Moore, T. 2007. The Later Iron Age in Britain and beyond. Oxford.

Haselgrove, C. and Pope, R. 2007. 'Characterising the Earlier Iron Age', in C. Haselgrove and R. Pope, (eds.), The Earlier Iron Age in Britain and the Near Continent. Oxford. 1-23.

Haselgrove, C. and Pope, R. 2007. The Earlier Iron Age in Britain and the Near Continent. Oxford.

Haslam, S.M. 1972. 'Phragmites Communis Trin. (Arundo Phragmites L.),Phragmites Australis (Cav.) Trin. ex Steudel)', Journal of Ecology 60 (2), 585-610.

Haslam, S.M. 2003. Understanding wetlands: fen, bog and marsh. London.

Hawkes, C. 1931. 'Hill-Forts', Antiquity 5 (17), 60-97.

Hawkes, C. 1951. 'Bronze-workers, cauldrons, and bucket animals in Iron Age and Roman Britain', in W.F. Grimes (ed.), Aspects of archaeology in Britain and beyond : essays presented to O.G.S. Crawford. London. 172-199.

Hawkes, C. 1954. 'Wenner-Gren Foundation Supper Conference: Archeological Theory and Method: Some Suggestions from the Old World', American Anthropologist 56 (2), 155-168.

Hawkes, C. 1959. 'The A B C of the British Iron Age', Antiquity 33 (131), 170-182.

Heaney, S. 1972. Door into the Dark. London.

Heaney, S. 1975. North. London.

Heaney, S. 1996. The Spirit Level. London. 
Heaney, S. 2002. Wintering out. London: Faber.

Henderson, J.C. 2007. The Atlantic Iron Age: settlement and identity in the first millennium BC. Abingdon; New York.

Heslop-Harrison, Y. 1955. 'Nymphaea L.', Journal of Ecology 43 (2), 719-734.

Hewett, D.G. 1964. 'Menyanthes Trifoliata L.', Journal of Ecology 52 (3), 723-735.

Hey, D. (ed.) 1981. The history of Myddle by Richard Gough, 1635-1723. Harmondsworth.

Hides, S. 1996. 'The genealogy of material culture and cultural identity', in P. Graves-Brown, S. Jones and C. Gamble (eds.), Cultural Identity and Archaeology: The Construction of European Communities. London and New York. 25-47.

Hill, J.D. 1995. 'How should we understand Iron Age Societies and Hillforts? A Contextual Study for Southern Britain', in J.D. Hill and C.G. Cumberpatch (eds.), Different Iron Ages: studies on the Iron age in temperate Europe Oxford. 45-60.

Hill, J.D. 1995a. 'The Pre-Roman Iron Age in Britain and Ireland (ca. 800 B.C. to A.D. 100): An Overview', Journal of World Prehistory 9 (1), 47-98.

Hill, J.D. 1995b. Ritual and rubbish in the Iron Age of Wessex: a study on the formation of a specific archaeological record. Oxford.

Hill, J.D. and Cumberpatch, C.G. 1995. Different Iron Ages: studies on the Iron age in temperate Europe. Oxford.

Hingley, R. 1983. 'Charney Bassett - Cherbury Camp', South Midlands Archaeology Newsletter 13, 123-125.

Hingley, R. 1984. 'Towards social analysis in archaeology: Celtic society in the Iron Age of the Upper Thames Valley', in B.W. Cunliffe and D. Miles (eds.), Aspects of the Iron Age in Central Southern Britain. Oxford. 72-88.

Hingley, R. 1990. 'Iron Age 'Currency Bars': The Archaeological and Social Context', Archaeological Journal 147 (1), 91-117.

Hingley, R. 1997. 'Iron, iron working and regeneration: a study of the symbolic meaning of metalworking in Iron Age Britain', in A. Gwilt and C. Haselgrove (eds.), Reconstructing Iron Age Societies: new approaches to the British Iron Age. Oxford. 9-18.

Hingley, R. 1999. 'The Creation of Later Prehistoric Landscapes and the Context of the Reuse of Neolithic and Earlier Bronze Age Monuments in Britain and Ireland', in B. Bevan (ed.), Northern Exposure: interpretative devolution and the Iron Ages in Britain. Leicester. 233-250.

Hingley, R. 2006. 'The Deposition of Iron Objects in Britain during the Later Prehistoric and Roman Periods: Contextual Analysis and the Significance of Iron', Britannia 37, 213-257.

Hingley, R. and Miles, D. 1984. 'Aspects of Iron Age Settlement in the Upper Thames Valley', in B.W. Cunliffe and D. Miles (eds.), Aspects of the Iron Age in Central Southern Britain. Oxford. 52-71.

Hirsch, E. 1995. 'Landscape : Between Place and Space', in E. Hirsch and M. O'Hanlon (eds.), The Anthropology of landscape : perspectives on place and space. New York and Oxford. 1-30.

Hodder, M. 2002. 'Burnt Mounds and beyond: the later prehistory of Birmingham and the Black Country', http://www.birmingham.ac.uk/schools/iaa/departments/archaeology/ research/wmrrfa/seminar2.aspx (accessed June 2012).

Hodder, M. and Barfield, L.H. 1991. 'Hot Stones: Hot Food or Hot Baths?', in M. Hodder and L.H. Barfield (eds.), Burnt mounds and hot stone technology: papers from the Second International Burnt Mound Conference, Sandwell, 12th-14th October 1990 West Bromwich. 59-66.

Hodder, M. and Barfield, L.H. 1991. Burnt mounds and hot stone technology: papers from the Second International Burnt Mound Conference, Sandwell, 12th-14th October 1990. West Bromwich. 
Hodson, F.R. 1964. 'Cultural Grouping within the British pre-Roman Iron Age', Proceedings of the Prehistoric Society 30, 99110.

Hogg, A.H.A. 1979. British hill-forts: an index. Oxford.

Hogg, A.H.A. 1975. Hill-forts of Britain. London.

Hogg, A.H.A. 1972 'The Size-Distribution of Hill-Forts in Wales and the Marches', in F. Lynch and C. Burgess (eds.), Prehistoric man in Wales and the West : essays in honour of Lily F. Chitty. Bath. 293-305.

Howard, A.J. Chapman, H. and Gearey, B.R. 2016. Down By The River: Archaeological, Palaeoenvironmental and Geoarchaeological Investigations of The Suffolk River Valleys. Oxford.

Howard, L. 2007. The reconstruction of river flow and habitats within the River Trent catchment based on sub-fossil insect remains: a multiproxy appraoch. PhD thesis. University of Loughborough.

Hu, D. 2012. 'Advancing Theory? Landscape Archaeology and Geographical Information Systems', http://www.piajournal.co.uk/articles/10.5334/pia.381/ (accessed June 2015).

Huang, S., Guo, Y., Robert, G.W., Shi, Y-H., Sun, K. 2001. 'Mechanism of underwater pollination in Najas marina (Najadaceae)', Aquatic Botany 70 (1), 67-78.

Hughes, G. 1994. 'Old Oswestry hillfort: excavations by W.J.Varley 1939-1940', Archaeologia Cambrensis 143, 46-91.

Hughes, G. and Woodward, A. 1995. 'A ring ditch and Neolithic pit complex at Meole Brace, Shrewsbury', Transactions of the Shropshire Archaeological and Historical Society 70, 1-22.

Hughes, P.D.M. and Barber, K.E. 2003. 'Mire Development across the Fen-Bog Transition on the Teifi Floodplain at Tregaron Bog, Ceredigion, Wales, and a Comparison with 13 Other Raised Bogs', Journal of Ecology 91 (2), 253-264.

Hughes, P.D.M., Barber, K.E., Langdon, P.G., and Mauquoy, D. 2000. 'Mire-development pathways and palaeoclimatic records from a full Holocene peat archive at Walton Moss, Cumbria, England', The Holocene 10 (4), 465-479.

Hunter, J. and Ralston, I. 2009. The archaeology of Britain: an introduction from the Upper Palaeolithic to the Industrial Revolution. London.

Hunter, M.C.W. 1971. 'The Royal Society and the origins of British archaeology', Antiquity 45 (178), 113-121.

Hurst, D. 2017a. 'Later prehistoric production and trade in the West Midlands', in D. Hurst (ed.), Westward on the HighHilled Plains: the Later Prehistory of the West Midlands. Oxford. 135-143.

Hurst, D. (ed.) 2017b. Westward on the High-Hilled Plains: the Later Prehistory of the West Midlands. Oxford.

Ingold, T. 1992. 'Beyond "The Original Affluent Society" by N. Bird-David. A Culturalist Reformulation; Comments and Reply', Current Anthropology 33 (1), 25-47.

Ingold, T. 1993 'The Temporality of the Landscape', World Archaeology 25 (2), 152-174.

Ingold, T. 2005. 'Comments on Christopher Tilley: The Materiality of Stone: Explorations in Landscape Phenomenology', Norwegian Archaeological Review 38 (2), 122-129.

Innes, J.B., Blackford, J.J. and Simmons, I.G. 2011. 'Mesolithic Environments at Star Carr, the Eastern Vale of Pickering and Environs: Local and Regional Contexts', Journal of Wetland Archaeology 11 (1), 85-108.

Iversen, J. 1958. 'The bearing of glacial and interglacial epochs on the formation and extinction of plant taxa', in O. Hedberg (ed.) Systematics of to-day. Proceedings of a symposium held at the University of Uppsala in commemorotion of the 250th anniversary of Carolus Linnaeus. Uppsala. 210-215. 
Jackson, D. 1999. 'Variation in the Size Distribution of Hillforts in the Welsh Marches and its Implication for Social Organisation', in B.Bevan (ed.), Northern Exposure: interpretative devolution and the Iron Ages in Britain. Leicester. 197216.

Jackson, G.F. 1883. Shropshire folk-lore: a sheaf of gleanings. London.

Jackson, R. and Miller, D. 2011. Wellington Quarry, Herefordshire (1986-96). Investigations of a Landscape in the Lower Lugg Valley. Oxford.

Jacques, D. 2016. 'The Cradle of Stonehenge'? Blick Mead - a Mesolithic Site in the Stonehenge Landscape', https://www.gresham.ac.uk/lectures-and-events/the-cradle-of-stonehenge-blick-mead-a-mesolithic-site-in-thestonehenge-landscape (accessed September 2017).

James, S. 1993. Exploring the World of the Celts. London.

James, S. 2007. 'A bloodless past: the pacification of early Iron Age Britain', in C. Haselgrove and R. Pope (eds.), The Earlier Iron Age in Britain and the Near Continent. Oxford. 160-173.

Johnson, M. 2010. Archaeological theory: an introduction. Chichester.

Jones, A. 1998. 'Where Eagles Dare: Landscape, Animals and the Neolithic of Orkney', Journal of Material Culture 3 (3), $301-$ 324.

Jones, B. and Mattingly, D. 1990. An Atlas of Roman Britain. Oxford.

Jones, E.W. 1959. 'Quercus L.', Journal of Ecology 47 (1), 169-222.

Jones, M.L. 1984. Society and settlement in Wales and the Marches 500 B.C. to A.D. 1100 Part 1. Oxford.

Jones, N.W., Hankinson, R. and Silvester, R.J. 2012. 'Llanymynech Hill: Cultural Heritage and Management'. The ClwydPowys Archaeological Trust.

Jowsey, P.C. 1966. 'An improved peat sampler', New Phytologist 65 (2), 245-248.

Joy, J. 2011. 'The Iron Age', in T. Insoll (ed.), Oxford Handbook of the Archaeology of Ritual and Religion Oxford. 405-421.

Joy, J. 2014. 'Fire Burn and Cauldron Bubble': Iron Age and Early Roman Cauldrons of Britain and Ireland', Proceedings of the Prehistoric Society 79, 1-36.

Kang, Y. 2017. A study into insect and plant macrofossil remains from the Berth, Shropshire. Unpublished Masters Thesis. University of Birmingham.

Keddy, P.A. 2000. Wetland ecology : principles and conservation. Cambridge.

Keeley, L.H. 1996. War before civilization. New York and Oxford.

Kennedy, C.E.J. and Southwood, T.R.E. 1984. 'The Number of Species of Insects Associated with British Trees: a ReAnalysis', Journal of Animal Ecology 53 (2), 455-478.

Kenney, J. 2012. 'Burnt mounds in north-west Wales: are these ubiquitous features really so dull?', in W.J. Britnell and R.J. Silvester (eds.), Reflections on the Past: Essays in honour of Frances Lynch. Welshpool. 254-279.

Kenward, H. 1975. 'Pitfalls in the environmental interpretation of insect death assemblages', Journal of Archaeological Science 2 (2), 85-94.

Kenward, H. 1976. 'Reconstructing ancient ecological conditions from insect remains: some problems and an experimental approach', Ecological Entomology 1, 7-17. 
Kenward, H. 1978. 'The analysis of archaeological insect assemblages: a new approach', in Archaeology of York 19 (1). London. 1-68.

Kenward, H. 1985. 'Outdoors - Indoors? The outdoor component of archaeological insect assemblages', in N.R.J. Fieller, D.D. Gilbertson and N.G.A.Ralph (eds.), Palaeobiological investigations: Research, Design, Methods and Data analysis. Oxford. 97-104.

Kenward, H. 1997. 'Synanthropic decomposer insects and the size, remoteness and longevity of archaeological occupation sites: applying concepts from biogeography to past 'islands' of human occupation', Quaternary Proceedings 5,135-152.

Kenward, H. 2006. 'The visibility of past trees and woodland: testing the value of insect remains', Journal of Archaeological Science 33 (10), 1368-1380.

Kenward, H. and Allison, E.P. 1994. 'A preliminary View of the Insect Assemblages from the Early Christian Rath site at Deer Park Farms, Northern Ireland', in M.O.H. Carver and D.J. Rackham (eds.), Environment and economy in Anglo-Saxon England : a review of recent work on the environmental archaeology of rural and urban Anglo-Saxon settlements in England York. London. 89-103.

Kenward, H. and Carrott, J. 2006. 'Insect species associations characterise past occupation sites', Journal of Archaeological Science 33 (10), 1452-1473.

Kenward, H. and Hall, A.R. 1995. 'Biological evidence from Anglo-Scandinavian deposits at 16-22 Coppergate', in P.V. Addyman (ed.), The Archaeology of York, Vol.14/7. York.

Kenward, H. and Hall, A. 1997. 'Enhancing Bioarchaeological Interpretation Using Indicator Groups: Stable Manure as a Paradigm', Journal of Archaeological Science 24 (7), 663-673.

Kenward, H. and Hall, A. 2000. 'Technical Report: Plant and invertebrate remains from Anglo-Scandinavian deposits at 11826 Walmgate, York (site code 78-9.8). Reports from the Environmental Archaeology Unit, York 2000/20'. York.

Kenward, H., Hall, A.R. and Jones, A.K.G. 1980. 'A tested set of techniques for the extraction of plant and animal macrofossils from waterlogged archaeological deposits', Science and archaeology 22, 3-15.

Kenward, H. and Large, F. 1997. 'Recording the Preservational Condition of Archaeological Insect Fossils', Environmental Archaeology 2 (1), 49-60.

Kenward, H. and Large, F. 1998. 'Insects in Urban Waste Pits in Viking York: Another Kind of Seasonality', Environmental Archaeology 3 (1), 35-53.

Kenyon, K.M. 1953. 'Excavations at Sutton Walls, Herefordshire, 1948-1951', Archaeological Journal 110 (1), 1-87.

Kenyon, K.M. 1942. 'Excavations on the Wrekin, Shropshire, 1939', Archaeological Journal 99 (1), 99-109.

King, M. 2003. The Penguin History of New Zealand. Auckland.

Kinory, J. 2012. Salt production, distribution and use in the British Iron Age. Oxford.

Knight, D. and Howard, A.J. 2004. Trent Valley landscapes : the archaeology of 500,000 years of change. King's Lynn.

Knight, M. 2009. 'Excavating a Bronze Age timber platform at Must Farm, Whittlesay, near Peterborough', Past 63, 1-16.

Koch, K. 1992. Die Käfer Mitteleuropas. Krefeld.

Lake, M. 2007. 'Viewing Space', World Archaeology 39 (1, Viewing Space), 1-3.

Lamb, H.H. 1981. 'Climate from 1000BC to 1000AD', in M. Jones and G.W.Dimbleby (eds.), The Environment of Man: the Iron Age to the Anglo-Saxon period. Oxford. 53-65. 
Lambrick, G. 1984. 'Clanfield, Burroway', CBA Group Newsletter 14, 104-105.

Lambrick, G. and Robinson, M. 1979. Iron Age and Roman riverside settlements at Farmoor, Oxfordshire, Vol. 32. Oxford.

Lambrick, G. Robinson, M. and Allen, T. 2009. The Thames through time: the archaeology of the gravel terraces of the upper and middle Thames: the Thames Valley in late Prehistory, 1500 BC - AD 50. Oxford.

Lang, A.O.T. 2016. 'Defining Banjo Enclosures: Investigations, Interpretations, and Understanding in the Iron Age of Southern Britain', Proceedings of the Prehistoric Society 82, 341-361.

Larsson, M. and Lagerås, P. 2015. 'New evidence on the introduction, cultivation and processing of hemp (Cannabis sativa L.) in southern Sweden', Environmental Archaeology 20 (2), 111-119.

Layton, R. and Ucko, P.J. 1999. 'Introduction: gazing on the landscape and encountering the environment', in P.J. Ucko and R. Layton (eds.), The Archaeology and Anthropology of Landscape. London. 1-20.

Leah, M.D. Wells, C.E. Appleby, C. and Huckerby, E. 1997. The wetlands of Cheshire. Lancaster.

Leah, M.D. Wells, C.E. Stamper, P., Huckerby, E. and Welch, C. 1998. The wetlands of Shropshire and Staffordshire. Lancaster.

Leary, J. 2017. 'Extending Histories: from Medieval Mottes to Prehistoric Round Mounds; \#RoundMoundsProject; University of Reading', https://roundmoundsproject.wordpress.com/2015/09/?blogsub=confirming\#blog_subscription(accessed July 2017).

Legge, A.J. and Rowley-Conwy, P.A. 1988. Star Carr revisited: a re-analysis of the large mammals. London.

Lenfert, R. 2013. 'Integrating Crannogs and Hebridean Island Duns: Placing Scottish Island Dwellings Into Context', The Journal of Island and Coastal Archaeology 8 (1), 122-143.

Lewis, A. S. G. 2015. Iron Age and Roman-era Vehicle Terrets from Western and Central Britain: An Interpretive Study. Doctor of Philosophy. University of Leicester.

Limbrey, S. and Evans, J.G. 1978. The effect of man on the landscape: the Lowland Zone. London.

Limbrey, S. Evans, J.G. and Cleere, H. 1975. The effect of man on the landscape: the Highland Zone. London.

Livarda, A. Madgwick, R. and Riera Mora, S. 2018. The bioarchaeology of ritual and religion. Oxford; Philadelphia.

Llobera, M. 2007. 'Reconstructing Visual Landscapes', World Archaeology 39 (1, Viewing Space), 51-69.

Llobera, M. 2001. 'Building Past Landscape Perception With GIS: Understanding Topographic Prominence', Journal of Archaeological Science 28 (9), 1005-1014.

Lock, G. 2011. 'Hillforts, Emotional Metaphors, and the Good Life: a Response to Armit', Proceedings of the Prehistoric Society $77,355-362$.

Lock, G. 2001. 'Theorising the practice or practicing the theory: archaeology and GIS', Archaeologia Polona 39, 153-164.

Lock, G. and Harris, T.M. 1996. 'Danebury Revisited: An English Iron Age Hillfort in a Digital Landscape', in M.S. Aldenderfer and H.D.G. Maschner (eds.), Anthropology, space and geographic information systems. New York and Oxford. 214-240.

Lock, G. and Ralston, I. 2017. 'An Atlas of Hillforts of Britain and Ireland', https://hillforts.arch.ox.ac.uk/ (accessed July 2017).

Losos, J. 2017. Improbable Destinies. How predictable is evolution? Allen Lane. 
Lowe, J.J. and Walker, M.J.C. 1997. Reconstructing quaternary environments. Harlow.

Lucht, W.H. 1987. Die Käfer Mitteleuropas [Katalog]. Krefeld.

Luff, M.L. 2007. The Carabidae (ground beetles) of Britain and Ireland. St. Albans.

Luke, Y. 2003. 'Rethinking Ingleborough. MA Thesis', http://www.hillfortsstudygroup.org.uk/Ingleborough.pdf.(accessed June 2017).

Lynch, F. 1970. Prehistoric Anglesey: the archaeology of the island to the Roman conquest. Llangefni, Anglesey.

Macan, T.T. 1960. A key to the British fresh-and brackish-water gastropods with notes on their ecology. Ambleside.

Macfarlane, R. 2015 Landmarks. London.

Macklin, M.G., Johnstone, E. and Lewin, J. 2005. 'Pervasive and long-term forcing of Holocene river instability and flooding in Great Britain by centennial-scale climate change', The Holocene 15 (7), 937-943.

Macklin, M.G. and Lewin, J. 2003. 'River sediments, great floods and centennial-scale Holocene climate change', Journal of Quaternary Science 18 (2), 101-105.

Maddy, D., Green, C.P., Lewis, S.G., and Bowen, D.Q. 1995. 'Pleistocene Geology of the Lower Severn Valley, U.K.', Quaternary Science Reviews 14, 209-222.

Malim, C. and Malim, T. 2010. 'The Walls of Troy: a Classical Labyrinth at the Wall, Kynnersley', Transactions of the Shropshire Archaeological and Historical Society 85, 81-114.

Malim, T. 2005. Stonea and the Roman Fens. Stroud.

Malim, T. and Hayes, L. 2010. 'An engineered Iron Age road, associated Roman activity (Margary Route 64) and Bronze Age activity recorded at Sharpstone Hill, Shropshire', Transactions of the Shropshire Archaeological and Historical Society 85, 780.

Manning, W.H. 1983. 'The Cauldron Chains of Iron Age and Roman Britain', in B. Hartley and J.S. Wacher (eds.), Rome and her northern provinces : papers presented to Sheppard Frere in honour of his retirement from the Chair of the Archaeology of the Roman Empire, University of Oxford, 1983. Gloucester. 132-154.

MAP Archaeological Consultancy Ltd. 1994. 'Presentation Survey, Skipwith Common', https://doi.org/10.5284/1025579 (accessed June 2016)

Marchant, T. 1989. 'The evidence for textile production in the Iron Age', Scottish Archaological Review 6, 5-11.

Martin, R. 1999. 'Introduction: The science of taphonomy', in R. Martin (ed.), Taphonomy: A Process Approach. Cambridge. $1-26$.

Mason, C.F. and Bryant, R.J. 1975. 'Production, Nutrient Content and Decomposition of Phragmites Communis Trin. and Typha Angustifolia L.', Journal of Ecology 63 (1), 71-95.

Matthews, D. 2006. 'Mapping hillfort intervisibility and its potential to define Iron Age tribal areas in the northern and mid Marches'. University of Leicester.

Matthews, D. 2014. 'Hillfort Intervisibility in the Northern and Mid-Marches', in T. Saunders (ed.), Hillforts in the North West and Beyond Archaeological North West: New Series: Volume 3. London. 7-27.

Matthews, K.J. 2001. 'From Roman to Saxon: the Late Fourth to Seventh Centuries A.D. in Cornovia', West Midlands Archaeology 44, 17-25. 
Matthews, K.J. 1999. 'The Iron Age of North-west England and Irish Sea Trade', in B. Bevan (ed.), Northern Exposure: interpretative devolution and the Iron Ages in Britain. Leicester. 173-196.

Mauquoy, D., Hughes, P.D.M. and van Geel, B. 2010. 'A protocol for plant macrofossil analysis of peat deposits', Mires and Peat 7 (6), 1-5.

Mauquoy, D. and van Geel, B. 2007. 'Mire and Peat Macros', in S.A. Elias (ed.), Encyclopedia of Quaternary Science, Volume 3: Plant Macrofossil Methods and Studies Amsterdam. 2315-2336.

McVean, D.N. 1953. 'Alnus Glutinosa (L.) Gaertn.', Journal of Ecology 41 (2), 447-466.

Mellars, P. and Dark, P. 1998. Star Carr in context : new archaeological and palaeoecological investigations at the Early Mesolithic site of Star Carr, North Yorkshire. Cambridge.

Merrifield, R. 1987. The archaeology of ritual and magic. London.

Meyer, W.J. and Crumley, C. 2011. 'Historical Ecology', in X. Armada and T. Moore (eds.), Atlantic Europe in the first millennium BC: crossing the divide. Oxford.

Miles, D. 1981. 'Social Landscape: Pattern and Purpose?', in M. Jones and G.W. Dimbleby (eds.), The Environment of man: the Iron Age to the Anglo-Saxon period. Oxford. 9-18.

Millett, M. 1992. The Romanization of Britain: an essay in archaeological interpretation. Cambridge.

Milner, N., Lane, P., Taylor, B., and Schadla-Hall, T. 2011. 'Star Carr in a Postglacial Lakescape: 60 Years of Research', Journal of Wetland Archaeology 11 (1), 1-19.

Minnitt, S. 2000. 'The Iron Age wetlands of central Somerset', in C.J. Webster (ed.), Somerset Archaeology: Papers to mark the 150 years of the Somerset Archaeological and Natural History Society Taunton. 73-78.

Mitchell, F.J.G. 2005. 'How Open Were European Primeval Forests? Hypothesis Testing Using Palaeoecological Data', Journal of Ecology 93 (1), 168-177.

Mitchell, F.J.G. 1990. 'The impact of grazing and human disturbance on the dynamics of woodland in S. W. Ireland', Journal of Vegetation Science 1 (2), 245-254.

Mitchell, G.F. 1965. 'Littleton Bog, Tipperary: An Irish Agricultural Record', The Journal of the Royal Society of Antiquaries of Ireland 95 (1), 121-132.

Mithen, S.J. 1999. 'Mesolithic archaeology, environmental archaeology and human palaeoecology', Journal of Quaternary Science 14 (6), 477-483.

Moore, P.D. 1975 ‘Origin of blanket mires', Nature 256 (24), 267-269.

Moore, P.D. Webb, J.A. and Collinson, M.E. 1991. Pollen analysis. Oxford.

Moore, T. 2011. 'Detribalizing the later prehistoric past: Concepts of tribes in Iron Age and Roman studies', Journal of Social Archaeology 11 (3), 334-360.

Moore, T. 2006. 'The Iron Age', in N. Holbrook and J. Jurica, J. (eds.), Twenty-five years of Archaeology in Gloucestershire: A review of new discoveries and new thinking in Gloucestershire, South Gloucestershire and Bristol 1979-2004. Cirencester. 61-96.

Moore, T. 2006. Iron Age societies in the Severn-Cotswolds: developing narratives of social and landscape change. Oxford.

Moreno-Larrazabal, A., Uribarri, E., Peñalver, X., and Zapata, L. 2014. 'Fuelwood, crops and acorns from Iritegi cave (Oñati, Basque Country)', Environmental Archaeology 19 (2), 166-175. 
Morley, N.J., Adam, M.E. and Lewis, J.W. 2004. 'The role of Bithynia tentaculata in the transmission of larval digeneans from a gravel pit in the lower Thames valley', Journal of Helminthology 78 (2), 129-135.

Morphy, H. 1995. 'Landscape and the reproduction of the ancestral past', in E. Hirsch and M. O'Hanlon (eds.), The Anthropology of landscape: perspectives on place and space. New York and Oxford. 184-209.

Morris, E. 1985. 'Prehistoric Salt Distributions: Two Case Studies from Western Britain', Bwletin y Bwrdd Gwybodau Celtaidd 32, 336-379.

Morris, E. 1991. 'Report on the Prehistoric Ceramics found at Wall Camp, Kynnersley', Transactions of the Shropshire Archaeological and Historical Society LXVII, 106-107.

Morris, E. and Gelling, P.S. 1991. 'Prehistory in Lowland Shropshire: A Note on the Berth', Transactions of the Shropshire Archaeological and Historical Society LXVII, 58-62.

Morris, E. 1994. 'Old Oswestry Hillfort: the prehistoric pottery and salt containers', in G. Hughes (ed.), Old Oswestry hillfort: excavations by W.J.Varley 1939-1940. Archaeologia Cambrensis 143, 65-79.

Morris, E. 1996. 'Iron Age artefact production and exchange', in T.C. Champion and J.R. Collis (eds.), The Iron Age in Britain and Ireland: recent trends. Sheffield. 41-66.

Morris, J.A. 1932. 'Bury Walls, Hawkstone', Transactions of the Shropshire Archaeological and Natural History Society 46, 59-63.

Morris, M.G. 2002. True weevils. Pt. 1, Coleoptera: Curculionidae (subfamilies Raymondionyminae to Smicronychinae). London.

Morris, M.G. 2008. True weevils. Pt. 2, Coleoptera: Curculionidae, Ceutorhynchinae. London.

Mulk, I. and Bayliss-Smith, T.P. 1999. 'The representation of Sami cultural identity in the cultural landscapes of northern Sweden: The use and misuse of archaeological evidence', in P.J. Ucko and R. Layton (eds.), The Archaeology and Anthropology of Landscape. London. 358-396.

Mullin, D. 2012. 'The river has never divided us: Bronze Age metalwork deposition in western Britain', Oxford Journal of Archaeology 31 (1), 47-57.

Murdie, R.E., White, R.H., Barratt, G., Gaffney, V. and Goulty, N.R. 2003. 'Geophysical surveys of Bury Walls hill fort, Shropshire', Archaeological Prospection 10 (4), 249-263.

Murphy, P.L. 1992. Stonea Camp, Cambridgeshire: Plant Macrofossils, and Molluscs from Iron Age fort ditch fills. Ancient Monuments Laboratory Reports (58).

Murphy, P.L. and Wiltshire, P.E.J. 1994. 'A proposed scheme for evaluating plant macrofossil preservation in some archaeological deposits', Circaea 11, 1-6.

Murray, T. and Walker, M.J. 1988. 'Like WHAT? A practical question of analogical inference and archaeological meaningfulness', Journal of Anthropological Archaeology 7 (3), 248-287.

Murton, D.K. and Murton, J. 2012. 'Middle and Late Pleistocene glacial lakes of lowland Britain and the southern North Sea Basin', Quaternary International 260, 115-142.

Musson, C.R., Smith, A.G. and Girling, M. 1977. 'Environmental evidence from the Breiddin hillfort', Antiquity 51 (202), 147-151.

Musson, C.R. Britnell, W.J. and Smith, A.G. 1991. The Breiddin Hillfort: a later prehistoric settlement in the Welsh Marches. London.

Natural England 2014. Fenn's \& Whixall Mosses History Trail. Meres \& Mosses Landscape Partnership Scheme. 
Natural England 2007. 'Lowland Grassland Management Handbook (Second edition) (GRASSLAND)', http://publications.naturalengland.org.uk/publication/35034 (accessed April 2017).

Needham, S. 2007. '800BC, The Great Divide', in C. Haselgrove and R. Pope (eds.), The Earlier Iron Age in Britain and the Near Continent. Oxford. 39-63.

Newman, J. and Pevsner, N., Sir. 2006. Shropshire. London.

Norton, S.M. 2013. 'The Weald Moors and Wall Camp: an investigation of geomorphology, human history and palaeoenvironment', etheses.bham.ac.uk/4727/1/Norton13MPhil1.pdf, University of Birmingham.

Norton, S.M. 2016. 'The Archaeological and Palaeoenvironmental Potential of the Weald Moors, Shropshire', Transactions of the Shropshire Archaeological and Historical Society 91, 109-116.

O'Brien, C., Selby, K., Ruiz, Z., Brown, A.G., Dinnin, M., Caseldine, C., Langdon, P.G., and Stuijts,I. 2005. 'A sediment-based multiproxy palaeoecological approach to the environmental archaeology of lake dwellings (crannogs), Central Ireland', The Holocene 15 (5), 707-719.

Olivier, A. 1996. Frameworks for Our Past. London.

Ó'Néill, J. 2009. Burnt Mounds in Northern and Western Europe: A study of prehistoric technology and society. VDM Verlag Dr. Müller.

Osborne, P. 1988. 'A late bronze age insect Fauna from the River Avon, Warwickshire, England: Its implications for the terrestrial and fluvial environment and for climate', Journal of Archaeological Science 15 (6), 715-727.

Oswald, A. 1997. 'A doorway on the past: practical and mystic concerns in the orientation of roundhouse doorways', in A. Gwilt and C. Haselgrove (eds.), Reconstructing Iron Age Societies: new approaches to the British Iron Age. Oxford. 87-95.

Owen, H. and Blakeway, J.B. 1825. A History of Shrewsbury, Volume 1. London.

Page, W. (ed.) 1908. The Victoria County History of Shropshire. London.

Parker Pearson, M. 1999. 'Food, Sex and Death: Cosmologies in the British Iron Age with Particular Reference to East Yorkshire', Cambridge Archaeological Journal 9 (01), 43-69.

Parker Pearson, M. and Sydes, R.E. 1997. 'The Iron Age Enclosures and Prehistoric Landscape of Sutton Common, South Yorkshire', Proceedings of the Prehistoric Society 63, 221-259.

Parker, A.G., Goudie, A.S., Anderson, D.E., Robinson, M. and Bonsall. C. 2002. 'A review of the mid-Holocene elm decline in the British Isles', Progress in Physical Geography 26 (1), 1-45.

Parkes, D. 1801-1832. Drawings of Shropshire. British Library MS21012.

Payne, A. and Corney, M. 2006. The Wessex hillforts project.The Regional Pattern. London.

Peacock, D.P.S. 1965-7. 'Romano-British Pottery Production in the Malvern District of Worcestershire', Transactions of the Worcestershire Archaeological Society (1), 15-28.

Peake, H.J.E. 1909. 'A Few Notes respecting the Entrenchments at Stockett', in Transactions of the Shropshire Archaeological and Natural History Society 9th ed. ix-x.

Pearce, E.J. 1957. Handbooks for the identification of British Insects: Coleoptera (Pselaphidae). London.

Pevsner, N., Sir 1958. Shropshire. Harmondsworth.

Philippsen, B. 2013 'The freshwater reservoir effect in radiocarbon dating', https://doi.org/10.1186/2050-7445-1-24. 
Phillips, G. and Keatman, M. 1992. King Arthur: The True Story. London.

Piggott, C.M. 1953. 'Milton Loch Crannog: A native house of the second century AD in Kirkcudbrightshire', Proceedings of the Society of Antiquaries of Scotland 87, 134-152.

Pigott, C.D. 1991. 'Tilia Cordata Miller', Journal of Ecology 79 (4), 1147-1207.

Piggott, S. 1931. 'Ladle Hill—an unfinished hillfort', Antiquity 5 (20), 474-485.

Piggott, S. 1952-3. 'Three Metal-work Hoards of the Roman Period from Southern Scotland', Proceedings of the Society of Antiquaries of Scotland 87, 1-52.

Piotrowska, N., Blaauw, M., Mauquoy, D., and Chambers, F.M. 2011. 'Constructing deposition chronologies for peat deposits using radiocarbon dating', Mires and Peat 7 (10), 1-14.

Plunkett, G., Whitehouse, N.J., Hall, V.A., Charman, D.J., Blaauw, M., Kelly, E. and Mulhall,I. 2009. 'A multi-proxy palaeoenvironmental investigation of the findspot of an Iron Age bog body from Oldcroghan, Co. Offaly, Ireland', Journal of Archaeological Science 36 (2), 265-277.

Powell, T. 1974. 'Iron Age Britain retraced', Antiquity 48 (192), 288-292.

Prentice, I.C. 1988. 'Records of vegetation in time and space: the principles of pollen analysis', in B. Huntley and T.I. Webb (eds.), Vegetation history Dordrecht and Boston. 17-42.

Prentice, I.C. 1985. 'Pollen representation, source area, and basin size: Toward a unified theory of pollen analysis', Quaternary Research 23 (1), 76-86.

Pryor, F. 2005. Flag Fen: life and death of a prehistoric landscape. Stroud.

Rackham, O. 2004. The history of the countryside. London.

Ragg, J.M. Beard, G.R. George, H., Heaven, H.W., Hollis, J.M., Jones, R.J.A., Palmer,R.C., Reeve, M.J., Robson,J.D. and Whitfield,W.A.D. 1984. Soils and their use in Midland and Western England. Harpenden.

Ralston, I. 2006. Celtic Fortifications. Stroud.

Ray, K. 2007. 'The Neolithic in the West Midlands: an overview', in P. Garwood (ed.), The Undiscovered Country. The Earlier Prehistory of the West Midlands Oxford. 51-78.

Reid, M.L. 1989. 'A room with a view: An examination of round-houses, with particular reference to northern Britain', Oxford Journal of Archaeology 8 (1), 1-39.

Renfrew, C. and Bahn, P.G. 2000 Archaeology: theories, methods and practice. 3rd ed. London.

Reynolds, C. 1979. 'Limnology of the eutrophic meres of the Shropshire-Cheshire plain: a review', Field Studies 5 (1), 93173.

Reynolds, C. and Sinker, C. 1976. 'The Meres: Britain's eutrophic lakes', New Scientist 1007, 10-12.

Richards, J.C. 1990. The Stonehenge Environs Project. London.

Richmond, I.A. 1963. 'The Cornovii', in I.L. Foster and L. Alcock (eds.), Culture and environment: essays in honour of Sir Cyril Fox. London. 251-262.

Riley, D.N. 1980. Early landscape from the air: studies of crop marks in South Yorkshire and North Nottinghamshire.Sheffield. 
Robbins, G. 1999. 'Research and Regionality: South Yorkshire as an example', in B. Bevan (ed.), Northern Exposure: interpretative devolution and the Iron Ages in Britain. Leicester. 43-49.

Roberts, N. 1998. The Holocene: an environmental history. Oxford.

Robinson, M. 2001. 'Insects as Palaeoenvironmental Indicators', in D.R. Brothwell and A.M. Pollard (eds.), Handbook of Archaeological Sciences. Chichester. 121-133.

Robinson, M. 2000. 'Middle Mesolithic to Late Bronze Age insect assemblages and an Early Neolithic assemblage of waterlogged macroscopic plant remains', in S. Needham (ed.), The Passage of the Thames: Holocene environment and settlement at Runnymede. London. 146-167.

Robinson, M. 1992. 'The Coleoptera from Flag Fen', Antiquity 66 (251), 467-469.

Robinson, M. 1991. 'The Neolothic and Late Bronze Age insect assemblages', in S.Needham (ed.) Excavation and salvage at Runnymede Bridge, 1978: the Late Bronze Age waterfront site. London. 277-325.

Robinson, M. 1983. 'Arable/Pastoral Ratios from Insects?', in M. Jones (ed.), Integrating the subsistence economy Oxford. 19-47.

Robinson, M. 1981. 'The use of ecological groupings of Coleoptera for comparing sites', in M. Jones and G.W. Dimbleby (eds.), The Environment of man: the Iron Age to the Anglo-Saxon period. Oxford. 279-286.

Roden, C. and Murphy, P. 2013. A survey of the benthic macrophytes of three hard-water lakes: Lough Bunny, Lough Carra and Lough Owel.Irish Wildlife Manuals, No. 70. National Parks and Wildlife Service, Ireland.

Rodwell, J.S.1991a. British plant communities. Volume 1. Woodlands and scrub. Cambridge.

Rodwell, J.S. 1991b. British plant communities. Volume 2. Mires and heaths. Cambridge.

Rodwell, J.S. 1995. British plant communities. Volume 4. Aquatic communities, swamps and tall-herb fens. Cambridge.

Roe, A. 1991. 'Prehistory in Lowland Shropshire: Excavations at Castle Farm, Shifnal, 1980', Transactions of the Shropshire Archaeological and Historical Society LXVII, 63-83.

Roslin, T. 2000. 'Dung beetle movements at two spatial scales', Oikos 91 (2), 323-335.

Ross, A. 1967. Pagan Celtic Britain: studies in iconography and tradition. London.

Ross-Craig, S. 1979. Drawings of British plants: being illustrations of the species of flowering plants growing naturally in the British Isles. Vol. 7 \& 8. London.

Rowlands, M. 1993. 'The Role of Memory in the Transmission of Culture', World Archaeology 25 (2), 141-151.

Rowley, T. 1972. The Shropshire landscape. London.

Royle, R. and Woodward, A. 1993. 'The Prehistoric Pottery', in P. Ellis (ed.), Beeston Castle, Cheshire: a report on the excavations by L. Keen and P. Hough, 1968-85. English Heritage Archaeological Report No. 23.

Sahlins, M.D. 1963. 'Poor Man, Rich Man, Big-man, Chief: Political Types in Melanesia and Polynesia', Comparative Studies in Society and History 5 (03), 285-303.

Schama, S. 1995. Landscape and memory. London.

Schiffer, M.B. 1972. 'Archaeological Context and Systemic Context', American Antiquity 37 (2), 156-165. 
Schoch, W.H. Pawlik, B. and Schweingruber, F.H. 1988. Botanical macro-remains - an atlas for the determination of frequently encountered and ecologically important plant seeds. Bern and Stuttgart.

Schoemwetter, J. 1982. 'Environmental archaeology of the Peckforton Hills', Cheshire Archaeological Bulletin 8, 10-11.

Seawright, C. 2015. "Time perspectivism': Time as a Methodological Tool in Archaeology',

http://www.thekeep.org/ kunoichi/kunoichi/themestream/ARC4ICA-3.html (accessed July 2017).

Shanks, M. and Tilley, C. 1987. Re-constructing archaeology: theory and practice. Cambridge.

Sharples, N. 2010. Social relations in later prehistory: Wessex in the first millennium BC. Oxford.

Sharples, N. 1991a. Maiden Castle: excavations and field survey 1985-6. Vol. 19. London.

Sharples, N. 1991b. 'Warfare in the Iron Age of Wessex', Scottish Archaeological Review 8, 79-89.

Sherratt, A. 1996. 'Why Wessex? The Avon route and river transport in later British prehistory', Oxford Journal of Archaeology 15 (2), 211-234.

Shotton, F.W. 1978. 'Archaeological inferences from the study of alluvium in the lower Severn-Avon valleys', in S. Limbrey and J.G. Evans (eds.). The effect of man on the landscape: the Lowland Zone. London. 27-32.

Simmons, I.G. and Innes, J.B. 1987. 'Mid-holocene adaptations and later Mesolithic forest disturbance in Northern England', Journal of Archaeological Science 14 (4), 385-403.

Simmons, I.G. and Innes, J.B. 1981. 'Tree remains in a North York Moors peat profile', Nature 294, 76-78.

Sinker, C. 1962. The North Shropshire meres and mosses: a background for ecologists. London.

Slater, F.M. 1972. 'A history of the vegetation of Wem Moss, Shropshire', Proceedings of the Birmingham Natural History Society 22, 92-118.

Smalley, R. 2011. Geophysical Survey Report: The Berth, Baschurch, Shropshire. Report J2862 Stratascan for Zig Zag Productions.

Smith, D.N. 1998. 'Beyond the Barn Beetles: Difficulties in Using Some Coleoptera as Indicators of Stored Fodder', Environmental Archaeology 1 (1), 63-70.

Smith, D.N. 2000. 'Disappearance of elmid 'riffle beetles' from lowland river systems - the impact of alluviation', in T. O'Connor and R. Nicholson (eds.), People as an Agent of Environmental Change (AEA Symposia No. 16). Oxford. 75-80.

Smith, D.N. 2009. 'The Insect Remains from Edgbaston Street and Park Street', in S. Rátkai and C. Patrick (eds.), The Bull Ring uncovered: excavations at Edgbaston Street, Moor Street, Park Street and the Row, Birmingham, 1997-2001. Oxford. 269-294.

Smith, D.N. 2013. 'Defining an indicator package to allow identification of 'cesspits' in the archaeological record', Journal of Archaeological Science 40 (1), 526-543.

Smith, D.N., Letts, J. and Jones, M. 2005. 'Modern Coleoptera from Non-cereal Thatch: A Poor Analogue for Roofing Material from the Archaeological Record', Environmental Archaeology 10 (2), 171-178.

Smith, D.N. Osborne, P. and Barrett, J.C. 2000. 'Beetles as indicators of past environments and human activity at Goldcliff', in M. Bell, A. Caseldine and H. Neumann (eds.), Prehistoric intertidal archaeology in the Welsh Severn Estuary York. 245261.

Smith, D.N., Roseff, R., Bevan, L., Brown, A.G., Butler, S., Hughes, G., Monckton, A. 2005. 'Archaeological and environmental investigations of a Lateglacial and Holocene river sedimentary sequence on the River Soar at Croft, Leicestershire, UK', The Holocene 15 (3), 353-377. 
Smith, D.N. and Whitehouse, N.J. 2005. 'Not Seeing the Trees for the Woods: A Palaeoentomological Perspective on Holocene Woodland Composition', I D.N. Smith, M.B. Brickley and K. Smith (eds.), Fertile Ground: Papers in Honour of Susan Limbrey. Oxford. 136-161.

Smith, D.N., Whitehouse, N.J., Bunting, M.J., and Chapman, H.P. 2010. 'Can we characterise 'openness' in the Holocene palaeoenvironmental record? Modern analogue studies of insect faunas and pollen spectra from Dunham Massey deer park and Epping Forest, England', The Holocene 20 (2), 215-229.

Smith, G. 1991. Pave Lane. West Midlands Archaeology, 34.

Smith, N. 2010. Old Oswestry, Selattyn and Gobowen, Shropshire. Analysis of Earthworks. Vol. 82 English Heritage.

Smith, R.A. 1907. 'Article in the Proceedings of the Society of Antiquaries (London)', Proceedings of the Society of Antiquaries of London XXI, 324-326.

Soltvedt, E.C. and Henningsmoen, K.E. 2016. 'Agricultural and household activities in Vestfold, Southeast Norway, as illustrated by pollen data and the charred remains of crops and wild plants', Environmental Archaeology 21 (1), 11-30.

Spelman, H., Sir. 1698. Reliquiæ Spelmannianæ: The posthumous works of Sir Henry Spelman kt. relating to the laws and antiquities of England. Oxford and London.

Spicer, R.A. 1989. 'The Formation and Interpretation of Plant Fossil Assemblages', Advances in Botanical Research 16, $95-$ 191.

Spikins, P. 2000. 'GIS Models of Past Vegetation: An Example from Northern England, 10,000-5000 BP', Journal of Archaeological Science 27 (3), 219-234.

Spurk, M., Hanns, H.L., Baillie, M., Briffa, K.R. and Friedrich,M. 2002. 'Depositional frequency of German subfossil oaks: Climatically and non-climatically induced fluctuations in the Holocene', The Holocene 12 (6), 707-715.

Squires, V.R. and Ayoub, A.T. 1992. Halophytes as a resource for livestock and for rehabilitation of degraded lands', in Proceedings of the International Workshop on Halophytes for Reclamation of Saline Wastelands and as a Resource for Livestock, Problems and Prospects, Nairobi, Kenya.

Stace, C.A. 2010. New flora of the British Isles. Cambridge.

Stanford, S.C. 1980. The archaeology of the Welsh Marches. London.

Stanford, S.C. 1977. 'Ebury Hill Camp - Excavations 1977', Transactions of the Shropshire Archaeological and Historical Society 64, 9-12.

Stanford, S.C. 1972a. 'The Function and Population of Hill-forts in the Central Marches', in F. Lynch and C. Burgess (eds.), Prehistoric man in Wales and the West: essays in honour of Lily F. Chitty. Bath. 307-319.

Stanford, S.C. 1972b. 'Welsh Border Hill-Forts', in C. Thomas (ed.), The Iron Age in the Irish Sea province: papers given at a C.B.A. Conference, Cardiff 1969. London. 25-36.

Stanford, S.C. 1967. 'Croft Ambrey hill-fort - some interim conclusions', Transactions of the Woolhope Naturalists Field Club, 39, 31-39.

Stanford, S.C., Bayley, J., Colledge, S.M., and Holgate, R. 1982. 'Bromfield, Shropshire - Neolithic, Beaker and Bronze Age sites, 1966-79', Proceedings of the Prehistoric Society 48, 279-320.

Stanford, S.C., Colledge, S.M., Greig, J., Holgate, R. and Morris, E. 1984. 'The Wrekin Hillfort Excavations 1973', Archaeological Journal 141 (1), 61-90.

Stansbie, D., Bashford, D. and Bridgman, R. 2012. From Mesolithic to motorway: the archaeology of the M1 (Junction 6a-10) Widening Scheme, Hertfordshire. Oxford. 
Stead, I. 1991. Iron Age cemeteries in East Yorkshire. English Heritage.

Stopforth, J. 1987. 'Danebury: an alternative view', Scottish Archaeological Review 4, 70-75.

Strang, V. 2005. 'Common Senses. Water, Sensory Experience and the Generation of Meaning', Journal of Material Culture 1, 92-120.

Strang, V. 2008. 'The social construction of water', in B. David and J. Thomas (eds.), Handbook of landscape archaeology. Walnut Creek (CA). 123-130.

Sturdy, D. and Case, H.J. 1961-62. 'Archaeological Notes', Oxoniensia 23 (7), 336-339.

Sugita, S. 1994. 'Pollen Representation of Vegetation in Quaternary Sediments: Theory and Method in Patchy Vegetation', Journal of Ecology 82 (4), 881-897.

Sugita, S., Gaillard, M. and Broström, A. 1999. 'Landscape openness and pollen records: A simulation approach', The Holocene 9 (4), 409-421.

Sugita, S., Hicks, S. and Sormunen, H. 2010. 'Absolute pollen productivity and pollen-vegetation relationships in northern Finland', Journal of Quaternary Science 25 (5), 724-736.

Sutton, J.E.G. 1966. 'Iron Age Hill-Forts and some other sites in Oxfordshire', Oxoniensia XXXI (28)

Swift, G. 1984. Waterland. London.

Taylor, C. 1975. Fields in the English landscape. London.

Taylor, M.P. and Lewin, J. 1996. 'River behaviour and Holocene alluviation: The River Severn at Welshpool, mid-Wales, U.K.', Earth Surface Processes and Landforms 21 (1), 77-91.

Ten Hove, H.A. 1968. 'The Ulmus fall at the transition Atlanticum-Sub-Boreal in pollen diagrams', Palaeogeography, Palaeoclimatology, Palaeoecology 5 (4), 359-369.

Thomas, D. Archdeacon. 1907. The Ordovices and Ancient Powys. Collections, historical \& archaeological relating to Montgomeryshire. https://journals.library.wales/view/1238716/1239453/183\#?xywh=-54\%2C1324\%2C2597\%2C1888. (accessed June 2017).

Thomas, J. 1993. 'The Politics of Vision and the Archaeologies of Landscape', in B. Bender (ed.), Landscape: politics and perspectives. Providence, Rhode Island and Oxford. 19-48.

Thomas, J. 2004. Archaeology and modernity. London.

Thomas, J. 2012. 'Archaeologies of Place and Landscape' in I. Hodder (ed.), Archaeological Theory Today. Cambridge. 293327.

Thomas, J. 2012. 'Some deposits are more structured than others', Archaeological Dialogues 19 (2), 124-127.

Thomas, P.A., El-Barghathi, M. and Polwart, A. 2007. Biological Flora of the British Isles: Juniperus communis L.', Journal of Ecology 95 (6), 1404-1440.

Thurston, T. 2009. 'Unity and Diversity in the European Iron Age: Out of the Mists, Some Clarity?', Journal of Archaeological Research 17 (4), 347-423.

Tilley, C. 1994. A phenomenology of landscape: places, paths and monuments. Oxford.

Tilley, C. 1999. Metaphor and material culture. Oxford. 
Tilley, C. 2010. Interpreting landscapes: geologies, topographies, identities. Walnut Creek, California.

Tinner, W., Hubschmid, P., Wehrli, M., Ammann, B., Conedera, M. 1999. 'Long-Term Forest Fire Ecology and Dynamics in Southern Switzerland', Journal of Ecology 87 (2), 273-289.

Tipping, R. 2008. 'Blanket peat in the Scottish Highlands: timing, cause, spread and the myth of environmental determinism', Biodiversity and Conservation 17 (9), 2097-2113.

Tittensor, R.M. and Steele, R.C. 1971. 'Plant Communities of the Loch Lomond Oakwoods', Journal of Ecology 59 (2), 561 582.

Toghill, P. 1990. Geology in Shropshire. Shrewsbury.

Tottenham, C.E. 1954. Handbooks for the identification of British Insects: Coleoptera : Staphilinidae. Vol. IV. Part 8a. London.

Trigger, B.G. 2006. A History of Archaeological Thought. Cambridge.

Trigger, B.G. 1990. 'Monumental Architecture: A Thermodynamic Explanation of Symbolic Behaviour', World Archaeology 22 (2, Monuments and the Monumental), 119-132.

Trinder, B.S. 1983. A history of Shropshire. Chichester.

Tuan, Y. 1974. 'Space and place: humanistic perspective', Progress in Geography 6, 211-252.

Tuan, Y. 2011. Space and place: the perspective of experience. Minneapolis.

Turner, J. 1964. 'The anthropogenic factor in vegetational history', New Phytologist 63 (1), 73-90.

Turner, R.C. and Penney, S. 1996.' Three Bog Bodies from Whixall Moss, Shropshire', Transactions of the Shropshire Archaeological and Historical Society, 71, 1-9.

Turner, R.C. and Scaife, R.G. 1995. Bog bodies: new discoveries and new perspectives. London.

Tweddle, J.C. and Edwards, K.J. 2010. 'Pollen preservation zones as an interpretative tool in Holocene palynology', Review of palaeobotany and palynology 161 (1-2), 59-76.

Twiddle, C. 2012, 'Pollen analysis: Not Just a Qualitiative Tool, in S.J. Cook, L.E. Clarke and J.M.Nield (eds.), Geomorphological Techniques London. Chapter 4; Sec.1.4.

Twigger, S. N. 1988. Late Holocene palaeoecology and environmental archaeology of six lowland lakes and bogs in North Shropshire. PhD thesis, University of Southampton.

Twigger, S.N. and Haslam, C.J. 1991. 'Environmental changes in Shropshire during the last 13,000 years', Field Studies 7, 743-758.

Tyler, A. 1981. 'The Berth', Archaeological Journal (138), 16-17.

Van de Noort, R. 2004. The Humber Wetlands: the archaeology of a dynamic landscape. Bollington.

Van de Noort, R., Chapman, H. and Cheetham, J.L. 2001. 'In situ preservation as a dynamic process: the example of Sutton Common, UK.' Antiquity 287, 94-100.

Van de Noort, R. Chapman, H. and Collis, J. 2007. Sutton Common: the excavation of an Iron Age 'marsh-fort'. York.

Van de Noort, R. and O'Sullivan, A. 2006. Rethinking wetland archaeology. London. 
van der Veen, M. and Jones, G. 2006. 'A re-analysis of agricultural production and consumption: implications for understanding the British Iron Age', Vegetation History and Archaeobotany 15 (3), 217-228.

Van Geel, B., Bohncke, S.J.P. and Dee, H. 1980. 'A palaeoecological study of an upper Late Glacial and Holocene sequence from "De Borchert", The Netherlands', Review of palaeobotany and palynology 31, 367-448.

van Gennep, A. 1960. The Rites of Passage (translated by M.B. Vizedom and G.L.Caffee). London.

Varley, W.J. 1948. 'The Hill-forts of the Welsh Marches', Archaeological Journal 105, 41-68.

Vera, F.W.M. 2000. Grazing ecology and forest history. Wallingford.

Vuorela, I. 1973. 'Relative pollen rain around cultivated fields', Acta Botanica Fennica 102, 1-27.

Waddington, C. 2011. Fin Cop Excavation: Archive Report for 2010. Archaeological Research Services Ltd.

Wait, G.A. 1985. Ritual and religion in Iron Age Britain. Oxford.

Walker, D. 1970. 'Direction and rate of change of some British post-glacial hydroseres', in D. Walker, and R.G. West (eds.), Studies in the Vegetational History of the British Isles. (Essays in honour of Harry Godwin). London. 117-139.

Walker, D. 1955. 'Studies in the Post-Glacial History of British Vegetation', New Phytologist 54 (2), 222-254.

Waltham, A.C. 2000. 'Landmark of Geology in the East Midlands; Peat Subsidence at the Holme Post', Mercian Geologist 15 (1), 49-51.

Watson, A. and Keating, D. 1999. 'Architecture and sound: an acoustic analysis of megalithic monuments in prehistoric Britain', Antiquity 73 (280), 325-336.

Watson, M. 2001. 'Wings over Shropshire: Aerial Archaeology in the Territory of the Cornovii', West Midlands Archaeology 44, 4-6.

Watson, M. 1991. 'Ring-Ditches of the Upper Severn Valley', Transactions of the Shropshire Archaeological and Historical Society LXXVII, 9-14.

Watson, M. and Musson, C.R. 1993. Shropshire from the air: man and the landscape. Shrewsbury.

Webster, G. 1991. The Cornovii. Stroud.

Webster, G. (ed.) 1988. Fortress into city: the consolidation of Roman Britain first century AD. London.

Webster, P.V. 1976. 'Severn Valley Ware', Transactions of the Bristol and Gloucestershire Archaeological Society 94, 18-46.

Wheatley, D. 1995. 'Cumulative Viewshed Analysis: a GIS-based method for investigating intervisibility, and its archaeological application', in G. Lock and Z. Stančič (eds.), Archaeology and GIS: A European Perspective. London. 5-13.

Wheatley, D. and Gillings, M. 2002. Spatial technology and archaeology : the archaeological applications of GIS. London.

Wheatley, D. and Gillings, M. 2000. 'Vision, perception and GIS: developing enriched approaches to the study of archaeological visibility', in G. Lock (ed.), Beyond the map : archaeology and spatial technologies. Amsterdam and Oxford. $1-27$.

Wheeler, B.D. 1980. 'Plant Communities of Rich-Fen Systems in England and Wales: I. Introduction. Tall Sedge and Reed Communities', Journal of Ecology 68 (2), 365-395.

Wheeler, R.E.M., Sir 1972. Maiden Castle, Dorset. London. 
Whimster, R. 1989. The emerging past: air photography and the buried landscape. London.

White, R.H. 2001. 'Wroxeter and the Civitas Cornoviorum', West Midlands Archaeology 44, 9-13.

White, R. 2002. 'The West Midlands in the Fifth and Sixth Centuries', in West Midlands Regional Research Framework, Univeristy of Birmingham.

White, R.H. and Barker, P. 2002. Wroxeter: life and death of a Roman city. Stroud.

White, R.H. Gaffney, C. and Gaffney, V. 2013. Wroxeter, the Cornovii and the urban process : final report on the Wroxeter hinterland project 1994-1997. Vol. 2, Characterizing the city. Oxford

White, R.H. and van Leusen, P.M. 1995. 'The Wroxeter Hinterland Project: Aspects of Romanization in the Wroxeter Hinterland', http://www.bham.ac.uk/BUFAU/Projects/WH/Lever/(accessed July 2017).

White, R.H. and Wigley, A. 2010.' Sharpstone Hill and Meole Brace in the Iron Age and Roman periods',Transactions of the Shropshire Archaeological and Historical Society LXXXV, 2-6.

Whitehouse, N.J. 1997. 'Insect faunas associated with Pinus Sylvestris L. from the Mid-Holocene of the Humberhead Levels, Yorkshire, U.K.', Quaternary Proceedings 5, 293-303.

Whitehouse, N.J. 2000. 'Forest fires and insects: palaeoentomological research from a subfossil burnt forest', Palaeogeography, Palaeoclimatology, Palaeoecology 164 (1-4), 231-246.

Whitehouse, N.J. 2004. 'Mire ontogeny, environmental and climatic change inferred from fossil beetle successions from Hatfield Moors, Eastern England', The Holocene 14 (1), 79-93.

Whitehouse, N.J. 2006. 'The Holocene British and Irish ancient forest fossil beetle fauna: implications for forest history, biodiversity and faunal colonisation', Quaternary Science Reviews 25 (15-16), 1755-1789.

Whitehouse, N.J. 2006. 'What can forest managers learn from research on fossil insects? Linking forest ecological history, biodiversity and management'. Asheville, North Carolina.

Whitehouse, N.J. and Smith, D.N. 2004. "Islands' in Holocene Forests: Implications for Forest Openness, Landscape Clearance and 'Culture-Steppe' Species', Environmental Archaeology 9 (2), 199-208.

Whitehouse, N.J. and Smith, D.N. 2010. 'How fragmented was the British Holocene wildwood? Perspectives on the "Vera" grazing debate from the fossil beetle record', Quaternary Science Reviews 29 (3-4), 539-553.

Whiting, C.E. 1936. 'Excavations at Sutton Common, 1933, 1934, and 1935', Yorkshire Archaeological Journal 33, 57-80.

Whittington, G., Buckland, P.C., Edwards, K.J., Greenwood, M., Hall, A., Robinson, M. 2003. 'Multiproxy Devensian Lateglacial and Holocene environmental records at an Atlantic coastal site in Shetland', Journal of Quaternary Science 18 (2),151-168.

Whittle, A. 2009. 'The Neolithic Period, c.4000-2400 CAL BC. A changing world', in J. Hunter and I. Ralston (eds.), The archaeology of Britain: an introduction from the Upper Palaeolithic to the Industrial Revolution. London. 78-102.

Whittle, A. 1993. 'The Neolithic of the Avebury area: sequence, environment, setlement and monuments', Oxford Journal of Archaeology 12, 29-53.

Wigley, A. 2001. 'Searching for the Cornovii in the Iron Age: a critical consideration of the evidence', West Midlands Archaeology 44, 6-9.

Wigley, A. 2002. Building Monuments, Constructing Communities: Landscapes of the first millennium BC in the central Welsh Marches. Unpublished PhD thesis. University of Sheffield. 
Wigley, A. 2007. 'Rooted to the spot: the 'smaller enclosures' of the later first millennium BC in the central Welsh Marches', in C. Haselgrove and T. Moore (eds.), The Later Iron Age in Britain and beyond Oxford. 173-189.

Wigley, A. 2017a. 'Fugitive pieces: towards a new understanding of the later second and first millennia BC in Shropshire', in D. Hurst (ed.), Westward on the High-Hilled Plains: the Later Prehistory of the West Midlands. The Making of the West Midlands, Volume 2 Oxford. 85-96.

Wigley, A. 2017b. 'Touching the void: Iron Age landscapes and settlement in the West Midlands', in D. Hurst (ed.), Westward on the High-Hilled Plains; the Later Prehistory of the West Midlands. The Making of the West Midlands. Volume 2 Oxford. 144-152.

Willis, S. 1999. 'Without and within: aspects of culture and community in the Iron Age of north-eastern England', in B. Bevan (ed.), Northern Exposure: interpretative devolution and the Iron Ages in Britain. Leicester. 81-110.

Witcher, R. 1999. 'GIS and Landscape Perception', in M. Gillings, D. Mattingly and J. van Dalen (eds.), Geographical Information Systems and Landscape Archaeology. The Archaeology of Mediterranean Landscapes 3. Oxford. 13-22.

Woodward, A. 2007. 'Ceremonial landscapes and ritual deposits in the Neolithic and Early Bronze Age periods in the West Midlands', in P. Garwood (ed.), The Undiscovered Country. The Earlier Prehistory of the West Midlands. Oxford. 182-193.

Woodward, A. and Leach, P. 1993. The Uley shrines: excavation of a ritual complex on West Hill, Uley, Gloucestershire, 1977-9. London.

Wright, D.J., Goodchild, M.F. and Proctor, J.D. 1997. 'Demystifying the Persistent Ambiguity of GIS as 'Tool' versus 'Science", Annals of the Association of American Geographers 87, 346-362.

Yates, D. and Bradley, R. 2010. 'Still water, hidden depths: the deposition of Bronze Age metalwork in the English Fenland', Antiquity 84 (324), 405-415.

Zhao, Y., Sayer, C.D., Birks, H.H., Hughes, M. and Peglar,S.M.2006. 'Spatial Representation of Aquatic Vegetation by Macrofossils and Pollen in a Small and Shallow Lake', Journal of Palaeolimology 35, 335-350. 